„Der intellectuelle Urheber bin doch ich!“

Der Konzertagent Hermann Wolff als Wegweiser des Berliner Konzertlebens 1880 bis 1902 


\title{
»Der intellectuelle Urheber bin doch ich!« Der Konzertagent Hermann Wolff als Wegweiser des Berliner Konzertlebens 1880 bis 1902
}

\author{
Dissertation \\ zur Erlangung des Doktorgrades \\ der \\ Fakultät »Musik« \\ der \\ Universität der Künste Berlin
}

vorgelegt von

Sayuri Hatano

aus

Tokio

Gutachter: 1. Prof. Dr. Dörte Schmidt

2. Dr. Dietmar Schenk

Veröffentlicht unter der Creative-Commons-Lizenz CC BY 4.0 


\begin{abstract}
Die vorliegende Arbeit zum Berliner Konzertagenten Hermann Wolff verfolgt zwei Ziele: Erstens erklärt sie die Bedeutung seiner Tätigkeit zwischen 1880 und 1902 für die Entwicklung Berlins als Musikmetropole aufgrund der Untersuchung seines Wirkungsbereiches und seiner Einflussmöglichkeit. Zweitens sichtet sie das noch vorhandene Quellenmaterial zu diesem Thema in möglichst umfassender Weise und macht es weiteren Kreisen zugänglich. Dadurch bildet sie auch die Grundlage für weitere Forschungen sowohl zu Hermann Wolff und der von ihm 1880 gegründeten Konzertdirektion Hermann Wolff (und Jules Sachs), die nach seinem Tod bis 1935 weitergeführt worden war, als auch zur Berliner Konzertkultur in wilhelminischer und Weimarer Zeit und der Zeit des frühen Nationalsozialismus.

Diese Arbeit wirft Licht auf Hermann Wolff als wichtige Triebkraft des Berliner Konzertlebens in den beiden letzten Jahrzehnten des 19. Jahrhunderts: Er richtete die Abonnementkonzerte des neu gegründeten Berliner Philharmonischen Orchesters ein und führte sie nicht nur im organisatorischen, sondern auch im künstlerischen Sinne; seine Firma organisierte etwa 300 bis 400 Konzerte pro Saison in Berlin; er unterstützte die Tätigkeit nicht nur von reproduzierenden Musikern, sondern auch von zeitgenössischen Komponisten; er gründete den Bechstein-Saal, einen Kammermusiksaal mit rund 500 Sitzplätzen, wo man ohne sehr großen Aufwand eigene Konzerte geben konnte; er brachte verschiedene Akteure des Musiklebens innerund außerhalb Berlins in Verbindung und ließ sie zusammen wirken; und er trug zur Infrastrukturbildung des Musiklebens der deutschen Reichshauptstadt in maßgeblicher Weise bei.

Die Auseinandersetzung mit diesem einflussreichen Hintermann des Konzertbetriebes beleuchtet mehr als relevante, jedoch bislang vernachlässigte Aspekte der Kulturgeschichte. Die Erkenntnisse, die die Beschäftigung mit Hermann Wolff als Wegweiser des Berliner Musiklebens des letzten 19. Jahrhunderts hervorbringt, führen uns auch zum besseren Verständnis von Tätigkeiten und Karrieren der damaligen Musiker, dem Netzwerk sowie dem Interessenkonflikt zwischen den verschiedenen Akteuren der damaligen Musikwelt, sowie schließlich von den Voraussetzungen, auf denen die Entwicklung Berlins als Musikstadt beruhte.
\end{abstract}




\section{Lebenslauf}

Sayuri Hatano studierte Klavier an der Kunitachi Musikhochschule in Tokio und erwarb ihren Magistertitel in Liberal Arts an der Tokio Gagugei Universität mit einer Magisterarbeit über Arthur Schnabels Edition der Klaviersonaten Beethovens. Ab 2012 studierte sie an der Universität der Künste Berlin, wo sie 2018 bei Dörte Schmidt mit der Dissertation »Der intellectuelle Urheber bin doch ich!« Der Konzertagent Hermann Wolff als Wegweiser des Berliner Konzertlebens 1880 bis 1902 promoviert wurde (summa cum laude). Zu ihren neuesten Veröffentlichungen gehören: Ein Paperchase. Auf der Suche nach dem Nachlass der Berliner Konzertagenten Hermann und Louise Wolff und ihrer Familie, in Archive zur Musikkultur nach 1945. Verzeichnis und Texte, hg. von Antje Kalcher und Dietmar Schenk, München 2016, S. 38-44; Bechstein-Saal. A Lost Concert Hall in Berlin, in Journal of Musicological Research 36 (2017), No. 3, S. 234-251; Die zweite Violinsonate von Ferruccio Busoni. Eine absolute Musik? (Japanisch) in Überlegung über die Welt durch Musik. Eine Festschrift für Eisaburo Tsuchida, hg. vom Tsuchida-Seminar für Musikwissenschaft der Tokio Universität der Künste, Tokio 2020, S.254-272. 


\section{Danksagung}

An dieser Stelle möchte ich mich bei all denjenigen bedanken, die durch ihre Unterstützung zur Entstehung dieser Arbeit beigetragen haben.

Zuerst gebührt mein Dank Frau Prof. Dr. Dörte Schmidt, die mich an der Universität der Künste Berlin betreut hat. Sie war wörtlich meine Doktormutter, aber gleichzeitig auch meine deutsche Mutter, wenn ich sie so nennen darf. Ohne ihre hilfreichen Anregungen und ausdauernden Ermutigungen wäre diese Arbeit keinesfalls zustande gekommen. Ebenfalls möchte ich mich bei Herrn Dr. Dietmar Schenk, dem Leiter des Archivs der Universität der Künste Berlin, bedanken. Ich übertreibe nicht, wenn ich sage, dass seine veröffentlichte Arbeit, die ich schon während meines Studiums in Japan gelesen hatte, mich zur Beschäftigung mit diesem Themenbereich führte. Es war mir eine große Ehre, dass er immer mit wachem Interesse den Vorgang meiner Arbeit verfolgt und meine Dissertation mit Frau Schmidt begutachtet hat.

Ebenso gilt mein Dank Frau Antje Kalcher, der Archivarin des gleichen Archivs. Mit großer Freundlichkeit und bewundernswerter Ausdauer hat sie mir beim Entziffern der handschriftlichen Quellen geholfen.

Ich bedanke mich auch bei meinen Kommilitonen in der Abteilung Musikwissenschaft der Universität der Künste Berlin, vor allem bei Daniela Fugellie und Susanne Heiter, die mir bei verschiedenen Gelegenheiten während meines Studiums in Deutschland (aber auch danach!) sowohl fachlich wie persönlich geholfen haben.

Ein besonderer Dank gilt den Nachkommen der Familie Wolff, die mich herzlich empfangen und mir ihre Quellen und Erinnerungen zur Verfügung gestellt haben. Die warme Beziehung mit ihnen ist ein Schatz meines Lebens.

Ich bedanke mich beim DAAD und der Rohm Music Foundation für die großzügige finanzielle Unterstützung, die mein Studium in Berlin ermöglicht hat. Der Zugang zu den verschiedenen originellen Quellen schaffte unerlässliche Voraussetzungen für diese Arbeit.

Außerdem bedanke ich mich bei Frau Christine Jakobi-Mirwald für das Korrekturlesen der Arbeit.

Abschließend möchte ich mich bei meinen Eltern bedanken, die aus Japan immer ihr Verständnis für meine Arbeit gezeigt und mich in all meinen Entscheidungen unterstützt haben. 


\section{Inhaltsverzeichnis}

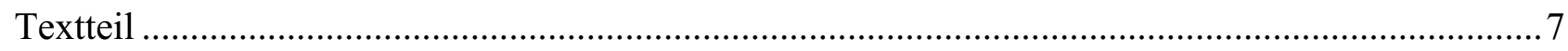

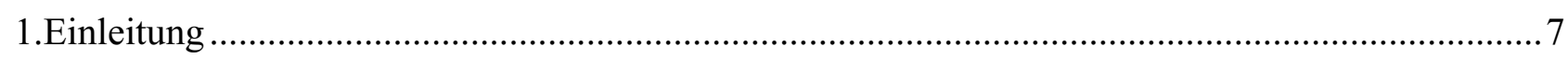

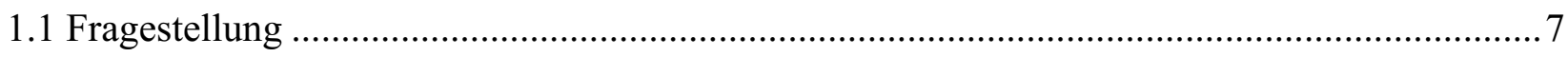

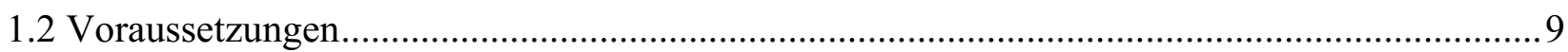

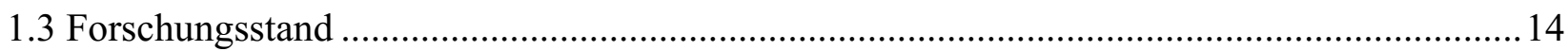

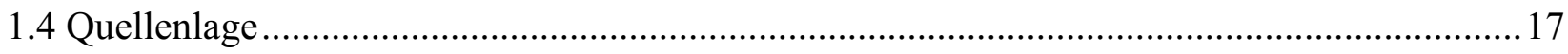

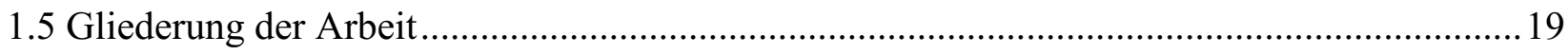

2.Entwurf zur Firmengeschichte der Konzertdirektion Hermann Wolff (und Jules Sachs) ..............22

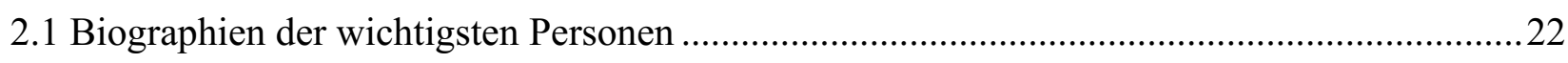

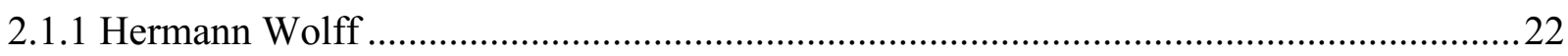

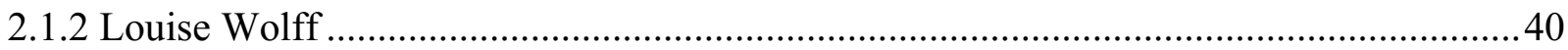

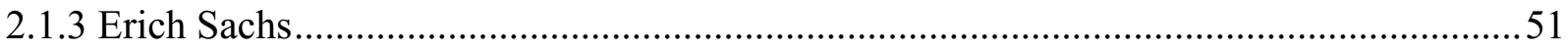

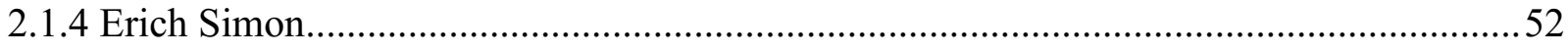

2.1.5 Edith Stargardt(-Wolff) ........................................................................................5

2.2 Personalstruktur der Konzertdirektion Hermann Wolff (und Jules Sachs) ................................57

2.2.1 Geschäftsbetrieb unter Hermann und Louise Wolff .......................................................57

2.2.2 Triumvirat unter Louise Wolff, Erich Sachs und Erich Simon..........................................61

2.2.3 Versuch des weiteren Betriebs unter nationalsozialistischem Einfluss ...............................64

2.3 Tätigkeit und Wirkungskreis der Konzertdirektion Hermann Wolff (und Jules Sachs) ............69

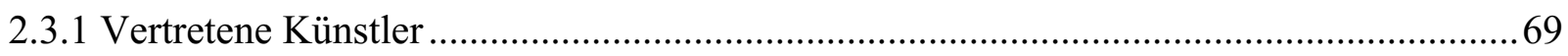

2.3.2 Konzertveranstaltungen und Konzertarrangements in Berlin...........................................82

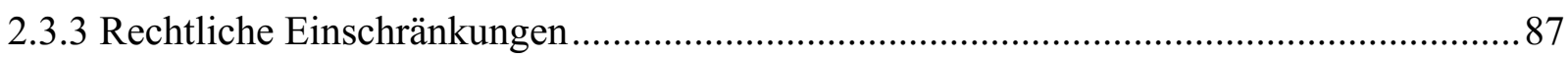

3. Hermann Wolff als Impulsgeber des Berliner Musiklebens .......................................................97

3.1 Hermann Wolff und Aufführungen von zeitgenössischer Musik............................................97

3.1.1 Die Abonnementkonzerte des Berliner Philharmonischen Orchesters als Forum für

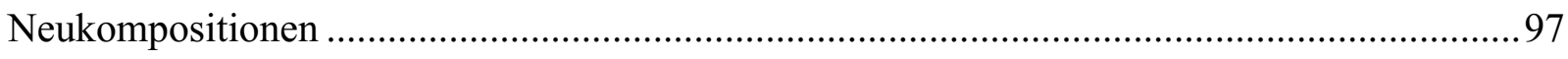

3.1.2 »Partheilichkeiten müssen schweigen«: Hermann Wolff als Schlüsselfigur für die Berliner Tonkünstlerversammlung des Allgemeinen Deutschen Musikvereins 1891 ...............123

3.1.3 Im Spannungsfeld zwischen Verlegern und Komponisten: Hermann Wolff in der frühen musikalischen Tantiemenbewegung in Deutschland .............................................................. 140

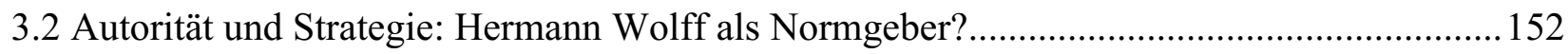

3.2.1 Historische Konzerte von Anton Rubinštejn: Entstehung eines Standards ..................... 152

3.2.2 Erläuternde Programmhefte: Das Konzert als Werk des Veranstalters ............................ 167

3.2.3 Auswahl der Mitwirkenden für die Abonnementkonzerte des Berliner Philharmonischen

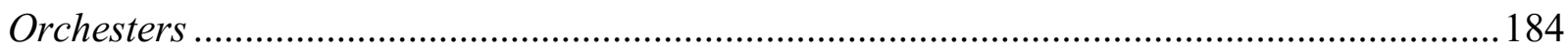

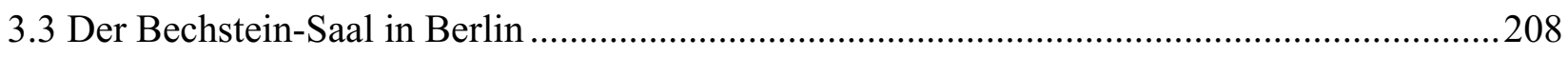

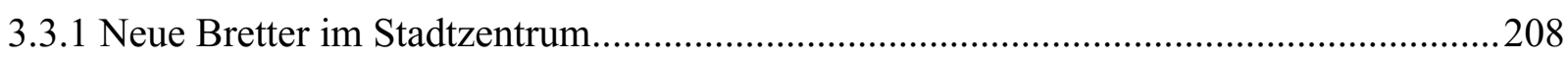

3.3.2 Idee des Konzertsaals »für nicht 〉sensationelle $<$ Concerte« .............................................216 


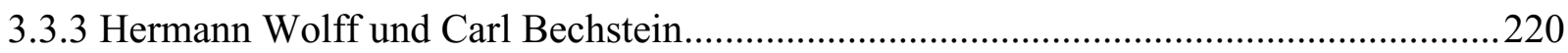

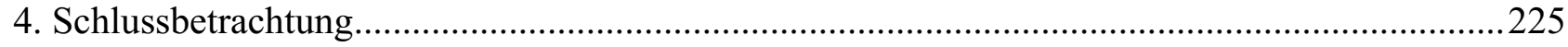

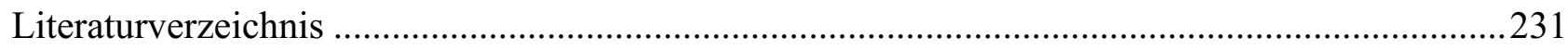

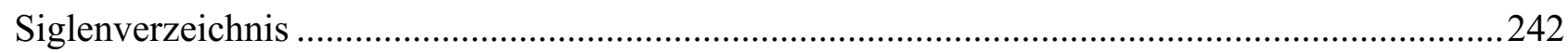

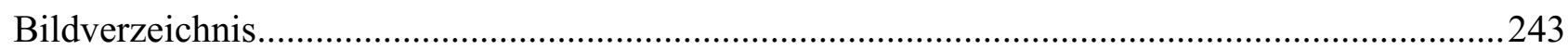

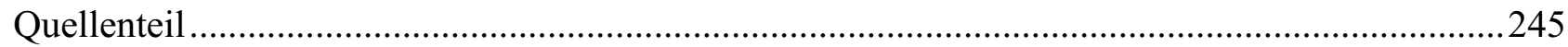

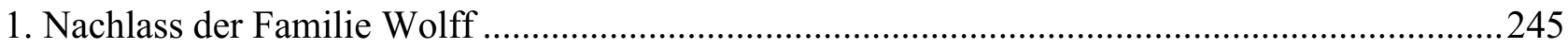

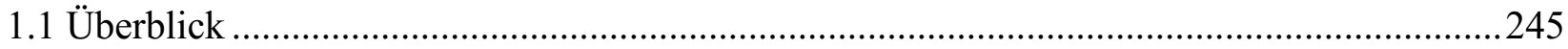

1.2 Ausgewählte Briefe und Dokumente (Transkription) …...................................................249

1.2.1 Briefe von Hermann an Louise Wolff......................................................................249

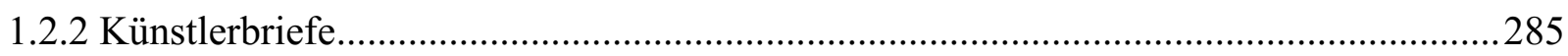

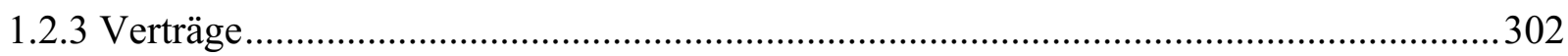

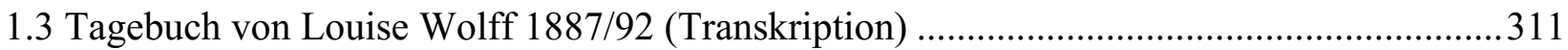

1.4 Manuskript des Rundfunkgesprächs von Edith Stargardt(-Wolff) [1957] ........................... 326

1.5 Gesprächsaufnahme von Wolfang Zuelzer "Queen Louise”, o. D. (Transkription) ...............332

2. Veranstaltungen im Concert-Verzeichnis 1902/03 (466 Konzerte).........................................347

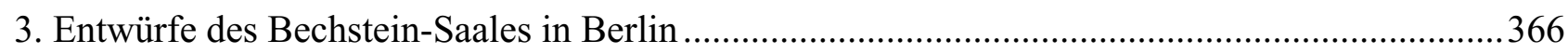

4. Vorschriften über den Betrieb der Konzertagenten vom 9. März 1914 (HMB1. S. 134).............369

Anhang: Nachlass der Familie Wolff (Datenbank mit 333 Einträgen) 


\section{Textteil}

\section{Einleitung}

\subsection{Fragestellung}

[D]er intellectuelle Urheber bin doch $\underline{\mathrm{ich}}$; ich habe die musikalische Anregung angeregt, und nur im gut künstlerischen Sinne gewirkt!

Sind Sie nicht auch der Meinung, daß man mich nicht umgehen darf? Man weiß doch, daß es keine Wuellner Concerte, sondern Wolff's Concerte gab [...]. ${ }^{1}$

Folgendes war geschehen: In Berlin wurde gerade ein Gründungsplan für eine Gesellschaft aufgestellt, die die Existenz des jungen Berliner Philharmonischen Orchesters sichern sollte. ${ }^{2}$ Man war im Begriff, Hermann Wolff, den Verfasser des Briefes, aus dem Unternehmen der Abonnementkonzerte dieses Orchesters, die er 1882 mit dem von ihm berufenen Dirigenten Franz Wüllner ins Leben gerufen hatte, auszuschließen, und hatte sich direkt an Wüllner gewandt, um ihn für die Konzerte der nächsten Saison zu gewinnen, Wolff somit nicht in die neue Gesellschaft einzubeziehen. ${ }^{3}$ Dagegen setzte sich Wolff zur Wehr: Diese Konzerte hätten ihm nicht nur die Geldquelle verdankt, sondern auch die künstlerische Bedeutung. »[E]s waren doch meine Concerte u. W[üllner] dirigierte sie bloß«. ${ }^{4}$

Hermann Wolff, ein erfolgreicher Kaufmann aus einer jüdischen Familie, wurde häufig als Profitjäger dargestellt, der kein Verständnis für Kunst zeige. Abbildung 1 bietet dafür ein typisches Beispiel: sie zeigt Hermann Wolff in Frack und Zylinder, wie er, ungerührt von der Musik, sein Geld zählt, während der Musikkritiker Otto Lessmann vom Flügel, wohl als allgemeines Symbol der Musik gemeint, fast erdrückt wird.

\footnotetext{
${ }^{1}$ Brief von Hermann Wolff an Hugo Bock vom 22.3.1884, Berlin SBPK Mus ep. H. Wolff 988. Hervorhebung im Original. Der zitierten Stelle geht unmittelbar voran: »Und warum schließt man mich jetzt aus, warum kommt man nicht im Augenblick wo man einen großen Erwerb, den ich meinem Fleiß und meiner Einsicht verdankte, mir entziehen will, u. versucht mich zu gewinnen u. - ganz geht es ja nicht - um etwas zu entschädigen, denn, man sage was man will.«.

${ }^{2}$ Den ganzen Aufruf zur Mitgliedschaft der Philharmonischen Gesellschaft vom 18.3.1884 vgl. Variationen mit Orchester. 125 Jahre Berliner Philharmoniker, hg. von der Stiftung Berliner Philharmoniker, [Leipzig] 2007, Bd. 1, S. 56-58.

${ }^{3}$ Dieser Plan ging nicht auf: Wolff wurde Geschäftsführer der Philharmonischen Gesellschaft.

${ }^{4}$ Brief von Hermann Wolff an Hugo Bock vom 24.3.1884, Berlin SBPK Mus ep. H. Wolff 986. Hervorhebung im Original.
} 


\section{KONZERT-SAISON 1898/99.}

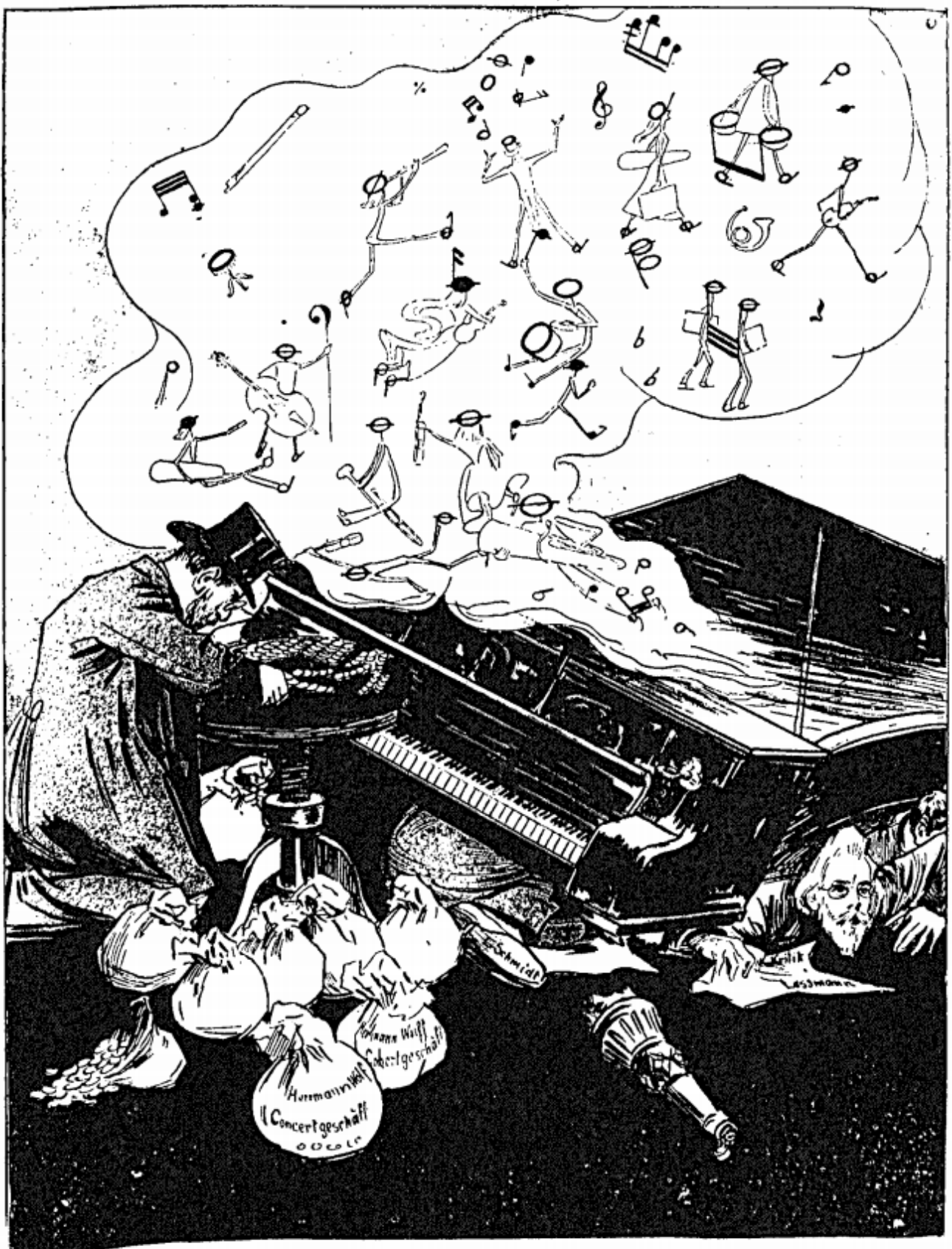

Der Imprefario: Gdade, oak fie alle iff. Ho bat ood einen guten Rlang gegeben.

Abbildung 1: »Karikatur auf den Geschäftssinn der Berliner Konzertunternehmer « ${ }^{5}$

Es gab jedoch auch Zeitgenossen, die von seiner Großzügigkeit und seinem großen Verständnis für Musik sprachen. In einem seiner Vorträge an der University of Chicago blickte Artur Schnabel 1945 auf sein Berliner Debüt fast ein halbes Jahrhundert zuvor zurück, wobei er Wolff im

Gegensatz zu amerikanischen Agenten als einen gewissenhaften Diener der Musik und Musiker

\footnotetext{
${ }^{5}$ Ulk vom 21.4.1899, abgedr. in Ruth Glatzer: Das Wilhelminische Berlin. Panorama einer Metropole 18901918, Berlin 1997, S. 210.
} 
darstellte. ${ }^{6}$ Auch die Tochter von Hermann Wolff, Edith Stargardt-Wolff, hat die künstlerische Gesinnung ihres Vaters eher als eine idealistische in Erinnerung:

Reine Spekulationsunternehmungen, wie sie später von anderen Seiten eingeführt wurden, Veranstaltungen mit einem Gemisch von Zugstücken und Schlagern und dem gleichzeitigen Auftreten mehrerer »Stars« widersprachen seinem Stilgefühl und künstlerischen Empfinden. Solche Zugeständnisse an den banalen Geschmack der Masse machte er nicht. ${ }^{7}$

Die Vorstellungen, etwa, dass Musiker immer auf die künstlerische Qualität bedacht sind, während Unternehmer nur den pekuniären Nutzen suchen, beruhen auf der imaginären Unvereinbarkeit von Kunst und Ökonomie, die nicht immer zutrifft. Die Ansicht von Heinrich Ehrlich, dass Hermann Wolff seinen Erfolg als Konzertagent sowohl seinem tüchtigen Geschäftsgeist als auch seiner scharfen künstlerischen Urteilskraft verdankt habe, ist wohl zutreffend. ${ }^{8}$ Wenn er nun auch auf die künstlerische Seite seiner Konzerte oder des Musiklebens Einfluss ausgeübt hätte: in welchem Sinne und auf welche Weise konnte das erfolgt sein?

Dies ist die zentrale Fragestellung der vorliegenden Arbeit. Welche Impulse hat Hermann Wolff dem Berliner Musikleben im Zeitraum zwischen der Gründung seiner Konzertdirektion 1880 und seinem Tod 1902 gegeben? Zu diesem Zusammenhang gehört ein ganzer Fragenkomplex: Wie groß war sein Wirkungsbereich? Worin lag der Schwerpunkt seiner Tätigkeit? Welche Ideale hatte er für das Konzert- und Konzertagentenwesen? In welchem Spannungsfeld des damaligen Berliner Musiklebens befand er sich? Was führte er in die öffentlichen Konzerte in Berlin ein? Wie hat seine Vermittlung die Tätigkeiten von Musikern verändert? Was erwartete man von ihm? Ob und inwieweit hat er die Verhaltensnorm, den Geschmack oder den Erwartungshorizont des Publikums beeinflusst? Auf welcher geschichtlichen und sozialen Grundlage entfaltete er seine Tätigkeit? Wie hängt seine Tätigkeit mit dem Strukturwandel des Musiklebens zusammen? Kann man in seiner Tätigkeit richtungsweisende oder gar normgebende Auswirkungen auf das Konzertleben finden?

\subsection{Voraussetzungen}

In der zweiten Hälfte des 19. Jahrhunderts vollzog sich in Deutschland ein grundsätzlicher Strukturwandel des öffentlichen Musiklebens. Dieser bildete einerseits die Voraussetzungen für die

\footnotetext{
${ }^{6}$ Artur Schnabel: Aus dir wird nie ein Pianist, Hofheim 1991, S. 53. Vgl. auch S. 152.

${ }^{7}$ Edith Stargardt-Wolff: Wegbereiter großer Musiker. Unter Verwendung von Tageblättern, Briefen und vielen persönlichen Erinnerungen von Hermann und Louise Wolff, den Gründern der ersten Konzertdirektion 18801935, Berlin u. a. 1954, S. 51.

${ }^{8}$ Heinrich Ehrlich: Dreißig Jahre Künstlerleben, Berlin 1893, S. 317.
} 
rapide Entwicklung der 1880 in Berlin gegründeten Konzertdirektion Hermann Wolff (und Jules Sachs) ${ }^{9}$ und brachte andererseits dem Konzertbetrieb grundlegende Veränderungen ein.

Der beträchtliche wirtschaftliche, industrielle und kommerzielle Aufschwung Berlins im Zeitraum zwischen der Reichsgründung und dem Ausbruch des Ersten Weltkriegs, der mit einem stabilen, kontinuierlichen Bevölkerungszuwachs Hand in Hand ging, wurde vielenorts dargestellt und muss hier nicht wiederholt werden. ${ }^{10}$ Als Voraussetzung für die vorliegende Arbeit muss jedoch erwähnt werden, dass sich die Reichshauptstadt in dieser Zeit auch als Musikmetropole unter den europäischen Großstädten etablierte. In den 1860er und 1870er-Jahren vollzogen sich Veränderungen der musikalischen Topographie in Deutschland: Berlin begann, den traditionellen Kunststädten den Rang abzulaufen, und bekam eine zentrale Rolle im deutschen Musikleben der Zeit. Damit büßte die Stadt Leipzig allmählich ihre Bedeutung als Mittelpunkt der Musikkultur ein. Rebecca Grotjahn legte überzeugend dar, ${ }^{11}$ dass die Verlagerung des Schwergewichtes von Leipzig auf Berlin nicht einfach auf die gewachsene politische Bedeutung der Reichshauptstadt zurückzuführen ist. Nach Grotjahn deutete die Übereinstimmung des politischen Zentrums mit dem Mittelpunkt des Konzertlebens darauf hin, dass Konzerte Teil des Prestiges einer Stadt geworden waren. Ihr zufolge sind sie auch ein Symptom für die »gewachsene Bedeutung der Institution Konzert für das gesellschaftliche Leben generell ${ }^{12}$

In seinem 1910 erschienenen Buch führte Karl Scheffler die Entwicklungsenergien, die für das Berlin der Zeit nach 1870 typisch sind, auf den internationalen Handels- und Industriegeist der Reichshauptstadt zurück, wobei er sie mit »den Städten der neuen Welt« verglich:

Was nun aber für Berlin außerordentlich bezeichnend ist und einen tiefen Blick in die Psyche dieses Stadtindividuums zu tun gestattet, das ist die Tatsache, daß die junge Reichshauptstadt sich mit wahrer Gier und mit Leidenschaft zum Anwalt der neuen Lebensidee gemacht hat, zur Vorkämpferin der neuen Industriekultur, daß es sich zuerst in Deutschland und am rücksichtslosesten in ganz Europa amerikanisiert hat.[...] Berlin konnte und mußte sich amerikanisieren, weil es an der Entfaltung des wirtschaftlichen Materialismus durch tief wurzelnde Traditionen nicht verhindert wurde, weil es auf dem

\footnotetext{
${ }^{9}$ Wie im Teilkapitel 2.2 der vorliegenden Arbeit gezeigt wird, schloss sich die Firma 1916 mit der Konzertdirektion Jules Sachs zusammen und trug bis 1933 den zusammengesetzten Namen »Konzertdirektion Hermann Wolff und Jules Sachs«.

${ }^{10}$ Vgl. z. B. Peter Ring: Bevölkerung. I. Von den Anfängen bis 1945, in Berlin Handbuch. Das Lexikon der Bundeshauptstadt, hg. vom Presse- und Informationsamt des Landes Berlin, Berlin 1992, S. 236-239, vor allem S. $237 \mathrm{f}$.

${ }^{11}$ Vgl. Rebecca Grotjahn: Die Sinfonie im deutschen Kulturgebiet 1850 bis 1875. Ein Beitrag zur Gattungs- und Institutionengeschichte, Sinzig 1998, S. 121.

${ }^{12}$ Grotjahn: Die Sinfonie im deutschen Kulturgebiet 1850 bis 1875, ebd.
} 
östlichen märkischen Boden seit Jahrhunderten eine Pionierstadt war, ähnlich den Städten der neuen Welt. ${ }^{13}$

Auch Adolf Weissmann fand amerikanische Tendenzen in Berlin und sprach in seinem 1911 veröffentlichten Buch Berlin als Musikstadt den »Amerikanismus« des Musiklebens dieser Stadt an. ${ }^{14} \mathrm{Zu}$ den »günstigste[n] Verhältnisse[n] «, die die Musiker aller Länder nach Berlin lockten, zählte Weissmann neben der Stadt selbst, deren Energie durch den kommerziellen und industriellen Aufschwung gewachsen war, dem jüdischen Publikum, das die Kosten für den musikalischen Genuss nicht scheute, dem gefestigten Musikleben und den musikalischen Erziehungsinstituten auch einen Mann, der ein »System« erfunden habe:

Noch mehr: ein genialer Mann, Musiker und Geschäftsmann zugleich, erfindet mit dem rechten Instinkt für die Zeit ein System. Ohne den Amerikanismus Berlins, ohne seinen Geschäftsgeist, ohne seinen Reichtum wäre es nicht möglich gewesen. Im Bunde mit ihm aber verspricht dieses System seinem Erfinder den höchsten Erfolg. [...] Das System ist in sich geschlossen. Hermann Wolff sein Erfinder.

Weissmann war nicht der einzige Beobachter, der Wolff als Erfinder eines Systems darstellte. Schon 1892 bemerkte Eugen Zabel, dass Wolff eine Antriebkraft des deutschen Konzertlebens geworden sei und dass sich sein »System« den Künstlern, wenn auch nicht ohne Einwände, als nützlich erwiesen habe:

So ist die Konzertdirektion Hermann Wolff in jedem Fall eine wichtige Triebfeder im deutschen Konzertleben geworden. Es lohnt sich das System, nach dem sie eingerichtet und geleitet wird, kennen zu lernen, so weit das einem ausserhalb des Unternehmens Stehenden überhaupt möglich sein kann. Mängel und Uebelstände werden sich dabei, wie bei jedem Menschenwerk[,] herausgestellt haben, aber als Ganzes betrachtet liegt hier die Schöpfung eines klugen und energischen Mannes vor, vor deren Nothwendigkeit die Künstler am Meisten überzeugt sein dürften. ${ }^{15}$

\footnotetext{
${ }^{13}$ Karl Scheffler: Berlin. Ein Stadtschicksal, Berlin ${ }^{3} 1910$, S. $140 f$.

${ }^{14}$ Dieses und das nächste Zitat aus Adolf Weissmann: Berlin als Musikstadt. Geschichte der Oper und des Konzerts von 1740 bis 1911, Berlin u. a. 1911, S. 352.

${ }^{15}$ Eugen Zabel: Konzert und Konzertunternehmer, in Neue Berliner Musikzeitung 46 (1892), S. 376.
} 
Um welches System handelt es sich hier? Als Aussage eines Zeitgenossen, der dieses System als Musiker - oder als »Ware« - erlebte, sind die Erinnerungen von Carl Flesch berücksichtigungswert. Er führt die Entwicklung des Berliner Konzertlebens auf das Vertriebssystem der Künstler zurück, das Hermann Wolff in großem Umfang in die Praxis umsetzte:

My first visit was to the Wolff Concert, to whom the arrangement of both my concerts had been entrusted. The head of the firm was Hermann Wolff, a remarkable man whose enterprising spirit could no doubt have proved itself in a much wider field too. [...] The development of German concert life under his influence during the next fifty years was in no way due to any artistic or social need. It was the outcome of Wolff's idea of the politicoeconomic correspondence between artistic performances and agricultural or industrial products. Why shouldn't a virtuoso be »ordered« and »dispatched« in the same way as wheat or steel? It was simply a question of organization; the concert-giving societies had to become accustomed to »ordering« their artists through a central agency. Supply and demand were to fix the artist's fee just as stocks and shares were priced on the exchange. When it is remembered that until then every distinguished artist had to have his own impresario, while for lesser-known musicians there were only slender possibilities of being heard outside their permanent place of residence, Wolff's theory must be described as entirely novel. ${ }^{16}$

Traditionell wurden Tätigkeiten von Musikern in ihrem Privatkreis verwaltet. Viele berühmte Musiker stellten einen Privatsekretär ein, der seinem Arbeitsgeber die lästigen geschäftlichen Anordnungen, die Korrespondenz, die Abmachungen mit Saalbesitzern und Konzertgesellschaften, die Ankündigungen, den Verkauf von Eintrittskarten, die Organisation von Tourneen und anderes abnahm. Im Verlauf der Zeit wurden Konzertleben und Musikmarkt immer größer und komplizierter, so dass die Selbst- oder Privatverwaltung der Tätigkeit Mitte des 19. Jahrhunderts nicht mehr effizient durchführbar wurde. In diesem Zusammenhang traten selbständige, fest ansässige Konzertagenten wie Albert Gutmann in Wien ${ }^{17}$ und Hermann Wolff in Berlin auf, die sich auf die Vorbereitung und Durchführung von Konzerten spezialisiert hatten und von ihrem Büro

\footnotetext{
${ }^{16}$ Carl Flesch: The Memoirs of Carl Flesch, übers. von Hans Keller und hg von demselben unter Mitarbeit von C. F. Flesch, London 1957, S. 133. Die Erinnerungen von Carl Flesch wurden, übersetzt aus seinem deutschen Manuskript, zunächst auf Englisch veröffentlicht. In der 1960 erschienenen deutschen Ausgabe ist ein Großteil der hier zitierten Stelle ausgelassen. Vgl. Carl Flesch: Erinnerungen eines Geigers, Freiburg i. Br. 1960, S. 93. ${ }^{17} \mathrm{Zu}$ Gutmann vgl. auch Albert Gutmann: Aus dem Wiener Musikleben. Künstlererinnerungen 1873-1908, Wien 1914; Die »Konzert-Direktion Gutmann«, hg. von Andreas Holzer, Wien 1999.
} 
aus verschiedenen Künstlern gleichzeitig dienten. ${ }^{18}$ Damit kamen die Privatsekretäre aus der Mode. $^{19}$

$\mathrm{Ab}$ der Mitte des 19. Jahrhunderts erfuhr das europäische Konzertwesen durch Amerikatourneen von Musikern wie Henri Herz, Leopold von Meyer, Camillo Sivori und anderen vom amerikanischen Konzertagentenwesen. ${ }^{20}$ Die dortigen Impresari, wie Phineas Taylor Barnum, ${ }^{21}$ Bernard Ullmann, ${ }^{22}$ Maurice $\mathrm{Grau}^{23}$ und Maurice Strakosch, ${ }^{24}$ erzielten große Erfolge in der Organisation amerikanischer Tourneen für Virtuosen aus Europa, und dadurch institutionalisierten sie sich in der Praxis des Konzertbetriebs, was auch in Europa bekannt wurde. ${ }^{25}$ Es ist zu vermuten, dass die Assoziation mit diesen geschäftstüchtigen amerikanischen Managern zumindest teilweise dazu führte, dass die Tätigkeit von Hermann Wolff, der selbst niemals in Amerika gewesen war, zu seiner Zeit oft als »amerikanisch« bezeichnet wurde.

Die »Konzertagentur« oder der »Konzertagent « als Vermittler von musikalischen Arbeitskräften und die »Konzertdirektion« oder der »Konzertdirektor« als Veranstalter von Konzerten werden funktionell unterschieden, obwohl sie institutionell oft identisch sind. ${ }^{26}$ Offensichtlich hatten die beiden letzten Begriffe im damaligen Wortgebrauch angenehmere Implikation als die beiden ersten. ${ }^{27}$ Mit Rücksicht auf seine selbständige Wirkungskraft im

${ }^{18} \mathrm{Zu}$ den Berufsgenossen Hermann Wolffs zu seiner Zeit vgl. Walter Salmen: Das Konzert. Eine Kulturgeschichte, München 1988, S. 72.

${ }^{19} \mathrm{Zu}$ diesem Verlauf vgl. z. B. Paul Bekker: Das Deutsche Musikleben, Stuttgart u. a. 1922, S. 145-148; William Weber: The Origins of the Concert Agent in the Social Structure of Concert Life, in Le concert et son public: Mutations de la vie musicale en Europe de 1780 à 1914, hg. von Hans Erich Bödeker u. a., Paris 2002, S. 121147, vor allem S. 122; Ders.: From the Self-Managing Musician to the Independent Concert Agent, in The Musician as Entrepreneur, 1700-1914. Managers, Charlatans, and Idealists, hg. von William Weber, Bloomington 2004, S. 105-129, vor allem S. 106.

${ }^{20}$ Heinrich W. Schwab: Konzert. Öffentliche Musikdarbietung vom 17. bis 19. Jahrhundert, Leipzig 1971 S. 116.

${ }^{21}$ Phineas Taylor Barnum ist bekannt vor allem wegen des Triumphs, den er mit der amerikanischen Tournee Jenny Linds von 1850 bis 1851 erzielte. Zu seinem Leben und seinen Geschäftstätigkeiten vgl. P.T. Barnum: The Life of P. T. Barnum, Written by Himself, New York 1855.

${ }^{22}$ Die Dissertation von Laurence Marton Lerner behandelt die Geschäftsmethoden, die Bernard Ullmann in seiner Tätigkeit für Henri Herz, Henriette Sontag, Sigismund Thalberg usw. ausarbeitete, und die kulturellen Hintergründe seiner Tätigkeit. Laurence Marton Lerner: The Rise of the Impresario: Bernard Ullman and the Transformation of Musical Culture in Nineteenth Century of America, Ph. D. The University of Wisconsin, 1970. Vgl. auch Schwab: Konzert, S. 116; Laure Schnapper: Bernard Ullmann-Henri Herz: An Example of Financial and Artistic Partnership, 1846-1849, in The Musicians as Entrepreneur, 1700-1914, S. 130-144.

${ }^{23}$ Maurice Grau war Mitarbeiter der bekannten Firma Abbey Schoeffel \& Grau und wurde später alleiniger Manager der Metropolitan Opera. Die Konzertdirektion Hermann Wolff war die auswärtige Vertreterin für die Abbey Schoeffel \& Grau in den 1890er Jahren. Vgl. Abschnitt 2.3.1 der vorliegenden Arbeit.

${ }^{24}$ Maurice Strakosch war zunächst sowohl als Konzertpianist wie als Impresario tätig und widmete sich später der Impresario-Tätigkeit in Amerika und Europa. Zu Strakosch vgl. Laurence Marton Lerner: The Rise of the Impresario, S. 38, Fn. 42.

${ }^{25}$ Heinrich Ehrlich: Modernes Musikleben, Berlin 1895, S. 10.

${ }^{26}$ Hanns-Werner Heister: Das Konzert. Theorie einer Kulturform, Bd. 1, Wilhelmshaven u. a. 1983, S. 355.

${ }^{27}$ Ebd., Bd. 2, S. 557f, Fn. $108^{\mathrm{a}}$. 
Musikleben nannte Eugen Zabel Hermann Wolff »Konzertdirektor« und sprach von der »Rangerhöhung«, derer er würdig sei:

Man spricht nicht mehr von einer Agentur, sondern von einer Konzertdirektion. »Agentur« klingt nicht gut, das Wort hat einen kleinlichen Zuschnitt, auch kleben daran allerlei unangenehme Nebenbegriffe, an die man lieber nicht erinnert. »Konzertdirektor « - das ist ein voller, vornehmer Auftakt, den man sich gefallen lassen kann. Hermann Wolff durfte sich diese Rangerhöhung verleihen; denn er war mittlerweile eine Macht geworden, mit der man rechnen musste. ${ }^{28}$

\subsection{Forschungsstand}

Trotz ihrer unzweifelhaften Bedeutung als treibende Kraft des Berliner Musiklebens am Ende des 19. Jahrhunderts und Anfang des 20. Jahrhunderts fehlt bislang eine detaillierte wissenschaftliche Untersuchung zu Hermann Wolff bzw. seiner Konzertdirektion. Als Monographie zu diesem Thema zu nennen ist nur das 1954 erschienene Erinnerungsbuch von Edith Stargardt-Wolff, ${ }^{29}$ einer Tochter von Hermann und Louise Wolff und einer Mitarbeiterin ihrer Konzertdirektion. Dieser mangelhafte Forschungsstand ist zum einen der Vernachlässigung des kommerziellen Unternehmertums als bedeutendes Element der Musikkultur in der traditionellen Musikgeschichtsschreibung allgemein geschuldet, zum anderen eine Folge der schlechten Quellenlage konkret zu diesem Thema.

Was den ersten Punkt betrifft, gab es in den letzten Jahrzehnten etwas Bewegung in der Forschung. Die Fragen, die seit den 1980er-Jahren vor allem im englischen Sprachraum gestellt wurden, um die vermeintliche Autonomie der Musik, die Begriffe wie Kanon, Kunstwerk und andere aufzuarbeiten, verlangten eine Aufklärung der »politischen« Dimension der kulturell bedingten Kriterien über Musik und erregten auch die Interessen für den Unternehmergeist, der früher als der »erhabenen« Kunst widersprechend gegolten hatte, sich jedoch als ein unübersehbarer Teil der - mehr oder weniger, bewusst oder unbewusst - marktorientierten musikalischen Praxis erwies. $^{30}$

In diesem Kontext wurde zunehmend auch die Rolle und Funktion der Machthaber hinter der Bühne einbezogen, vor allem aus der Perspektive der Programmpolitik und der Propagandastrategie. In seiner Arbeit zur politischen Dimension der musikalischen Interpretation Hans von Bülows analysierte Hans-Joachim Hinrichsen die Programmgestaltung Bülows in der

\footnotetext{
${ }^{28}$ Zabel: Konzerte und Konzertunternehmer, S. 373.

${ }^{29}$ Stargardt-Wolff: Wegbereiter großer Musiker.

${ }^{30}$ Vgl. z. B. die Aufsätze in The Musicians as Entrepreneur, 1700-1914.
} 
letzten Phase seiner Karriere als Ergebnis seiner Zusammenarbeit mit Hermann Wolff. ${ }^{31}$ Laure Schnapper erklärte, wie effektiv und strategisch Bernard Ullman und Henri Herz für die amerikanische Tournee im Jahr 1851 kooperierten. ${ }^{32}$ In einem größeren Umfang untersuchte die Arbeit von R. Allen Lott, mit welchen persönlichen und institutionellen Unterstützungen die europäischen Klaviervirtuosen in der zweiten Hälfte des 19. Jahrhunderts die amerikanischen Tourneen in Angriff nahmen, wobei der Verfasser den Rollen der amerikanischen Manager und ihren strategischen Verfahren eingehend nachging. ${ }^{33}$ Aufgrund der Untersuchung unerforschter Archivmaterialien verfolgte die umfangreiche Arbeit von Christopher Fifield die Geschichte der führenden Londoner Konzertagentur Ibbs and Tillett von ihrer Gründung 1906 bis zur Liquidation 1990. ${ }^{34}$ In ihrem Aufsatz zu Wanda Landowska legte Annegret Fauser exemplarisch dar, wie diese Cembalistin zu Beginn ihrer Laufbahn, vor allem zwischen 1904 und 1906 in Paris, durch ihre Kleidung, Darbietung und Sprache ihre Weiblichkeit und Eleganz strategisch unterstrich und sich dadurch erfolgreich das Image der »Göttin des Cembalos« verschaffte, wobei Fauser auf die Wirkung der Imagepflege von Gabriel Asturc aufmerksam macht. ${ }^{35}$ Mit dem Fokus auf Albert Gutmann erklärte Laetitia Corbière, wie die Konzertagenten des späten 19. Jahrhunderts bei europäischen Tourneeveranstaltungen den jeweils unterschiedlichen Geschmack und die Gewohnheit jedes Publikums berücksichtigten und dadurch zum stärkeren Bewusstsein der Nationalidentität beitrugen. ${ }^{36}$ In seiner kürzlich erschienenen Arbeit über Hugo Botstiber beleuchtete Robert Lackner die Karriere dieses Wiener Kulturmanagers zwischen 1900 und 1938 im Detail und evaluierte seinen Einfluss auf das Wiener Musikleben allgemein sowie seine Leistungen für das Wiener Konzerthaus im Besonderen. ${ }^{37}$

Was die Primärquellen angeht, die uns Informationen zur Tätigkeit von Hermann Wolff und seiner Konzertdirektion vermitteln könnten, war die Ansicht verbreitet, dass sie nach der Beschlagnahmung durch die Nationalsozialisten verbrannt seien, ${ }^{38}$ wobei man sich auf die

\footnotetext{
${ }^{31}$ Hans-Joachim Hinrichsen: Musikalische Interpretation Hans von Bülow, Stuttgart 1999, vor allem S. 81-87.

${ }^{32}$ Schnapper: Bernard Ullman - Henri Herz. An Example of Financial and Artistic Partnership, 1846-1849.

${ }^{33}$ R. Allen Lott: From Paris to Peoria. How European Piano Virtuosos Brought Classical Music to the America Heartland, New York 2003.

${ }^{34}$ Christopher Fifield: Ibbs and Tillett: The Rise and Fall of a Musical Empire, Aldershot 2005.

${ }^{35}$ Annegret Fauser: Creating Madame Landowska, in Women and Music. A Journal of Gender and Culture 10 (2006), S. 1-23. Vor kurzem wurden auch die Lebenserinnerungen von Astruc, die im französischen Original erst 2013 erschienen waren, auf Deutsch veröffentlicht. Vgl. Gabriel Astruc: Meine Skandale. Strauss, Debussy, Stravinsky, Berlin 2015.

${ }^{36}$ Laetitia Corbière : Le Concert et la Tournée. Perspectives sur la Direction de Concerts Albert Gutmann, in Artl@s Bulletin 4 (2015), S. 26-38.

${ }^{37}$ Robert Lackner: Hugo Botstiber und das Wiener Konzerthaus. Leben und Wirken eines Kulturmanagers von Fin de Siècle bis zum Anschluss, Wien u. a 2016.

${ }^{38}$ Beatrix Borchard: Stimme und Geige. Amalie und Joseph Joachim: Biographie und Interpretationsgeschichte, Wien u. a. 2005, S. 49.
} 
Schilderung von Edith Stargardt-Wolff zu dem Ereignis stützte, das sich im Jahr 1936 im Büro der bereits geschlossenen Firma abspielt habe:

Einige Wochen darauf schrieb mir meine Schwester Lili in meinen Ferienaufenthalt in die Schweiz, daß plötzlich - ohne vorherige Anmeldung - einige Herren der Reichsmusikkammer im Büro erschienen seien. Sie fand sie bei eifriger Lektüre unserer Akten vor. Sie ließen sich durch ihren Eintritt nicht im geringsten stören, erwiderten nicht einmal ihren Gruß, sondern machten sich ab und zu gegenseitig auf einige ihnen besonders interessant erscheinende Briefstellen aufmerksam. Dann hatten sie den Dachboden durchstöbert, das dort ruhende Material aber für viel zu umfangreich erklärt, um bei einem einmaligen Besuch durchzukommen. Einige Tage darauf aber sei die Gestapo mit einem großen Lastwagen vorgefahren, habe dem Kastellan streng untersagt, die Eigentümer zu benachrichtigen, und habe alles, was nicht niet- und nagelfest war, weggeschleppt. ${ }^{39}$

Während ein Wiederauftauchen der Geschäftsakten, die im Büro der Konzertdirektion verblieben waren, ziemlich unwahrscheinlich ist, deutet die Autorin in der Einleitung zum gleichen Buch jedoch an, dass einige Papiere, die die Tätigkeiten ihrer Eltern dokumentieren, beim Verfassen ihres Erinnerungsbuches noch in ihrem Besitz waren. ${ }^{40}$ Der Untertitel dieses Buches enthält sogar die Angabe »Unter Verwendung von Tagebuchblättern, Briefen und vielen persönlichen Erinnerungen von Hermann und Louise Wolff«, und tatsächlich finden sich darin zahlreiche Zitate aus den genannten Quellen.

In ihrem undatierten, doch höchstwahrscheinlich im Frühling 1948 in New York entstandenen Brief an Serge Koussevitzky erwähnt Stargardt-Wolff diese Überlieferung und führt zur Veröffentlichung ihres Erinnerungsbuchs aus:

I began to write my memoirs, very far reaching remembrances, things that happened already before I was born down to the present time. It was lucky that some of my parents diaries were saved and that they could be sent to me. Then there is still quite a number of letters written by my father in 1881 during a tour with Rubinstein in Spain, much about Bülow and Brahms, all very vivid and personal things and very much about the golden age of music in Berlin and - before all - my mother's person ability, contracts with artists etc. etc. All they

\footnotetext{
${ }^{39}$ Stargardt-Wolff: Wegbereiter großer Musiker, S. 304.

${ }^{40}$ Ebd., S. 12.
} 
has been written down now and has been translated perfect in English and I'm just here in New York for the last touches and then will try to find a publisher. ${ }^{41}$

Diese Angabe deutet an, dass Briefe und Tagebücher von Hermann und Louise Wolff während der Nazi- und Kriegszeit in Berlin aufbewahrt worden waren und danach nach Amerika geschickt wurden, wo Edith Stargardt-Wolff, die bis Mai 1945 fast drei Jahre lang im Konzentrationslager in Theresienstadt interniert worden war, ${ }^{42}$ damals mit ihrem zweiten Mann zeitweilig bei ihrem Sohn wohnte.

Glücklicherweise wurde der Verfasserin der vorliegenden Arbeit ein Teil dieser Materialien (in Form eines Nachlasses der Familie Wolff, die sich in Amerika im Privatbesitz befanden und noch befinden) im Verlauf der Untersuchung mit sehr freundlicher Genehmigung der Nachkommen der Familie zugänglich gemacht. ${ }^{43} \mathrm{Zu}$ diesem Nachlass gehören ein Tagebuch von Hermann Wolff aus der Zeit des Deutsch-Französischen Krieges, ein weiteres von Louise Wolff, das ihren Alltag im Umgang mit vielen Künstlern widerspiegelt, zahlreiche Familienkorrespondenzen, deren Großteil Briefe von Hermann bilden, die auf Geschäftsreisen an Louise in Berlin geschrieben worden waren, viele Briefe von Musikern, Verträge der Konzertdirektion in ihrer früheren Zeit, verschiedene Unterlagen, Konzertprogramme, Zeitungsausschnitte, Familienfotos, ein Gästebuch von Edith Stargardt-Wolff und weitere Materialien. Diese neu zugänglich gewordenen Quellen sind in der Datenbank als Anhang zur vorliegenden Arbeit erfasst. ${ }^{44}$

\subsection{Quellenlage}

Außer diesem Nachlass der Familie Wolff stützt sich die vorliegende Arbeit auf verschiedene archivalische Quellen. Da der derzeitige Verbleib der oben erwähnten Geschäftsakten, die im

\footnotetext{
${ }^{41}$ Brief von Edith Stargardt-Wolff an Serge Koussevitzky, o. D [1948?]. Serge Koussevitzky Archive, Library of Congress, Box-Folder 58/12. Es ist ein wörtliches Zitat aus einem Brief von Edith Stargardt-Wolff, die keine englische Muttersprachlerin war. Aus diesem Brief geht hervor, dass die Verfasserin beabsichtigte, ihren Erinnerungsband eigentlich in Amerika auf Englisch zu veröffentlichen. Im gleichen Brief bat sie den Dirigenten darum, ein Vorwort für ihr Buch zu schreiben. Diese Bitte wurde jedoch wegen Zeitmangels abgelehnt. Der Erinnerungsband wurde schließlich erst 1954 vom Berliner Verlag Bote \& Bock in der deutschen Sprache mit einem Vorwort von Bruno Walter veröffentlicht, nachdem die Autorin aus ihrer Emigration wieder in Berlin im März 1951 zurückgekommen war. Kürzlich erschien eine englische Übersetzung dieses Buches von Edmund Sallis. Vgl. Edith Stargardt-Wolff: Pathfinder of Great Musicians, übrs. von Edmund Sallis, New York 2017. ${ }^{42}$ Entschädigungsakte (Edith Stargardt), Entschädigungsbehörde Berlin (im Folgenden EBB), Reg. Nr. 22238, B1. C1.

${ }^{43} \mathrm{Zu}$ diesem Vorgang vgl. Sayuri Hatano, Ein Paperchase. Auf der Suche nach dem Nachlass der Berliner Konzertagenten Hermann und Louise Wolff und ihrer Familie, in Archive zur Musikkultur nach 1945. Verzeichnis und Texte, hg. von Antje Kalcher und Dietmar Schenk, München 2016, S. 38-44.

${ }^{44}$ Die Datenbank wird in Kürze in den Kalliope-Verbundkatalog eingeschlossen und öffentlich zugänglich: https://kalliope-verbund.info, 02.06.2020.
} 
geschlossenen Büro der Konzertdirektion verblieben waren, nicht bekannt ist, war die Recherche verstreuter Akten und Korrespondenzen, die in öffentlichen Archiven oder in den Nachlässen von Geschäftspartnern der Konzertdirektion überliefert sind, notwendig. Im Folgenden werden nur die wichtigsten Bestände, die für die vorliegende Arbeit in Frage kommen, angegeben.

Im Landesarchiv Berlin sind die Polizeiakten zugänglich, die uns die wesentlichen Informationen zur Geschichte der Konzertdirektion Hermann Wolff vor allem in der Zeit nach ihrer Vereinigung mit der Konzertdirektion Jules Sachs 1916 vermitteln. Im Rahmen der vorliegenden Arbeit werden das Handelsregister dieser vereinigten Firma und die ihm beigefügten Akten (140 Blätter), ${ }^{45}$ die Akten zu ihrer Geschäftsführung von 1905 bis 1929 (231 Blätter ${ }^{46}$ sowie von 1930 bis 1935 (94 Blätter), ${ }^{47}$ zu Louise Wolff und Hermann Fernow (33 Blätter), ${ }^{48}$ sowie zu den Taxen und Gebührentarifen für Konzertagenten (212 Blätter) ${ }^{49}$ untersucht.

Die Entschädigungsbehörde des Landes Berlin bewahrt die Akten zur Entschädigung der Opfer des Nationalsozialismus auf. Die dort überlieferten Entschädigungsakten zur Konzertdirektion Hermann Wolff und Jules Sachs, ${ }^{50}$ Edith Stargardt, ${ }^{51}$ Erich Sachs ${ }^{52}$ und Werner Wolff $^{53}$ sind hilfreich, um die Geschichte dieser Firma und die Biographien ihrer Mitarbeiter aufzuarbeiten.

Der Bestand des Goethe- und Schiller-Archives in Weimar enthält die Akten des Allgemeinen Deutschen Musikvereins (im Folgenden ADMV). Im Rahmen der vorliegenden Arbeit werden vor allem 33 Briefe von Hermann Wolff an Hans Bronsart von Schellendort bezüglich der Veranstaltung der Berliner Tonkünstlerversammlung des gleichen Vereins im Jahr 1891 ausgewertet. $^{54}$

Der Nachlass von Richard Strauss wird von der Familie des Komponisten aufbewahrt und auf Anfrage im Richard-Strauss-Institut in Garmisch-Partenkirchen zur Verfügung gestellt. Er

\footnotetext{
45 »Handelsregister B (HRB) Konzert-Direktion Hermann Wolff GmbH«, Landesarchiv Berlin (im Folgenden LAB), A. Rep. 342-02, Nr. 59673.

$46 »$ Theateragenten Nr. 2134- Theateragent Hermann Wolff und Jules Sachs«, LAB, A. Pr. Rep. Br. 030-05, Nr. 3670.

${ }^{47} »$ Theateragenten Nr. 2134- Theateragent Hermann Wolff und Jules Sachs«, LAB, A. Pr. Rep. Br. 030-05, Nr. 3671.

48 »Auskunftserteilung über die Inhaber der Konzertdirektion Hermann Wolff, die Witwe Louise Wolff geb. Schwarz und Direktor Hermann Fernow«, LAB, A. Pr. Rep. Br. 030, Nr. 14355.

$49 »$ Taxen für Stellenvermittler, Gebührentarif für Konzertagenten«, LAB, A. Pr. Rep. Br. 030-05, Nr. 3370.

${ }^{50}$ Entschädigungsakte (Fa. Konzertdirektion Hermann Wolff u. Jules Sachs GmbH., Antragsteller: Werner Wolff), EBB, Reg. Nr. 40762.

${ }^{51}$ Entschädigungsakte (Edith Stargardt), EBB, Reg. Nr. 22238.

${ }^{52}$ Entschädigungsakte (Erich Sachs), EBB, Reg. Nr. 74085.

${ }^{53}$ Entschädigungsakte (Werner Wolff), EBB., Reg. Nr. 271967.

${ }^{54}$ Goethe- Schiller-Archiv (im Folgenden GSA) 70/61, »ADMV II. Allgemeiner Schriftwechsel, Akten Hans Bronsart v. Schellendorf, Schriftwechsel 1890-1891«.
} 
enthält 58 Briefe von Hermann Wolff an Richard Strauss aus dem Zeitraum 1887 und 1898, die im Rahmen dieser Arbeit untersucht werden.

Die Staatsbibliothek zu Berlin Preußischer Kulturbesitz verwaltet viele Nachlässe, die mit dem Thema der vorliegenden Arbeit eng verbunden sind. Der Nachlass von Hans von Bülow enthält knapp 1.000 Briefe von Hermann Wolff. ${ }^{55}$ Diese Briefe konnten im Rahmen dieser Arbeit leider nur teilweise untersucht werden. ${ }^{56}$

Die sonstigen Einzelquellen, die im Verlauf der vorliegenden Arbeit hinzugezogen werden, werden jeweils in der Fußnote angegeben.

\subsection{Gliederung der Arbeit}

Anschließend an dieses einleitende Kapitel wird im zweiten Kapitel versucht, die innere Organisation und den Wirkungskreis der Konzertdirektion Hermann Wolff (und Jules Sachs) von ihrer Eröffnung 1880 bis zu ihrer Liquidation 1935 möglichst ausführlich darzustellen. Wegen der begrenzten Quellenlage muss die Darstellung ein Entwurf zur Firmengeschichte bleiben und der Schwerpunkt notwendigerweise auf die Zeit nach der Fusion der zwei Konzertdirektionen 1916 gelegt werden. Trotzdem liefert hier die Untersuchung bisher unerforschter Quellen neue Erkenntnisse zum Geschäft und zur Tätigkeit der Konzertdirektion Hermann Wolff (und Jules Sachs).

Im Teilkapitel 2.1 werden die Biographien der wichtigsten Mitarbeiter der Konzertdirektion aufgearbeitet. Abschnitt 2.1.1 über Hermann Wolff erschließt ausführlich seine Tätigkeit als Musikkritiker im Zeitraum zwischen 1878 und 1880, da die Interessen und das

Problembewusstsein, die in seinen Beobachtungen zutage treten, die Grundlage für seine zukünftige Tätigkeit als Konzertagent bilden. Unter der Auswertung der Quellen im Wolff-Nachlass verfolgt Abschnitt 2.1.2 den Lebensweg von Louise Wolff, der Frau Hermann Wolffs, die nach seinem Tod sein Geschäft übernahm. Die Abschnitte von 2.1.3 bis 2.1.5 widmen sich jeweils den wichtigen Mitarbeitern der Konzertdirektion, namentlich Erich Sachs, Erich Simon und Edith Stargardt(-

\footnotetext{
${ }^{55}$ Die Briefe von Hermann Wolff an Hans von Bülow waren bislang nur pauschal verzeichnet; ihre Erfassung im Verbundkatalog Kalliope ist im März 2018 im Gang. Nach den Signaturen sollen im Bülow-Nachlass 983 Briefe von Hermann Wolff an Bülow vorliegen, außerdem vier Schreiben von Louise Wolff. Tatsächlich befinden sich aber darunter auch einzelne Briefe von Dritten an Hermann Wolff, sodass die tatsächliche Zahl der Briefe von Wolff an Bülow etwas geringer als 983 sein dürfte (E-Mail-Antwort von Dr. Roland Schmidt-Hensel, dem Leiter des Mendelssohn-Archivs Staatsbibliothek zu Berlin, vom 29.3 2018).

${ }^{56}$ Zum Briefwechsel Bülow-Wolff vgl. Hans-Joachim Hinrichsen: Die Reisen der Meininger Hofkapelle und ihre Organisation durch die Agentur Hermann Wolff, in Le musicien et ses voyages. Pratiques, réseaux et représentations, hg. von Christian Meyer, Berlin 2003, S. 283-290, vor allem S. 283, Fn. 3.
} 
Wolff), deren bisher unbekannte Lebensläufe durch die Untersuchung archivalischer Quellen beleuchtet werden.

Teilkapitel 2.2 geht der inneren Organisation der Konzertdirektion nach. Dabei behandelt Abschnitt 2.2.1 die erste Phase der Entwicklung der Firma, die durch den Charakter des Familienbetriebs noch stark geprägt war. Im Abschnitt 2.2.2 wird der Zeitraum betrachtet, in dem die Firma unter der stabilen Geschäfts- und Aufgabeverteilung ihrer drei Geschäftsführer Louise Wolff, Erich Sachs und Erich Simon stand. Abschnitt 2.2.3 wirft Licht auf den Arisierungsversuch, den die Konzertdirektion nach der Machtergreifung durch die Nationalsozialisten für ihr Fortbestehen selbst unternahm, ohne ihn abschließen zu können.

Im Teilkapitel 2.3 wird versucht, den Einflussbereich der Konzertdirektion Hermann Wolff (und Jules Sachs) einzuschätzen. Abschnitt 2.3.1 analysiert die Künstlerlisten der Konzertdirektion, um einen Überblick über die vertretenen Künstler zu schaffen. Abschnitt 2.3.2 beschäftigt sich mit der Frage, wie viele und welche Konzerte unter ihrer Organisation zustande kamen und wo genau sie stattfanden, versucht also einen umrisshaften Überblick über ihre Konzertveranstaltungstätigkeit in Berlin. Im Abschnitt 2.3.3 wird betrachtet, unter welcher Rechtslage die Konzertdirektion ihre Tätigkeit entfalten durfte, bzw. wie ihr Wirkungsbereich eingeschränkt war.

Das dritte Kapitel fokussiert auf die Tätigkeit Hermann Wolffs als Impulsgeber des Berliner Musiklebens von 1880 bis 1902 . Teilkapitel 3.1 behandelt seine Auseinandersetzung mit neuen Kompositionen und zeitgenössischen Komponisten in drei Abschnitten. Im Abschnitt 3.1.1 wird herausgearbeitet, dass die Abonnementkonzerte des Berliner Philharmonischen Orchesters in erster Linie als Forum für Neukompositionen konzipiert worden waren. Wenn es dort offensichtlich auch nicht beabsichtigt war, bestimmte Werke als Standardrepertoire zu etablieren, so veranlasste Wolff doch in maßgeblicher Weise, dass dort neue Werke aufgeführt wurden. Als Beispiel wird aufgrund der Untersuchung der überlieferten Korrespondenzen festgestellt, dass das Berliner Konzertpublikum am Ende des 19. Jahrhunderts seine unverzügliche Bekanntschaft mit Strauss' sinfonischen Dichtungen zu einem hohen Maß auch Hermann Wolff verdankte, der ihre Aufführungen umsichtig plante. Im Abschnitt 3.1.2 wird gezeigt, dass Wolff für die Abhaltung der Tonkünstlerversammlung des ADMV 1891 in Berlin als Schlüsselfigur fungierte. Es wird deutlich, dass er die alten und neuen Kräfte des Berliner Musiklebens geschickt spielen lassen konnte, und dass diese zum ersten Mal in Berlin abgehaltene Tonkünstlerversammlung -wiederum ein Forum für Neukompositionen-ihren künstlerischen Erfolg in nicht geringem Maße ihm verdankte.

Abschnitt 3.1.3 verfolgt die Diskussion zum musikalischen Aufführungsrecht in Deutschland in den 1890er-Jahren, an der Wolff sich in seiner Eigenschaft als Konzertagent beteiligte. Es wird gezeigt, dass er im Spannungsfeld zwischen Verlegern und Komponisten als ein Dritter die frühe Phase der deutschen musikalischen Tantiemenbewegung förderte. 
Teilkapitel 3.2 evaluiert die Autorität und normgebende Wirkung Hermann Wolffs in drei Abschnitten. Abschnitt 3.2.1 widmet sich einer Fallstudie zu den historischen Konzerten Anton Rubinštejns in der Saison 1885/1886 in den europäischen Musikmetropolen, ein großes Projekt, das in Zusammenarbeit dieses international berühmten Musikers mit dem frischgebackenen Konzertagenten verwirklicht wurde. Betrachtet wird der Prozess, in dem das aus einer historischen Perspektive durchgearbeitete Programm an sich wie ein Kunstwerk behandelt und aufgenommen wurde, sodass es die Autorität eines Standards historischer Klavierabende bekam. Abschnitt 3.2.2 wirft das Licht auf die von Hermann Wolff erstellten Programmhefte für die Abonnementkonzerte des Berliner Philharmonischen Orchesters. Aufgrund der Untersuchung der überlieferten Korrespondenzen und des Vergleichs von den damals entstandenen Analysen wird der Meinungsunterschied zwischen Hermann Wolff und Richard Strauss zum Programmheft herausgearbeitet. Es wird auch darauf hingewiesen, dass Wolff seine Programmhefte als Lesestoff mit überdauerndem Wert konzipierte, möglicherweise mit der Absicht, um dem Konzert, eigentlich einem einmaligen, lokalen Ereignis, eine dauernde, allgemeine Bedeutung zu verleihen. Im Abschnitt 3.2.3 werden Wolffs Auswahl der Dirigenten für die Abonnementkonzerte des Berliner Philharmonischen Orchesters, namentlich Franz Wüllner, Hans von Bülow, Richard Strauss und Arthur Nikisch, und die Folgen dieser Auswahl in Erwägung gezogen. Erklärt wird, dass Wolff durch seine Entschlüsse nicht nur die Entwicklung eines Orchesters entschied, sondern auch die Signifikanz Berlins als Musikstadt lenkte.

Teilkapitel 3.3 konzentriert sich auf den Bechstein-Saal in Berlin, einen Kammermusiksaal, den Hermann Wolff 1892 gründete. Im Abschnitt 3.3.1 werden die Einzelheiten dieser Einrichtung unter der Auswertung der zeitgenössischen Quellen ermittelt. Im Abschnitt 3.3.2 wird erklärt, dass die Gründung dieses Saales eine zukunftsweisende Idee von Wolff war, die sowohl den Interessen seines Geschäfts als auch dem Bedürfnis der Musiker zugutekam. Abschnitt 3.3.3 geht dem Verhältnis von Hermann Wolff und Carl Bechstein und dem Ursprung sowie der Folge des missverständlichen Namens dieses Saales nach.

Diese Betrachtungen werden durch eine Schlussbetrachtung abschließend zusammengefasst und bewertet.

Diese Arbeit hat darüber hinaus einen Quellenteil, der unter anderem eine Datenbank, Transkription der ausgewählten Materialien und Entwürfe des Bechstein-Saales enthält 


\section{Entwurf zur Firmengeschichte der Konzertdirektion Hermann Wolff (und Jules Sachs)}

\subsection{Biographien der wichtigsten Personen}

In diesem Teilkapitel werden die Biographien der wichtigsten Mitarbeiter der Konzertdirektion Hermann Wolff (und Jules Sachs) als Grundlage der Beschäftigung mit diesem Thema aufgearbeitet. Vorgestellt werden der Gründer der Firma Hermann Wolff, seine Frau Louise, die nach dem Tod ihres Mannes die Firma übernahm, und ihre Mitarbeiter Erich Sachs, Erich Simon und Edith Stargardt-Wolff.

\subsubsection{Hermann Wolff}

\section{Jugendzeit und Ausbildung}

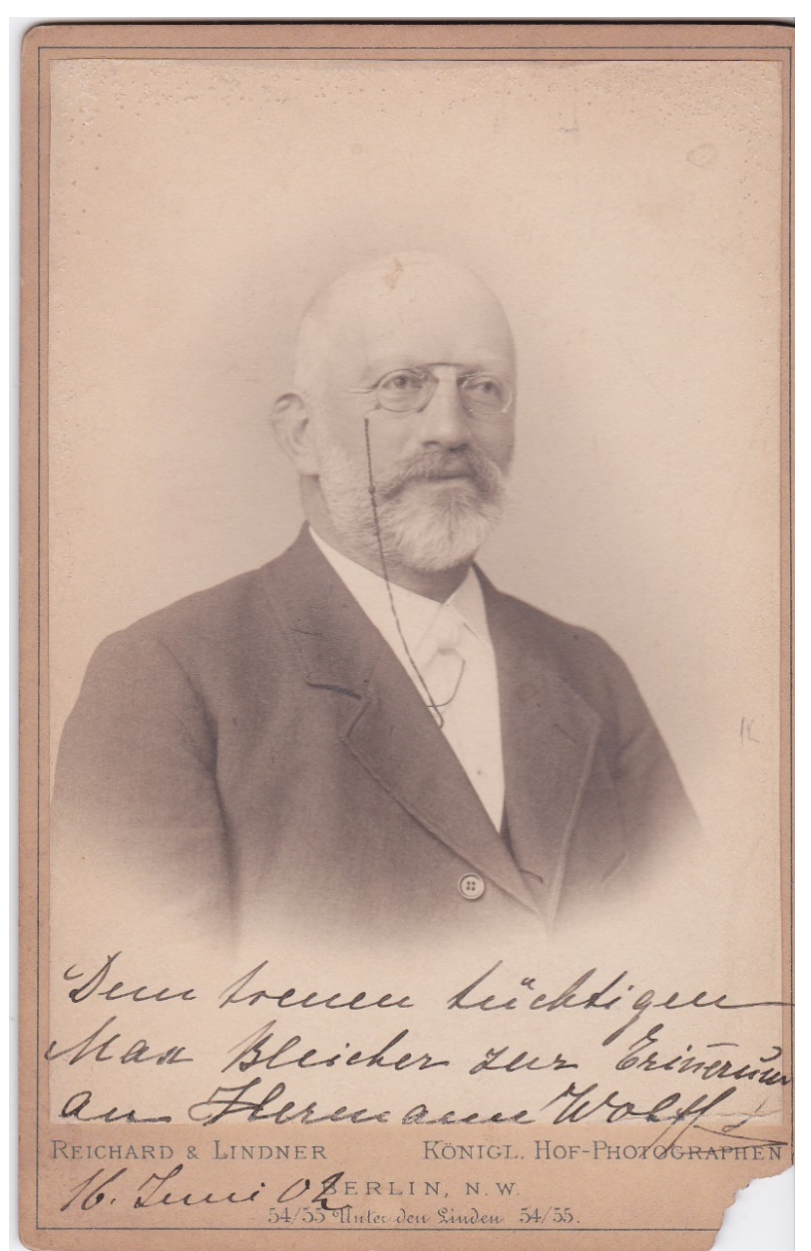

Abbildung 2: Portrait von Hermann Wolff mit handschriftlicher Notiz von Louise Wolff: »Dem treuen tüchtigen Max Bleicher zur Erinnerung an Hermann Wolff, 16. Juni 02« (Wolff-Nachlass: ID 272)

Hermann Wolff (Abbildung 2) wurde am 4. September 1845 in Köln am Rhein geboren (Abbildung 3). Er war der älteste Sohn von Samuel Wolff und seiner Ehefrau Sophia (Sophie) 
Kapferer, die seit 1843 verheiratet waren. Sein Vater Samuel war ebenfalls in Köln geboren worden und arbeitete dort als Kaufmann, und zwar als Kommissionär. Die in Koblenz geborene Sophia hatte einen jüdischen Kaufmann zum Vater, der 1840 den Familiennamen Kapferer und den Vornamen Heinrich angenommen hatte. ${ }^{57}$ Im Kölner Adressbuch aus den Jahren zwischen 1857 und 1859 ist die Firma Kapferer et Wolff, die Heinrich Kapferer und Samuel Wolff gemeinsam führten, nachzuweisen. ${ }^{58}$

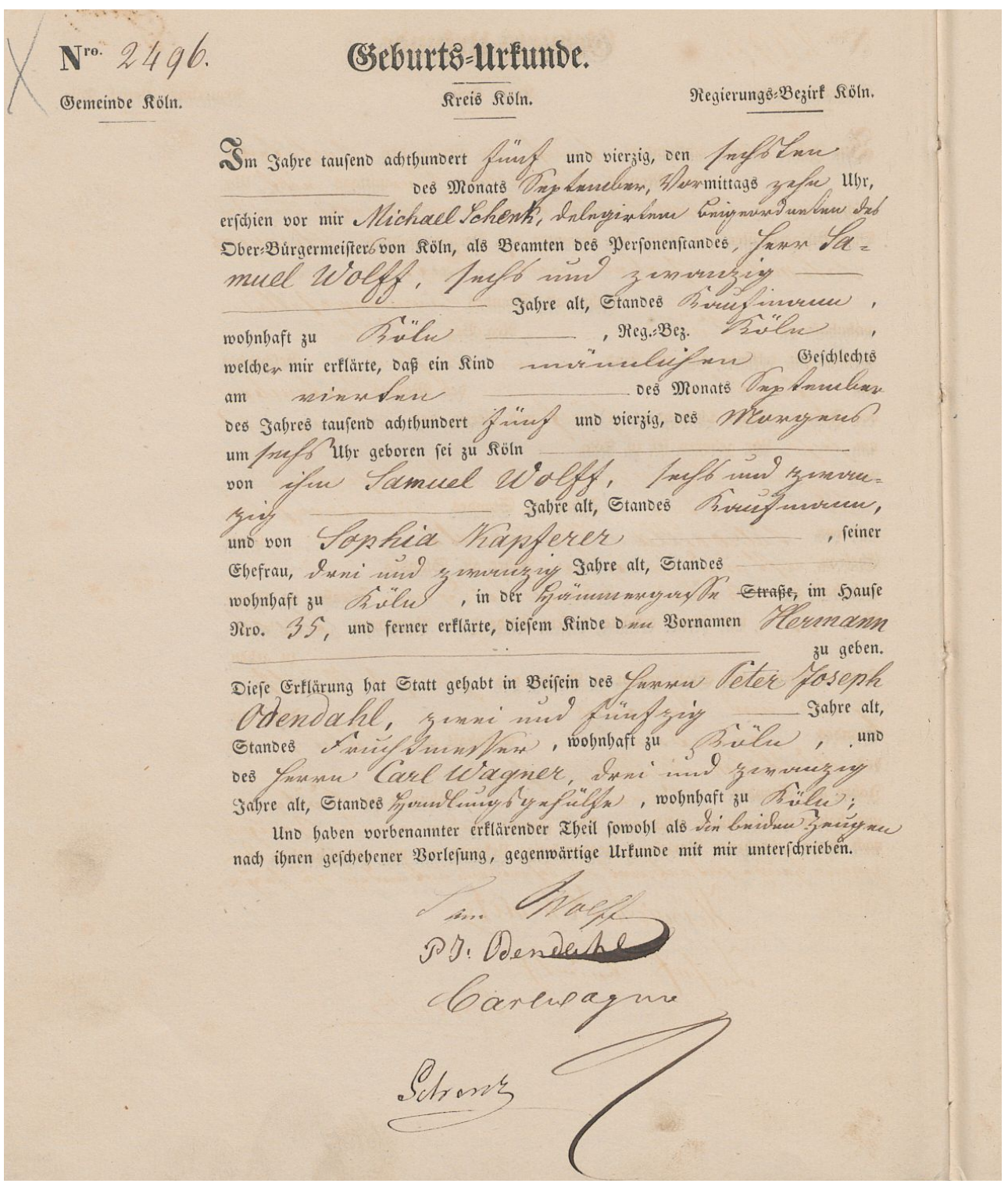

\footnotetext{
${ }^{57}$ Heiratsurkunde von Samuel Wolff und Sophia Kapferer vom 25.10.1843. Zivilstandsregister, Landgerichtsbezirk Köln, Standesamt Köln, Heiraten, 1843, Nr. 658. Die Heiratsurkunde ist online verfügbar unter:

historischesarchivkoeln.de/lav/index.php?img=/Zivilstandsregister/Landgerichtsbezirk_Koeln/Standesamt_ Koeln/Heiraten/1843/1843_Bd_02/0261.jpg, 18.05.2016.

${ }^{58}$ Ich bedanke mich bei Frau Beatrix Alexander aus dem Kölnischen Stadtmuseum, die mir diese Information in einer E-Mail vom 28. Januar 2014 mitgeteilt hat.
} 
Abbildung 3: Geburtsurkunde von Hermann Wolff ${ }^{59}$

1855 begab sich Samuel Wolff nach Berlin, um dort für sich und seine Familie eine neue Existenz aufzubauen. Schon bald danach, im Jahr 1857, ließ er seine Frau und Kinder nach Berlin nachkommen. ${ }^{60}$ Dort absolvierte Herman Wolff das Friedrichswerdersche Gymnasium und wurde kaufmännisch ausgebildet. Seit früher Jugend hatte er jedoch eine Neigung zur Musik und bat seinen Vater, sich auch musikalisch ausbilden zu dürfen. So studierte er Harmonielehre bei Richard Wüerst, einem Kompositionsschüler von Felix Mendelssohn, und Klavierspiel bei Franz Kroll, einem Schüler von Franz Liszt, ${ }^{61}$ wohl am Stern'schen Konservatorium, wie sein Enkel Wolfgang Zuelzer schreibt. ${ }^{62}$

Seine umfangreichen musikalischen Fähigkeiten lassen sich anhand verschiedener Aussagen zeigen: Edith Stargardt-Wolff erinnert daran, dass er praktisch jede Partitur vom Blatt spielen, jede Klavierbegleitung selbst übernehmen konnte. So habe er den Musikern als par inter pares gegolten, was ihn über seine Berufskollegen weit hinausgehoben habe. ${ }^{63}$ Wolfgang Zuelzer schreibt zur musikalischen Fähigkeit seines Großvaters:

[Hermann Wolff...] could read an orchestral score, was thoroughly familiar with both the classical and the contemporary repertoire - he was an ardent admirer of Richard Wagner - and, quasi as a side line, served as an occasional music critic for several Berlin newspapers. [...] Later he composed piano pieces in the manner of Anton Rubinstein, not great or even original music but good enough to earn mention in German music dictionaries down to my time. ${ }^{64}$

\footnotetext{
${ }^{59}$ Zivilstandsregister, Landgerichtsbezirk Köln, Standesamt Köln, Geburten, 1845, Nr. 2496. Diese Geburtsurkunde ist online einsehbar unter:

historischesarchivkoeln.de/lav/index.php?img=/Zivilstandsregister/Landgerichtsbezirk_Koeln/Standesamt_ Koeln/Geburten/1845/1845_Bd_05/0499.jpg, 18.05.2016.

${ }^{60}$ Stargardt-Wolff: Wegbereiter großer Musiker, S. 13.

${ }^{61}$ Ebd., S. 14.

${ }^{62}$ Wolfgang Zuelzer: Queen Louise - a Portrait, in seiner unveröffentlichten Selbstbiographie, WolffNachlass: ID 285, S. 18. Tatsächlich lehrten Richard Wüerst und Franz Kroll am 1850 gegründeten Stern'schen Konservatorium.

${ }^{63}$ Stargardt-Wolff: Wegbereiter großer Musiker, S. 14.

${ }^{64}$ Zuelzer: Queen Louise - a Portrait, S. 18. In Pazdireks Handbuch sind 13 Werke mit Opus-Nummer und 3 Werke ohne Opus-Nummer unter dem Komponistennamen »Hermann Wolff« angegeben: UniversalHandbuch der Musikliteratur aller Zeiten und Völker, hg von Franz Pazdirek, 12 Bde., Wien 1904-1910, Nachdruck Hilversum 1967, Bd. 12, S. 794. Diese Werke wurden im Zeitraum vom 1871 bis 1893 von verschiedenen Verlagen veröffentlicht.
} 
Seiner Beschäftigung als Konzertagent ging jedoch eine berufliche Tätigkeit an der Berliner Börse voraus, wodurch er wirtschaftliche Kenntnisse erwerben und geschäftliche Erfahrung sammeln konnte. Außer diesem Broterwerb erschloss er weitere Einnahmequellen im Schreiben: Er verfasste Artikel für Zeitungen, Humoresken und Singspiele, und als geschickter Verseschmied auch verschiedene Gelegenheitsgedichte auf Bestellung. ${ }^{65}$

Im Deutsch-Französischen Krieg 1870/71 wurde er zum Militär eingezogen, wurde aber wegen seiner guten Kenntnisse in der französischen Sprache als Dolmetscher eingesetzt. ${ }^{66}$ Doch er wirkte hier nicht nur als Dolmetscher, sondern auch als Journalist, und lieferte Berichte an Berliner Zeitungen wie die Vossische Zeitung und den Berliner Börsenkurier. In der Lutherstadt Wittenberg, wo seine Abteilung zuerst lag, beschäftigte er sich auch mit der Veranstaltung eines Konzerts, das unter dem Protektorat des dortigen Bürgermeisters und der Honoratioren stattfand. Als Solistin trat die junge Sängerin Selma Nicklaß auf, ${ }^{67}$ die später von der Firma Hermann Wolffs vertreten werden und sich als Konzertsängerin einen Namen machen sollte.

Nach der Heimkehr aus dem Krieg nahm er seine beiden früheren Tätigkeiten an der Börse und als Schriftsteller wieder auf. 1878 wurde er Nachfolger seines Lehrers Richard Wüerst als Redakteur der im Verlag Bote \& Bock erscheinenden Neuen Berliner Musikzeitung. In diese Zeit fällt seine Vermählung mit der aus Wien stammenden Schauspielerin Aloysia Wilhelmine (genannt Louise) Schwarz, die im September 1878 in Wien erfolgte. ${ }^{68}$ Das junge Paar fand seine erste Wohnung in jener Wilhelmstraße, die als Sitz wichtiger Regierungsbehörden schon damals bekannt gewesen war. Das Haus Nr. 28 befand sich jedoch im weniger vornehmen Teil der Straße. ${ }^{69}$ Diese Wohnung wurde übrigens zum Geburtshaus des 1880 geborenen ersten Kindes von Hermann und Louise Wolff, Edith. In den Berliner Adressbüchern der Jahre 1879 und 1880 ist ein Kaufmann »H. Wolff« unter dieser Anschrift eingetragen, ${ }^{70}$ aber für die folgenden Jahre kann der Wohnort der Familie nicht nachgewiesen werden. Das Geburtsregister ihres zweiten Kindes, Werner, der am 13. Oktober 1883 geboren wurde, lässt jedoch vermuten, dass die Familie zuvor in die Wohnung Lützowstraße 75 eingezogen war. ${ }^{71}$

\footnotetext{
${ }^{65}$ Stargardt-Wolff: Wegbereiter großer Musiker, S. 14.

${ }^{66}$ Der Wolff-Nachlass enthält sein Tagebuch mit 210 geschriebenen Seiten aus dieser Zeit, WolffNachlass: ID 128.

${ }^{67}$ Stargardt-Wolff: Wegbereiter großer Musiker, S. 15.

${ }^{68}$ Ebd., S. 25.

${ }^{69}$ Ebd., S. 26.

${ }^{70}$ Berliner Adreß-Buch für das Jahr 1879, hg von W. \& S. Loewenthal, Berlin 1879, S. 1035; Berliner Adreß-Buch für das Jahr 1880, hg von W. \& S. Loewenthal, Berlin 1880, S. 1078.

${ }^{71}$ Geburtsregister von Werner Wolff, LAB, P Rep. 804, Nr. 545 Standesamt Berlin III, Nr. 1586.
} 


\section{Hermann Wolff als Musikkritiker}

Im Zeitraum vom Sommer 1878 bis zum Herbst 1880 lieferte Hermann Wolff in der Neuen Berliner Musikzeitung die meisten Beiträge. Sie sind meistens nicht mit seinem Namen, sondern mit »-f« gekennzeichnet. ${ }^{72}$ In diesen Berichten zeigen sich sicherlich auch einige Auffassungen und Interessen Wolffs, welche die Grundlage seiner künftigen Tätigkeit als Konzertagent bildeten.

Hermann Wolff war, vor allem in seiner Jugend, ein fanatischer Bewunderer Richard Wagners. ${ }^{73}$ Auch als Musikkritiker entwickelte er ein großes Interesse an Wagners Werken und ihren Aufführungen. Sein erster langer Beitrag in der Neuen Berliner Musikzeitung behandelt die Aufführung der Oper Siegfried in Leipzig im September 1878, die erste Aufführung dieses Werks außerhalb Bayreuths. ${ }^{74}$ Die Verwirklichung dieses kühnen Projekts im Leipziger Stadttheater bewertet Wolff sehr hoch:

\section{Leipzig, 29. September 1878}

Noch vor wenigen Jahren, ja selbst nach dem grossen Bayreuther Unternehmen, hat man die vollständige Aufführung der Wagner'schen Nibelungen-Trilogie auf anderen Bühnen, als der eigens dafür hergerichteten, für unmöglich gehalten. Aber das wahrhaft Bedeutende in jeder Kunst muss sich einmal Bahn brechen und so ward vielerorten auch schliesslich das gewonnen, was zur allgemeinen Verwirklichung der künstlerischen Ideen Wagner's nöthig war: der Muth, die richtige Kenntniss und der überzeugte Glaube an die Bedeutung des Werkes. Zu den Allerersten, welche keine Anstrengung und keine Opfer scheuend, die Nibelungen vollständig zur Aufführung gebracht haben, gehört das Leipziger Theater und diese grosse, echt künstlerische That verdient wahrlich die unbedingteste laute Anerkennung und eine um so rückhaltlosere Bewunderung, als das Institut die Aufgabe in nahezu vollendeter Weise gelöst hat. Nachdem im Frühjahr »Rheingold« und »Walküre« in Scene gegangen, gelangte am

\footnotetext{
${ }^{72}$ Vgl. Inhaltsverzeichnis, in Neue Berliner Musikzeitung 32 (1878), Inhaltsverzeichnis, S. VII; Ehrlich: Dreißig Jahre Künstlerleben, S. 311.

${ }^{73}$ Er nahm auch an der Grundsteinlegung des Bayreuther Festspielhauses im Jahr 1872 teil. StargardtWolff: Wegbereiter großer Musiker, S. 17.

${ }^{74} \mathrm{Zu}$ den öffentlichen Reaktionen auf die Leipziger Erstaufführung von Wagners Ring des Nibelungen 1878 vgl. Janina Moelle: Die Leipziger Erstaufführung des Ring des Nibelungen und ihre zeitgenössische Rezeption, in Musik und Bürgerkultur. Leipzigs Aufstieg zur Musikstadt, hg. von Stefan Horlitz u. a, Leipzig 2007. S. 334-357.
} 
21. und 22. September »Siegfried« und die »Götterdämmerung« zur ersten Darstellung. ${ }^{75}$

Wolff glaubt, dieses riesige Werk übersteige die Aufnahmefähigkeit des zeitgenössischen Publikums; doch hält er sie für entwicklungsfähig und prognostiziert, dass das Publikum in nicht ferner Zukunft dazu fähig sein wird, die Werke Wagners ohne Schwierigkeiten zu genießen.

[...] der Gesamteindruck bleibt ein tiefer und Niemand kann so unempfänglich sein, dass er, sei er selbst auch Gegner der Richtung, nicht mit dem Gefühle das Theater verliesse, etwas Bedeutendes, Neues und Geniales erlebt zu haben. Da es fest steht, dass in den letzten 50 Jahren unsere musikalische Genussfähigkeit sich sehr entwickelt hat, so darf man wohl mit Recht annehmen, dass sie auch einer ferneren Entwicklung fähig ist und uns allmählich in den Stand setzen wird, diese Riesenwerke ohne Ermüdung zu geniessen, was uns heute - wenn wir offen sein wollen - noch nicht möglich ist.

Seiner Ansicht nach verdient die Leipziger Aufführung Lob, auch im Vergleich mit dem Bayreuther Vorbild:

Die Leipziger Darstellung hält sich genau an die Wagner'schen - in Bayreuth verwirklichten - Intentionen. Wir wollen keine Vergleiche anstellen, denn in Leipzig ist das Aeusserste geleistet worden und wenn vielleicht Manches nicht so gelang wie in Wagner's Theater, so wurde auch Manches wieder besser gemacht als in Bayreuth. Der hohe Einfluss der persönlichen Führung Wagner's war durch die echt künstlerische Hingabe, und die Liebe zu dem genialen Werke ersetzt und da war es denn bei dem allgemeinen Eifer, dem Fleiss und dem reinen Enthusiasmus der Künstler, der Unermüdlichkeit und dem selbstlosen, verständnissreichen Kunstsinn der Direction Dr. Förster-Angelo Neumann selbstverständlich, das ein unbestrittener Erfolg das kühne Unternehmen krönte. Was wir gestern sahen und hörten, war durchweg gelungen, sowohl in scenischer, gesanglicher wie instrumentaler Hinsicht.

\footnotetext{
${ }^{75}$ Dieses und die folgenden Zitate aus -f [Hermann Wolff]: Correspondenzen. Leipzig, 29. September 1878, in Neue Berliner Musikzeitung 32 (1878), S. 325.
} 
Die Dekoration, Maschinerien, Kostüme, Sänger, Orchester und dessen Leiter Joseph Sucher ernten sein Lob; er bedauert nur, dass das Orchester im Unterschied zu Bayreuth nicht tiefer lag und somit sichtbar war, was mit dem klanglichen Effekt zusammenhängt. ${ }^{76}$

In der nächsten Nummer berichtet er weiter vom noch größeren Erfolg der Götterdämmerung-Aufführung, die tags darauf stattfand. In diesem ausführlichen Artikel kommt die Rede unter anderem auf die inszenatorische Änderung, die mit Wagners Genehmigung in der Leipziger Aufführung vollzogen wurde, die hohe Leistung der Musiker, den Erfolg des Werks selbst und auf die Anerkennung für die Veranstalter dieses kühnen Projekts. Mit Rücksicht auf das Bayreuther Vorbild, aber auch auf die Schwierigkeiten der Aufführung dieses großen Werks rezensiert er die Leipziger Götterdämmerung wie folgt:

Auch gestern hielt man sich vernünftigerweise an das Bayreuther Vorbild und wo man geändert hatte, war's zum Besten der Wirkung geschehen. Einiges - um das sich dem Auge Bietende zuerst zu erwähnen, war vollendet geschaffen; die Halle Gunter's und der Tod Brunhildens [sic!] in den Flammen. Dass hin und wieder etwas misslang, war, da man in vielen Punkten noch immer mit Versuchen zu thun hat, leicht entschuldbar. Der Untergang der Götter war zu wenig erhaben, zu kleinlich dargestellt - und doch ist grade diese eigentliche »Götterdämmerung« der Augenblick, welcher den Titel des Dramas rechtfertigt, dem Publikum also in möglichst eindringlicher und grossartiger Weise vorgeführt werden muss. Aber wie gesagt, wir halten dies Bild nur für einen Versuch, der schon zu besseren Resultaten führen wird, auch das Misslingen hat seine vortheilhaften Seiten. Ferner wollen wir noch erwähnen, dass auch Siegfried's Tod der Vorhang ein wenig zu früh zusammengezogen wird. Erst nachdem sich der Trauerzug in Bewegung gesetzt, schloss sich, wenn wir uns recht erinnern, in Bayreuth der Vorgang. Und um schliesslich das decorative Element ganz zu erledigen, beklagen wir noch, dass die mitunter angewendeten Dämpfe mehr Geräusch als Wirkung machen. ${ }^{77}$

Sein unerschöpfliches Interesse an den Werken Wagners, verbunden mit seiner ursprünglichen Frankophilie, zeigt sich wieder im nächsten Jahr in zwei aufeinanderfolgenden Artikeln, die das Pariser Konzert vom Orchestre Pasdeloup am 20. April 1879 behandeln. ${ }^{78}$

\footnotetext{
${ }^{76}$ Ebd., S. 326.

77 -f. [Hermann Wolff]: Correspondenzen. Leipzig, 30. September 1878, in Neue Berliner Musikzeitung 32 (1878), S. 333.

${ }^{78}$-f [Hermann Wolff]: Pariser Musikzustände. I. Lohengrin in Paris, in Neue Berliner Musikzeitung 33 (1879), S. 145-147; S. 153f.
} 
Hier wurde der erste Akt aus Lohengrin mit Auslassungen zum ersten Mal aufgeführt. Wolff spricht vom »herrlichen Siege«, den die Musik von Wagner in Paris erwarb, und erwartet die »Einbürgerung des Lohengrin«, die durch die Gründung eines neuen Theaters möglich sein wird:

Ich selbst war zu ergriffen, um applaudiren zu können, ergriffen von dem herrlichen Siege, den deutsches Genie - ein in seinem Vaterlande noch angefochtenes - in dem herrlichen Frankreich, und in diesem Falle ist Paris Frankreich, errungen. Es war klar, unbestreitbar, dass nach diesem Erfolge die lang erhoffte Einbürgerung des Lohengrin wohl kaum mehr auf sich wird warten lassen. Und es wird das nur von dem Zustandekommen eines neuen Theatre Lyrique abhängen, welches trotz der Missgeschicke der zu Grunde gegangenen 2. Operninstitute bei dem jetzigen Geschmack des Publicums und bei der Production der Pariser Operncomponisten ein unabweisbares Bedürfniss ist. ${ }^{79}$

Die oben zitierten Berichte über die Aufführung der Musik Wagners enthalten einige Vorzeichen der zukünftigen Tätigkeit Hermann Wolffs als Konzertagenten. Wie der Vertrag im Wolff-Nachlass zeigt, übernahm er Ende 1882 das Arrangement der Tournee von Neumanns Wagner-Wandertheater und brachte den Ring des Nibelungen in zahlreiche Städte mehrerer europäischer Länder in Zusammenarbeit mit diesem Operndirektor. ${ }^{80}$ Und ein Brief, der ebenfalls im Wolff-Nachlass aufbewahrt wird, beweist, dass er im Jahr 1887 die Absicht hatte, eine Aktiengesellschaft für den Lohengrinn und Tannhäuser im Théâtre de l'Éden in Paris zu gründen. ${ }^{81}$ Was aus diesem Plan wurde, ist der Verfasserin der vorliegenden Arbeit nicht bekannt. Der gleiche Brief teilt immerhin mit, dass Hermann Wolff am gleichen Tag ein Konzert von Charles Lamoureux besuchte, der sich neben Jules Pasdeloup für die Verbreitung der Werke Wagners in Frankreich einsetzte und Lohengrin im Mai 1887 im Théâtre de l'Éden auf die Bühne brachte.

Sein Interesse an der Musik Wagners erfüllte sich später in der Wiederaufführung der C-Dur-Sinfonie WWV 29, eines Jugendwerks, dem der Komponist auch in späterer Zeit einen

\footnotetext{
${ }^{79}$ Ebd., S. 154.

${ }^{80} »$ Vereinbarungen zwischen Angelo Neumann aus dem Richard-Wagner-Theater und Hermann Wolff« (Wolff-Nachlass: ID 226). Vgl. 1.2.3 im Quellenteil der vorliegenden Arbeit. Zur Zusammenarbeit von Wolff mit Neumann vgl. auch: Angelo Neumann, Erinnerungen an Richard Wagner, Leipzig ${ }^{5}$ 1907, S. $268 f$.

${ }^{81}$ Brief von Hermann Wolff an Louise Wolff vom 23.4.1886 aus Paris (Wolff-Nachlass: ID 24). Vgl. 1.2.1 im Quellenteil der vorliegenden Arbeit.
} 
gewissen Wert beigemessen hatte. Diese Sinfonie entstand vermutlich vom April bis Juni 1832, als der Komponist 19 Jahre alt war. Sie wurde im November des gleichen Jahres unter der Leitung von Friedrich Dionys Weber in Prag uraufgeführt, daran schlossen zwei Aufführungen in Leipzig an. Seitdem Wagner die originale Partitur 1836 Felix MendelssohnBartholdy geschenkt hatte, ${ }^{82}$ der sich um die Handschrift nicht gekümmert zu haben scheint, war sie verloren gegangen. 1876 beauftragte Wagner Wilhelm Tappert, dem Aufführungsmaterial dieses Jugendwerkes nachzuforschen. Auf der Grundlage eines von Tappert wiederaufgefundenen Stimmensatzes erstellte der damalige Assistent Wagners, Anton Seidl, im Frühjahr 1878 eine neue Partitur, die der Komponist überarbeitete. Wagner führte dieses Werk kurz vor seinem Tod noch einmal auf: am 24. Dezember 1882, anlässlich einer Geburtstagsfeier für Cosima, im Teatro La Fenice in Venedig. ${ }^{83}$

Von den Erben Wagners übernahm Wolff das Aufführungsrecht für diese Sinfonie für eine Saison, 1887/88, gegen 50.000 Mk. ${ }^{84}$ und brachte sie in verschiedenen Städten zur Aufführung, etwa in Scheveningen (29.9.1887), Basel (23.10.1887), Wiesbaden (24.10.1887), Breslau (25.10.1887), Dresden und Mainz (beide 28.10.1887). In Berlin wurde sie am 31. Oktober 1887 in einem Konzert des Wagner-Vereins unter der Leitung von Joseph Sucher zum ersten Mal gespielt. ${ }^{85}{ }$ Somit namentlich den Hörern dieses ungedruckte Werk eine bleibende Erinnerung bietet $«,{ }^{86}$ veröffentlichte Wolff eine Broschüre, zu der Oscar Eichberg Erläuterungen und eine Analyse beitrug. ${ }^{87}$

Die Reaktion auf die Aufführungen dieser viersätzigen Jugendsinfonie war sehr unterschiedlich. ${ }^{88}$ Dass diejenige, welche »eine echt Wagner'sche Composition« erwartet

\footnotetext{
${ }^{82} \mathrm{Zu}$ dieser Schenkung vgl. Richard Wagner: »Ich schreibe keine Symphonien mehr«. Richard Wagners Lehrjahre nach erhaltenen Dokumenten, zusammengestellt und hg. von Otto Daube, Köln [1960], S. 185.

${ }^{83}$ Richard Wagner. Dokumentarbiographie, bearbeitet von Egon Voss, München 1982, S. 553f.

${ }^{84}$ Vermischtes, in Neue Zeitschrift für Musik 14 (1887), S. 228. Vgl. auch Nachrichten, in Neue Berliner Musikzeitung 41 (1887), S. 166. Wie im Text gezeigt wird, ist die Angabe, dass diese Symphonie davor nur einmal öffentlich gespielt worden war, nicht korrekt.

${ }^{85}$ Daran schlossen Aufführungen in zwei Populärkonzerten des Philharmonischen Orchesters unter der Leitung von Gustav F. Kogel an (1.11.1887 und 16.1.1887).

${ }^{86}$ Concerte, in Neue Berliner Musikzeitung 41 (1887), S. 349.

${ }^{87}$ Vgl. Richard Wagner's Sinfonie in C-Dur analysiert von Oscar Eichberg, Berlin 1887. In der Vorbemerkung erklärt Eichberg den Zusammenhang zwischen dieser Schrift und den Aufführungen wie folgt: »Die folgende Analyse der ungedruckten Wagner'schen Sinfonie ist in genauem Anschlusse an die Programmbücher verfasst, die der Unterzeichnete auf Veranlassung der Concert-Direktion Hermann Wolff bei Gelegenheit der grossen Orchesterconcerte in Berlin, Hamburg und Dresden im letzten Winter herausgegeben hat, und die auch fernerhin fortgesetzt werden sollen. Indem also dieser kleinen Arbeit bestimmte und ziemlich enge Grenzen gesteckt sind, bittet der Unterzeichnete bei der Lektüre derselben sich dieses Umstandes freundlichst erinnern zu wollen.« Zur Auseinandersetzung Wolffs mit erläuternden Programmheften dieser Art, vgl. Abschnitt 3.2.2 der vorliegenden Arbeit.

${ }^{88}$ Neue Berliner Musikzeitung 41 (1887), S. 360.
} 
hatten, »sehr enttäuscht« wurden, ${ }^{89}$ ist nicht schwer vorzustellen. In Berlin scheint dieses Werk im Großen und Ganzen positiv angenommen worden zu sein. Otto Lessmann sei völlig überrascht worden von der meisterhaften Sicherheit des jungen Komponisten in der Behandlung der Form, und war überzeugt, dass dieser Sinfonie »über den zweifellosen kunsthistorischen Werth hinaus auch ein bedeutender musikalischer Werth innewohnt «.90 Aber als dauerhaftes Konzertrepertoire fand dieses Werk keine Anerkennung. Heinrich Ehrlich im Berliner Tageblatt vermutete »den eigentlichen Zweck« der Aufführung dieser Sinfonie wie folgt:

Ich wiederhole, als Werk eines Neunzehnjährigen ist diese Symphonie staunenswerth; sie wird allüberall ein- bis zweimal mit großem Interesse gehört werden, damit ist ja der eigentliche Zweck erfüllt: Viel Gewinn für die Konzertunternehmer, kein großer für die Kunst. ${ }^{91}$

Wenn diese Auffassung auch nicht unzutreffend sein kann, ist es doch sicher, dass Hermann Wolff viele Jahre lang große Begeisterung für die Musik Wagners empfunden hatte. Solange der Schwerpunkt seiner Werke in der Bühnenmusik gewesen war, hatte der Konzertagent nicht viel Gelegenheit, seine Musik auf die Bühne zu bringen. Das Projekt in der Saison 1887/1888 kann deshalb vielleicht als Versuch von Hermann Wolff angesehen werden, das Konzertrepertoire dieses Komponisten zu erschließen.

Während Hermann Wolff die Kunst Richard Wagners hoch schätzte, war es aber Johannes Brahms, der ihm und seiner Familie sowohl persönlich wie geschäftlich besonders nahekam. Wenn man an die enge Freundschaft und Kooperation zwischen den beiden in späterer Zeit denkt, ist es umso bemerkenswerter, dass Hermann Wolff als Musikkritiker das Konzert von Brahms für Violine und Orchester in D-Dur, op. 77, öffentlich scharf kritisiert hatte. ${ }^{92}$ Seine Rezension zu diesem neuen Violinkonzert beginnt er mit einem Verweis auf Wagners Ausspruch zum Einfall: ${ }^{93}$

\footnotetext{
${ }^{89}$ Dur und Moll, Signale 45 (1887), S. 871.

${ }^{90}$ Otto Lessmann: Aus dem Konzertsaal, in Allgemeine Musikzeitung 14 (1887), S. 430.

${ }^{91}$ H. E. [Heinrich Ehrlich]: Richard Wagners Jugendsymphonie, in Berliner Tageblatt vom 1.11.1887, Morgen-Ausgabe, S. 2f. hier: S. 3.

${ }^{92}$ Dazu vgl. auch Ehrlich: Dreißig Jahre Künstlerleben, S. 311.

${ }^{93}$ Zum historischen Kontext des Inspirationsgedankens im Kunstschaffen vgl. z. B.: Reinhard Ermen: Musik als Einfall. Hans Pfitzners Position im ästhetischen Diskurs nach Wagner, Aachen 1986, S. 58-66.
} 
Erst jüngst brachten wir einen treffenden Ausspruch Wagners über das Componiren: »Im Ganzen wäre wohl zu rathen, dass Componisten Stimmungen, Einfälle abwarten. Ich kann durchaus nichts componieren, wenn mir nichts einfällt, aber vielleicht befinden sich die Meisten besser dabei, wenn sie Einfälle nicht abwarten«. Das Studium des vorliegenden Werkes (op. 77 im Verlage von N. Simrock hier im Klavierauszug erschienen) hat uns leider zu der Ueberzeugung geführt, dass Brahms diesmal die Einfälle nicht abwarten zu müssen glaubte, - so hat er denn ohne Einfälle gearbeitet und das Resultat ist - ein schwaches, zum Theil verfehltes Werk. ${ }^{94}$

Seine Kritik gilt vor allem dem ersten Satz, in dem »das Dunkel, das Unerquickliche« sich aus den »wenig bedeutenden und wenig neuen Themen« nur mühevoll entwickele. Diesem Satz fehle es völlig an »Fantasie, Poesie und warme Empfindung« und er sei weder originell noch neu.

Ja, der erste Satz ist einige Lichtblicke, wie die Orchester-Einleitung, aber sie lassen uns das Dunkel, das Unerquickliche des Uebrigen nur um so greller erscheinen. Wie schwer das vorwärts schreitet, wie mühselig sich alles entwickelt - und woraus? Aus wenig bedeutenden und wenig neuen Themen. Wer, der ehrlich gegen sich sein will, kann von diesem ersten Satze auch nur die geringste Anregung, von Stimmung, von Begeisterung ganz zu schweigen, empfangen haben, fehlen doch Fantasie, Poesie und warme Empfindung leider total. Dabei ist die Violinpartie, trotz der Schwierigkeiten, ganz undankbar; sie wimmelt von den unglaublichsten Passagen, Figuren, Sprüngen, die man auch bei der grössten Nachsicht nur unschön finden kann. Und wenn der Satz wenigstens noch originell wäre; aber vergeblich sucht man nach einem neuen Gedanken; verzwickte findet man genug, und das ist gerade bei Brahms nichts Neues.

Seine Kritik am zweiten und dritten Satz ist etwas milder, aber im Prinzip äußert er auch hier die ähnliche Auffassung, dass es sich hier um ein kaltes, herzloses Werk handele und es ihm an neuen Gedanken fehle:

\footnotetext{
${ }^{94}$ Dieses und die folgenden Zitate aus -f. [Hermann Wolff]: Ein neues Violin-Concert von Johannes Brahms, in Neue Berliner Musikzeitung 33 (1879), S. $332 \mathrm{f}$.
} 
Einfacher, natürlicher giebt sich der zweite Satz in F-dur; jedoch auch ihm fehlt die Seele. Kalt und herzlos, bis auf den etwas wärmeren Schluss, geht das kurze Stück, dessen vortheilhafteste Seite seine Kürze ist, an uns vorüber. [...]

Frischer, lebensvoller gestaltet sich das Finale; das fliesst wenigstens keck dahin, wenn man auch an keiner Stelle durch neue Gedanken gestört wird, allerdings kommt das Gefühl wieder zu kurz. Indess der Satz ist gut gearbeitet, effectvoller wie die vorhergehenden und beschliesst doch das Werk so, dass der Eindruck des ersteren gemildert wird.

Interessant ist, dass Wolff dieses Werk mit einem Handelsunternehmen vergleicht, an dem sich ein Komponist, ein Verleger und ein ausübender Künstler beteiligen. Die Zusammenarbeit kann nicht gelingen und die Kunst bleibt auf der Strecke:

Das Violinconcert von Brahms scheint seiner äusseren Form wie seinem inneren Werthe nach in jene Kategorie musikalischer Handelsunternehmen zu gehören, bei welchen drei Personen, ein Componist, ein Verleger und ein ausübender Künstler, quasi betheiligt sind. Diese drei arbeiten sich einander in die Hände und die Kunst geht so ziemlich leer aus.

In einer späteren Nummer des gleichen Jahres wurde eine »Erklärung« veröffentlicht, in der die Redaktion ihr Bedauern äußerte, dass ihr Referent »durch einen unrichtig gewählten Vergleich zu einer falschen Auffassung seiner Ansicht über die Entstehung des Concertes Veranlassung gegeben hat $\ll .{ }^{95}$

Dass dieses Werk Wolff auch im Konzertsaal nicht gefiel, ist aus seinem von Edith Stargardt-Wolff zitierten Brief an seine Frau anlässlich der ersten Aufführung in Hamburg zu ersehen:

Gestern in der öffentlichen Aufführung vor einem Publikum vor 1500 Personen hat Joachim, der Brahmssche Protektor in Brahms' Vaterstadt Hamburg, mit diesem Konzert ein noch nicht erlebtes Fiasko gemacht. Denke: Nicht eine Hand hat sich gerührt, nicht einmal, um Joachims herrliches Spiel zu applaudieren. Rubinstein war

\footnotetext{
${ }_{95} \gg$ Die Redaction«: Erklärung, in Neue Berliner Musikzeitung 33 (1879)., S. 364.
} 
mit da; er fand es miserabel und meinte von der Komposition: sie sei ein anständiges, aber häßliches, uninteressantes Mädchen. ${ }^{96}$

Zum Vergleich seien hier einige zeitgenössische Besprechungen anderer Kritiker aufgeführt. Das im Sommer 1878 in Pörtschach entstandene Violinkonzert wurde am 1. Januar 1879 im Leipziger Gewandhaus unter der Leitung des Komponisten mit dem Solisten Joseph Joachim uraufgeführt; danach folgten rasch Aufführungen in Budapest, Wien, Köln, London und Amsterdam. ${ }^{97}$ Die Pressereaktionen waren gemischt. Alfred Dörffel rezensierte zum Beispiel die Leipziger Uraufführung ganz positiv und sah das Werk in einer Reihe mit den »beiden großen Violinkonzerte[n] von Beethoven und Mendelssohn. ${ }^{98}$ Er schreibt:

\begin{abstract}
Welche Freude erlebten wir doch! Brahms hat ein solch drittes Werk im Bunde geschaffen. Der ursprüngliche Geist, der das ganze durchwaltet, der feste Organismus, in dem es auftritt, die Wärme, die es durchstrahlt, Raum gebend der Freude, im Lichte zu wandeln: es kann nicht anderes sein, als daß das Werk aus neuester und - so glauben wir - aus glücklichster Zeit des Komponisten hervorgegangen ist. [...] wir waren selten so vom Genius des Komponisten erfaßt worden. Aber Joachim spielte auch mit einer Liebe und Eingebung, die aus jedem Takt den Anteil erkennen und fühlen ließen, welche er an dem Werke mittelbar und unmittelbar hatte. Der Erfolg war: der 1. Satz ließ das Neue in der Zuhörerschaft nicht entschieden zum Bewußtsein kommen; der 2. Satz schlug sehr durch; der Schlußsatz entzündete großen Jubel. ${ }^{99}$
\end{abstract}

Eduard Hanslick ${ }^{100}$ dagegen bezweifelte, ob dieses neue Konzert in der allgemeinen Gunst jemals mit jenen beiden rivalisieren werde. Es fehle ihm die unmittelbar verständliche und entzückende Melodie, der nicht bloß zu Beginn, sondern im ganzen Verlauf klare rhythmische Fluss, wodurch das Beethovensche und das Mendelssohnsche Konzert so einzigartig wirken. Manch herrliche Gedanken kämen nicht zur vollen Wirkung, weil sie zu rasch verschwänden oder zu dicht von kunstvollem Geflecht umrankt seien. In der Solopartie gebe es sogenannte

\footnotetext{
${ }^{96}$ Stargardt-Wolff: Wegbereiter großer Musiker, S. 67, Hervorhebung im Original.

${ }^{97} \mathrm{Zu}$ den ersten Aufführungen dieses Werks vgl. z. B. Max Kalbeck: Johannes Brahms, III, erster Halbband: 1874-1881, Berlin ${ }^{2} 1912$, S. $211 \mathrm{f}$.

${ }^{98}$ Alfred Dörffel: Leipziger Nachrichten (4.1.1879), Beilage S. 2, abgedr. in Johannes Brahms. Das Symphonische Werk: Entstehung, Deutung, Wirkung, hg von Renate Ulm, Kassel 1996, S. 154.

${ }^{99}$ Ebd.

${ }^{100}$ Eduard Hanslick: Concerte, Componisten und Virtuosen der letzten fünfzehn Jahre. 1870-1885, Berlin ${ }^{2} 1886$, S. 265-268.
} 
riskante Stellen, die selbst Joachim nicht immer ganz rein zustande gebracht hätte. Schließlich fasst er seinen Eindruck wie folgt zusammen: »... ein Musikstück von meisterhaft formender und verarbeitender Kunst, aber von etwas spröder Erfindung und gleichsam mit halbgespannten Segeln auslaufender Phantasie. «101

Unter den zeitgenössischen Musikkritikern gehörte Hermann Wolff zu denjenigen, die das Violinkonzert von Anfang an relativ scharf kritisierten, wobei sein Kriterium nicht in der Tradition des betreffenden Genres, vor allem in den entsprechenden Werken von Beethoven und Mendelssohn, sondern in der von Wagner beeinflussten Kunstauffassung lag.

Hermann Wolffs zurückblickender Artikel »Die Berliner Concertsaison 1878/79« behandelt hauptsächlich die Neuheiten, die in der vergangenen Saison in Berlin vorgestellt wurden und die Musiker, die sich für die Aufführung neuer Werke einsetzten. ${ }^{102}$ Seiner Meinung nach sei das gesamte Berliner Musikleben der vorangegangenen Saison ziemlich konservativ ausgerichtet gewesen.

Das Interesse und der Muth für neue Werke, grosse und kleine, in die Schranken zu treten, ist hier leider noch geringer, wie in anderen bedeutenden musikliebenden Städten unseres Vaterlandes; denn wenn wir auch zahlreiche Novitäten verzeichneten, so stehen sie doch in keinem Verhältnis zu der Zahl der Concerte, und in überwiegend vielen Fällen ist ihre Aufführung nur ihren Componisten selbst und nicht fremder Initiative zu verdanken gewesen. Hoffentlich bessern sich diese Verhältnisse. ${ }^{103}$

Als eine der wenigen Persönlichkeiten in Berlin, die sich für die Einführung neuer Werke einsetzen, betrachtet Wolff in erster Linie Benjamin Bilse, ${ }^{104}$ der seit 1867 im Konzerthaus in der Leipziger Straße am Dönhoffplatz mit seiner Kapelle oft neue Werke zur Aufführung brachte und aus dessen Kapelle sich später ein neues Orchester - das Philharmonische

${ }^{101}$ Ebd., S. 268.

102 -f. [Hermann Wolff]: Die Berliner Concertsaison 1878/79, in Neue Berliner Musikzeitung 33 (1879), S. $220 f$.

${ }^{103}$ Ebd., S. 221.

${ }^{104}$ Die Musikalienhandlung Bote \& Bock, bei der Hermann Wolff für die Neue Berliner Musikzeitung arbeitete, war übrigens als Bilses Reiseagentur tätig. Variationen mit Orchester. 125 Jahre Berliner Philharmoniker, hg. von der Stiftung Berliner Philharmoniker, Bd. 1, S. 27. Später auf der Reise nach Spanien mit Anton Rubinštejn im Jahre 1881 bereitete Hermann Wolff eine Tournee der Kapelle von Bilse vor, die in den Sommermonaten erfolgen sollte. Stargardt-Wolff: Wegbereiter großer Musiker, S. 35. 
Orchester, die jetzigen Berliner Philharmoniker - entwickeln sollte. ${ }^{105}$ Für die Saison 1878/79 zählt Wolff die Bekanntschaft mit folgenden Werken dem Verdienst Bilses zu: »die D-dur Symphonie von Brahms, eine Ballade von E. E. Taubert, die Franzeska da Rimini des Tschaikowski, die Sinfonie espagnole von Lalo, eine neue Symphonie (F-dur) von Radecke, Dvorak'sche Slavische Tänze, 3 Schumann'sche Clavierstücke von H. Urban orchestrirt, eine Reissmann'sche Sinfonie und die symphonische Dichtung von Mor. Moczkowski Jeanne d'Arc «. ${ }^{106}$

Dass Wolff Bilses Tätigkeit große Bedeutung beimaß, ist aber auch aus der Tatsache ersichtlich, dass er in der nächsten Saison eine Artikelreihe unter der Rubrik »Bilse-Woche« eröffnete, in der die in den Bilse-Konzerten aufgeführten neuen Werke immer vorgestellt werden sollten. Die Einrichtung dieser Artikelreihe begründet er wie folgt:

Bei der grossen Bedeutung, welche die Concerte Bilse's für unser ResidenzMusikleben insofern haben, als sie uns stets mit den neuesten Erscheinungen ohne Unterschied der Richtung auf dem Laufenden erhalten, glauben wir genannten Concerten eine stehende Rubrik eröffnen. ${ }^{107}$

Obwohl diese Artikelreihe aus unbekannten Gründen nicht lang erschien, ${ }^{108}$ ist im Licht seiner zukünftigen Bemühungen zur Einrichtung der Abonnementkonzerte des Berliner Philharmonischen Orchesters die Tatsache bedeutsam, dass Wolff als Musikkritiker Bilses Tätigkeit verfolgte. ${ }^{109}$

Neben der Vorstellung von neuen Kompositionen war eine gute Orchesterbegleitung der Solisten der Anspruch, den Wolff von den zeitgenössischen musikalischen Institutionen in Berlin erfüllt sehen wollte. Über die Mängel des Berliner Musiklebens berichtet er wie folgt:

Oft genug haben wir es in unseren Concertreferaten des vorigen Winters betont, wie notwendig für unser Musikleben ein tüchtiges Orchester sei, welches Künstlern, die eines solchen zu ihren Concerten bedürften, zur Disposition stehen und stets für die

\footnotetext{
${ }^{105} \mathrm{Zu}$ Bilse und seiner Kapelle, vgl. Abschnitt 3.2.1 der vorliegenden Arbeit.

106 -f. [Hermann Wolff]: Die Berliner Concertsaison 1878/79, 220f. Hermann Wolff hatte diese Konzerte in den früheren Nummern des Jahres besprochen. Vgl. Neue Berliner Musikzeitung 33 (1879), S. 52 und S. 68.

107 -f. [Hermann Wolff]: Bilse-Woche, in Neue Berliner Musikzeitung 33 (1879), S. 310.

${ }^{108}$ Die Artikel unter der Rubrik »Bilse-Woche« von Hermann Wolff sind sonst nur in zwei Nummern der gleichen Saison zu finden. Vgl. ebd., S. 318, S. 340f. und S. 413.

${ }^{109} \mathrm{Vgl}$. Abschnitt 3.1.1 der vorliegenden Arbeit.
} 
nothwendigen Proben bereit sei, ohne dass durch diese die Kosten des Concertes zu gross würden. Jul. Liebig, dessen Circular wir unlängst ausführlich mitteilten, hat die Absicht, dem den obenerwähnten Mangel durch sein Emser Curorchester zu ersetzen und führte sich zu diesem Zwecke am Sonntag Mittag im Saale der Singakademie vor einem geladenen Publikum mit seinen gesammten Kräften ein. ${ }^{110}$

Julius Liebigs Vater Carl hatte 1843 die sogenannte »Liebig'sche Kapelle« gegründet und durch ihre populären Sinfoniekonzerte großen Anklang im Berliner Musikleben gefunden. Seit 1869 entwickelte sein Sohn diese Kapelle unter dem Namen »Berliner Symphoniekapelle« weiter. Seiner Erwartung an ein tüchtiges begleitendes Orchester gibt Wolff wie folgt Ausdruck:

[...] wir wollen aber erst ein definitives Urtheil fällen, wenn die Kapelle in ihrem eigentlichen Wirkungskreise, der speciell für uns von Wichtigkeit ist, als begleitendes Orchester, gehört haben werden.

Wir wünschen Herrn Liebig, dem es als dem Sohne des Begründers unserer populären Sinfonieconcerte an Sympathien nicht fehlen wird, Glück zu seinem nicht leichten Unternehmen. Möge er nicht übersehen, dass es sehr darauf ankommt, Besseres zu leisten, als Berlin in den letzten Jahren gewohnt war und dass er nur durch die Erfüllung dieser grösseren Ansprüche ein glückliches Resultat erzielen, eine dauernde Stellung in unserm Musikleben erringen kann.

Die Funktion eines tüchtigen Begleitorchesters, das Solisten in ihren Konzerten unterstützen sollte, sollte das 1882 gegründete Philharmonische Orchester übernehmen. ${ }^{111}$

\section{Nach der Gründung der Konzertdirektion}

Hermann Wolff schlug den Weg zum Konzertagenten über die Position als Reisesekretär von Anton Rubinštejn ein, die er durch die Empfehlung von Hugo Bock, dem Inhaber des Musikverlages Bote \& Bock, erhalten hatte. ${ }^{112}$ In der Tätigkeit für Rubinštejn und für verschiedene andere Künstler kam ihm der Gedanke, aus dem Rahmen seiner bisherigen

\footnotetext{
${ }^{110}$ Dieses und das nächste Zitat aus: -f. [Hermann Wolff]: Berlin. Revue, in Neue Berliner Musikzeitung 33 (1879), S. 325f.

${ }^{111}$ Zum Solistenkonzert dieses Orchesters vgl. Peter Muck: Einhundert Jahre Berliner Philharmonisches Orchester. Darstellung in Dokumenten, Bd. 1, Tutzing 1982, S. 15.

${ }^{112}$ Stargardt-Wolff: Wegbereiter großer Musiker, S. 27.
} 
Tätigkeit herauszutreten und auf dem Gebiet des Konzertwesens eine Institution ins Leben zu rufen, wie sie im Bereich des Theaterwesens schon lange bestand. In freundschaftlichem Übereinkommen löste er seinen Vertrag mit Bote \& Bock auf und gründete die Konzertdirektion Hermann Wolff, die als Vermittlungsstelle zwischen Künstlern und Konzertgesellschaften fungieren sollte.

Aus den zeitgenössischen Aussagen entsteht der Gesamteindruck von Hermann Wolff als einer erfinderischen, kunstverständigen und geschäftssinnigen Persönlichkeit mit Humor, obwohl es wegen seines großen, fast monopolistischen Einflusses im damaligen Musikleben verständlicherweise auch nicht wenige negative Auffassungen zu ihm gibt. Der Journalist und Arzt Isidor Kastan sieht die Besonderheit von Hermann Wolff in dessen vielfältigen Fähigkeiten:

Hermann Wolff vereinigte in seiner Person eine ganze Reihe von Fähigkeiten, wie solche sich nicht allzuoft beieinanderfinden. Er hatte sich eine große Belesenheit angeeignet, war sprachgewandt, außerordentlich schlagfertig, witzig, ungemein findig und bei aller Geschäftstüchtigkeit für künstlerische Interessen empfänglich. ${ }^{113}$

Edith Stargardt-Wolff meint, dass die Konzertdirektion Hermann Wolff ihren raschen Aufstieg dem richtigen musikalischen Entdeckersinn ihres Begründers verdanke:

Der Unterschied zwischen ihm und seinen Nachahmern bestand darin, dass er nicht nur als früherer Sekretär bedeutender Musiker reiche Erfahrung besaß, sondern daß er neue Ideen mitbrachte, die nichts von Schablone an sich hatten, vielmehr von dem Entdeckersinn des künstlerisch veranlagten Mannes Zeugnis gaben. [...] Und so kamen und drängten sich Künstler und Musikaspirannten, um von ihm gehört und gefördert zu werden. Kaum ein Tag verging, an dem nicht unbekannte, junge Musiker zu ihm kamen zum Probespiel oder um, von ihm begleitet, vorzusingen. ${ }^{114}$

Die letzten fast 20 Jahre seines Lebens nach Gründung seiner Konzertdirektion hatte er der Tätigkeit für Musiker und für das Musikleben gewidmet, bevor er am 3. Februar 1902 im Alter von 56 Jahren starb. Der Schilderung seiner Tochter Edith Stargardt-Wolff nach konnte ein akut auftretendes Darmleiden nicht rechtzeitig operiert werden, weil man wegen eines

\footnotetext{
${ }^{113}$ Isidor Kastan: Berlin wie es war, Berlin 1919, S. 275f. Ich bedanke mich bei Herrn Dr. Dietmar Schenk, der mich auf diese Quelle hinwies.

${ }^{114}$ Stargardt-Wolff: Wegbereiter großer Musiker, S. 46.
} 
großen Chirurgenkongresses, der genau an diesem Tag in Berlin tagte, keinen der zahlreichen Chirurgen erreichen konnte. Als dessen Folge sei er seit Oktober 1901 schwer krank gewesen. ${ }^{115}$ Wolfgang Zuelzer schreibt, es sei sein Vater gewesen, also der erste Mann von Edith, Georg Ludwig Zuelzer, der den an Magenkrebs leidenden Hermann Wolff untersuchte. Zur Hochzeit von Edith mit diesem jungen Arzt, an der der leidende Konzertagent nur mit Schwierigkeiten teilnehmen konnte, berichtet Wolfgang Zuelzer:

The wedding date was advanced so that the young couple would not have to wait while observing a prolonged period of mourning. Hermann must have known this; a photograph of the wedding party (now lost) showed him, the erstwhile $»$ victorious field marshal, « sitting in a wheel chair apart from the rest of the company, emaciated, withdrawn, embittered, as if he resented the cruel joke life had played on him. ${ }^{116}$

In der Allgemeinen Musik-Zeitung berichtete Otto Lessmann vom Tod »einer der markantesten und einflußreichsten Persönlichkeiten Berlins, man darf wohl sagen, des deutschen Musiklebens« ${ }^{117}$ Er würdigt die Verdienste Wolffs, vor allem seine Bemühungen, das Philharmonische Orchester als Körperschaft zusammen zu halten, und schreibt weiter:

Wie seine Stellung und seine Tätigkeit es mit sich brachten, war Herm. Wolff in der Künstlerwelt den vielfachsten Anfeindungen ausgesetzt; wer ihm indeß persönlich näher trat, mußte doch vor den hervorragenden Eigenschaften des geistvollen Mannes Respekt bekommen. Nun hat dem Rastlosen, Vielgewanderten und Vielgewandten nach langem Ringen der Sensenmann den Lebensfaden abgeschnitten; gerade während im siebenten seiner philharmonischen Konzerte die erhabenen Klänge des EroicaTrauermarsches ertönten, schloß sich ihm das Auge zu ewigem Schlummer.

Die Trauerfeier fand am Sonntag, den 9. Februar 1902 in der Philharmonie mit Darbietungen des Philharmonischen Orchesters und des Philharmonischen Chores statt. Nach einem von Heinrich Reimann gespielten Orgelpräludium leitete Arthur Nikisch den Trauermarsch aus

\footnotetext{
${ }^{115}$ Ebd., S. 173.

116 Zuelzer: Queen Louise - a Portrait, S. 25. Das Gästebuch von Edith, das momentan im Archiv der Berliner Philharmoniker aufbewahrt ist, enthält die Namen zahlreicher Teilnehmer dieser Hochzeit vom 22. Januar 1902, darunter viele bekannte Musiker wie Richard Strauss, Arthur Nikisch, Siegfried Ochs, Ferruccio Busoni usw.

${ }^{117}$ Dieses und das nächste Zitat aus Otto Lessmann: Hermann Wolff $\uparrow$, in Allgemeine Musik-Zeitung 29 (1902), S. 113f.
} 
der Eroica-Symphonie von Beethoven, Josef Řebiček das Parsifal-Vorspiel von Wagner und dann Siegfried Ochs das Schicksalslied von Brahms. Zwischen dem Trauermarsch und Parsifal-Vorspiel hielt Reimann die Trauerrede, in der die vielseitigen Tätigkeiten des verstorbenen Freundes beleuchtet wurden. ${ }^{118}$ Das Orchester war durch ein Pflanzenarrangement dem Auge des Hörers vollständig entzogen, sodass es als »verdecktes Orchester« eine unbeschreibliche Wirkung entfaltete. ${ }^{119}$

\subsubsection{Louise Wolff 120}

\section{Jugendzeit und Ausbildung}

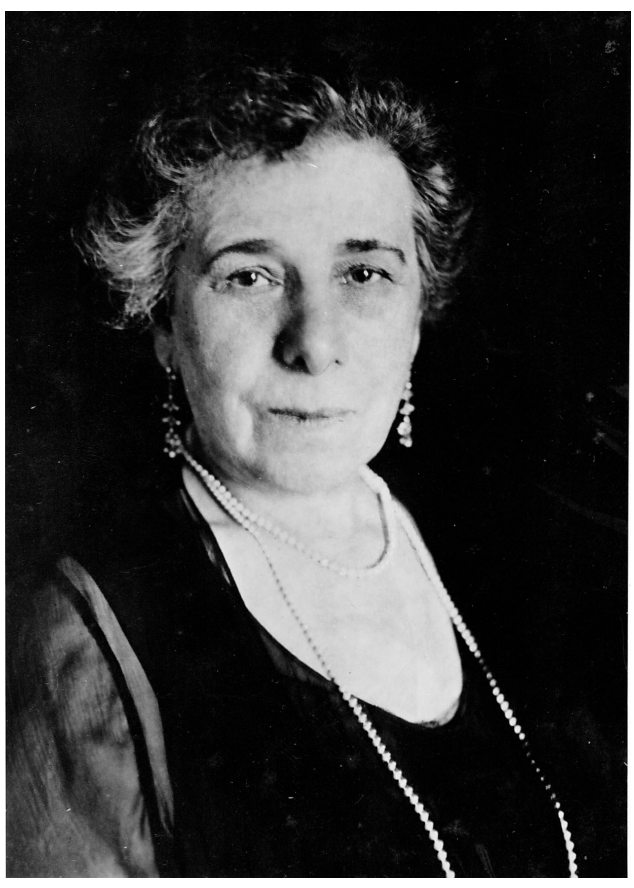

Abbildung 4: Portrait von Louise Wolff, o. D. (Wolff-Nachlass: ID 257)

Louise Wolff (Abbildung 4), die am 25. März $1855^{121}$ in der mährischen Hauptstadt Brünn als Tochter des kaiserlichen und königlichen Militäroberrechnungsrats Johann Evangelist

\footnotetext{
${ }^{118}$ N.N.: Berichte und kleine Mittheilungen, in ebd., S. 139.

${ }^{119}$ N.N.: Tageschronik, in Die Musik. Illustrierte Halbmonatsschrift 1 (1902), I. Märzheft, S. 1011.

${ }^{120} \mathrm{Im}$ Vergleich zu Hermann Wolff gibt es relativ wenige biographische Darstellungen zu Louise Wolff. Ihr Enkel Wolfgang Zuelzer schreibt, dass ihre enge Freundin Geraldine De Courcy, Korrespondentin der Musical Courier in Berlin, sie immer wieder drängte, ihre Erinnerungen zu schreiben oder lieber zu diktieren, was sich schließlich nicht verwirklichte, weil sie bis kurz vor ihrem Tod zu viel zu tun hatte. Zuelzer: Queen Louise - a Portrait, S. 13.

${ }^{121}$ Dieses Geburtsdatum ist in den amtlichen Akten einheitlich zu finden. Es ist nicht bekannt, warum sie dem Herausgeber der neuen Ausgabe des Riemannschen Musiklexikons 1857 als ihr Geburtsjahr mitteilte. Brief von Louise Wolff an Alfred Einstein vom 2.8.1928. Alfred Einstein papers, Archives Einstein Coll.1, The Music Library, University of California, Berkeley, Part IX. Correspondence of Alfred Einstein: Folder 1042 .
} 
Schwarz und dessen Frau Elisabeth zur Welt kam, erhielt zuerst den Namen Aloysia Wilhelmine Schwarz. Später nannte sie sich Louise, während sie von ihrer Familie »Olly« genannt wurde. ${ }^{122}$ Unter den Geschwistern scheinen der am 11. Juni 1858 geborene Bruder Franz, der ein großherzoglicher Kammersänger wurde, und die am 13. Juni 1866 geborene Schwester Marie, genannt Mitzi, auch in den späteren Jahren Louise nahegestanden zu haben.

Als fünfjähriges Kind kam sie mit ihrer Familie nach Wien, wo sie ihre allgemeine Bildung empfing. $\mathrm{Zu}$ Hause und auch in der von Nonnen geführten Schule, in der sie vor allem Handarbeit und die französische Sprache lernte, erhielte sie eine gute katholische Erziehung. ${ }^{123}$ So blieb sie zeitlebens Katholikin, wenngleich sie in den späteren Jahren nur selten die Kirche besuchte. Sie heiratete keinen Katholiken und ließ ihre drei Kinder evangelisch erziehen. Dies sei ein Kompromiss zwischen der Religion ihrer Vorfahren und dem Agnostizismus ihres Mannes gewesen. ${ }^{124}$

Ihr Vater, ein zu Hause zuweilen tyrannischer Mann, war literarisch interessiert und versiert. Er verehrte schwärmerisch die alt-wienerischen Poeten wie Johann Nestroy sowie Ferdinand Raimund und konnte ihre Werke auswendig vortragen. Diese Theaterleidenschaft übernahm seine älteste Tochter: Sie hatte den sehnlichen Wunsch, Schauspielerin zu werden. Eine Prüfung bei »Herrn Strakosch «, ${ }^{125}$ vermutlich dem österreichischen Theaterschauspieler Alexander Strakosch, eröffnete ihr den Weg zur Schauspielausbildung, die später zur Mitwirkung bei einer reisenden Theatertruppe führte. $\mathrm{Zu}$ den Eigenschaften der jungen Schauspielerin und ihren damaligen Schwierigkeiten schreibt ihr Enkel Wolfgang Zuelzer, der erst 1909 zur Welt kam, wie folgt:

The life of an unattached actress was not an easy one in those days. Louise Schwarz was not a classical beauty, but attractive enough to the opposite sex though strikingly different from the demure, blond, young women she saw in Germany. With her expressive brown eyes, high Slavic cheekbones, the slightly retroussé nose that somehow looked mischievous, delicately curved lips, and firm chin, the whole surmounted by a mass of black tresses, she was not easily overlooked in any group of

\footnotetext{
${ }^{122}$ In den Familienbriefen im Wolff-Nachlass wird sie oft mit diesem Vornamen genannt. Nicht zu verwechseln mit »Ully (oder Ulli)«, dem Spitznamen ihres Enkels Wolfgang Zuelzer.

${ }^{123}$ Stargardt-Wolff: Wegbereiter großer Musiker, S. 18.

${ }^{124}$ Zuelzer: Queen Louise - a Portrait, S. 14f. In den Geburtsregistern der drei Kinder ist sie als Dissidentin eingetragen. Geburtsregister von Edith Wolff: LAB, P Rep. 801, Nr. 256, Standesamt Berlin II, 1880, Nr. 50; Geburtsregister von Werner Wolff: LAB, P Rep. 804, Nr. 545, Standesamt Berlin III, 1883, Nr. 1586; Geburtsregister von Lili Wolff: LAB, P. Rep 804, Nr. 552, Standesamt Berlin III, 1885, Nr. 916. ${ }^{125}$ Zuelzer: Queen Louise - a Portrait, S. 16; Stargardt-Wolff: Wegbereiter großer Musiker, S. 19.
} 
women. As for men, she was very particular and rejected the attention of the clerks and commercial travelers who were the only unattached males a young actress was likely to encounter in the backwater of provincial towns. Her virtue, or was it pride, threatened to become an obstacle to her career, for as she confided to her diary, »word got around « and ticket sales fell when the company's best customers realized that the leading lady was unapproachable, even the manager complained! ${ }^{126}$

Die Stücke, die die Truppe nach dem Geschmack der Provinzbewohner in Böhmen, Schlesien und Pommern aufführte - hauptsächlich Melodramen und Possen -, befriedigten aber keinesfalls die idealistische junge Schauspielerin, die, der Vermutung ihres Enkels nach, wohl davon träumte, in Rollen wie der keuschen Iphigenie von Goethe oder einer der großen Heroinen in den Werken von Schiller oder Hebbel die Bühne zu betreten. ${ }^{127}$

Ihre Situation änderte sich durch eine Begegnung, die sie bei einem kurzen Aufenthalt in Berlin erlebte. Im Königlichen Schauspielhaus, das sie als Zuschauerin besuchte, lernte sie einen Platznachbarn kennen, der sich als intelligent sowie sachkundig herausstellte und mit dem sie sich anfreundete. Diesen Geschäftsmann - es war Hermann Wolff - heiratete sie schließlich und beschloss, sich von der Bühne zu verabschieden. ${ }^{128}$ Wolfgang Zuelzer beschreibt die gegensätzlichen Eigenschaften dieses Paares wie folgt:

The marriage was a success, the attraction of opposites. He was a rationalist to the core, cool, witty, ironic, whereas she was guided by instinct and temperament, his analytical mind, hers relying largely on intuition. She was more than a good wife and mother to their three children, an equal to be consulted in all matters of importance, a hostess with poise and charm capable of receiving the most distinguished guests. For soon they would have very distinguished guests indeed. But, the strongest bond between husband and wife was love of music, resting in his case on solid technical knowledge, in hers on inborn musicality. ${ }^{129}$

\footnotetext{
${ }^{126}$ Zuelzer: Queen Louise - a Portrait, S. 17.

${ }^{127}$ Ebd.

${ }^{128}$ Zur detaillierten Geschichte der Entwicklung dieser Beziehung vgl. Stargardt-Wolff: Wegbereiter großer Musiker, S 21-23.

${ }^{129}$ Zuelzer: Queen Louise - a Portrait, S. 18.
} 


\section{Von einer Ehefrau zur »Königin«}

Dass Hermann Wolff gewohnt war, mit seiner ihm 1878 angetrauten Frau jede künstlerische Angelegenheit zu besprechen, zeigen die Quellen im Wolff-Nachlass vielfach. Von Louise Wolff ist im Wolff-Nachlass ein Tagebuch überliefert, dessen erster Eintrag vom 8. Januar 1887 und dessen letzter vom 14. März 1892 datiert; dazwischen wurde es nur sporadisch geführt. ${ }^{130}$ Am 24. September 1888, am zehnten Hochzeitstag des Ehepaares, blickt Louise auf die letzten zehn Jahre zurück und schreibt etwas stolz über das Vertrauen, das ihr Mann ihr entgegenbrachte, ohne zu ahnen, dass sie die Aufgaben ihres Mannes schon bald übernehmen würde müssen:

\section{Unser 10 jähriger Hochzeitstag!}

Möge das zweite - $\mathrm{u}$. so Gott will die folgenden Decennien nicht schlechter sein! Viel Glück, Freude, Ehre - u. nur wenig ernste - keine traurigen Momente haben uns diese Jahre gebracht. Wie gering sind die Enttäuschungen im Verhältnis zu den unerwarteten Freuden gewesen, die die Ehe uns gebracht hat: das junge Elternglück, dieses höchste u. schönste aller menschlichen Empfindungen - wäre es nur dieses Glück allein - es lohnte sich, gelebt zu haben!

Unser Verhältnis ist in diesen Jahren ein innigeres festeres geworden, als es selbst im Rausche der Leidenschaft zu werden versprach. Hermann hat zur Liebe für mich, auch noch das eisernste Vertrauen hinzugewonnen $-\mathrm{u}$. ich habe kennengelernt, daß das meinige nie getäuscht wurde. - Hermann hat uns durch sein Thatkraft, Energie u. Intelligenz eine Stellung geschaffen, auf die ich in den ersten Jahren unserer Ehe nie zu hoffen gewagt hätte. - $\underline{\text { Ich }}$ kann mir ruhig das Zeugnis ausstellen, daß ich die Frau geworden bin, die er braucht, - nach innen u. außen. - Man kann es sich nicht länger verhehlen: Ich komme allmä[h]lig in das Alter, wo man sich vertieft, wo Äußerlichkeiten aufhören einen größeren Wert zu haben, als den, den sie in Wirklichkeit verdienen. - Ich arbeite an mir um besser u. vielseitiger zu werden, um gewappnet zu sein gegen die Schrecknisse des Älterwerdens; Viel denke ich über die Erziehung der geliebten Kinder nach $-\mathrm{u}$. hoffe sie dereinst zu guten braven wahrhaftigen $u$. mutigen Menschen zu machen. ${ }^{131}$

\footnotetext{
${ }^{130}$ Tagebuch von Louise Wolff 1892/94 (Wolff-Nachlass: ID 130). Vgl.1.3 im Quellenteil der vorliegenden Arbeit. Im Wolff-Nachlass befindet sich jetzt nur ein Tagebuch von ihr. Das 1954 veröffentlichte Erinnerungsbuch von Stargardt-Wolff lässt jedoch vermuten, dass sie bei der Verfassung dieses Buches mehr als ein Tagebuch von ihrer Mutter besaß.

${ }^{131}$ Ebd., S. 29-32. Hervorhebung im Original.
} 
Im Wolff-Nachlass sind zwar keine Briefe von Louise Wolff an Hermann vorhanden. Es ist aber aus den überlieferten Briefen von Hermann Wolff an seine Frau klar, dass das Ehepaar während der Abwesenheit Hermanns, der sehr oft auf Geschäftsreisen war, brieflich in ständigem Kontakt stand, wobei es Louise oblag, nicht nur die Familienangelegenheiten, sondern auch die geschäftlichen Ereignisse und Verhältnisse mit ihrem »Hühnerauge ${ }^{132} \mathrm{zu}$ beobachten und ihm ausführlich zu berichten. ${ }^{133}$

Die andere wichtige Aufgabe von Louise war die der Gastgeberin bei Gesellschaften. Die Tradition des »Philharmonischen Diners, « ${ }^{134}$ eines regelmäßigen Treffens bei den Wolffs am Sonntagmittag nach der öffentlichen Probe in der Philharmonie, begann in der Dienstzeit von Hans von Bülow als Dirigent der Philharmonischen Konzerte. Dort bewirte Louise die am Konzert beteiligten Künstler und Gäste mit ihrer heimatlichen österreichischen Kochkunst. ${ }^{135}$ Wolfgang Zuelzer erzählt seine Erinnerung an diese prächtige Gesellschaft wie folgt:

All these thoughts and decisions he [Hermann Wolff] shared with his wife, but what was equally important, together they created in their home a rich social life. In that stimulating and enjoyable atmosphere, business relationships were forgotten, artists dropped their poses and become human beings, expressed themselves about their art or their personal lives, relished the hostess' superb cuisine, the informality of style and the delights of good conversation. It was then that the tradition of the celebrated Philharmonic Dinners was started which my grandmother continued in her house after her husband's death and which I remember being allowed to attend in my adolescence. As a child I was often in the house but kept out of sight until the party adjourned from the great dining room to the salon for coffee and liqueurs, at which time I could admire the now abandoned table with its damask cloth, its flower pieces, crystal glasses with remnants of delicious wines which I was not above sipping secretly, its finger bowls and the aroma of very good perfumes and expensive cigar smoke hanging

${ }^{132}$ Brief von Hermann Wolff an Louise Wolff vom 21.05.1886 (Wolff-Nachlass: ID 4).

${ }^{133}$ Briefe von Hermann Wolff an Louise Wolff vom 18., 19., 20. und 21.05.1886 (Wolff-Nachlass: ID 1-

4). Vgl. 1.2.1 im Quellenteil der vorliegenden Arbeit.

${ }^{134}$ Stargardt-Wolff: Wegbereiter großer Musiker, S. 95.

${ }^{135}$ Als Beispiel der Einladung von Louise Wolff zu dieser Gesellschaft, vgl. Louise Wolff: Brief an Johannes Brahms vom 9.11.1895, Wienbibliothek im Rathaus, H.I.N. 165.596. Edith Stargardt-Wolff zitiert offenbar aus einer früheren Fassung dieses Briefes mit dem Datum 3. November 1895, die momentan im Staatlichen Institut für Musikforschung Preußischer Kulturbesitz (im Folgenden SIM) unter der Signatur »A Wolff 100« aufbewahrt ist. Vgl. Stargardt-Wolff: Wegbereiter großer Musiker, S. 142f. 
in the air. The guest of honor who presided over the table company was always the conductor of the Philharmonic Concert which had been given the same day in public rehearsal and would be repeated the following night, and, family apart, the company consisted of the soloist of the day and, if he was from abroad, usually diplomatic representatives of his country, other musicians or music lovers, critics, writers, editors, sculptors and painters. ${ }^{136}$

Das oben genannte Tagebuch von Louise Wolff zeigt, wie eng sie mit den namhaften Künstlern umging. Die Rede kommt auf Künstler wie Marcella Sembrich, Wladimir von Pachmann, Josef und Amalie Joachim, Karl Klindworth, Pablo de Sarasate, Józef Hofmann, Hans von Bülow, Paul Friedrich Meyerheim, Carl Bechstein, Johannes Brahms, Giuseppe Martucci, Julius Stettenheim, Alice Barbi, Emma Koch und viele mehr. Ihr Eintrag vom 9. Dezember 1891 dokumentiert etwa einen Besuch von Brahms und Joachim:

Soeben gingen Brahms u. Joachim von uns, wo sie gemütlich ein echt österreichisches $\mathrm{Ma}[\mathrm{h}] 1$ - Suppenfleisch u. Paprikahuhn - mit größtem Enthusiasmus verzehrt hatten. Brahms - der Held des Tages - in 3 Tagen zum zweiten Male bei mir, vorgestern mit Bülow - heute mit Joachim! Ich bin stolz u. glücklich über die Art[,] in der er bei uns verkehrt. Ich glaube, er fü[h]lt sich wo[h]l - so fern von allem Parteigetriebe und lästigen Lobhudeleien - er weiß, daß wir ihn verehren und lieben $-u$. daß ich keine schlechte Küche führe - quelle attraction! - Wenn große Geister ihre Göttlichkeit abstreifen u. liebenswürdige Menschen werden, gewährt es einen eigentümlichen mit nichts zu vergleichenden Reiz. Brahms ist als Mensch ebenso bedeutend wie als Künstler, er ist gelehrt - ohne jeden Anflug von Pedanterie, ironisch, ohne - oder doch nur mit einer wo[h]ltuenden Art von Bosheit - eine glückliche - ehrliche Natur, der im Stande ist, die höchsten Forderungen, die er an sich stellt - auch zu befriedigen. - Und wer kann das von sich sagen? Heute drehte sich das Gespräch meistens um Musik und Musiker. Joachim[,] der auf ziemlich einseitigem Standpunkt steht, ist voll von Schwäche u. Vorurteilen - Brahms bekämpft alles Kleinliche - Zimperliche Akademische mit Feuereifer[.] $]^{137}$

\footnotetext{
${ }^{136}$ Wolfgang Zuelzer: Unvollendete, unveröffentlichte Selbstbiographie, VI-19f, Privatbesitz. Hervorhebung im Original.

${ }^{137}$ Tagebuch von Louise Wolff, S. 37-40. Hervorhebungen im Original.
} 
Durch ihr warmes Wesen beliebt und vertraut, betreute Louise die Künstler nicht nur in künstlerischen Angelegenheiten, sondern auch in persönlichen, wie der folgende Eintrag über Hans von Bülow vom 14. März 1892 exemplarisch zeigt:

Es war am 28[.] November 1889 - ich weiß den Tag so genau, weil Hermann gerade zu dem 50 jährigen Rubinstein-Jubiläum nach Petersburg fuhr - als Bülow zu mir kam und mich um Rat frug, ob er sich scheiden solle. Er weinte $u$. fluchte $u$. knirschte $-u$. sagte[,] er könne mit seiner Frau nicht mehr leben. [...] Er erzä[h]lte mir[,] daß sie ihm Briefe der Frau M. aus dem Schreibtisch gesto[h]len, und sie auswendig gelernt, um sie nun bei jeder Gelegenheit zu citiren. - Er hätte die größte Dummheit seines Lebens begangen indem er diese Person geheirat[et] - daß er überhaupt geheiratet, sei ein Verbrechen - er erzä[h]lte mit welchem Haß uns seine Frau beehre, wie jeder Brief meines Mannes - Anlaß zu Streit gebe! - ich widerrieth ihm tro[t]zdem, sich scheiden zu lassen u. das war gut - denn 8 Tage darauf - als er wieder kam, erschien auch Madame - u. er war - der gehorsamste Diener - knirschte zwar - aber fügte sich mit Grazie ins Joch. ${ }^{138}$

Louise brachte insgesamt drei Kinder zur Welt: Edith, geboren am 8. Januar 1880, Werner, am 2. Oktober 1883 und Lili, am 9. Juni 1885. Später traten die beiden Töchter in die Konzertdirektion als Mitarbeiter ein, während Werner sich als Dirigent einen Namen machte.

Nachdem ihr Gründer am 3. Februar 1902 starb, behielt die Konzertdirektion unter der Leitung von Louise und ihren Teilhabern, zuerst Hermann Fernow, später Erich Sachs und Erich Simon, ihre führende Rolle, auch in der Zeit des Ersten Weltkriegs und der Inflation. Wegen ihres großen Einflusses im Berliner Musikleben wurde die Chefin der weltbedeutenden Konzertagentur als »Königin Louise « bekannt. ${ }^{139}$

Die Tradition des Philharmonischen Diners setzte sie auch in der neuen Wohnung in der Rankestraße 13 in Charlottenburg fort, wohin sie nach dem Tod ihres Mannes gezogen war. An den Dienstagnachmittagen hatte sie dort auch ihren jour fixe, »zu dem sich ungezwungen Freunde und Fremde, einheimische und auswärtige Künstler einfanden «. ${ }^{140}$ Als die interessantesten musikalischen Häuser Berlins gibt Eugen Szatmari dasjenige der Witwe

\footnotetext{
${ }^{138}$ Tagebuch von Louise Wolff, S. 60-62. Hervorhebung im Original.

${ }^{139}$ Vgl. z. B. Hans Heinz Stuckenschmidt: Zum Hören geboren. Ein Leben mit der Musik unserer Zeit, München 1979, S. 131.

${ }^{140}$ Stargardt-Wolff: Wegbereiter großer Musiker, S. 176.
} 
von Hans von Bülow und dasjenige von Louise Wolff an und stellt die große Wichtigkeit von letzterem im Berliner Sozialleben wie folgt dar:

Frau Louise Wolff ist dafür die ungekrönte Königin der Berliner Musikwelt. Sie ist die Inhaberin der größten Konzertagentur in Berlin, aber darüber hinaus führt sie einen Salon wie ehemals die Prinzessin Metternich. In ihrem Hause trifft sich ganz Berlin. In ihrem Salon werden Erfolge geschaffen und die Grundlagen zu künftigem Weltruhm gelegt. Sie hat Dusolina Giannini und Benjamino Gigli nach Berlin gebracht, sie hat die besten Beziehungen zu allen Leuten, sie hat Beziehungen zu der Presse, zu den Ministerien und zu den Akademien, sie erfährt alles, sie weiß alles, und ihre Hand führt eine ganze Reihe von unsichtbaren Fäden hinter den Kulissen der musikalischen Welt. ${ }^{141}$

Dass ihr Heim für lange Jahre ein musikalischer und gesellschaftlicher Mittelpunkt Berlins war, spiegelt auch ihr Gästebuch wider, das von 1901 bis 1935 zwar nur sporadisch geführt wurde, aber die wichtigen Gelegenheiten verzeichnete. ${ }^{142}$ Zum Beispiel veranstaltete Louise Wolff am 29. Februar 1920, anlässlich des fünfundzwanzigsten Jubiläums von Arthur Nikischs Wirken als Dirigent der Berliner Philharmonischen Konzerte ein großes Fest in ihrem Haus. ${ }^{143}$ Die Unterschriften, die an diesem Tag eingetragen wurden (Abbildung 5), nehmen acht Seiten im Gästebuch ein und enthalten zahlreiche prominente Namen: Arthur, Amélie und Mitja Nikisch, Richard Strauss, Alexander Moszkowski, Ludwig Wüllner, Adolf Weissmann, Wilhelm Altmann, Georg Schumann, Hugo Bock, Nora Pisling-Boas, Heinrich Grünfeld, Walter Kirchhoff, Felix Weingartner, Frederic Lamond, Irene Triesch, Elisabeth van Endert, Max Schillings, Barbara Kemp, Konrad Harnisch, Carl Ludwig Schleich, Gustav Noske und viele mehr.

\footnotetext{
${ }^{141}$ Eugen Szatmari: Das Buch von Berlin, München [1927], S. 194.

${ }^{142}$ Dieses Gästebuch war lange Zeit im Besitz der Nachkommen der Familie Wolff und wurde um das Jahr 2012 mit sechs weiteren Objekten dem Archiv der Berliner Philharmoniker überlassen. Zu diesem Gästebuch vgl. auch Stargardt-Wolff: Wegbereiter großer Musiker, S. 176ff.

${ }^{143} \mathrm{Zu}$ dieser Feier vgl. auch Louise Wolff: Arthur Nikisch und Berlin. Aus meinen Erinnerungen, in Arthur Nikisch. Leben und Wirken, hg von Heinrich Chevalley, Berlin: Bote \& Bock, 1922, S. 161-171, hier: S. 170; Stargardt-Wolff: Wegbereiter großer Musiker, S. 216f.; N. N.: Notizen, in Zeitschrift für Musik 87 (1920), S. 39.
} 


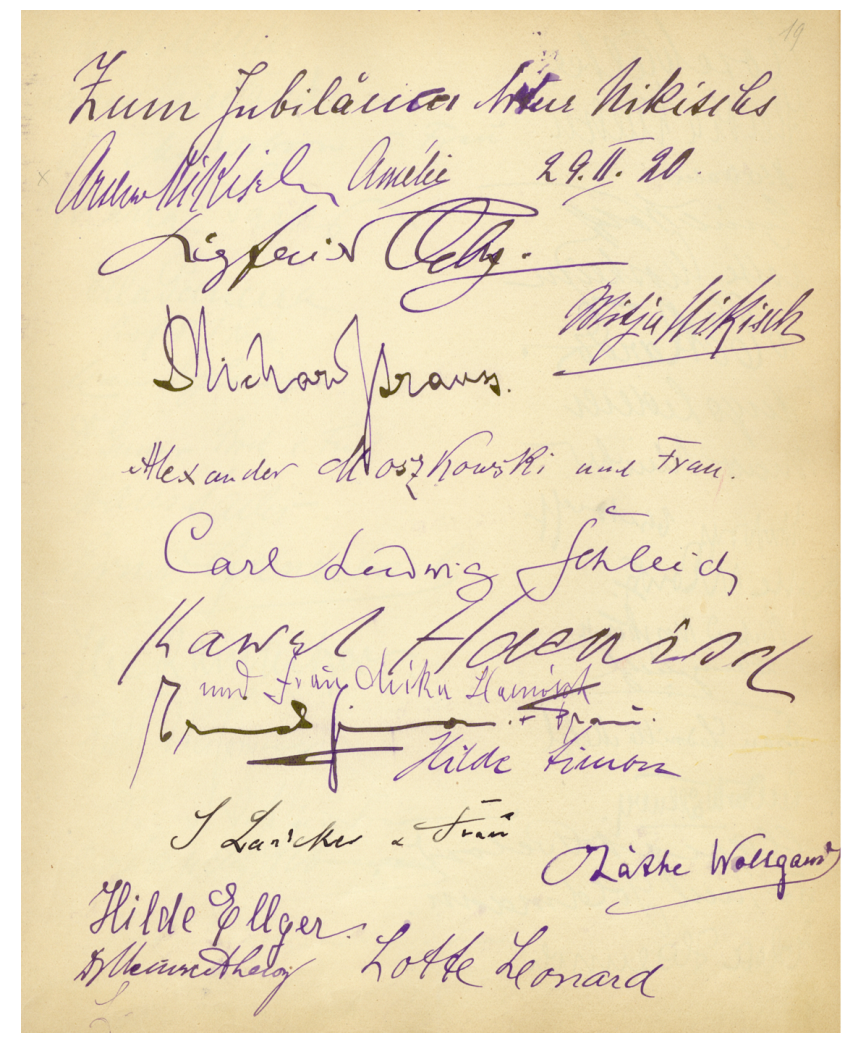

Abbildung 5: Gästebuch von Louise Wolff, »Zum Jubiläum Arthur Nikisch« am 29. Februar $1920^{144}$ Im Wolff-Nachlass ist ein Exemplar des Arthur-Abendblatts überliefert (Abbildung 6), ${ }^{145}$ das bei diesem Jubiläum nach der in Berlin sehr verbreiteten Zeitung Acht-Uhr-Abendblatt in der gleichen Druckart erstellt wurde. Dieses Blatt ist mit scherzhaften Geschichten und Anekdoten über den gefeierten Dirigenten gefüllt, unter denen der Dialogartikel »In der Konzertdirektion« ein Bild des lebendigen Alltags von Louise Wolff inmitten der Künstler auf launige Weise darstellt.

${ }^{144}$ Gästebuch von Louise Wolff, Archiv der Berliner Philharmoniker, S. 19. Diese Seite enthält die Signaturen von Arthur, Amélie und Mitja Nikisch, Richard Strauss, Siegfried Ochs, Alexander Moszkowski und seiner Frau, Carl Ludwig Schleich (Chirurg), Konrad Haenisch und seiner Frau und Erika, Erich Simon und seiner Frau, S. Landeker und seiner Frau, Käthe Wollgandt (Tochter von Arthur Nikisch) und Lotte Leonard.

${ }^{145}$ Wolff-Nachlass: ID 284. 


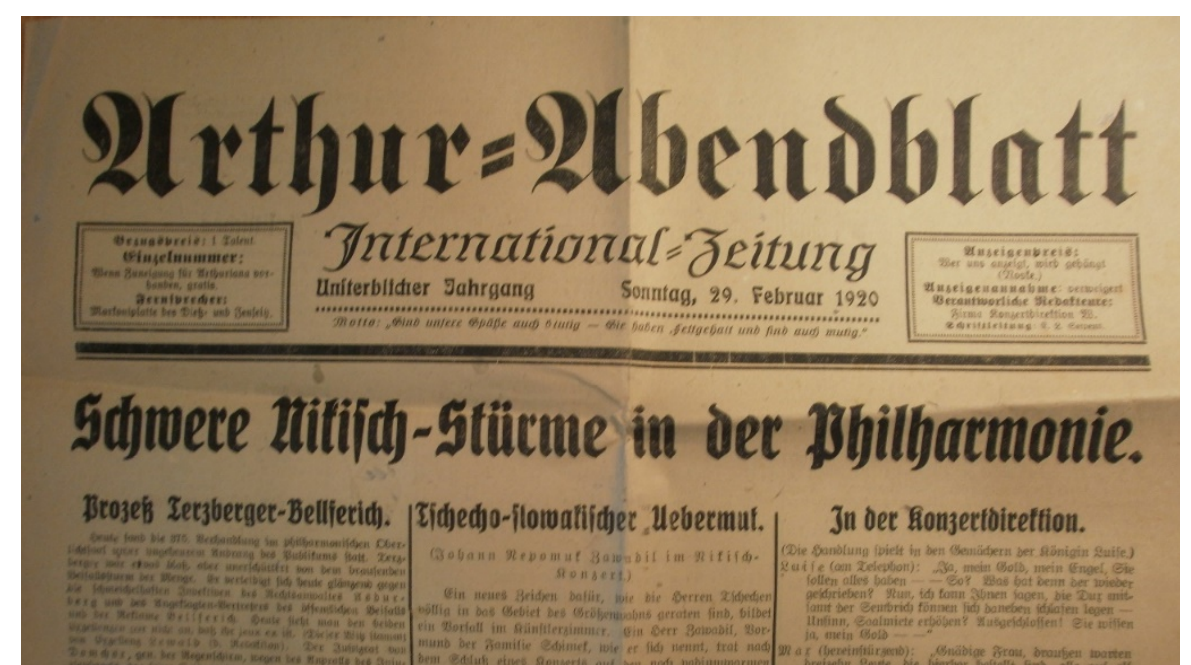

Abbildung 6: Arthur-Abendblatt vom 29. Februar 1920

\section{Liquidierung der Konzertdirektion und Tod}

$\mathrm{Ab}$ Hitlers Machtergreifung fielen einige Haupteinnahmequellen der Konzertdirektion, vor allem die Philharmonischen und die Bruno-Walter-Konzerte, infolge der Verfolgung der Firma weg. ${ }^{146}$ Der langjährige Mitarbeiter von Louise Wolff, Erich Sachs, musste die Konzertdirektion wegen seiner Abstammung verlassen.

Was Louise Wolffs Biographie angeht, muss die in der Literatur verbreitete Angabe, dass sie Jüdin gewesen sei, ${ }^{147}$ korrigiert werden. Die Konzertdirektion Hermann Wolff war zwar insofern »jüdisch«, ${ }^{148}$ als die beiden langjährigen Geschäftsführer Erich Sachs und Erich Simon im Sinne des Nürnberger Gesetzes »Volljuden« und Louise Wolffs Töchter, die an der Firma arbeiteten, wegen der Abstammung ihres 1902 verstorbenen Vaters »Mischlinge« waren, aber Louise Wolff selbst war »Arierin«. Dies beweisen unter anderen die Akten, die in der Nachkriegszeit beim Entschädigungsantrag für die Konzertdirektion Hermann Wolff entstanden:

Frau Wolff, die selbst sogenannte Arierin war, war nicht möglich, mit Rücksicht auf die nationalsozialistischen Bestrebungen, die bereits im Jahre 1933, zum Teil ohne »gesetzliche« Grundlage erfolgten, das Geschäft ihren Kindern, die als so genannte Mischlinge galten, zu übertragen. In den Augen der Nationalsozialisten war die Firma

\footnotetext{
${ }^{146}$ Die im Wolff-Nachlass überlieferten Aufzeichnung (ID 135) ist vermutlich in dieser Zeit entstanden.

${ }^{147}$ Gerhard Splitt: Richard Strauss 1933-1935. Ästhetik und Musikpolitik zu Beginn der nationalsozialistischen Herrschaft, Pfaffenweiler 1987. S. 54; Erik Ryding und Rebecca Pechefsky: Bruno Walter. A World Elsewhere, New Haven u. a. 2001, S. 146; Misha Aster: »Das Reichsorchester « Die Berliner Philharmoniker und der Nationalsozialismus, München 2007, S. 185.

${ }^{148}$ Splitt: Richard Strauss 1933-1935, S. 49.
} 
auf Grund einer jahrzehntelangen »jüdischen Versippung« ebenfalls ein jüdisches Unternehmen, das beseitigt werden musste. ${ }^{149}$

Es war vorauszusehen, dass ihre beiden Töchter nicht mehr lange ungehindert würden arbeiten können. ${ }^{150}$ Nach gescheiterten Versuchen, die Firma weiterzuführen, ${ }^{151}$ traf Louise Wolff 1934 den Entschluss, die Konzertdirektion aufzulösen.

Louise Wolff konnte noch am 25. März 1935 ihren achtzigsten Geburtstag feiern, wobei wieder eine große festliche Versammlung abgehalten wurde. Nur drei Monate danach, am 25. Juni 1935, und zwar gerade einmal vier Tage vor dem Ende des Liquidationsverfahrens ihrer Konzertdirektion, verstarb sie in ihrer Wohnung. Bei der Trauerfeier am 28. Juni 1935 hielt der Bibliothekar Wilhelm Altmann die Gedächtnisrede, in der er die Schwierigkeiten, denen sie in ihrem Geschäft nach dem Ersten Weltkrieg gegenüberstanden hatte, wie folgt beschreibt, und sich damit von der »Königin« verabschiedet:

Hatte selbst noch in der Kriegszeit fast in jeder kleinen Stadt ein Verein bestanden, der im Winter vier und auch noch mehr Konzerte veranstaltete und die dazu nötigen Künstler auf die Empfehlung der Konzertdirektion Wolff kommen ließ, so verschwanden diese Vereine während der Nachkriegszeit zum großen Teil oder sahen sich gezwungen, ihre Veranstaltungen sehr einzuschränken, zumal auch die betrübende Tatsache immer mehr bemerkbar wurde, daß das überhandnehmende Interesse weitester Kreise am Sport und der Rückgang der Musikpflege seitens der Jugend den Konzertbesuch aufs ungünstigste beeinflußte. Wie diesem Übelstand abzuhelfen sei, darüber hat auch Frau Louise Wolff vergeblich ihr Gehirn zermartert. Ohne einen Weg zur Besserung zu sehen, mußte sie erleben, daß ihr Wirkungskreis immer kleiner wurde. Nur aus Rücksicht auf ihre Angestellten ließ sie sich bestimmen weiter auszuharren, bis sie das in der Bibel als Höchstgrenze des Lebens bezeichnete Alter erreicht hatte. ${ }^{152}$

\footnotetext{
${ }^{149}$ Entschädigungsakte (Fa. Konzertdirektion Hermann Wolff u. Jules Sachs GmbH., Antragsteller: Werner Wolff), Entschädigungsbehörde Berlin, Reg. Nr. 40762, Bl. D6r-v. Vgl. auch das im Abschnitt 2.2.3 der vorliegenden Arbeit zitierte Schreiben von Siegried Lütgert an Hans Henkel vom 26.4.1933.

${ }^{150}$ Stargardt-Wolff: Wegbereiter großer Musiker, S. 298.

${ }^{151}$ Dazu vgl. Abschnitt 2.2.3 der vorliegenden Arbeit.

${ }^{152}$ Wilhelm Altmann: Gedächtnisrede für Louise Wolff, [S. 1] (Wolff-Nachlass: ID 286).
} 


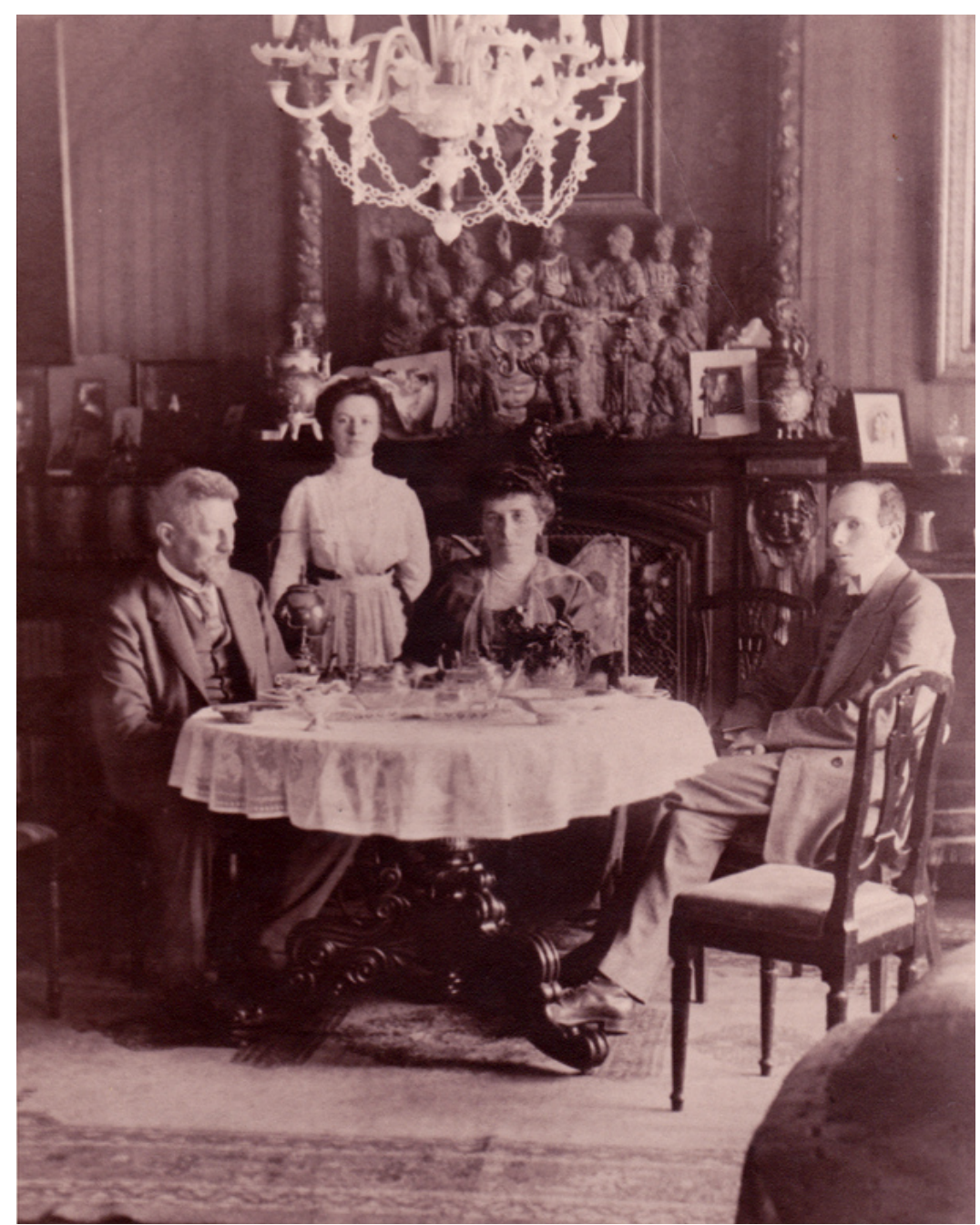

Abbildung 7: Louise Wolff (Mitte) mit ihrem Sohn Werner (rechts) in ihrer Wohnung, o. D. (WolffNachlass: ID 269)

\subsubsection{Erich Sachs ${ }^{153}$}

Erich Sachs wurde am 16. April 1882 in Berlin als Sohn »volljüdischer« Eltern geboren. Er absolvierte das Französische Gymnasium Berlin, machte dort mit 17 Jahren sein Abitur und studierte anschließend an der Friedrich-Wilhelms-Universität Jura und Philosophie. Durch den plötzlichen Tod seines Vaters im Jahr 1901 sah er sich als einziger Sohn beziehungsweise einziges Kind gezwungen, die väterliche Firma zu übernehmen. Er brach sein Studium ab und übernahm die Leitung der im Jahre 1881 von seinem Vater ins Leben gerufenen Konzertdirektion Jules Sachs. 1905 schloss er seine erste Ehe, aus der drei Kinder hervorgingen.

\footnotetext{
${ }^{153}$ Diese biographische Beschreibung beruht hauptsächlich auf seinem Lebenslauf, der von seiner verwitweten Frau zum Zweck des Entschädigungsantrags verfasst wurde. Lebenslauf verfasst von Espyra Sachs vom 18. Januar 1956, Endschädigungsakte (Erich E. Sachs), EBB, Reg. Nr. 71702, B1. M $79 f$.
} 
Im Herbst 1916 wurden die ältesten Berliner Konzertdirektionen, die Konzertdirektion Jules Sachs und die Konzertdirektion Hermann Wolff, zu einer Firma zusammengeschlossen, die sich nun als eine Gesellschaft mit beschränkter Haftung Konzertdirektion Hermann Wolff und Jules Sachs nannte. Neben Louise Wolff wirkte er in dieser Firma als Gesellschafter sowie Geschäftsführer. Am 5. Dezember 1929 erfolgte seine zweite Ehe mit Espyra Sachs, geborene Mohrus, die ebenfalls »Volljüdin« im Sinne der Nürnberger Gesetze war. Aus dieser Ehe stammte ein einziger Sohn: Peter Julius.

Die Machtergreifung Hitlers bereitete Erich Sachs in seiner beruflichen Karriere erhebliche Schwierigkeiten, die schließlich im April 1933 zwangsweise zum Ausscheiden aus der Konzertdirektion führten. Am 10. November 1938 wurde er in seiner Wohnung in Wilmersdorf, in die er nach dem zwangsweise erfolgten Verkauf seiner Villa in Lichterfelde eingezogen war, verhaftet und ins Konzentrationslager Sachsenhausen verbracht. Unter der Voraussetzung, dass eine Auswanderung gesichert war, konnte er am 12. Dezember 1938 aus dem Konzentrationslager entlassen werden und emigrierte dann mit seiner Frau nach Israel.

Während dieser Haftzeit wurde er zu schwersten Außenarbeiten gezwungen, so dass sein Gesundheitszustand zum Zeitpunkt der Haftentlassung derartig schlecht war, dass er nicht sofort reisefähig war. Als er etwa eine Woche nach der Entlassung emigrieren musste, war die Reise für ihn noch lebensgefährlich. Von diesen schweren Gesundheitsschäden konnte er sich nicht wieder erholen und blieb arbeits- und erwerbsunfähig, bis er am 20. Februar 1948 in Israel starb.

\subsubsection{Erich Simon ${ }^{154}$}

Erich Simon wurde am 20. März 1882 in Berlin geboren. Seine Eltern, der Kaufmann Siegmund Simon und seine Frau Betty geborene Liebenthal, waren Juden. ${ }^{155}$ Er lernte Cello bei Leo Schrattenholz, der an der Berliner Hochschule für Musik unterrichtete, und zeigte großes musikalisches Talent. Doch aufgrund einer chronischen Sehnenscheidenentzündung wurde er kein Berufsmusiker. Nach der Absolvierung des Gymnasiums trat er in die Berliner Getreidefirma M. Neufeld und Co. ein und ging dann für einige Zeit in das gleichartige Unternehmen seines Onkels Louis Liebenthal nach Edinburgh.

\footnotetext{
${ }^{154}$ Die folgende Biographie von Erich Simon beruht hauptsächlich auf der Darstellung von seiner Frau vom 17. April 1958. Biographical Sketch of Erich Simon, Written by his Wife Hildegard, Leo Baeck Institut (im Folgenden LBI), Call/Accession Number: AR 346.

${ }^{155}$ Geburtsregister von Erich Simon, LAB, P Rep. 801, Nr. 264, Standesamt Berlin II, 1882, Nr. 385.
} 
Ursprünglich begeistert für Musik und von allem, was mit Musik zusammenhing, trat er in die Konzertdirektion Hermann Wolff ein, vermutlich im Jahr 1904. 1906 verlobte er sich mit Hildegard Cahn, der zweiten Tochter des Geheimen Legationsrats Wilhelm Cahn und seiner Frau Lina. Die Hochzeit fand im Jahr 1908 statt. Kurz vor dieser Eheschließung unterbrach er seine Tätigkeit bei der Konzertdirektion Hermann Wolff, um Musikgeschichte zu studieren. ${ }^{156}$ Zwei Jahre später trat er als Mitinhaber in die Berliner Chemiefabrik Teichgräber ein, aber kurz vor dem Ersten Weltkrieg kehrte er zur Konzertdirektion Hermann Wolff zurück.

Im Sommer 1915 wurde er als Armierungssoldat an die Front in Flandern geschickt. In Lille hatte er Schwierigkeiten mit seiner chronischen Sehnenscheidenentzündung und lag für längere Zeit im dortigen Lazarett. In dieser Oktober 1914 von den Deutschen eingenommenen Stadt bekam er dann Gelegenheit, bei regelmäßigen Kammermusikabenden sowie in einem Soldatenorchester als Cellist aufzutreten und als Manager die Leitung der Konzerte und Opern zu übernehmen, die im neuen Stadttheater von Lille stattfinden sollten. Dafür engagierte er große Opernensembles aus Dresden, Stuttgart, Mannheim und Lübeck.

Im Jahr 1917 wurde Erich Simon aus dem Militärdienst entlassen. Er kehrte zu der inzwischen mit der Firma von Erich Sachs zusammengeschlossenen Konzertdirektion zurück, an der er sich ab 1919 als Prokurist, ${ }^{157}$ und ab 1921 dann als Geschäftsführer beteiligte. ${ }^{158} \mathrm{Er}$ erledigte dort in erster Linie die internationalen Verhandlungen. Zu seinen wichtigsten Geschäftspartnern gehörte die Metropolitan Opera in New York. Seit 1924 wurde er unabhängig von seiner Eigenschaft als Mitinhaber der Konzertdirektion Angestellter der Metropolitan Opera. Seine Aufgabe war, Artur Bodanzky und Giulio Gatti-Casazza auf hervorragende Künstler aufmerksam zu machen, für deren Engagement sich die Metropolitan Opera interessieren könnte. ${ }^{159}$

Am 15. November 1931 schied Erich Simon aus der Geschäftsführung der Konzertdirektion Hermann Wolff und Jules Sachs aus, ${ }^{160}$ um in den Paritätischen-

\footnotetext{
${ }^{156}$ Im Studentenverzeichnis, das im Universitätsarchiv der Humboldt-Universität aufbewahrt ist, ist nachgewiesen, dass ein Mann »Erich Simon« sich am 1. November 1907 an der Friedrich-WilhelmsUniversität als Gasthörer immatrikulierte. Vgl. »Gasthörer, männlich, 1901-1908«, Winter-Semester 1907/08, Nr. 458. Die Möglichkeit, dass es sich hier um eine gleichnamige andere Person handelt, ist jedoch nicht ausgeschlossen.

157 „Zu Registerakten betr. Konzertdirektion Hermann Wolff und Jules Sachs G.m.b.H.« vom 12. April 1919, LAB, A Rep. 342-02, Nr. 59673, B1. 18.

${ }^{158}$ Entschädigungsakte (Fa. Konzertdirektion Hermann Wolff u. Jules Sachs GmbH.), EBB, Reg. Nr. 40762, B1. M 9.

${ }^{159} \mathrm{Zu}$ dieser Tätigkeit von Erich Simon vgl. Abschnitt 2.3.3 der vorliegenden Arbeit.

${ }^{160}$ Protokoll der Gesellschafterversammlung vom 17.12.1931, LAB, A Rep. 342-02, Nr. 59673, Bl. 62.
} 
Stellennachweis der deutschen Bühnen (kurz: Bühnennachweis) einzutreten, wo er mit André Mertens die Opernabteilung übernahm. Am 9. März 1933 überfiel ein SS-Trupp das Büro des Bühnennachweises, und fast alle Angestellten, Erich Simon eingeschlossen, wurden fristlos entlassen. Er ging dann am 3. April 1933 zuerst nach Holland, von dort nach Paris, wo er zusammen mit Paul Schiff von der Westdeutschen Konzertdirektion und Fritz Horwitz von der Konzertdirektion Hermann Wolff und Jules Sachs die Organisation Artistique Internationale gründete. Auch von dieser Position aus gewann er Künstler für die Metropolitan Opera. 1938 wanderte er offiziell nach Amerika aus und setzte seine Arbeit in New York fort, wo er 1943 starb. ${ }^{161}$ Seine Agentur wurde von einem seiner Söhne, Gerald Semon, mit seiner Frau Marianne Semon, geborenen Marx, im Rahmen der National Artists Cooperation weitergeführt. ${ }^{162}$

\subsubsection{Edith Stargardt(-Wolff)}

Das erste Kind von Hermann und Louise Wolff, Edith, wurde am 8. Januar 1880 in Berlin geboren. ${ }^{163}$ Sie besuchte die höhere Mädchenschule von Lucie Crain in der Keithstraße und heiratete im Jahr 1902 den Arzt Georg Zuelzer, ${ }^{164}$ einen der Ärzte, die damals im Gebiet der Diabetes-Behandlung experimentelle Studien durchführten, die schließlich zur Insulintheorie führten. ${ }^{165}$ In dieser Ehe brachte Edith drei Kinder zur Welt: Hertha Louise, ${ }^{166}$ Wolfgang

\footnotetext{
${ }^{161}$ In New York wurde der Name »Simon« offiziell für die gesamte Familie in »Semon« geändert.

${ }^{162}$ Dieses Ehepaar wurde vor allem als Agent von Plácido Domingo bekannt. Vgl. Jeannie Williams: Jon Vickers. A Hero's Life, Boston 1999, S. 254; Plácido Domingo / Helena Matheopoulos: My operatic roles, London 2000, S. 54.

${ }^{163}$ Geburtsurkunde von Edith Stargardt, LAB, P Rep. 801, Nr. 256, Standesamt Berlin II, 1880, Nr. 50.

${ }^{164}$ Lebenslauf von Edith Stargardt-Wolff vom 7.4.1951, Entschädigungsakte (Edith Stargardt), EBB, Reg.
} Nr. 22238, B1. 4.

${ }^{165} \mathrm{Zu}$ seinen ärztlichen, wissenschaftlichen Leistungen vgl. Klaus Helmut Mellinghoff: Georg Ludwig Zuelzers Beitrag zur Insulinforschung, Düsseldorf 1971.

${ }^{166}$ Die am 30. April 1904 geborene Hertha Louise, deren Taufpate Arthur Nikisch war, lernte Rezitationskunst bei Marie Steiner. Sie wurde eine Sprachgestalterin sowie Schauspielerin, die am Goetheanum tätig war. 1938 schloss sie mit dem Philologen Johann Wolfgang Ernst die Ehe. Gemeinsam beschäftigten sie sich intensiv mit dem Methoden-Studium der Kunst Marie Steiners in Dornach in der Schweiz, wo Hertha Louise sich vor der Judenverfolgung schützen konnte. In der Nachkriegszeit leitete das Ehepaar das »Kleine Theater Schloss Calenberg « und brachte vor allem griechische Dramen in der Übersetzung von Johann Wolfgang Ernst zur Freilichtaufführung. Hertha Louise starb am 6. September 1974 in Karlsruhe. Zu ihrer Biographie vgl. jwernst.ch/wordpress/biografie-hertha-louise-ernst-zuelzer/, 14.11.2016. Aufgrund der Forschung mittelalterlicher Quellen rekonstruierte sie das Spiel Marienklage und veröffentlichte das Libretto 1952. Marienklage. Spiel nach mittelalterlichen Handschriften rekonstruiert von Hertha Louise Ernst-Zuelzer, Hannover 1952. 
Wilhelm ${ }^{167}$ und Werner Georg. ${ }^{168}$ Nach Angaben ihrer Tochter wurde diese Ehe 1922 geschieden. ${ }^{169}$

Im gleichen Jahr trat sie in die Konzertdirektion ein und war dort zwischen 1923 und 1935 als Prokuristin tätig. ${ }^{170}$ Am 28. Juni 1924 heiratete sie in zweiter Ehe den Landgerichtsrat Otto Stargardt. ${ }^{171} \mathrm{Ihr}$ Ehemann war sogenannter »Volljude«, während Edith im Sinne der Nürnberger Gesetze »Mischling I«, infolge ihrer Eheschließung nach der damaligen Terminologie »Geltungsjüdin« war. ${ }^{172}$ Das Ehepaar wurde am 30. Juni 1942 durch Gestapobeamte verhaftet ${ }^{173}$ und vom diesem Tag bis zum 7. Mai 1945 im Konzentrationslager Theresienstadt interniert, ${ }^{174}$ wo Edith als Krankenschwester tätig war. ${ }^{175}$ Das Ehepaar konnte die fast dreijährige Inhaftierung überleben und verließ Theresienstadt im August 1945. ${ }^{176}$ Beide kamen zuerst übergangsweise bei Ediths Tochter Hertha Louise in Dornach in der Schweiz unter, dann im Zeitraum zwischen 1946 und 1951 bei ihrem Sohn Wolfgang in Michigan in den USA. Im März 1951 kamen sie nach Berlin, nachdem ihnen Ediths Wohneigentum in Berlin-Dahlem zurückgegeben worden war. ${ }^{177}$

\footnotetext{
${ }^{167}$ Der am 24. Mai 1909 geborene Wolfgang Wilhelm studierte zuerst französische Literatur, Philosophie und romantische Philologie in Deutschland sowie Frankreich und wechselte dann zum Medizinstudium. Nach dem Abschluss seines Studiums in Prag im Jahr 1935 emigrierte er nach Amerika und wurde dort ein angesehener Hämatologe sowie Kinderarzt. Er betätigte sich auch schriftstellerisch. Zu seinen Schriften gehört die Biographie des deutschen Arztes sowie Physiologen Georg Friedrich Nicolai. Vgl. Wolf Zuelzer: The Nicolai Case. A Biography, Detroit 1982.

${ }^{168}$ Werner Georg, genannt Wego, wurde am 1. Juni 1911 geboren und verunglückte 1933 tödlich in den Alpen; Lebenslauf von Edith Stargardt-Wolff vom 7.4.1951, Entschädigungsakte (Edith Stargardt), EBB, Reg. Nr. 22238, B1. 4.

${ }^{169}$ Verhandlungsniederschrift vom 24.10.1967 konzipiert von Hertha Louise Ernst, geb. Zuelzer, Entschädigungsakte (Georg Ludwig Zuelzer), EBB, Reg. Nr. 201808, Bl. M107.

${ }^{170}$ Lebenslauf von Edith Stargardt-Wolff vom 7.4.1951, Entschädigungsakte (Edith Stargardt), EBB, Reg. Nr. 22238, B1. 4. Nach ihrem Buch trat sie in die Firma 1921 ein. Vgl. Stargardt-Wolff: Wegbereiter großer Musiker, S. 197.

${ }^{171}$ Vorläufiger Antrag auf Leistungen nach $\S \S 14,15$ BEG von Edith Stargardt vom 24.10.1952, Ebd., B1. B29r.

${ }^{172}$ Eidesstattliche Erklärung von Martha Mosse vom 20.5.1951, Ebd., Bl. C8. Ihre Schwester Lili war ebenfalls »Mischling I «, war aber mit einem sogenannten Arier, dem Maler Martin Brandenburg, verheiratet und wurde deshalb vom Naziregime nicht verfolgt.

${ }^{173}$ Eidesstattliche Erklärung von Edith Stargardt geb. Wolff vom 25.10.1951, Ebd., B1. C6r; Eidesstattliche Erklärung von Augusta von Sell vom 27.10.1951, Ebd., Bl. C7r.

174 „Schaden an Freiheit« von Edith Stargardt vom 17.5.1951, Ebd., B1. C1,

${ }^{175}$ Stargardt-Wolff, Wegbereiter großer Musiker, S. 171

${ }^{176}$ Eidesstattliche Versicherung von Alice Lesser vom 18.5.1951, Entschädigungsakte (Edith Stargardt), EBB, Reg. Nr. 22238, B1. C9r.

${ }^{177}$ Lebenslauf von Edith Stargardt-Wolff vom 7.4.1951, Ebd., Bl. 4.
} 


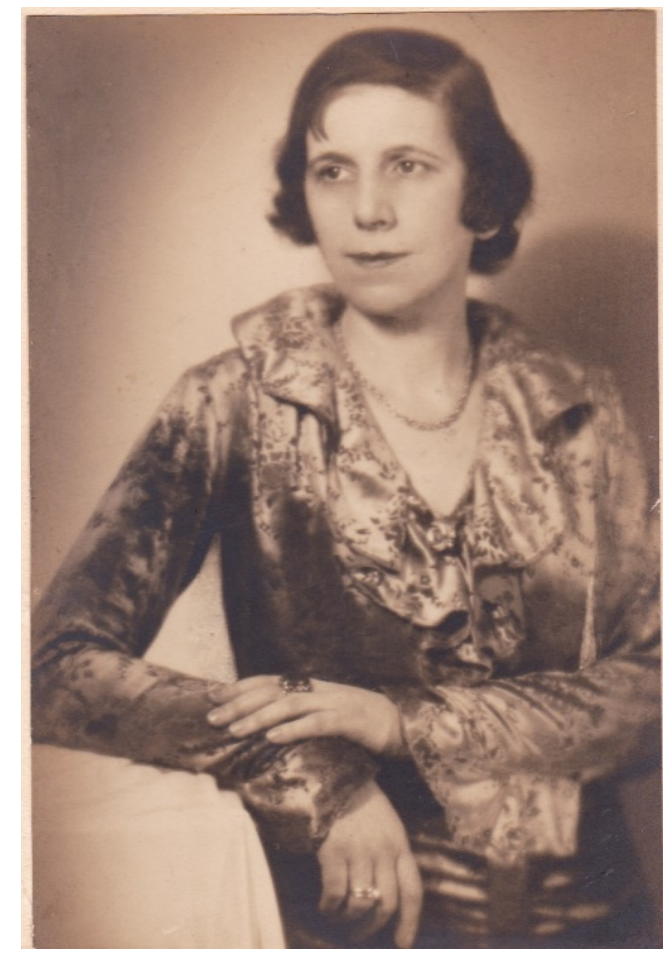

Abbildung 8: Portrait von Edith Wolff, o. D. (Wolff-Nachlass: ID 244)

Wie ihre Mutter war Edith in ihrer Wohnung in Berlin-Dahlem eine gute Gastgeberin und blieb dies auch in der Zeit nach ihrer Inhaftierung. Im Wolff-Nachlass ist ein Gästebuch von Edith mit mehr als 140 geschriebenen Seiten überliefert. Es beginnt mit einer Unterschrift von Louise Wolff vom 21. August 1928, unterbricht dann mit einer Unterschrift vom 2.

September 1941 und geht dann wieder vom 22. Juni 1951 bis zum 2. Januar 1967 weiter. In diesem Gästebuch dokumentierten internationale Gäste aus verschiedenen Gebieten ihren Besuch: Artur Schnabel, Bruno Walter, Fritz Stiedry, Ossip Schnirlin, Michael Raucheisen, Gerda Busoni, Wolfgang Stresemann, Michiko de Kowa-Tanaka und viele mehr.

Nach der Veröffentlichung ihres Erinnerungsbandes Wegbereiter großer Musiker im Jahr 1954 hatte Edith offensichtlich noch einige Gelegenheiten, öffentlich von ihren Eltern und deren Konzertdirektion zu erzählen. ${ }^{178}$ Dem im Wolff-Nachlass überlieferten Manuskript mit dem gestrichenen Titel »Musiker von nah gesehen« fehlt ein Datum und Zweck, aber es ist aus seinem Aufbau ersichtlich, dass er für ein Rundfunkprogramm konzipiert worden war. ${ }^{179}$ Grundsätzlich ist dieser wohl 1957 entstandene Text ein Auszug aus ihren Memoiren von 1954 und enthält zahlreiche Geschichten verschiedener großer Musiker, die sie bei ihren

\footnotetext{
${ }^{178}$ Brief von Edith Stargardt-Wolff an Wolfgang und Margery Zuelzer vom 16.3.1955 (Wolff-Nachlass: ID $52)$.

${ }^{179}$ Edith Stargardt-Wolff: Musiker von nah gesehen (Wolff-Nachlass: ID 131). Vgl. 1.4 im Quellenteil der vorliegenden Arbeit.
} 
Eltern kennenlernte. Edith Stargardt-Wolff starb am 7. April 1967 im Alter von 87 Jahren in Berlin-Zehlendorf.

\subsection{Personalstruktur der Konzertdirektion Hermann Wolff (und Jules Sachs)}

\subsubsection{Geschäftsbetrieb unter Hermann und Louise Wolff}

Es gibt nur wenige Quellen, die den Geschäftsbetrieb der Konzertdirektion Hermann Wolff in der Zeit unter ihrem Gründer dokumentieren. Der Anzeige in Signale zufolge eröffnete Hermann Wolff sein Büro am 15. September 1880. ${ }^{180}$

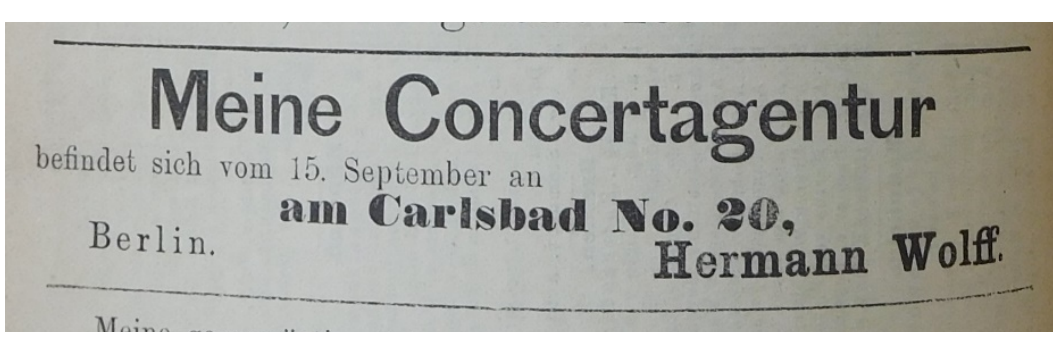

Abbildung 9: Anzeige der »Concertagentur« Hermann Wolffs (1880) $)^{181}$

In ihrer Nummer vom 23. September 1880 berichtet die Neue Berliner Musikzeitung von der Gründung seines Unternehmens und wies auf seine Bedeutung wie folgt hin:

Eine Concertagentur, wie sie für Deutschland längst ein Bedürfnis war, hat Herr Hermann Wolff, der bisherige Redacteur unseres Blattes, eröffnet. Die grössten Künstler, wie Bülow, Rubinstein, Saint Saëns und viele Andere, lassen sich durch ihn vertreten. Das Bureau befindet sich Berlin W., am Carlsbad No. $20 .{ }^{182}$

Das Büro befand sich zuerst Am Karlsbad 20 in Berlin-Tiergarten. Seine Adresse lautete ab Frühling 1882 Am Karlsbad 19, ${ }^{183}$ ab Ende 1887 Am Karlsbad 18 und ab Mitte 1900

\footnotetext{
${ }^{180}$ Eugen Zabel zufolge ist das Eröffnungsdatum der Konzertdirektion der 1. Oktober 1880. Vgl. Eugen Zabel: Konzerte und Konzertunternehmer, in Neue Berliner Musikzeitschrift 46 (1892), S. 374.

${ }^{181}$ Signale 38 (1880), S. 780. In der nächsten Nummer der gleichen Zeitschrift zeigte Wolff ferner an, dass Camille Saint-Saëns, Carl Heymann und Max Stägemann ihm die Besorgung ihrer Konzertangelegenheiten übertrugen. Vgl. ebd., S. 795.

${ }^{182}$ Neue Berliner Musikzeitung 34 (1880), S. 310.

${ }^{183}$ Neue Berliner Musikzeitung 36 (1882), S. 112.
} 
Flottwellstraße 1. ${ }^{184}$ Die räumliche Vergrößerung des Büros, die die positive geschäftliche Entwicklung der Firma widerspiegelt, beschrieb Eugen Zabel im Jahr 1892 wie folgt:

Ehemals war das Wolff'sche Bureau am Karlsbade ein einziger niedriger Raum, der zu einer kleinen Parterrewohnung gehörte. Jetzt ist der Mann mit all’ seinen Kontrakten, Briefen, Abrechnungen und sonstigen Schreibereien in die Höhe gezogen, und in demselben Maasse, in dem die geschäftlichen Verbindungen sich immer mehre auszweigten und verbreiteten, wuchsen auch die Räume. Jetzt hat er bereits ein ganzes Stockwerk inne, in dem der grosse, zum Bureau gehörende Apparat nur schwer untergebracht werden kann. ${ }^{185}$

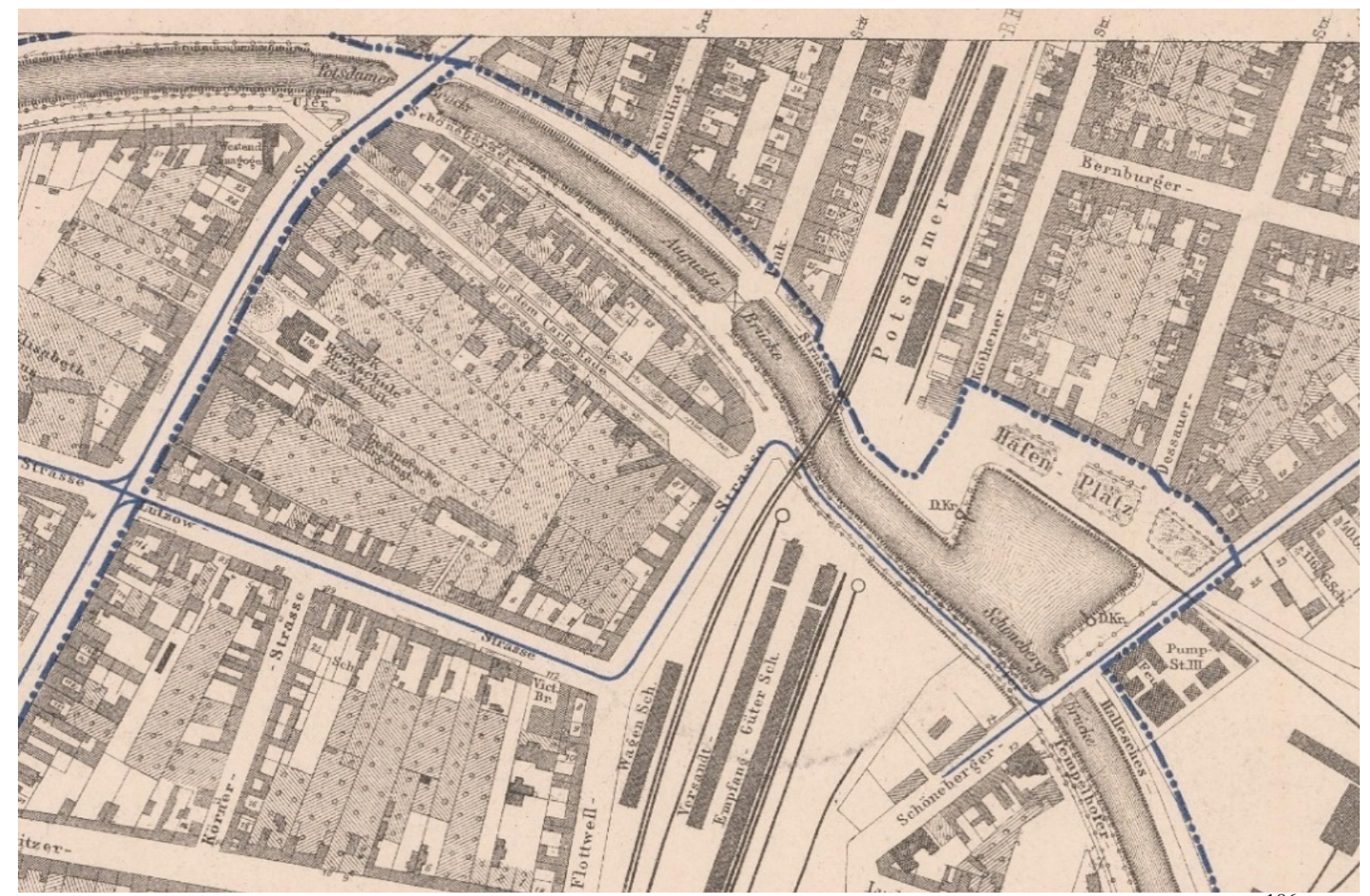

Abbildung 10: Gegend um Am Karlsbad, Flottwell- und Linkstraße in Berlin-Tiergarten (1888) ${ }^{186}$

Als die ersten Mitarbeiter des Gründers in seiner Firma nennt Edith Stargardt-Wolff Hermann Wolffs jüngeren Bruder Charles Wolff und Hermann Fernow. ${ }^{187}$ Offensichtlich war Charles Wolff in der Firma in erster Linie für die Planung und Erledigung amerikanischer Tourneen

\footnotetext{
${ }^{184}$ Das Grundstück Am Karlsbad 18 lag an der Ecke Am Karlsbad und der Flottwellstraße.

${ }^{185}$ Zabel: Konzerte und Konzertunternehmer, S. 373.

${ }^{186}$ LAB, F Rep. 270, A 8162, 1888, Ausschnitt.

${ }^{187}$ Stargardt-Wolff: Wegbereiter großer Musiker, S. 53.
} 
verschiedener Musiker zuständig. ${ }^{188}$ Nach den Erinnerungen von Edith Stargardt-Wolff begleitete er Józef Hofmann und Eugen d'Albert auf ihren Tourneen durch die Vereinigten Staaten. ${ }^{189}$ Die überlieferten Briefe dokumentieren, dass er auch das bekannte Gastspiel von Pëtr Il'ič Čajkovskij beim Eröffnungsfestival der Carnegie Hall im Mai 1891 arrangierte. ${ }^{190}$ Der Brief von Hermann Wolff an Joseph Joachim, in dem der Konzertagent versuchte, den Violinisten und sein Quartett zum Auftreten im gleichen Eröffnungsfestival in New York zu gewinnen, erwähnt diese Funktion seines Bruders und dessen Erfahrungen in Amerika:

Ich würde auch, wenn Sie darauf Werth legen, meinen Bruder Carl beauftragen Ihnen auf dieser ganzen Reise zur Seithe zu sein, und ich bin überzeugt, daß er mit seinen vielfachen Erfahrungen (er hat bereits 4 große amerikanische Tournée theils geleitet theils begleitet) Vieles sehr erleichtern und angenehmer gestalten wird. Mein Bruder würde mitgehen, ohne daß dafür vor Ihnen und Ihren Herren Collegen außerhalb der üblichen Provision irgendeine Entschädigung beansprucht würde. ${ }^{191}$

Hermann Fernow, der am 5. März 1849 in Inowrocław geboren wurde, ${ }^{192}$ trat bereits im Jahre 1881, etwa zwölf Wochen nach Eröffnung des Büros, als Mitarbeiter Hermann Wolffs ${ }^{193}$ in die Firma ein und wurde deren Mitinhaber. Auch nach dem Tod des Gründers blieb er Mitarbeiter der Firma. Wann er sie verließ, ist jedoch nicht genau ermittelbar. Nachgewiesen ist, dass alle Arrangements der Bach-Beethoven-Brahms-Festwoche, die unter der Organisation der Konzertdirektion Hermann Wolff anlässlich des 25. Regierungsjubiläums von Kaiser Wilhelm II. im April 1913 stattfand, noch in seinen Händen lagen. ${ }^{194}$ Er starb nach langem Leiden am 26. Juni 1917 in Berlin. ${ }^{195}$

\footnotetext{
${ }^{188}$ Nach dem Erinnerungsbuch von Edith Stargardt-Wolff arbeitete auch Emil Wolff, der andere Bruder von Hermann Wolff, für die Konzertdirektion, als der Gründer der Firma 1902 starb. Vgl. Stargardt-Wolff: Wegbereiter großer Musiker, S. 175.

${ }^{189}$ Stargardt-Wolff: Wegbereiter großer Musiker, S. 53.

${ }^{190}$ Briefe von Charles Wolff an Pëtr Il'ič Čajkovskij vom 21.3 (Sig.: a ${ }^{4} 457$ ), 22.3 (Sig.: a ${ }^{4} 459$ ), 26.3 (Sig.: $\mathrm{a}^{4}$ 458), 30.3 (Sig.: $\mathrm{a}^{4}$ 460) und 3.4. (Sig.: $\mathrm{a}^{4}$ 461) 1891, Tchaikovsky State House-Museum, Klin (im Folgenden TSHM).

${ }^{191}$ Brief von Hermann Wolff an Joseph Joachim vom 7.8.1890, SIM, Doc. orig. Hermann Wolff 1.

${ }^{192}$ Antrag auf Verleihung des königlichen Kronenordens 4. Klasse vom 22.10.1913, LAB, Pr. Br. Rep. 030, Nr. 14355, Bl. 30r.

${ }^{193}$ N.N.: Totenschau (Hermann Wolff), in Die Musik, Illustrierte Halbmonatsschrift 1 (1902), II. Februarheft, S. 906.

${ }^{194}$ Brief von Louise Wolff an Berliner Polizeipräsidenten vom 30.5.1913, LAB, A. Pr. Br. Rep. 030, Nr. 14355, B1. 23.

195 Allgemeine Musikzeitung 44 (1917), S. 480.
} 
Max Bleicher arbeitete insgesamt 43 Jahre für die Firma ${ }^{196}$ und hatte die Billetabteilung unter sich. Er stand in zuständigem Kontakt mit der Firma Bote \& Bock, die jahrzehntelang den alleinigen Verkauf sämtlicher Konzertkarten der Konzertdirektion übernahm, und sorgte auch dafür, dass die Freikarten angemessen verteilt wurden. ${ }^{197}$

Nachdem Hermann Wolff am 3. Februar 1902 gestorben war, ergriff Louise Wolff, gemäß der Darstellung von Edith Stargardt-Wolff, »rasch entschlossen und energisch die Zügel ${ }^{198}$ seines Lebenswerkes. Da Die Musik jedoch in ihrem zweiten Februarheft desselben Jahres Hermann Fernow und Charles Wolff als »jetzige Teilhaber« der Firma nannte, ${ }^{199}$ dauerte es möglicherweise etwas, bis sie tatsächlich das Steuer übernahm.

In seinem Schreiben an das Königliche Polizeipräsidium vom 1. April 1914 meldete Fernow seine Firma wie folgt an:

Aufgrund der Ziffer der Vorschriften über den Geschäftsbetrieb der Conzertagenten vom 9. März 1914 meldeten wir für die Concertdirection und Concertagentur Hermann Wolff | Inhaber: Frau Luise [sic!] Wolff und Hermann Fernow | den Geschäftsbetrieb für folgende Zweige an:

Wir beabsichtigen, wie bisher als eigene Unternehmungen Instrumentalconcerte, Vokalconcerte, Gesangs- oder ähnliche Vorträge - bei denen ein höheres Interesse der Kunst oder Wissenschaft obwaltet, zu veranstalten und für die gleichen Veranstaltungen die Geschäftsbesorgung für Künstler zu übernehmen. Ebenso werden wir für die genannten Veranstaltungen eine Vermittlertätigkeit |Verschaffen von Engagements für Künstler| ausüben.

Gleichzeitig bitten wir, uns die Erlaubnis generell zu erteilen, vorkommenden Falles auch für Tanzvorführungen, so weit sie im höheren Kunstinteresse liegen, als Unternehmer, als Arrangeur |Geschäftsbesorgung| und Agent arbeiten zu dürfen. ${ }^{200}$

\footnotetext{
${ }^{196}$ Eidesstaatliche Versicherung von Max Bleicher vom 14.1.1958, Entschädigungsakte (Fa. Konzertdirektion Hermann Wolff u. Jules Sachs GmbH.), EBB, Reg. Nr. 40762, B1. M 18 und 20. ${ }^{197} \mathrm{Zu}$ Max Bleicher und seiner Aufgabe in der Konzertdirektion vgl. Stargardt-Wolff: Wegbereiter großer Musiker, S. 54f. Als Edith Stargardt-Wolff im Jahr 1967 starb, diktierte der 93jährige Max Bleicher als »der Letzte aus der Konzert-Direktion« seiner Tochter eine Kondolenz in die Feder, die im Wolff-Nachlass noch erhalten ist. Vgl. Brief von Max Bleicher an Hertha Louise Ernst-Zuelzer vom 18.4.1967 (WolffNachlass: ID 125).

${ }^{198}$ Stargardt-Wolff: Wegbereiter großer Musiker, S. 175.

${ }^{199}$ N.N.: Totenschau, in Die Musik (1902), II. Februarheft, S. 906.

${ }^{200}$ Schreiben von Hermann Fernow an das Königliche Polizeipräsidium, Abteilung VIII vom 1.4.1914, LAB, A Pr. Br. Rep. 030-05, Nr. 3670, B1. 25r. Hervorhebung im Original.
} 
Am 20. September 1916 schlossen Louise Wolff und Erich Sachs einen Gesellschaftsvertrag ab. Daraus entstand die Konzertdirektion und-Agentur Hermann Wolff und Jules Sachs Gesellschaft mit beschränkter Haftung, ${ }^{201}$ die nach nur zwei Wochen in Konzertdirektion Hermann Wolff und Konzertdirektion Jules Sachs Gesellschaft mit beschränkter Haftung umbenannt wurde. ${ }^{202}$ Die Firma wurde unter der Handelsregisternummer »HRB 14362« im Handelsregister beim Amtsgericht Charlottenburg eingetragen.

Diese Fusion war eine Hilfsmaßnahme in einer Notlage: Louise Wolff, die nach dem Tod ihres Mannes mit Hermann Fernow als Mitinhaber die Firma geführt hatte, hatte wegen des Heeresdiensts in der Kriegszeit fast alle männlichen Arbeitskräfte verloren. ${ }^{203}$ Der Vertragspartner Erich Sachs war Inhaber der Konzertdirektion Jules Sachs, die von seinem Vater im Jahr 1881, und damit ein Jahr später als diejenige von Hermann Wolff, gegründet worden war. ${ }^{204}$ Edith Stargardt-Wolff beschrieb diese Vereinigung als ein »recht ungleiches Paar«, das sich sehr durch »Alter, Beziehungen und Herkommen $\aleph^{205}$ unterschieden habe.

\subsubsection{Triumvirat unter Louise Wolff, Erich Sachs und Erich Simon}

Der Geschäftssitz der vereinigten Firmen lag in der Linkstraße 42 (vgl. Abbildung 10 und 33), wo sich der von Hermann Wolff im Jahr 1892 errichtete Bechstein-Saal befand. Louise Wolff war Eigentümerin dieses Grundstücks. ${ }^{206}$ Die Gesellschaft war dafür bestimmt, die Geschäftsbetriebe der beiden Konzertdirektionen im Prinzip fortzusetzen, das heißt. den Betrieb einer Konzertagentur und einer Konzertunternehmung zu führen. ${ }^{207}$

Als Geschäftsführer der neu errichteten Gesellschaft wurden Louise Wolff und Erich Sachs bestellt. Sie waren beide berechtigt, die Gesellschaft allein zu vertreten, ${ }^{208}$ während sich das alleinige Verfügungsrecht über den Bechstein-Saal ausschließlich in der Hand von Louise befand. ${ }^{209}$ Das Stammkapital des ersten Geschäftsjahres wurde auf 60.000 Mark festgesetzt und die beiden Gesellschafter teilten diese Summe im Verhältnis 60 \% zu 40 \%: Louise Wolff übernahm 36.000 Mark und Erich Sachs 24.000 Mark. ${ }^{210}$ In der Inflationszeit nach dem

\footnotetext{
${ }^{201}$ Protokoll der Gesellschafterversammlung vom 20.9.1916, LAB, A. Rep. 342-02, Nr. 59673, Bl. 2 v.

${ }^{202}$ Protokoll der Gesellschafterversammlung vom 4.10.1916, Ebd., Bl. $12 \mathrm{v}$.

${ }^{203}$ Stargardt-Wolff: Wegbereiter großer Musiker, S. 196.

${ }^{204}$ Ausschnitt aus Nr. 450 des Berliner Börsen-Courier, LAB, A Pr. Br. Rep. 030-05, Nr. 3670, Bl. 45r.

${ }^{205}$ Ebd., S. 196.

${ }^{206}$ Protokoll der Gesellschafterversammlung vom 20.9.1916, LAB, A. Rep. 342-02, Nr. 59673, Bl. 5r.

${ }^{207}$ Ebd., Bl. 3r.

${ }^{208}$ Ebd., Bl. 5v-6r.

${ }^{209}$ Ebd., Bl. 5r.

${ }^{210}$ Ebd., B1. 3r-v.
} 
Ersten Weltkrieg stieg das Stammkapital der Gesellschaft zunächst auf 200.000 Mark an, das Louise Wolff und Erich Sachs wieder im Verhältnis 6:4 aufteilten. ${ }^{211}$

Das Stammkapital der Gesellschaft wurde durch Beschluss vom 10. Dezember 1921 erneut um 24.000 Mark, also auf insgesamt 224.000 Mark erhöht. Den neuen Anteil von 24.000 Mark übernahm der neu bestellte Geschäftsführer Erich Simon, der die gleichen Rechte wie die bisherigen beiden Gesellschafter hinsichtlich der Mitbestimmung erwarb. ${ }^{212}$ Die Geschäftsanteile der einzelnen Gesellschafter blieben bis zum Rücktritt von Erich Simon im gleichen Verhältnis. ${ }^{213}$ Das Diagramm 1 zeigt die Geschäftsanteile der drei Gesellschafter von 1922 bis 1930 .

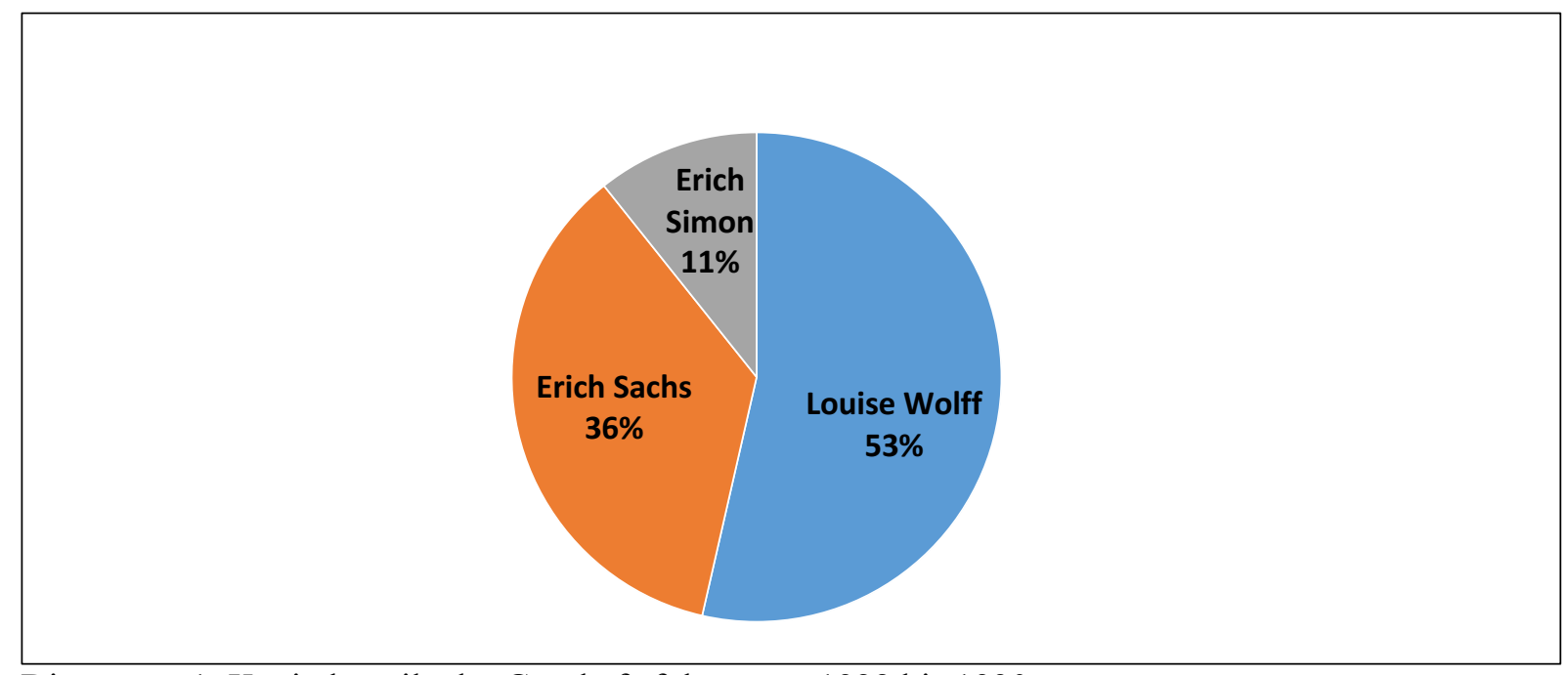

Diagramm 1: Kapitalanteile der Geschäftsführer von 1922 bis 1930

Wie Edith Stargardt-Wolff sich erinnert, hatte jeder der Gesellschafter der Firma sein eigenes Aufgabenfeld. ${ }^{214}$ Die Geschäftsverteilung jedes Geschäftsführers kann etwa so beschrieben werden: Louise Wolff betreute hauptsächlich die Philharmonischen Konzerte in Berlin, Erich Sachs organisierte Veranstaltungen in Deutschland und Erich Simon erledigte die Verhandlung mit ausländischen Körperschaften.

Über die personale Struktur der Konzertdirektion gibt es nur wenige Dokumente. In den Akten, die beim Berliner Polizeipräsidium zum Zweck der amtlichen Meldung vorgelegt wurden, sind drei Listen der beschäftigten Personen dieser Firma überliefert: die

\footnotetext{
${ }^{211}$ Protokoll der Gesellschafterversammlung vom 10.3.1921, Ebd., B1. 25v-26r.

${ }^{212}$ Protokoll der Gesellschafterversammlung vom 10.12.1921, Ebd., B1. 32v.

${ }^{213}$ Schreiben von Erich Sachs und Louise Wolff an das Amtsgericht Berlin-Mitte vom 31.12.1922, 31.12.1923, 2.1.1925, 31.12.1925, 31.12.1926, 31.12.1927, 31.12.1928, 31.12.1929 und 31.12.1930. Ebd., B1. 42f. und B1. 53-59.

${ }^{214}$ Stargardt-Wolff: Wegbereiter großer Musiker, S. 196.
} 
Angestelltenlisten aus den Jahren 1919, ${ }^{215} 1925^{216}$ und 1931, ${ }^{217}$ in denen je 17 (darunter 15 Frauen), 19 (12) und 19 (12) Angestellten eingetragen sind. In der Liste aus dem Jahr 1925 ist dazu die Zuständigkeit der 19 Angestellten verzeichnet (vgl. Tab. 1).

\begin{tabular}{|l|l|}
\hline \multirow{2}{*}{$\begin{array}{l}\text { Auswärtige } \\
\text { Abteilung }\end{array}$} & Lili Brandenburg \\
\cline { 2 - 2 } Berliner Abteilung & Fritz Horwitz \\
\cline { 2 - 2 } & Carl Schley \\
\cline { 2 - 2 } & Edith Stargardt \\
\cline { 2 - 2 } Billet-Abteilung & Sophie Wiwinis \\
\cline { 2 - 2 } & Max Bleicher \\
\hline \multirow{3}{*}{ Buchhaltung } & Eotte Friedländer \\
\cline { 2 - 2 } & Ema Schenk \\
\cline { 2 - 2 } & Max Seeligmann \\
\hline Kassiererin & Erna Lüttke \\
\hline Kontoristin & Käte Tretau \\
\hline Laufjunge & Willi Gain \\
\hline Registraturbeamter & Karl Neumann \\
\hline \multirow{2}{*}{ Sekretärinnen } & Margit Krauss \\
\cline { 2 - 2 } & Cilly Reichenbach \\
\hline Stenotypistinnen & Lisa Dalesch \\
\cline { 2 - 2 } & Antoine Hudemank \\
\hline Telefonistin & Margarete Unger \\
\hline
\end{tabular}

Tabelle 1: Die 19 Angestellten der Konzertdirektion Hermann Wolff und Jules Sachs (1925) ${ }^{218}$

Institutionell war die Firma in fünf Teile gegliedert: die auswärtige Abteilung, Berliner Abteilung, Billet-Abteilung, Rechnungsabteilung und Korrespondenzabteilung. Aufgrund dieser Quellen kann man annehmen, dass in der Konzertdirektion Hermann Wolff und Jules Sachs, wenigstens in der Zeit des Triumvirats, ungefähr 20 Personen einschließlich ihrer Geschäftsführer arbeiteten. ${ }^{219}$

Die ausgewogene Geschäftsverteilung, die die Konzertdirektion Hermann Wolff und Jules Sachs in den 1920er-Jahren charakterisiert hatte, ging allerdings verloren, als Erich Simon mit dem 15. November 1931 aus der Geschäftsführung der Firma zum Zweck des Eintritts in den Paritätischen-Stellennachweis der deutschen Bühnen ausschied. ${ }^{220}$ In den

\footnotetext{
${ }^{215}$ Abschrift des Tarifabkommens, o. D., LAB, A. Br. Rep. 030-05, Nr. 3370, B1. 84.

${ }^{216}$ Brief von Erich Sachs an das Berliner Polizeiamt vom 18.9.1925 und 9.10.1925, LAB, A. Pr. Br. Rep. 030-05, Nr. 3670, B1. 76f.

${ }^{217}$ Schriftliche Mitteilung von Erich Sachs am Polizeipräsidium Berlin vom 29.5.1931, LAB, A. Pr. Br. Rep. 030-05, Nr. 3671, B1. 15.

${ }^{218}$ Brief von Erich Sachs an das Polizeiamt vom 18.9.1925 und 9.10.1925, LAB, A. Pr. Br. Rep. 030-05, Nr. 3670, B1. 76f.

${ }^{219}$ Nach Erich Sachs musste die Firma aber in der Inflationszeit einen Teil ihres Personals entlassen. Schreiben von Erich Sachs an das Berliner Polizeipräsidium vom 13.9.1923, LAB, A Pr. Br. Rep 030-05, Nr. 3370, B1. 143.

${ }^{220}$ Protokoll der Gesellschafterversammlung vom 17.12.1931, LAB, A. Rep. 342-02, Nr. 59673, B1. 62v.
} 
Jahren 1931 und 1932 wurde das Stammkapital 2.240 Mark ${ }^{221}$ von Louise Wolff und Erich Sachs, wie sie vor dem Eintritt von Erich Simon ausgemacht hatten, im Verhältnis 60 \% zu $40 \%$ verteilt. $^{222}$

Auf der Gesellschafterversammlung vom 19. April 1933 wurde der Austritt von Erich Sachs aus der Firma beschlossen, was zum Zwecke der Gleichschaltung im Sinne der nationalsozialistischen Regierung zwangsweise erfolgte. ${ }^{223}$ Louise Wolff war nunmehr die alleinige Geschäftsführerin und ihrer jüngeren Tochter Lili Brandenburg wurde die Prokura erteilt. ${ }^{224}$ Die Firma hieß nun förmlich Konzertdirektion Hermann Wolff (vormals Konzertdirektion Hermann Wolff und Jules Sachs) Gesellschaft mit beschränkter Haftung. ${ }^{225}$

In der kurzen Zeit zwischen 1930 und 1932 bildete diese Konzertdirektion mit der Westdeutschen Konzertdirektion in Köln eine Interessegemeinschaft. Die beiden Betriebe wurden selbstständig weitergeführt und auch der Sitz jeder einzelnen Agentur blieb unverändert. ${ }^{226}$

\subsubsection{Versuch des weiteren Betriebs unter nationalsozialistischem Einfluss}

In ihren Erinnerungen schreibt Edith Stargardt-Wolff zur Nachfolgesuche der Konzertdirektion nach der Machtergreifung durch die Nationalsozialisten ${ }^{227}$ wie folgt:

\footnotetext{
${ }^{221}$ Das Stammkapital dieser Firma 224.000 Mark wurde durch Beschluss vom 24. September 1925 auf 2240 Goldmark umstellt. Protokoll der Gesellschafterversammlung vom 24.9.1924, Ebd., B1. 48r.

${ }^{222}$ Schreiben von Erich Sachs an Amtsgericht Berlin-Mitte, Ebd., B1. 67f.

${ }^{223}$ Entschädigungsakte (Fa. Konzertdirektion Hermann Wolff u. Jules Sachs GmbH, Antragsteller: Werner Wolff), EBB, Reg. Nr. 40762, Bl. M 34.

${ }^{224}$ Die ältere Tochter Edith Stargardt war seit 1923 Prokuristin der Firma. Lebenslauf von Edith StargardtWolff vom 7.4.1951, Entschädigungsakte (Edith Stargardt), EBB, Reg. Nr. 22238, B1. 4.

${ }^{225}$ Protokoll der Gesellschafterversammlung vom 19.4.1933, LAB, A. Rep. 342-02, Nr. 59673, Bl. 72r.

${ }^{226}$ Der gesamte Schriftverkehr der Westdeutschen Konzertdirektion ist dem Krieg und den damit verbundenen Bränden zum Opfer gefallen, somit gibt es für diese noch heute existierende Firma keine Dokumente zum Zusammenschluss mit der Konzertdirektion Hermann Wolff und Jules Sachs. E-MailAntwort von Nicole Verres von der Westdeutschen Konzertdirektion an die Verfasserin vom 27.1.2014. ${ }^{227} \mathrm{Im}$ Lexikon der Juden in der Musik heißt es, dass diese Firma vor allem durch die Unterstützung jüdischer Musiker prosperierte: »Die Geschäftsmethoden waren darauf gerichtet, in erster Linie jüdischen Künstlern zum Weltruhm zu verhelfen und arische auszubeuten. Die Konzertdirektion Wolff und Sachs behauptete eine Monopolstellung[,] die sie in diktatorischer Weise skrupellos ausnützte, meist unter raffinierter Umgebung der gesetzlichen Bestimmungen. «Lexikon der Juden in der Musik. Mit einem Titelverzeichnis jüdischer Werke. Zusammengestellt im Auftrag der Reichsleitung der NSDAP. auf Grund behördlicher, parteiamtlich geprüfter Unterlagen, bearbeitet von Theo Stengel, Berlin 1940, abgedr. in Eva Weissweiler, Ausgemerzt! Das Lexikon der Juden in der Musik und seine mörderischen Folgen, unter Mitarbeit von Lilli Weissweiler, Köln 1999, S. 333f.
} 
Die Wahl eines Nachfolgers für die ausgeschiedenen Mitchefs war äußerst schwierig. Weniger denn je gab es geeignete Fachleute. Zwei Versuche in dieser Richtung erwiesen sich als Fehlschläge. Wohl mangelte es nicht an Angeboten, an Annährungsversuchen zum Teil nazistisch eingestellter Elemente, die einen Übergang des altrenommierten Hauses in nationalsozialistische Hände nur allzu gern vollzogen hätten. Natürlich kam eine solche Verbindung überhaupt nicht in Frage. [...] Meine Schwester und ich, die in der Konzertdirektion jahrelang tätig gewesen waren, hätten als »Mischlinge« nicht lange mehr unbehindert arbeiten können. ${ }^{228}$

Diese Darstellung stimmt mit den in den Handelsregisterakten dokumentierten Tatsachen nicht überein: Ab 1933 beschäftigte sich die Firma mit einem massiven Arisierungsversuch. ${ }^{229}$

Auf der außerordentlichen Gesellschafterversammlung vom 9. Mai 1933 wurde Siegfried Lütgert, der die Konzertabteilung der Hamburger Firma J. A. Böhme geleitet hatte, zum weiteren Geschäftsführer der Konzertdirektion mit der Maßgabe bestellt, gemeinschaftlich mit einem anderen Geschäftsführer oder mit einem Prokuristen die Gesellschaft zu vertreten. ${ }^{230}$ Er hatte auch den Verband der deutschen Konzertdirektionen gegründet und war damals als erster Vorsitzender dieses Verbandes tätig. In dieser Eigenschaft hatte er seit Anfang April 1933 mit dem Staatskommissar Hans Hinkel bezüglich der Richtlinien korrespondiert, die für die Geschäftsführung der Konzertagenturen maßgebend sein sollten und mit denen sich die Mitgliedsfirmen »der völligen Umstellung des politischen, wirtschaftlichen und auch kulturellen Lebens $«^{231}$ anpassen könnten. In diesem Kontext teilte er dem Reichskulturverwalter die Aussicht seines Eintritts in die Konzertdirektion Hermann Wolff wie folgt mit:

Die Möglichkeit aus unserem Berufsstande unliebsame und völlig unerwünschte Elemente auszuschalten, müßte uns so schnell wie möglich gegeben werden, da es nicht wünschenswert erscheint, daß wir solche Belastungen weiter ertragen.

\footnotetext{
${ }^{228}$ Stargardt-Wolff: Wegbereiter großer Musiker, S. 298.

${ }^{229}$ In seiner Arbeit zu Furtwängler und seiner politischen Lage im Dritten Reich wies Fred K. Prieberg auf den Arisierungsversuch dieser Firma hin. Fred K. Prieberg: Kraftprobe. Wilhelm Furtwängler im dritten Reich, Wiesbaden 1986, S. 460, Fn. 49.

${ }^{230}$ Schreiben von Louise Wolff an das Amtsgericht Berlin-Mitte vom 9.5.1933, LAB, A. Rep. 342-02, Nr. 59673, B1. 76f.

${ }^{231}$ Schreiben von Siegfried Lütgert an Hans Henkel vom 4.4.1933, Bundesarchiv, Standort BerlinLichtersfelde (im Folgenden BArch) R9361-V81232 (Die Blätter in dieser Mappe sind nicht durchnummeriert.)
} 
[...] Persönlich möchte ich Ihnen mitteilen, daß die Firma bisher Wolff \& Sachs, nachdem Herr Sachs ausgeschieden ist, mich geboten hat einzutreten und die gesamte Leitung der Geschäfte zu übernehmen. Da es sich um die ausgesehendste [sic!] europäische Konzertfirma handelt, habe ich dazu bereit erklärt und werde in der allernächsten Zeit praktisch die Leitung übernehmen.

Die Firma ist also in absolut arischen Händen und wird von mir im Geiste meines Exposés geführt werden. Frau Louise Wolff ist einwandsfrei von väterlicher und mütterlicher Seite her arischer Herkunft. ${ }^{232}$

Nachdem Siegfried Lütgert sein Amt bei der Konzertdirektion Hermann Wolff schon im November 1933 aus unbekannten Gründen niedergelegt hatte, ${ }^{233}$ trat Louise Wolff mit Rudolf Vedder in Verhandlung. ${ }^{234}$ Er hatte früher die Konzertabteilung der Firma Steinway \& Sons geleitet und war im Jahr 1927 entlassen worden, weil er mehrfach anfallende Künstlerentgelte unterschlagen hatte. Als selbstständiger Konzertagent hatte er sich dann an prominente Musiker, einschließlich Wilhelm Furtwängler, herangemacht, wobei seine Methoden, die oft Verleumdungen und Verdächtigungen einschlossen, vielseitig Streitigkeiten entfacht hatten. ${ }^{235}$ In seiner Denkschrift vom 28. November 1933 sind die von ihm gesammelten Auskünfte zur Lage der Konzertdirektion Hermann Wolff notiert. Sein Interesse gilt vor allem dem Personalstand und der wirtschaftlichen Situation der Firma:

I. Die Firma hieß WOLF [sic!] \& SACHS GmbH. Anfang Juni [19]33 wurde der Name in Hermann Wolf geändert und als Geschäftsführer SIEGFRIED LÜTGERT aus Hamburg bestellt. Bei Wolf \& Sachs waren die Inhaber: Louise Wolf, Erich Sachs und Erich Simon. Herr Sachs ist vor zwei Monaten ausgeschieden, und soll noch für drei Jahre das Rückkaufrecht seiner Anteile haben. Herr Simon ist vor einem Jahr ausgeschieden. Bedingungen unbekannt. Jetzt ist Louise Wolf alleiniger Inhaber und Geschäftsführer. Der andere Geschäftsführer, Herr Lütgert, mußte vor vierzehn Tagen die Firma verlassen.

\footnotetext{
${ }^{232}$ Schreiben von Siegried Lütgert an Hans Henkel vom 26.4.1933, BArch, R9361-V81232.

${ }^{233}$ Schreiben von Louise Wolff an das Amtsgericht Charlottenburg vom 8.11.1933, LAB, A. Rep. 342-02, Nr. 59673, B1. 103.

${ }^{234}$ Zum Beziehung zwischen Rudolf Vedder und der Konzertdirektion Hermann Wolff vgl. Sam H. Shirakawa: The Devil's Music Master. The Controversial Life and Career of Wilhelm Furtwängler, New York u. a. 1992, S. 238-240.

${ }^{235}$ Prieberg: Kraftprobe, S. 320-322.
} 
II. In der Firma sind zwei Töchter von Louise Wolf angestellt. Frau Dr. Stargardt und Frau Brandenburg. Die Erbin soll Frau Dr. Stargardt sein.

III. Louise Wolf ist angeblich Christin, die Töchter Halbjüdinnen. Gegen die Beschäftigung der Töchter wird von allen Seiten Widerstand gezeigt, vor allem vom Geschäftsführer des Philharmonischen Orchesters (Herren Höber)

IV. Der Vertrag mit dem Philharmonischen (10 Furtwängler Konzerte) ist in dieser Saison gekündigt. Die Verlängerung des Vertrags ist unklar. Furtwängler will Frau Wolf unterstützen und die Konzerte bei der Firma lassen. Der Geschäftsführer HÖBER wünscht keine Verlängerung des Vertrages falls in der Inhaberschaft und in der Frage der Töchter keine Änderung erfolgt.

V. Bilanz vom 1. Juli muß vorgelegt werden und Bilanz der letzten Monate. Die Firma hat vor drei Jahren Mk. 220 000.- verdient, vor zwei Jahren etwa über Mk. 100 000.und im letzten Mk. 75 000.-. Die Bilanz zum 1. Juli soll mit einem Minus von Mk. 4000.- abgeschlossen haben. Der Zustand der letzten Monate muß meiner Schätzung nach Mk. 30 000.- betragen.

VI. Ich habe vertrauliche Informationen, daß die Steuern der Firma nicht korrekt gezahlt worden sind.

VI. Keine Konkurrenzklausel.

VII. Ich verdiene augenblicklich Mk. 1500.- netto, d.h. nach Abzug der Steuern und meiner Geschäftsunkosten. Erhalte das Gehalt im Voraus, müsste zur Verbesserung meiner Position Mitinhaber werden.

VIII. Vier Wochen bezahlter Urlaub.

IX. Feststellung, ob die Töchter Prokura haben. ${ }^{236}$

Die Verhandlung mit Vedder dauerte bis zum Anfang des nächsten Jahres. Die noch erhaltenen Korrespondenzen dokumentieren, dass zwei Vertragsvorschläge Louise Wolffs von Vedder durch seinen Anwalt rundweg abgelehnt wurden und dass die Verhandlung schließlich scheiterte. ${ }^{237}$

Der erste Vertragsentwurf ${ }^{238}$ setzte Vedders Monatsgehalt für das erste Jahr auf 1.000 Mark fest, für das zweite Jahr auf 1.100, und für das dritte Jahr auf 1.200, außerdem

\footnotetext{
${ }^{236}$ BArch R/9361/V 83853 Bl. 1724-1725. Diese Schrift ist von Prieberg im Auszug zitiert und deren Kopie auch im Archiv Prieberg im Musikwissenschaftlichen Institut der Christian-Albrechts-Universität zu Kiel aufbewahrt. Vgl. Prieberg: Kraftprobe, S. 322.

${ }^{237}$ Schreiben von Helmut Ellerholz an Louise Wolff vom 29.12.1933 und 5.1.1934, BArch R/9361/V 83853, Bl. 1616 und 1612.

${ }^{238}$ Abschrift des Anstellungsvertragsentwurfs, o. D., BArch R/9361/V 83853, B1. 1720-23.
} 
eine Tantieme vom Reingewinn für das erste Jahr in Höhe von 10 \%, für das zweite Jahr $15 \%$, und für das dritte Jahr $20 \%$. Der Vertrag sollte zunächst auf die Dauer von drei Jahren geschlossen und, wenn keiner der beiden Vertragsteile ihn sechs Monate vor dem Ablauf kündigt, sich jeweils um ein Jahr verlängert werden. Er enthielt dazu die Klausel, die eigenmächtiges Handeln von Vedder verhinderte, wobei die Absicht deutlich wird, die Stellung der »halbjüdischen« Prokuristinnen - der Töchter von Louise Wolff - vor eigenmächtigen Entlassung durch ihn zu schützen:

\section{$\S 7 . \mathrm{Zu}$ Entnahmen in Anrechnung auf seine Bezüge und zu irgend welchen} Dispositionen in Kassenangelegenheiten ist Herr VEDDER nur in Gemeinschaft mit einem anderen Geschäftsführer berechtigt. Entsprechendes gilt für Neueinstellungen, Kündigungen, Gehaltsregelungen, Anschaffungen oder ähnliche Geschäftsvorkommnisse. Eine Kündigung der derzeitigen Prokuristin Frau Stargardt und Frau Brandenburg ist nur mit Genehmigung der Gesellschafterversammlung zulässig. ${ }^{239}$

Was Louise Wolff im ihrem zweiten Vertragsvorschlag Vedder anbot, ist nicht bekannt. Aus dem Schreiben des Anwaltes von Vedder geht jedoch hervor, dass sie die materiellen Bedingungen zugunsten Vedders änderte, während er in anderen Punkten eher nicht zufrieden sein konnte. ${ }^{240}$ Nachdem diese Verhandlung scheiterte, wurde Vedder am 16. März 1934 als Leiter der Konzertabteilung in die Reichsmusikerschaft bestellt, die im Februar des gleichen Jahres ihre Tätigkeit aufgenommen hatte.

Die Suche nach einem neuen Geschäftsführer fiel dann auf den Amtswalter der NSDAP, Max R. Müller, Vedders »Erzfeind «. ${ }^{241}$ Er wurde im März 1934 zum Geschäftsführer der Konzertdirektion bestellt, mit der Maßgabe, dass er gemeinschaftlich mit einem anderen Geschäftsführer oder mit einem Prokuristen zur Vertretung der Gesellschaft berechtigt sei. ${ }^{242}$ Müller wurde als Sohn eines Organisten und Kirchenmusikdirektors geboren und war viele Jahre bei der Firma Steinway \& Sons Büro- und Verkaufsorganisator sowie Prokurist gewesen. ${ }^{243}$ In der bei seinem Eintritt veröffentlichten Anzeige stellte Louise Wolff heraus, dass er »durch seine in- und ausländische Tätigkeit als Leiter der Konzertabteilung der

\footnotetext{
${ }^{239}$ Abschrift des Anstellungsvertragsentwurfs, o. D., BArch R/9361/V 83853, B1. 1721.

${ }^{240}$ Schreiben von Helmut Ellerholz an Louise Wolff vom 5.1.1934, BArch R/9361/V 83853 Bl. 1612.

${ }^{241}$ Prieberg: Kraftprobe, S. 325.

${ }^{242}$ Protokoll der Gesellschafterversammlung vom 2.3.1934, LAB, A. Rep. 342-02, Nr. 59673, B1. 109.

${ }^{243}$ Allgemeine Musik-Zeitung 61 (1934), S. 128.
} 
Firma Steinway \& Sons weitreichende Kenntnisse und Erfahrungen auf dem Gebiet des Musik- und Konzertwesens « besitze. ${ }^{244}$ Auch diese Einstellung ${ }^{245}$ konnte jedoch die Existenz der Firma nicht verlängern, und sie wurde durch einen Gesellschaftsbeschluss vom 6. April 1935 aufgelöst. ${ }^{246}$

\subsection{Tätigkeit und Wirkungskreis der Konzertdirektion}

\section{Hermann Wolff (und Jules Sachs)}

\subsubsection{Vertretene Künstler}

Eine komplette Liste der von der Konzertdirektion Hermann Wolff (und Jules Sachs) vertretenen Künstler kann, wenigstens nach jetzigem Quellenstand, nicht erstellt werden. Es gibt allerdings einige veröffentlichte Künstlerlisten, in denen die Namen der Künstler, deren Vertretung die Konzertdirektion übernommen hatte, aufgelistet sind. Offensichtlich erheben sie aber keinen Anspruch auf Vollständigkeit und weisen selbstverständlich nicht das Zustandekommen der Engagementsvermittlung für jeden Künstler auf. Exklusive Verträge kamen nur in Ausnahmefällen vor, und Künstler standen normalerweise mit verschiedenen Agenten gleichzeitig in Verbindung. Die Künstlerlisten der Konzertdirektion Hermann Wolff (und Jules Sachs) fungieren also nicht als lückenlose Quelle ihrer Klienten. Trotz dieses Vorbehalts und der begrenzten Verfügbarkeit ist es sinnvoll, sie zu betrachten, um den Wirkungskreis dieser Konzertdirektion einschätzen zu können. ${ }^{247}$

Ein Blick auf die Künstlerlisten, die in der Neuen Zeitschrift für Musik von 1886 bis 1888, 1890 und 1891 erschienen (Abbildung 11-15), ${ }^{248}$ mag den Wirkungskreis der Konzertdirektion um 1890 umreißen. Der auffällige Anstieg der vertretenen Künstler spiegelt

\footnotetext{
${ }^{244}$ Schreiben vom Louise Wolff vom 1.3.1934, LAB, A. Pr. Br. Rep. 030-05, Nr. 3671, B1. 92.

${ }^{245}$ Gerade in dieser Zeit suchte die Verwaltung des Berliner Philharmonischen Orchesters nach zwei neuen Geschäftsführern, einem kaufmännischen und einem künstlerischen. Für den kaufmännischen Geschäftsführer kam zuerst Max R. Müller in Frage, er geriet aber unter Einwirkung von Rudolf Vedder ins Hintertreffen. Prieberg: Kraftprobe, S. 170f.

${ }^{246}$ Protokoll der Gesellschafterversammlung vom 6.4.1935, LAB, A. Rep. 342-02, Nr. 59673, B1. 128.

${ }^{247}$ Aufgrund der Auswertung der auf der Neuen Berliner Musikzeitung und Neuen Zeitschrift für Musik zwischen 1880 und 1900 erschienenen Werbeanzeigen erstellte Christine Fornoff ihre eigene Liste der Künstler, die von der Konzertdirektion Hermann Wolff vertreten waren. Christine Fornoff: Die Konzertagentur Wolff und ihre Bedeutung für Virtuosinnen im Berliner Musikleben des 19. Jahrhunderts, in Musikerinnen im Netzwerke im 19. Jahrhunderts, hg. von Annkatrin Babbe u. a., Oldenburg 2016, S. 4167 , vor allem vgl. S. 60-67.

${ }^{248}$ Die Künstlerliste in dieser Art ist weder 1889 noch vor und nach dem hier untersuchten Zeitraum in dieser Zeitschrift zu finden.
} 
die rasche Entwicklung der Firma in dieser Zeit wider. Die aufgelisteten Künstler unterscheiden sich nach Alter, Herkunft und künstlerischer Ausrichtung.

Bei den Pianisten prägen die führenden Persönlichkeiten des damaligen Berliner Musiklebens - Hans von Bülow, Heinrich Barth und Xaver Scharwenka - den grundsätzlichen Charakter der Künstlerlisten, während Josef Hoffmann, Otto Hegner, Eugen d'Albert und Ferruccio Busoni die jüngere Generation vertreten. Auffällig ist die starke Verbindung der Konzertdirektion zu den Musikern im Kreis um das St. Petersburger Konservatorium, wie Theodor Leschetizky, Anna Nikolaevna Esipova, Sofie Menter, Benjamino Cesi und Aleksandr Il'ič Ziloti, was sie wohl ihrem ältesten Klienten Anton Rubinštejn verdankte. Zahlenmäßig überwiegen die Liszt-Schüler, einschließlich Emma Koch, Robert Freund, Sofie Menter, Max von de Sandt, Emil Sauer, Bernhard Stavenhagen, José Vianna da Motta, Alfred Sormann, Josef Weiss und Józef Wieniawski. ${ }^{249}$ Auch Pariser Pianisten, wie Clotide Kleeberg, Bertha Marx, Francis Planté und Camille Saint-Saëns, nehmen einen beträchtlichen Teil dieser Künstlerlisten ein.

Bei anderen Instrumentalisten ist der Kreis um die Berliner Musikhochschule dominierend, vor allem die Schüler von Joseph Joachim wie Heinrich de Ahna, Robert Hausmann, Geraldine Morgan, Marie Soldat-Roeger, Willy Hess, Jenő Hubay, Johann Kruse, Waldemar Meyer, Tivadar Nachèz und Carl Prill. Carl Halir, Hans Wihan und Joachim Andersen stammen aus der Kapelle von Benjamin Bilse. ${ }^{250}$ Auch international bekannte Namen wie Leopold Auer, Wilma Normann-Neruda, Pierre Marsick, Franz Ondricek, David Popper und Pablo de Sarasate sind zu finden.

Während die Instrumentalisten in ihrer künstlerischen Ausrichtung mannigfaltig sind, sind viele der aufgelisteten Sänger in erster Linie Träger der deutschen Gesangliteratur. Die Liste wird vor allem von zwei Sängergruppen charakterisiert: einerseits von den Wagnertenören wie Georg Anthes, Max Alvary, Erneste van Dyck und Heinrich Gudehus, andererseits von den Konzert- oder Oratoriensängerinnen aus dem Schülerkreis von Julius Stockhausen wie Wally Schauseil, Hermine Spies und Amalie Joachim. Auch Raimund von Zur Mühlen, der sich ausschließlich als Konzertsänger betätigte und den Liederabend im Konzertleben etablierte, gehörte zum früheren Stammklientel der Konzertdirektion.

\footnotetext{
${ }^{249}$ Die Möglichkeit, dass Liszt seine Schüler Wolff persönlich vorgestellt hatte, bevor er 1886 starb, ist nicht belegt, aber denkbar. Zum Verhältnis zwischen Hermann Wolff und Franz Liszt, vgl. StargardtWolff: Wegbereiter großer Musiker, S. 53.

${ }^{250}$ Zum Verhältnis zwischen Wolff und der Kapelle von Benjamin Bilse vgl. Abschnitt 3.1.1 der vorliegenden Arbeit.
} 
Die Konzertdirektion veranstaltete Orchesterabonnementkonzerte in Berlin, ${ }^{251}$ Hamburg, ${ }^{252}$ Dresden ${ }^{253}$ und Stettin. Dazu vertrat sie die Philharmonischen Konzerte unter Leitung von Johann Svendsen in Kopenhagen, die Londoner Sinfonie-Concerte unter der Leitung von Georg Henschel in London, die Châtelet-Konzerte unter Leitung von Édouard Colonne in Paris und die Kaiserlich-Russische Musikgesellschaft, geleitet von Max Endmannsdörfer, in Moskau. Der Wirkungskreis der Konzertdirektion erreichte um 1890 die USA, wo sie das Orchester in Boston unter der Leitung von Arthur Nikisch und dasjenige unter Walter Damrosch in New York vertrat. In diesen Listen nennt sie sich ferner als auswärtige Vertreterin für Abbey, Schoeffel \& Grau in New York, D. Mayer in London und $\mathrm{H}[\mathrm{enrik}]$ Hennings in Kopenhagen.

${ }^{251} \mathrm{Zu}$ den Abonnementkonzerten des Berliner Philharmonischen Orchesters vgl. 3.1.1 der vorliegenden Arbeit.

${ }^{252}$ Die von Hermann Wolff in Zusammenarbeit mit dem Theaterdirektor Bernhard Pollini in der Saison 1886/87 eingerichteten Abonnementkonzerte in Hamburg wurden in Konkurrenz zu den Konzerten der Hamburger Philharmonischen Gesellschaft »Neue Abonnement-Concerte « genannt. In den ersten beiden Saisons fanden je sechs Konzerte unter der Leitung von Hans von Bülow statt, wobei Pollini ihnen das Orchester des Hamburger Stadttheaters zur Verfügung stellte, an dem Bülow außerdem ein zusätzliches Engagement für eine Opernsaison einging. Als Bülow sich mit Pollini Anfang 1888 endgültig überwarf, wurde Wolff zum alleinigen Unternehmer dieser Konzerte und organisierte für sie ein neues Orchester aus Hamburger Musikern, das sogenannte »Orchester der Neuen Abonnement-Concerte«. Zum Ende der Saison 1892/93 legte Bülow wegen Krankheit die Leitung endgültig nieder. In der anschließenden Saison 1893/94 vertraute Wolff die zehn Konzerte wechselnden Dirigenten an, bevor er Gustav Mahler, der schon in Hamburg als Opernkapellmeister großes Ansehen genossen hatte, für die acht Konzerte der Spielzeit 1894/95 zum alleinigen Dirigenten berief. In den Saisons 1895/96 und 1896/97 fanden vier bzw. acht Hamburger Abonnementkonzerte unter der Leitung von Felix Weingartner statt. Ab 1895/96 übernahm das Berliner Philharmonische Orchester auch diese Hamburger Abonnementkonzerte. Die Dirigenten, Daten und Programme der Hamburger Neuen Abonnementkonzerte zwischen den Saisons 1890/91 und 1897/98 sind aufgelistet in Bernd Schabbing: Gustav Mahler als Konzert- und Operndirigent in Hamburg, S. 322336. Zur Gründung dieser Abonnementkonzerte vgl. Brief von Hermann Wolff an Hans von Bülow vom 12.12.1885, in Hans von Bülow, Briefe. VII. Band: Höhepunkt und Ende. 1886-1894, hg. von Maria von Bülow, Leipzig 1908 (Hans von Bülow. Briefe und Schriften, Bd. 8) (im Folgenden: Bülow-Briefe 7), S. 13. Zur Bedeutung dieser Konzertreihe im Hamburger Musikleben vgl. Josef Sittard: Geschichte des Musik- und Concertwesens in Hamburg, Altona u. a. 1890, S. 367-369.

${ }^{253}$ Die Dresdner Philharmonischen Concerte richtete Hermann Wolff 1885 ein und übertrug ihre Ausführung Jean Louis Nicodé und dem sogenannten Gewerbehausorchester. Als Nicodé 1888 von seinem Amt zurücktrat und Mahler die Nachfolge ablehnte, wurde Carl Schroeder zunächst als sein Nachfolger genannt, aber schließlich stellte Wolff mit Ende der Saison 1888/89 die Konzertreihe ein. Vgl. Gustav Mahler »Verehrter Herr College!", Briefe an Komponisten, Dirigenten, Intendanten, hg. von Franz Willnauer, Wien 2010, S. 78; Neue Berliner Musikzeitung 41 (1887), S. 328. 


\section{Hermann Wolff \\ am Carlsbad 19. Berlim, W. am Carlsbal 10. Concert-Direction.}

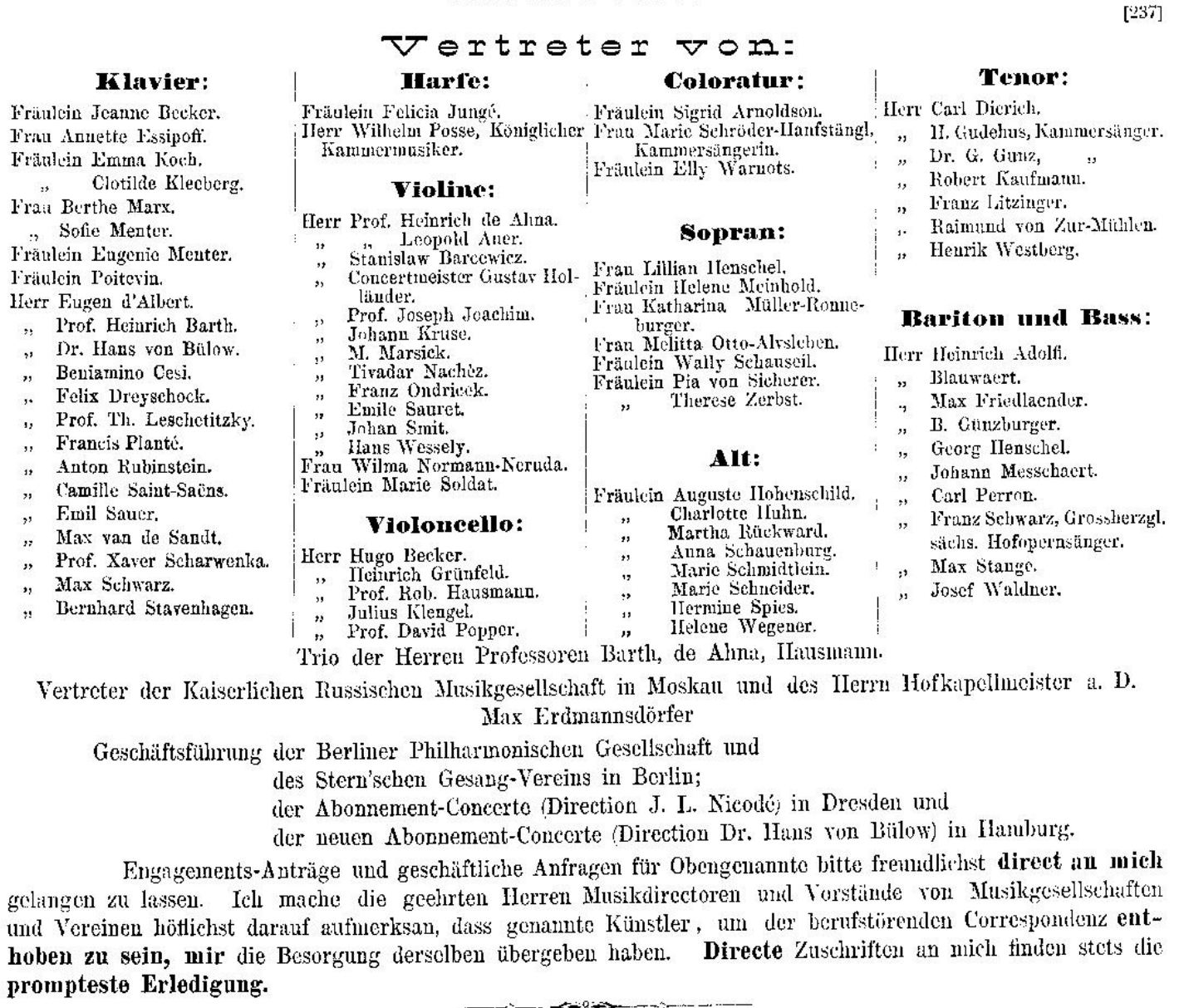

\section{Die Concert-Direction Hermann Wolff besorgt:}

Engagements bei allen Concert- und Irivat-Gesellschaften des In- und Auslandes; Engagements von 0rchester - Mitgliedern, complette 0ratorienbesetzungen;

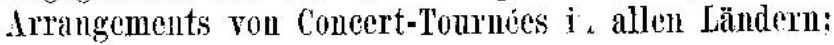

Arrangements der Berliner Concerte; Engragements von Lehrern and Lehrerinnen an Conservatorien mod Musikinstituten: Vermittelung von Aufführungen bedeutender musikaliseher Sovitäten.

Drữ von Bär \& Germann in Seipzig.

Abbildung 11: Anzeige der Konzertdirektion Hermann Wolff $(1886)^{254}$

${ }^{254}$ Neue Zeitschrift für Musik 53 (1886), S. 264. 


\section{Berlin w. Hermann Wolff Berlin w.

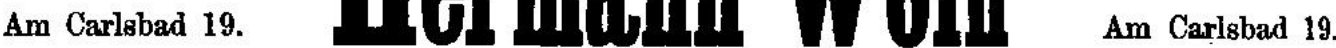

\section{Concertilirection.}

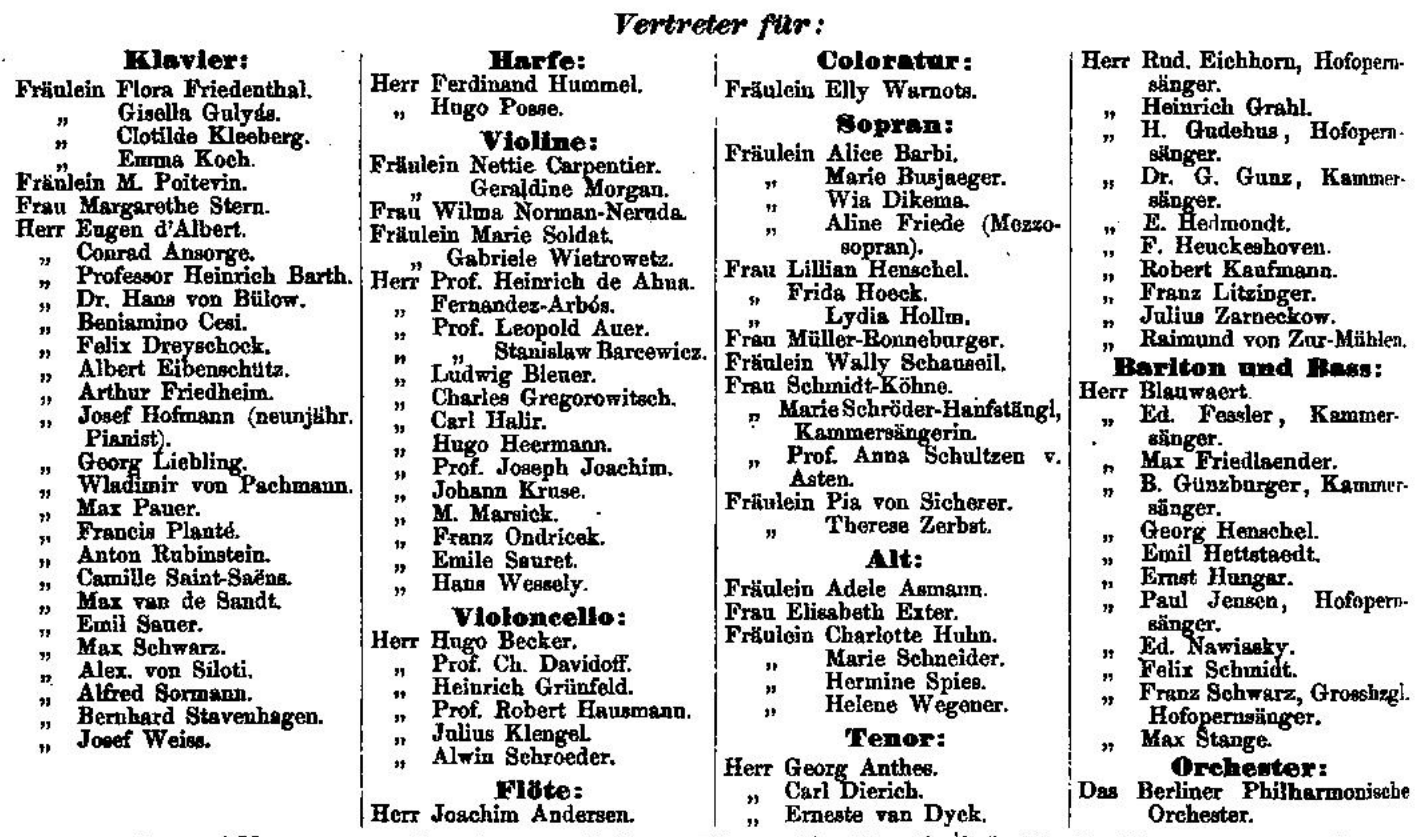

Fran Albany (aus London) und Frau Marcella Sembrich, K. Pr. Kammersängerinnen. - Herrn E. Lassaile von der grossen Oper inParis. - Den Stern'schen, sowie den Siegfiried Ochs'schen Gesangrerein in Berlin. - Das Streichquartett der Herren Prof. Joachim, de Ahun, Wirth, Hausmann. - Das Trio der Herren Prof. Barth, de Ahna, Hausmann. La Société de Husique de Chambre pour instruments a vent: MM. Taffanel, Gillet, Turban, Mimart, Garigue, Bremond, Espaignet et Bourdeau (Professoren am Conservatorium in Paris). - Die Philhamonischen Concerte unter Leitung von Herrn Johan Svendsen in Kopenhagen. - Die London Symphony-Concerts unter Leitung von Herrn Georg Henschel in London. - Die Châteletel Loncerte unter Leitung von Herrn Ed. Colonne in Paris. - Die K. Kuss. Musik-Gesellschaft in Moskau. - Herm Kapellmeister Max Erdmannsdörfer in Moskau.

\section{Ausgchliessliche Geschăftsführung}

Der Philharmonischen Concerte unter Leitung von Herm Dr. Hans v. Bülow in Berlin.- Der Neuen Abonnements-Concerte nuter Leitung von Herrn Dr. Hane v. Bülow in Hamburg. - Der Philharmonizchen Concerte unter Leitung von Herrn J. L. Nicodé in Dresden. Der Nenen Abonnemento-Concerto in Berlin.

Engrgements-Auträge und geschäfliche Mittheilungen für Obengenannte bitte freundlichst direet an mieh gelangen zu lassen, da gensnnte Kinstler, um der berufstörenden Correspondenz enthoben zu sein, mir die Bessrgung derselben ubergeben haben.

\section{Die Concertdirection Hermann Wolff besorgt:}

Engagements bei allen Concert- und Privat-Gesellschaften des In- und Auslendes; Complete Oratorienbesetzungen; Arrangements von Concert-Tournées in allen Ländern; Arrangements von Berliner Concerten etc. etc. und ertheilt unentgeltileh Auskunft tiber alle Concert-Angelegenheiten.

Srud van sereging in seipgig.

Abbildung 12: Anzeige der Konzertdirektion Hermann Wolff $(1887)^{255}$ 


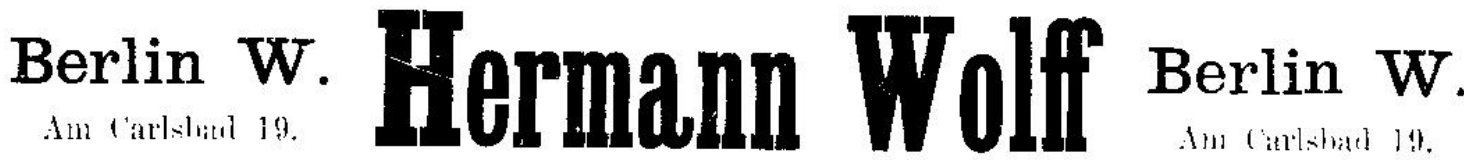 Concertdirection.}

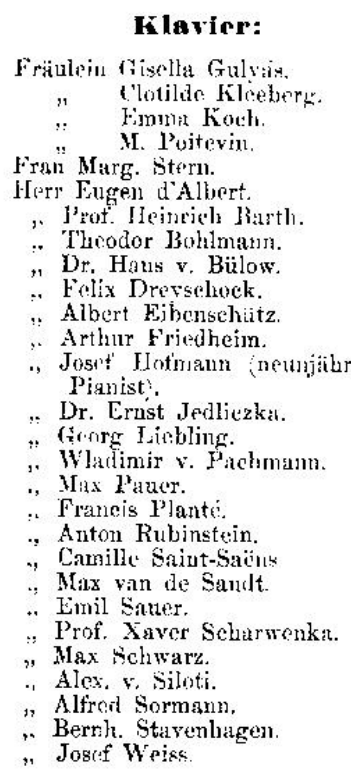

Harfe:

Herr Ferdinawi Itummel. " Hing Pcsse. Wilheln I'asse.

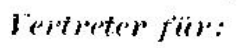

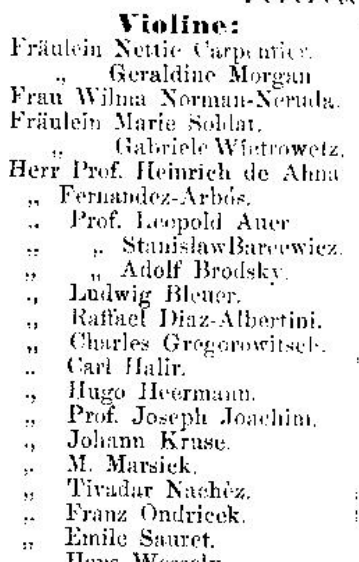
Eialina:

Fräulin Setic Carpentit:

Frau Winta Normats-Sortula

Fräuleing Marie tionlat.

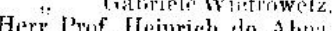

rich de Aherit

Fernotuda-Arbris

Prof. Iatupoled Aixer

Stamislaw Barminice.

Atdolf Broctsky

Judwig J3l:aer

Rattiel IVicz-Albertini.

Churles Grogerumitsel.

(aid Halir.

Hugro Hiermatus.

Prof. Joseph . Tointhin

Johismn Krast

M. Marsick.

Tivilditr Nikhizz.

lvamz Ondricek.

Einile Saturet.

Fiolomedlo:

Irerr Jugi, Becker.

Prof, Ch, Davisloff.

Heino, Grünfeld

?'rof. Rob. Rimlatmat!ì

Julius Klengel.

Alwin schroeder.

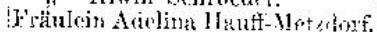
Wlibte:

Herr Joachim Andiersen. Colorntur:

Frä ulein Elisab. Jejsinger, $\mathrm{K}_{\mathrm{gl}} \mathrm{I}$ Pr. JIofoj)(rnsängerin.

\author{
Sopran: \\ Frändoin Alice Barki. \\ I.olia Bcetl, li. K \\ II of preverts. \\ Marie J3usjatiner. \\ Wiat Dikeinn. \\ Alin Friede Mezzo- \\ sonpran? \\ rita Lillian lemsched. \\ Frida Hoeck-lectimur. \\ I rodia Il Ilulm.

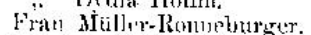 \\ Fritulein Wally sehanseil. \\ Frat Schnidt-Köha \\ .: Marieschrider.Jlutstän \\ Kammersingerin: \\ , I'mof. Anua Sibultzen vom \\ Asterl. \\ Erimiein Jerw. Sicea. \\ 1'is x. Sicherer \\ Thrrese \%erbst.
}

Alt :

Frïulein Adele Asm:

Friu Elisabeth Exter

Fräulein Charlotte Hubn.

F'rau Amolie Joactim.

Frötulein Marie Selineider.

$$
\text { Jernuine Spies. }
$$

Prä Emilie Wirth.

Tenor:

Ilerr fieorg Anthes.

. (cirl Jerierich.

$\because$ Errieste san Dyek.
IHerr Rud. Eichhom. Hofopemsiingex.

Heinr. Gralt.

iI. Guchehus, Itotoperm-

Jiinger. Gr. Gnn, kitunuersïinger.

I:. Ilisinondt

1. Heackeshoren.

Robert Kituf(n:tur.

Finz l.jtzinger.

Julius Zarneckow.

Raimund on Zur-Mfïlılen.

Huritou and Bams:

lisre Blauwatert.

Ir. turtius
Ed. Fessier, Kammor-

sïriger.

M:x Friedlatender.

I3. Günzburger, liammer-

sianger.

tixeorg Henschel.

Emil Fiettsta edt.

Frust ULungar.

linul Jensen, Iotiopen-

siinger.

Ed. Nawiasky.

liud. Schmilhlfeld

Frinz Schwirz, Grose

herzogl. I lof opermatinger.

Mix Stange

Jos. Staueligl, Kamıner:

Orchester:

I)is Berliner l'] lilh:trmouisebe

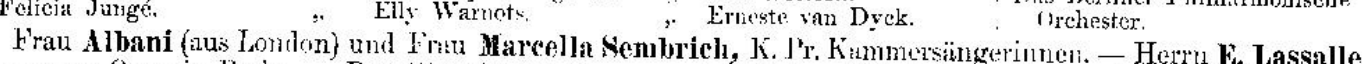

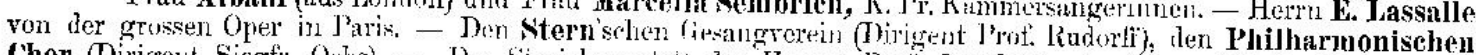
Chor (Dirigent. Siegfr. Oehs - - Das Streichquartet. dex Herwen Prot. Joachim, de Alna, Wirth, Hausmann. - Damin-Streichquartett. Soldat, Tsehetsebulin, Roy, Campbell. - La Socítét de Musique de Chambre pour

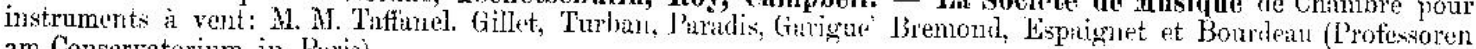
am Conservatorium in Paris).

Vertreter fiir Earopa ron: Abbey Seloeffel a Grau, New Jork, 1212 Broaldwa.

Concerte der. Concert-Iirection Hernin no Wolff:

Der Philharmonischen Concerte unter Leitumir vor Iterrn Dr. Hans ron Bülow in Berlin.

Der Neuen Abonnement-Concerte nuter Leitung ron Herrn Dr. Hans ron Bülow i॥ Hamburg.

Der Phibharmonischen Concerte unter Leitung von Herrm J. I. Nicodo in Ibresden.

Der Feuen Abonuement-Concerte in stettin.
Vertreter

[) Philharmonischen Concerte unter Keitung des Herrn Johann Srendsen in Kopenhagen.

Des Londoner Sinfonie-Concerte tunter Leitung des Ilerr Georg. Henschel in Jondon.

[)es Chitelet -Concerte unter leitung ders Herrn Ed. Colonne in Paris.

Der K. Russ. Musik-Gesellschaft Herrn Kanpellueister Max Frolmannsdörfer in Moskau.

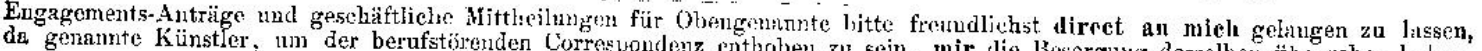
da genannte Künstler, um der berufstötenden Correspondenz enthoben zu sein, mir lie besorgung derselben übergcben haben.

Die Concertdirection Hermann Wolff besorgt:

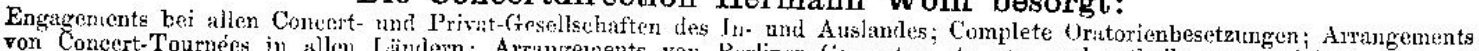
von Concert-Tournées in wllen Lïndern; Arrangenents von Birliner Concerten ete. ete. und ertheilt umentgeltieh Auskunft
uber alle Concert-Angelegenheiten.

Zruf tron

Abbildung 13: Anzeige der Konzertdirektion Hermann Wolff $(1888)^{256}$

${ }^{256}$ Neue Zeitschrift für Musik 55 (1888), S. 230. 


\section{Hermann Wolff; Concertdirection.}

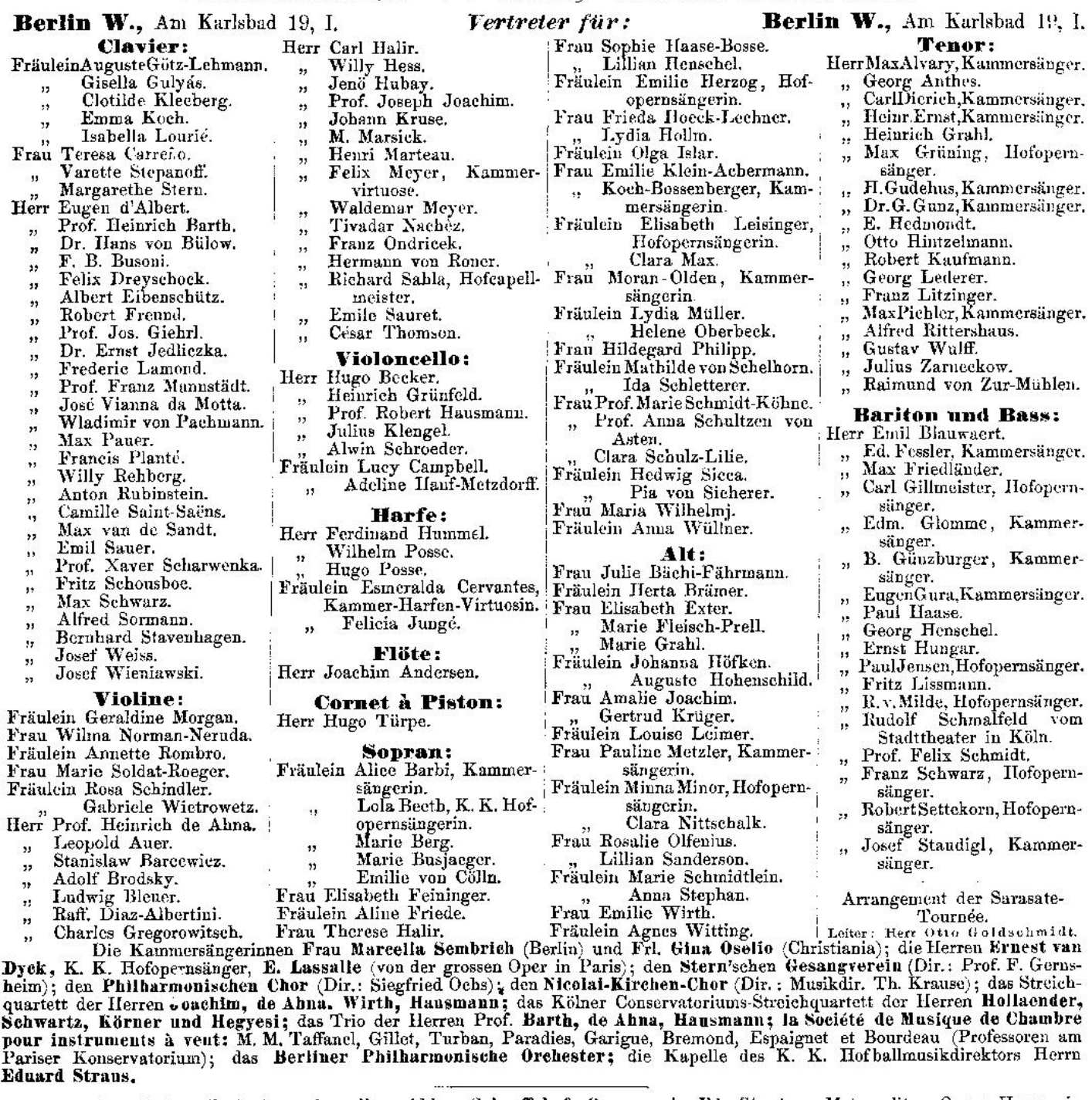

Answirirtige Yertreter. Amerika: Abbey Sehoeffel \& Grau sowie Ld. Stanton, Metropolitan Opera House, in New.York, Englind : D. Mayer in London; Seandivarten: Hennriek Henuings in Kopenhagen.

\section{vextretum $\mathbf{x} \boldsymbol{x} \ddot{x}$}

A. Concerte der Concert-lbirection Hermann Woln:

Philharmonische Concerte unter Leitung von. Dr. Hzan von Bïlow : Symphony-Orehestra Concerte im Auslande:

in Berlin.

Syphony-Orchestra unter Leitung von Arthur Nikisch in Boston. ine Abonnement-1 Philharmonische Concer

Symphonic-Concerte unter Leitung von Georg Henschel in London. Concerte der Kaiserlich Russ. Musikgesellsehaft in Moskau. Chatelet-Concerte unter Leitung von Ed. Colonne in Paris.

Engagements-Anträge und geschäftliche Mittheilungen für Obengenannte bitte freundlichst direkt an mich gelangen zu lassen, da genannte Künstler, um der berufatörenden Correspondenz enthoben zu sein, wir die Besorgung derselben übergeben habeu. Die Concertdirection Hermann Wolff besorgt:

Engagements bei allen Concert und Privat-Gesellschaften des In- und Auslandes; Complette Oratorienbesetaungen; Arrangement von Concert-Tournées in allen Ländern; Arrangements von Concerten in Berlin etc. etc., und ertheilt unentgeltlieh Auskunft über aile Concert-Angelegenheiten.

Trud oot b. Siregiting in $2 \mathrm{cip} i \mathrm{~B}$.

Hierza eine Beilage von J. Aibl, Kgi. Hof-Musikhandlung, München, C. F. Kahnt Nachfolger, Leipzig und Fr. Luckhardt, Berlin.

Abbildung 14: Anzeige der Konzertdirektion Hermann Wolff $(1890)^{257}$ 


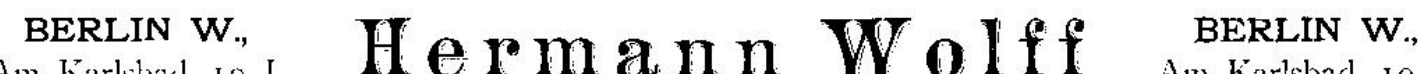

Am Karlsbad i 9 Telegraunm-Adresse: Musikwolff, Berlin

\section{Claviex:}

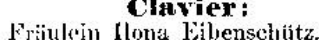
lleleme G('isle't.

A ugurusterätz-Lehmanu. (:isella Gulyís. Auna Hansters. Clotilde Kleeberg. Emma Koch. Mhirit Kriuse. C. Reilfersehoid. Limitur Rositrstock v " Elisabeth Rougc.

Fran Teresa Catreño.

" Margarethe Stern

Herr Eugen dibert.

Firitz voul bose

Prof. Heinrieh liarth.

Lonis Breitner.

Dr. Hans von J3iilew.

k. B. Busoni

Fielix Dreyschock.

Nibert Wibenscliitz.

liobert Freund.

Prof. Jos. Gicurl.

Otto Ilegner 14 jühr.

Dr. Ernst Jedliczka.

Erederic: Jamond.

Gustav lizarus.

Prof. Franz Mannstält.

Josi Viame da Motta.

Wladimir von Pachmann.
Wlading

J. J. P'aderiswsy.

Max l'auce.

Francis Plante.

Willy Rehberg.

Antun Rubinstein.

Camille Saint-Siäns.

Max van de sandt.

Prof. Xaver Scharwenkí.

Fritz Sthousboe.

Percy Sherword.

Itax Seliwarz.

Alfred Sorminn.

Beruhard staveniligen.

Stefan 'llisunán.

Stefan Thisun

Joseph Wieninwski.

Violine:

Fräulein Irene von Brennerberg.

Fräulein Geraldine Morgan.

Frau Wilma Norman-Neruida.

Fräulein Annette Rombro.

Fran Marie Soldat-lioeger.

Fräulein Rosia Schindler.

" Frida Scott

Frida Scotta.
$" \quad$ Gabritle Wietrowetz. Herr Hugot aürye.

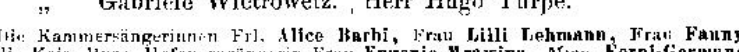

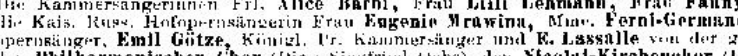

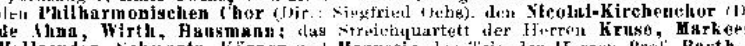

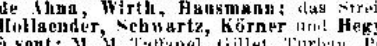

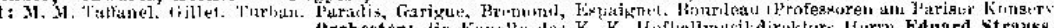

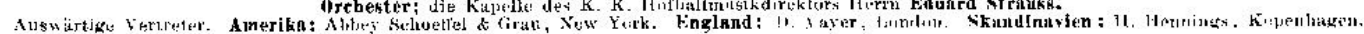

\section{Vertretung für:}

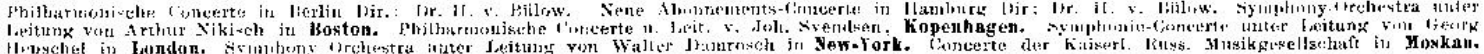

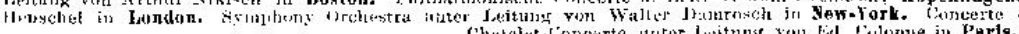

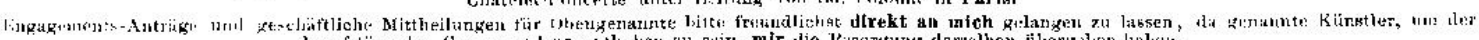

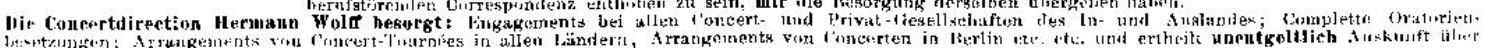

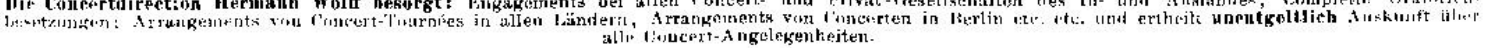

Abbildung 15: Anzeige der Konzertdirektion Hermann Wolff $(1891)^{258}$

Ausgehend von einem »Prospekt« der Konzertdirektion für die Saison 1892/93 berichtet Eugen Zabel in seinem Artikel in der Neuen Berliner Musikzeitung, dass »nicht weniger als

${ }^{258}$ Neue Zeitschrift für Musik 58 (1888), S. 268. 
115 Instrumentalisten, 132 Vokalisten, 10 Künstlervereinigungen, sechs verschiedene Abonnementskonzerte in London, Paris, New York, Boston, Moskau und Kopenhagen« von Hermann Wolff bzw. seiner Konzertdirektion betreut wurden. Zabel nannte ferner die Philharmonischen Konzerte in Berlin sowie die Neuen Abonnementkonzerte in Hamburg als eigene Unternehmen dieser Firma und führte Abbey Schoeffel \& Grau in New York, N. Vert in London sowie Henrik Hennings in Kopenhagen als wichtige ausländische Vertreter an. ${ }^{259}$

Was die späteren Jahre nach dem Tod Hermann Wolffs betrifft, so waren die Künstlerlisten im Konzertkalender, den die Konzertdirektion jede Saison veröffentlichte, der Verfasserin zugänglich. ${ }^{260}$ Die jeweilige Liste der Saison enthält ungefähr 400 bis 600 Künstler und Künstlervereinigungen (vgl. Diagramm 2). ${ }^{261}$ Die meisten Namen sind in der zweiten Hälfte der 1910er-Jahre zu finden.

Die Kreisdiagramme zeigen die Anteile der aufgelisteten KünstlerInnen nach ihrem Fach. Die Ergebnisse der Untersuchung der 27 Jahrgänge des Konzertkalenders, die der Verfasserin zugänglich sind, sind hier zugunsten der Anschaulichkeit in fünf Zeiträume eingeteilt (vgl. Diagramm 3-6). Über den gesamten Zeitraum machen die Pianisten ungefähr $20 \%$ und die Sänger ungefähr 40 \% der aufgelisteten Künstler aus. Bei Alter, Herkunft und künstlerischer Ausrichtung sind sie wieder so unterschiedlich, dass es nicht sehr sinnvoll schien, bestimmte Voraussetzungen oder ästhetische Kriterien für die Übernahme der Vertretung anzunehmen.

Der Anstieg der Künstlerzahlen insgesamt in der zweiten Hälfte der 1910er-Jahre liegt in erster Linie an der Zunahme der Künstler, die sich mit Sprachkunst beschäftigen. Hierin sind Persönlichkeiten der unterschiedlichen Wirkungsbereiche aufgelistet, etwa Journalisten,

\footnotetext{
${ }^{259}$ Eugen Zabel: Konzerte und Konzertunternehmer, S. 374.

${ }^{260}$ Concertkalender, hg. von der Concert-Direction Hermann Wolff (in späteren Jahren »Konzertkalender «). Vermutlich veröffentlichte die Konzertdirektion den ersten Jahrgang dieses Konzertkalenders in der Saison 1895/96. Leider waren die Jahrgänge dieses Kalenders vor 1902/03 und einige spätere Jahrgänge nicht aufzufinden. Die Lücke der Jahre in den Diagrammen liegt an diesem Quellenbefund.

${ }^{261}$ Bei der Erstellung der folgenden Diagramme habe ich im Prinzip die Kategorisierung der Künstler aus der Quelle übernommen. Zugunsten der Anschaulichkeit bedarf es jedoch einiger Modifikationen: Die Pianistenpaare, die in einigen Jahrgängen unter der selbständigen Kategorie »Vorträge auf zwei Klaviere« aufgelistet sind und in anderen unter »Künstlervereinigungen « erscheinen, habe ich einheitlich unter »Künstlervereinigungen« zusammengestellt. Im Verlauf der Zeit wurden einige Kategorien umbenannt oder umstrukturiert. Die Kategorie der SängerInnen, die sich hauptsächlich mit Unterhaltungsliedern beschäftigen, wurde zuerst in der Saison 1917/18 unter »Volks-Kinderlieder « eingeordnet, später unter »Volks-Kinderlieder und Chansons« und letztendlich unter »Chansons«. In den Diagrammen sind sie einheitlich unter »Chansons « geführt. Die Künstler, die in der Saison 1910/11 unter der Kategorie »Autoren, Schriftsteller, Rezitation und Bühnenkünstler« in der Liste erschienen, wurden, nachdem ihre Kategorie unterschiedlich bezeichnet wurde, ab 1927/28 unter der Kategorie »Vortragskünstler und Redner« verzeichnet, die ich hier übernahm.
} 
Schauspieler, Schriftsteller, Bühnenautoren und Dichter. (vgl. Abbildung 16). Ab 1913/14 sind Tänzerinnen und Tanzlehrer unter der Kategorie »künstlerischer Tänze« hinzugefügt. Die Zahl der unter dieser Kategorie aufgelisteten Künstler nahm in den 1920er-Jahren deutlich zu.

Die Konzertdirektion Hermann Wolff (und Jules Sachs) vertrat die Künstler nicht nur in Deutschland, sondern auch für ihre Tätigkeit in »Oesterreich, Frankreich, England, Italien, Schweiz, Spanien, Russland, Holland, Skandinavien und in den Hauptstädten der Vereinigten Staaten von Nord-Amerika«. ${ }^{262}$ In den 1910er-Jahren waren auch »die grössten Städte SüdAmerikas $«^{263}$ in ihrer Reichsweite.

${ }^{262}$ Concertkalender 11 (1905/1906), S. 116.

${ }^{263}$ Concertkalender 17 (1911/1912), S. 108. 


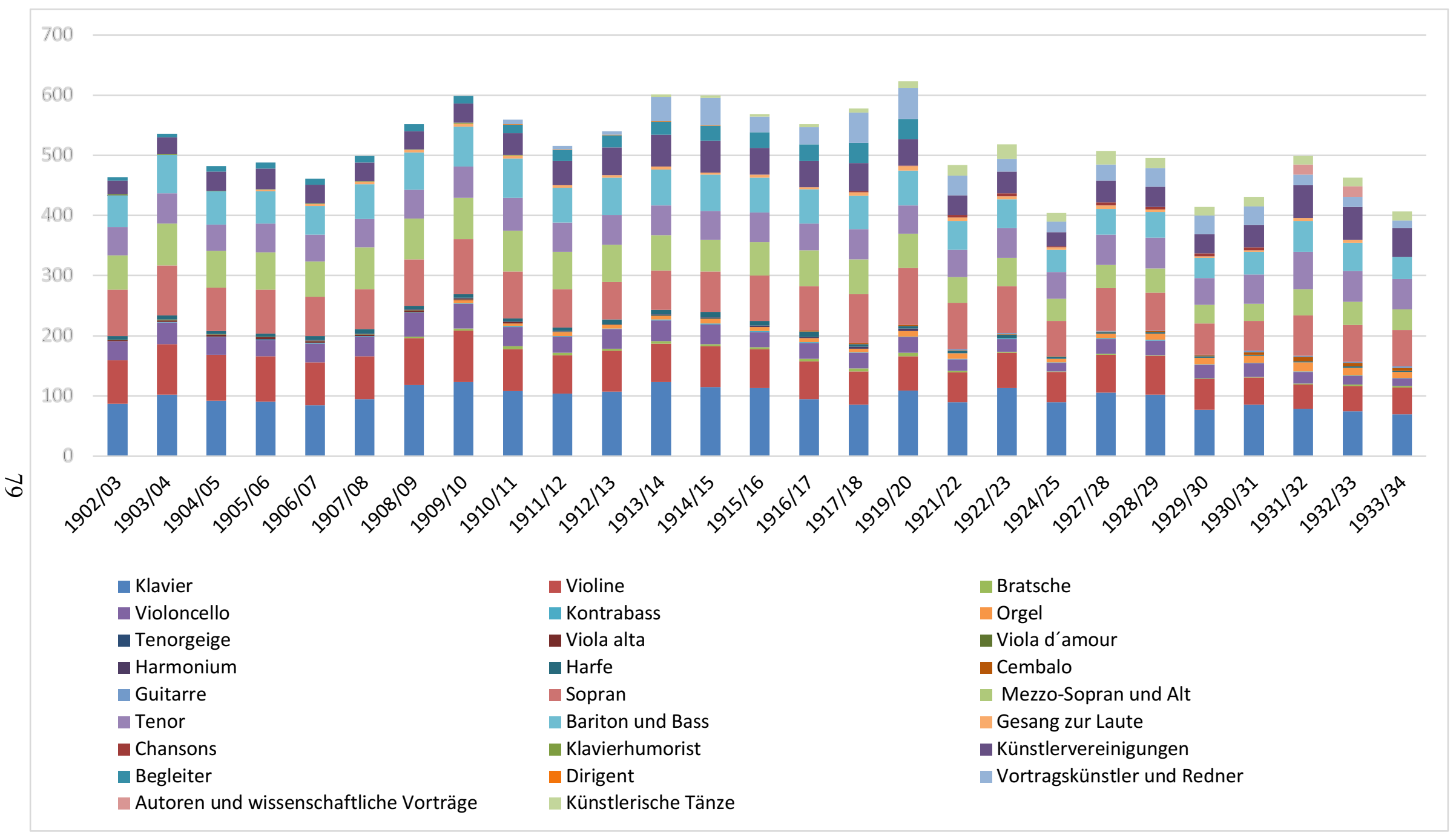

Diagramm 2: Künstler, aufgelistet im Konzertkalender (1902/03-1933/34) 


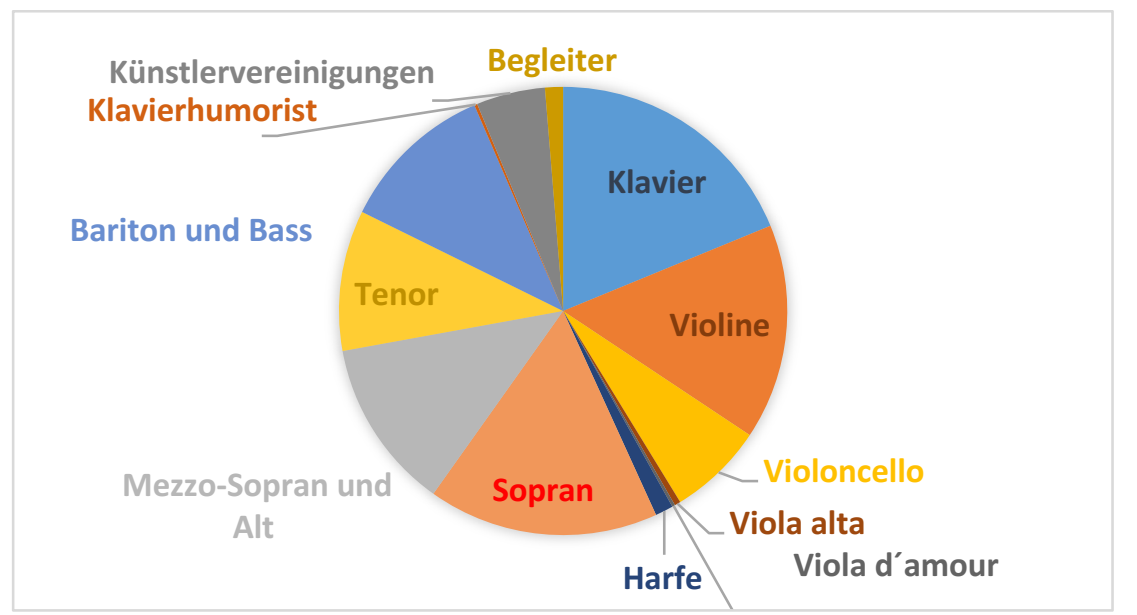

Diagramm 3: Künstler im Konzertkalender 1902/03-1907/08 (6 Jahrgänge)

$\stackrel{\infty}{0}$

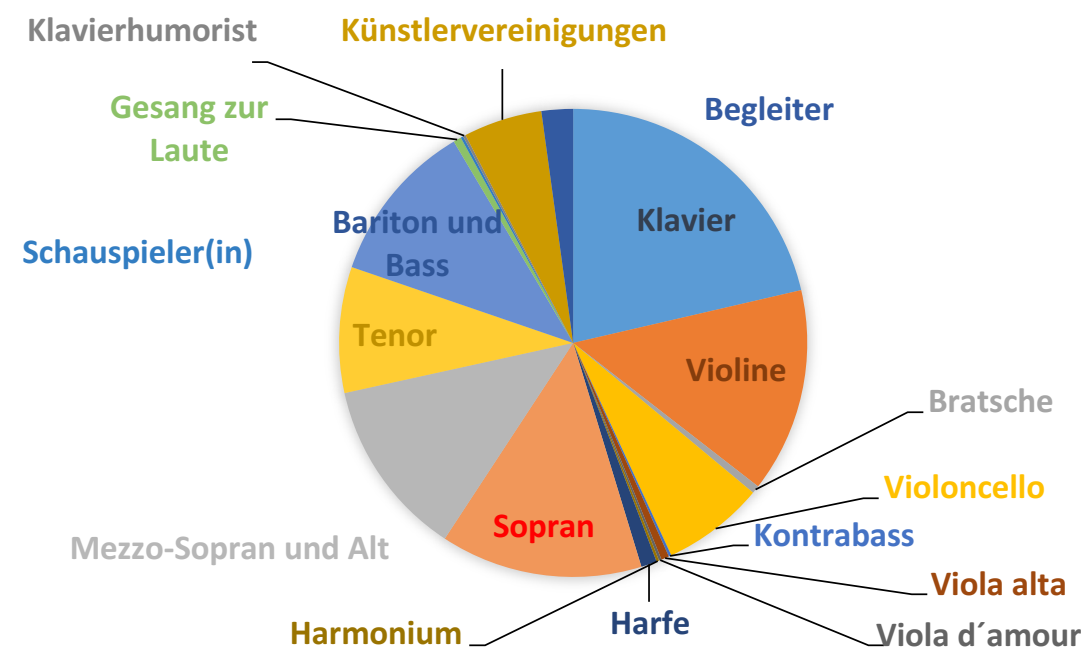

Diagramm 4: Künstler im Konzertkalender 1908/09-1913/14 (6 Jahrgänge)

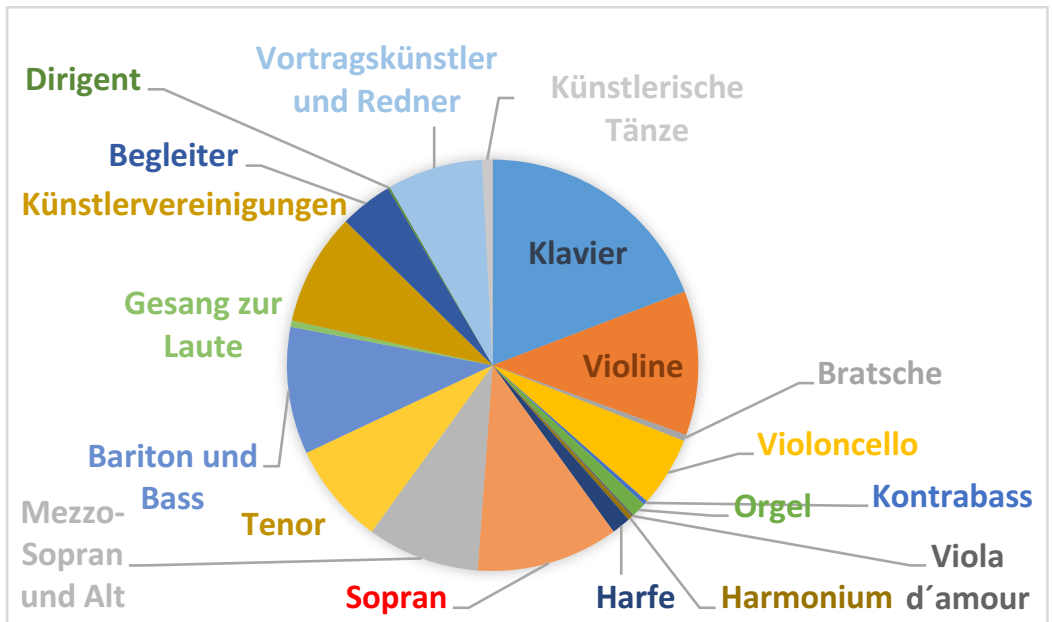

Diagramm 5: Künstler im Konzertkalender 1914/15-1919/20 (5 Jahrgänge)

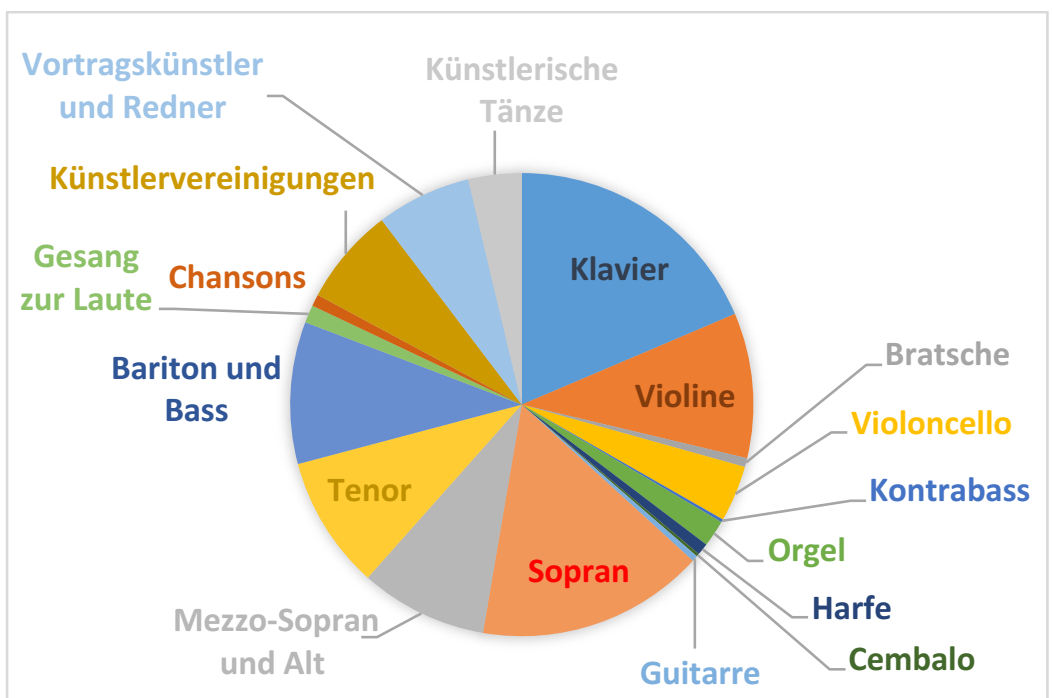

Diagramm 6: Künstler im Konzertkalender 1921/22-1928/29 (5 Jahrgänge) 


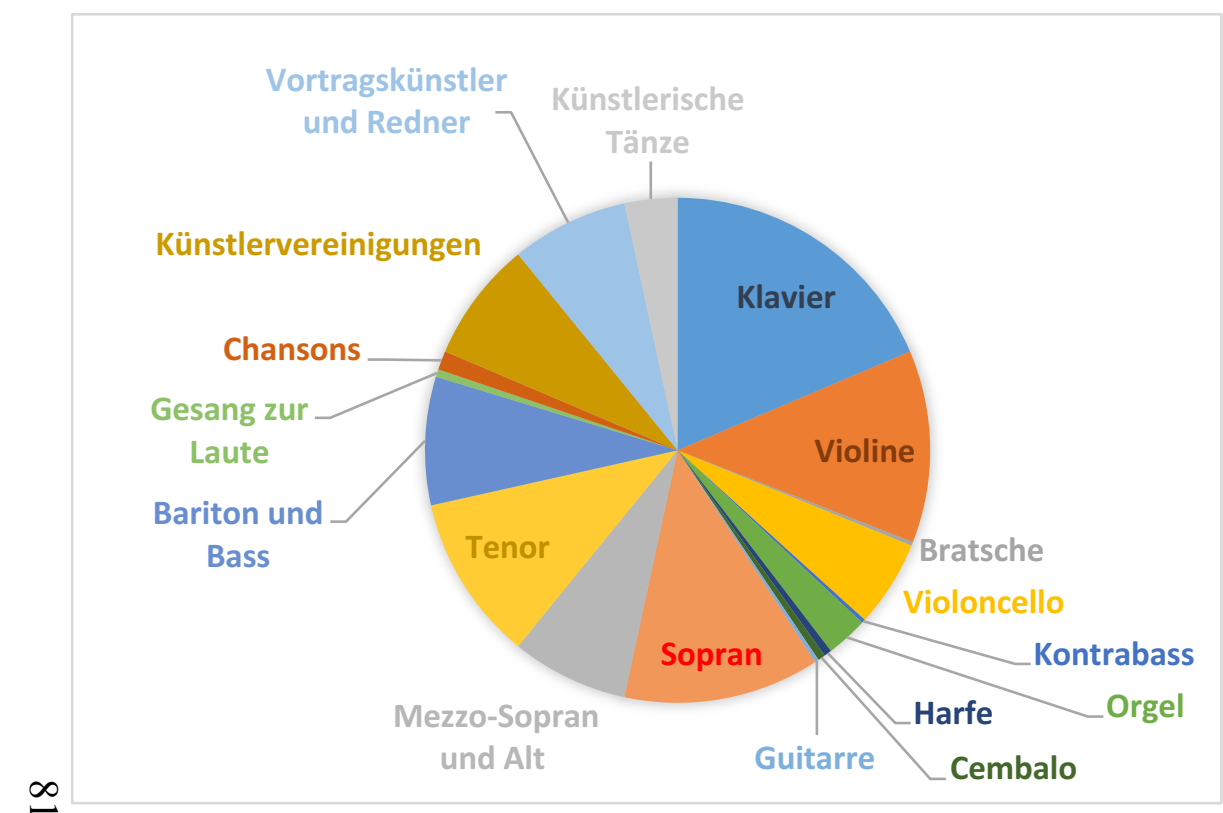

Diagramm 7: Künstler im Konzertkalender 1929/30-1933/34 (5 Jahrgänge)
Konzert-Direktion Hermann Wolff und Jules Sachs G. m. b. H.

\section{Vortragskünstler.}

IIermann Boetteher

Carl Clewing

Ernst Deutseh

Dr. Erieh Draeh

Friedrieh Erhard

Gertrud Eysoldt

Maria Fein

Ludwig Hardt

Else Heims

IIse Kamnitzer

Friedrich Kayssler

Resi Langer

Ulrieh Fr. Krolop

Emil Mamelok

Mlexander Moissi

Johannes Riemann

Lia Rosen

E. Senfr-Georgi

Waldemar Staegemann

Helene Thimig

IIermann Thimig

Gertrud Tressnitz

Irene Trieseh

Conrad Veidt

Paul Wegener

Ililda Wegner

Theodora Wertseh

Eduard ron Winterstein

Anna Wiillner

Dr. Ludwig Wüllner

\section{Künstlerische Tänze.}

Dorothea Albu

Anita Berber

OIga Desmond

Elizabeth Dunean

mit ihren Schalerinner

IIse Eilers

Toni Freeden

Jrail Gadeseor

Valeska Gert

Lo Hesse

Ronny Johansson

Luey Kieselhausen

Erust Matray und Katta

Lere Sello

Ruth Sehwarzkopf

Mary Wigman

Elsa, Berta, Marta

Wiesenthal

Hannelore Ziegler

Mary Zimmermann

mit ihrem Ballett

Abbildung 16: Auszug aus der Künstlerliste im Konzertkalender 27

$(1921 / 22)^{264}$

\footnotetext{
${ }^{264}$ Konzert-Kalender 27 (1921/22), S. 69.
} 


\subsubsection{Konzertveranstaltungen und Konzertarrangements in Berlin}

Die Geschäftstätigkeit der Konzertdirektion Hermann Wolff (und Jules Sachs) bestand hauptsächlich aus drei Tätigkeitsfeldern: dem eigenen Konzertunternehmen, dem Arrangieren von Konzerten (inkl. Tourneen ${ }^{265}$ ) und Engagementsvermittlung. ${ }^{266}$ Als Unternehmer veranstaltete sie Konzerte auf eigene Rechnung. Beim Konzertarrangement übernahm sie Geschäftsbesorgungen für die auf Rechnung der auftretenden Künstler stattfindenden Konzerte. Durch die Vermittlungstätigkeit brachte sie verschiedene Engagements zustande, meistens Konzertengagements zwischen Künstlern und Konzertveranstaltern, aber in den späteren Jahren auch Radioengagements, Tonfilmengagements und Schallplattenverträge.

Die meisten Konzertagenten profitierten in erster Linie von Provisionen, die sie durch das Konzertarrangement und die Engagementsvermittlung bekamen. Um Risiken zu umgehen, vermieden sie es oft, auf eigene Rechnung Konzerte zu veranstalten, ${ }^{267}$ aber es kam auch vor, dass sie als vollverantwortlicher Veranstalter fungierten. Als »hervorragendstes Beispiel $\aleph^{268}$ können die Philharmonischen Konzerte des Berliner Philharmonischen Orchesters gelten, die von Hermann Wolff ins Leben gerufen und auch nach seinem Tod von seiner Konzertdirektion weitergeführt wurden. Dem Bericht des Berliner Polizeipräsidenten an das Handelsministerium aus dem Jahr 1919 zufolge zog die Konzertdirektion ihre Haupterträge aus eigenen Veranstaltungen, vor allem durch die Philharmonischen Konzerte. ${ }^{269}$ Auch in den Entschädigungsakten dieser Firma sind ihre eigenen Unternehmungen, die Philharmonischen und Bruno-Walter-Konzerte, als ihre Haupteinnahmequellen aufgeführt. ${ }^{270}$

Um den Umfang des Einflusses, den diese Konzertdirektion auf das damalige Berliner Musikleben ausübte, einzuschätzen, sollen hier drei Fragen gestellt werden: Wie viele

\footnotetext{
${ }^{265}$ Zum Tourneemanagement von Hermann Wolff, vgl.: Sayuri Hatano: »Wohlgemuth ziehe zur Schweiz, lass' tönen die herrliche Fidel.« Arrangement der Konzerttournee von der Konzertdirektion Hermann Wolff, in Jahresblätter für japanische und deutsche Forschung in Japan 6 (2013), S. 31-41.

${ }^{266}$ Bericht von der Besichtigung der Konzertdirektion Hermann Wolff vom 3.12.1913, LAB, A. Pr. Br. Rep. 030-05, Nr. 3670, Bl. 13r. Vgl. auch: Stargardt-Wolff: Wegbereiter großer Musiker, S. 51. ${ }^{267}$ W[ilhelm] d'Albert: Die Verwertung des musikalischen Aufführungsrechts in Deutschland, Jena 1907, S. $54 f$.

${ }^{268}$ Ebd., S. 55.

${ }^{269}$ Bericht vom Berliner Polizeipräsidenten an das Handelsministerium vom 19.3.1919, LAB, Nr. 3370, B1. 56.

${ }^{270}$ Vermerk der Unterhaltung im Entschädigungsamt vom 21.7.1959, Entschädigungsakte (Fa. Konzertdirektion Hermann Wolff u. Jules Sachs GmbH.), EBB, Reg. Nr. 40762, Bl. D6v. Der eidesstattlichen Versicherung des langjährigen Mitarbeiters Max Bleicher zufolge brachten die 10 Philharmonischen Konzerte unter Wilhelm Furtwängler durchschnittlich die Einnahme von etwa 200.000 RM brutto, die Bruno Walter-Konzerte etwa 100.000 RM brutto. Eidesstattliche Versicherung von Max Bleicher vom 7.4.1959, Ebd., Bl. M 23.
} 
Konzerte sind unter ihrer Organisation entstanden? Was für Konzerte waren dies? Und wo fanden diese Konzerte statt? Ein Gesamtbild ihrer umfangreichen Tätigkeit zu bekommen ist schwierig, denn die jetzige Quellenlage reicht nicht aus, ihre Entwicklung fortlaufend nachvollziehen zu können. Trotzdem soll hier - basierend auf den der Verfasserin zugänglichen Quellen - versucht werden, ein Bild der unter ihrer Organisation entstandenen Konzerte in Berlin in groben Umrissen zu umreißen.

Nach dem Bericht der Allgemeinen Musik-Zeitung fanden 273 Konzerte und Vorlesungen in der Saison 1893/94 durch das Arrangement der Konzertdirektion Hermann Wolff statt:

Die Konzertdirektion Hermann Wolff begann mit dem 1. April den 15. Jahrgang ihrer Thätigkeit. In der jetzt abschließenden Saison 1893/94 hat sie allein in Berlin das Arrangement von 273 Konzerten und Vorlesungen besorgt; davon fanden im Saal Bechstein 147, in der Singakademie 80, in der Philharmonie 40, im Saal des Hôtel de Rome 4, und ferner 2 in Kirchen statt. Wohltätigkeitskonzerte wurden von der Direktion 12 arrangirt, die übrigen vertheilen sich ungefähr auf 11 große Orchesterkonzerte, 12 große Chorkonzerte, 18 Quartett- und Kammermusik-Abende, 50 Klavier-Abende, 20 Violinisten-Abende, 117 Lieder-Abende, 12 Konzerte mit eigenen Kompositionen der Veranstalter, ferner auch Vorlesungen, KonservatoriumsAufführungen etc. ${ }^{271}$

Unter den 273 Konzerten nehmen die Liederabende mit insgesamt 117 Veranstaltungen einen auffallend großen Raum ein. Es folgen Klavierabende mit 50, Violinkonzerte mit 20, Kammermusikabende mit 18 Veranstaltungen, und dann Orchester-, Chor- und Komponistenkonzerte mit fast gleichen, geringeren Anteilen (11-12). Mehr als die Hälfte der Konzerte wurde im Bechstein-Saal abgehalten, der von Hermann Wolff 1892 erbaut wurde und ihm gehörte. ${ }^{272}$

Im Concert-Verzeichnis der Konzertdirektion für die vier Saisons 1901/02 bis 1904/05 sind 1.704 Veranstaltungen in Berlin verzeichnet. ${ }^{273}$ Auch hier stehen die $»$ Solistenkonzerte

\footnotetext{
${ }^{271}$ Allgemeine Musik-Zeitung 21 (1894), S. 200.

${ }^{272} \mathrm{Zu}$ diesem Konzertsaal vgl. Teilkapitel 3.3 der vorliegenden Arbeit.

${ }^{273}$ Es ist der Verfasserin nicht bekannt, ob dieses Verzeichnis auch vor und nach diesen Spielzeiten verlegt wurde. Dem in der Staatsbibliothek zu Berlin preußischer Kulturbesitz zugänglichen Exemplar, das im Rahmen der vorliegenden Arbeit untersucht wurde, fehlen einige Blätter. Es ist allerdings nicht sicher, ob dieses offenbar als Werbungsmittel erstellte Verzeichnis alle Konzerte verzeichnet, die in dieser Zeit von der Konzertdirektion veranstaltet oder arrangiert wurden. Trotzdem ist dieses Verzeichnis, in dem mehr als
} 
(vokal)« (hauptsächlich Liederabende) mit $30 \%$ an der Spitze. Diesen folgen

»Solistenkonzerte (instrumental)« mit 24 \%, während die Konzerte in großer Besetzung, wie Orchesterkonzerte und Chorkonzerte, nur kleine Anteile je von $7 \%$ bzw. $5 \%$ einnehmen

(Diagramm. 8). 34 \% der Veranstaltungen wurden im Bechstein-Saal abgehalten (Diagramm 9).

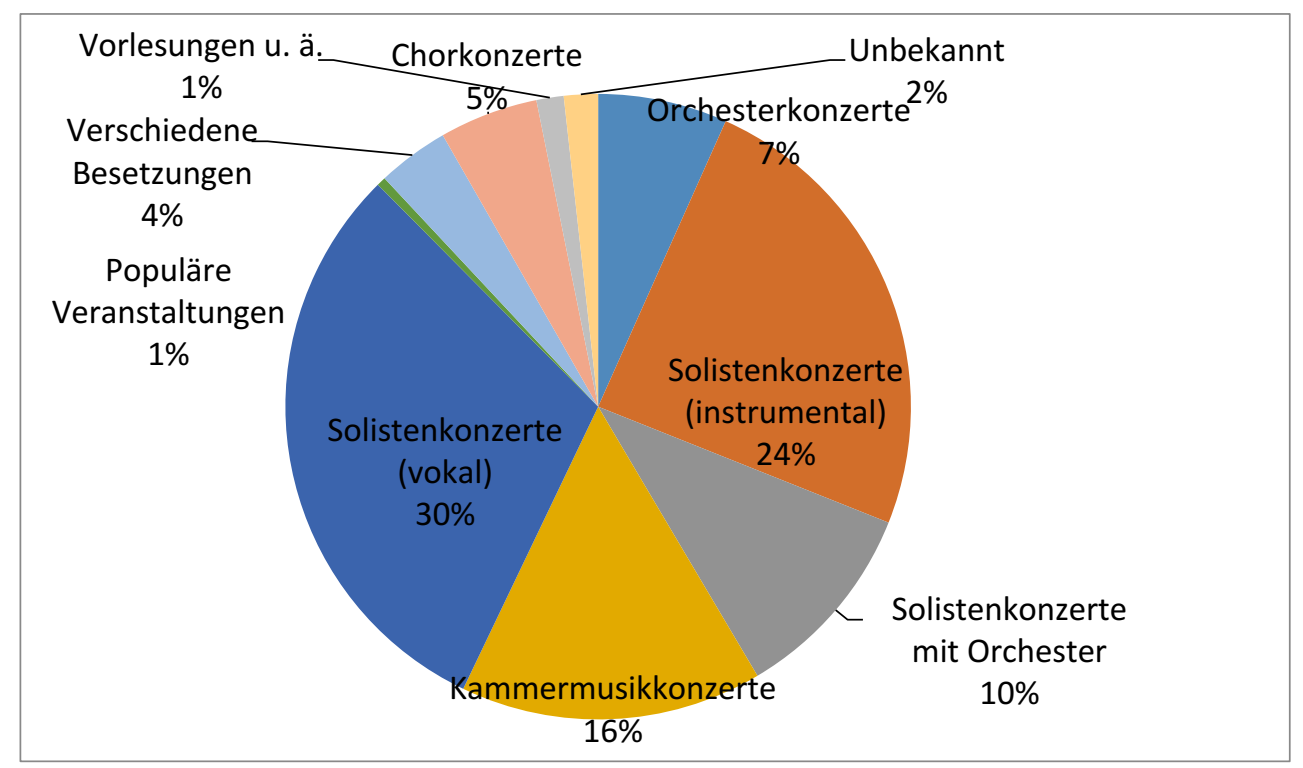

Diagramm 8: 1.704 Veranstaltungen der Konzertdirektion Hermann Wolff $(1901 / 02-1904 / 05)^{274}$

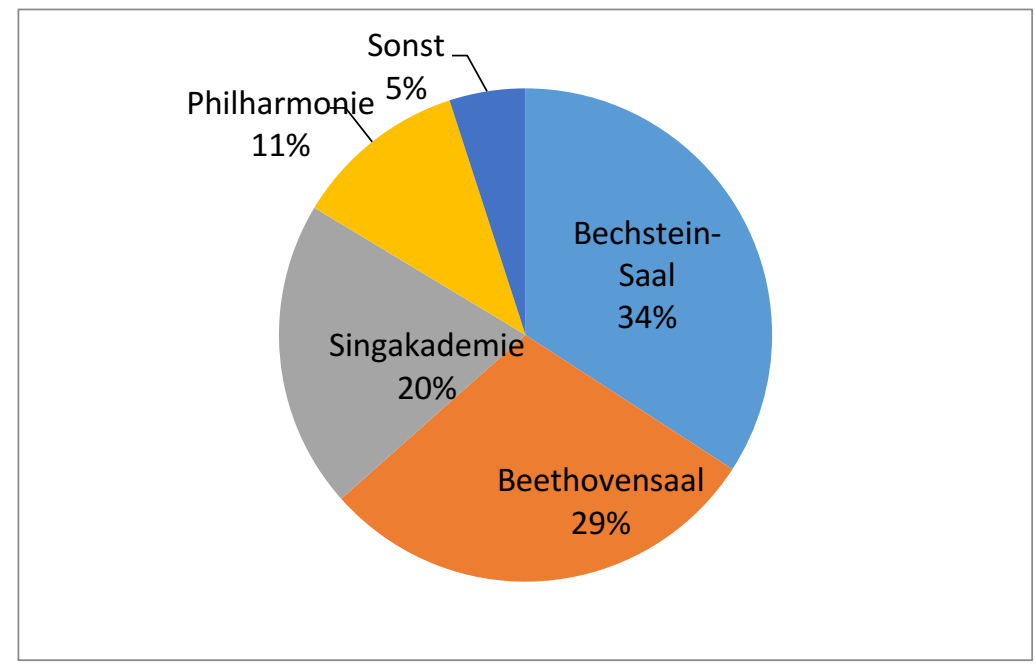

Diagramm 9: Ort der 1.704 Veranstaltungen der Konzertdirektion Hermann Wolff (1901/02$1904 / 05)^{275}$

400 Konzerte für jede Saison verzeichnet sind, nach jetziger Quellenlage von herausragender Bedeutung, um ein Gesamtbild ihrer Tätigkeit zu bekommen.

${ }^{274}$ Quelle: Concert-Verzeichnis für die Spielzeiten 1901/02-19014/05, hg. von der Konzertdirektion Hermann Wolff.

${ }^{275}$ Quelle: Ebd. 
Aus diesem Verzeichnis wird ersichtlich, dass das Arrangement von kleinen, auf Rechnung der Künstler stattfindenden Konzerte den größten Teil der gewöhnlichen Veranstaltungen dieser Konzertdirektion ausmacht. Als Beispiel werden unter 2 des Quellenteiles der vorliegenden Arbeit die 466 Veranstaltungen der Saison 1902/03 angeführt.

Wie der Erste Weltkrieg und die anschließende Wirtschaftskrise den Umfang der Geschäftstätigkeit der Konzertdirektion Hermann Wolff und Jules Sachs beeinflusste, kann anhand der jetzigen Quellenlage nicht beantwortet werden. Der Verfasserin ist nur das Schreiben von Erich Sachs an das Berliner Polizeipräsidium vom 26. Januar 1924 bekannt, in dem er davon berichtete, dass die Anzahl der Konzertarrangements durch die allgemeine Wirtschaftslage auf ein Drittel bis ein Viertel der normalen Anzahl zurückging. ${ }^{276}$

Der Angabe des Jahrbuchs der deutschen Musikorganisation aus dem Jahr 1931 zufolge veranstaltete oder arrangierte die Konzertdirektion in der Saison 1928/29 etwa. 75 Orchester- und Chorkonzerte, etwa 25 Kammermusikabende und rund 300 Solistenkonzerte und Vorträge. ${ }^{277}$ Diese Daten sind nicht weit entfernt von denjenigen der obengenannten Spielzeiten 1893/94 und 1901/02 bis1904/05. Aufgrund der bislang zugänglichen Quellen kann man grob schätzen, dass die Konzertdirektion Hermann Wolff (und Jules Sachs) in jeder Saison in Berlin an die 400 Konzerte veranstaltete oder arrangierte, deren großen Teil Vokalund Instrumentenkonzerte in kleiner Besetzung waren. Ebenso ist es zu vermuten, dass sie den Bechstein-Saal, einen Kammermusiksaal mit rund 500 Sitzplätzen, der in Besitz von Hermann Wolff war, zu großem Gewinn für die Organisation solch kleinerer Konzerte einsetzte.

${ }^{276}$ Schreiben von Erich Sachs an die II. Abteilung des Berliner Polizeipräsidiums vom 26.1.1924, LAB, A Pr. Br. Rep. 030-05, Nr. 3370, B1. 166.

277 Jahrbuch der deutschen Musikorganisation 1931, hg. von Leo Kestenberg, Berlin 1931, S. 242. 


\begin{tabular}{|c|c|c|c|c|}
\hline \multirow[b]{2}{*}{1904} & \multicolumn{4}{|c|}{ 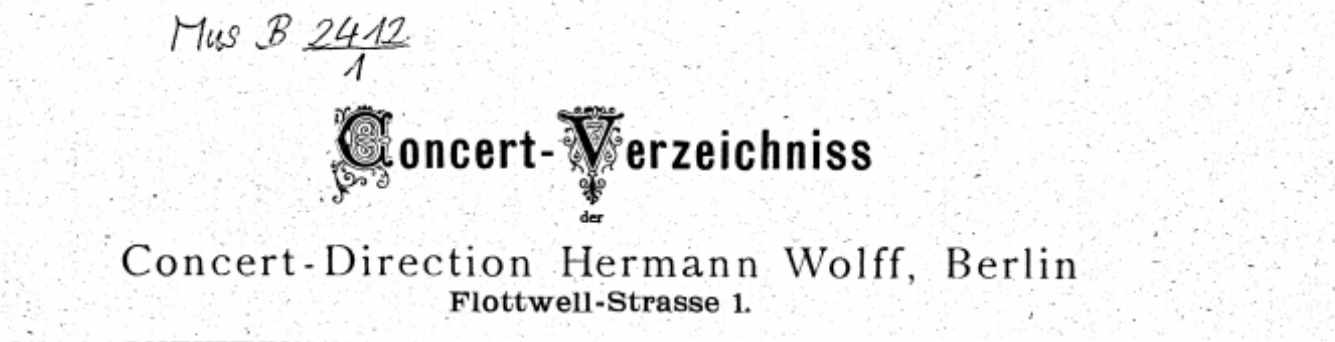 } \\
\hline & Saal Bechstein & Beethoven-Saal & Sing-Akademie & Philharmonie \\
\hline $\begin{array}{c}\text { Somutag } \\
\text { 10. Januar }\end{array}$ & & & & $\begin{array}{l}\text { Oeffentl. Hauptprobe } \\
\text { VI. Philharmon. Concert } \\
\text { Dhir: Arthur Nikisch } \\
\text { Solist: Conrad Ansorge } \\
\text { Mittagm 12 Ulir. } \\
\end{array}$ \\
\hline $\begin{array}{c}\text { Montag } \\
\text { 11. Januar }\end{array}$ & $\begin{array}{c}\text { Lieder-Abend } \\
\text { von } \\
\text { Ciska Schattka } \\
\boldsymbol{\tau}^{1 / 3} \text { Uhr. }\end{array}$ & & & $\begin{array}{l}\text { VI. Philharmon. Concert } \\
\text { Dir: Arthur Nikiseh } \\
\text { Solist: Conrad Ansorge } \\
\text { 71/a Unr pracise. }\end{array}$ \\
\hline $\begin{array}{l}\text { Dienstag } \\
\text { 12. Januar }\end{array}$ & & $\begin{array}{l}\text { Il. Lieder-Abend } \\
\text { Lula Mysz-Gmeiner } \\
\text { \& vhr. }\end{array}$ & 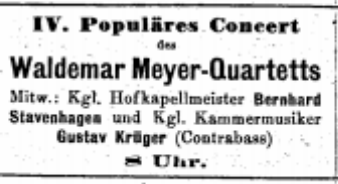 & \\
\hline $\begin{array}{l}\text { Mittwoch } \\
\text { 13. Januar }\end{array}$ & $\begin{array}{c}\text { II. Klavier-Abend } \\
\text { Lucien Wurmser } \\
\boldsymbol{r}^{1 / \mathrm{S} \text { Uhr. }}\end{array}$ & $\begin{array}{c}\text { CONCERT } \\
\text { Aldo Antonietti (Viol.) } \\
\text { \& uhr. }\end{array}$ & & 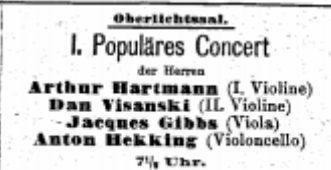 \\
\hline $\begin{array}{l}\text { Donnerstag } \\
\text { 14: Januar }\end{array}$ & $\begin{array}{c}\text { Lieder-Abend } \\
\text { Fanny Freystädt } \\
\text { vur. }\end{array}$ & 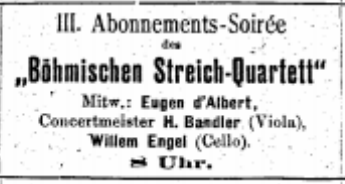 & 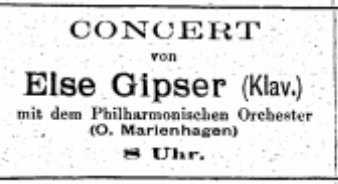 & 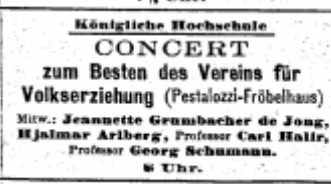 \\
\hline $\begin{array}{c}\text { Freitag } \\
\text { 15. Januar }\end{array}$ & $\begin{array}{c}\text { Klavier-Abend } \\
\text { Artur Schnabel } \\
\gamma^{1 / 2 \text { Uhr. }}\end{array}$ & 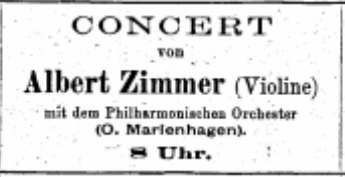 & $\begin{array}{c}\text { Lieder-Abend } \\
\text { Clar a } \\
\text { a vhr. }\end{array}$ & \\
\hline $\begin{array}{l}\text { Sonnabend } \\
\text { 16. Januar }\end{array}$ & 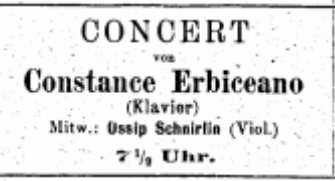 & 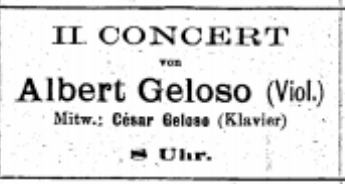 & 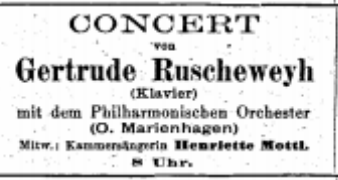 & \\
\hline $\begin{array}{c}\text { Sonntag } \\
\text { 17. Januar }\end{array}$ & 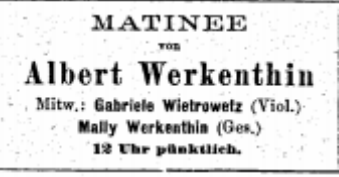 & & 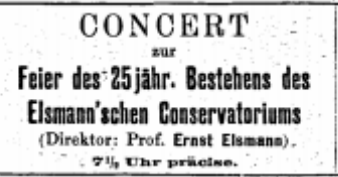 & \\
\hline $\begin{array}{l}\text { Montag } \\
\text { 18. Januar }\end{array}$ & 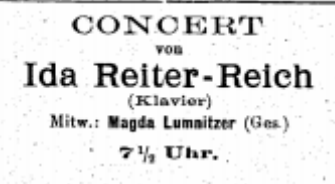 & 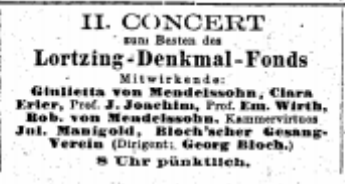 & . & 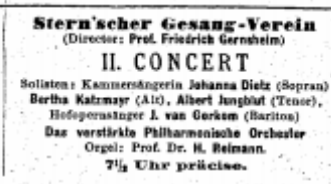 \\
\hline & $\begin{array}{r}\text { Billetverkauf fiir a } \\
\text { von }\end{array}$ & $\begin{array}{l}\text { ben angezeigten Con } \\
\text { BOTE \& G. BOCK, }\end{array}$ & $\begin{array}{l}\text { findet in der Hofmus } \\
\text { zigerstr. } 37 \text {, statt. }\end{array}$ & alienhandlung \\
\hline
\end{tabular}

Abbildung 17: Concert-Verzeichnis (10.-18. Januar 1904) 


\subsubsection{Rechtliche Einschränkungen}

Die Vorschriften über den Geschäftsbetrieb der Konzertagenten vom 9. März 1914 (HMB1. S. 134) $)^{278}$ - die ersten Ministerialvorschriften spezifisch für den Konzertagentenbetrieb gingen von der Voraussetzung aus, dass ein Konzertagent Stellenvermittler im Sinne des Stellenvermittlergesetzes vom 2. Juni 1910 (RGB1. S. 860) sei, ${ }^{279}$ und bestimmten den Befugnisumfang seines Geschäftsbetriebs wie folgt:

1. Konzertagent im Sinne dieser Bestimmungen ist, wer das Gewerbe eines Stellenvermittlers ( $§ 1$ Nr. 1 und 2 StVG.) vorbehaltlich der Bestimmung in Ziff. 10 Abs. 2 nur für solche gewerbsmäßig oder nicht gewerbsmäßig betriebene Unternehmungen ausübt, durch welche Instrumentalkonzerte, Vokalkonzerte,

${ }^{278}$ Die gesamten Vorschriften sind unter 4 im Quellenteil der vorliegenden Arbeit zu finden.

${ }^{279}$ Die Frage, ob es angemessen ist, das Stellenvermittlergesetz vom 2. Juni 1910 auf die Vermittlungstätigkeit der Konzertagenten anzuwenden, wurde zuerst vom Justizrat R. Wolff als Bevollmächtigter der Konzertdirektion Hermann Wolff beim Polizeipräsidenten im September 1911 aufgeworfen. Vgl. Schreiben von R. Wolff an Glasenapp vom 5.9.1911, LAB, A Pr. Br. Rep 030-05, Nr. 3361, Bl. 9-23. Angesichts der Notwendigkeit der systematischeren Stellenvermittlung für die Invaliden sowie der Überhandnahme illegaler Vermittlungstätigkeit steigerte sich nach dem Ersten Weltkrieg in Deutschland der Wunsch nach strengerer Kontrolle über die gewerbsmäßige Vermittlungstätigkeit. In diesem Kontext wurde das Reichsamt für Arbeitsvermittlung 1920 errichtet und auch das Arbeitsnachweisgesetz vom 22. Juli 1922 (RGBl. S. 657) verabschiedet, dessen $\S 48$ die gewerbsmäßige Stellenvermittlung ab dem 1. Januar 1931 grundsätzlich verbot. Ab Beginn des Jahres 1929 nahm die Konzertdirektion Hermann Wolff und Jules Sachs, die bisher die Befugnis und Pflicht als Stellenvermittler im Sinne des Gesetzes angenommen hatte, den Standpunkt ein, dass sie dem Stellengvermittlergesetz und somit den Vorschriften über den Geschäftsbetrieb der Konzertagenten nicht unterworfen sei. Diesen Standpunkt begründete Erich Sachs wie folgt: »Nach unserer Ansicht hat derjenige eine Stelle inne, der für längere Zeit fortlaufend von einem Arbeitgeber angestellt ist und sich der Organisation des Arbeitsgebers dadurch einfügt, also etwa der Musiklehrer eines Konservatoriums, der Musiker eines Orchesters, das für längere Zeit verpflichtete Mitglied eines Theaters oder einer Opernbühne. Dagegen ist die einmalige Mitwirkung eines Künstlers in einem Konzert resp. die Veranstaltung eines abendfüllenden Konzerts nicht als Stellung anzusprechen.« Schreiben von Erich Sachs an Oberregierungsrat Adriani vom 28.1.1929, LAB, A Pr. Br. Rep 030-05, Nr. 3670, Bl. 182r. Der Artikel 3 des Gesetzes über die Entschädigung der gewerbsmäßigen Stellenvermittler vom 25. März 1931 (RGBl. I. S. 69) ließ den Konzertagenten seine gewerbsmäßige Vermittlung bis auf weiteres fortführen. Die Ausdehnung des Verbotes gewerbsmäßiger Stellenvermittlung auf Künstlerberufe führte jedoch dazu, dass die Mehrzahl der führenden deutschen Künstleragenten sich im Ausland niederließ. In der Besprechung beim Polizeipräsidium vom 24. April 1931 äußerte Erich Simon, dass auch die Konzertdirektion Hermann Wolff und Jules Sachs tatsächlich erwäge, im Hinblick auf die steigenden Schwierigkeiten um den Konzertagentenbetrieb ganz nach New York zu übersiedeln. Vgl. Vermerk der Abteilung II des Polizeipräsidiums vom April 1931, LAB, A Pr. Br. Rep 030-05, Nr. 3671, Bl. 11v. Der Wunsch nach einer einheitlichen Regelung der Arbeitsvermittlung wurde schließlich im Musikbereich von der Reichsmusikkammer erfüllt, die eine zentrale Stellenvermittlung hatte und für Einheitsverträge für Musiker sorgte. 
Gesangs- oder andere Vorträge dargeboten werden, bei denen ein höheres Interesse der Kunst oder Wissenschaft obwaltet.

Diese Vorschriften legten das Objekt des Geschäftsbetriebs eines Konzertagenten auf »Instrumentalkonzerte, Vokalkonzerte, Gesangs- oder andere Vorträge« fest und forderten, dass diese Konzerte oder Vorträge sich durch »ein höheres Interesse der Kunst oder Wissenschaft« auszeichnen sollten. $§ 13$ der Vorschriften untersagte den Konzertagenten, in den Geschäftsbereich von Theateragenten einzugreifen, erlaubte jedoch, eigene Konzerte als Unternehmer zu veranstalten:

13. Den Konzertagenten ist untersagt, die in Ziff. 1 der Vorschriften über den Geschäftsbetrieb der gewerbsmäßigen Stellenvermittler für Bühnenangehörige bezeichneten Unternehmungen zu betreiben, sich an solchen Unternehmungen geschäftlich zu beteiligen, den Unternehmern Darlehen zu gewähren oder mit ihnen in irgend einer anderen Art in vertragliche Verbindung zu treten, welche die unparteiische und ordnungsmäßige Ausübung ihrer Berufspflichten als Konzertagenten in Frage stellt.

Die Konzertagenten sind jedoch befugt, Instrumental- und Vokalkonzerte sowie deklamatorische oder andere Vorträge, bei denen ein höheres Interesse der Kunst und Wissenschaft obwaltet, als Unternehmer zu veranstalten. [...]

\section{$\S 14$ der gleichen Vorschriften genehmigte den Konzertagenten ferner die}

Geschäftsbesorgung für die Veranstaltungen und setzte die Bedingungen dafür fest, einschließlich des höchsten Satzes der Arrangementsgebühr.

Bei dieser Rechtslage gab es drei Bereiche, die der Konzertdirektion Hermann Wolff (und Jules Sachs) nur mit Einschränkungen zugestanden wurden oder über deren Legitimität diskutiert wurde: die Alleinvertretung der Künstler, Vermittlungstätigkeit für die Oper und Veröffentlichung des Künstleralmanachs.

\section{Alleinvertretung der Künstler}

Der Alleinvertretungsvertag war nach $§ 4$ des Stellenvermittlergesetztes vom 2. Juni 1910 nichtig ${ }^{280}$ und nach $\S 15$ der Vorschriften über den Geschäftsbetrieb der Konzertagenten vom

\footnotetext{
$280 » \S 4$. Verträge, durch die sich ein Arbeitsnehmer oder Arbeitsgeber verpflichtet oder verpflichtet hat, sich auch in späteren Fällen der Mitwirkung eines bestimmten gewerbsmäßigen Stellenvermittlers zu bedienen, sind nichtig.«
} 
9. März 1914 verboten. Der zweite Absatz des $§ 15$ der gleichen Vorschriften ließ jedoch zu, dass die Konzertagenten unter jeweiliger Genehmigung der Ortspolizeibehörde ausnahmsweise mit Künstlern einen Vertrag als Alleinvertreter abschließen durften.

15. Auch abgesehen von den Fällen des $§ 4$ des Stellenvermittlergesetztes ist es den Konzertagenten untersagt, mit konzertierenden Künstlern, Vortragenden oder solchen Personen, für welche sie eine Vermittlungstätigkeit ausnahmsweise ausüben dürfen (Ziff. 10 Abs. 2), als Impresarien oder Alleinvertreter Verträge einzugehen, durch welche die Verwertung der Tätigkeit der genannten Personen oder eine Geschäftsbesorgung für diese nicht nur für einzelne bestimmte Veranstaltungen übernommen wird.

Die Ortspolizeibehörde kann den Abschluss von Verträgen, welche hiernach verboten sind, ausnahmsweise mit einzelnen Personen auf einen Zeitraum bis längstens 3 Jahre gestatten.

Es scheint, als habe die Konzertdirektion Hermann Wolff und Jules Sachs erst ab 1928 begonnen, bei derartigen Verträgen um polizeiliche Genehmigung rechtmäßig nachzusuchen. Auf Anregung des Verbandes der konzertierenden Künstler Deutschlands schickte der Berliner Polizeipräsident im Januar 1928 eine Anfrage zum Vertrag mit Gregor Piatigorsky an die Konzertdirektion, ${ }^{281}$ worauf Erich Sachs schriftlich erwiderte, mit dem Cellisten sei kein Agenturvertrag abgeschlossen, sondern ein Unternehmervertrag, der durch keine gesetzlichen Bestimmungen eingeengt ist. ${ }^{282}$

Den bei der Polizeibehörde nachträglich eingereichten Abmachungen zufolge garantierte die Konzertdirektion Piatigorsky für den Zeitraum vom 1. Mai 1927 bis 30. April 1928 ein Minimum von zehn Konzerten innerhalb Deutschlands auf Basis von 500 Mark Honorar netto. Bei einem Bruttohonorar von 600 Mark gehörten 500 Mark dem Cellisten und 100 der Konzertdirektion. Derjenige Ertrag, der durch diese zehn Konzerte über 6.000 Mark einging, wurde zwischen dem Cellisten und der Konzertdirektion im Verhältnis von 7 zu 3 geteilt. Auch ab dem 11. Engagement bekam der Cellist 500 Mark, die Konzertdirektion 100 Mark, und was darüber hinaus einging, wurde im Verhältnis von 7 zu 3 zwischen den beiden geteilt. Gingen beispielsweise insgesamt 7.000 Mark durch die zehn Konzerte ein, bekam der Künstler seine 5.000 Mark zuzüglich 700 Mark, die Konzertdirektion 1.000 Mark

\footnotetext{
${ }^{281}$ Schreiben vom Polizeipräsidenten in Berlin an die Konzertdirektion Hermann Wolff und Jules Sachs vom 30.1.1928, LAB, A Pr. Br. Rep. 030-05, Nr. 3670, B1. 146.

${ }^{282}$ Schreiben von Erich Sachs an das Polizeipräsidium Abteilung II, Ebd., Bl. 147.
} 
zuzüglich 300 Mark. Die Konzertdirektion war auch berechtigt, Konzerte zu kleineren Honoraren zu veranstalten, die dann als Engagements mit 10 \% Provision vereinbart wurden. Solche provisionspflichtigen Engagements wurden nicht unter die Minimumgarantie von zehn Konzerten gerechnet. Es wurde ferner abgemacht:

Sie [Piatigorsky, A. d. V] haben die Verpflichtung übernommen, uns sämtliche an Sie gelangenden beruflichen Anfragen unerledigt zur Erledigung zu übergeben, und Sie dürfen keinerlei Konzertverpflichtungen annehmen, ohne uns davon vorher unterrichtet zu haben. Wir dagegen sind ebenfalls verpflichtet, Sie von jedem Abschluss vorher in Kenntnis zu setzen. Sie räumen uns die Opion [sic!] ein, mit Ihnen für die Saison 1928/29 neue vertragliche Vereinbarungen zu treffen und verpflichten sich, mit keiner anderen Stelle vertragliche Vereinbarungen zu treffen, ohne uns vorher rechtzeitig davon in Kenntnis gesetzt zu haben. ${ }^{283}$

Sachs sah solche Alleinvertrerungsverträge nicht als Agenturverträge an, sondern als Impresariatsverträge, wobei er beziehungsweise seine Firma nicht als Konzertagent, sondern als Unternehmer fungieren solle. Auf diesem Verständnis beruhend behauptete er, dass das Stellungvermittlergesetz auf diesen Vertrag keine Anwendung finde. ${ }^{284}$ Es ist fraglich, ob er im Jahr 1928 wirklich keine Kenntnis vom Verbot des Impresariatsvertrags durch die Vorschriften über den Geschäftsbetrieb der Konzertagenten aus dem Jahr 1914 gehabt hatte. Auf jeden Fall genehmigte der Berliner Polizeipräsident diesen Vertrag nachträglich, wies ihn aber darauf hin, dass derartige Verträge seiner Genehmigung bedürften, weil sie »keineswegs reine Unternehmerverträge sind, sondern Verträge durch welche die Konzertagentur als Impresario, oder Alleinvertreter die Verwertung der Tätigkeit von Künstlern oder eine Geschäftsbesorgung für diese nicht nur für einzelne bestimmten Veranstaltungen übernimmt« und ersuchte darum, ihm alle Verträge, die unter $\S 15$ der Vorschriften fielen, umgehend zur Genehmigung vorzulegen. ${ }^{285} \mathrm{Zu}$ den Künstlern, die in dieser Zeit auf diese Weise unter der Genehmigung des Polizeipräsidiums mit der Konzertdirektion Hermann Wolff und Jules Sachs ausnahmsweise einen Alleinvertretungsvertrag abschlossen, gehören Poldi Mildner,

\footnotetext{
${ }^{283}$ Abmachungen mit Piatigorsky für den Winter 1927/28 abgeschlossen am 27.12.1926, Ebd., B1. 153. $284 »$ Beschwerde gegen die Konzertdirektion Wolff \& Sachs« von Rudolf Cahn-Speyer vom 25.1.1928, Ebd., B1. 142v.

${ }^{285}$ Schreiben vom Berliner Polizeipräsidenten an die Konzertdirektion Hermann Wolff und Jules Sachs vom 24.2.1928, Ebd., B1. 154.
} 
Lubka Kolessa, Nathan Milstein und Dusolina Giannini (die Opernengagements ausgenommen). ${ }^{286}$

\section{Vermittlungstätigkeit für die Oper}

Für die gewerbsmäßige Vermittlung von Theaterpartien, die eigentlich die genannten Vorschriften den Konzertagenten untersagten, konnte ausnahmsweise auf entsprechenden Antrag eine Sondergenehmigung von der Ortspolizeibehörde erteilt werden. Zum Beispiel wurde Jacques Urlus im Jahr 1926 durch die Konzertdirektion Hermann Wolff und Jules Sachs unter dieser Sonderkonzession an der Berliner Staatsoper für drei Monate engagiert. Das zehnmalige Gastspiel Maria Müllers an der Berliner Städtischen Oper im gleichen Jahr wurde ebenfalls unter der Genehmigung des dortigen Polizeipräsidiums von der Konzertdirektion vermittelt. ${ }^{287} \mathrm{Ihr}$ wachsender Einfluss auf den Opernbereich wurde in den 1920er-Jahren mehrmals zum Zielscheibe der Beschwerde von Berliner Theateragenten. ${ }^{288}$

Wie im Abschnitt 2.1.4 dargelegt, war Erich Simon ab 1924 »unabhängig von seiner Eigenschaft als Mitinhaber der Konzertdirektion $\aleph^{289}$ an der Metropolitan Opera angestellt. Diese Berliner und New Yorker Institutionen waren jedoch durch Erich Simon eng verbunden. ${ }^{290}$ Gelegentlich nannte sich die Konzertdirektion selbst Vertreter oder Repräsentant der Metropolitan Opera ${ }^{291}$ und auch die Oper autorisierte diese Konzertdirektion als ihren Vertreter für Europa. ${ }^{292}$

\footnotetext{
${ }^{286}$ Schreiben vom Berliner Polizeipräsidenten an die Konzertdirektion Hermann Wolff und Jules Sachs vom 13.8.1931, LAB, A Pr. Br. Rep. 030-05, Nr. 3671, Bl. 35. Vgl. auch die einzelnen Verträge: Ebd., B1. 20-26.

${ }^{287}$ LAB, A Pr. Br. Rep 030-05, Nr. 3670, B1. 106 und 108.

${ }^{288}$ LAB, A Pr. Br. Rep 030-05, Nr. 3670, passim, vgl. z. B. B1. 103, 112 und 120.

${ }^{289}$ Dies wurde sowohl in seiner biographischen Darstellung von seiner Frau (vgl. Abschnitt 2.1.4 der vorliegenden Arbeit) wie in seiner Besprechung mit dem Regierungsrat Dr. Behl und der Polizeirätin Dr. Mosse vom 24. April 1931 betont. Für diese Tätigkeit wurde Simon direkt von der Oper honoriert. Vgl. Vermerk der Abteilung II des Berliner Polizeipräsidiums, o. D. [April 1931], LAB, Nr. 3671, Bl. 10 r; Schreiben von Gatti-Casazza an Erich Simon vom 30.9.1930, Ebd., Bl. 29.

${ }^{290} \mathrm{Im}$ Archiv der Metropolitan Opera in New York werden zahlreiche Telegramme und Briefe von Erich Simon und von einigen der Mitarbeiter der Konzertdirektion an Edward Ziegler von der Oper aufbewahrt. Die meisten Korrespondenzen sind auf dem Briefpapier der Konzertdirektion Hermann Wolff und Jules Sachs maschinengeschrieben. Im Durchschnitt kam es mindestens einmal in der Woche oder alle zehn Tage zu einem ausführlichen Brief. Im Folgenden sind die im Archiv dieser Oper aufbewahrten Materialien mit »AMO« kennzeichnet. Sie sind mit keinen Signaturen versehen.

${ }^{291}$ LAB, A Pr. Br. Rep 030-05, Nr. 3670, B1. 130 und 158.

${ }^{292}$ Es ist sehr wahrscheinlich, dass diese zwei Institutionen schon Ende des 19. Jahrhunderts geschäftlich verbunden waren, weil, wie im Abschnitt 2.3.1 ausgeführt, Hermann Wolff sich in den 1890er Jahren als auswärtiger Vertreter für die Abbey, Schoeffel \& Grau in New York bezeichnete, die als Intendant der Metropolitan Opera fungierte. Aber diese Verbindung wurde durch die Untersuchung im Archiv der Metropolitan Opera nicht belegt.
} 
Die Aufgaben, die Erich Simon für die Metropolitan Opera erfüllte, können in folgende vier Bereiche eingeordnet werden. Die erste Aufgabe war die Erteilung von Informationen über europäische Musiker und Werke, deren Engagement oder Aufführung in New York in Frage kam oder kommen könnte. ${ }^{293}$ Wenn die Metropolitan Opera an Sängern Interesse zeigte, wurden die ausgewählten Sänger zum Vorsingen vor Giulio Gatti-Casazza oder Artur Bodanzky in Europa eingeladen, was wiederum Simon organisierte. ${ }^{294}$ Aus den Korrespondenzen geht aber auch hervor, dass er respektive seine Konzertdirektion auf die Besetzung der städtischen Oper in Berlin mindestens so viel Einfluss nehmen konnte, dass die Gäste aus New York die Kandidaten tatsächlich in einer Aufführung hören konnten. ${ }^{295}$

Die zweite Aufgabe war die vertragliche Vermittlung zwischen der Oper und den Künstlern, was eigentlich nach den oben genannten Vorschriften nicht gestattet war und durch Sondererlaubnis der Berliner Polizeibehörde im Einzelfall stattfand. ${ }^{296}$ Im Vergleich mit der großen Menge der erteilten Auskünfte über Musiker waren die abgeschlossenen Verträge nicht sehr zahlreich. Zu den durch seine Vermittlung in dieser Zeit engagierten Musikern gehörten jedoch die wichtigsten Wagner-Sänger, wie Grete Stückgold, Lauritz Melchior, Richard Mayr, Gustav Schützendorf, der Dirigent Joseph Rosenstock (Abbildung 18), der Korrepetitor Erich Riede sowie der Regisseur Ernst Lert. ${ }^{297}$

Seine dritte Aufgabe war die Besorgung der verschiedenen Materialien. Aus den Briefen im Archiv der Metropolitan Opera ergibt sich, dass Erich Simon an das Theater in New York verschiedene Noten schickte. Besonders interessant ist, dass er nach Anforderung der Oper manchmal bearbeitete Noten besorgte. Zu den übersandten Noten gehören Wagners Walküre, Siegfried, Götterdämmerung, Lohengrin, Tannhäuser und Tristan und Isolde, jeweils mit Strichen von Leo Blech, ${ }^{298}$ und Verdis Luisa Miller mit Strichen von Fritz Zweig. ${ }^{299}$ Leider sind diese Noten heute in der Oper nicht mehr erhalten. Diese Tatsache deutet aber an,

\footnotetext{
${ }^{293}$ Briefe von Erich Simon an Edward Ziegler, AMO, passim.

${ }^{294}$ Briefe von Erich Simon an Edward Ziegler vom 24.1.1926, 31.3.1926, 5.7.1930 und vom 20.6.1931, 18.9.1931; Brief von Erich Simon an Artur Bodanzky vom 11.7.1927, AMO.

${ }^{295}$ Briefe von Erich Simon an Edward Ziegler vom 24.1.1926, 31.3.1926, 4.7.1928 und vom 29.8.1928, AMO.

${ }^{296}$ LAB, A Pr. Br. Rep 030-05, Nr. 3670, Bl. 122.

${ }^{297}$ Bei der Engagementsvermittlung nahm Erich Simon, respektive seine Konzertdirektion, 5 \% Provision vom gesamten Einkommen, das der Künstler von der Oper bekam. Im Vergleich zur Vermittlungsgebühr, die die Konzertdirektionen in Berlin erhielten oder andere Agenturen hier verlangten, ist diese Rate auffallend niedrig.

${ }^{298}$ Briefe von Erich Simon an Edward Ziegler vom 25.1.1929 und 15.2.1929, AMO.

${ }^{299}$ Briefe von Erich Simon an Edward Ziegler vom 25.1.1929, 29.1.1929 und 15.2.1929, AMO.
} 
dass Erich Simon das Interesse der Metropolitan Opera an der aktuellen Aufführungspraxis in Deutschland, vor allem derjenigen der Berliner Staatsoper, zufrieden stellte. ${ }^{300}$

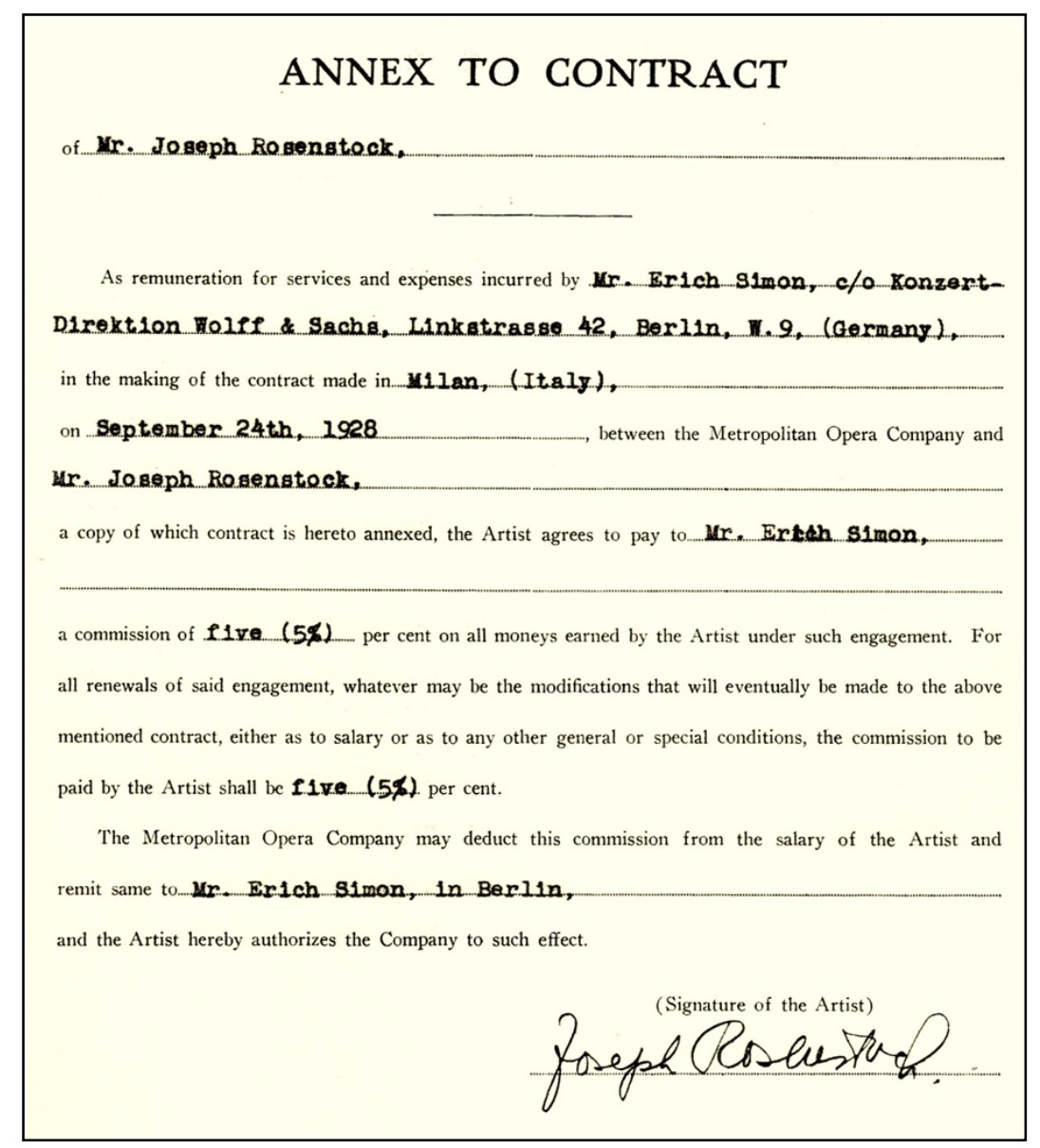

Abbildung 18: Beilage zum Vertrag für Joseph Rosenstock vom 24.9.1928 (AMO)

Als seine vierte Aufgabe wirkte Simon auch als Korrespondent der Metropolitan Opera in Europa. Ständig schickte er Presseartikel nach New York, die für die Oper von Interesse sein könnten, und teilte an der Metropolitan Opera mit, wie die deutsche Presse über

\footnotetext{
${ }^{300}$ Tatsächlich wurde Luisa Miller, deren Noten Erich Simon für die Metropolitan Opera im Januar 1929 besorgt hatte, im Dezember des gleichen Jahres zum ersten Mal in diesem Haus aufgeführt. Und Nikolaj Andreevič Rimskij-Korsakovs Oper Sadko, deren Partitur und Klavierauszug mit französischem Text in einem Telegramm vom 13. März 1929 angefordert wurden, wurde im Januar des nächsten Jahres zum ersten Mal in Amerika in der Metropolitan Opera auf Französisch aufgeführt. Allerdings gibt es keinen Beweis dafür, dass die von ihm gebrachten Noten dabei benutzt wurden, aber es liegt nahe, dass sie bei der Vorbereitung der Aufführung irgendeine Rolle spielten. Es ist auch nachgewiesen, dass Erich Simon im Jahr 1925 eine Beckmesser-Harfe für die amerikanische Oper besorgt hat. Laut dem Musikbibliothekar der Oper, Robert Sutherland, besitzt das Theater diese Harfe noch, und sie wurde für die Aufführungen von Die Meistersinger von Nürnberg Wagners im Dezember 2014 wieder aus dem Lager geholt. E-Mail-Antwort von Robert Sutherland an die Verfasserin vom 30.10.2014.
} 
sie und ihre Künstler berichtete. Wenn etwas Falsches oder Ungünstiges berichtet wurde, erhielt er vom Direktorium der Oper den Auftrag, geeignete Maßnahmen zu ergreifen. ${ }^{301}$

Wie bisher deutlich wurde, war die Engagementsvermittlung nur ein nebensächlicher Teil der Aufgaben, die Erich Simon für die Metropolitan Opera erfüllte. Angesichts der engen Verbindung der beiden Institutionen gingen aber aus Verdacht auf die Verletzung der Vorschrift mehrere Beschwerden im Polizeipräsidium ein. Als Erklärung dazu drückte Erich Sachs in seinem Brief an den Regierungsrat Adriani vom 23. Juli 1926 die Partnerschaft seiner Konzertdirektion zur Metropolitan Opera als »Gesamtvertretung« wie folgt aus:

Bei unseren Beziehungen zu der Metropolitan Opera in New York handelt es sich ja auch nicht darum, dass wir hin und wieder einzelne Gastspiele unserer Künstler dorthin vermitteln, sondern um die Gesamtvertretung der Oper, die sich auch auf die Beschaffung von Requisiten Notenmaterial etc. etc. erstreckt. ${ }^{302}$

Im Zusammenhang mit seiner umfangreichen Tätigkeit für die Metropolitan Opera wies Simon auf ein wesentliches Problem der Bestimmungen über den Geschäftsbetrieb der Konzertagenten hin. Es ging um die Rechtslage, nach der die Opern- und Konzertvermittlung nicht von derselben Person betrieben werden dürfen. Simon äußerte die Ansicht, dass dies Hindernisse für die Tätigkeit der Künstler bringe:

Die Grenze zwischen Opern- und Konzertvermittlung lässt sich überhaupt nicht streng ziehen. Die meisten Sänger und Sängerinnen sind irgendwie mit der Oper verknüpft. Wenn wir die Vertretung eines Künstlers übernommen haben, so ergibt es sich wohl von selbst, dass wir seine gesamten Interessen wahren. Hierdurch ist es natürlich oft nötig, dass auch Verhandlungen wegen Opernengagements geführt werden. M.E. würde es eine grosse Hemmung für die künstlerische Tätigkeit der von uns Vertretenen bedeuten, wenn sie, nachdem wir sie in ihren Qualitäten kennen gelernt haben, mit Rücksicht auf ein Opernengagement sich an einen ihnen völlig fremden Agenten wenden müssen. ${ }^{303}$

\footnotetext{
${ }^{301}$ Briefe von Erich Simon an Edward Ziegler vom 24.1.1926, 19.11.1928, 26.11.1928; Brief von Giulio Gatti-Casazza an Erich Simon vom 13.11.1928, AMO.

${ }^{302}$ Schreiben von Erich Sachs an den Regierungsrat Adriani vom 23.7.1926, Nr. 3670, B1. 116.

${ }^{303}$ Schreiben von Erich Simon an den Berliner Polizeipräsidenten vom 11.9.1926, LAB, Nr. 3670, B1. 118v.
} 
In der Tat spezialisierte sich Erich Simon später auf den Bereich der Oper: 1931 schied er aus der Konzertdirektion aus und trat in den Paritätischen-Stellennachweis der deutschen Bühnen ein, wo er die Opernabteilung übernahm. Seine geschäftliche Verbindung zum Opernhaus in New York wurde auch während und nach seiner Emigration nach Amerika über Paris aufrechterhalten. ${ }^{304}$

\section{Veröffentlichung des Künstleralmanachs}

Gemeinsam mit der Westdeutschen Konzertdirektion in Köln veröffentlichte die Konzertdirektion Hermann Wolff und Jules Sachs einen Künstleralmanach ${ }^{305}$ für die Saison 1931/32 im Namen der Arbeitsgemeinschaft beider Konzertdirektionen. Die von ihnen vertretenen Musiker konnten dort für 120 Mark ein zweiseitiges Inserat mit Kritikauszügen, Bildern und ähnlichem schalten. ${ }^{306}$ Nach $§ 16$ e der Vorschriften über den Geschäftsbetrieb der Konzertagenten vom 9. März 1914 war es den Konzertagenten untersagt, »Druckschriften herauszugeben oder zu verlegen oder sich an der Herausgabe oder dem Verlage von Druckschriften zu beteiligen, wenn darin entgeltliche Ankündigungen oder Besprechungen Aufnahme finden, die ein von den Konzertagenten betriebenes Unternehmen, die Tätigkeit des Konzertagenten oder eines konzertierenden Künstlers oder einer Person, welche deklamatorische oder andere Verträge darbietet, zum Gegenstande haben«.

Im Auftrag des Verbandes der konzertierenden Künstler Deutschlands unterbreitete der Justizrat Dr. Marwitz der Reichsanstalt für Arbeitsvermittlung und Arbeitslosenversicherung, dass dieses Unternehmen gegen die oben genannten Vorschriften verstoße. ${ }^{307}$ In seinem ausführlichen Schreiben vom 30. Juli 1931 erklärte Heinrich Dubois von der Westdeutschen Konzertdirektion, dass es sich hier um nichts anderes als um die Zusammenfassung der Werbeprospekte handele, die die Konzertagenturen üblicherweise für einzelne Künstler erstellten, um die Konzert- und Orchestervereine auf die Erfolge des Künstlers aufmerksam zu machen, sein Repertoire vorzustellen und die Konzertunternehmer über die Termine zu unterrichten, die dem Künstler zur Ausübung seiner Tätigkeit in den

\footnotetext{
${ }^{304}$ Zur Geschäftstätigkeit Erich Simons nach seinem Austritt aus der Konzertdirektion, vgl. Abschnitt 2.1.4 der vorliegenden Arbeit.

${ }^{305}$ Künstler-Almanach 5 (1931/1932), hg. von der Arbeitsgemeinschaft Konzertdirektion Hermann Wolff und Jules Sachs, Berlin, Westdeutsche Konzertdirektion (Dubois und Dr. Schiff), Köln. Der Jahrgang zählt hier fünf, weil die Westdeutsche Konzertdirektion ihren Almanach seit fünf Jahren herausgegeben hatte.

${ }^{306}$ Angebot für die Aufgabe von Annoncen von der Arbeitsgemeinschaft der Westdeutsche Konzertdirektion und Konzertdirektionen Wolff und Sachs vom 29.1.1931 LAB. A Pr. Br. Rep. 030-05, Nr. 3671, B1. 49.

${ }^{307}$ Schreiben vom Justizrat Dr. Marwitz an die Reichsanstalt für Arbeitsvermittlung und Arbeitslosenversicherung vom 27.3.1931. Ebd., Bl. 51.
} 
einzelnen Ländern zur Verfügung standen. Die Zusammenstellung zu einem Heft sei geschehen, um den Künstlern die Kosten dieser Werbung zu verbilligen. Der Almanach werde weder verkauft noch öffentlich vertrieben, sondern lediglich kostenlos etwa 500 Dirigenten, Konzertvorständen und -unternehmern in Europa zugestellt. ${ }^{308}$

Während der Kölner Regierungspräsident »zulässige Mittel gegen die Herausgabe des Künstler-Almanachs« finden wollte, ${ }^{309}$ erklärte der Berliner Polizeipräsident die »Herausgabe durch die Konzertdirektion Wolff \& Sachs und die Westdeutsche Konzertdirektion für rechtlich zulässig«. ${ }^{310}$ Als das Verfahren dieser Angelegenheit noch im selben Jahr wiederaufgenommen wurde, schloss sich die Konzertdirektion Hermann Wolff und Jules Sachs dem Standpunkt von Dubois an. Vor allem interessant ist ihre Auffassung, dass ihre Idee die Propagandatätigkeit der ausländischen Konzertdirektionen beeinflusste.

Ein Beweis, dass die Herausgabe eines solchen Werks notwendig war, ist dadurch gegeben, dass 2 grosse ausländische Konzertdirektionen, die ja überhaupt unserem Gesetz nicht unterliegen, nicht nur unsere Idee nachgeahmt haben, sondern teilweise sich auch sklavisch an die Firm [sic!] unseres Almanachs gehalten haben. Die Ausländer versenden diese Bücher ebenfalls in Deutschland, unsere deutschen Künstler wären so geschädigt, wenn nur von Ausland aus die Ausländer in Deutschland propagiert würden und nicht im gleichen Mass die deutschen Künstler. Wir betonen ausdrücklich, dass der holländische und amerikanische Almanach Nachahmungen des unseren sind, nicht etwa umgekehrt. ${ }^{311}$

Die Herausgabe des Almanachs scheint als legal anerkannt worden zu sein. Für die Saison 1932/33 wurde noch ein Almanach in der gleichen Form im Namen der Arbeitsgemeinschaft veröffentlicht, ${ }^{312}$ bevor sich die Arbeitsgemeinschaft im selben Jahr auflöste.

\footnotetext{
${ }^{308}$ Schreiben von Heinrich Dubois an das Kölner Amtsgericht vom 30.7.1931. Ebd., Bl. 62f, hier B1. 62v$63 r$.

${ }^{309}$ Schreiben vom Registerpräsident in Köln an den preußischen Minister für Handel und Gewerbe in Berlin vom 3.8.1931. Ebd., B1. 64v.

${ }^{310}$ Schreiben vom Berliner Polizeipräsidenten an den Oberstaatsanwalt bei Amtsgericht vom 13.8.1931, Ebd., B1. 66v.

${ }^{311}$ Schreiben von der Konzertdirektion Hermann Wolff und Jules Sachs an die Polizeirätin Dr. Mosse vom 1.12.1931. Ebd., B1. 82.

${ }^{312}$ Künstler-Almanach 6 (1932/1933), hg. von der Arbeitsgemeinschaft Konzertdirektion Hermann Wolff und Jules Sachs, Berlin, Westdeutsche Konzertdirektion (Dubois und Dr. Schiff), Köln.
} 


\section{Hermann Wolff als Impulsgeber des Berliner Musiklebens}

\subsection{Hermann Wolff und Aufführungen von zeitgenössischer Musik}

In welchem Sinne kann Hermann Wolff als Impulsgeber des damaligen Berliner Musiklebens angesehen werden? Auf verschiedene Weise arbeitete er mit zeitgenössischen Komponisten zusammen, und tatsächlich gab er den Anstoß zur Aufführung einiger ihrer Werke. Es ist möglich, dass er die Rezeption einiger Komponisten in Berlin beeinflusste - positiv wie negativ. Vielleicht konnte er durch seine Konzertveranstaltungen sogar ein Modell dafür vorlegen, wie man künftig ein Werk zu hören hatte: in welchem Programm, an welcher Stelle im Programm, in welcher Atmosphäre, durch wen interpretiert. Denkbar ist auch, dass einige Komponisten versuchten, seinen Geschmack zu treffen, oder sich mit eigenen Kompositionen bei ihm beliebt zu machen, um bevorzugt oder in günstigen Bedingungen aufführen zu können. Hier wird exemplarisch aufgezeigt, wie Hermann Wolff sich mit neuen Kompositionen und zeitgenössischen Komponisten auseinandersetzte.

\subsubsection{Die Abonnementkonzerte des Berliner Philharmonischen Orchesters als Forum für Neukompositionen}

\section{Die Aufführungen von musikalischen Neuheiten unter der Ägide Hermann Wolffs}

Die Einrichtung der Abonnementkonzerte des Berliner Philharmonischen Orchesters ist wohl die bekannteste Leistung Hermann Wolffs. ${ }^{313}$ Er betrachtete sich selbst als »der intellectuelle Urheber $\aleph^{314}$ dieser Konzerte, und in den Worten seiner Frau Louise waren sie die »ureigenste Schöpfung meines Mannes «. ${ }^{315}$ Eine der grundsätzlichen Ideen dieser Einrichtung war sicherlich die Aufführung von Neukompositionen. Dies bestätigt zum Beispiel Siegfried

\footnotetext{
${ }^{313}$ In der heutigen Berliner Philharmonie gibt es einen kleinen Saal, der zum Gedenken an seine Tätigkeit für das Orchester »Hermann-Wolff-Saal« genannt wird. Der Saal heißt so erst seit 2005. Davor war er schlicht »Chorprobensaal« benannt. E-Mail-Antwort von Frau Katja Vobiller, der Archivarin der Berliner Philharmoniker, vom 17.6.2015.

${ }^{314}$ Brief von Hermann Wolff an Hugo Bock vom 22.3.1884, Berlin SBPK, Mus. ep. H. Wolff 988.

${ }^{315}$ Louise Wolff: Arthur Nikisch und Berlin aus meinen Erinnerungen, S. 163.
} 
Ochs, der als Gründer und Leiter des Philharmonischen Chors lang mit Wolff zusammenarbeitete:

Man sollte jedoch nicht vergessen, selbst wenn dieser oder jener Vorwurf berechtigt wäre, den man Hermann Wolff in seiner Geschäftsführung gemacht hat, dass wir seinem genialen Eingreifen in jenem kritischen Augenblick unser ganzes heutiges Berlin als Musikstadt zu danken haben. Schon lange, eigentlich seit Jahreszehnten, war die Klage darüber allgemein gewesen, dass in den Konzerten des königlichen Orchesters neue Werke fast gar nicht oder dass doch nur solche aufgeführt wurden, die der alten Richtung angehörten, und die klassischen Tondichtungen dort eine mehr als fragwürdige Wiedergabe erfuhren. Jedermann sprach darüber, jedermann beklagte diese Zustände, aber Hermann Wolff war der einzige, der den Augenblick erkannte, in dem eine Änderung herbeigeführt werden konnte. ${ }^{316}$

Aus verschiedenen Korrespondenzen Wolffs mit zeitgenössischen Komponisten geht hervor, dass er Wert auf die Aufführung ihrer Werke in diesen Konzerten legte. ${ }^{317}$ Wenn auch die Dirigenten das letzte Wort zum Programm hatten, ${ }^{318}$ war er $»$ immer die directe Veranlassung, daß die Novitäten gemacht werden «, ${ }^{319}$ wie er selbst an Richard Strauss schrieb. Die Geschichte des Orchesters, auch in seiner Gründungszeit, wurde vielenorts dargestellt ${ }^{320}$ und muss hier nicht wiederholt werden. Im Folgenden wird stattdessen betrachtet, wie es sich in seinen Abonnementkonzerten unter der Ägide von Hermann Wolff mit Neukompositionen auseinandersetzte.

Das Berliner Philharmonische Orchester wurde, wie bekannt, von den aus der Kapelle von Benjamin Bilse ausgetretenen Musikern im Frühling 1882 gegründet. Seit den 1840er-

\footnotetext{
316 Siegfried Ochs, Geschehenes, Gesehenes, Leipzig u. a. 1922, S. 132.

${ }^{317}$ Vgl. z. B. den Brief von Hermann Wolff an Engelbert Humperdinck vom 3.2.1899, Universitätsbibliothek Johann Christian Senckenberg, 5714, 9203. Vgl. auch »Hermann Wolff und die sinfonischen Dichtungen von Richard Strauss« in diesem Abschnitt.

${ }^{318} \mathrm{Vgl}$. Abschnitt 3.2.3 der vorliegenden Arbeit.

${ }^{319}$ Brief von Hermann Wolff an Richard Strauss vom 27.11.1895, Richard-Strauss-Institut, GarmischPartenkirchen (im Folgenden RSI).

${ }^{320}$ Zur Mitwirkung von Hermann Wolff bei der Gründung dieses Orchesters und in seiner Anfangsphase, vgl. u. a.: Wilhelm Altmann: Chronik des Berliner Philharmonischen Orchesters (1882-1901), Berlin 1902, S. 11-35; Siegfried Ochs: Geschehenes, Gesehenes, S. 132; Muck: Einhundert Jahre Berliner Philharmonisches Orchester, Bd. 1, S. 3-56; Variationen mit Orchester, Bd. 1: Orchestergeschichte, S. 3569; Volker Tarnow: Ein Mythos besteht. Die frühen Jahre der Berliner Philharmoniker, in Musik! Die Entstehung eines Weltorchesters. Die Berliner Philharmoniker im 19. Jahrhundert, hg von Barbara Wagner und Matthias Winzen, Oberhausen 2015, S. 33-46.
} 
Jahren hatte der Liegnitzer Kapellmeister Bilse fast 20 Jahre lang mit seiner Kapelle Konzertreisen in größere und kleinere Nachbarorte unternommen, um so eine wichtige zusätzliche Einnahme zur Liegnitzer Tätigkeit zu schaffen. Wie Rebecca Grotjahn bemerkt, leisteten die vielen reisenden Orchester der 1850er- bis 1870er-Jahre wichtige Arbeit sowohl für die Verbesserung musikalischer Bildung generell als auch für die Verbreitung der zeitgenössischen Sinfonik an der Peripherie des deutschen Kulturgebietes. ${ }^{321}$ Auch die BilseKapelle hatte durch ihre Konzerttournee die gehobene Musikkultur in solchen Städten verbreitet, wo sich Abonnementkonzerte des ernsthaften Typus noch nicht etabliert hatten. $\mathrm{Ab}$ 1867 ließ sich Bilse in Berlin nieder, wo er mit seiner Kapelle fast in jedem Winter Abonnementkonzerte im Schauspielhaus veranstaltete. ${ }^{322}$ Diese Konzerte bewahrten zwar noch den Sozialcharakter in ihrer Veranstaltungsform, galten aber hauptsächlich wegen des hohen Anteils zeitgenössischer Musik in ihrem Programm als ausgesprochen anspruchsvoll und bildeten dadurch einen Kontrast zu den konservativ ausgerichteten Sinfonie-Soireen der Königlichen Kapelle. ${ }^{323}$

Das von den »Abtrünnigen« dieser Bilse-Kapelle gegründete Orchester ${ }^{324}$ übergab Hermann Wolff die ausschließliche Vertretung. Der große Saal der Rollschuhbahn, den er im Januar des gleichen Jahres für die Gastspiele der Meininger Hofkapelle gemietet hatte, sollte ab Herbst unter dem Namen »Philharmonie« nur noch künstlerischen Zwecken dienen. Durch die Vermittlung von Wolff konnte dieses Orchester von seiner ersten Saison an in diesem Saal regelmäßig konzertieren. ${ }^{325}$ Wie Altmann bemerkte, erkannte Wolff richtig, wie vorteilhaft es auch für sein Geschäft war, ein tüchtiges Orchester als stehende Institution zur Verfügung zu haben. ${ }^{326}$ Und das Bedürfnis nach einem solchem Orchester im Berliner Musikleben hatte er schon als Musikkritiker geäußert. ${ }^{327}$ Durch die Vermittlung der Engagements, Organisierung der Tourneen und Einrichtung der Abonnementkonzerte erwarb er sich wesentliche Verdienste um das neu gegründete Orchester.

\footnotetext{
${ }^{321}$ Grotjahn: Die Sinfonie im deutschen Kulturgebiet 1850 bis 1875, S. 122.

${ }^{322}$ Zur Beurteilung Wolffs zur Konzerte von der Bilse-Kapelle in Berlin, vgl. Abschnitt 2.1.1 der vorliegenden Arbeit.

${ }^{323}$ Rebecca Grotjahn: Die Entdeckung der Terra incognita. Benjamin Bilse und sein reisendes Orchester, in Le musicien et ses voyages. Pratiques, réseaux et représentations, S. 253-281, vgl. vor allem: S. 276278.

${ }^{324}$ Zur Trennung der ca. 50 Musiker von der Bilse-Kapelle, vgl. u. a. Muck: Einhundert Jahre Berliner Philharmonisches Orchester, Bd. 1, S. 5; Variationen mit Orchester, Bd. 1, S. 31-34.

${ }^{325}$ Vgl. Altmann: Chronik des Berliner Philharmonischen Orchesters (1882-1901), S. $11 \mathrm{f}$.

${ }^{326} \mathrm{Ebd}$

${ }^{327}$ Vgl. Abschnitt 2.1.1 der vorliegenden Arbeit.
} 
In ihrer ersten Saison 1882/83 fanden sechs Philharmonische Konzerte in zwei Zyklen unter der Leitung von Franz Wüllner statt. ${ }^{328}$ Das Motto der Programmgestaltung war: »Jedes Concert wird eine Orchesternovität und die Mitwirkung eines hervorragenden Instrumentalsolisten bringen $\ll .{ }^{329}$ Die Programme der ersten Saison sind tatsächlich durch den hohen Anteil zeitgenössischer Werke gekennzeichnet.

\begin{tabular}{|c|c|}
\hline I. Zyklus & Programme \\
\hline $\begin{array}{l}23.10 .1882 \\
\text { Klavier: Sofie Menter }\end{array}$ & $\begin{array}{l}\text { Beethoven: Ouvertüre Leonore Nr. } 3 \\
\text { A. Rubinštejn: Klavierkonzert G-Dur } \\
\text { Wagner: Parsifal-Vorspiel } \\
\text { Liszt: Ungarische Fantasie für Klavier und Orchester } \\
\text { R. Schumann: Sinfonie Nr. } 2\end{array}$ \\
\hline $\begin{array}{l}\text { 13.11.1882 } \\
\text { Violine: Martin Marsick }\end{array}$ & $\begin{array}{l}\text { Wagner: Eine Faust-Ouvertüre } \\
\text { Čajkovskij: Suite op. } 43 \text { (zum ersten Mal) } \\
\text { Mendelssohn: Andante und Finale aus dem Violinkonzert } \\
\text { Ten Brink: Violinkonzert Nr. } 2 \text { (neu) } \\
\text { Beethoven: Sinfonie Nr. } 5\end{array}$ \\
\hline $\begin{array}{l}4.12 .1882 \\
\text { Violine: Pablo de Sarasate }\end{array}$ & $\begin{array}{l}\text { Beethoven: Ouvertüre zu Die Weihe des Hauses } \\
\text { Bruch: Violinkonzert Nr. } 1 \\
\text { Godard: Scènes poétiques für Orchester (Neuheit) } \\
\text { Raff: Suite für Violine u. Orchester } \\
\text { Brahms: Sinfonie Nr. } 2\end{array}$ \\
\hline II. Zyklus & Programme \\
\hline $\begin{array}{l}22.1 .1883 \\
\text { Klavier: Eugen d'Albert }\end{array}$ & $\begin{array}{l}\text { Mozart: Sinfonie g-Moll } \\
\text { Liszt: Klavierkonzert Es-Dur } \\
\text { Wagner: Karfreitagszauber aus Parsifal (Novität) } \\
\text { [R. Schumann: Arie aus der Sonate fis-Moll } \\
\text { Chopin: Barcarole Fis-Dur und Etüde a-Moll] } \\
\text { Saint-Saëns: Sinfonie Nr. } 2 \text { (Novität) }\end{array}$ \\
\hline $\begin{array}{l}\text { 5.2.1883 } \\
\text { Violine: August Wilhelmj }\end{array}$ & $\begin{array}{l}\text { Haydn: Sinfonie G-Dur } \\
\text { Bruch: Violinkonzert Nr. } 1 \\
\text { Grammann: Vorspiel zu Melusine (Novität) } \\
\text { Laub-Wilhelmj: Konzert-Polonaise für Violine und Orchester } \\
\text { Berlioz: } 3 \text { Sätze aus Romeo und Julia } \\
\text { Rüfer: Fest-Ouvertüre zur Antwerpener Rubensfeier }\end{array}$ \\
\hline $\begin{array}{l}26.2 .1883 \\
\text { Sopran: Lilli Lehmann } \\
\text { Klavier: Franz Rummel } \\
\text { Gesangsvereinigungen: } \\
\text { Eichberg-, Handwerg- } \\
\text { und Radecke'sche Verein }\end{array}$ & $\begin{array}{l}\text { Wagner }{ }^{331} \text { : Trauermarsch aus der Götterdämmerung } \\
\text { Beethoven: Sinfonie Nr. } 3 \\
\text { Schubert: Phantasie für Klavier (orchestr. von Fr. Liszt) } \\
\text { Wagner: Vorspiel und Liebestod aus Tristan und Isolde } \\
\text { Weber: Konzertstück für Klavier und Orchester } \\
\text { Wagner: Kaisermarsch für Orchester und Chor }\end{array}$ \\
\hline
\end{tabular}

${ }^{328} \mathrm{Zu}$ Wüllner und seine Berufung als Dirigent dieser Konzerte, vgl. Abschnitt 3.2.3 der vorliegenden Arbeit.

${ }^{329}$ Dresdner Zeitung vom 19.9.1882, abgedr in Muck: Einhundert Jahre Berliner Philharmonisches Orchester, Bd. 1, S. 12.

${ }^{330}$ Klaviersoli.

${ }^{331}$ Richard Wagner war kurz davor am 13.2.1883 gestorben.

${ }^{332}$ Quelle: Aufstellung der Konzertprogramme des Orchesters und der mit den verschiedensten Gesangsund anderen Vereinigungen aufgeführten Werke seit der Gründung des Orchesters im Jahre 1882, in Muck: 
Aus den folgenden Besprechungen geht hervor, dass diese Konzerte vor allem wegen der intensiven Beschäftigung mit den Neukompositionen als Impuls für das Berliner Musikleben angesehen wurden:

So trübe also die theatralisch-musikalischen Gewässer dahinfließen, so erfreulich ist das Leben in den Concertsälen: da hört man jetzt sogar Novitäten, wo sonst von solchen gar nicht die Rede war, und man kann in Wahrheit sagen: Es lebe die Concurrenz! Hauptsächlich verdanken wir das den Wüllner Concerten, wie die Aufführungen unseres Philharmonischen Orchesters unter dem Dresdner Hofcapellmeister Franz Wüllner kurzweg genannt werden. Da diese Concerte stets nur große Dinge bringen und hauptsächlich auf Neuigkeiten für Berlin fahnden, so müssen auch die Anderen einige Anstrengungen machen, wenn sie nicht ganz ins Hintertreffen kommen wollen. ${ }^{333}$

Zurückkehrend zu den Orchesterconcerten mögen zunächst das zweite und dritte Wüllner-Concert Platz finden. Diese Concerte haben sich für den Unternehmer, Agentur Herm. Wolff, zu einem durchaus lucrativen Unternehmen gestaltet; wenn die bisweilen recht gute italienische Oper, welche vor Zeiten in den Räumen der Philharmonie (damals Central-Skating-Rink) stattfand, nur den dritten Teil der Menschen anzuziehen vermocht hätte, die zu den Wüllner-Concerten den Weg nicht scheuen, dann hätten wir sie vielleicht heute noch. Die Italiener aber vermochten Berlin nicht zu locken, obwohl sie, wie gesagt, bisweilen ganz treffliche Leistungen in ihrer Art boten, und zu den Wüllner-Concerten drängen sich die Menschen förmlich, sodass es oft schwer hält, ein Billett zu bekommen. So war es mit dem zweiten der Fall, in welchem Rubinstein mitwirkte. Dessen Name freilich war der Hauptmagnet gewesen, denn er spielte nicht nur das Concert in Es dur von Beethoven, sondern dirigirte zum Schluss dramatische Symphonie. [...] Interessant werden diese Concerte aber nicht durch die mitwirkenden Solisten, deren die Direction immer nur die ersten

\footnotetext{
Einhundert Jahre Berliner Philharmonisches Orchester, Bd. 3, S. 3. Die Anmerkungen in Klammern sind ebenfalls von dieser Quelle übernommen, die sich ihrerseits »an die Angaben der Programme oder Zeitungsmeldungen« hielt. Ebd., S. V. Auch die folgenden Betrachtungen zu den in diesen Abonnementkonzerten aufgeführten Werke in der vorliegenden Arbeit berufen sich auf die Aufstellung bei Muck.

${ }^{333}$ N.N.: Tagesgeschichte. Musikbrief. Berlin, in Musikalisches Wochenblatt 14 (1883), S. 580, Hervorhebung im Original.
} 
Namen heran zu ziehen sucht, sondern auch durch die Novitäten, die Prof. Wüllner regelmässig seinen Programmen einverleibt. ${ }^{334}$

Wie bei den entsprechenden Institutionen in Leipzig, Wien und Brüssel entwickelte sich in dieser Zeit in Berlin ein Kooperationsplan zwischen der Musikhochschule und dem neuen Orchester. Der als dessen Folge zwischen Joseph Joachim und den Orchestermitgliedern am 31. Januar 1883 abgeschlossene Vertrag verpflichtete die Musiker, sich Joachim für die Honorare von 42.000 Mark vom Oktober 1883 bis April 1884 wöchentlich an drei Abenden zur Verfügung zu stellen. Ohne Joachims Zustimmung durfte das Orchester kein Engagement abschließen, sei es mit neuen Mitgliedern, sei es mit Dirigenten. Freiwerdende Stellen des Orchesters wurden naturgemäß aus Hochschülern ergänzt. Während dieser Vertrag den Bestand des Orchesters für eine bestimmte Zeit sicherte, rief er auch den Vorwurf hervor, dass Joachim das Orchester in Beschlag nahm und monopolisierte, was für die künstlerische Richtung dieses Orchesters nicht einflusslos sein würde. ${ }^{335}$ In seinem Artikel »Die >Verstaatlichung « des philharmonischen Orchesters« schreibt Otto Lessmann zu dieser Angelegenheit:

Berlin hat in diesem Winter in den Wüllner-Conzerten wirklich Orchesterconzerte ersten Ranges gehabt, mit denen künstlerisch kein anderes der hiesigen Orchester concurriren konnte, das haben Kritik und Publikum übereinstimmend anerkannt und das Orchester hätte in der Erinnerung an die ehrenvollen künstlerischen Erfolge, die es unter Männern wie Wüllner und Klindworth hat erringen helfen, nicht so leichthin seine Unabhängigkeit preisgeben sollen. Dem gerade in diesem Winter so kräftig aufgeblühten Berliner Musikleben ist durch die Monopolisierung des philharmonischen Orchesters ein empfindlicher Schlag versetzt worden, da anzunehmen ist, dass das Orchester, welches bisher der Propaganda für moderne Musik unter Wüllner und Klindworth dienstbar war, unter dem direkten Einfluss der Hochschulregenten derselben einseitigen Richtung zugeführt werden wird, der die Hochschulencoterie von jeher geschuldigt hat und da ausgesprochenermassen das Orchester dem sonstigen öffentlichen Musikleben nur noch zu Statten kommen wird in

\footnotetext{
${ }^{334}$ Ebd., S. 636. Hervorhebungen im Original.

${ }^{335} \mathrm{Zu}$ diesem Vertrag und dem Vorwurf gegen ihn, vgl. Muck: Einhundert Jahre Berliner Philharmonisches Orchester, Bd. 1, S. 19-30.
} 
solchen Fällen, in denen die Herren Joachim, Rudorff und Spitta ihre Approbation ertheilen. ${ }^{336}$

Im Februar 1883 standen Joachim, sein Stellvertreter Ernst Rudorff und Wolff in brieflicher Verhandlung über das Engagement des Philharmonischen Orchesters in der nächsten Saison. ${ }^{337}$ Gleichzeitig war Wolff aber auch in Verhandlung mit Bilse, um seine Kapelle im Notfall für die Wüllner-Konzerte zu engagieren. Der Auftritt der Bilse-Kapelle wurde tatsächlich Anfang März des gleichen Jahres öffentlich angekündigt. ${ }^{338}$ In der Verhandlung mit dem Hochschulkreis setzte Wolff sich jedoch durch und gewann das Philharmonische Orchester für die Wüllner-Konzerte der nächsten Saison. ${ }^{339}$ Der Hauptgrund für die Bewilligung war, wie man aus dem folgenden Brief von Rudorff an Joachim ersehen kann, der Wunsch des Hochschulkreises, sich von der Verpflichtung zu befreien, Neuheiten im Rahmen der Konzerte der Königlichen Akademie der Künste zur Aufführung zu bringen.

Ich hatte ein sehr langes Gespräch mit Bock, aus dem mir schließlich klar wurde, daß es bei weitem gescheuter ist, zu Wüllner's Concerten das Orchester herzuleihen, als zu provocieren, daß Wolff ein Arrangement mit Bilse zu Stande bringt und dann die ganze Preße mit einem Schein von Recht gegen uns in Bewegung setzt. Unsere 12 Concerte werden doch Bestand haben, wenn wir auch auf Rubinstein - wie mir Bock es sehr wahrscheinlich machte, - verzichten müssen, ${ }^{340}$ und wenn auch die WüllnerConcerte daneben ihre Erfolge haben. Uns wird damit einerseits die Verpflichtung, so und so viel Novitäten zu bringen, auf bequeme Weise abgenommen, und außerdem ziehen wir das Geld für das Orchester ein, statt es Bilse in den Rachen zu werfen, was auch nicht zu verachten ist. ${ }^{341}$

\footnotetext{
${ }^{336}$ Allgemeine Deutsche Musik-Zeitung 10 (1883), S. 57. Hervorhebungen im Original.

${ }^{337}$ Joachim war gerade auf einer von Hermann Wolff organisierten Tournee in die Schweiz und nach Mitteldeutschland. Wolff besuchte Joachim auf seiner Reise, um über diese Sache auch mündlich zu verhandeln. Brief von Hermann Wolff an Joseph Joachim vom 6.2.1883, SIM, Sig.: Doc. org. Hermann Wolff 1.

${ }^{338}$ N.N.: Vermischte Mittheilungen und Notizen, in Musikalisches Wochenblatt 14 (1883), S. 128.

${ }^{339}$ Brief von Hermann Wolff an Ernst Rudorff vom 27.2.1883, Briefe von und an Joseph Joachim, gesammelt und herausgegeben von Johannes Joachim und Andreas Moser, Bd. 3: Die Jahre 1869-1907, Berlin 1913, S. 247.

${ }^{340}$ Wolff war dafür zuständig, sowohl für die Wüllner-Konzerte wie für die Konzerte der Königlichen Akademie der Künste Solisten zu engagieren. Tatsächlich erschien Anton Rubinštejn in der Saison 1883/84 im 2. Wüllner-Konzert vom 12.11.1883, spielte den Solopart im 5. Klavierkonzert von Beethoven und dirigierte seine eigene vierte Sinfonie.

${ }^{341}$ Brief von Ernst Rudorff an Josef Joachim vom 11.2.1883, Briefe von und an Joseph Joachim. S. 242.
} 
In diesem Machtkampf konnte Wolff also hauptsächlich wegen seines Prinzips,

Neukompositionen ins Programm aufzunehmen, das Orchester für seine Konzerte zur Verfügung halten.

Ein Jahr darauf, im Frühjahr 1884, wurde dann die Philharmonische Gesellschaft, die sich um die materielle Sicherheit des Orchesters bemühen sollte, gegründet, als deren Geschäftsführer Hermann Wolff fungierte. Die Wüllner-Konzerte gingen in den Abonnementkonzerten dieser Gesellschaft auf, demzufolge bot die Gesellschaft in der Saison 1884/85 16 Abonnementkonzerte in vier Serien an, die von Joachim (Serie A und B), Wüllner (Serie C) und Klindworth (Serie D) geleitet wurden. ${ }^{342}$ Nachdem Wüllner sie verlassen hatte, bestanden die Abonnementkonzerte aus zwei Serien von Joachim und Klindworth, wie die Übersicht 2 zeigt.

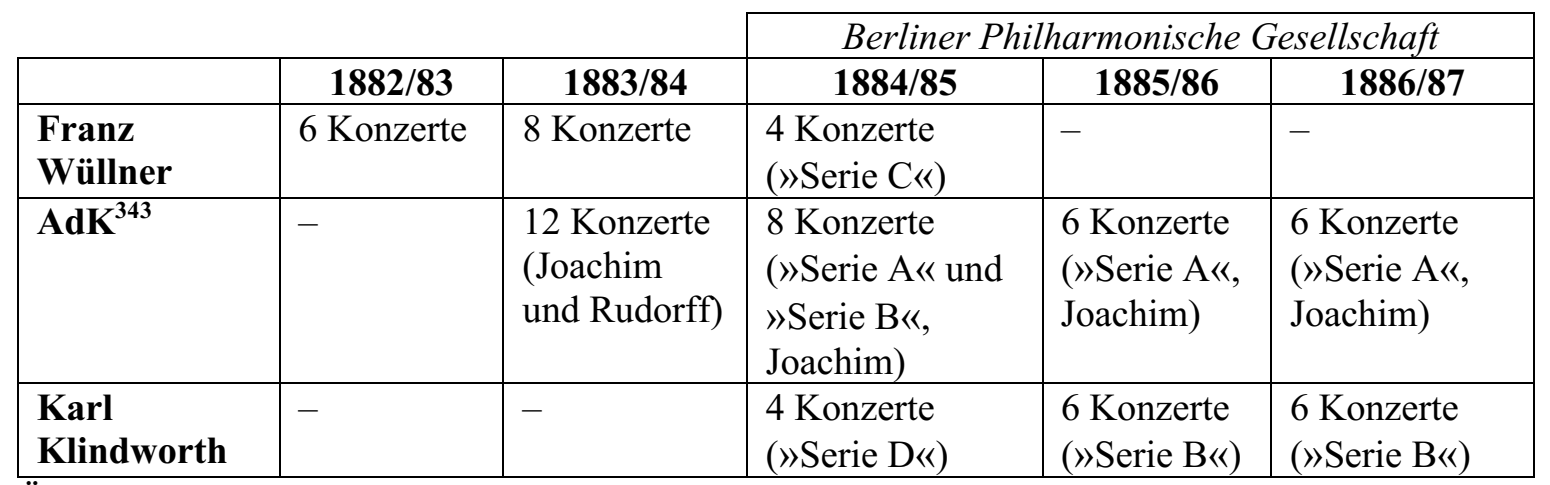

Übersicht 2: Abonnementkonzerte des Berliner Philharmonischen Orchesters (1882/83-1886/87).

Die Tabellen 2-4 zeigen, wie oft Werke jedes Komponisten in den Abonnementkonzerten zwischen 1882/83 und 1886/87 aufgeführt wurden; im Diagramm 10 sind die Komponisten nach ihren Geburtsjahren in sechs Gruppen klassifiziert. Sie zeigen deutlich die Eigenschaften, die die Programme jeder Serie charakterisierten. Die Wüllner-Konzerte boten durch drei Spielzeiten hindurch Rahmen für Neukompositionen. Ihre Programme waren durch den hohen Anteil der Werke der zur »R2« (zweiten Generation der sogenannten »Romantiker«) klassifizierten Komponisten und durch die Vielfalt der ausgewählten Komponisten geprägt. Klindworth brachte viele Werke von den Komponisten der Neudeutschen Schule zur Aufführung, während die Konzerte der Königlichen Akademie der Künste unter Joachim und Rudorff ihren Schwerpunkt auf die Wiener Klassiker und die von deren Tradition geprägten Komponisten legte

\footnotetext{
${ }^{342}$ Außerdem veranstaltete das Orchester in dieser Saison noch vier Extrakonzerte unter diesen drei Dirigenten. Zur Wolffs Zuständigkeit gehörte die Beschaffung der Solisten für diese alle Konzertreihen.

${ }^{343}$ Konzerte der Königlichen Akademie der Künste.
} 
Tab. 2: Wüllner (1882/831884/85, 18 Konzerte).

\begin{tabular}{|c|c|}
\hline Wagner & 14 \\
\hline Beethoven & 12 \\
\hline Brahms & 5 \\
\hline Berlioz & 4 \\
\hline Mozart & 4 \\
\hline Rubinštejn & 4 \\
\hline Schubert & 4 \\
\hline Bruch & 3 \\
\hline Raff & 3 \\
\hline Schumann & 3 \\
\hline Haydn & 2 \\
\hline Liszt & 2 \\
\hline Mendelssohn & 2 \\
\hline Moszkowski, M. & 2 \\
\hline Saint-Saëns & 2 \\
\hline Čajkovskij & 2 \\
\hline Weber & 2 \\
\hline Bach, J. S. & 1 \\
\hline Borodin & 1 \\
\hline Bülow & 1 \\
\hline Chopin & 1 \\
\hline Draeseke & 1 \\
\hline Godard, B. & 1 \\
\hline Grammann, K. & 1 \\
\hline Grieg & 1 \\
\hline Händel & 1 \\
\hline Krug, A. & 1 \\
\hline Laub & 1 \\
\hline Nicodé & 1 \\
\hline Reinecke & 1 \\
\hline Rheinberger & 1 \\
\hline Rüfer, R & 1 \\
\hline Scharwenka, X. & 1 \\
\hline Smetana & 1 \\
\hline ten Brink, J. & 1 \\
\hline Vieuxtemps & 1 \\
\hline Volkmann & 1 \\
\hline
\end{tabular}

Tab. 3: AdK (1883/841886/87, 32 Konzerte).

\begin{tabular}{|c|c|}
\hline Beethoven & 23 \\
\hline Brahms & 11 \\
\hline Haydn & 8 \\
\hline Schumann & 8 \\
\hline Mendelssohn & 7 \\
\hline Weber & 7 \\
\hline Mozart & 5 \\
\hline Cherubini & 4 \\
\hline Bruch & 3 \\
\hline Schubert & 3 \\
\hline Spohr & 3 \\
\hline Bach, J. S. & 2 \\
\hline Chopin & 2 \\
\hline Händel & 2 \\
\hline Joachim & 2 \\
\hline Kiel & 2 \\
\hline Saint-Saëns & 2 \\
\hline Taubert & 2 \\
\hline Viotti & 2 \\
\hline Bargiel & 1 \\
\hline Bennett & 1 \\
\hline Bizet & 1 \\
\hline Gade & 1 \\
\hline Gernsheim & 1 \\
\hline Glinka & 1 \\
\hline Goldmark & 1 \\
\hline Götz & 1 \\
\hline Grädener & 1 \\
\hline Herzogenberg & 1 \\
\hline Holstein & 1 \\
\hline Monsigny & 1 \\
\hline Popper & 1 \\
\hline Rubinštejn & 1 \\
\hline Rudorff & 1 \\
\hline Scharwenka & 1 \\
\hline Seyffard & 1 \\
\hline Smetana & 1 \\
\hline Stanford & 1 \\
\hline Volkmann & 1 \\
\hline Wagner & 1 \\
\hline
\end{tabular}

Tab. 4: Klindworth (1884/85-1886/87, 16 Konzerte).

\begin{tabular}{|l|r|}
\hline Liszt & 7 \\
\hline Wagner & 7 \\
\hline Beethoven & 6 \\
\hline Brahms & 5 \\
\hline Berlioz & 4 \\
\hline Meyerbeer & 3 \\
\hline Raff & 3 \\
\hline d'Albert & 2 \\
\hline Mendelssohn & 2 \\
\hline Rubinštejn & 2 \\
\hline Saint-Saëns & 2 \\
\hline Auer, L. & 1 \\
\hline Bach, J. S. & 1 \\
\hline Borodin & 1 \\
\hline Bruch & 1 \\
\hline Bruckner & 1 \\
\hline Cherubini & 1 \\
\hline Chopin & 1 \\
\hline de Swert & 1 \\
\hline Godard & 1 \\
\hline Haydn & 1 \\
\hline Henschel, G. & 1 \\
\hline Hofmann, H. & 1 \\
\hline Lalo & 1 \\
\hline Mehúl & 1 \\
\hline Moszkowski & 1 \\
\hline Mozart & 1 \\
\hline Schubert & \\
\hline Strauss, R. & Cajkovskij \\
\hline Weber & 1 \\
\hline
\end{tabular}




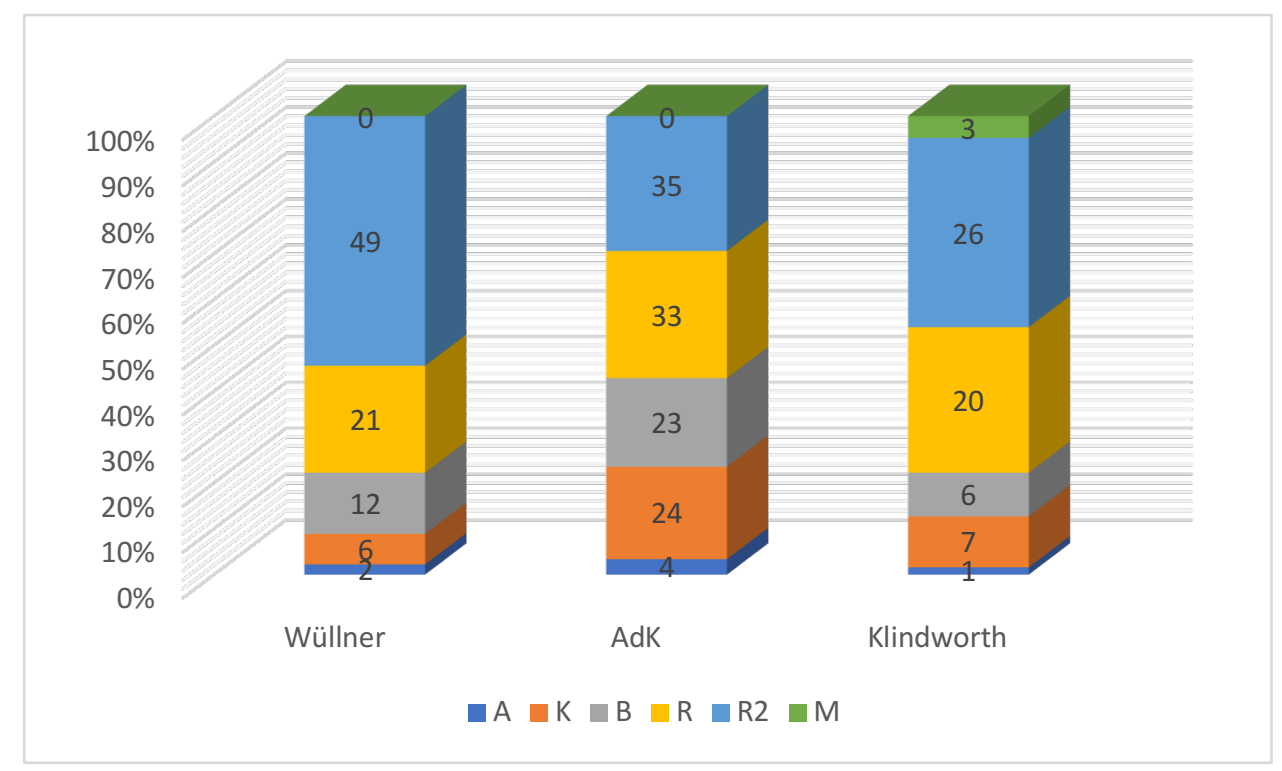

Diagramm 10: Relative Anteile der in den Abonnementkonzerten des Berliner Philharmonischen Orchesters aufgeführten Werke (1882/83-1886/87) $)^{344}$

Die Philharmonische Gesellschaft wurde 1887 nach dem dreijährigen Bestehen aufgelöst. Das Orchester trug Wolff wieder die Führung seiner geschäftlichen Angelegenheiten an, und die Abonnementkonzerte gingen ab 1887/88 in die selbstständige Verwaltung der Konzertdirektion Hermann Wolff über. Diese Berliner Abonnementkonzerte bekamen nun offiziell den bekannten Namen »Philharmonische Concerte« und Wolff gewann ihnen einen neuen Dirigenten: Hans von Bülow. ${ }^{345}$ Da viele zeitgenössische Komponisten ihre Werke in den Abonnementkonzerten ${ }^{346}$ aufführen lassen wollten, musste Bülow kurz vor dem Beginn der Saison die folgende Erklärung veröffentlichen:

Nothgedrungene Erklärung.

\footnotetext{
${ }^{344}$ A: Komponisten, die vor dem 18. Jahrhunderts geboren wurden, K: Komponisten, die im 18. Jahrhunderts geboren wurden, B: Beethoven, R: Komponisten, die zwischen den 1800er und 1820er Jahren geboren wurden, R2: Komponisten, die zwischen den 1830er und 1850er Jahren geboren wurden, M: Komponisten, die nach 1860 geboren wurden. Was die Klassifikation angeht, habe ich mich auf die Arbeit von Rebecca Grotjahn gestützt, jedoch die Definition der Kategorien dem Zweck der vorliegenden Arbeit angepasst. Vgl. Grotjahn, Die Sinfonie im deutschen Kulturgebiet 1850 bis 1875, S. 163-170.

${ }^{345}$ Ein Vertrag zwischen dem Orchester und Wolff in der Bülow-Zeit ist im Wolff-Nachlass überliefert. Vgl. Vertrag zwischen dem Berliner Philharmonischen Orchester und Hermann Wolff vom 29.1.1891, Wolff-Nachlass: ID 223. Seine Transkription ist unter $1.3 \mathrm{im}$ Quellenteil der vorliegenden Arbeit.

${ }^{346}$ Seit 1886/87 hatte Bülow die von Hermann Wolff und Bernhard Pollini gemeinsam veranstalteten Neuen Abonnementkonzerte in Hamburg geleitet. In der folgenden Erklärung meinte er wohl die beiden Konzertreihen.
} 
Nachdem ich durch die Güte derjenigen Herren Componisten, welche ihre Werke in den von mir geleiteten Orchesterconcerten aufgeführt zu haben wünschen, mit einer grösseren Anzahl von Novitäten versehen worden bin, als ich bis Ende laufenden Jahrhunderts zu berücksichtigen in der Lage wäre, muss ich jede fernere Musikaliensendung von jetzt ab zurückweisen.

Hamburg, 8. October 1887.

Dr. Hans von Bülow ${ }^{347}$

Wie hat sich das eigentliche Prinzip dieser Konzerte, »Orchesternovität« aufzuführen, unter den Nachfolgern Wüllners geändert? Die Tabellen 5-7 zeigen, wie viel Mal die Werke jedes Komponisten in den Philharmonischen Konzerten unter Bülow, Strauss und Nikisch zur Aufführung gebracht wurden. Das Diagramm 11 vergleicht die Anteile der Komponisten, die wieder nach jedem Geburtsjahr in sechs Gruppen eingeordnet sind.

${ }^{347}$ Hans von Bülow: Nothgedrungene Erklärung, in Signale für die musikalische Welt 45 (1887), S. 874, Hervorhebungen im Original. 
Tab. 5: Bülow (1887/881891/92, 50 Konzerte).

\begin{tabular}{|c|c|c|c|}
\hline \multirow{2}{*}{\multicolumn{2}{|c|}{$\begin{array}{l}\text { Tab. 5: Bülow (1887/88- } \\
\text { 1891/92, } 50 \text { Konzerte). }\end{array}$}} & \multirow{2}{*}{$\begin{array}{l}\text { Lalo } \\
\text { Lassen }\end{array}$} & \multirow{2}{*}{$\frac{1}{1}$} \\
\hline & & & \\
\hline Beethoven & 48 & I aub & 1 \\
\hline Wagner, R. & 28 & & \\
\hline Brahms & 25 & Mranter & 1 \\
\hline & & Massenet & 1 \\
\hline Mozart & 16 & Méhul & 1 \\
\hline Mendelssohn & 11 & Paderewski & 1 \\
\hline Berlioz & 10 & Radecke & 1 \\
\hline Saint-Saëns & 10 & Reinecke & 1 \\
\hline Haydn & 8 & Rudorff & 1 \\
\hline Schumann, R. & 8 & Stanford & 1 \\
\hline Bruch & 6 & Svendsen & 1 \\
\hline Liszt & 6 & Taubert & 1 \\
\hline Raff & 6 & & \\
\hline
\end{tabular}

\begin{tabular}{l|l} 
Rubinštejn & 6 \\
\hline
\end{tabular}

\begin{tabular}{|l|l|}
\hline Weber & 6 \\
\hline
\end{tabular}

\begin{tabular}{l|l} 
Cherubini & 5 \\
\hline
\end{tabular}

\begin{tabular}{|l|r|}
\hline Dvořák & 5 \\
\hline
\end{tabular}

\begin{tabular}{|l|l|}
\hline Meyerbeer & 5 \\
\hline
\end{tabular}

\begin{tabular}{l|l}
\hline Strauss, R. & 5 \\
\hline
\end{tabular}

\begin{tabular}{|l|l|}
\hline Joachim & 4 \\
\hline
\end{tabular}

\begin{tabular}{|l|l|}
\hline Schubert & 4 \\
\hline
\end{tabular}

\begin{tabular}{|l|l}
\hline d'Albert & 3 \\
\hline
\end{tabular}

\begin{tabular}{l|l} 
Grieg & 3 \\
\hline
\end{tabular}

Moszkowski, M.

Čajkovskij

Bach, J. S.

Bazzini

Chopin

Delibes

Draeseke

\begin{tabular}{|l|l}
\hline Gernsheim & 2 \\
\hline
\end{tabular}

\begin{tabular}{|l|l|}
\hline Glinka & 2 \\
\hline
\end{tabular}

\begin{tabular}{|l|r|}
\hline Goldmark & 2 \\
\hline Spohr & 2 \\
\hline
\end{tabular}

\begin{tabular}{|l|l|}
\hline Baussnern & 1 \\
\hline
\end{tabular}

\begin{tabular}{|l|r|}
\hline Borodin & 1 \\
\hline Damrosch & 1 \\
\hline
\end{tabular}

\begin{tabular}{|l|l|}
\hline Damrosch & 1 \\
\hline Davidoff &
\end{tabular}

\begin{tabular}{|l|l|}
\hline Davidoff & 1 \\
\hline Gade & 1 \\
\hline
\end{tabular}

Gavaert

\begin{tabular}{|l|r|}
\hline Gluck & 1 \\
\hline Halévy & 1 \\
\hline Hubay & 1 \\
\hline Hummel & 1 \\
\hline Kahn & 1 \\
\hline
\end{tabular}

Tab. 6: Richard Strauss (1894/95, 10 Konzerte)

\begin{tabular}{|c|c|}
\hline Beethoven & 7 \\
\hline Liszt & 4 \\
\hline Wagner, R. & 3 \\
\hline Brahms & 2 \\
\hline Haydn & 2 \\
\hline Rameau & 2 \\
\hline Rubinštejn & 2 \\
\hline Saint-Saëns & 2 \\
\hline Berlioz & 1 \\
\hline Bruch & 1 \\
\hline Bülow & 1 \\
\hline d'Albert & 1 \\
\hline Dvořák & 1 \\
\hline $\begin{array}{l}\text { Friedrich der } \\
\text { Große } \\
\end{array}$ & 1 \\
\hline Gernsheim & 1 \\
\hline Glazunow & 1 \\
\hline Mahler & 1 \\
\hline Mendelssohn & 1 \\
\hline Mozart & 1 \\
\hline Paganini & 1 \\
\hline Ritter & 1 \\
\hline Sauret & 1 \\
\hline Schillings & 1 \\
\hline Schubert & 1 \\
\hline Schumann, R. & 1 \\
\hline Smetana & 1 \\
\hline Spohr & 1 \\
\hline Stenhammar & 1 \\
\hline Strauss, J. & 1 \\
\hline Strauss, R. & 1 \\
\hline Čajkovskij & 1 \\
\hline Weber & 1 \\
\hline Widor, Ch. & 1 \\
\hline
\end{tabular}


Tab. 7: Nikisch (1895/961901/02, 60 Konzerte). ${ }^{348}$

\begin{tabular}{|c|c|}
\hline Beethoven & 52 \\
\hline Wagner, R. & 29 \\
\hline Čajkovskij & 17 \\
\hline Schumann, R. & 13 \\
\hline Weber & 13 \\
\hline Berlioz & 12 \\
\hline Liszt & 12 \\
\hline Brahms & 10 \\
\hline Mendelssohn & 9 \\
\hline Mozart & 9 \\
\hline Strauss, R. & 8 \\
\hline Haydn & 7 \\
\hline Schubert & 7 \\
\hline Saint-Saëns & 6 \\
\hline Bach, J. S. & 5 \\
\hline d'Albert & 5 \\
\hline Dvořák & 4 \\
\hline Gluck & 4 \\
\hline Bruch & 3 \\
\hline Cherubini & 3 \\
\hline Chopin & 3 \\
\hline Händel & 3 \\
\hline Lalo & 3 \\
\hline Raff & 3 \\
\hline Verdi & 3 \\
\hline Berger, W. & 2 \\
\hline Bruckner & 2 \\
\hline Draeseke & 2 \\
\hline Fauré & 2 \\
\hline Gernsheim & 2 \\
\hline Goldmark & 2 \\
\hline Rubinštejn & 2 \\
\hline Schillings & 2 \\
\hline Smetana & 2 \\
\hline Thomas, A. & 2 \\
\hline Volkmann & 2 \\
\hline Arensky & 1 \\
\hline Averkamp, A. & 1 \\
\hline Bellini & 1 \\
\hline Bizet & 1 \\
\hline Conus, J. & 1 \\
\hline
\end{tabular}

\begin{tabular}{|l|r|} 
d'Indy & 1 \\
\hline Dittersdorf & 1 \\
\hline Dohnányi & 1 \\
\hline Donizetti & 1 \\
\hline Franck, C. & 1 \\
\hline Giordani & 1 \\
\hline Glazunow & 1 \\
\hline Gleitz, K. & 1 \\
\hline Gounod & 1 \\
\hline Grieg & 1 \\
\hline Halévy & 1 \\
\hline Hausegger & 1 \\
\hline Hofmann, H. & 1 \\
\hline Hofmann, J. & 1 \\
\hline Huber, H. & 1 \\
\hline Humperdinck & 1 \\
\hline Kjui, C. & 1 \\
\hline Kleemann, C. & 1 \\
\hline Klughardt, A. & 1 \\
\hline Koessler & 1 \\
\hline Lindner, A. & 1 \\
\hline Mahler & 1 \\
\hline Martucci, G. & 1 \\
\hline Massenet & 1 \\
\hline Meyerbeer & 1 \\
\hline Moszkowski, M. & 1 \\
\hline Novaček & 1 \\
\hline Osterzee & 1 \\
\hline Pfohl, F. & 1 \\
\hline Rimsky- & 1 \\
\hline Korsakow & 1 \\
\hline Ritter & 1 \\
\hline Sarasate & 1 \\
\hline Scharwenka, Ph. & 1 \\
\hline Scholz, B. & 1 \\
\hline Wolbach, F. & 1 Jagner, S. \\
\hline
\end{tabular}

${ }^{348}$ Arthur Nikisch blieb in dieser Position bis zu seinem Tod im Jahr 1922. Die vorliegende Arbeit beschränkt die Betrachtung auf Hermann Wolffs Lebzeiten. 


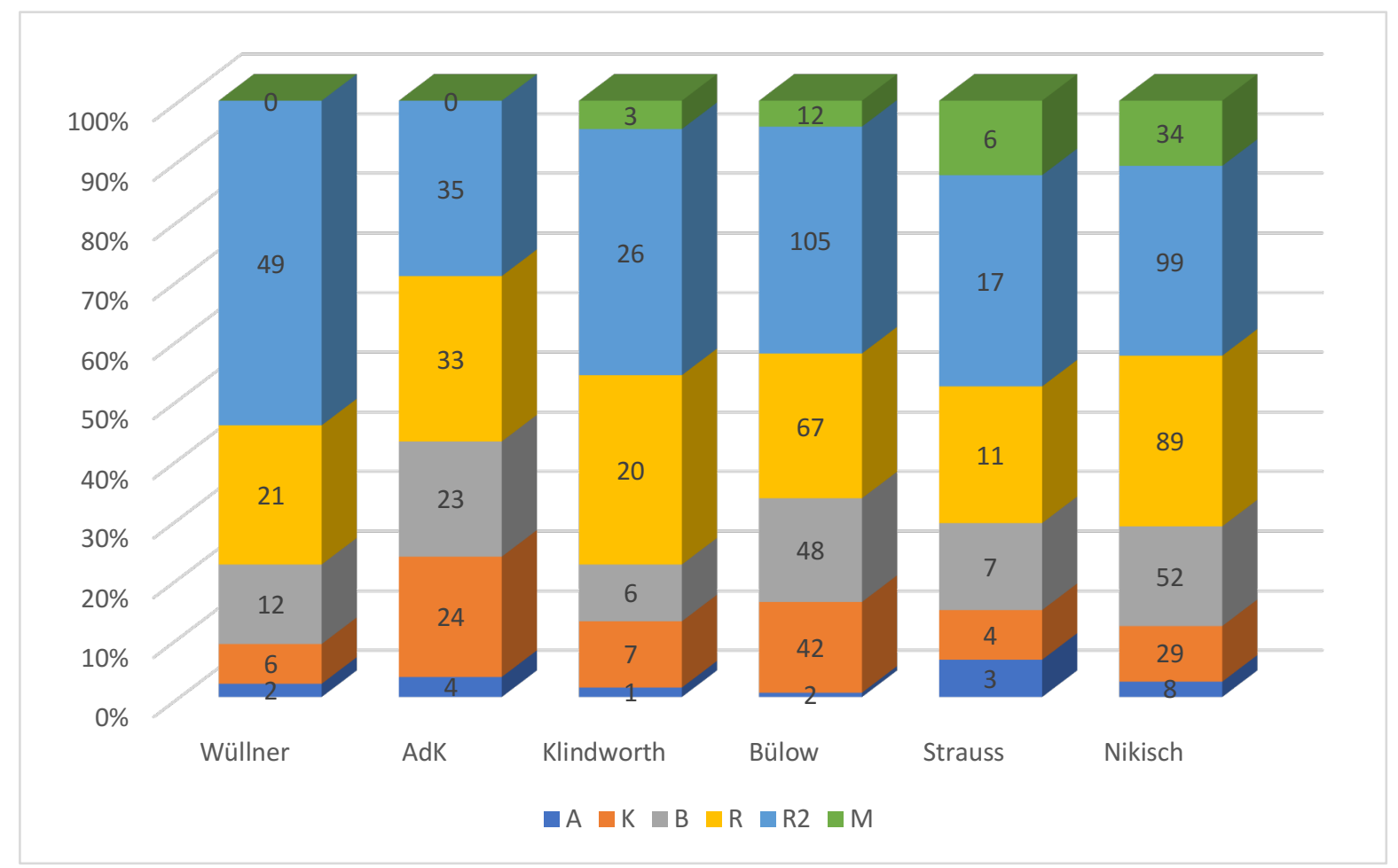

Diagramm 11: Relative Anteile der in den Abonnementkonzerten des Berliner Philharmonischen Orchesters aufgeführten Werke (1882/83-1901/02).

Bei diesen Tabellen von verschiedenen Komponistennamen ist auffällig, dass viele zeitgenössische Komponisten nur einmal auf dem Programm der Philharmonischen Konzerte erschienen. Das Diagramm zeigt, dass, die hohen Anteile von Werken zeitgenössischer Komponisten auch unter Bülow, Strauss und Nikisch im Prinzip aufrechterhalten wurde, auch wenn sich die Physiognomie des Programms unter jedem Dirigenten etwas änderte.

Wie sein Antrittskonzert vom 21. Oktober 1887 ausschließlich aus Sinfonien von Haydn, Mozart und Beethoven bestand, so bekamen in den Bülow-Konzerten die klassischen Werke oft wichtigen Stellenwert. Diagramm 11 zeigt freilich, dass die Werke der zu »R2« und »M« gehörten Komponisten auch bei den Bülow-Konzerten noch mehr als $40 \%$ des gesamten Programms ausmachten, ${ }^{349}$ womit diese Rate fast so hoch war wie bei den Klindworth- und Nikisch-Konzerten, wenn sie auch nicht diejenige der Wüllner-Konzerte erreicht. Da Strauss die Philharmonischen Konzerte nur eine Saison komplett dirigierte, gibt es zu wenige Daten, um eine sinnvolle statistische Auswertung zu leisten. Die Programme der

\footnotetext{
${ }^{349}$ Weissmann vertritt die Ansicht, dass die Bülow-Konzerte Wolff die »Buntheit« des Programms verdankten. »Und nun zu den grossen philharmonischen Konzerten, die der Stolz Berlins wurden. Bülows Grosstaten, das wusste man, lagen auf dem Gebiete der Beethoven Sinfonie. Die Neigung für Brahms kam hinzu. Aber Doktrinarismus war auch da nicht am Platze, wo der Name Bülow Rattenfängerdienste verrichtete. Der Geschäftstüchtige Hermann Wolff sorgte darum auch für die nötige Buntheit.« Weissmann: Berlin als Musikstadt, S. 359.
} 
Strauss-Saison zeichnen sich aber durch den weiten historischen Umfang aus: von der Musik von Jean-Philippe Rameau und Friedrich dem Großen bis zu den vielfältigen Neuheiten, einschließlich der Werke von Max von Schillings, Charles-Marie Widor, Alexander Ritter, Wilhelm Stenhammar, Antonin Dvořák und dreier Sätze aus der zweiten Sinfonie von Gustav Mahler. Die Programme unter Nikisch sind durch den hohen Anteil von Werken von Čajkovskij, Robert Schumann und Carl Maria von Weber sowie eine große Zahl von zeitgenössischen Komponisten - die meisten von ihnen freilich nur einmal - charakterisiert.

Wie im Abschnitt 3.2.2 ausgeführt wird, führte Wolff am Anfang der Saison 1886/87 in diesen Abonnementkonzerten Programmhefte ein. Die neuen, unpublizierten oder zum ersten Mal in Berlin oder in diesen Konzerten aufzuführenden Werke wurden im Programmheft mit den Bemerkungen »neu«, »Neuheit«, »Novität«, »Manuscript« oder »zum ersten Mal« gekennzeichnet und oft vom Komponisten selbst analysiert, worauf Wolff Wert legte. Möglicherweise lag ein Motiv zur Einführung des Programmhefts darin, der Aufführung der Neuschöpfungen Leitfäden beizulegen. Die Übersicht 3 zeigt, welche Werke in den Berliner Abonnementkonzerten mit diesen Bemerkungen im Programmheft zur Aufführung gebracht wurden. Wenn auch diese Angaben offensichtlich keinen Anspruch auf die Einheitlichkeit und wissenschaftliche Genauigkeit erheben, gibt diese Übersicht doch eine interessante Einsicht, welche Musik als Neuheit zu Gehör gebracht wurde.

\begin{tabular}{|c|c|c|}
\hline $\begin{array}{c}\text { Saison } \\
\text { (Dirigent) }\end{array}$ & \begin{tabular}{|c} 
Gastdirigent \\
eigener Werke
\end{tabular} & Neuheiten \\
\hline $\begin{array}{l}1882 / 83 \\
\text { (Wüllner) }\end{array}$ & & $\begin{array}{l}\text { Čajkovskij: Suite op. } 43 \text { (zum ersten Mal); Ten Brink: } \\
\text { Violinkonzert Nr. } 2 \text { (neu); Godard: Scènes poétiques für Orchester } \\
\text { (Neuheit); Wagner: Karfreitagszauber aus Parsifal (Novität); Saint- } \\
\text { Saëns: Sinfonie Nr. } 2 \text { (Novität); Gramman: Vorspiel zu Melusine } \\
\text { (Novität) }\end{array}$ \\
\hline $\begin{array}{l}1883 / 84 \\
\text { (Wüllner) }\end{array}$ & $\begin{array}{l}\text { Anton } \\
\text { Rubinštejn; } \\
\text { Johannes } \\
\text { Brahms }\end{array}$ & $\begin{array}{l}\text { Nikodé: Sinf. Variationen op. } 27 \text { (Manuskript); M. Moszkowski. } \\
\text { Violinkonzert (neu); Raff: Suite in italienischer Weise (Manuskript, } \\
\text { Uraufführung); Brahms: Sinfonie Nr. } 3 \text { (Manuskript); Borodin: } \\
\text { Sinfonie Nr. } 1 \text { (neu); Grieg: Herzwunden und Frühling (neu); } \\
\text { Schubert: Hirtenweise aus Rosamunde (neu); X. Scharwenka: } \\
\text { Sinfonie c-Moll (neu); Smetana: Lustspiel Ouvertüre (neu) }\end{array}$ \\
\hline $\begin{array}{l}\text { (Joachim, } \\
\text { Rudorff) }\end{array}$ & & $\begin{array}{l}\text { Brahms: Gesang der Parzen (Novität); Brahms: Sinfonie Nr. } 3 \\
\text { (Manuskript, neu); Kiel: Idylle für Soli, Chor und Orchester } \\
\text { (Uraufführung); Kiel: Der Stern von Bethlehem (Uraufführung) }\end{array}$ \\
\hline $\begin{array}{l}\text { 1884/85 } \\
\text { (Serie A: } \\
\text { Joachim) }\end{array}$ & & Stanford: Ouvertüre The Canterbury Pilgrims (Novität) \\
\hline $\begin{array}{l}\text { (Serie B: } \\
\text { Joachim) }\end{array}$ & & $\begin{array}{l}\text { Goldmark: Violinkouzert (zum ersten Mal); Seyffard: } \\
\text { Schicksalsgesang für Alt, Chor und Orchester (neu); Schubert: } \\
\text { Sinfonie C-Dur (nach dem Klavierduo instr. von J. Joachim, zum } \\
\text { ersten Mal) }\end{array}$ \\
\hline
\end{tabular}




\begin{tabular}{|c|c|c|}
\hline $\begin{array}{l}\text { (Serie C: } \\
\text { Wüllner) }\end{array}$ & & $\begin{array}{l}\text { Draeseke: Sinfonie Nr. } 2 \text { (neu); Čajkovskij: Serenade für } \\
\text { Streichorchester (neu); Rheinberger: Ouvertüre zu Der } \\
\text { Widerspenstigen Zähmung (zum ersten Mal); A. Krug: Othello, } \\
\text { sinf. Prolog (Novität) }\end{array}$ \\
\hline $\begin{array}{l}\text { (Serie D: } \\
\text { Klindworth) }\end{array}$ & & d'Albert: Ouvertüre Hyperion (zum ersten Mal) \\
\hline $\begin{array}{l}\text { 1885/86 } \\
\text { (Serie A: } \\
\text { Joachim) }\end{array}$ & & $\begin{array}{l}\text { Herzogenberg: Sinfonie c-Moll (zum ersten Mal); Brahms: Sinfonie } \\
\text { Nr. } 4 \text { (Manuskript, zum ersten Mal); H. Hofmann: Suite Im } \\
\text { Schloßburg (Uraufführung) }\end{array}$ \\
\hline (Klindworth) & & $\begin{array}{l}\text { Liszt: Orpheus, sinf. Dichtung (zum ersten Mal); G. Henschel: } \\
\text { Ballade für Violine (zum ersten Mal); L. Auer: Ungarische } \\
\text { Rhapsodie für Violine (zum ersten Mal); Čajkovskij: Suite Nr. } 3 \\
\text { (neu); E. Rudorff: Sinfonie B-Dur (neu); d'Albert: Sinfonie F-Dur } \\
\text { (Manuskript); Brahms: Rinaldo, Kantate für Tenor, Männerchor und } \\
\text { Orchester (zum ersten Mal in Berlin) }\end{array}$ \\
\hline $\begin{array}{l}1886 / 87 \\
\text { (Joachim) }\end{array}$ & & $\begin{array}{l}\text { Bruch: Sinfonie Nr. } 3 \text { (Manuskript); E. Rudorff: Variationen für } \\
\text { Orchester d-Moll (neu); Grädener: Lustspiel-Ouvertüre (neu) }\end{array}$ \\
\hline (Klindworth) & & $\begin{array}{l}\text { M. Moszkowski: Suite F-Dur (neu); Bruckner: Sinfonie Nr. } 7 \text { (zum } \\
\text { ersten Mal in Berlin); Méhul: Ouvertüre zu Horatius Cocles (zum } \\
\text { ersten Mal) }\end{array}$ \\
\hline $\begin{array}{l}1887 / 88 \\
\text { (Bülow) }\end{array}$ & \begin{tabular}{l|} 
Eugen d'Albert; \\
Richard \\
Strauss; \\
Friedrich \\
Gernsheim
\end{tabular} & $\begin{array}{l}\text { d'Albert: Ouvertüre zu Esther (neu); Reinecke: Variationen über } \\
\text { Eine feste Burg (zum ersten Mal); R. Strauss: Aus Italien (neu); } \\
\text { Saint-Saëns: Tarantella für Flöte und Klarinette (neu); Brahms: } \\
\text { Konzert für Violine, Cello und Orchester (neu, Manuskript); } \\
\text { Stanford: Sinfonie Nr. } 3 \text { (neu); Bazzini: Ouvertüre zu König Lear } \\
\text { (neu); Gernsheim: Sinfonie Nr. } 3 \text { (neu, Manuskript); E. E. Taubert: } \\
\text { Lustspiel-Ouvertüre (neu); Moszkowski: Fantastischer Zug (neu) }\end{array}$ \\
\hline $\begin{array}{l}1888 / 89 \\
\text { (Bülow) }\end{array}$ & $\begin{array}{l}\text { Eduvard Grieg; } \\
\text { Johannes } \\
\text { Brahms }\end{array}$ & $\begin{array}{l}\text { E. Lassen: Violinkonzert D-Dur; Draeseke: Sinfonie Nr. } 3 \\
\text { (Erstaufführung); Halévy: Ouvertüre zu Die Jüdin (zum ersten Mal); } \\
\text { Grieg: Konzert-Ouvertüre Im Herbst (zum ersten Mal); Grieg: } \\
\text { Orchestersuite zu Peer Gynt (zum ersten Mal); Brahms: Serenade } \\
\text { D-Dur op. } 11 \text { (zum ersten Mal) Bazzini: Francesca da Rimini } \\
\text { (Manuskript) }\end{array}$ \\
\hline $\begin{array}{l}\text { 1889/90 } \\
\text { (Bülow) }\end{array}$ & $\begin{array}{l}\text { Carl Goldmark; } \\
\text { Waldemar von } \\
\text { Baussnern }\end{array}$ & $\begin{array}{l}\text { Dvořák: Sinfonie Nr. 2; Carl Goldmark: Ouvertüre zum Gefesselten } \\
\text { Prometheus (Uraufführung Manuskript); Draeseke: Klavierkonzert } \\
\text { Es-Dur (zum ersten Mal), Baussnern: Gesang der Sappho } \\
\text { (Manuskript, zum ersten Mal); Raff: Violinkonzert Nr. } 2 \text { (zum } \\
\text { ersten Mal), Richard Strauss: Don Juan (zum ersten Mal); Dvořák: } \\
\text { Slavische Rhapsodie Nr. 1 (zum ersten Mal in den Philh. } \\
\text { Konzerten); M. Moszkowski: Präldium und Fuge, Suite Nr. } 2 \\
\text { (Manuskript, zum ersten Mal); Damrosch: Violinkonzert Nr. } 2 \\
\text { (Manuskript, zum ersten Mal) }\end{array}$ \\
\hline $\begin{array}{l}\text { 1890/91 } \\
\text { (Bülow) }\end{array}$ & Richard Strauss & $\begin{array}{l}\text { Kahn: Serenade für Orchester (neu, Manuskript); Svendsen: } \\
\text { Rhapsodie norvégienne Nr. } 2 \text { (zum ersten Mal); Rubinštejn: } \\
\text { Ouvertüre Antonius und Cleopatra (zum ersten Mal); Paderewski: } \\
\text { Klavierkonzert a-Moll (zum ersten Mal); E. Rudorff: Sinfonie Nr. } 2 \\
\text { (neu); R. Strauss: Burleske für Klavier und Orchester (Manuskript, } \\
\text { neu); Joachim: Ouvertüre zu Heinrich IV. (Manuskript, zum ersten } \\
\text { Mal); Richard Strauss: Tod und Verklärung (Manuskript, zum } \\
\text { ersten Mal) }\end{array}$ \\
\hline
\end{tabular}




\begin{tabular}{|c|c|c|}
\hline $\begin{array}{l}\text { 1891/92 } \\
\text { (Bülow) }\end{array}$ & Richard Strauss & $\begin{array}{l}\text { Bruch: Violinkonzert Nr. } 3 \text { (zum ersten Mal); Radecke: Capriccio c- } \\
\text { Moll (Manuskript, zum ersten Mal); Dvoř́k: Drei Legenden für } \\
\text { Orchester op. 59 Nr. 5, } 6 \text { und } 7 \text { (zum ersten Mal); Gernsheim: } \\
\text { Waldmeisters Brautfahrt (zum ersten Mal in den Philh. Konzerten), } \\
\text { Konzertouvertüre im italienischen Stil (zum ersten Mal); Glinka: } \\
\text { Ouvertüre zu Ruslan und Ludmilla (zum ersten Mal); Berlioz: } \\
\text { Ouvertüre zu Beatrice und Benedict (zum ersten Mal); Hubay: } \\
\text { Violinkonzert a-Moll (zum ersten Mal); Richard Strauss: Macbeth } \\
\text { (zum ersten Mal); Liszt: Klavierkonzert A-Dur (zum ersten Mal); } \\
\text { Massenet: Arie aus Herodiade (zum ersten Mal) }\end{array}$ \\
\hline $\begin{array}{l}1892 / 93 \\
\text { (Richter, } \\
\text { Maszkowski, } \\
\text { Mottl, Levi, } \\
\text { Bülow) }\end{array}$ & - & - \\
\hline $\begin{array}{l}1893 / 94 \\
\text { (Levi, } \\
\text { Schuch, R. } \\
\text { Strauss, } \\
\text { Mannstaedt) }\end{array}$ & $\begin{array}{l}\text { Anton } \\
\text { Rubinštejn }\end{array}$ & $\begin{array}{l}\text { Mozart, Sinfonie Nr. } 29 \text { (zum ersten Mal); Bruckner: Sinfonie d- } \\
\text { Moll Nr. } 3 \text { (zum ersten Mal); Chabrier: Vorspiel zum 2. Akt von } \\
\text { Gwendoline (zum ersten Mal); Händel: Concerto grosso Nr. 10 } \\
\text { (zum ersten Mal); Goldmark: Ouvertüre zu Sappho (Manuskript); R. } \\
\text { Fuchs: Serenade D-Dur für Streichorchester (zum ersten Mal in den } \\
\text { Philharmonischen Konzerten); W. Berger: Dramatische } \\
\text { Orchesterfantasie in Ouvertürenform (Manuskript, zum ersten Mal) }\end{array}$ \\
\hline $\begin{array}{l}\text { 1894/95 (R. } \\
\text { Strauss) }\end{array}$ & Gustav Mahler & $\begin{array}{l}\text { Schilling: Vorspiel zum II. Akt Ingwelde (zum ersten Mal); } \\
\text { Schubert: Fantasie f-Moll op. } 103 \text { (instr. von Mottl, zum ersten } \\
\text { Mal); J. Strauß: Perpetuum mobile (zum ersten Mal); Ch. Widor: } \\
\text { Sinfonie A-Dur (zum ersten Mal); Glazunow: Frühling, Tongemälde } \\
\text { für Orchester (zum ersten Mal); Ritter: Olafs Hochzeitsreigen, sinf. } \\
\text { Walzer (zum ersten Mal); d'Albert: Vorspiel zu Der Rubin (zum } \\
\text { ersten Mal); W. Stenhammar: Klavierkonzert op. 1; Dvořák: } \\
\text { Carneval, Ouvertüre op. 92; Čajkovskij: Suite Nr. } 3 \text { (zum ersten } \\
\text { Mal); Mahler: Drei Sätze aus der Sinfonie Nr. 2 (Manuskript, } \\
\text { Uraufführung); Richard Strauss: Vorspiel zum II. Akt Guntram } \\
\text { (zum ersten Mal) }\end{array}$ \\
\hline $\begin{array}{l}\text { 1895/96 } \\
\text { (Nikisch) }\end{array}$ & & $\begin{array}{l}\text { Čajkovskij: Sinfonie Nr. } 5 \text { (zum ersten Mal); J. S. Bach: Präludium, } \\
\text { Adagio. Gavotte und Rondo für Streichorchester (eingerichtet von } \\
\text { S. Bachrich, zum ersten Mal); Lalo: Namouna, Orchestersuite (zum } \\
\text { ersten Mal); Dvořák: Ouvertüre In der Natur (zum ersten Mal); B. } \\
\text { Scholz: Suite für Orchester (zum ersten Mal); G. Martucci: Sinfonie } \\
\text { op. } 75 \text { (zum ersten Mal); W. Berger: Gesang der Geister über den } \\
\text { Wassern (neu) }\end{array}$ \\
\hline $\begin{array}{l}1896 / 97 \\
\text { (Nikisch) }\end{array}$ & & $\begin{array}{l}\text { Humperdinck: Vorspiele zum III. und II. Akt von Königskinder } \\
\text { (zum ersten Mal); Novaček: Klavierkonzert op. } 8 \text { (zum ersten Mal); } \\
\text { Mahler: Was mir die Blumen auf der Wiese erzählen, aus der } \\
\text { Sinfonie Nr. } 3 \text { (Manuskript, Uraufführung), Dvořák: Scherzo } \\
\text { capriccioso (zum ersten Mal in diesen Konzerten); Richard Strauss: } \\
\text { Also sprach Zarathustra (zum ersten Mal); Gernsheim: Sinfonie } \\
\text { Nr. } 4 \text { (zum ersten Mal); Sarasate: Viva Sevilla (zum ersten Mal); C. } \\
\text { von Osterzee: Sinf. Stücke aus Königsidyllen (zum ersten Mal); } \\
\text { Saint-Saëns: Klavierkonzert Nr. } 5 \text { (zum ersten Mal) }\end{array}$ \\
\hline $\begin{array}{l}1897 / 98 \\
\text { (Nikisch) }\end{array}$ & & $\begin{array}{l}\text { Wagner: Ouvertüre Die Feen (zum ersten Mal); d'Albert: Vorspiel } \\
\text { zum II. Akt Gernot (zum ersten Mal); J. Suk: Serenade für } \\
\text { Streichorchester op. } 6 \text { (zum ersten Mal); C. Frank: Sinf. Variationen } \\
\text { für Klavier (zum ersten Mal); F. Pfohl: Fraziella für Orchester (zum } \\
\text { ersten Mal); Berlioz: Sinfonie phantastique (zum ersten Mal in } \\
\text { diesen Konzerten) }\end{array}$ \\
\hline
\end{tabular}




\begin{tabular}{|c|c|c|}
\hline $\begin{array}{l}\text { 1898/99 } \\
\text { (Nikisch) }\end{array}$ & & $\begin{array}{l}\text { Rimsky-Korsakow: Scheherazade (zum ersten Mal in diesen } \\
\text { Konzerten); Bruckner: Sinfonie Nr. } 5 \text { (zum ersten Mal); Moritz } \\
\text { Moszkowski: Klavierkonzert E-Dur (zum ersten Mal); J. Conus: } \\
\text { Violinkonzert (zum ersten Mal); Draeseke: Festouvertüre (neu, zum } \\
\text { ersten Mal); K. Gleitz: Fata Morgana, sinf. Dichtung (Manuskript, } \\
\text { zum ersten Mal); C. Kleemann: Lustspiel-Ouvertüre (zum ersten } \\
\text { Mal); Čajkovskij: Francesca da Rimini (zum ersten Mal in diesen } \\
\text { Konzerten); Józef Hofmann: Klavierkonzert B-Dur (Manuskript, } \\
\text { zum ersten Mal); G. Schumann: Zur Carnavalszeit, Orchestersuite } \\
\text { (neu, zum ersten Mal) }\end{array}$ \\
\hline $\begin{array}{l}\text { 1899/1900 } \\
\text { (Nikisch) }\end{array}$ & $\begin{array}{l}\text { Friedrich } \\
\text { Gernsheim }\end{array}$ & $\begin{array}{l}\text { C. Franck: Sinfonie d-Moll (zum ersten Mal); Dittersdorf: Sinfonie } \\
\text { C-Dur (zum ersten Mal); Dvoŕák:Heldenlied, sinf. Dichtung (zum } \\
\text { ersten Mal); Ritter: Zwei Orchesterstücke, Charfreitag und } \\
\text { Frohnleichnam (zum ersten Mal); Glazunow: Sinfonie Nr. } 6 \text { (neu, } \\
\text { zum ersten Mal); H. Hofmann: Irrlichter und Kobolde (zum ersten } \\
\text { Mal in diesen Konzerten); Dohnányi: Klavierkonzert e-Moll (neu, } \\
\text { Manuskript); Čajkovskij: Hamlet, Fantasie-Ouvertüre (zum ersten } \\
\text { Mal); Gernsheim: Sinfonie Nr. } 1 \text { (zum ersten Mal in diesen } \\
\text { Konzerten) }\end{array}$ \\
\hline $\begin{array}{l}\text { 1900/01 } \\
\text { (Nikisch) }\end{array}$ & \begin{tabular}{|l} 
August \\
Klughardt
\end{tabular} & $\begin{array}{l}\text { Schillings: Sinf. Prolog zu König Oedipus (zum ersten Mal); } \\
\text { Čajkovskij: Sinfonie Nr. } 4 \text { (zum ersten Mal in diesen Konzerten); } \\
\text { Sinding: Violinkonzert (zum ersten Mal in diesen Konzerten); Lalo: } \\
\text { Ouvertüre zu Le Roi d'Ys (zum ersten Mal in diesen Konzerten); } \\
\text { Richard Strauss: Till Eulenspiegel (zum ersten Mal in diesen } \\
\text { Konzerten); Ph. Scharwenka: Dramatische Fantasie (zum ersten } \\
\text { Mal); J. S. Bach: Violinkonzert G-Dur mit Orgel, zwei Flöten und } \\
\text { Streichorchester (zum ersten Mal in diesen Konzerten); Haydn: } \\
\text { Sinfonie Nr. 17 C-Dur (zum ersten Mal in diesen Konzerten); A. } \\
\text { Klughardt: Sinfonie Nr. 5; Zöllner: Waldfantasie, sinf. Dichtung } \\
\text { (Manuskript, zum ersten Mal); d'Albert: Cellokonzert C-Dur (zum } \\
\text { ersten Mal in diesen Konzerten); Koesseler: Sinf. Variationen (zum } \\
\text { ersten Mal); d'Albert: Klavierkonzert op. } 2 \text { (zum ersten Mal in } \\
\text { diesen Konzerten) }\end{array}$ \\
\hline $\begin{array}{l}\text { 1901/02 } \\
\text { (Nikisch) }\end{array}$ & & $\begin{array}{l}\text { Hausegger: Barbarossa, sinf. Dichtung (zum ersten Mal in diesen } \\
\text { Konzerten); A. Averkamp: Elaine und Lancelot, sinf. Dichtung } \\
\text { (zum ersten Mal); F. Volbach: Es waren zwei Königskinder, sinf. } \\
\text { Dichtung (zum ersten Mal); H. Huber: Sinfonie Nr. } 2 \text { (zum ersten } \\
\text { Mal) }\end{array}$ \\
\hline
\end{tabular}

Übersicht 3: »Neuheiten« in den Abonnementkonzerten des Berliner Philharmonischen Orchesters $(1882 / 83-1901 / 02)$

Wie die Übersicht 3 zeigt, brachten die Abonnementkonzerte des Berliner Philharmonischen Orchesters viele neue Werke zur Aufführung. Angesichts der großen Menge der vorgestellten Neuheiten muss man sich wundern, wie wenige davon sich für lange Zeit hindurch in den Konzertprogrammen behaupten konnten. In seinem 1911 veröffentlichten Buch Berlin als Musikstadt wies Adolf Weissmann schon darauf hin:

Endlich am 21. Oktober 1887 gaben nach Auflösung der philharmonischen Gesellschaft Bülow und das philharmonische Orchester, für das nun Hermann Wolff verantwortlich zeichnete, ihr erstes Konzert. Aber selbst jetzt, wo die 
philharmonischen Konzerte unter Dach und Fach gebracht sind, kann mich weder die Aufzählung sämtlicher in ihnen aufgeführten Novitäten noch der für die Mitwirkung gewonnenen Solisten sonderlich reizen. Denn über die meisten neuen Kompositionen hat die Zeit ihr Urteil gesprochen; sie sind gekommen und gegangen, Versuche im Kampf ums Dasein auf dem Gebiete des musikalischen Schaffens, an sich notwendig, aber nur als Durchgangsstationen, als Wegbahner für das erwartende Genie. ${ }^{350}$

Diese Auffassung bestätigt unsere Erkenntnis bei der Auswertung der aufgeführten Werke, dass nämlich viele Kompositionen und Komponisten nur einmal auf dem Programm erschienen. Die Etablierung bestimmter Werke oder die Wiederholung der Werke von bestimmten Komponisten als Standardrepertoire scheint nicht die Hauptsache bei der Programmgestaltung dieser Konzerte gewesen zu sein.

Wenn es auch sich hier um eine etwas spätere Zeit handelt, könnte diese Betrachtung zu Rebecca Grotjahns Bemerkung zur Funktion zeitgenössischer Orchestermusik im Konzert in der Zeit zwischen 1860 und 1880 in Beziehung gesetzt werden. Grotjahn bezeichnet diese zwei Jahrzehnte, die in der verbreiteten Musikgeschichtsschreibung als »tote Zeit« in der Gattungsgeschichte der Sinfonie gelten, als »eine Blütezeit für die Sinfoniekomposition«. ${ }^{351}$ Ihrer Ansicht nach hatte die zeitgenössische Orchestermusik seit dem Auftreten Beethovens bis in die heutige Zeit hinein nie bessere Chancen als in dieser Zeit, die Anzahl der in diesem Zeitraum entstandenen sinfonischen Werke gehe in die Hunderte. Neukompositionen erlebten jedoch nur in Ausnahmefällen Aufführungswiederholungen am selben Ort, während sich klassische Sinfonien als etabliertes Repertoire konsolidiert hatten. »Neu« zu sein war die Funktion, die man von Neuheiten erwartete, wobei die Erweiterung des Repertoires und die Etablierung der Werke offenbar von zweitrangiger Bedeutung war. ${ }^{352}$

Wie im Abschnitt 2.1.1 verdeutlicht, hatte Wolff als Musikkritiker über die Konservativität des Berliner Musiklebens geklagt. Ein Forum für Neuheiten in dieser Stadt anzubieten und neue Werke als Attraktion vorzustellen scheinen die grundsätzlichen Ideen bei der Einrichtung der Abonnementkonzerte des Philharmonischen Orchesters gewesen zu sein.

\section{Hermann Wolff und die sinfonischen Dichtungen von Richard Strauss}

Nachdem festgehalten wurde, dass Hermann Wolff die Abonnementkonzerte des Berliner

Philharmonischen Orchesters wohl als ein Forum für Neuheiten geplant hatte, ist nun zu

\footnotetext{
${ }^{350}$ Weissmann: Berlin als Musikstadt, S. 357.

${ }^{351}$ Grotjahn: Die Sinfonie im deutschen Kulturgebiet 1850 bis 1875, S. 199.

${ }^{352}$ Ebd., S. 220f.
} 
fragen, wie und inwieweit er auf die Aufnahme der neuen Werke in die Programme einwirken konnte. Der Vorgang, wie ein neues Werk ins Programm kam, ist jedesmal unterschiedlich und nur teilweise nachvollziehbar. Hier sei als Beispiel betrachtet, wie die sinfonischen Dichtungen von Richard Strauss in die Programme dieser Konzerte aufgenommen wurden.

Dass Bülow die Begabung des jungen Richard Strauss früh erkannte und sich für die Aufführung seiner Werke einsetzte, ist bekannt. ${ }^{353}$ Aus der Auswertung der überlieferten Briefe ergibt sich jedoch, dass das Berliner Konzertpublikum am Ende des 19. Jahrhunderts seine unverzügliche Bekanntschaft mit Strauss' sinfonischen Dichtungen zu einem hohen Maß auch Hermann Wolff verdankte, der die Aufführungen seiner Werke umsichtig plante.

Im Sommer 1887 trat Wolff mit Strauss in Verhandlung ein, um seine erste sinfonische Dichtung Aus Italien op. 16 in den Berliner Philharmonischen Konzerten in der kommenden Saison aufzuführen, und zwar der ersten Saison unter Bülow. Wolff bat den Komponisten darum, »eine kleine Analyse« für das Programmheft zu verfassen, ${ }^{354}$ und sagte zu, dieses Werk »an Henschel u andere [zu] empfehlen« ${ }^{355}$ Dieses Werk war am 2. März 1887 im Münchner Odeon-Saal von der lokalen Hofkapelle unter der Leitung des Komponisten uraufgeführt und beim Aibl-Verlag veröffentlicht worden. Anschließend an diese Münchener Premiere, eine Aufführung im Gürzenich in Köln vom 8. Januar 1888 und eine weitere im Museumskonzert in Frankfurt am Main vom 18. Januar 1888 war das Berliner Philharmonische Konzert vom 23. Januar 1888 unter der Leitung des Komponisten die vierte Aufführung dieses Werkes. Die Neuheiten, die in den Philharmonischen Konzerten zur Aufführung gebracht worden waren, wurden oft in den populären Konzerten des gleichen Orchesters wieder gespielt. ${ }^{356}$ Auch dieses Werk wurde zwei Tage später im populären Konzert vom 25. Januar 1888 unter der Leitung vom Komponisten wieder aufgeführt. 357 Die Don Juan-Aufführung im Berliner Philharmonischen Konzert vom 31. Januar 1890 unter der Leitung von Bülow war die dritte Aufführung dieses Werkes, anschließend an die erfolgreiche Premiere vom 11. November 1889 unter der Leitung des Komponisten in Weimar und die zweite Aufführung vom 10. Januar 1890 unter Adolf Hagen in Dresden. Den

\footnotetext{
${ }^{353}$ Vgl. z. B.: Thomas-M. Langner: Bülow, Strauss und die Berliner Erstaufführung von »Tod und Verklärung«, in Philharmonische Blätter 6 (1973/74), S. 2-5, hier S. 2. Vgl. auch: Briefwechsel von Bülow und Strauss in Lieber Collega! Richard Strauss im Briefwechsel mit zeitgenössischen Komponisten und Dirigenten 1, hg. von Gabriele Strauss, Berlin 1996, S. 14-101.

${ }^{354}$ Brief von Hermann Wolff an Richard Strauss vom 14.8.[1887], RSI.

${ }^{355}$ Brief von Hermann Wolff an Richard Strauss vom 29.8.[1887], RSI.

${ }^{356}$ Vgl. z. B.: Brief von Hermann Wolff an Engelbert Humperdinck vom 17.8.1898, Universitätsbibliothek Johann Christian Senckenberg, 5710, 9198.

${ }^{357}$ Dieses Werk erzielte danach in der Wiesbadener Tonkünstlerversammlung des Allgemeinen Deutschen Musikereins 1889 einen großen Erfolg.
} 
Grund, warum nicht er selbst, sondern Bülow die Berliner Erstaufführung dieses Werkes dirigierte, führte der Komponist in seinem Brief an die Eltern auf den »Geschäftskniff Wolffs« zurück, »der wünschte, daß Bülow persönlich für dieses allermodernste sinfonische Werk eintrete und damit einen Schlag gegen den Wagner-Verein führe durch den Beweis, daß die Firma Wolff nicht bloß abgelagerte, sondern auch die allerneuesten Artikel führe«. ${ }^{358}$ Strauss war sehr unzufrieden mit der Aufführung von Bülow, der sich, obwohl er vom Komponisten über die genauen Metronomangaben im Voraus brieflich informiert worden war, ${ }^{359} »$ in Tempi, in allem total [vergriffen] «, trotzdem ein großes Aufsehen gemacht habe. ${ }^{360}$ Dieser Berliner Erstaufführung folgte das populäre Konzert vom 4. Februar 1890, in dem der Komponist selbst das Werk leitete.

In der Saison 1890/91 führten die Philharmonischen Konzerte zwei Werke von Richard Strauss ins Berliner Musikleben ein: die Burleske und Tod und Verklärung. Beide waren auf der Eisenacher Tonkünstlerversammlung des ADMV im Juni 1890 erfolgreich uraufgeführt worden. Gegenüber Wüllner verriet Strauss, dass Wolff sich durchsetzen musste, um die sinfonische Dichtung Tod und Verklärung ins Programm des Philharmonischen Konzerts in der laufenden Saison einzuplanen:

[...] ich weiß jetzt schon nicht, was ich mit Hermann Wolff anfange, der mir in einer günstigen Stunde, eigentlich gegen meinen Willen, das Versprechen abgepreßt hat, ihm das Manuscript von Tod u. Verklärung für den Januar zu überlassen. ${ }^{361}$

Dem Wunsch von Eugen Spitzweg entsprechend, der die Veröffentlichung dieses Werkes vorhatte und dessen Aufführung gern beiwohnen wollte, wurde seine Berliner Erstaufführung unter der Leitung des Komponisten für das Philharmonische Konzert vom 23. Februar 1891 angesetzt $\mathrm{t}^{362}$ und auch im populären Konzert des Folgetages wurde es wieder aufgeführt.

Dass die revidierte, dritte Fassung von Macbeth in einem Philharmonischen Konzert zur Uraufführung kam, ist, wie Walter Werbeck hinweist, wohl vor allem dem Drängen Spitzwegs bei Bülow zu verdanken. ${ }^{363}$ Bülow, der den Komponisten zur Revision veranlasst

\footnotetext{
${ }^{358}$ Brief von Richard Strauss an seine Eltern vom 5.2.1890, Richard Strauss, Briefe an die Eltern. 18821906, S. $128 f$.

${ }^{359}$ Brief von Richard Strauss an Hans von Bülow vom 15.1.1890, Lieber Collega!, S. 89.

${ }^{360}$ Brief von Richard Strauss an seine Eltern vom 5.2.1890, Richard Strauss: Briefe an die Eltern, S. 128.

${ }^{361}$ Brief von Richard Strauss an Franz Wüllner vom 17.12.1890, Richard Strauss und Franz Wüllner im Briefwechsel, S. 17.

${ }^{362}$ Briefe von Hermann Wolff an Richard Strauss vom 15.1.[1891] und 19.1.1891, RSI.

${ }^{363}$ Walter Werbeck: »Macbeth « von Richard Strauss. Fassungen und Entstehungsgeschichte, in Archiv für Musikwissenschaft 50 (1993), S. 232-253, hier S. 251.
} 
hatte, äußerte sich zur bearbeiteten Fassung positiv ${ }^{364}$ und ließ den Komponisten diese neue Fassung im Philharmonischen Konzert vom 29. Februar 1892 selbst dirigieren. Aus der Perspektive der vorliegenden Arbeit ist aber interessant, dass Wolff, unabhängig von Bülow, zu einem viel früheren Zeitpunkt die Idee der Aufführung dieses Werkes geäußert hatte.

Strauss vollendete die erste Fassung dieses Werkes Anfang Januar 1888. ${ }^{365}$ Wann Bülow sie kennenlernte, ist nicht bekannt. Es ist aber denkbar, dass der Komponist Bülow während seines Berlinaufenthalts in der zweiten Hälfte des gleichen Monates eine Einsicht in die Partitur von Macbeth gewährte und dieser dessen formale Konzeption bemängelte. Strauss war sich schon darüber bewusst, dass er in Aus Italien den Weg des Sinfonikers in der Nachfolge Brahms' verlassen und sich mit Macbeth an den Neudeutschen ausgerichtet hatte, was ihm keine Zustimmung von Bülow einbringen sollte. Trotzdem scheint Bülows Kritik den Komponisten nicht entmutigt, sondern sogar zur Umarbeitung des Werkes veranlasst zu haben. Im Sommer des gleichen Jahres, wahrscheinlich im August, traf Strauss erneut mit Bülow zusammen und zeigte ihm offenbar die neue Fassung von Macbeth. Bülow kritisierte erneut das Stück hart, vor allem dessen Reichtum an Dissonanzen, und nutzte wohl auch die Gelegenheit, Strauss' neuen Weg als Komponist grundsätzlich infrage zu stellen. Der junge Komponist machte nun dem alten Mentor seine Selbstsicherheit klar, ${ }^{366}$ wobei die ästhetischen Differenzen zwischen den beiden erstmals offen aufbrachen. Es scheint, dass Strauss nach diesem Ereignis nicht mehr sicher war, welche Fassung er definitiv wählen sollte: die formal »traditionellere« erste mit glanzvollem Dur-Finale oder die formal »logischere« zweite mit kurzem düsterem Moll-Schluss. Erst im Verlauf des ersten Viertels des Jahres 1889, in dem das Werk Vorspielen in Mannheim und Meiningen erfuhr, hatte Strauss sich nach den Ausführungen Werbecks definitiv für die zweite Fassung entschieden. ${ }^{367}$

Im September des gleichen Jahres trat Strauss seinen neuen Dienst als Weimarer Kapellmeister an. In diesem Herbst lud Hermann Wolff ihn zum ersten Mal zu einem Konzert des Dresdner Gewerbehausorchesters, der heutigen Dresdner Philharmonie, ein. Während der Planung dieses Konzertes vom 24. Oktober 1889 nannte Wolff in seinem Brief vom 4.

\footnotetext{
364 »Hing egen glaube ich, den »Macbeth« talem qualem übernehmen zu können.« Brief von Hans von Bülow an Eugen Spitzweg vom 16.11.1891. Bülow-Briefe 7, S. 350. Hervorhebung im Original.

${ }^{365}$ Der folgende Abriss der Entstehungsgeschichte von Macbeth bezieht sich auf: Walter Werbeck: »Macbeth« von Richard Strauss, S. 239-252.

$366 »$ Der genaue Ausdruck meines künstlerischen Denkens und Empfindens, u[nd] im Stil das selbständigste und zielbewußteste Werk, das ich bis jetzt gemacht habe, ist nun »Macbeth«. Brief von Richard Strauss an Hans von Bülow. 24. August 1888. Lieber Collega!, S. 83.

${ }^{367}$ Walter Werbeck: »Macbeth« von Richard Strauss, S. 244.
} 
September 1889 Macbeth. ${ }^{368}$ Diese Idee wurde zwar nicht verwirklicht, wohl, wie er selbst schrieb, wegen des zu hohen Anspruchs des Werkes für das Orchester. Aber die Tatsache, dass Hermann Wolff zu einem Zeitpunkt, in dem Bülow und Strauss zu Macbeth klar gegensätzliche Stellung zeigten, an eine Aufführung dieses Werkes im Rahmen der Abonnementkonzerte denken konnte, die im Unterschied zu den Berliner und Hamburger Abonnementkonzerten nicht in Bülows Hand lagen, zeigt, dass er sich auch unabhängig von Bülow aus freiem Willen für die Aufführung der Musik von Strauss einsetzen konnte und wollte.

Etwa ein Jahr später, am 13. Oktober 1890, brachte Strauss die zweite Fassung von Macbeth in Weimar zur Uraufführung. Während er ihren Inhalt und ihre Form für gelungen halten konnte, war er unzufrieden mit ihrer Instrumentierung. Eine umfassende Umarbeitung begann dann am 26. Oktober 1890 und war am 4. März 1891 abgeschlossen. Erst Mitte Dezember des gleichen Jahres erschien die dritte Fassung von Macbeth, die auch Bülow überzeugte $^{369}$ und Ende Februar 1892 im Berliner Philharmonischen Konzert uraufgeführt wurde.

Wie Scott Warfield in seinem Aufsatz ausführlich darlegte, gelang Strauss und seinem Verleger Spitzweg erst bei Till Eulenspiegels lustige Streiche, die Erfahrungen beider in den vorangegangenen Jahren zur Anwendung zu bringen: Geradezu propagandistisches Knowhow war erforderlich, um die Synergie zwischen guten Aufführungen und der rechtzeitigen Publikation der Noten zu maximieren. ${ }^{370}$ Strauss vollendete die Komposition dieses Werkes am 6. Mai 1895. Nur etwa vier Monate später konnte Spitzweg in Zeitschriften Werbung für die demnächst erscheinende Partitur, Stimmen und den Klavierauszug dieses Werkes machen, die die Bemerkung enthielt, dass eine Reihe von Konzertinstituten schon Aufführungen dieses Werkes für die gerade beginnende Saison planten, und dass das Recht zur Aufführung nur beim Verlag eingeholt werden könne (vgl. Abbildung 19)

Das Werk wurde am 5. November 1895 in Köln unter der Leitung von Franz Wüllner uraufgeführt. Dieser Premiere folgten die Mannheimer Aufführung vom 12. November 1895 unter der Leitung von Hugo Röhr und die Berliner Erstaufführung im Sinfonieabend der

\footnotetext{
$368 \gg$ Ich hatte an Ihren Macbeth gedacht, aber für das Orchester - noch dazu im ersten Concert - ist das eine zu große Aufgabe. « Brief von Hermann Wolff an Richard Strauss vom 4.9.1889, RSI.

369 »Übrigens macht es mir Vergnügen, Ihnen hiermit zu bekennen, daß mir die Umarbeitung Ihres »Macbeth « trotz aller Herbheiten und Materialmontrositäten hoch imponiert hat. Ich sympathisiere - qua spezifischer Musiker - weit mehr mit diesem Opus als mit dem vorherge[he]nden »T[od] und V[erklärung]«: ich finde Logik und Genialität.« Brief von Hans von Bülow an Richard Strauss vom 1.2.1892, Lieber Collega!, S. 93.

${ }^{370}$ Scott Warfield: Strauss and the Business of Music, in The Cambridge Companion to Richard Strauss, hg. von Charles Youmans, Cambridge 2010, S. 242-256, hier: S. 248f.
} 
Königlichen Kapelle vom 15. November 1895 unter der Leitung von Felix Weingartner. Innerhalb eines Jahres gab es wenigstens 25 weitere Aufführungen dieses Werkes, was keine früheren Orchesterwerke des Komponisten erlebt hatten. ${ }^{371}$

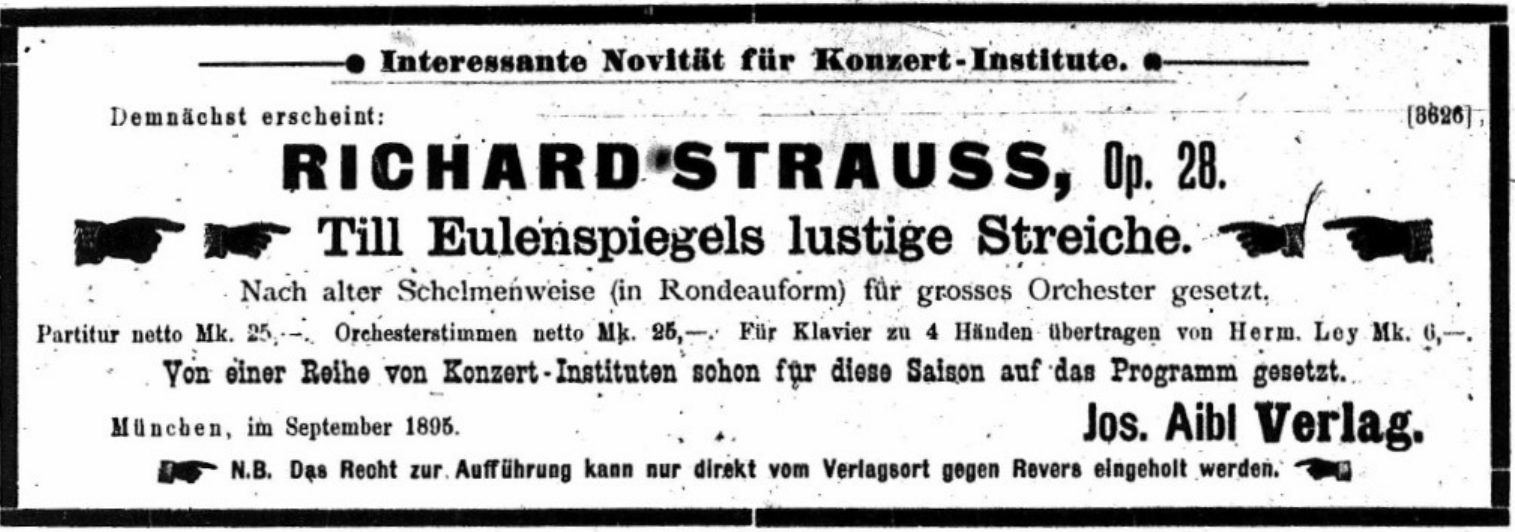

Abbildung 19: Werbung für die Druckausgabe von Till Eulenspiegels lustige Streiche von Richard Strauss $^{372}$

Auch nachdem Strauss als Dirigent der Philharmonischen Konzerte keinen gewünschten Erfolg hatte erzielen können und Nikisch seine Stelle übernommen hatte, engagierte Wolff sich weiter dafür, neue Werke dieses Komponisten für Berliner Erstaufführungen zu bekommen. Die neue sinfonische Dichtung Till Eulenspiegels lustige Streiche schätzte Wolff als »Ihr bestes, reinstes Werk«, und sogar als »eines der besten Orchesterwerke überhaupt, die ich außerhalb der klassischen Literatur kenne« ein. ${ }^{373}$ Aber diesmal musste er der Hofkapelle unter Weingartner die Berliner Erstaufführung abtreten. Als Wolff Ende Juni oder Anfang Juli das Werk verlangte, habe Spitzweg ihm geschrieben, dass es noch nicht fertig gedruckt sei. Der folgende Brief von Wolff an Strauss ist interessant, weil er uns nicht nur den Vorgang dieser Angelegenheit, sondern auch das Selbstbewusstsein Wolffs als »Veranlassung« zur Aufführung von Neuheiten vermittelt:

Die Wahrheit aber bleibt doch, daß er [Spitzweg, A. d. V.] unanständig gehandelt hat. Beweis: Wir hatten alle Werke von Ihnen gebracht, die Sinf. Capelle nur etwas. [...] Hätte damals Weingart[ner] schon danach verlangt, so würde Sp[itzweg] mir damals das mitgetheilt haben! Nein, er hat gedacht es ist vortheilhafter für ihn, es bei

\footnotetext{
${ }^{371}$ Scott Warfield: Strauss and the Business of Music, S. 249.

372 Allgemeine Musik-Zeitung 22 (1895), S. 479.

${ }^{373}$ Brief von Hermann Wolff an Richard Strauss vom 23.11.[1895], RSI.
} 
$\mathrm{W}$ [eingartner] machen zu lassen $\mathrm{u}$. darum hat er jede abständige Rücksicht hintan gesetzt $[\ldots]$.

So aber ist die Sache für mich erledigt. Ich bringe Eulenspiegel u. Spitzweg existiert für mich einfach nicht. Er hat übrigens auch die blöde Bemerkung in einem Brief gemacht: an mir läge es nicht, daß Ihre Werke in diesen Concerten gemacht werden seien. Nein, dirigiert habe ich sie nicht, aber meine Concerte sind es u. $\underline{\text { ich }}$ bin immer die directe Veranlassung daß die Novitäten gemacht werden. ${ }^{374}$

Warum Spitzweg diesmal auf Weingartners Seite stand, konnte im Rahmen der vorliegenden Arbeit nicht ermittelt werden. Bekannt ist nur, dass Weingartner dieses Werk schon vor Ende August 1895 verlangt hatte. ${ }^{375}$ Vielleicht waren das Misslingen Strauss' in der letzten Saison als Dirigent der Philharmonischen Konzerte oder sein Wunsch, Nachfolge von Weingartner zu werden, ${ }^{376}$ mittelbar oder unmittelbar für den Vorzug der Königlichen Kapelle verantwortlich. Aber offensichtlich hinderte Strauss' Misserfolg als Dirigent Wolff nicht daran, neue Werke von ihm weiterhin auf das Programm seiner Konzerte zu setzen. Ende der Saison bekundete er dem Komponisten erneut das Interesse für seine neuen Werke und bat darum, »daß diesmal Ihr neues Werk seine Premiere in den Philharmonischen Concerten erlebt. $\ll^{377}$

Ab 1896/97 übernahm das Berliner Philharmonische Orchester auch die von Wolff veranstalteten Neuen Philharmonischen Konzerte in Hamburg. Die Berliner und Hamburger Abonnementkonzerte mussten nun aus organisatorischen Gründen in einigen Punkten aufeinander bezogen werden. Da die in Hamburg verfügbare Probezeit für die Einstudierung neuer Werke nicht ausreichte, konnte Felix Weingartner, der seit 1895/96 die Hamburger Abonnementkonzerte leitete, dort im Prinzip nur die Neuheiten aufführen, die das Orchester in Berlin schon studiert und gespielt hatten. ${ }^{378}$

Nach diesem Prinzip wurden in der Saison 1896/97 zwei neue Werke in Berlin und Hamburg hintereinander zur Aufführung gebracht: Till Eulenspiegels lustige Streiche von Strauss ${ }^{379}$ und

\footnotetext{
${ }^{374}$ Brief von Hermann Wolff an Richard Strauss vom 27.11.[1895], RSI. Hervorhebungen im Original.

${ }^{375}$ Brief von Richard Strauss an Franz Wüllner vom 28.8.[1895], Richard Strauß und Franz Wüllner im Briefwechsel, S. 27.

${ }^{376}$ Dazu vgl. 3.2.3 der vorliegenden Arbeit.

${ }^{377}$ Brief von Hermann Wolff an Richard Strauss vom 1.4.1896, RSI.

${ }^{378}$ Brief von Hermann Wolff an Richard Strauss vom 2.4.1896, RSI.

${ }^{379}$ Aus unbekannten Gründen fand die Berliner Aufführung nicht im Philharmonischen Konzert, sondern im Konzert der Wagner-Vereine Berlin und Berlin-Potsdam vom 2. November1896 statt, in dem das Berliner Philharmonische Orchester das Werk unter der Leitung vom Komponisten spielte. Die Hamburger Aufführung wurde von Weingartner im Neuen Abonnementkonzert vom 12. November 1896 gegeben. In
} 
Was mir die Blumen auf der Wiese erzählen aus der dritten Sinfonie von Gustav Mahler. ${ }^{380}$ In der gleichen Saison wurde noch dazu Strauss' neueste sinfonische Dichtung Also sprach Zarathustra im Philharmonischen Konzert vom 30. November 1896, also nur drei Tage nach ihrer Uraufführung in Frankfurt am Main, in Berlin unter der Leitung von Nikisch aufgeführt. ${ }^{381}$

Unter diesen sinfonischen Dichtungen von Strauss erlangte Don Juan op. 20 bald einen besonders festen Platz im Repertoire dieses Orchesters. Nicht nur in den Berliner Konzerten, ${ }^{382}$ sondern auch auf den großen Tourneen, die ebenfalls von Wolff organisiert wurden, wurde das Werk mehrmals unter der Leitung von verschiedenen Dirigenten aufgeführt. ${ }^{383}$ Auch die anderen sinfonischen Dichtungen wie Till Eulenspiegels lustige Streiche, ${ }^{384}$ Tod und Verklärung ${ }^{385}$ und Also sprach Zarathustra ${ }^{386}$ wurden zu Lebzeiten Wolffs in den Philharmonischen Konzerten unter Nikisch wieder aufgeführt. Im Vorwort zu seinem oben erwähnten Buch Berlin als Musikstadt sprach Weissmann von einer $»$ Richard Strauss-Epoche $«^{387}$ als einer Phase - oder Mode -, die auf die Epoche Richard Wagners gefolgt war. ${ }^{388}$ Unter den zahlreichen Wagner-Epigonen ragte Strauss, so Weissmann, »als ein Eigener [...] hervor« durch seine sinfonischen Dichtungen, in denen er »Programm und Form zu vermählen « ${ }^{389}$ wusste. Nach Weissmanns Einschätzung war Strauss zwar nichts anderes als ein an Poesie ärmlicher Epigone von Wagner. Aber wenigstens gab es die Jahrzehnte, auf die man als »Richard Strauss-Epoche« zurückblicken konnte. Dem obigen

den Berliner Philharmonischen Konzerten wurde dieses Werk erst am 19. November 1900 unter Nikisch gespielt.

380 Philharmonisches Konzert vom 9. November 1896 in Berlin und Neues Abonnementkonzert vom 7.

Dezember 1896 in Hamburg.

${ }^{381}$ Nikisch wiederholte das Werk noch einmal in der gleichen Saison im Philharmonischen Konzert vom 22. Februar 1897.

${ }^{382}$ Konzert vom 31.1.1890 (Bülow), 4.2.1890 (Strauss), 29.1.1894 (Strauss), 17.2.1896 (Nikisch) und vom 6.3.1899 (Nikisch).

${ }^{383}$ Reise nach Deutschland, Frankreich und der Schweiz im Mai 1897 (Nikisch), Russische Tournee im Mai 1899 (Nikisch) und Frühjahrstournee durch Europa im April und Mai 1900 (Richter).

${ }^{384}$ Das 4. Philharmonische Konzert der Saison 1900/01 (19.11.1900).

${ }^{385}$ Das 4. Philharmonische Konzert der Saison 1901/02 (25.11.1901).

${ }^{386}$ Das 6. Philharmonische Konzert der Saison 1901/02 (20.1.1902).

${ }^{387}$ Adolf Weissmann: Berlin als Musikstadt, S. 8.

${ }^{388}$ Zur Formel von Berlins »Richard Strauss-Epoche« von Weissmann, vgl.: Dietmar Schenk: Berlins $»$ Richard- Strauss-Epoche«. Richard Strauss und das Musikleben im kaiserlichen Berlin, in Richard Strauss. Der Komponist und sein Werk. Überlieferung, Interpretation, Rezeption. Bericht über das internationale Symposium zum 150. Geburtstag München 26.-28. Juni 2014, hg. von Sebastian Bolz u. a., München 2017, S. 37-49, vor allem S. 44f.

${ }^{389}$ Weissmann: Berlin als Musikstadt, S. 350. 
Zitat zu den Philharmonischen Konzerten als »Durchgangsstation« von verschiedenen Werken aus diesem Buch folgt:

Warum ich selbst Richard Strauss nicht für ein solches [ein erwartetes Genie nach Wagner, A. d. V.] halten kann, habe ich verraten. Auch von seinen Werken hat bis jetzt nur das eine oder das andere seinen festen Platz in den Konzertprogrammen behaupten können. Will sich aber der Komponist auf Richard Wagner und sein langes Verkanntsein berufen, so ist demgegenüber festzustellen, dass kein Schaffender je so enthusiastisch begrüßt, keiner mit solcher Geschwindigkeit auf den Schild erhoben wurde, wie Richard Strauss. ${ }^{390}$

Sicherlich waren die neuen sinfonischen Dichtungen von Strauss eine Attraktion, die Wolff in den Berliner Philharmonischen Konzerten fast wie eine Serie fortlaufend anbieten konnte. Wie Mark-Daniel Schmidt schrieb, sind diese Werke vor allem durch die fortlaufende Auseinandersetzung des Philharmonischen Orchesters im Berliner Musikleben frühzeitig bekannt geworden. ${ }^{391}$ Offensichtlich beabsichtigte Wolff nicht gezielt, diese Werke als Standardrepertoire zu etablieren. Aber wenn man von einer $»$ Richard Strauss-Epoche« in Berlin sprechen kann, hat Hermann Wolff, der diese Auseinandersetzung wesentlich veranlasste, sicherlich als eine Schlüsselfigur zu gelten, die sie entstehen ließ.

\subsection{2 »Partheilichkeiten müssen schweigen«: Hermann Wolff als Schlüsselfigur für die Berliner Tonkünstlerversammlung des Allgemeinen Deutschen Musikvereins 1891}

Vom 31. Mai 1891 bis zum 3. Juni1891 tagte der Allgemeine Deutsche Musikverein ${ }^{392}$ zum ersten Mal in Berlin. Die Tonkünstlerversammlungen dieses Vereins, die es sich zur Aufgabe

\footnotetext{
${ }^{390}$ Ebd., S. 357f.

${ }^{391}$ Mark-Daniel Schmidt ist der Ansicht, dass das Philharmonische Orchester der wichtigste Vertreter der sinfonischen Dichtungen von Strauss in Berlin war. Er schätzt die Zahl der Aufführung dieser Werke vom Berliner Philharmonischen Orchester zwischen 1887 und 1908 auf 23 und diejenigen des Berliner Tonkünstler Orchesters als sein zweiter Vertreter auf 10. Mark-Daniel Schmidt: The Early Reception of Richard Strauss's Tone Poems, in The Richard Strauss Companion, hg. von Mark-Daniel Schmidt, London 2003, S. 145-190, hier S. 178.

${ }^{392}$ Dieser Verband wurde, wie bekannt, zur Pflege der Tonkunst und zur Förderung der Musiker unter Franz Liszt als spiritus rector 1861 in Weimar gegründet. Den verbreiteten Terminus »Neudeutsch« prägte
} 
machten, in erster Linie zeitgenössische Musik aufzuführen und als Forum zeitgenössischen Schaffens zu dienen, ${ }^{393}$ wurden zuvor in Städten mittlerer Größe wie Weimar, Leipzig, Altenburg, Magdeburg, Karlsruhe, Zürich, Wiesbaden, Köln, Erfurt, Dessau und Eisenach abgehalten. Die Nachricht, dass dieser Verein nach seinem 30-jährigen Bestehen sein Musikfest endlich in der Reichshauptstadt abhalten würde, wurde mit Freude und Begeisterung aufgenommen. In der Neuen Zeitschrift für Musik, dem Organ des ADMV, schreibt William Wolf über das sich verändernde Verhältnis zwischen Berlin und dem Verein wie folgt:

Es herrschte in dem Musikübenden [sic!] und [-]liebenden Bevölkerungstheil des früheren Berlin ein nicht bloß schwer anregbarer und nüchtern-kritischer, sondern geradezu erkältender Geist, der das Neue schon vorweg ablehnte, weil es neu war, eine Richtung mithin, welche mit der leben-fördernden und für die Gegenwart Gerechtigkeit verlangenden des Allgemeinen Musikvereins in direktem Widerspruch stand. Das ist aber längst anders geworden; und wenn der Verein nicht etwa in den entgegengesetzten Fehler verfallen und alles Neue, das er bringt, gepriesen wissen wollte, schon weil es neu ist, so konnten zweifellos Berlin und der Verein sich nunmehr symphathisch zusammenfinden. ${ }^{394}$

Angesichts dieser Veränderung träumte man in Berlin, wie Martin Krause schrieb, »von Riesenveranstaltungen, wie sie einer Riesenstadt entsprächen, von Concerten, welche alles Dagewesene überbieten sollen, von einer Betheiligung unseres kunstsinnigen Kaisers, von

der erste Vorsitzende Franz Brendel bei der Gründung des Vereins, um den von den Gegnern abschätzig benutzten Terminus »Zukunftsmusik« zu überwinden. Zu diesem Verein und dessen Tonkünstlerversammlungen vgl. z. B. Irina Kaminiarz: Richard Strauss. Briefe aus dem Archiv des Allgemeinen Deutschen Musikvereins (1888-1909), Weimar u. a. 1995, S. 9-20; Samuel Weibel: Die deutschen Musikfeste des 19. Jahrhunderts im Spiegel der zeitgenössischen musikalischen Fachpresse, Kassel 2006, S. 545-678.

${ }^{393}$ Die eigentliche Aufgabe der Tonkünstlersammlung war, »bedeutende, wenig gehörte, insbesondere neue Tonwerke jeglicher Art [aufzuführen]. Jedoch auch ältere Werke, welche selten oder gar nicht mehr zu öffentlichen Aufführungen gelangen und dennoch durch ihre Bedeutsamkeit von allgemeinem Interesse sind« aufzuführen. Irina Lucke-Kaminiarz: Der Allgemeine Deutsche Musikverein und seine Tonkünstlerfeste 1859-1886, in Liszt und die Neudeutsche Schule, hg. von Detlef Altenburg, Laaber 2006, S. 221-235, hier S. 223.

${ }^{394}$ William Wolf: Die 28. Tonkünstler-Versammlung des Allgemeinen Deutschen Musikvereins zu Berlin. 31. Mai bis 3. Juni. Erstes und zweites Concert, in Neue Zeitschrift für Musik 58 (1891), S. 277-279. hier S. 277. 
einer grossartigen Theilnahme der Bevölkerung, die alle materiellen Gefahren beseitigen sollte ${ }^{395}$

Wie die von Eugen John für die Festnummer der Neuen Berliner Musikzeitung gezeichnete Karikatur andeutet (Abbildung 20), war es Hermann Wolff, ${ }^{396}$ in dessen Hand alle Fäden der Berliner Tonkünstlerversammlung zusammenliefen. ${ }^{397}$ Etwa elf Monate vor der Veranstaltung schreibt Wolff an Oscar Eichberg, seinen Kollegen im geschäftsführenden Ausschuss des Vereins:

Ich werde persönlich meine ganze Kraft einsetzen u. ohne mich zu überschätzen, glaube ich dafür einzustehen, daß so weit ich in den Arrangements meiner Hand haben werde, alles klappen soll, wie nur ja! Auch die auf allen bisherigen Versammlungen sehr schlecht organisierten Proben-Eintheilungen müssen in Berlin als Muster Eintheilung hergestellt wurden. Das alles ist möglich.

Haben Sie über die Dirigentenfrage noch nachgedacht? Wenn auch viele Dirigenten ihre Werke selbst u. Gernsheim den Stern Verein leitete, so scheint mir doch für Berlin ein eigentlicher Festdirigent nöthig. Ich muß offen gestehen, ich habe noch keinen richtigen Einfall nach dieser Richtung hin gehabt.

Die Programmfrage wird uns am meisten bei Bronsart zu schaffen machen! Ich glaube aber, daß wir Liszt in der Hauptsache mit der bereits projectirten komischen heiligen Elisabeth erledigen müssen. Berlioz's Damnation de Faust u. sonst womöglich nur $\underline{\text { sehr Lebende. }}{ }^{398}$

\footnotetext{
${ }^{395}$ M[artin] Krause: Die 28. Tonkünstler-Versammlung des Allgemeinen Deutschen Musikvereins zu Berlin, in Musikalisches Wochenblatt 22 (1891), S. 327.

${ }^{396}$ Als »Musikschriftsteller u. Inhaber einer Concert-Agentur« war er seit den 1880er Jahren ein aktives Mitglied dieses Vereins. Verzeichnis der Mitglieder des Allgemeinen Deutschen Musikvereins 1882, S. 22, GSA 70/10.

${ }^{397}$ Auch im Artikel Die beim Musikfeste mitwirkenden Künstler in der gleichen Nummer ist Hermann Wolff, neben den namhaften Künstlern wie Lilli Lehmann, Siegfried Ochs und Eugen d'Albert, mit einem Foto als jemand vorgestellt, »der sich um das Zustandekommen des Tonkünstlerfestes in der Reichshauptstadt, das mit den grössten Schwierigkeiten verknüpft war, in hervorragender Weise verdient [gemacht] hat [...].« Neue Berliner Musikzeitung 45 (1891), S. 197.

${ }^{398}$ Brief von Hermann Wolff an Oscar Eichberg vom 12.7.1890, Berlin SBPK, Mus. ep. H. Wolff 990. Hervorhebung im Original.
} 


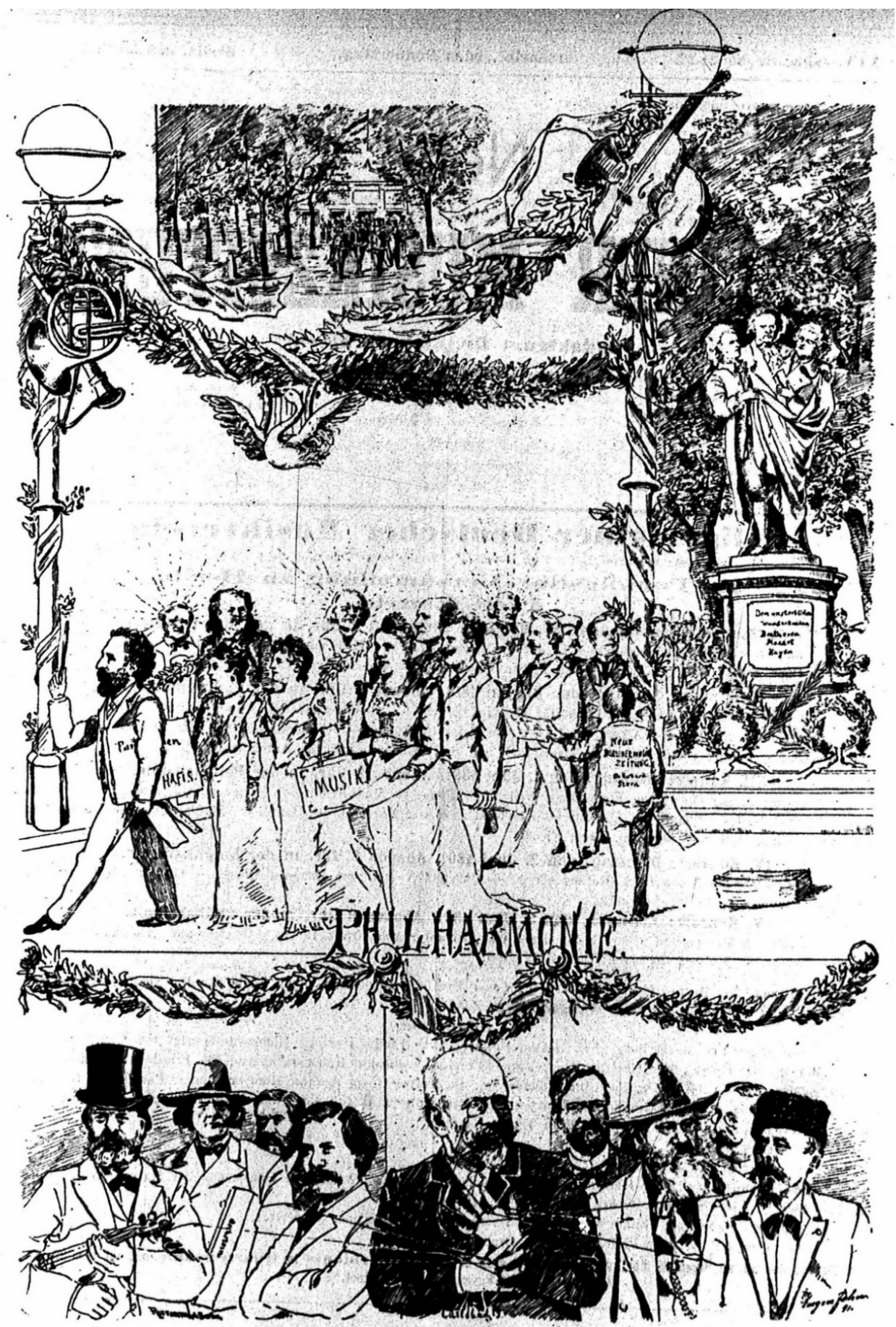

Abbildung 20: Eugen John, Bild zum Berliner Tonkünstlerfest des ADMV $1891^{399}$

\begin{abstract}
${ }^{399}$ Neue Berliner Musikzeitung 45 (1891), S. 184. Die Zeichnung ist in der gleichen Nummer wie folgt erklärt: »Mit Gernsheim, dem Festdirigenten, an der Spitze, gleich einem zweiten Rattenfänger von Hameln, eilen die Künstler und Künstlerinnen auf der mit den Hermen von Berlioz, Liszt und Richard Wagner geschmückten Strasse der Philharmonie zu. Wir sehen im Zuge Lilli Lehmann, die Musikalische, Theresa Carreño als höhere Konservatoristin mit der Musikmappe an Arm, als Vertreterin und Direktorin des ältesten Musikinstitutes Berlins Jenny Meyer, den anderen Festdirigenten Siegfried Ochs, die Klaviervirtuosen Max van de Sandt und Felix Dreyschock, im Hintergrunde Xaver Scharwenka, der mit seinem Fusse bereits jenseits des Oceans steht, und Emil Götze, von dem nur Cylinder und Nasenspitze sichtbar. Da nun einmal die Kritik nicht ausbleiben wird, so ist auch ihrer berufensten Vertreter, Wilhelm Tappert's und Heinrich Ehrlich's gedacht. [...] Hermann Wolff, seine ruhmgekrönten Klienten behutsam am Schnürchen führend, wie Joseph Joachim, eines der hellsten Lichter, das wohl einen grösseren Cylinder verdient. Eugen d'Albert und seine personificirte
\end{abstract}


Um die Bedeutung der Berliner Tonkünstlerversammlung 1891 richtig einschätzen zu können, sollen zunächst zwei Kontexte berücksichtigt werden: der damalige Zustand des ADMV und der des Berliner Musiklebens.

Der erste bezieht sich auf die Krise, in die der ADMV in den vorangegangenen Jahren geraten war. In den zwei Jahrzehnten seit 1868, in denen er sich in den sicheren Händen von Carl Riedel befand, konnte der Verein seine starke Stellung im zeitgenössischen Musikleben festigen und sogar noch ausbauen. Franz Liszt, der diesen Verein und seine Veranstaltungen von Anfang an stark geprägt hatte, starb 1886. Riedel starb nur zwei Jahre später. Seit der Übergabe des Präsidiums an Hans von Bronsart von Schellendorf, ${ }^{400}$ der als Komponist und Generalintendant des Weimarer Hoftheaters tätig war, häuften sich gravierende Missstände, sodass immer mehr Mitglieder tiefgreifende Reformen der Führung des Vereins und von dessen Tonkünstlerversammlungen forderten.

Außer der Überfrachtung der Tonkünstlerversammlungsprogramme, die bis 1887 die primäre Zielscheibe der Kritik gewesen war, kam ab 1888 das musikalische Niveau ins Kreuzfeuer der Kritik. Wegen der unterdurchschnittlichen Qualität der Aufführung und der belanglosen Kompositionen, die das Programm füllten, wurde die erste von Bronsart organisierte Tonkünstlerversammlung 1888 zu Dessau von der Presse kurzerhand zur schlechtesten Veranstaltung seit Bestehen des Vereins erklärt. Bei der nächsten Jahresversammlung in Wiesbaden fand sich erheblich weniger Publikum als sonst ein, sodass die Festbilanz ungünstig ausfiel. Im künstlerischen Sinne verlief die Tonkünstlerversammlung 1889 viel befriedigender als diejenige des Jahres zuvor, aber die übermäßige Bevorzugung vielgehörter Werke von renommierten Komponisten rief Einwände gegen das junge Präsidium hervor. Dieser Kritik nachkommend, erklangen in der Eisenacher Tonkünstlerversammlung 1890 vorwiegend neue Kompositionen. Hierbei ist vor allem wichtig, dass zwei Werke von Richard Strauss, die Burleske in d-Moll sowie die sinfonische Dichtung Tod und Verklärung hier ihre Uraufführung erlebten. Aber insgesamt wurde der

Oper an er Seite der $»$ Rubin-stein «, Martin Blumner vor seinem »Falle« als neugebackener Dr. hon. causa, auf der anderen Seite Arno Kleffel, der Kölner Stadttheater Kapellmeister und liebenswürdige Liederkomponist, endlich der grosse »Johannes«, dessen Bild manchen in dem Schmerz über seine Abwesenheit trösten wird. Paul Bulss und zuletzt Hans von Bülow, der als erster an die Stätte seiner Triumphe eilt.« Neue Berliner Musikzeitung 45 (1891), S. 185. Hervorhebungen im Original. ${ }^{400}$ Zur Karriere von Bronsart und der Änderung der musikparteilichen Verhältnisse zu seiner Zeit vgl. Arnfried Edler: Von Joachim zu Bronsart. Ästhetische Positionen zwischen 1850 und 1890 im Spiegel des hannoverschen Musiklebens, in Schubert und Brahms. Kunst und Gesellschaft im frühen und späten 19. Jahrhundert, hg. von Arnfried Edler, Augsburg 2001, S. 97-114. 
Niedergang der Tonkünstlerversammlung sowohl in der Qualität der aufgeführten Werke als auch in der Teilnehmerzahl deutlich. ${ }^{401}$

Wie Samuel Weibel vermerkt, war Otto Lessmann, der Redakteur der Allgemeinen Musik-Zeitung in Berlin, einer der schärfsten Kritiker der Missstände dieses Vereins. ${ }^{402}$ Eigentlich war er dem Verein und der Neudeutschen Schule freundlich gesinnt und amtierte auch als Vereinssekretär. Als Musikkritiker scheute er sich aber nicht, die Mängel und Fehlentwicklungen der Tonkünstlerversammlungen schonungslos zu kritisieren. In der Zusammenarbeit mit Lessmann und dem oben genannten Eichberg beschäftigte sich Wolff mit der Organisation der erwarteten Berliner Tonkünstlerversammlung.

Der zweite Kontext bezieht sich auf die Erschließungsmöglichkeit des Berliner Musiklebens. Lessmann schreibt, dass die größeren, für den Konzertsaal bestimmten neueren Kompositionen in der Reichshauptstadt nur wenig fruchtbaren Boden vorfanden.

Diese Erscheinung dürfte zunächst auf die ablehnende Haltung zurückzuführen sein, welche unsere beiden hervorragendsten Chorvereine bisher den grossen Vokalwerken Liszt's und Berlioz' gegenüber eingenommen haben, dann aber auch auf die gänzliche Nichtbeachtung, mit welcher der Leiter der augenblicklich tonangebenden Philharmonischen Konzert an den Orchesterwerken der genannten Meister vorübergeht. Die löblichen Anstrengungen, welche der Wagnerverein und einzelne Künstler im Verlauf der letzten Jahre gemacht haben, um Liszt und Berlioz die ihnen gebührende Beachtung zu verschaffen, sind von nachhaltigem Erfolge leider nicht begleitet gewesen, und erst im verflossenen Winter haben die kgl. Kapelle mit zwei sinfonischen Dichtungen von Liszt, der Philharmonische Chor mit desselben Meisters Missa choralis, vornehmlich aber der Wagnerverein mit Berlioz’ »Verdammung Faust's « wirklich tiefgehende Wirkungen hervorgebracht. ${ }^{403}$

Lessmann sieht die Singakademie, der Stern'sche Gesangverein und Hans von Bülow sicherlich als konservativ an, wie seine Anspielung vermuten lässt. In Berlin gab es damals noch den Raum, in dem sich die Bestrebungen des Allgemeinen Deutschen Vereins entwickeln könnten. Und hier etablierten sich zunehmend lokale Musiker und Konzertinstitute, welche die eigentliche Richtung des Vereins bei der

\footnotetext{
${ }^{401}$ Weibel: Die deutschen Musikfeste des 19. Jahrhunderts, S. 653-661.

402 Ebd., S. 651.

${ }^{403}$ Otto Lessmann: Zur 28. Tonkünstler-Versammlung des Allgemeinen Deutschen Musikvereins, in Allgemeine Musikzeitung 18 (1891), Nr. 22/23 (29.5. und 5.6.1891), S. 267f., hier: S. 268.
} 
Tonkünstlerversammlung, aber auch darüber hinaus, vertreten könnten. Karl Klindworth hielt sich beispielsweise ab 1882 in Berlin auf und hatte in den Abonnementkonzerten des Berliner Philharmonischen Orchesters ${ }^{404}$ und in den Konzerten des Berliner Wagner-Vereins als Vertreter der Musik von Liszt und Richard Wagner fungiert. Ein anderer Liszt-Schützling, Xaver Scharwenka, der 1881 sein eigenes Konservatorium und 1886 eine Orchesterkonzertreihe gegründet hatte, war ebenfalls in Berlin. $\mathrm{Zu}$ seinen gewagten Leistungen gehört die Aufführung der Dante-Symphonie und des 137. Psalms von Liszt, die in Zusammenarbeit mit dem Ochs'schen Gesangverein im Jahr 1886 erfolgte. Aus diesem von Siegfried Ochs gegründeten Chor, der ab 1887 Philharmonischer Chor geheißen hatte, war ein beachtlicher Konkurrent der Singakademie geworden. Während dieser alte, konservativ ausgerichtete Chor bis 1900 keine Werke von Liszt und von Hector Berlioz aufführte, hatte sich der junge Chor verstärkt als unentbehrliches Element des Berliner Musiklebens in erster Linie durch seine Beschäftigung mit musikalischen Neuheiten etabliert. »Der Folge so kräftigen Aufstiegs war«, so Adolf Weißmann zu diesem Gesangverein, »daß auch Hermann Wolff den Chor für voll ansah, mit ihm einen Vertrag schloss und Berlin den Genuss von drei Konzerten des >philharmonischen Chors` alljährlich sicherte. $\aleph^{405}$

In den Städten mittler Größe hingen die künstlerischen Erfolge zunächst von der Leistungsfähigkeit der vorhandenen Chöre und Orchester ab. In Berlin bestehe die Möglichkeit, dass mehrere qualifizierte lokale Konzertinstitute zum Zweck gemeinschaftlichen Wirkens zusammenarbeiteten. Diese Stadt habe aber auch große Anziehungskraft für auswärtige Künstlerinnen und Künstler von hohem Rang. Außerdem gebe es dort geeignete Lokalitäten: die Singakademie und die Philharmonie. ${ }^{406}$ Auf diese Weise begründete das Direktorium des ADMV die Wahl der Reichshauptstadt zum Veranstaltungsort der 28. Tonkünstlerversammlung. ${ }^{407}$

\begin{tabular}{|l|l|l|}
\hline & \multicolumn{1}{|c|}{ Werke } & \multicolumn{1}{|c|}{ Mitwirkende } \\
\hline $\begin{array}{l}\text { 1. Konzert } \\
\text { (31.5.1891, }\end{array}$ & Pëtr Il'ič Čajkovskij: Quartett D-Dur, op. & Rosé-Quartett \\
& Robert Volkmann: Quartett a-Moll, op. 9 & \\
\hline
\end{tabular}

\footnotetext{
${ }^{404} \mathrm{Zu}$ den Programmen der Abonnementkonzerte des Berliner Philharmonischen Orchesters unter Klindworth, vgl. Abschnitt 3.1.1 der vorliegenden Arbeit.

${ }^{405}$ Weissmann: Berlin als Musikstadt, S. 371.

${ }^{406}$ Die Philharmonie wurde kurz zuvor in der Sommerzeit 1888 aufwendig umgebaut.

${ }^{407}$ Lessmann: Zur 28. Tonkünstler-Versammlung des Allgemeinen Deutschen Musikvereins, S. 268; XXVIII. Tonkünstler-Versammlung des unter dem Protectrate Sr. Kgl. Hoheit des Grossherzogs von Sachsen-Weimar stehenden Allgemeinen Deutschen Musikverein, Schreiben vom Direktorium des Allgemeinen Deutschen Vereins vom 9.5.1891, GSA 70/5.
} 


\begin{tabular}{|c|c|c|}
\hline \multirow[t]{2}{*}{$\begin{array}{l}11 \text { Uhr } 45, \\
\text { Singakademie) }\end{array}$} & $\begin{array}{l}\text { Lieder von Hans Sommer, Grafen zu } \\
\text { Eulenburg, Robert Kahn und August } \\
\text { Bungert }\end{array}$ & Lillian Sanderson, Hans Brüning \\
\hline & $\begin{array}{l}\text { Friedrich Gernsheim: Hafis für Chor, } \\
\text { Solostimme und Klavier }\end{array}$ & $\begin{array}{l}\text { Lydia Müller, Hertha Braemer, } \\
\text { Hintzelmann, Paul Bulss, Rudolf } \\
\text { von Milde, Stern'scher Verein, } \\
\text { Wilhelm Berger, Friedrich } \\
\text { Gernsheim }\end{array}$ \\
\hline \multirow{7}{*}{$\begin{array}{l}\text { 2. Konzert } \\
\text { (31.5.1891, } \\
\text { 20 Uhr, } \\
\text { Philharmonie) }\end{array}$} & J. S. Bach: Präludium c-Moll & Heinrich Reimann \\
\hline & $\begin{array}{l}\text { Max Bruch: Drei Messensätze für } \\
\text { Doppelchor, zwei Sopransoli, Orchester } \\
\text { und Orgel }\end{array}$ & $\begin{array}{l}\text { Emilie Herzog, Marie Berg, } \\
\text { Dietzel, Philharmonischer Chor, } \\
\text { Philharmonisches Orchester, } \\
\text { Heinrich Reimann, Siegfried Ochs }\end{array}$ \\
\hline & $\begin{array}{l}\text { Anton Bruckner: Te Deum für Chor, Soli } \\
\text { und Orchester }\end{array}$ & $\begin{array}{l}\text { Emilie Herzog, Cäcilie } \\
\text { Kloppenburg, Dietzel, Joseph } \\
\text { Mödlinger, Philharmonischer Chor, } \\
\text { Philharmonisches Orchester, } \\
\text { Siegfried Ochs }\end{array}$ \\
\hline & $\begin{array}{l}\text { Antonín Dvořák: Konzert für Violine und } \\
\text { Orchester }\end{array}$ & $\begin{array}{l}\text { Carl Halir, Philharmonisches } \\
\text { Orchester, Felix Weingartner }\end{array}$ \\
\hline & $\begin{array}{l}\text { Edward MacDowell: 2. Konzert für Klavier } \\
\text { und Orchester d-Moll, op. } 23\end{array}$ & $\begin{array}{l}\text { Teresa Carreño, Philharmonisches } \\
\text { Orchester, Felix Weingartner }\end{array}$ \\
\hline & Peter Cornelius: Lieder aus op. 4 & Paul Kalisch, Felix Weingartner \\
\hline & $\begin{array}{l}\text { Felix Draeseke: Serenade für kleines } \\
\text { Orchester, op. } 49\end{array}$ & $\begin{array}{l}\text { Philharmonisches Orchester, Felix } \\
\text { Weingartner }\end{array}$ \\
\hline \multirow{7}{*}{$\begin{array}{l}\text { 3. Konzert } \\
(1.6 .1891, \\
20 \text { Uhr, } \\
\text { Philharmonie) }\end{array}$} & $\begin{array}{l}\text { Alexander Ritter: Ouvertüre zu Der faule } \\
\text { Hans }\end{array}$ & $\begin{array}{l}\text { Philharmonisches Orchester, Felix } \\
\text { Weingartner }\end{array}$ \\
\hline & $\begin{array}{l}\text { Männerchöre von Franz Liszt, Franz } \\
\text { Schubert und Julius Rietz }\end{array}$ & Berliner Liedertafel, Adolf Zander \\
\hline & $\begin{array}{l}\text { Giuseppe Martucci: Konzert für Klavier } \\
\text { und Orchester, op. } 66\end{array}$ & $\begin{array}{l}\text { Eugen d'Albert, Philharmonisches } \\
\text { Orchester, Felix Weingartner }\end{array}$ \\
\hline & $\begin{array}{l}\text { Eugen d'Albert: Szenen aus der Oper } \\
\text { Rubin }\end{array}$ & $\begin{array}{l}\text { Georg Anthes, Philharmonisches } \\
\text { Orchester, Eugen d'Albert }\end{array}$ \\
\hline & $\begin{array}{l}\text { Jean Louis Nicodé: Das Meer für } \\
\text { Männerchor, Solostimmen und Orchester }\end{array}$ & $\begin{array}{l}\text { Charlotte Huhn, Heinrich Grahl, } \\
\text { Heinrich Reimann, Berliner } \\
\text { Liedertafel (Adolf Zander), Jean } \\
\text { Louis Nicodé }\end{array}$ \\
\hline & Reinhold Becker: Lieder & Paul Bulss \\
\hline & $\begin{array}{l}\text { Franz Liszt: Symphonische Dichtung } \\
\text { Hungaria }\end{array}$ & $\begin{array}{l}\text { Philharmonisches Orchester, Felix } \\
\text { Weingartner }\end{array}$ \\
\hline $\begin{array}{l}\text { 4. Konzert } \\
\text { (2.6.1891, } \\
\text { 20 Uhr, } \\
\text { Singakademie) }\end{array}$ & $\begin{array}{l}\text { Heinrich von Herzogenberg: Quartett in f- } \\
\text { Moll } \\
\text { Eugen d'Albert: Quartett in a-Moll } \\
\text { Johannes Brahms: 2. Quintett in G-Dur }\end{array}$ & $\begin{array}{l}\text { Joachim-Quartett, Heinrich } \\
\text { Jacobsen }\end{array}$ \\
\hline \multirow[t]{2}{*}{$\begin{array}{l}\text { 5. Konzert } \\
\text { (3.6.1891, } \\
\text { 20 Uhr, } \\
\text { Philharmonie) }\end{array}$} & $\begin{array}{l}\text { Liszt: Missa solemnis (Graner Festmesse) } \\
\text { für Chor, Soli, Orgel und Orchester }\end{array}$ & $\begin{array}{l}\text { Elisabeth Leisinger, Cäcilie } \\
\text { Kloppenburg, Dietzel, R. v. Milde, } \\
\text { Berliner Stern'scher Chor, } \\
\text { Philharmonisches Orchester, } \\
\text { Friedrich Gernsheim }\end{array}$ \\
\hline & Berlioz: Szenen aus der Oper Trojaner & $\begin{array}{l}\text { Lilli Lehmann, Cäcilie } \\
\text { Kloppenburg, Paul Kalisch, } \\
\text { Hintzelmann, Paul Bulss, O. } \\
\text { Kulicke, Berliner Stern'scher Chor, } \\
\text { Philharmonisches Orchester, } \\
\text { Friedrich Gernsheim }\end{array}$ \\
\hline
\end{tabular}




\begin{tabular}{|l|l|l|}
\hline & Wagner: Kaisermarsch & $\begin{array}{l}\text { Philharmonisches Orchester, } \\
\text { Friedrich Gernsheim }\end{array}$ \\
\hline
\end{tabular}

Übersicht 4: Aufgeführte Werke und Mitwirkende der 28. Tonkünstlerversammlung des ADMV zu Berlin $^{408}$

Die Berliner Tonkünstlerversammlung setzte sich schließlich aus zwei Kammer- und drei Orchesterkonzerten zusammen. ${ }^{409}$ Im Prinzip lag es in Händen der »musikalischen Sektion« des Vereins, die Werke, die entweder vom Komponisten oder Verlag auf dem Postweg eingesandt oder innerhalb des Vorstandes zur Aufführung vorgeschlagen wurden, zu begutachten und das Programm aufzustellen. ${ }^{410}$ Aber aus den überlieferten Briefen von Hermann Wolff an Hans Bronsart von Schellendorff ${ }^{411}$ geht hervor, dass die vielseitigen Tätigkeiten von Hermann Wolff die Veranstaltung nicht nur organisatorisch, sondern auch künstlerisch und somit inhaltlich prägten. Es ist keine Übertreibung zu sagen, dass Wolff zum künstlerischen Gelingen des Musikfestes viel beitrug.

Ein »Berliner« Musiker, dessen Teilnahme am dortigen Musikfest von allen Seiten sehr erwünscht war, war Joseph Joachim, der Direktor der Königlichen Hochschule für Musik. Während drei Werke von Joachim in den vier früheren Tonkünstlerversammlungen aufgeführt worden waren, ${ }^{412}$ hatte er sich nie persönlich am Musikfest beteiligt. Zuerst schlug Wolff vor, die neue Sinfonie von Heinrich von Herzogenberg, dem früheren Vorstand der Kompositionsabteilung der Musikhochschule ${ }^{413}$ und Komponist des Brahms-Kreises, unter Joachims Leitung auf das Programm zu setzen, da er glaube, »daß Joachim mit seinem Quartett nur dann an der Tonkünstlerversammlung theilnehmen wird, wenn er als Capellmeister der königlichen Academie aufgefordert wird, in einem der Orchesterconcerte zu dirigiren ${ }^{4} .14$

\footnotetext{
${ }^{408}$ Quelle: Programmbuch der 28. Tonkünstlerversammlung des Allgemeinen Deutschen Musikvereins 1891 zu Berlin. Die Werke sind nicht nach der Reihenfolge der Aufführung, sondern nach der Besetzung geordnet.

${ }^{409}$ Dazu gab es einen Orgelvortrag von Heinrich Reimann am Nachmittag des 1. Juni 1891, und die Mitglieder des Vereins bekamen am Vorabend des Festes (30.5.1891) freien Zugang zur TannhäuserAufführung in ihrer Pariser Fassung in der Hofoper.

${ }^{410}$ Zur gutachtlichen Methode der Vorsitzenden des Allgemeinen Deutschen Vereins vgl. Kaminiarz: Richard Strauss. Briefe aus dem Archiv des Allgemeinen Deutschen Musikvereins (1888-1909), S. 24f.

${ }^{411}$ Briefe von Hermann Wolff an Hans Bronsart von Schellendorff aus den Jahren 1890-1891, GSA 70/61.

${ }^{412}$ Konzert für Violine und Orchester in ungarischer Weise bei der Karlsruher (1864) und Dessauer (1888)

Tonkünstlerversammlung, Variationen für Violine mit Orchesterbegleitung bei der Wiesbadener Tonkünstlerversammlung (1889) und Konzert für Violine und Orchester in G-Dur bei der Eisenacher Tonkünstlerversammlung (1890).

4131887 musste Heinrich von Herzogenberg seine Tätigkeit an der Musikhochschule aus Krankheitsgründen einmal unterbrechen, nahm sie aber nach dem Tod seines Nachfolgers Woldemar Bargiel 1897 wieder auf.

${ }^{414}$ Brief von Hermann Wolff an Hans Bronsart von Schellendorff vom 3.12.[1890], GSA 70/61.
} 
Bei der Anwerbung Joachims verhielt Wolff sich vor allem vorsichtig, damit die »Partheilichkeiten ${ }^{415}$ dem Plan keine Hindernisse in den Weg legen. Aus Rücksicht auf die »empfindliche« Natur von Joachim sorgte er dafür, die Einladung ihm, als ob sie aus eigener Initiative des Vereins entstanden wäre, direkt vom Verein zugehen zu lassen, ohne ihn wissen zu lassen, dass die Aufforderung von ihm veranlasst worden war. Schließlich trat Joachim bei der Tonkünstlerversammlung auf, und zwar nicht mit dem Orchester der Hochschule, sondern mit seinem Quartett, und spielte das Streichquartett in f-Moll, op. 63, von Herzogenberg, dasjenige in a-Moll, op. 7, von Eugen d'Albert und das zweite Quintett in G-Dur, op. 111, von Johannes Brahms. Dieser Quartettabend, der auf das vierte Konzert des Musikfestes fiel, erzielte einen glänzenden Erfolg, sodass jeder Berichterstatter ihn zum künstlerischen Höhepunkt der Berliner Tonkünstlerversammlung kürte. ${ }^{416}$

Da Brahms' Werke nach dem Tod Franz Brendels seit 1869 bei fast allen Tonkünstlerversammlungen aufgeführt worden waren und Brahms selbst seit 1887 Mitglied des Vereins war, ${ }^{417}$ ist es nicht erstaunlich, dass hier ein neues Werk von dem Komponisten, der im bekannten Manifest aus dem Jahr 1860 Gegenposition zu Brendel und Liszt eingenommen hatte und damit auch gegen ihren sich gerade in Gründung befindenden Verein gewesen war, gespielt und hochgeschätzt wurde. Aber Wolffs Bedenken gegen die »Partheilichkeiten« ist insofern verständlich, als dieser Quartettabend von Joachim, einem Mitunterzeichner jenes Manifestes, dessen Bruch mit Liszt sehr bekannt war, mit der Singakademie als Veranstaltungsort auf die bekannten Quartettsoireen des gleichen Musikers anspielen könnte, die unter dem »Geist der Hochschule « ${ }^{418}$ seit 1869 an dieser Stätte stattfanden und das Zentrum der Anti-Wagner-Partei in Berlin waren. ${ }^{419}$ Dieser Quartettabend der Tonkünstlerversammlung brachte zwar keine reine Neukompositionen für Berlin, aber

\footnotetext{
415 »Sie wissen, daß mich nur ein Interesse leitet, die Tonkünstlerversammlung glänzend gestalten zu helfen. Partheilichkeiten müssen schweigen. « Brief von Hermann Wolff an Hans Bronsart von Schellendorff vom 3.12.[1890], GSA 70/61.

${ }^{416}$ Heinrich Ehrlich: Theater, Kunst, Wissenschaft, Berliner Tageblatt und Handels-Zeitung vom 4.6.1891, S. 2; M[artin] Krause: Die 28. Tonkünstler-Versammlung des Allgemeinen Deutschen Musikvereins zu Berlin, S. 351; Karl Homann: Von der 28. Tonkünstler-Versammlung, Neue Berliner Musikzeitung 45 (1891), S. 256.

${ }^{417}$ Lucke-Kaminiarz: Der Allgemeine Deutsche Musikverein und seine Tonkünstlerfeste 1859-1886, S. 229f.

${ }^{418}$ Weissmann: Berlin als Musikstadt, S. 311.

${ }^{419}$ Robert W. Eshbach: The Joachim Quartet Concerts at the Berlin Singakademie: Mendelssohnian Geselligkeit in Wilhelmine Germany, in Brahms in the Home and the Concert Hall. Between Private and Concert Performance, hg. von Katy Hamilton u. a., Cambridge 2004, S. 22-42, hier S. 25.
} 
dort zeigten sich deutlich die neueren Verhältnisse des ADMV, der die alte Parteilichkeit zwischen den Neudeutschen und ihren Gegnern gewissermaßen überwunden hatte. ${ }^{420}$

Dem »Berliner« Quartett setzte Wolff ein »Wiener« Quartett entgegen: ${ }^{421}$ das RoséQuartett von Arnold Rosé, August Siebert, Sigismund Bachrich und Reinhold Hummer. Dieses Ensemble trat im ersten Konzert der Tonkünstlerversammlung zum ersten Mal in Berlin auf und spielte mit Erfolg die Werke, die auf Rosés Vorschlag hin auf das Programm kamen: das D-Dur-Quartett, op. 11, von Čajkovskij und das a-Moll-Quartett, op. 9, von Robert Volkmann. ${ }^{422}$

Die Berliner Tonkünstlerversammlung brachte in ihrem zweiten Konzert zwei geistliche Vokalwerke unter der Leitung von Siegfried Ochs mit seinem Philharmonischen Chor zur Aufführung: Kyrie, Sanctus und Agnus Dei für Doppelchor, Orchester und Orgel, op. 35, von Max Bruch und das Te Deum in C-Dur für Soli, gemischtem Chor, Orchester und Orgel, WAB 45, von Anton Bruckner. Die Bruchschen Messensätze waren in Berlin bis dato nur einmal vor vielen Jahren aufgeführt worden. Das Te Deum war nun das zweite Werk dieses Komponisten, das in Berlin zur Aufführung kam, anschließend an seine siebte Symphonie in E-Dur, die Klindworth 1887 mit dem Philharmonischen Orchester aufgeführt hatte. $^{423}$

Aus den Briefen an Bronsart geht hervor, dass Wolff dafür eintrat, das Te Deum ins Programm zu nehmen, obwohl er gegenüber diesem Komponisten und seinen Werken sehr kritisch war.

Was Bruckner's Tedeum anbetrifft, so ist es doch ein merkwürdiges Stück, das kaum Spuren jener Logiklosigkeit an sich trägt, wie die mir wolbekannten Symphonien. Jedenfalls werde ich mir erlauben, Ihnen den in meinem Besitz befindlichen Klav. Ausz. zu senden. ${ }^{424}$

Uebrigens lege ich nicht gerade so besondere Werth auf Bruckner, ich glaube nur daß es einen wirklichen Erfolg haben wird! Im Uebrigen habe ich persönlich gar keine

\footnotetext{
${ }^{420}$ Dieser Verein sollte aber bald ins neue Spannungsfeld zwischen Historismus und Moderne geraten. $\mathrm{Zu}$ diesem Konflikt vgl. Kaminiarz, Richard Strauss. Briefe aus dem Archiv des Allgemeinen Deutschen Musikvereins (1888-1909), S. 13.

${ }^{421}$ Brief von Hermann Wolff an Hans Bronsart von Schellendorff vom 7.4.[1891], GSA 70/61

${ }^{422}$ Brief von Arnold Rosé an Hermann Wolff vom 22.4.1891, GSA 70/61.

${ }^{423}$ Lessmann: Zur 28. Tonkünstler-Versammlung des Allgemeinen Deutschen Musikvereins, S. 317f.

${ }^{424}$ Brief von Hermann Wolff an Hans Bronsart von Schellendorff vom 19.12.[1890], GSA 70/61.
} 
Sonderinteressen. Ich will nur mit redlichsten Kräften das Meine zum Gelingen des Festes thun. ${ }^{425}$

Dem alten Wiener Komponisten bot diese Aufführung die Gelegenheit, die deutsche Reichshauptstadt zum ersten Mal zu besuchen. Der stürmische Beifall, den der anwesende Komponist aus Wien nach der Aufführung erntete, war der Beweis des »BrucknerTriumphs«, der, so Martin Krause, »wohl der erhebendste, merkwürdigste Moment des ganzen Festes « war. ${ }^{426}$ Diese Aufführung bildete eine Grundlage der Bruckner-Pflege in Berlin, in der zuerst Lessmann und Ochs, und später auch Weingartner und Nikisch als Hauptfiguren beitragen sollten. Im Januar 1894, beim zweiten und letzten Berlin-Besuch des Komponisten, wurden seine siebte Sinfonie und sein Te Deum jeweils von der Königlichen Kapelle unter Karl Muck und vom Philharmonischen Chor unter Ochs wieder gespielt. Bis 1903 sind alle Sinfonien Bruckners mindestens einmal in Berlin aufgeführt worden. ${ }^{427}$

Das gewagteste Unternehmen der Berliner Tonkünstlerversammlung 1891 war sicherlich die Aufführung der Ode-Sinfonie Das Meer für Soli, Männerchor, großes Orchester und Orgel, op. 31, von Jean Louis Nicodé, nach Dichtungen von Karl Woermann. ${ }^{428}$ Dieses Werk besteht aus sieben Sätzen: zwei Sätzen nur für Orchester, bezihungsweise mit Orgel, zwein Sätze für Männerchor, Tenorsolo, Orchester und Orgel, einem Satz für a capella-Chor, einem Satz für Doppelchor und Orchester und einem Satz für Altsolo und Orchester. Die Schwierigkeiten der Aufführung dieses Werkes lagen verständlicherweise in der Beschaffung eines hervorragenden Männerchores. Seine Bedenken äußerte Wolff wie folgt aus:

Nicode's Meer kenne ich; es ist sehr interessant aber - für Männerchor! Es wird schon Opfer kosten, unsere gemischten Chor tüchtig zu verstärken, aber ein Werk mit imposanten Männerchor allein scheint mir schwierig. Unsre Männergesangvereine im Allgemein wären dieser Aufgabe kaum gewachsen. ${ }^{429}$

\footnotetext{
${ }^{425}$ Brief von Hermann Wolff an Hans Bronsart von Schellendorff vom 4.2.[1891], GSA 70/61. Hervorhebungen im Original.

${ }^{426}$ Krause: Die 28. Tonkünstler-Versammlung des Allgemeinen deutschen Musikvereins zu Berlin, S. 328. Zur Festnummer der Allgemeinen Musik-Zeitung trug Siegfried Ochs mit einer analytischen Erklärung dieses Werk bei. Siegfried Ochs: Tedeum. Für Chor, Soli, Orchester und Orgel von Anton Bruckner, in Allgemeine Musik-Zeitung 18 (1891), S. 275f.

${ }^{427}$ Anton Bruckner. Ein Handbuch, hg. von Uwe Harten, Salzburg u. a. 1996, S. 92 f.

${ }^{428}$ Zwischen 1885 und 1888 veranstaltete Hermann Wolff die Dresdner Abonnementkonzerte, die von diesem Komponisten geleitet wurden.

${ }^{429}$ Brief von Hermann Wolff an Hans Bronsart von Schellendorff vom 4.2.[1891], GSA 70/61. In einem späteren Brief bemerkt Hermann Wolff auch, dass Berlin mit Chören nicht so gesegnet wie Köln sei. Vgl. Brief von Hermann Wolff an Hans Bronsart von Schellendorff vom 10.3.[1891], GSA 70/61.
} 
Beispielsweise bei Das Liebesmahl der Apostel von Wagner und beim Auszug aus der Oper Guntrun von Felix Draeseke, die im sechsten Konzert der Wiesbadener Tonkünstlerversammlung 1889 aufgeführt wurden, waren Männerchöre auch bisher in die Programme der Tonkünstlerversammlung einbezogen worden. Bedenkt man aber die hohen Ansprüche, die das Werk von Nicodé stellt, ${ }^{430}$ ist das Zögern von Wolff verständlich. Die kühne Idee konnte schließlich unter der Mitwirkung der Berliner Liedertafel verwirklicht werden, die 1884 von Adolf Zander gegründet worden war. Dieser junge, zuerst mit 27 Sängern ins Leben gerufene Männerchor hatte bereits im zweiten Vereinsjahr 1885117 Sänger, und diese Zahl wuchs, sodass der Chor im Jahr 1909254 Sänger stark war. ${ }^{431}$ Die Ode-Sinfonie von Nicodé hatte, seit sie im Februar 1889 von dem Leipziger Universitätssängerverein zu St. Paul zur Uraufführung gebracht worden war, erst wenige Aufführungen erlebt. ${ }^{432}$ Allein die Aufführung dieses schwierigen, großangelegten Werkes war also schon ein Verdienst. Unter der Leitung des Komponisten sang die Berliner Liedertafel »die von Zander vortrefflich eingeübten, sehr schwierigen Chorstellen mit gutem Gelingen «, so Lessmann. ${ }^{433}$

Die Wünsche oder Bedingungen für den Auftritt, welche die mitwirkenden Musiker dem Ausschuss stellten, konnten durch Vermittlung von Wolff auf die Programmbestimmung einwirken. Zum Beispiel wurde der von Strauss und Draeseke von der »musikalischen Sektion« des Vereins zur Aufführung positiv begutachtete Liederzyklus Hafisa von Oscar Eichberg ${ }^{434}$ in dieser Tonkünstlerversammlung nicht aufgeführt, wohl zugunsten des Hafis, op. 56, von Friedrich Gernsheim, der als Leiter des Stern'schen Gesangvereins die vom Direktorium vorgeschlagenen großen Vokalwerke von Liszt und Berlioz im Chorkonzert dirigieren sollte. ${ }^{435}$ Die Werke von Luigi Mancinelli kamen infrage, weil Marcella Sembrich, die Wolff für die Berliner Tonkünstlerversammlung gewinnen wollte, diesen italienischen

\footnotetext{
${ }^{430}$ Für eine stilgerechte Aufführung sei nach spezieller Angabe der Partitur nötig: ein Männerchor in der Besetzung durch mindestens 50 erste, 40 zweite Tenöre und 40 erste und 50 zweite Bässe. Vgl. Georg Riemenschneider: Jean Louis Nicodé. Das Meer, Symphonie-Ode für Männerchor, Solostimmen, grosses Orchester und Orgel. Op. 31, Leipzig o. J. [1902], S. 4.

${ }^{431}$ Ingeborg Allihn: Art. Berlin (Stadt), A.III.2., in MGG Online, hg. von Laurenz Lütteken, Kassel u. a. 2016-, veröffentlicht 2015-06-18, www-1mgg-2online-1 com-1875008798.erf.sbb.spkberlin.de/mgg/stable/ 11667, 28.01.2018.

${ }^{432}$ Hermann Kretzschmar: Das Meer, in Neue Berliner Musikzeitung 45 (1891), S. 188f., hier: S. 189.

${ }^{433}$ Lessmann: Zur 28. Tonkünstler-Versammlung des Allgemeinen Deutschen Musikvereins, S. 331. Zu diesem Erfolg vgl. auch Ernst Schlicht: Berliner Liedertafel 1884-1909, o. O. o. J. [Berlin 1909], S. 39f. ${ }^{434}$ Gutachten über die eingesandten Kompositionen für die Berliner Tonkünstlerversammlung, GSA 70/161.

${ }^{435}$ Brief von Hermann Wolff an Hans Bronsart von Schellendorff vom 17.3.[1891], GSA 70/61.
} 
Komponisten propagierte und »gern eines seiner Orch. Werke in Berlin dirigirt sähe«. ${ }^{436}$ Offenbar schickte Wolff an Bronsart auch Noten einer Suite dieses Komponisten zur Durchsicht. ${ }^{437}$ Weder die Aufführung seiner Werke noch die Mitwirkung von Sembrich wurden aber schließlich verwirklicht.

Das fünfte und letzte Konzert der Berliner Tonkünstlerversammlung widmete sich den Werken der geistlichen Väter des ADMV: Liszts Missa solemnis (Graner Festmesse) und die Fragmente aus Berlioz' Oper Die Trojaner. Die beiden Werke erklangen zum ersten Mal in Berlin. Die Trojaner wurde kurz davor im Dezember 1890 in Karlsruhe zum ersten Mal vollständig an zwei Abenden aufgeführt, was als »ein bedeutendes bühnengeschichtliches Ereignis « ${ }^{438}$ galt. Wie seit der Tonkünstlerversammlung 1878 in Erfurt üblich, kam das Musikfest zum Abschluss mit dem Kaisermarsch von Wagner.

Im Unterschied zu den bisherigen Konzerten der Berliner Tonkünstlerversammlung fallen bei diesem letzten Konzert negative Kritiken auf. Vor allem bemerkenswert ist die Kritik von Lessmann, in der er sich, seine abfällige Beurteilung der Werke nur andeutend, der Aufführungsbetrachtung widmet. Seiner Meinung nach haben die Bestrebungen sowohl von Gernsheim wie vom Stern'schen Gesangverein nicht ausgereicht, um »das rechte Verständnis für den Geist dieser modernen Musik zu erschliessen «. ${ }^{439}$ Die negativen Kritiken zu den beiden Werken, die erst nach der Tonkünstlerversammlung veröffentlicht wurden, seien der Aufführung zuzuschreiben, da sie weder bei der Liszt'schen Messe noch bei Berlioz'schen Opernmusik »eine rechte Vorstellung von dem tiefen poetischen Gehalt« auszudrücken vermochte. ${ }^{440}$ Der Kernpunkt seiner Kritik liegt im »blossen Formalismus«, der bei der Aufführung von Gernsheim und dem Stern'schen Gesangverein unverkennbar war.

Liszt'sche Kirchenmusik ist nun einmal vom Standpunkt des blossen Formalismus aus nicht zu verstehen. Liszt unterhielt sich, wenn er Kirchenmusik schrieb, mit seinem Gott; sein ganzes Empfinden löste sich auf in Anbetung der dogmatischen Geheimnisse, die seiner dichterischen Fantasie krystallklar sich offenbarten, und deren tiefsinnigen Inhalt er mit Inbrunst in seine geliebte Tonsprache zu übertragen sich bemühte. Wer mit seiner Fantasie, seinem Empfinden dem Komponisten auf diesem Wege nicht zu folgen vermag, der lasse seine Hände von Liszt'scher Kirchenmusik. ${ }^{441}$

\footnotetext{
${ }^{436}$ Brief von Hermann Wolff an Hans Bronsart von Schellendorff vom 30.1.[1891], GSA 70/61.

${ }^{437}$ Brief von Hermann Wolff an Hans Bronsart von Schellendorff vom 4.2.[1891], GSA 70/61.

${ }^{438}$ Allgemeine Musik-Zeitung 18 (1891), S. 383.

${ }^{439}$ Lessmann: Zur 28. Tonkünstler-Versammlung des Allgemeinen Deutschen Musikvereins, S. 331.

${ }^{440}$ Ebd.

${ }^{441}$ Ebd.
} 
Lessmann stellt »den Dirigenten der älteren Schule«, denen die Hanslick’sche Theorie vom musikalischen Schönen noch zu sehr in den Gliedern sitzt, die »in der Schule Wagner's und Liszt's gebildeten Dirigenten« gegenüber und sagt, dass die ersteren diese Theorie nicht nur an den »Werken der Klassiker und Nachklassiker« üben, sondern glauben, damit auch »den Werken moderner Richtung« beikommen zu können. ${ }^{442}$

Das ist aber von jeher vergebliche Mühe gewesen, wie die Thatsache beweist, dass die Werke Wagner's und Liszt's, so lange sie eben unter den Händen solcher »klassischen« buchstabengläubigen Dirigenten sich befanden, gar nicht oder falschverstanden wurden, während die jüngeren, sagen wir, anti-Hanslick'schen Dirigenten wohl im Stande gewesen sind, auch dem grossen Publikum die Schönheiten dieser Werke zugänglich zu machen. ${ }^{443}$

Während Lessmann bei den bisherigen Konzerten die jungen musikalischen Kräfte in Berlin, wie Siegfried Ochs mit dem Philharmonischen Chor, die Berliner Liedertafel und Felix Weingartner mit dem Philharmonischen Orchester wegen ihrer Leistung bei der Musik der sogenannten Neudeutschen und ihren Anhänger hoch einschätzte, wies er Gernsheim als jemanden zurück, dem die Werke von Liszt und Berlioz »Hieroglyphen [sind und bleiben], die er vielleicht recht hübsch und korrekt nachzeichnet, deren Inhalt er aber nicht zu ergründen vermag $\ll{ }^{444}$

Über das künstlerische Ergebnis der 28. Tonkünstlerversammlung zu Berlin wird im Großen und Ganzen günstig berichtet. ${ }^{445}$ Und soweit man aus den zeitgenössischen Berichten ableiten kann, scheint das Programm als befriedigend angenommen worden zu sein. Zum Beispiel schreibt Martin Krause im Musikalischen Wochenblatt wie folgt:

Das Angebot an künstlerischen Kräften war sicher sehr ehrenvoll und der Entwurf des Programmes sehr lobenswerth; dass die Pläne sich nicht im Sinne eines Musikfestes

\footnotetext{
${ }^{442}$ Ebd., S. 332.

${ }^{443}$ Ebd.

${ }^{444}$ Ebd.

${ }^{445}$ Die Beurteilungen stimmten jedoch nicht vollkommen überein. Der Berichterstatter der Hamburger Signale sprach aber von »einem künstlerischen Fiasco« dieses Musikfestes. Vgl. Weibel, Die deutschen Musikfeste des 19. Jahrhunderts, S. 659.
} 
verwirklichen liessen, liegt zumeist am Charakter der Riesenstadt, die zu schneller Erledigung aller Verkommnisse drängt und keine Musse zur Vertiefung lässt. ${ }^{446}$

Bei der Berliner Tonkünstlerversammlung konnte Hermann Wolff die lokalen Institutionen spielen und wirksam zusammenarbeiten lassen. Während er mit den neuen Kräften des Berliner Musiklebens, die erst in den letzten zehn Jahren entstanden waren und sich vor allem mit der Aufführung von Neukompositionen beschäftigt hatten, eng zusammenarbeitete, gelang es ihm, auch die Kräfte der Berliner Musikhochschule, die eigentlich als Hochburg des konservativen Kreises gegen den Verein waren, reibungslos einzubeziehen und damit das künstlerische Gelingen zu gewährleisten. Er konnte auch die lokalen publizistischen Kräfte einbinden. Die Neuen Berliner Musikzeitung, deren früherer Redakteur er war, ${ }^{447}$ und die Allgemeine Musik-Zeitung, die Lessmann redigierte, widmeten diesem Musikfest je eine Doppelnummer. Sie enthielt Erläuterungen und Analysen der in der Tonkünstlerversammlung aufzuführenden Hauptwerke und funktionierte gewissermaßen wie ein Festführer. ${ }^{448}$ Auch nachträglich wurde über diese Veranstaltung viel berichtet, und sie regte in Berlin zu aufschlussreicher Diskussion über die Aufführung der Programmmusik an.

Aber es muss auch bemerkt werden, dass Berlin sich nicht als richtiger Festort erweisen konnte. Karl Homann schreibt über das, was der Berliner Tonkünstlerversammlung fehlte, wie folgt:

Nur Eines werden sie [unsere Gäste, d. h. die Besucher der Tonkünstlerversammlung, A. d. V.] vermisst haben: daß die Reichshauptstadt, was äusserliche und innere Antheilsbezeigung betrifft, sich auch als Festort im wirklichen Sinne des Wortes bewährt hätte. In der That, von den anderthalb Millionen Einwohnern waren es keine tausend, die sich an dem Feste betheiligt haben. Von dem sehr zahlreichen musikliebenden Publikum, das den Winter über unsere Konzertsäle - oft drei bis vier an einem einzigen Abend zugleich - füllte, nahmen nur Wenige, Auserwählte im doppeldeutigen Sinne des Wortes theil. [...] Für die Oeffentlickeit bedeutete das Fest nicht mehr und nicht weniger, als eine Folge grosser, vielleicht nur durch Ueberlänge ausgezeichneter Konzerte, wie sie die ganze Zeit hindurch auf der Tagesordnung stehen, und dass man nach einer Konzertzeit von Oktober angefangen bis in den Mai

\footnotetext{
${ }^{446}$ Krause: Die 28. Tonkünstler-Versammlung des Allgemeinen deutschen Musikvereins zu Berlin, S. 352.

${ }^{447}$ Bis 1889 erschien diese Musikzeitschrift im Verlag Bote \& Bock, bei dem Wolff arbeitete.

${ }^{448}$ Neue Berliner Musikzeitung 45 (1891), Nr. 21/22, S. 267-314; Allgemeine Musik-Zeitung 18 (1891), Nr. 22/23, S. 183-210.
} 
hinein wohl etwas musikmüde geworden sein kann, wird auch der begeistertste Verehrer der Tonkunst zugestehen. ${ }^{449}$

Während die Mitglieder des Vereins »in stattlicherer Anzahl als sonst $\aleph^{450}$ herbeiströmten, konnte die Berliner Tonkünstlerversammlung kein großes lokales Publikum anziehen. Und viele Erwartungen, die man für das Musikfest in der Reichshauptstadt gehegt hatte, wurden enttäuscht. Der Berichterstatter des Musikalischen Wochenblatts führt dieses Versagen auf die Eigenschaften der großen Stadt zurück:

Wer blickte nicht enttäuscht nach des Reiches Hauptstadt, welche nur wenig von diesen grossen Erwartungen erfüllt hat; wer wäre nicht davon überzeugt, dass Berlin sich der Tonkünstler-Versammlung so ungünstig wie nur möglich gezeigt? Wen trifft die Schuld? Sicher nicht das Directorium des Vereins, sicher nicht das Comité, welches der Versammlung die erlesenen künstlerischen Kräfte zur Verfügung stellte. Berlin ist zu gross geworden für eine Versammlung von einigen hundert Musikern, Berlin ist zu reich in seinem Musikleben, als dass Concerte von nicht ganz ausserordentlicher Art sich bedeutsam abheben könnten. ${ }^{451}$

Wolffs Vorschlag für Bronsart vom 23. April 1891, von der Aufnahme neuer Vereinsmitglieder bis nach der Versammlung vorübergehend abzusehen, um zu verhindern, dass »wir bei überfüllten Häusern ein Defizit haben« ${ }^{452}$ mag auf seiner Vorahnung, »ein pekuniäres nicht unerhebliches Deficit ${ }^{453}$ stünde bevor, beruht haben. Wenn das hochstehende Musikleben Berlins der dortigen Tonkünstlerversammlung wirklich zum Verhängnis wurde, war das wohl eine ironische Folge für Hermann Wolff, weil er seit der Gründung seiner Konzertdirektion 1880 eine Hauptfigur war, die $» j$ jenes Übermaß von Konzerten ${ }^{454}$ Berlins bewirkt hatte. ${ }^{455}$

\footnotetext{
${ }^{449}$ Homan: Von der 28. Tonkünstler-Versammlung, S. 223.

${ }^{450}$ Lessmann: Zur 28. Tonkünstler-Versammlung des Allgemeinen Deutschen Musikvereins, S. 316.

${ }^{451}$ Krause: Die 28. Tonkünstler-Versammlung des Allgemeinen deutschen Musikvereins zu Berlin, S. 327.

${ }^{452}$ Brief von Hermann Wolff an Hans Bronsart von Schellendorff vom 23.4.[1891], GSA 70/61.

${ }^{453}$ Hamburger Signale 4 (1891/92), S. 17, zit. in Weibel: Die deutschen Musikfeste des 19. Jahrhunderts, S. 659 .

${ }^{454}$ Ehrlich: Dreißig Jahre Künstlerleben, S. 317.

${ }^{455}$ Dazu vgl. die Schlussbetrachtung der vorliegenden Arbeit.
} 
Tatsächlich kam die Tonkünstlerversammlung des ADMV nie wieder nach Berlin zurück. Aber die Konzertdirektion Hermann Wolff entwickelte sich weiter, ebenso auch Berlin als Musikstadt, teilweise als Wegbereiter zeitgenössischer Komponisten.

\subsubsection{Im Spannungsfeld zwischen Verlegern und Komponisten:}

\section{Hermann Wolff in der frühen musikalischen Tantiemenbewegung in}

\section{Deutschland}

Im Unterschied zu Frankreich, wo die Société des Auteurs, Compositeurs et Editeurs de Musique (SACEM) bereits Mitte des 19. Jahrhunderts gegründet worden war, begann man in Deutschland erst in den 1890er-Jahren, die Frage im grundlegenden Sinn zu erörtern, wie die Erhebung von Tantiemen bei Aufführungen nichtdramatischer Musik zweckmäßig zu organisieren sei. ${ }^{456}$ An dieser Diskussion beteiligte sich Hermann Wolff Ende des 19. Jahrhunderts in seiner Eigenschaft als Konzertagent.

Laut $\S 50$ des Gesetzes zum Urheberrecht an Schriftwerken, Abbildungen, musikalischen Kompositionen und dramatischen Werken vom 11. Juni 1870 (UrhG von 1870) stand dem Urheber bzw. dessen Rechtsnachfolger das ausschließliche Aufführungsrecht an dramatischen, musikalischen und dramatisch-musikalischen Werken zu. Während dramatischmusikalische Werke hier bedingungslos geschützt waren, wurde das Aufführungsrecht von gedruckten musikalischen Werken nur bewahrt, wenn ein Aufführungsvorbehalt auf dem Notenmaterial vermerkt war. Da die Verleger sowie Komponisten befürchteten, dass sich der Aufführungsvorbehalt für die Verbreitung des Werks und des Notenmaterials nachteilig auswirke, unterblieb meist dieser Zusatz, sodass die sogenannten »kleinen Rechte« in der Tat in Deutschland kaum zur Anwendung kamen.

Den ersten Anstoß zur deutschen Tantiemenbewegung gab die Tagung des 17. Kongresses der Association Littéraire et Artistique Internationale (ALAI) vom 21. bis 28. September 1895 in Dresden. Diese Vereinigung für den internationalen Schutz geistiger Urheberrechte war 1878 unter dem Ehrenvorsitz von Victor Hugo gegründet worden und hatte 1886 zum Abschluss der Berner Übereinkunft zum Schutz von Werken der Literatur und

\footnotetext{
${ }^{456} \mathrm{Zu}$ den Diskussionen über die musikalischen Aufführungsgebühren Ende des 19. Jahrhunderts und Anfang des 20. Jahrhunderts in Deutschland vgl. Manuela Maria Schmidt: Die Anfänge der musikalischen Tantiemenbewegung in Deutschland, Berlin 2005. Für einen Überblick dieses Themas über eine längere Zeitspanne vgl. Albrecht Dümling: Musik hat ihren Wert. 100 Jahre musikalische Verwertungsgesellschaft in Deutschland, Regensburg 2003.
} 
Kunst beigetragen. In ihrem Dresdner Kongress - der ersten Tagung der Vereinigung auf deutschem Boden - sollte eine Revision der Berner Übereinkunft für die Pariser Konferenz im nächsten Frühling vorbereitet werden.

Victor Souchon, der Generalsekretär der SACEM, nutzte diese Gelegenheit, um eine Verbesserung des Aufführungsrechtes sowie die Gründung einer der SACEM entsprechenden Verwertungsgesellschaft in Deutschland anzuregen. Oskar von Hase, der Inhaber des Leipziger Verlags Breitkopf \& Härtel und Vorsteher des Vereins der Deutschen Musikalienhändler (VddM), bezog zuerst energisch gegen alle Tantiemenpläne Stellung. Seiner Ansicht nach würde eine Steuer die Musikpflege in Deutschland schwer schädigen, nur ein auf das deutsche Musikleben Rücksicht nehmendes Nationalgesetz könne das vorbehaltlose Aufführungsrecht in Deutschland einführen. In der Berichtsreihe zu diesem Kongress »Zur Frage des musikalischen Urheberrechts« von Arthur Seidl ${ }^{457}$ ist Hases Äußerung wie folgt dokumentiert:

Die Musikpflege in den germanischen Ländern beruht auf besonderen Verhältnissen. Eine Fülle von Vereinen aller Art, deren Mitglieder unentgeltlich, nur durch gelegentlich zugezogene bezahlte Solisten unterstützt, mitwirken, schafft einer ungezählten Menge von Kompositionen, unterstützt durch ein vielmaschiges Netz von Buch- und Musikalien-Sortimentshandlungen, Eingang im ganzen Volke. Diese Art der Musikpflege, die für die künstlerische Erziehung unseres Volkes von größter Wichtigkeit ist, darf nicht dadurch gestört werden, daß irgend jemand, sei es der Urheber oder sein Rechtsnachfolger, das Wasser absperren darf, das bisher in Bächen und Flüssen das Land befruchtet hat. ${ }^{458}$

Während Hase der Streichung des Aufführungsvorbehalts zustimmte, warnte er vor der Übertragung der französischen Regelung und einer weitergehenden Angleichung an Frankreich. In Deutschland müsse seiner Meinung nach der rechtmäßige käufliche Erwerb des Notenmaterials Voraussetzung für einen Schutz werden.

So ist denn zwar für alle Länder bei dem Berner Bunde zum Schutz des Urheberrechtes das Recht auf Schutz der musikalischen Werke anzustreben, ebenso der Wegfall eines den Schutz bedingenden Vorbehaltes; es muß aber den einzelnen

\footnotetext{
${ }^{457}$ Arthur Seidl: Zur Frage des musikalischen Urheberrechtes. Kritischer Bericht über die Verhandlungen des Dresdener Kongresses, in Allgemeine Musik-Zeitung 22 (1895), S. 547f.; S. 561ff.; S. 577f; S. 595f. ${ }^{458}$ Ebd., S. 548.
} 
Staaten vorbehalten bleiben, die Grenzen zu bestimmen, innerhalb deren und wie weit das Recht der öffentlichen Musikpflege dem gegenüber geltend gemacht werden kann. ${ }^{459}$

An einem anderen Tag des Kongresses sprach Hugo Bock, der Inhaber des Berliner Verlags Bote \& Bock, wobei er nicht nur für den voraussetzungslosen Schutz der musikalischen Werke unter Wegfall des Aufführungsvorbehalts eintrat, sondern auch für die Erhebung von Aufführungshonoraren, die den Komponisten eine wichtige Einnahmequelle verschaffen könnten. Sein Argument verzeichnet Seidl wie folgt:

Es ist ja richtig, daß, wie Herr Dr. von Hase hervorhebt, durch den unbedingten Schutz des Aufführungsrechtes auch den Verlegern besser die Möglichkeit geboten werden würde, zu überwachen, daß in den Konzerten nur rechtmäßig hergestelltes Notenmaterial benutzt werde, und daß nicht das nur für ein Konzertinstitut abgegebene Notenmaterial, z. B. von Oratorien u. a. größeren Werken, aus einer Hand in die andere gehe u. s. w.; aber ich sehe nicht ein, warum abgesehen hiervon, die Einziehung von Aufführungshonoraren für musikalische Werke in Deutschland, wie Herr Dr. von Hase meint, unzulässig sei.[...] Was uns in Deutschland bis jetzt fehlt, ist die Vereinigung der Komponisten und der bedeutendsten Verleger zu diesem Zwecke und ihr Entschluß, die Ausübung des Aufführungsrechtes einem Vereine zu übertragen, welcher die Schwierigkeiten beseitigen würde, die sich dem Einzelnen auf diesem etwas heiklen Gebiete entgegenstellen würden. ${ }^{460}$

So stellte Bock seine Vorstellung einer Organisation für das musikalische Aufführungsrecht dar, an denen sich sowohl die Komponisten als auch die bedeutendsten Verleger beteiligen sollen. Dümling bezeichnet diese Äußerung Bocks als »hellsichtig«, da der Berliner Verleger hier »wohl als erster Deutscher eine deutsche Anstalt für musikalisches Aufführungsrecht forderte $\ll .{ }^{461}$

Diese Rede fand Anklang bei Hermann Wolff, der mit Bock lange Jahre zusammengearbeitet hatte. ${ }^{462}$ Der offene Brief von Victor Souchon an Oskar von Hase zitiert Wolffs Argumentation auf dieser Tagung: »Je sais que je serais un des premiers à payer des

\footnotetext{
${ }^{459}$ Ebd.

${ }^{460}$ Ebd., S. 561. Hervorhebungen im Original.

${ }^{461}$ Dümling: Musik hat ihren Wert, S. 37.

${ }^{462}$ Zum Verhältnis zwischen Wolff und Bock vgl. Abschnitt 2.1.1 der vorliegenden Arbeit.
} 
droits, mais je considère qu'ils doivent être payés et je mettrais mon orgueil à aider toute tentative des éditeurs et des auteurs allemands dans cette voie «. ${ }^{463}$ Diese Stellungnahme von Wolff als zukünftigem Gebührenpflichtigen scheint unerwartet gewesen zu sein. Arthur Seidl berichtete von der Haltung, die Wolff im Kongress einnahm, wie folgt:

Sogar Hr. Hermann Wolff-Berlin, der bekannte Konzertagent, schien diesmal großmüthige und hochherzige Anwandlungen zu verspüren. Selbst weder Autor noch Verleger, stellte er sich doch persönlich für seine Unternehmungen auf die Seite seines Kollegen Bock und hoffte nur, daß dies auch von anderen »Kollegen« geschehen möge. ${ }^{464}$

In der gleichen Berichtsreihe kam Seidl auf diese Stellungnahme noch einmal zurück, und vermutete als ihren Hintergedanken:

Das auffällige Eintreten aber der übrigen Herren Verleger und Konzertagenten für die »schärfere Tonart« muß - die Herren mögen mir das verzeihen! - auf alle Fälle verdächtig erscheinen. Wahrscheinlich kalkuliren sie so: Wenn wir uns jetzt rechtzeitig an die Spitze der Bewegung stellen, so gelten wir als die fortschrittlich Erleuchteten, Humandenkenden und bekommen zum Ruhm und der Ehre, allen vorangegangen zu sein, auch noch die Tantièmenfrage in unsere Hand; später wird sie uns von den Künstlern diktirt werden, und dem wollen wir denn noch vorbeugen. ${ }^{465}$

Engelbert Humperdinck, der als einziger deutscher Komponist am Dresdner Kongress teilnahm, meldete sich vor Ort nur indirekt durch Henri Marteau zu Wort, und später präzisierte er seine eigenen Gedanken zur Einnahmeeinteilung zwischen Verleger und Komponisten in seinem Beitrag zur Kongressberichtsreihe Seidls. Ihm zufolge sollten das Verlagsrecht und das Aufführungsrecht gesondert betrachtet werden, und die Verleger sollten sich unter keinen Umständen an den Aufführungstantiemen beteiligen dürfen. ${ }^{466}$ Während Bock die Beteiligung der Verleger an den Tantiemen nicht ausgeschlossen hatte, forderte der Komponist hier, sämtliche Tantiemen unverkürzt dem Komponisten zuzusprechen.

\footnotetext{
${ }^{463}$ Victor Souchon, Brief an Oskar von Hase vom 12.12.1895, in Mittheilungen des Vereins der Deutschen Musikalienhändler 33 (1896), S. 330-336, hier S. 334.

${ }^{464}$ Seidl: Zur Frage des musikalischen Urheberrechtes, S. 562. Hervorhebung im Original.

${ }^{465}$ Ebd., S. 595.

${ }^{466}$ Ebd., S. 596.
} 
So wurden im Dresdner Kongress zum ersten Mal in Deutschland die Meinungen zur Tantiemenfrage aus verschiedenen Perspektiven ausgetauscht. Angesichts der Mehrheit der Stellungnahmen für die Einführung des Tantiemensystems äußerte sich Hase in seinem zusammenfassenden Schlusswort etwas milder, forderte aber noch, »dass sich der deutsche Musikverlag gegen eine schablonisirende radikale und rigorose Gesetzdiktirung von Paris aus unter allen Umständen sperren werde «. ${ }^{467}$ Der Kongress beschloss den uneingeschränkten und voraussetzungslosen Schutz musikalischer Werke als Vorschlag für die Pariser Konferenz.

Vom 20. bis 22. Januar 1896 wurde im Berliner Auswärtigen Amt eine Anhörung als Vorbereitung für die Pariser Konferenz abgehalten. Daran nahmen 20 Sachverständige ${ }^{468}$ teil, zu denen wieder Hase, Bock und Wolff gehörten. Der Frage, ob der Vorbehalt bei musikalischen Kompositionen aufgegeben werden solle, stimmten fast alle Teilnehmer zu. ${ }^{469}$ Aus dem Protokoll dieser Anhörung ergibt sich jedoch, dass die Sachverständigen unterschiedliche Vorstellungen zur Frage hatten, wie und von wem dies verwirklicht werden sollte.

Hase trat für eine Erweiterung des Schutzes der Komponisten hinsichtlich der Aufführung ihrer Kompositionen ein, präzisierte aber seinen Wunsch nach der Möglichkeit, den Grad des Schutzes in den einzelnen Verbandsländern je nach den besonderen Bedürfnissen ihrer Musikkultur zu regeln.

Die Wichtigkeit der Frage trete besonders hervor auf dem Gebiete des Konzertwesens, denn hier seien die Unterschiede des musikalischen Lebens in den verschiedenen Verbandsländern besonders erheblich, öffentliche Aufführungen von Vereinen, Privatchören $u$. ä. seien in den romanischen Ländern fast unbekannt. Auch müssten Ausnahmen für die Aufführung musikalischer Werke in der Schule, Kirche, Heer usw. getroffen werden, ebenso, wie es derartige Ausnahme bei literarischen Werken für die Herstellung von Chrestomathie und dergl. gebe. Man möge also den Komponisten Tantiemen gewähren, sein Recht, aus der Aufführung pekuniären Nutzen zu ziehen, aber man solle andererseits die Vereine und Konzertunternehmen nicht in die Lage

\footnotetext{
${ }^{467}$ Ebd., S. 577.

468 Protokoll der Sachverständigen-Anhörung im Auswertigen Amt zu Berlin vom 20. bis 22. Januar 1896, BArch, R 1501/107440: Internationaler Schutz des Urheberrechts, Bd. 5: Januar 1896-Dezember 1896, Bl. 20v-21r. Die Verteilung der 20 Sachverständigen war: 7 Buch (Musikalien) -händler, 4 Schriftsteller, 3 Intendanten, 2 Anwälte, 2 Professoren, 1 Komponist und 1 »Konzertdirektor« (Hermann Wolff).

${ }^{469}$ In dieser Anhörung erklärte Hase auch, dass von 100 befragten Verlegern sich 96 gegen und nur 4 für den Vorbehalt ausgesprochen haben. Ebd., Bl. 46r.
} 
bringen, erst bei den Komponisten herumfragen zu müssen, ob sie ihre Werke zur Aufführung bringen dürfen. ${ }^{470}$

Hase hielt es für notwendig, vor dem Wegfall des Aufführungsvorbehalts nationale Regelungen unter Berücksichtigung der jeweiligen Verhältnisse aufzustellen und betonte, dass die deutsche Organisation nicht das System der SACEM übernehmen, sondern eine eigene Struktur schaffen solle, mit einer Direktion an ihrer Spitze, die mit den deutschen Verhältnissen vertraut sein solle. ${ }^{471}$

Als Inhaber eines der wenigen Verlage, die den Vorbehalt regelmäßig angewandt hatten, berichtete Hugo Bock vom aktuellen Zustand, in dem der Vorbehalt dem Komponisten sowie dem Verleger nur Nachteile bringe, aber keinen Vorteil. ${ }^{472}$ Er sei der Ansicht, dass die Komponisten gewiss mit dem Fortfall des Vorbehalts einverstanden wären, wenn ein Mittel gefunden würde, wodurch ihre Kompositionen nicht nur zur Aufführung gelangen, sondern auch noch Einnahmen erzielen könnten. Die Gründung einer notwendigen Organisation sei ohne ein Zusammengehen der großen Verleger aussichtslos. Er schlug ferner vor, die Erträge zwischen dem Komponisten, dem Textdichter und dem Verleger, oder, wenn kein Textdichter beteiligt sei, zwischen dem Komponisten und dem Verleger zu gleichen Teilen zu teilen, wie es bereits in Frankreich und in Belgien praktiziert werde. ${ }^{473}$

Dass Wolff im Dresdner Kongress keine »Anwandlungen« verspürt hatte, beweist seine konkretere Rede in dieser Anhörung. Das Protokoll lautet:

Herr Concertdirektor Hermann Wolff erklärte, die Componisten müssen ebenso geschützt werden wie die Dichter und alle anderen Autoren. Die wirksame Durchführung des Schutzes gegen öffentliche Aufführung hänge aber von der Schaffung einer Organisation nach Art der in Frankreich und Belgien bestehenden ab. Die Gründung einer solchen Organisation werde sich auch in Deutschland ermöglichen lassen, aber erst nach Fortfall des Vorbehalts.

Das musikalische Leben in Deutschland werde durch diesen Fortfall nicht geschädigt werden; denn die Organisation werde sich über das ganze Land verzweigen, auch an den kleinsten Orten ihre Vermittler (Agenten, Lehrer) für die Aufführung haben, und

\footnotetext{
${ }^{470}$ Ebd., Bl. 45 r.

${ }^{471}$ Ebd., Bl. $46 \mathrm{v}$.

${ }^{472}$ Zur Beschäftigung Bocks mit dem Aufführungsrechtsvorbehalt seit den 1870er Jahren vgl. Dümling: Musik hat ihren Wert, S. 30.

${ }^{473}$ Protokoll der Sachverständigen-Anhörung im Auswertigen Amt zu Berlin vom 20. bis 22. Januar 1896, B1. $47 \mathrm{r}-47 \mathrm{v}$.
} 
eine Monopolisierung des Aufführungsrechtes in den Händen einiger weniger großen Concertunternehmer sei nicht zu befürchten. Ebenso wenig werde eine Erschwerung der volkstümlichen Konzertunternehmungen (billige Concerte, Aufführung in Vereinen, Bildung von Gesangsvereinen etc.) eintreten; in Belgien gebe es fast in jeder Fabrik einen Gesangverein, und im ganzen Lande werde dort ebenso viel gesungen und aufgeführt sein wie bei uns. Es würden auch keine massenhaften Denunziationen und dem Volksbewusstsein widersprechenden Strafprozesse zu befürchten sein, ebenso wenig wie bis jetzt solche vorgekommen sein. Er selbst habe noch niemals für eine Aufführung im Concert die Genehmigung des Componisten oder sonst Berechtigten eingeholt und sei doch noch niemals denunziert worden, und in Frankreich frage kein Concertunternehmer die Organisation, die das Aufführungsrecht besitzt, um Erlaubnis, ob sie die Aufführung gestatten wolle, sondern es würden nur die Tantieme für die Aufführung nach den dafür bestehenden Sätzen entrichtet. Es gebe viele Componisten, die nie wieder eine Einnahme aus ihrer Composition erzielen, nachdem sie dieselbe einmal dem Verleger verkauft haben, und die vielleicht bittere Noth leiden, obwohl ihr Werk Jahrzehnte hindurch das Musikleben Deutschlands nährt. Zum Schutze der Komponisten verlange er deshalb den Fortfall des Vorbehalts und die Bildung der erwähnten Organisation, er wolle damit indessen nicht erreichen, dass die Genehmigung des Componisten zu jeder Aufführung seines Werkes eingeholt werden müsse, sondern nur, dass eine Zwangstantieme von Musikwerken eingeführt werde, und in diesem Sinne wolle er die Proposition VI [der französischen Regierung zu Artikel 9 der Berner Übereinkunft, A. d. V.] verstanden und angenommen wissen. ${ }^{474}$

Von seinem Standpunkt des »Konzertdirektors« aus denke Hermann Wolff, dass das Tantiemensystem ins deutsche Musikleben reibungslos eingeführt werden könne. Aufgrund seiner Kenntnis des ausländischen Musiklebens gehe er auch davon aus, dass eine Erschwerung der volkstümlichen Konzertunternehmungen (preiswerte Konzerte, Aufführung in Vereinen, Bildung von Gesangsvereinen und anderes) ebensowenig eintreten werde. Zum Schutz der Komponisten (das Interesse der Verleger ist dagegen in seiner Rede nicht erwähnt) verlangte er den Wegfall des Vorbehalts und die Einrichtung einer Organisation nach den französischen und belgischen Vorbildern, wobei er betonte, dass es möglich sein müsse, die

${ }^{474}$ Ebd., Bl. 48r-49r. 
Werke mit einer Zwangstantieme ohne jeweilige Genehmigung der Komponisten öffentlich aufzuführen.

Von einer internationalen Regelung des vorbehaltlosen Aufführungsrechts wurde in der Pariser Konferenz vorläufig abgesehen, weil man der Meinung war, eine Verwirklichung dieser Frage werde in Hases Sichtweise erst möglich sein, wenn die Verbandsländer entsprechende nationale Regelungen erlassen hätten. Die Pariser Konferenz für die Tantiemenbewegung war ein wichtiger Schritt, der das Bewusstsein hervorrief, dass die Gründung einer deutschen Verwertungsanstalt geboten sei. ${ }^{475}$

Nach der Pariser Konferenz ergriffen Hase und sein VddM die Initiative zur Gründung einer deutschen Verwertungsanstalt. Hase kam sozusagen den Komponisten zuvor und verhinderte, dass sie mit Unterstützung der Regierung an die Spitze der Bewegung traten. Hase, der nicht nur dem VddM, sondern auch dem Direktorium des ADMV angehörte, gelang es, für die Errichtung der Tantiemenanstalt den ADMV als Partner des VddM zu gewinnen. Im Verhältnis beider Vereine zeichnete sich aber ein Missverhältnis ab: Der Anteil des ADMV war deutlich geringer. In der Generalversammlung des ADMV am 31. Mai 1897, die im Rahmen seiner Tonkünstlerversammlung zu Mainz stattfand, wurde eine Resolution verabschiedet, in der der ADMV das Vorhaben des Musikalienhändlervereins »begrüßte«, eine Anstalt zu begründen, und sich bereit erklärte, die ehrenamtliche Oberaufsicht über diese Anstalt nach ihrer Errichtung zu übernehmen. ${ }^{476}$ Von einer gemeinsamen Errichtung der zwei Vereine war also nicht die Rede, und eine Mitwirkung der ADMV-Mitglieder in der Verwaltung der zu errichtenden Anstalt war nicht vorgesehen. Gestützt auf die Beschlüsse dieser Versammlung setzte sich Hase mit der zuständigen Reichsbehörde in Verbindung, ${ }^{477}$ und der VddM stellte den Entwurf zu Satzungen der Anstalt für musikalisches Aufführungsrecht auf, der am 10. Mai 1898 in der Hauptversammlung des Musikalienhändlervereins bestätigt wurde. Diese Satzung setzte die Vergütungshöhe auf 1 \% der Bruttoeinnahmen fest, eine sehr bescheidene Quote im Vergleich zur den durchschnittlich

\footnotetext{
${ }^{475}$ Schmidt: Die Anfänge der musikalischen Tantiemenbewegung in Deutschland, S. 95.

$476 »$ Der Allgemeine Deutsche Musikverein begrüßt das Vorgehen des Vereins der deutschen Musikalienhändler, eine Anstalt für musikalisches Aufführungsrecht zu begründen, die auf Grund ehrenamtlicher Betheiligung der deutschen Musikalienhändler in allen wesentlichen Arten deutschen Musiklebens besondere Bedingungen der öffentlichen deutschen Musikpflege, zumal in Kirche, Schule und Haus sowie bei volksthümlichen Veranstaltungen berücksichtigt, und erklärt sich im Falle bereit, die ehrenamtliche Oberaufsicht über diese Anstalt zu übernehmen.«, Protokoll der Sitzung des Gesamtvorstandes des $A D M V$ vom 28.5.1897, zit. in Schmidt: Die Anfänge der musikalischen Tantiemenbewegung in Deutschland, S. 107.

${ }^{477}$ Ebd., S. 108.
} 
$12 \%$, die die SACEM damals erzielte. Die Tantiemen sollten zu gleichen Teilen unter Komponisten und Verlegern aufgeteilt werden.

Erst im Sommer 1898 begann der systematische Kampf der Komponisten um ihre Aufführungsrechte. Inzwischen hatte sich der ADMV als ungeeigneter Ort erwiesen, um den Interessen der Komponisten in angemessener Weise Gehör zu verschaffen, weil sie in dieser aus Musikliebhabern der verschiedenen Tätigkeitsbereiche bestehenden Versammlung nur unzureichend vertreten waren. Obwohl Richard Strauss, Max Schillings und Hans Sommer die komponierenden Mitglieder des Vereins im Voraus zur Teilnahme an der Hauptversammlung der Mainzer Tonkünstlerversammlung im Juni 1898 aufgerufen hatten, reisten nur wenige Kollegen an, und der vom VddM vorgelegte Entwurf wurde, trotz des Antrags von Rösch auf Vertagung der Debatte, mit 17 gegen 14 Stimmen angenommen. Der Entschluss, ein Vorgehen außerhalb des ADMV zu erwägen, führte zur Gründung einer Genossenschaft, die die Interessenvertretung von Komponisten zur Aufgabe hatte. Am 30. September 1898 fand in Leipzig die erste Versammlung von Komponisten statt, in der die Gründung der Genossenschaft deutscher Komponisten (GDK) beschlossen wurde.

Trotz des Einspruchs der Komponisten nahm die Leipziger Anstalt für musikalisches Aufführungsrecht (LA) ihre Tätigkeit am 1. Oktober 1898 auf, einen Tag nach der eben genannten Komponistenversammlung, musste sie aber nach kaum drei Monaten einstellen. Dies war die Folge des Widerstands der Komponisten, die diesmal als Genossenschaftsmitglieder solidarisch gegen die LA auftreten konnten.

Wie Manuela Maria Schmidt belegt, wies die LA viele Schwächen auf, die auf einer Verkennung der Rechtslage beruhten. ${ }^{478}$ Es gab keinen Rechtsgrund, der ihr gewährte, die Aufführungsrechte sämtlicher geschützten Werke zu verwalten und ihre Tantiemen zu erheben. »Soweit der Rechtsinhaber die Leipziger Anstalt nicht zu einer Verwertung seiner Aufführungsrechte ermächtigt hatte, ist die Besteuerung von Aufführungen dieser Werke als Urheberrechtsanmaßung und angemaßte Geschäftsführung zu betrachten, und rechtswidrig «. ${ }^{479}$ Ebensowenig war die LA berechtigt, die Aufführungsrechte an vorbehaltlos veröffentlichten Werken zu verwalten.

Die GDK forderte »alle Interessenten in der Tantiemenfrage wie KonzertUnternehmer und -agenten, -dirigenten, Vereinsvorstände, alle Tonkünstler, sonstige gewerbliche Unternehmer von Musikaufführungen sowie alle Besitzer oder Pächter

\footnotetext{
478 Ebd., S. 183.

479 Ebd., S. 170.
} 
gewerblicher Unternehmungen, mit denen Musikaufführungen verknüpft sind $\aleph^{480}$ auf, jede geschäftliche Auskunft an die LA zu verweigern, jede sonstige Verhandlung mit ihnen rundweg abzulehnen und keinerlei Tantiemenzahlung, auch nicht die geringste Pauschalsumme, zu bewilligen. In diesem Interessenkonflikt versuchten die Komponisten also, die gebührenpflichtigen Konzertgeber für sich zu gewinnen, um der LA zu widersprechen. Ob Hermann Wolff an diesem Boykott teilnahm, konnte im Rahmen dieser Arbeit nicht belegt werden, scheint aber wahrscheinlich, weil er, wie noch auszuführen ist, kurz danach in dieser Frage dezidiert für die Komponisten eintreten sollte. Dieser Boykottaufruf, der sechs Wochen nach Tätigkeitsbeginn der LA erlassen wurde, beeinträchtigte die LA so stark, dass in der außerordentlichen Hauptversammlung der Anstalt vom 21. Januar 1899 beschlossen wurde, bis zu einer Einigung mit den Komponisten auf die Erhebung zu verzichten.

Noch während dieser Auseinandersetzung wurde mehrmals versucht, eine Verständigung zwischen Verlegern und Komponisten zu erzielen. ${ }^{481}$ Das Reichsjustizamt veranlasste diese Bemühung, als es bei der Sachverständigenberatung am 10. Oktober $1898^{482}$ den Verlegern, die Hase dort vertrat, signalisierte, dass sie ohne Verständigung mit den Komponisten bei der Reichsregierung nichts erreichen würden. ${ }^{483}$ Die Verständigungsverhandlungen scheiterten endgültig, als der Plan einer gemeinsamen Petition zur Streichung des Vorbehalts an das Reichsjustizamt ergebnislos blieb. ${ }^{484}$

Auf der Hauptversammlung des ADMV am 11. Mai 1899 in Dortmund stellte Rösch im Namen von den komponierenden Vereinsmitgliedern einen Antrag auf Rückzug des ADMV von der LA mit der Begründung, dass die inzwischen entstandene GDK nun die

\footnotetext{
${ }^{480}$ Bureau der Genossenschaft deutscher Komponisten, »Die Anstalt für musikalisches Aufführungsrecht und ihr unberechtigtes Vorgehen in der Frage der Aufführungsteuer für nichtdramatische Musik «, SeparatAbdruck aus der Deutschen Musiker-Zeitung 1898, Bl. 47, zit. in Schmidt: Die Anfänge der musikalischen Tantiemenbewegung in Deutschland, S. 243.

${ }^{481} \mathrm{Zu}$ diesem Verständigungsversuch vgl. Dümling: Musik hat ihren Wert, S. 56f; Schmidt: Die Anfänge der musikalischen Tantiemenbewegung in Deutschland, S. 256-268.

${ }^{482}$ Auch an dieser Beratung nahm Hermann Wolff als Sachverständiger teil. Das Protokoll enthält seine Äußerung zur Aufführung des Werkes in veränderter Gestalt: »Hingegen wurde hervorgehoben, dass durch das Verbot der Kürzung von Tonwerken das musikalische Leben Deutschlands schwer geschädigt werde. Für Orchester in kleineren Städten sei es häufig unmöglich, ein Werk ohne Änderungen aufzuführen, und die jedesmalige Einholung der Einwilligung des Komponisten sei undurchführbar.« BArch, R 3001/6352: Reichsjustizamt, Urheberrecht, insbesondere an Schriftwerken usw., an Werken der Literatur und der Tonkunst, Bd. 4: Oktober 1898-August 1899, Bl. 19v.

${ }^{483}$ Schmidt: Die Anfänge der musikalischen Tantiemenbewegung in Deutschland, S. 264f.

${ }^{484}$ Der geschäftsführende Ausschuss der GDK wies am 5. Mai 1899 die sieben Bedingungen zurück, die Hase nach der letzten Verständigungssitzung vom 24. April 1899 der Petition hinzugefügt hatte. Diese Bedingungen sind nicht mehr erhalten. Ebd., S. 337.
} 
Interessen der Komponisten vertrete. Interessant ist, dass der Gegenantrag von Hase, der VddM möge sich nun in Zusammenarbeit mit der GDK weiter mit der Tantiemenfrage beschäftigen, in der Versammlung von Hermann Wolff abgeändert wurde, und dass diese Fassung, welche die weitere Teilnahme des VddM an dieser Angelegenheit gründlich ablehnte und die Neugestaltung des Aufführungsrechts der GDK übergab, mit großer Mehrheit angenommen wurde. Die Übersicht 5 stellt die beiden Fassungen einander gegenüber:

\begin{tabular}{|c|c|}
\hline Der Gegenantrag (Oskar von Hase) & Die angenommene Fassung ${ }^{485}$ \\
\hline $\begin{array}{l}\text { Die ordentliche Hauptversammlung des } \\
\text { Allgemeinen Deutschen Musikvereins erklärt sich } \\
\text { grundsätzlich damit einverstanden, zu Gunsten der } \\
\text { neubegründeten »Genossenschaft Deutscher } \\
\text { Komponisten« von der mitbegründeten »Anstalt } \\
\text { für musikalisches Aufführungsrecht« } \\
\text { zurückzutreten, sobald die Genossenschaft } \\
\text { Deutscher Komponisten unter Anerkennung der } \\
\text { von ihrem geschäftsführenden Ausschusse } \\
\text { vereinbarten und von der ordentlichen } \\
\text { Hauptversammlung der »Anstalt« am 3. Mai } \\
\text { angenommenen »Grundsätze für die Ausübung } \\
\text { des musikalischen Aufführungsrechtes« und nach } \\
\text { Berathung der von der Hauptversammlung der } \\
\text { »Anstalt« aufgestellten } \\
\text { »Ausführungsbestimmungen für die } \\
\text { Wahrnehmung des Aufführungsrechtes an } \\
\text { Werken der Tonkunst« sich mit dem »Verein der } \\
\text { Deutschen Musikalienhändler« über die } \\
\text { gemeinsame Einrichtung und Verwertung der } \\
\text { Anstalt zur Wahrnehmung des } \\
\text { Aufführungsrechtes geeint haben wird. [...] }\end{array}$ & $\begin{array}{l}\text { Die ordentliche Hauptversammlung des } \\
\text { Allgemeinen Deutschen Musikvereins erklärt } \\
\text { sich grundsätzlich damit einverstanden, zu } \\
\text { Gunsten der neubegründeten »Genossenschaft } \\
\text { deutschen Komponisten« von der } \\
\text { mitbegründeten »Anstalt für musikalisches } \\
\text { Aufführungsrecht« zurückzutreten, nachdem } \\
\text { von Seiten des Vertreters der } \\
\text { »Genossenschaft« die Verdienste des } \\
\text { Allgemeinen Deutschen Musikvereins um die } \\
\text { Interessen der deutschen Komponisten in der } \\
\text { Frage einer Neugestaltung des } \\
\text { Aufführungsrechtes ausdrücklich anerkannt } \\
\text { worden sind. }\end{array}$ \\
\hline
\end{tabular}

Übersicht 5: Vergleich des Gegenantrags von Hase mit seiner von Wolff bearbeiteten Fassung

Die Gründung der von Komponisten geführten Verwertungsgesellschaft verzögerte sich durch die laufende Gesetzgebungsdiskussion. Erst 1903, also nach dem Tod von Hermann Wolff,

\footnotetext{
${ }^{485}$ Mittheilungen des Allgemeinen Deutschen Musikvereins 26 (10. Juli 1899), S. 26.
} 
wurden die Genossenschaft Deutscher Tonsetzer (GDT) und die von ihr kontrollierte Anstalt für Musikalisches Aufführungsrecht (AFMA) gegründet.

Vom Dresdner Kongress der ALAI bis zum Rückzug des ADMV aus der LA beteiligte sich Hermann Wolff an der Diskussion der musikalischen Tantiemenfrage kraft seiner Eigenschaft, weder der Komponisten- noch der Verlegergruppe anzugehören. Die Tatsache, dass er zu den amtlichen Beratungen als ein Sachverständiger eingeladen wurde, und dass er sich bei den Versammlungen als Vertreter seiner Berufsgenossen äußern konnte, beweist, dass er als ein wesentlicher Faktor des Musiklebens galt. Aus seinen Äußerungen, soweit sie dokumentiert sind, ergibt sich, dass er von Anfang an für die Einführung des Tantiemensystems plädierte, und in erster Linie für das Interesse von Komponisten eintrat. Dies entspricht seiner Äußerung in der Hauptversammlung des ADMV zu Dortmund, die die Tantiemenfrage nach langem Konflikt zwischen Verlegern und Komponisten schließlich den letzteren unterstellte. In diesem Kontext gewinnt die oben erwähnte Vermutung, dass auch er dem Boykottaufruf der GDK zustimmte, an Plausibilität.

Über seine Motive, der Einführung des Tantiemensystems zuzustimmen, kann man nur spekulieren. Vermutlich schien durch das in der Entstehung begriffene deutsche Tantiemensystem dem Geschäftsbetrieb seiner Berufsgenossen kein großer Schaden zu drohen, denn erstens war die Vergütungshöhe in Deutschland nicht sehr hoch und zweitens profitierten die meisten seiner Berufsgenossen, wie im Abschnitt 2.3.2 dargelegt, in erster Linie nicht vom eigenen Unternehmen, sondern von Provisionen aus Konzertarrangements und Engagementsvermittlungen.

Aus seinen Äußerungen geht hervor, dass er klare Vorstellungen vom zukünftigen Aufführungsgebührensystem und eine pragmatische Ansicht zur Entwicklung des deutschen Konzertlebens hatte. In seiner Eigenschaft als Inhaber einer einflussreichen Konzertdirektion beteiligte er sich nicht nur an gewinnbringenden Geschäften, sondern auch an dem Prozess, die gesellschaftliche Grundlage der deutschen Musikkultur zu gestalten. 


\subsection{Autorität und Strategie: Hermann Wolff als Normgeber? 3.2.1 Historische Konzerte von Anton Rubinštejn: Entstehung eines}

\section{Standards}

Seit Hermann Wolff den Weg zum Konzertagenten Ende der 1870er-Jahre eingeschlagen hatte, war Anton Rubinštejn einer seiner wichtigsten Klienten. Ihre Kooperation beschränkte sich nicht nur auf die Veranstaltung von Konzerten. Rubinštejns Oper Kaufmann Kalašnikov, die in Russland nach ihrer Uraufführung im Jahr 1880 Aufführungsverbot erhielt, übersetzte der sprachkundige Wolff ins Deutsche, ihre Noten mit deutschem Text und ihr Libretto sind im Leipziger Verlag Senff erschienen. ${ }^{486}$ Darüber hinaus wurde das letzte literarische Werk von Rubinštejn, eine Sammlung von Aphorismen, die der Autor für die Veröffentlichung nach seinem Tod bestimmt hatte, von Wolff herausgegeben und mit seinem Vorwort unter dem Titel Anton Rubinstein's Gedankenkorb veröffentlicht. ${ }^{487}$

Das größte, einflussreichste Projekt in der langjährigen, vielseitigen Zusammenarbeit zwischen Wolff und Rubinštejn waren sicherlich die historischen Konzerte, die dieser international bekannte Künstler in der Saison 1885/86 in den europäischen Musikmetropolen gab. Es ging dabei nicht um ein Interesse an der Wiederbelebung der Alten Musik, ${ }^{488}$ sondern um ein Virtuosenkonzert, bei dem ein aus einer musikgeschichtlichen Perspektive aufgestelltes umfangreiches Programm das Publikum unterhalten sollte. Die Idee der erklingenden Musikgeschichte war in den 1880er-Jahren nicht mehr neu, und historische Klavierabende waren besonders seit der Mitte des 19. Jahrhunderts in den europäischen Musikmetropolen beliebt. ${ }^{489}$ Die Konzertreihe Rubinštejns aber erstaunte die Zeitgenossen besonders, da er von englischer Spinettmusik bis zur zeitgenössischen russischen Musik ein besonders breites Spektrum abdeckte. 490

Für Hermann Wolff, der 1880 seine Konzertdirektion gegründet hatte, waren die historischen Konzerte von Rubinštejn in der Saison 1885/86 das größte Projekt, das er bis

\footnotetext{
${ }^{486}$ Anton Rubinštejn: Kalaschnikoff, der Kaufmann von Moskau: Oper in drei Acten nach einer Dichtung von Lermontoff (mit Beibehaltung der Originalverse) bearbeitet von N. Kulikoff, Deutsch von Hermann Wolff, Klavierauszug: Leipzig 1880; Textbuch: Leipzig 1881.

${ }^{487}$ Anton Rubinstein's Gedankenkorb, mit einem Vorwort von Hermann Wolff, Leipzig 1897. Zuerst erschienen in Vom Fels zum Meer 16, 1. Bd. (Oktober 1896-März1897) und 2. Bd. (April-September 1897).

${ }^{488}$ Zur Idee des historischen Konzerts mit Renaissancebestrebungen vgl. Monika Lichtenfeld: Zur Geschichte, Idee und Ästhetik des historischen Konzerts, in Die Ausbreitung des Historismus über die Musik, hg. von Walter Wiora, Regensburg 1969, S. 41-53.

${ }^{489}$ Z. B. zu den historischen Klavierabenden von Hans von Bülow in München 1868 vgl. Hinrichsen: Musikalische Interpretation. Hans von Bülow, S. 79.

${ }^{490}$ Philip S. Taylor: Anton Rubinstein. A Life in Music, Bloomington 2007, S. 194f.
} 
dahin organisiert hatte. Rubinštejn hingegen, der seine Absicht zum Rücktritt aus der Virtuosenlaufbahn bereits erklärt hatte, wollte mit dem monumentalen Projekt seine Karriere als Pianist abschließen. ${ }^{491}$ Der Zyklus mit sieben Konzerten begann in Berlin im Oktober 1885, dann wurde er in Wien, St. Petersburg, Moskau, Leipzig und Paris fortgesetzt und im Mai 1886 in London beendet. In den meisten Städten wurden die Konzerte für eingeladene Fachkreise tags darauf wiederholt. Außerdem trat Rubinštejn mit einem Auszug aus dem Zyklus in kleineren Städten wie Dresden, Prag, Brüssel, Utrecht, Liverpool und Manchester auf. Insgesamt gab der 56-jährige Musiker innerhalb von acht Monaten 107 historische Konzerte.

Abgesehen von dem St. Petersburger und dem Moskauer Konzert ${ }^{492}$ lag der geschäftliche Teil der ganzen Konzertreihe in der Hand von Hermann Wolff. Seine während dieser Tournee entstandenen, im Wolff-Nachlass überlieferten Briefe an seine Frau ${ }^{493}$ dokumentieren, dass er selbst Rubinštejn zumindest auf der zweiten Hälfte des Reisewegs begleitete.

Im Kontext von Rubinštejns Tätigkeit ist der Zyklus von sieben historischen Klavierkonzerten im Mai 1873 in New York, mit dem der Pianist die erfolgreiche Saison in Amerika abschloss, als das Urbild der historischen Konzerte in Europa 1885/86 anzusehen. Dem »gefährlichen « ${ }^{494}$ Plan des historischen Zyklus in Amerika gab sein damaliger Impresario Maurice Grau nur widerwillig nach. Die Konzerte wurden jedoch, mit Ausnahme des ersten und zweiten, gut besucht und erzielten guten Gewinn. ${ }^{495}$

Die Idee eines riesigen historischen Zyklus’ für die europäischen Musikmetropolen ist also, wie Rubinštejn auch in seinen Erinnerungen schrieb, tatsächlich auf den Musiker selbst zurückzuführen. ${ }^{496}$ Aber ein Vergleich der Programme der amerikanischen und europäischen Zyklen zeigt die Änderungen auf, die man vielleicht als Strategien für das Unternehmen in Europa verstehen kann.

\footnotetext{
491 Anton Rubinštejn: Erinnerungen aus fünfzig Jahren. 1839-1889, aus dem Russischen übersetzt von Eduard Kretschmann, Leipzig ${ }^{2} 1895$, S. 110-115.

492 Das russische Konzertarrangement übernahm der Moskauer Musikverlag P. Jurgenson, der außerdem eine Notensammlung der von Rubinštejn in diesen Konzerten gespielten Werke veröffentlichte. $A$.

Rubinstein. Concerts historiques, 7 Bde., Moskau o. J.

${ }^{493}$ Briefe von Hermann Wolff an Louise Wolff vom 11.3.1886 bis zum 30.5.1886, vgl. 1.2.1 im Quellenteil der vorliegenden Arbeit.

${ }^{494}$ Lott: From Paris to Peoria, S. 224.

${ }^{495}$ Ebd., S. 224f.

${ }^{496}$ Rubinštejn: Erinnerungen aus fünfzig Jahren. 1839-1889, S. 110.
} 


\begin{tabular}{|c|c|c|}
\hline & \begin{tabular}{|l|} 
"Rubinstein's Farewell New York \\
Recitals« (12-22.5.1873)
\end{tabular} & $\begin{array}{l}\text { "Clavier-Vorträge« von Rubinštejn in den } \\
\text { europäischen Städten }(\mathbf{1 8 8 5}-86)^{498}\end{array}$ \\
\hline 1. & $\begin{array}{l}\text { J. S. BACH } \\
\text { Well-Tempered Clavier } \\
\quad \text { Preludes and Fugues }\{2 \text { or } 3\} \\
\text { [Partita No. } 1 \text { in B bf] } \\
\text { Giga } \\
\text { Chromatic Fantasia and Fugue } \\
\text { C. P. E. BACH } \\
\text { Rondo [= 3rd movement from Sechs } \\
\text { Clavier-Sonaten für Kenner und } \\
\text { Liebhaber, Vol. 1, No. } 3 \text { in b, H. 245] } \\
\text { HANDEL } \\
\text { Suite in d, [HWV 428] } \\
\quad \text { Air and Variations } \\
\text { Suite in g, [HWV 432] } \\
\quad \text { Sarabande } \\
\text { Passacaille } \\
\text { Suite in A, [HWV 426] } \\
\quad \text { Gigue } \\
\text { Suite in E-Dur, HWV 430 } \\
\quad \text { Air and Variations ("The } \\
\quad \text { Harmonious Blacksmith") } \\
\text { HAYDN } \\
\text { Andante and Variations [in f, Hob. } \\
\text { XVII:6] } \\
\text { DOMENICO SCARLATTI } \\
\text { Cat's Fugue } \\
\text { Sonata } \\
\text { MOZART } \\
\text { Fantasia in c, K. 475 } \\
\text { Gigue in G, K. 574 } \\
\text { Rondo in a, K. 511 } \\
\text { Sonate in A, K. 331 } \\
\quad \text { Rondo (,alla Turca“) }\end{array}$ & $\begin{array}{l}\text { WILLIAM BIRD. } \\
\text { „The Carmans Whistle.“ Variationen über die } \\
\text { englische Volksweise: „Des Fuhrmanns Pfeife.“ } \\
\text { JOHN BULL. } \\
\text { „The King's Hunting Jigg.“ Variationen über eine } \\
\text { volksthümliche Melodie: „Des Königs lustiges } \\
\text { Jagstück.“ } \\
\text { FRANÇOIS COUPERIN. } \\
\text { Fünf Charakterstücke. (1713.) } \\
\quad \text { La Ténébreuse. } \\
\quad \text { Le Réveil-matin. } \\
\quad \text { La Favorite. } \\
\quad \text { Le Bavolet flottant. } \\
\quad \text { La Bandoline. } \\
\text { JEAN-PHIL. RAMEAU. } \\
\text { „Pièces de Clavecin.“ Paris, 1730 (?) und 1736. } \\
\quad \text { Le Rappel des Oiseaux. } \\
\quad \text { La Poule. } \\
\quad \text { Gavotte avec variations. } \\
\text { DOM. SCARLATTI. } \\
\text { Katzenfuge. } \\
\text { Sonate A-dur. } \\
\text { SEB. BACH. } \\
\text { Präludien und Fugen (C-moll, D-dur,) } \\
\text { Präludien in Es-moll, Es-Dur u. B-Moll (aus dem } \\
\text { wohltemperirten Clavier.[)] } \\
\text { Chromatische Fantasie. } \\
\text { Gigue B-Dur. } \\
\text { Sarabande. } \\
\text { Gavotte. } \\
\text { GEORG FRIEDR. HAENDEL. } \\
\text { Fuge (aus der E-moll-Suite). } \\
\text { The harmonious blacksmith (Thema und } \\
\text { Variationen, E-Dur). } \\
\text { Sarabande und Passecaille aus der G-moll-Suite. } \\
\text { Gigue (aus der Suite in A). } \\
\text { Lied mit Variationen (D-moll). } \\
\text { K. PHIL. EM. BACH. } \\
\text { Rondo in H-moll (Bülow’sche Ausgabe). } \\
\text { „La Xénophone“ und „,Sybille“. } \\
\text { Les langueurs tendres. } \\
\text { La complaisante. } \\
\text { JOS. HAYDN. } \\
\text { Thema und Variationen (F-moll) } \\
\end{array}$ \\
\hline
\end{tabular}

${ }^{497}$ Quelle: Lott: From Paris to Peoria, S. 305-307. Lott bemerkt, dass das Programmheft dieser Konzertreihe viele Fehler enthält und eine endgültige Liste der aufgeführten Kompositionen nicht erstellbar ist, weil Rubinštejn oft Werke hinzufügte und ausließ, und die hinzugefügten Werke nicht immer von den Kritikern in ihren Besprechungen identifiziert wurden. Vgl. Ebd.: S. 336, Fn. 23. Alle Ergänzungen in eckigen und geschlungenen Klammern wie bei Lott.

${ }^{498}$ Quelle: Anton Rubinstein's Cyclus von sieben Klavier-Vorträgen mit historischen und erläuternden Anmerkungen versehen von Wilhelm Tappert, hg. von der Concertdirection Hermann Wolff, Berlin. o. J. [1885], S. 6-40. Die im Programmbuch nur sporadisch angegebenen Entstehungsdaten usw. sind übernommen, woran die Uneinheitlichkeit der Übersicht liegt. 


\begin{tabular}{|c|c|c|}
\hline & & $\begin{array}{l}\text { WOLFG. MOZART. } \\
\text { Fantasie C-moll (1785). } \\
\text { Gigue in G-Dur (Als Stammbuchblatt componirt in } \\
\text { Leipzig, 17. Mai 1789.) } \\
\text { Rondo A-moll, ,alla Turca“, aus der Sonate in A- } \\
\text { dur (1779. Köchels Verzeichniss No. 331.) }\end{array}$ \\
\hline 2. & 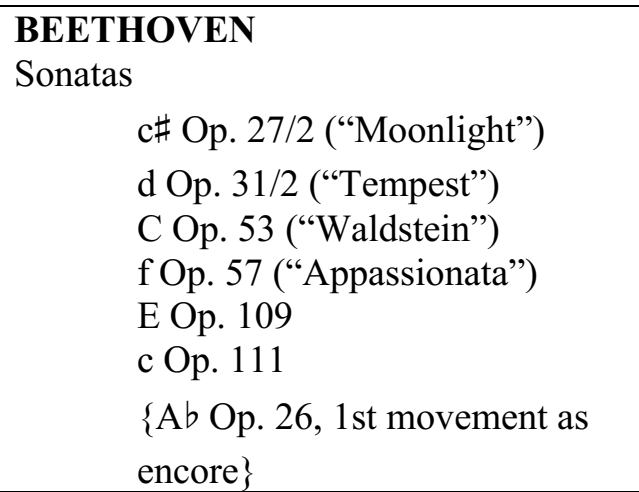 & $\begin{array}{l}\text { BEETHOVEN. } \\
\text { Acht Sonaten } \\
\text { Op. } 27 . \text { Cis-moll (1801.) } \\
\text { Op. } 31 . \text { D-moll (1802.) } \\
\text { Op. 53. C-dur (1803.) } \\
\text { Op. } 57 . \text { F-moll. Appasionata (1804.) } \\
\text { Op. } 90 . \text { E-moll (1814.) } \\
\text { Op. 101. (1815.) } \\
\text { Op. } 109 .(1821 .) \\
\text { Op. } 111 .(1822 .)\end{array}$ \\
\hline 3. & $\begin{array}{l}\text { SCHUBERT } \\
\text { Fantasy in C ("Wanderer") } \\
\text { Sonata in G, op. } 78 \\
\quad \text { Menuetto } \\
\text { Moments musicaux, Op. 94/1-3 } \\
\text { WEBER } \\
\text { Sonata No. } 2 \text { in Ab } \\
\text { Momento capriccioso } \\
\text { Inviation to the Dance } \\
\text { Polacca brillante } \\
\text { MENDELSSOHN } \\
\text { Songs without Words in E, g, Eb. f\#, Eb, } \\
\text { Ab, b, F, A, a, E } \\
\text { Scherzo a capriccio } \\
\text { Scherzo fantasie } \\
\text { Variations sérieuses }\end{array}$ & $\begin{array}{l}\text { FRANZ SCHUBERT. } \\
\text { Fantasie C-dur. (Wanderer-Fantasie.) } \\
\text { Moments musicals, Nr. 1-6. } \\
\text { Menuet H-moll. } \\
\text { Impromptus in C-moll und Es-dur. } \\
\text { CARL MARIA v. WEBER. } \\
\text { Sonate As-dur (1816 in Berlin componirt). } \\
\text { Momento capriccioso (1808 in Stuttgart). } \\
\text { Invitation à la valse (Aufforderung zum Tanz; } \\
1819 \text { in Klein-Hosterwitz bei Pillnitz). } \\
\text { Polacca brillante in E-dur (1819). } \\
\text { FELIX MENDELSSOHN. } \\
\text { Variations sérieuses. } \\
\text { Capriccio in E-moll. } \\
\text { Zehn Lieder ohne Worte: E-dur (Heft I, Nr. 1.) A- } \\
\text { moll (I, 2.) Gondellied Fis-moll (II, 6.) } \\
\text { Frühlingslied A-dur (V, 6.) Es-dur (III, 1.) H-moll } \\
\text { (VI, 5.) E-dur (VI, 6.) As-dur, Es-dur, F-dur und a- } \\
\text { moll (Volkslied) aus dem IV. Hefte. } \\
\text { Presto e Capriccio. }\end{array}$ \\
\hline 4. & $\begin{array}{l}\text { SCHUMANN } \\
\text { Symphonic Etudes, Op. } 13 \\
\text { Kreisleriana, Op. } 16 \\
\text { Phantasiestücke, Op. } 12 \\
\quad \text { Warum? } \\
\quad \text { Des Abends } \\
\quad \text { Traumes Wirren } \\
\text { Klavierstücke, Op. } 32 \\
\quad \text { Romanze } \\
\text { Waldszenen. Op. } 82 \\
\quad \text { Vogel als Prophet } \\
\text { Studies for the Pedal Piano, Op. } 56 \text { in a, } \\
\text { Ab, b } \\
\text { Carnaval, Op. } 9\end{array}$ & $\begin{array}{l}\text { ROBERT SCHUMANN. } \\
\text { Fantasie in C-dur, op. } 17 . \\
\text { Kreisleriana, op. 16, 1-8. } \\
\text { Etudes symphoniques, op. } 13 . \\
\text { Sonate, Fis-moll, op. } 11 . \\
\text { Fantasiestücke, op. } 12 . \\
\quad \text { Abends. } \\
\text { Nachts. } \\
\text { Traumeswirren. } \\
\quad \text { Warum? } \\
\text { Vogel als Prophet. } \\
\text { Romanze, D-moll, op. } 28 . \\
\text { Carneval; op. 9. }\end{array}$ \\
\hline 5. & $\begin{array}{l}\text { CHOPIN } \\
\text { Fantasie in } \mathrm{f} \\
\text { Preludes in } \mathrm{e}, \mathrm{A}, \mathrm{b}, \mathrm{D} b, \mathrm{~d} \\
\text { Mazurkas in } \mathrm{f} \#, \mathrm{eb}\end{array}$ & $\begin{array}{l}\text { MUZIO CLEMENTI. } \\
\text { Sonate B-dur mit der Toccata als Schluss (Erster } \\
\text { und letzter Satz.) } \\
\text { JOHN FIELD. }\end{array}$ \\
\hline
\end{tabular}




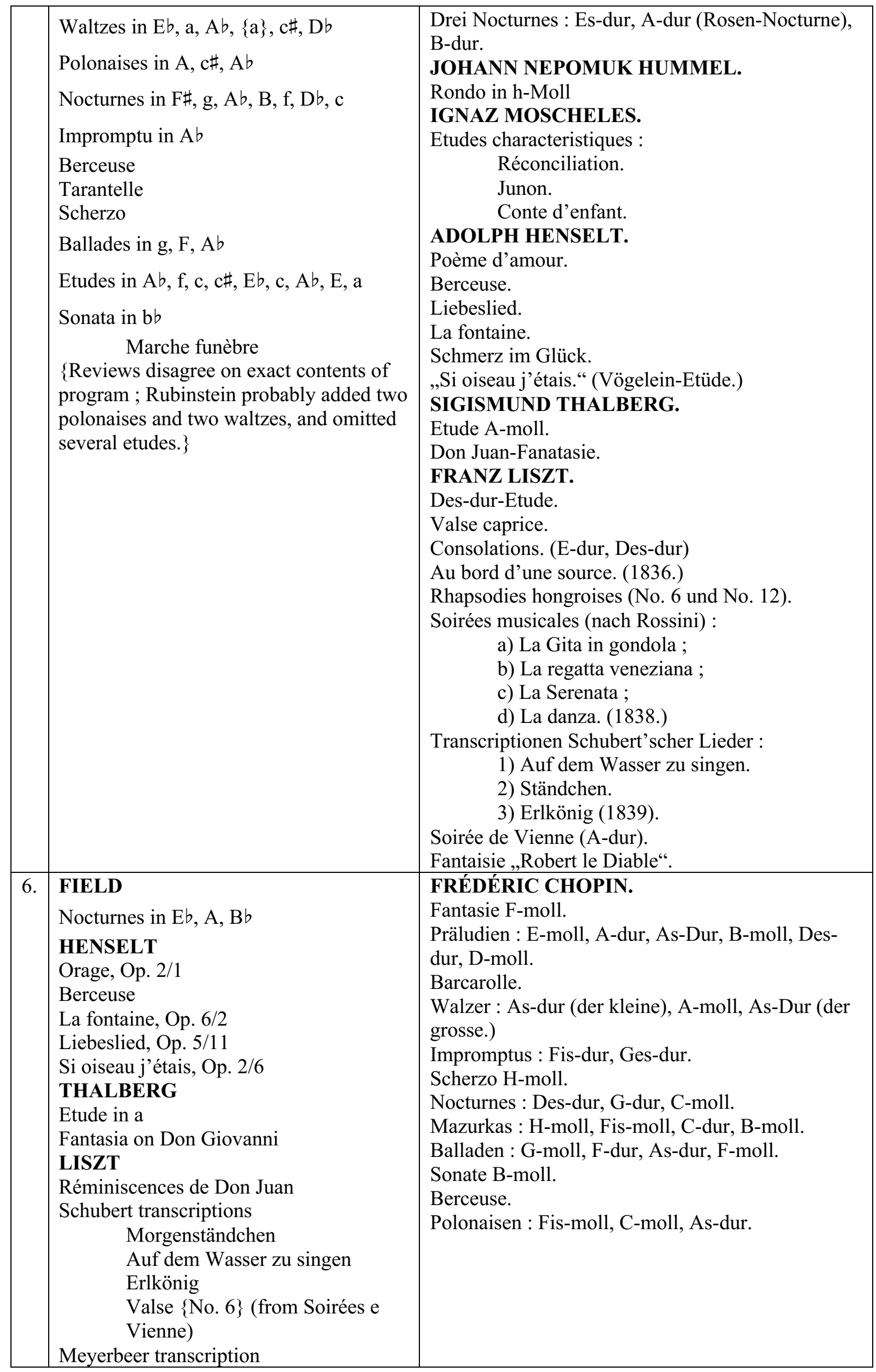




\begin{tabular}{|c|c|c|}
\hline & $\begin{array}{l}\text { Le moine } \\
\text { Rossini transcriptions } \\
\text { La gita in condola, La regata } \\
\text { veneziana, La serenata, La danza } \\
\text { (from Soirées musicales) } \\
\text { Valse impromptu in } \mathrm{A} b \\
\text { Hungarian Rhapsody in } \mathrm{D} b\end{array}$ & \\
\hline 7. & $\begin{array}{l}\text { RUBINSTEIN } \\
\text { Prelude and Fugue in Ab } \\
\text { Preludes in E, b } \\
\text { Theme and Variations } \\
\text { Mélodies in F, B } \\
\text { Album des danses populaires des } \\
\text { différentes nations } \\
\quad \text { Valse } \\
\quad \text { Mazurka } \\
\text { Barcarolles in } \mathrm{f}, \mathrm{G}, \text { a } \\
\text { Romances in F, Ab } \\
\text { Tarantelle } \\
\text { Le bal } \\
\quad \text { Valse } \\
\quad \text { Polonaise } \\
\text { Suite Sarabande } \\
\quad \text { Passepied } \\
\quad \text { Courante } \\
\quad \text { Gavotte } \\
\text { Sérénade russe } \\
\text { Album de Peterhof } \\
\quad \text { Caprice russe } \\
\text { Nouvelle mélodie } \\
\text { Impromptu } \\
\text { Nocturne in Gb } \\
\text { Scherzo } \\
\text { Miniatures } \\
\quad \text { Sérénade } \\
\quad \text { Près du ruisseau } \\
\text { Etüden in f, F, C } \\
\text { Nocturne in A } b \\
\text { Variations on "Yankee Doodle" } \\
\text { \{at least several and as many as eight of } \\
\text { the above works omitted }\}\end{array}$ & $\begin{array}{l}\text { FR. CHOPIN. } \\
\text { Etuden : As-dur, F-moll, E-dur. C-moll, Es-moll, } \\
\text { Es-dur, H-moll, As-dur (aus der „Méthode des } \\
\text { méthodes“), A-moll, Cis-moll, C-moll. } \\
\text { ANTON RUBINSTEIN. } \\
\text { Sonate F-dur. } \\
\text { Thema und Variationen (aus der Sonate C-moll). } \\
\text { Scherzo (aus der A-moll-Sonate). } \\
\text { MICHAEL GLINKA. } \\
\text { Tarantelle. } \\
\text { Barcarolle. } \\
\text { Souvenir de Mazurka. } \\
\text { M. ALEX BALAKIREFF. } \\
\text { Scherzo. } \\
\text { Mazurka. } \\
\text { Islamé (orientalische Fantasie). } \\
\text { PETER TSCHAIKOWSKY. } \\
\text { Chant sans paroles. } \\
\text { Valse, Romance, Scherzo à la Russe. } \\
\text { CESAR CUI. } \\
\text { Scherzo-Polonaise. } \\
\text { RIMSKY-KORSAKOFF. } \\
\text { Etude, Novelette, Valse. } \\
\text { LIADOFF. Etude, Intermezzo. } \\
\text { NICOLAUS RUBINSTEIN. } \\
\text { Feuillet d'album. } \\
\text { Valse. }\end{array}$ \\
\hline
\end{tabular}

Übersicht 6: Programme der amerikanischen und europäischen historischen Konzerte von Anton Rubinštejn

Jedes Konzert des europäischen Zyklus' ist inhaltsreicher als diejenigen des amerikanischen, wegen deren Länge sich schon das amerikanische Publikum beschwerte. ${ }^{499}$ Die wesentlichen Änderungen können wie folgt zusammengefasst werden: 1. Die Musik vor Johann Sebastian Bach, die im New Yorker Zyklus keine Rolle spielte, ist im ersten Konzert erschlossen. 2.

${ }^{499}$ Lott: From Paris to Peoria, S. 226. 
Das fünfte Konzert besteht in erster Linie aus romantischen Virtuosenstücken, und das sechste ist ein reines Chopin-Programm, während diese Reihenfolge in Amerika umgekehrt war. 3. Das letzte Konzert, das sich in Amerika ausschließlich seinen eigenen Werken widmete, besteht aus Werken von Chopin und den Komponisten, die im Programmhaft als »neu-russische Schule $\aleph^{500}$ deklariert sind.

In den europäischen historischen Konzerten wechseln monolithische Konzerte zu einem Komponisten mit zusammengesetzten Programmen mehrerer Komponisten ab. Dieser Ablauf kann als Darstellung einer Geschichtslinie ausgelegt werden: Das Grundgerüst bildet Musik von Beethoven, Schumann und Chopin. Die englischen, französischen, italienischen und deutschen Werke, aus denen sich das erste Konzert bunt zusammensetzte, münden ins reine Beethoven-Programm des zweiten Konzertes. Im dritten Konzert führt die Linie über Schubert, Weber und Mendelssohn zu Schumann als Gipfel der deutschen Romantik im vierten Konzert. Dann geht das Programm weiter in die Richtung der deutschen Klaviervirtuosen, an deren Endpunkt und gleichzeitig als Anschluss an Chopin Franz Liszt gestellt ist. Das sechste Konzert ist ausschließlich Chopin gewidmet. Das siebte und letzte ist ein russisches Programm. Es beginnt wieder mit Chopin, nun als Ahnherr der slawischen Komponisten, darauf folgen eigene Kompositionen von Rubinštejn, dann Werke von Glinka, Balakirev, Čajkovskij, Kjui, Rimskij-Korsakov, Ljadov und Antons Bruder Nikolaj Rubinštejn.

Dieses Programm wurde seit Oktober 1885 in den verschiedenen Musikzeitschriften und Zeitungen verschiedener Sprachen veröffentlicht, ${ }^{501}$ und diese Auswahl selbst wurde oft und eingehend diskutiert, vielleicht öfter und eingehender als die Ausführungen von Rubinštejn im Konzert. Zum Beispiel weist Cezar’ Kjui als St. Petersburger Korrespondent für Le Ménestrel auf die Einseitigkeit des Programms wie folgt hin:

Tel était le programme, colossal et vraiment sans précédent, de M. Rubinstein[.] Malgré l'importance de ce programme, on pourrait y signaler quelques lacunes, telles

\footnotetext{
${ }^{500}$ Tappert: Anton Rubinstein's Cyclus von sieben Klavier-Vorträgen, S. 41.

${ }^{501}$ Otto Lessmann schreibt zum Beispiel: »Wir sind in der glücklichen Lage, nachstehend Rubinstein's Programme für seine Claviervorträge in Berlin zu veröffentlichen. Es ist wohl die gigantischste Clavierleistung, welche bisher dem Berliner Publikum geboten worden ist. Eine Durchsicht der Programme zeigt die enorme Vielseitigkeit des genialen Mannes, der ein ungebeugtes Vertrauen in seine physische wie geistige Kraft setzt. Dass das Publikum ihm mit dem früheren Enthusiasmus entgegen kommen wird - wer würde das bezweifeln. Erfreulich ist auch, dass die Conzert-Direction Hermann Wolff, der die Arrangements für die Conzerte hier, wie in Wien, Prag, Leipzig, Paris und London übergeben sind, die Abonnementspreise verhältnissmässig sehr niedrig angesetzt hat.« Allgemeine Musik-Zeitung 12 (1885), S. $361 f$.
} 
que l'absence de Tausig, dont la virtuosité mérite le premier rang après Liszt;

l'absence des Allemands contemporains, Brahms, Raff, et des Français contemporains, Saint-Saëns, Fauré, etc..$^{502}$

Chopin wurde offenbar, wie sich aus dem Vergleich der amerikanischen und europäischen Programme ergibt, absichtlich ins russische Programm des siebten Konzerts gesetzt, um die Geschichtsauffassung darzustellen, dass er die Entwicklung der deutschen Klaviermusik mit der neuen Bewegung der jungen russischen Komponisten verknüpft. Diese Setzung scheint, wenigstens im deutschsprachigen Raum, die Rezensenten zwar verwundert, ihnen aber auch eingeleuchtet zu haben. Zum Beispiel fand Albert Löschhorn von der Neuen Berliner Musikzeitung diese »kleine Gewalttat« eher sympathisch:

Am Mittwoch fand Rubinstein's siebenter und letzter Clavier-Vortrag statt. Derselbe war nur oder doch vorzugsweise russischen Componisten gewidmet. Obgleich Chopin zu einer Zeit in Warschau geboren, bevor Polen dem russischen Reiche einverleibt war, so hatte Rubinstein denselben dennoch annectiert und zu seinem Landsmann gestempelt. Wir freuen uns dieser kleinen Gewaltthat, da durch die Wahl und vorzügliche Ausführung von 11 Etuden Chopin's eine fühlbare Lücke des vorigen Programms ausgefüllt wurde. ${ }^{503}$

Der am häufigsten geäußerte Zweifel am Programm war, ob die Werke der »neu-russischen Schule« geeignet wären, um dieses Unternehmen, das die Entwicklung des Klavierspiels exemplarisch zeigen sollte, abzuschließen. ${ }^{504}$ Adolf Ruthardt vom Leipziger Musikalischen Wochenblatt beurteilt diese Entscheidung abfällig:

Die warmen Beifallsspenden bezogen sich gewiss nicht auf die einerseits hässlichen und verworrenen, andererseits faden und schwächlich-epigonenhaften russischen Hervorbringungen, sondern galten dem geliebten Meister, welcher uns diese, kaum

${ }^{502}$ Le Ménestrel 52 (1886), S. 149.

${ }^{503}$ Albert Löschhorn: Anton Rubinstein's Concerte, in Neue Berliner Musikzeitung 39 (1885), S. 372. Adolf Ruthhardt bringt ebenfalls dieser Entscheidung Sympathie entgegen. Adolf Ruthardt: Bericht, in Musikalisches Wochenblatt 17 (1886), S. 206. Vgl. auch: Wiener Sonn- und Montags-Zeitung vom 21.12.1885, S. 3.

${ }^{504}$ Z. B. Otto Lessmann: Aus dem Konzertsaal, Allgemeine Musik-Zeitung 12 (1885), S. 439; Löschhorn: Anton Rubinstein's Concerte, S. 372; Ruthardt: Bericht, in Musikalisches Wochenblatt 17 (1886), S. 206; Bernhard Vogel: Anton Rubinstein. Biographischer Abriß nebst Charakteristik seiner Werke, Leipzig 1888, S. 28. 
begehrte Bekanntschaft, geleitet oder vielmehr verleitet durch an sich achtenswerthen Patriotismus, vermittelte. ${ }^{505}$

In der Allgemeinen Musik-Zeitung spricht Otto Lessmann darüber im Zusammenhang mit dem Fehlen von Brahms im ganzen Programm:

Ich habe aus meiner Bewunderung des eminenten Könnens der zeitgenössischen russischen Componisten nie ein Hehl gemacht, bekenne sogar, dass sie mir trotz ihrer vielfachen unleugbaren Extravaganzen geistreicher und origineller erscheinen, als z. B. der Böhme Dvorák und einzelne Imitatoren der ungarischen Musik, allein als Deutsche müssen wir uns denn doch erinnern, dass wir einen Meister wie Johannes Brahms besitzen, der es mit den zeitgenössischen Meistern anderer Nationen nicht nur an technischem Können aufnimmt, sondern sie auch wohl an Gedankentiefe unbeschadet der Bedeutung jener - übertrifft. Einen solchen Meister hätte Rubinstein nicht übersehen sollen. ${ }^{506}$

Dieses Fehlen von Brahms ist wohl auf die persönliche Antipathie von Rubinštejn gegen den deutschen Komponisten zurückzuführen. ${ }^{507}$ Was hier jedoch bemerkt werden sollte, ist, dass Rubinštejn durch die Programmaufstellung der historischen Konzerte ein spezielles Geschichtsverständnis transportierte. Der Standpunkt von Rubinštejn bildete zu demjenigen von Joseph Joachim und Hans von Bülow einen starken Kontrast, die beide seit den 1870erJahren durch ihre Tätigkeiten zur Etablierung der Reihung Bach-Beethoven-Brahms und damit zur »Konstruktion einer deutschen Instrumentalmusik im Sinne eines ästhetischen Paradigmas $\aleph^{508}$ wesentlich beigetragen hatten.

Die Hervorhebung der russischen Musik der jungen Generation und die unübersehbare Bildungsabsicht dieses Unternehmens sind untrennbar verbunden mit der Tatsache, dass Rubinštejn, der Gründer und erste Direktor des St. Petersburger Konservatoriums, im In- und Ausland als Leitfigur des russischen Musiklebens galt. ${ }^{509}$ In den 1860er-Jahren hatte es unter

\footnotetext{
${ }^{505}$ Ruthardt: Bericht, in Musikalisches Wochenblatt 17 (1886), S. 206.

${ }^{506}$ Lessmann: Aus dem Konzertsaal, in Allgemeine Musik-Zeitung 12 (1885), S. 439.

${ }^{507}$ Zur Antipathie von Rubinštejn gegen Brahms vgl. z. B. Taylor: Anton Rubinstein. A Life in Music, S. ix.

${ }^{508}$ Hinrichsen: Musikalische Interpretation. Hans von Bülow, S. 55.

${ }^{509}$ Rubinštejn gründete das erste russische Konservatorium in St. Petersburg 1862 und war dessen Direktor bis 1867. Nach den historischen Konzerten trat er 1887 dieses Amt am gleichen Konservatorium wieder an, wo er 1888/89 32 zweistündige Gesprächskonzerte »Kurse zur Geschichte der Klaviermusik« gab. In diesen erweiterte er seinen Gegenstand auf 877 Werke von 57 Komponisten, die er vortrug und erklärte.
} 
den Komponisten, die im Programmheft dieser historischen Konzerte unter der Kategorie »neu-russische Schule« zusammengefasst sind, Meinungsverschiedenheiten um die Verwirklichung einer eigenständigen nationalen Musikkultur gegeben. Die am Westen orientierten Komponisten strebten danach, das europäische Niveau zu erreichen und gründeten die Institutionen, die die Basis für das öffentliche Musikleben bilden sollten, wie die russische Musikgesellschaft (1859), das Konservatorium in St. Petersburg (1862) und das in Moskau (1866). Zu dieser Gruppe gehörten die Brüder Anton und Nicolaj Rubinštejn und später Čajkovskij. Die andere Gruppe um Balakirev, das »mächtige Häuflein« oder die »neurussische Schule $«,{ }^{510}$ zielte auf die Erneuerung der Kunstmusik und auf die Gründung der russisch-nationalen Musik aus dem Geist der unverfälschten Volksmusik. Zu dieser Gruppe gehörten die Musiker, die als Nachfolger Glinkas galten: Balakirev, Borodin, Kjui, Musorgskij und Rimskij-Korsakov. Diese Gruppengegensätze waren schon in den 1870erJahren weitgehend verwischt. Aber es ist doch beachtenswert und wohl strategisch, dass Rubinštejn hier wie der Vertreter einer Schule Russlands vorgestellt wurde.

$\mathrm{Zu}$ dieser Konzertreihe druckte Hermann Wolff im Eigenverlag ein Programmheft mit dem Titel »Anton Rubinstein's Cyclus von sieben Klavier-Vorträgen mit historischen und erläuternden Anmerkungen versehen von Wilhelm Tappert« (vgl. Abbildung 21).

\footnotetext{
${ }^{510}$ Christoph Flamm, Art. Musikkritik, B.II.2., in $M G G$ Online, hg. von Laurenz Lütteken, Kassel u. a. 2016-, veröffentlicht 2015-07-12, https://www-1mgg-2online-1 com-1875008798.erf.sbb.spkberlin.de/mgg/stable/13449, 1.4.2018.
} 


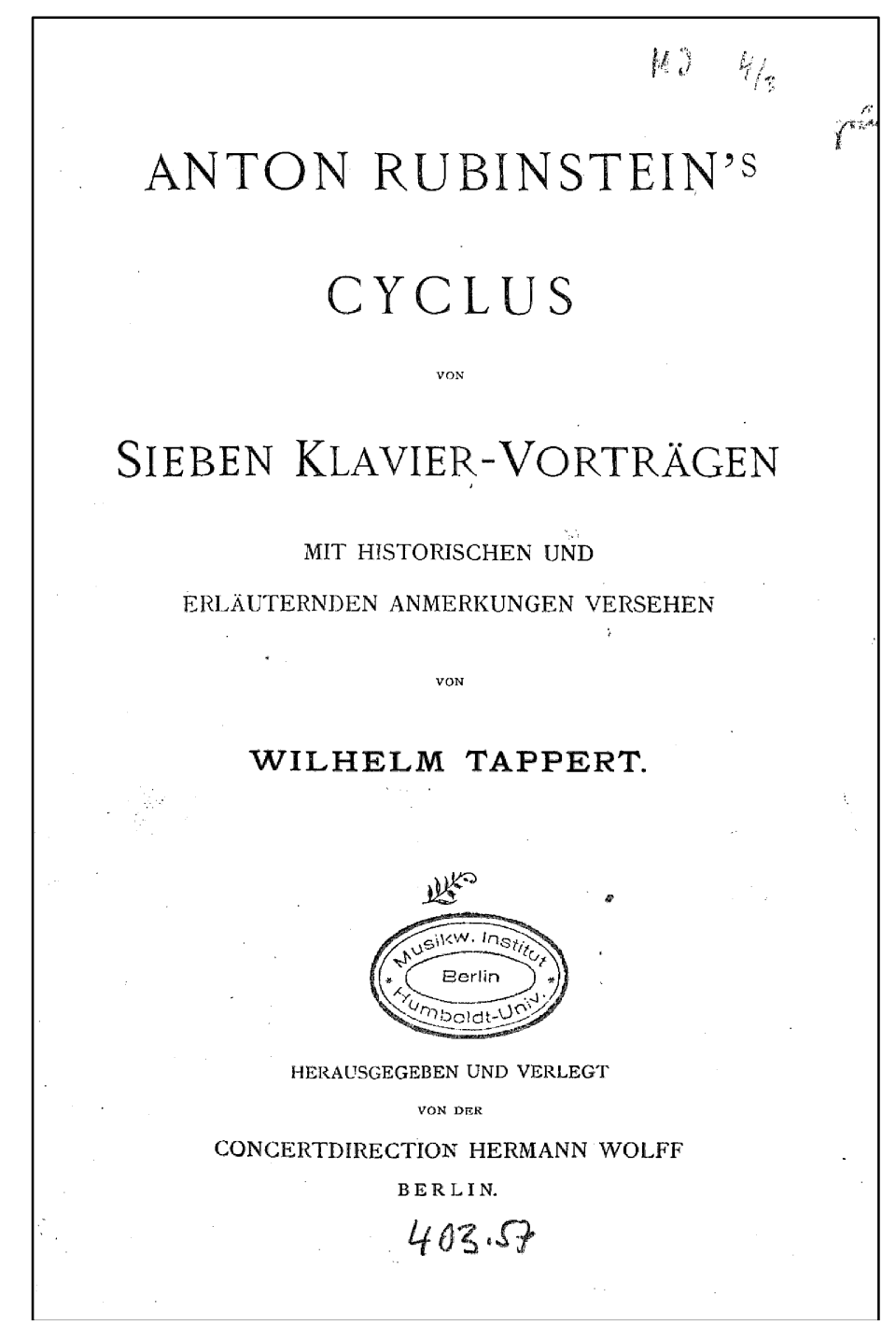

Abbildung 21: Titelblatt des Programmheftes Anton Rubinstein's Cyclus von sieben Klavier-Vorträgen mit historischen und erläuternden Anmerkungen versehen von Wilhelm Tappert

Auch in London erschien für den Rubinštejn-Zyklus ein ähnliches englisches Programmbuch, das einen aus dem Deutschen übersetzten Text von Oscar Eichberg enthielt. ${ }^{511}$ Obwohl die Beteiligung von Wolff an dieser englischen Ausgabe nicht nachgewiesen werden kann, scheint er auch an ihrer Erstellung mitgewirkt zu haben, da Eichberg ein Berliner Pianist, Komponist und Schriftsteller war, der zu den Publikationen der Konzertdirektion Hermann Wolff häufig beitrug. In der Tat sind die beiden Programmhefte sowohl stilistisch wie inhaltlich so ähnlich, dass es verwunderlich ist, dass sie unterschiedliche Autorennamen tragen. Die beiden Programmhefte umfassen je ungefähr 40 Seiten, beginnen mit einer instrumentengeschichtlichen Abhandlung über das Klavier, enthalten auch biographische

\footnotetext{
${ }^{511}$ Piano Recitals by Anton Rubinstein. Analytical and Historical Remarks on Anton Rubinstein's Cycle of Seven Pianoforte Recitals by Oscar Eichberg, übersetzt von George E. Prince, [London 1886].
} 
Daten der Komponisten und zeigen charakteristische Themen als Notenbeispiele mit Erläuterungen (vgl. Abbildung 22 und 23).

I.

Die ersten gelungenen Versuche, einen selbständigen, von fremdem Einflusse möglichst unabhängigen Clavierstil zu finden, gingen überraschenderweise von England aus. Zur Zeit als die Italiener sich noch unter dem Zwange der kontrapunktischen Vocalmusik befanden, bewegten sich die Eng]änder Tallis, Bird, Bull, ziemlich frei und in gefälligen, der Natur des Instrumentes glücklich angepassten Formen. Zwei englische Sammlungen, eine geschriebene, das Virginal-Book (Clavierbuch) im Fitz-William-Museum zu Cambridge und eine etwa gleichzeitige gestochene aus dem Jahre 1611 enthalten zahlreiche Compositionen für Clavier von den bestén Vertretern der ältesten englischen Pianisten-Schule. Den Vortritt im Reigen darf William Bird für sich beanspruchen. Seine Variationen über ein volksthümliches Lied: „des Fuhrmann's Pfeife," sind bemerkenswerth, wenn man in Betracht zieht, dass William Bird schon 1575 als „königlicher Organist" angestellt war.

Das populäre Thema lautet:

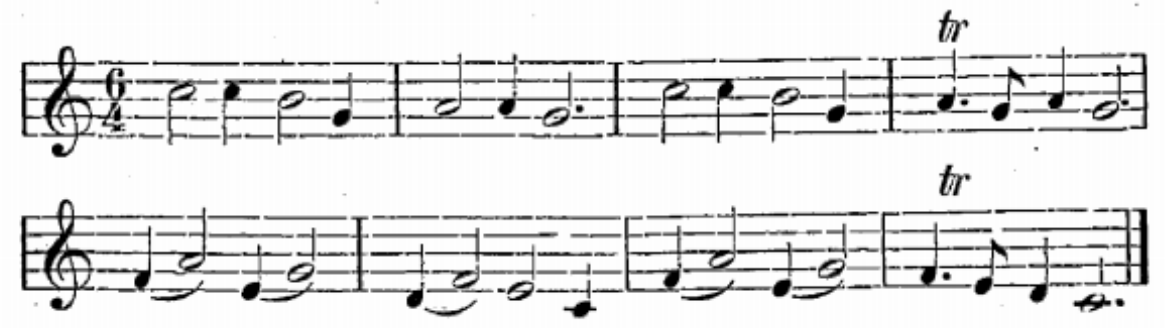

Abbildung 22: Auszug aus dem deutschen Programmheft Anton Rubinstein's Cyclus von sieben Klavier-Vorträgen mit historischen und erläuternden Anmerkungen versehen von Wilhelm Tappert ${ }^{512}$

512 Anton Rubinstein's Cyclus von sieben Klavier-Vorträgen, S. 7. 


\section{I.}

Wriliam Brad. Born about 1540, in London; died 4th July, 1623.

Variations on the popular melody, "The Carman's Whistle."

JoHx BuLl. Born 1568, in Somersetshire; died 12th March, 1628 , at Antwerp.

Variations on the populer melody, "The King's Hunting Jigg."

At a time when nearly everywhere strict counterpoint was the rule and when there was a complete want of freedom in the treatment of instrumental music, a new departure was. made in England, where extraordinary general activity in musical matters was displayed until the middle of the sixteenth century. We allude to the attempt to place pianoforte music on a basis of its own, and one suited to the nature of the instrument. For this endeavour we have mainly to thank the efforts of William Bird and John Bull; but a great number of. contemporary composers co-operated, and the results may be chiefly found in two collections, viz. the manuscript "Virginal. Book," in the Fitz-William Museum at Cambridge, and a printed book of pianoforte music, dated 1611.

Taking all things into consideration, this essay may be said to have been eminently successful. Both theme and development seem intended for the nature of the instrument and almost emancipate it from the influenco of the musical conventionalism of that day.

"The Carman's Whistle," the subject of Bird's variations, is as follows:-

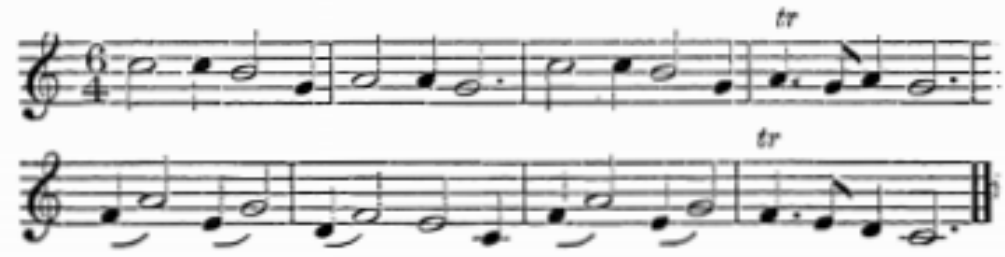

On the other hand, John Bull is said to have composed. "God Save the King," but this is very hypothetical.

Abbildung 23: Auszug aus dem englischen Programmheft Piano Recitals by Anton Rubinstein.

Analytical and Historical Remarks on Anton Rubinstein's Cycle of Seven Pianoforte Recitals by Oscar Eichberg ${ }^{513}$

Wie Otto Lessmann in seiner Rezension zum historischen Konzert von Rubinštejn schrieb, waren derartig ausgestattete Programmbroschüren damals für Berlin Neuheiten. ${ }^{514}$ Das Programmheft für die historischen Konzerte Rubinštejns gehört zu den ersten Publikationen dieser Art, die Hermann Wolff als Konzertagent erstellte und die er in den darauffolgenden Jahren bei den wichtigen Veranstaltungen gezielt verwertete, nämlich bei den von ihm gegründeten Abonnementkonzerten des Berliner Philharmonischen Orchesters ab der Saison

\footnotetext{
513 Piano Recitals by Anton Rubinstein, S. 7.

${ }^{514}$ Otto Lessmann, Aus dem Conzertsaal, in Allgemeine Musik-Zeitung 12 (1885), S. 398.
} 
1886/87515 und bei den Aufführungen der C-Dur Sinfonie von Richard Wagner - hier mit einer Analyse von Oscar Eichberg. ${ }^{516}$ Schrifttum, das dem Publikum Wissen über Musik nahebringen sollte, etablierte sich aber vor allem bei den historischen Konzerten. Bei den historischen Liederabenden »Geschichte des deutschen Liedes« von Amalie Joachim ab 1891 gab Hermann Wolff Werkerläuterungen von Heinrich Reimann in Form einer Broschüre heraus. ${ }^{517}$ Und auch bei den historischen Konzerten von Ferruccio Busoni im Jahr 1898, bei denen er an vier Abenden die Entwicklung des Klavierkonzertes demonstrierte, wurde ein von José Vianna da Motta verfasstes, fast 90-seitiges Programmheft von Wolff verlegt. ${ }^{518}$

Wenn auch Rubinštejn im Konzert einige unwesentliche Abweichungen vom vorher angegebenen Programm gemacht haben mag, bestätigen die Besprechungen, dass er weder den Rahmen jedes Konzertes überschritt, noch die chronologische Folge grundsätzlich veränderte. Um dem Publikum besser zu gefallen, hätte er die Struktur des Programms dem Geschmack oder der Geschichtsauffassung des lokalen Publikums anpassen und aus seinen umfangreichen Repertoire verschiedene Musikgeschichten konstruieren können, was aber nicht geschah. Die Idee des durchstrukturierten, ausgearbeiteten Programms deutet an, dass dieses hier wie ein Kunstwerk aufgefasst wurde. Neben der Veröffentlichung des Programms durch die Presse war die Erstellung des erläuternden Programmheftes die geeignete Maßnahme, um das Programm an sich wie ein Werk zu inszenieren.

In der Tat wurde die Programmgestaltung dieser historischen Konzerte zu einer Art von Standard. Als Riccardo Viñes 1905 in Paris einen Zyklus von vier historischen Konzerten gab, nahm Michel-Dimitri Calvocoressi in der Revue Musicale de Lyon auf die historischen Konzerte von Rubinštejn 20 Jahren zuvor Bezug und stellte das neue Programm von Viñes im eingehenden Vergleich mit demjenigen von Rubinštejn vor. ${ }^{519} 1910$ stützte sich Berthe MarxGoldschmidt auf dieses Programm Rubinštejns, als sie eine Reihe von historischen Konzerten in Paris gab (vgl. Abbildung 24). ${ }^{520}$

\footnotetext{
${ }^{515}$ Dazu vgl. Abschnitt 3.2.2 der vorliegenden Arbeit.

${ }^{516} \mathrm{Zu}$ diesen Aufführungen vgl. Abschnitt 2.1.1 der vorliegenden Arbeit.

${ }^{517} \mathrm{Zu}$ den historischen Liederabenden von Amalie Joachim, vgl. Beatrix Borchard: Stimme und Geige. Amalie und Joseph Joachim, S. 465-479.

${ }^{518}$ Ferruccio Busoni's Cyclus von vier Clavier-Orchester-Abenden. Die Haupterscheinungen auf dem Gebiete des Clavier-Concertes von J. S. Bach bis Fr. Liszt. Mit historisch-kritischen Erläuterungen von José Vianna da Motta und einer thematischen Uebersicht der zum Vortrag gelangenden Clavier-Concerte, Berlin 1898.

${ }^{519}$ Michel-Dimitri Calvocoressi: A propos de Concerts Historiques. D'Antoine Rubinstein à Ricardo Vines, in Revue Musicale de Lyon 2 (1905), S. 325-327.

${ }^{520}$ L'Actualité musicale: annexe de la Revue musicale S.I.M. vom 15.4.1910, S. $128 f$.
} 


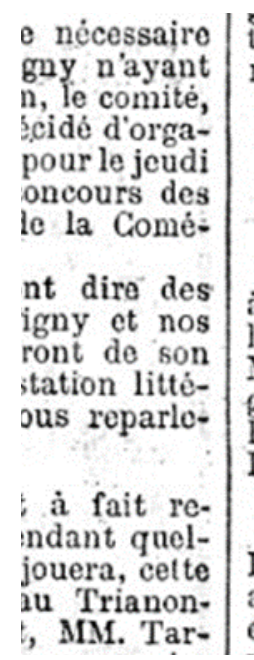

tournée d’Allemagne, détaille á ravir los spirituels couplets des cartos postales.

\section{COORRIER MUSICAL}

Ce soir lundi, à la Salle des Agriculteurs, à 9 heures (soirées dart), premier concert historique d'Antoine Rubinstein, donné par Mme Berthe Marx Goldschmidt. Au programme, des ceuvres de William Bord, John Bull, Couperin, Rameau, Scarlatti, Bach, Hændol, Mozart, ete.

Entre la $1^{\text {ro }}$ et la $2^{\circ}$ partic du Messie de Hændel qui sera exécuté en soirée le 23 avril au Trocadéro, M. A. Guelmant exécutera le concorto on fa pour orgue et orchestre, sui- aamirade pa

Danac, deux Baptiste-Mar. sont pas fréq cependant, a de Rome en borieuse car: productions; œuvre de $\mathrm{P}_{1}$ succès - suc que l'on cor trois estamp lithographic, gravure. $\mathrm{La}$ i jolie Tête de trait de $\mathrm{fcmm}$ quesse, et 1 d'après Falco

Abbildung 24: Ankündigung des ersten historischen Konzerts von Berthe Marx-Goldschmidt im April $1910^{521}$

In seinem Aufsatz zur Entwicklung des europäischen Konzertagentenwesens weist William Weber auf die Möglichkeit hin, dass die Konzertagenten der zweiten Hälfte des 19.

Jahrhunderts bei der Kanonisierung der Klassiker und bei der Internationalisierung des Konzertrepertoires ihre Hände im Spiel hatten:

On a certain plane, concert agents and classical-music repertoires emerged as central new aspects of authority within the musical world during the second half of the nineteenth century. [...] The repertories built around works by Handel, Haydn, Mozart, Beethoven, and a large number of other composers became international in scope, as the early tendencies toward canon in eighteenth-century Britain and France had not been. The cosmopolitan nature of the canon was a critically important aspect of its authority, for it balanced the nationalistic tendencies that emerged within musical styles and music conservatories. In the process, a new generation of virtuosi Joseph Joachim and Anton Rubinstein, most prominently - performed classical works often, both in orchestral and chamber music concerts. Great performers were now in a certain sense canonized as well as great works, and the two processes related closely with each other. The authority of concert agents was linked closely to the hegemony of classical music within concert life. As core repertoires of classical works grew within most types of concerts, so also agents emerged not only as managers of concert activity but also as arbiters of taste for both performers and repertory. ${ }^{522}$

${ }^{521}$ Le Figaro vom 10.4.1910, S. 5.

${ }^{522}$ William Weber: From Self-Managing to Independent Concert Agent, S. 116f. 
Die Konzertagenten in der zweiten Hälfte des 19. Jahrhunderts haben sicherlich durch ihre Tätigkeiten einige ästhetische Normen gesetzt. Dieser Abschnitt hat gezeigt, dass das Programm des Zyklus Rubinštejns durch die gezielte Strategie von Hermann Wolff wie ein Kunstwerk dargestellt und von weiten Kreisen wie ein Kunstwerk diskutiert wurde. Von einem renommierten Pianisten als »Geschichte« in einem beispiellos großen Umfang vorgelegt, errang das Programm schließlich die Stellung eines Standards. Dadurch bekamen sowohl der Künstler wie der Konzertagent Autorität als Normgeber.

\subsubsection{Erläuternde Programmhefte: Das Konzert als Werk des}

\section{Veranstalters}

Wie im Abschnitt 3.2.1 gezeigt, setzte Hermann Wolff beim großen historischen Zyklus Anton Rubinštejns in der Saison 1885/86 gezielt erläuternde Programmhefte ein, um das ausgearbeitete Programm wie ein Kunstwerk zu inszenieren. Mit Beginn der Saison 1886/87 begann er, derartige Programmbroschüren für die unter seiner Geschäftsführung stehenden Orchesterabonnementkonzerte in Berlin, Hamburg und Dresden zu veröffentlichen. Ein unter dem Namen der »Concert-Direction Hermann Wolff« abgegebenes Angebot für die Aufgabe von Annoncen in den Programmheften enthielt einige bemerkenswerte Angaben:

Die unterzeichnete Concertdirection gibt in diesem Winter für die unter ihrer Geschäftsführung stehenden grossen Abonnementsconcerte Programmbücher (mit Analysen der hauptsächlichen Instrumentalwerke) heraus, welche in den betreffenden Concertlocalen und vorher in den Musik- und Buchhandlungen zu Ausgabe gelangen.

Die Concerte sind:

in Berlin

\section{Concerte der Philharmonischen Gesellschaft}

a) 6 Concerte der Königl. Akademie der Künste unter Leitung ihres Kapellmeisters Herrn Professor Jos. Joachim

b) 6 Concerte unter Leitung des Herrn Professor K. Klindworth

in Hamburg

2. 6 Concerte unter Leitung des Herrn Dr. Hans von Bülow

in Dresden 


\section{6 Concerte unter Leitung des Herrn Jean Louis Nicodé}

Für diese Programmbücher, welche mit einem Annoncentheil versehen sind, übernimmt die unterzeichnete Concertdirection die Annahme von Annoncen.

Da der Besuch obiger Concerte, von einem musikalischen Publikum, bekanntlich ein sehr bedeutender ist und die Bücher durch ihren Inhalt - ein grosser Theil der Analysen neuster Werke wird von den Componisten selber verfasst - einen mehr wie vorübergehenden Werth für das Publikum haben und aufbewahrt werden, so empfehlt sich diese Gelegenheit als vielleicht die günstigste, die bisher für Anzeigen von Musikalien, Musikinstrumenten, Musikinstituten etc. (nur solche werden angenommen) geboten worden ist. ${ }^{523}$

In diesem Angebot wurde schon hervorgehoben, dass die Programmhefte mit »Analysen der hauptsächlichen Instrumentalwerke« versehen werden. Auch war vorgesehen, dass die Komponisten Analyse ihrer eigenen Werke beitragen würden. Wie Christiane Tewinkel bemerkt, unterscheiden sich Musikeinführung und Programmheft durch ihre Rezeptionssituationen. Eigentlich wird das Programmheft »nicht auf eine überall und jederzeit mögliche Lektüre, sondern auf ein konkretes Ereignis hin konzipiert«. ${ }^{524}$ Wenn man auch darauf Rücksicht nehmen muss, dass es sich hier um Werbetexte handelt, die etwas übertrieben formuliert sein könnten, ist doch bemerkenswert, dass Hermann Wolff für die noch zu schaffenden Programmhefte bereits einen dauerhaften inhaltlichen Wert vorsah.

Als Konzertveranstalter setzte Hermann Wolff die Idee der erläuternden Programmbroschüren erst ab Mitte der 1880er-Jahre in die Praxis um. ${ }^{525}$ Die Idee von Leitfäden für Konzerte, welche die Zuhörer durch Werkanalysen mit den aufzuführenden Kompositionen vertraut machen und dadurch ein besseres Verständnis ermöglichen sollten, scheint jedoch schon früher im Kreis um Hermann Wolff ausgesprochen worden zu sein. Zum Beispiel äußerte Otto Lessmann 1883 in einem Artikel seine Erwartung für die Einführung solcher Programmhefte ins Berliner Konzertleben:

\footnotetext{
${ }^{523}$ Concert-Direction Hermann Wolff: Angebot für die Aufgabe von Annoncen in den Programmheften, o. D. (»Datum des Poststempels«) [1886], GSA 55/11207, Hervorhebungen im Original.

${ }^{524}$ Christiane Tewinkel: Muss ich das Programmheft lesen? Zur populärwissenschaftlichen Darstellung von Musik seit 1945, Kassel u. a. 2016, S. 59.

${ }^{525}$ Dazu vgl. Abschnitt 3.2.1 der vorliegenden Arbeit.
} 
Ich möchte hier die Gelegenheit benutzen, überhaupt auf eine sehr wünschenswerthe Reform der äusseren Erscheinung unserer Conzert-Programme hinzuweisen, deren dieselben im Interesse der aufzuführenden Kunstwerke wie der Künstler und des Publikums bedarf. England und Amerika sind uns in dieser Hinsicht mit gutem Beispiele vorangegangen. Dort erhalten die Conzertgeher für einen geringen Preis an Stelle des Conzertzettels eine kleine Broschüre in die Hand, in welcher neben dem Verzeichnis der zur Aufführung kommenden Musikstücke und der Namensliste der mitwirkenden Künstler eine mehr oder weniger ausführliche Analyse der Hauptwerke des Programms enthalten ist. Notenbeispiele veranschaulichen die Einzelheiten dieser Analyse und geben dem Publikum gleichzeitig Hilfsmittel zum Verständnis des thematischen Aufbaues des Kunstwerkes in die Hand. Ich habe derartige Programme von englischen Conzertaufführungen und amerikanischen Musikfesten gesehen, die wahrhaft mustergiltige, ganz objektiv gehaltene Zergliederungen Beethoven'scher Schumann'scher Liszt'scher Wagner'scher und Brahms'scher u. s. w. sinfonischer Werke enthalten und einen weit über den Gebrauch am Conzertabend hinausreichenden Werth besitzen. [...] Ich empfehle diesen Gedanken den Herren Kollegen von der Presse und den Leitern unserer grossen Conzertinstitute zur freundlichen Erwägung und Verbreitung. Welchen Nutzen die empfohlene Einrichtung für Novitäten haben würde, brauche ich kaum noch auseinanderzusetzen und deswegen haben Conzert-unternehmungen, deren Tendenz die Vorführung von Novitäten ist, das allgrösste Interesse an derselben. ${ }^{526}$

Hier stellt Lessmann die Idee eines entgeltlichen Programmheftes konkret vor, das die Übersicht der aufzuführenden Werke sowie aufzutretenden Künstler und Analyse einiger Werke des Programms liefert, vor allem in Zusammenhang mit der Aufführung von Neukompositionen. Wie Wolff im oben zitierten Angebot seine Programmbroschüre als dauerhafte Lektüre ansah, stellt sich auch Lessmann die erwarteten Programmhefte als musikalische Erläuterungsliteratur mit dauerhaftem Wert vor. Zu den Vorbildern, die Lessmann hier nennt, gehören offenbar die Konzertveranstalter, die in den 1840er und 1850er-Jahren in England Programmhefte zu einem regelmäßigen schriftlichen Angebot an die Konzertbesucher gemacht hatten. Vor allem der Londoner Konzertagent John Ella, der schon in den 1840er-Jahren mittels analytischer Programmhefte die Bildung des Publikums

\footnotetext{
${ }^{526}$ Otto Lessmann: Aus dem Conzertsaal, in Allgemeine Deutsche Musik-Zeitung 10 (1883), S. 44. Hervorhebungen im Original.
} 
anstrebte, ${ }^{527}$ und George Grove, der als Geschäftsführer der Crystal Palace Company ab 1856 fast vierzig Jahre lang ausführliche Programmnotizen für die in der Londoner Ausstellungsstelle stattfindenden Konzertreihen schrieb, ${ }^{528}$ waren bekannt als Träger der englischsprachigen Programmheftkultur. ${ }^{529}$ Im deutschsprachigen Raum löste Hans von Wolzogen mit seinem Thematischen Leitfaden durch Richard Wagners Ring des Nibelungen, ${ }^{530}$ den er 1876 zur Uraufführung des Werkes in Bayreuth veröffentlichte, »eine Flut von Nachahmerschriften aus, die in den kommenden Jahrzehnten zunehmend mit der Konzert- und Opernführer-Literatur verschmolzen«. ${ }^{531}$ Hermann Kretzschmar, der im Jahr 1877 die Stelle des Universitätsmusikdirektors in Rostock angetreten hatte, gab diesem Trend dadurch wichtige Impulse, dass er in Vorbereitung auf einzelne Konzerte vorwegnehmende Werkerläuterungen in der Rostocker Zeitung veröffentlichte, die ihrerseits den Grundstein bildeten für seinen Führer durch den Konzertsaal, dessen erste Auflage 1887 erschien.

Edith Stargardt-Wolff zählte die Einführung der erläuternden Programmhefte in die Abonnementkonzerte des Berliner Philharmonischen Orchesters zu den Leistungen ihres Vaters. Zu den Musikschriftstellern, die zu seinen Lebzeiten als Redakteure dieser Programmhefte fungiert hatten, schrieb sie in ihrem Erinnerungsbuch:

Mein Vater führte für die Philharmonischen Konzerte eine Neuerung ein, die seither Allgemeingut geworden ist, nämlich Programmbücher, welche kurze Analysen der aufzuführenden Werke mit eingefügten Notenbeispielen enthielten. Der erste Redakteur dieser Programmbücher war der bekannte Musikschriftsteller Wilhelm Langhans. Ihn löste später der ausgezeichnete Organist und Musikschriftsteller Heinrich Reimann ab. Reimann, ursprünglich Philologe, hatte sich später ganz dem

\footnotetext{
${ }^{527} \mathrm{Zu}$ dieser Tätigkeit von John Ella vgl. Christina Bashford: The Pursuit of High Culture. John Ella and Chamber Music in Victorian London, Woodbridge 2007, vor allem S. 120f. Vgl. auch Schwab: Konzert, S. 118.

${ }^{528} \mathrm{Zu}$ dieser Tätigkeit von George Grove vgl. Christina Bashford: Not Just »G. «: Towards a History of the Programme Note, in George Grove. Music and Victorian Culture, hg. von Michael Musgrave, London 2003, S. 115-142.

${ }^{529}$ Zur von viktorianischer Philanthropie ausgeprägten Praxis der erläuternden Programmnotizen in Großbritannien des 19. Jahrhunderts vgl. Catherine Dale: The »Analyrical« Content of the Concert Programme Note Re-examined: its Growth and Influence in Nineteenth-Century Britain, in NineteenthCentury British Music Studies 2, hg. von Jeremy Dibble u. a., Aldershot 2002, S. 199-222.

${ }^{530}$ Hans v. Wolzogen: Thematischer Leitfaden durch die Musik zu Richard Wagners Festspiel. Der Ring des Nibelungen, Leipzig 1876.

${ }^{531}$ Christian Thorau: Die Hörer und ihr Cicerone. Werkerläuterung in der bürgerlichen Musikrezeption, in Musik - Bildung - Textualität, hg. von Andreas Jacob u. a., Erlangen 2007, S. 207-220, hier S. 209f. Vgl. auch: ders.: Semantisierte Sinnlichkeit. Studien zu Rezeption und Zeichenstruktur der Leitmotivtechnik Richard Wagners, Stuttgart 2003, vor allem S. 106-156.
} 
Musikstudium zugewandt; seine musikgeschichtlichen Werke tragen daher den Stempel gründlichen Wissens auf beiden Gebieten. Am bekanntesten ist wohl sein Brahms-Buch und die Sammlung »Das deutsche Lied«, welche er für Amalie Joachim zusammengestellt hatte. ${ }^{532}$

Diese Erinnerung bedarf einer Korrektur. Es war Oscar Eichberg, der als erster die Programmhefte dieser Abonnementkonzerte in den Spielzeiten 1886/87 und 1887/88 redigierte. In seiner Nachfolge war Wilhelm Langhans in den Spielzeiten 1888/89 und 1890/91 für ihre Redaktion verantwortlich gewesen, bevor Heinrich Reimann ihn ablöste. ${ }^{533}$

Die Berliner, Hamburger und Dresdner Programmhefte entstanden unter dem gleichen Redakteur, und der Erläuterungstext wurde oft über den Rahmen der Konzertreihe hinaus benutzt, wenn ein Werk auch andernorts in einem Konzert gespielt wurde. Manche Erläuterungstexte wurden bei der Wiederaufführung des Werkes auch von einem anderen Redakteur mit Angabe des Verfassers ohne oder mit kleiner Bearbeitung wieder abgedruckt, andere neu verfasst. Inwieweit ein Werk zu erläutern war, wurde nach dem vermuteten Bekanntheitsgrad des Werkes und des Komponisten einzeln entschieden. Im Verzeichnis der aufzuführenden Werke auf der ersten Seite des Programmheftes wurden die Novitäten mit Zusätzen wie »neu«, »Neuheit«, »Manuscript« gekennzeichnet. ${ }^{534}$ Die meisten Analysen stammen aus der Feder des jeweiligen Redakteurs, einige der neuen Werke der des Komponisten selbst. Als Ausnahmebeiträger zu nennen ist Hermann Wolff, der eine Analyse zum fünften Klavierkonzert op. 103 von Camille Saint-Saëns zum Philharmonischen Konzert vom 22. Februar 1887 schrieb.

Das erste Programmheft der Saison 1886/87 enthält die folgende Erklärung unter dem Namen Eichberg:

Zur Einführung.

\footnotetext{
${ }^{532}$ Stargardt-Wolff: Wegbereiter großer Musiker, S. 61f.

${ }^{533}$ Nach Reimanns Tod im Jahr 1906 übernahm Paul Bekker diese Aufgabe. Die Programmhefte in der Bekker-Zeit werden in der vorliegenden Arbeit nicht berücksichtigt, weil sie in die Zeit nach dem Tod Hermann Wolffs fallen.

${ }^{534}$ Hermann Wolff meinte diese Kennzeichnungen im Programmheft, wenn er an Bülow wie folgt schrieb: »Im großen Ganzen scheinen mir also Ihre Programme kaum noch mit Bemerkungen zu versehen, wenn ich noch einen Wunsch äußern soll, so müsste ich - gleichviel wo - noch eine Novität mache, gleichviel welche, nur wegen der Parenthese (neu). « Brief von Hermann Wolff an Hans von Bülow vom 4.9.[1886], Berlin SBPK, Mus. ep. Hermann Wolff 409. Der vorausgegangene Brief von Bülow an Wolff vom 3. September 1886 ist veröffentlicht in Bülow-Briefe 7, S. 46f.
} 
In der jetzt beginnenden Saison soll der Versuch gemacht werden, das Interesse der Concertbesucher für ausführliche, systematisch redigierte Programmbücher zu wecken, die, nach dem Vorbilde der vortrefflichen Englischen Sitte, bei Gelegenheit der bedeutsamsten Musikaufführungen ausgegeben werden sollen. ${ }^{535}$

Wie Lessmann im oben zitierten Artikel nennt Eichberg hier ebenfalls die englische Verfahrensweise der Programmnotiz als Vorbild. Er betonte aber auch, dass hier keinesfalls ihre »weit ausholenden, kritischen und ästhetischen Excurse $«^{536}$ nachgeahmt werden sollen.

[...] Die beabsichtigten Programmbücher sollen für alte und neue Compositionen Daten geben, die den Hörer über wissenswerte, mit dem besprochenen Werke zusammenhängende Umstände unterrichten; sie sollen ferner kurze musikalische Analysen grösserer, besonders neuer und bisher nicht oder nur wenig gekannter Compositionen bringen, um das (technische!) Verständnis und das Behalten des in vielen Fällen zum ersten Male Gehörten zu erleichtern; - sie sollen und dürfen aber nicht durch kritische Urteile oder ästhetische Betrachtungen irgend welcher Art die Meinung des Hörers vorweg zu beeinflussen suchen. Es ist stets festzuhalten, dass der Hörer der Erste ist, dem nach der Aufführung eines Werkes die Abgabe eines Urteils geziemt.

Ein Teil der in Aussicht genommenen Analysen grösserer Werke wird die Componisten der letzteren selbst zu Verfassern haben, was durch besondere Notiz am Kopfe des betreffenden Abschnittes gekennzeichnet werden wird.

Berlin, 1. October 1886.

\section{Oscar Eichberg. ${ }^{537}$}

Deutlich wird, dass sich die in diesen Programmheften vorgesehenen Erläuterungen in ihrer sachlichen, objektiven Ausrichtung von konventionellen Texten zum Konzert, etwa Kritiken oder Werkbesprechungen in Fachzeitschriften, abgrenzen und keinesfalls die Meinung oder Beurteilung des Publikums beeinflussen wollen. Wie Christian Thorau zur Parsifal-Schrift

\footnotetext{
${ }^{535}$ Oscar Eichberg: Zur Einführung, in Programm-Buch der Concerte der Berliner Philharmonischen Gesellschaft, redig. von Oscar Eichberg, hg, und verl. von der Concert-Direction Hermann Wolff, Saison 1886/87, Serie A (15.10.1886), S. 3.

${ }^{536}$ Ebd.

${ }^{537}$ Ebd., S. 4.
} 
Eichbergs im Vergleich mit den Maximen anderer Wagner-Exegeten aufzeigte, zielen die Erläuterungstexte von Eichberg weder auf semantische noch auf kontextuelle Instruktion. ${ }^{538}$ Bei Eichberg geht es in erster Linie darum, Hauptmotive im Notenbeispiel zu zeigen und die syntaktische Struktur des jeweiligen Werks zu erklären. Wie Christiane Tewinkel bemerkt, setzt er offensichtlich nicht nur eine musikalische Lesefähigkeit der Leser voraus, sondern auch ihre Vertrautheit mit dem Fachvokabular und der Faktur musikalischer Formen. ${ }^{539}$

Aus der Auswertung der Programmhefte der Berliner Philharmonischen Konzerte, die zu Hermann Wolffs Lebzeiten in den 16 Spielzeiten zwischen 1886/87 und 1901/02 erschienen, ergibt sich, dass die oben gezeigten Prinzipien Eichbergs von seinen beiden Nachfolgern ohne wesentliche Veränderung übernommen wurden. Möglicherweise ist die konsequente Grundhaltung dieser Publikation auf den Initiator und Auftraggeber Hermann Wolff zurückzuführen.

Ein typisches Programmheft dieser Konzerte in der betreffenden Zeit besteht aus einer Titelseite mit dem Verzeichnis der aufzuführenden Werke und Künstler, einem Erläuterungsteil und einem Annoncenteil. Normalerweise brachten die Programmhefte keine anderen Beiträge, etwa Artikel zu Musik allgemein oder Biographien der auftretenden Musiker. Der folgende Text von Hans von Bülow mit der offensichtlichen Absicht der Publikumsbildung ist deshalb als Ausnahme beachtenswert. Er erschien im ersten Programmheft der Saison 1894/95, der Saison nach dem Tod des Verfassers, mit einer Einleitung von Hermann Wolff (Abbildung 25 und 26).

\footnotetext{
${ }^{538}$ Thorau: Semantisierte Sinnlichkeit, S. 268. Christiane Tewinkel weist drauf hin, dass das Vorgehen Eichbergs in den Programmheften der Philharmonischen Konzerten sich mit jenem in Eichbergs Erläuterungsschrift zu Richard Wagners Parsifal deckt, die zur Uraufführung 1882 erschienen war. Christiane Tewinkel: »In Ansehung der erheblichen für unser Musikleben zu erhoffenden Vorteile«: Einige Beobachtungen zu den Programmheften der Berliner Philharmoniker, in Gibt es sie noch: »die« Musik? Vorüberlegungen zu einer Allgemeinen Musiklehre, hg. von Marie-Agnes Dittrich u. a., Wien 2011, S. 198-221, hier S. 203.

${ }^{539}$ Tewinkel: »In Ansehung der erheblichen für unser Musikleben zu erhoffenden Vorteile«, S. 210.
} 


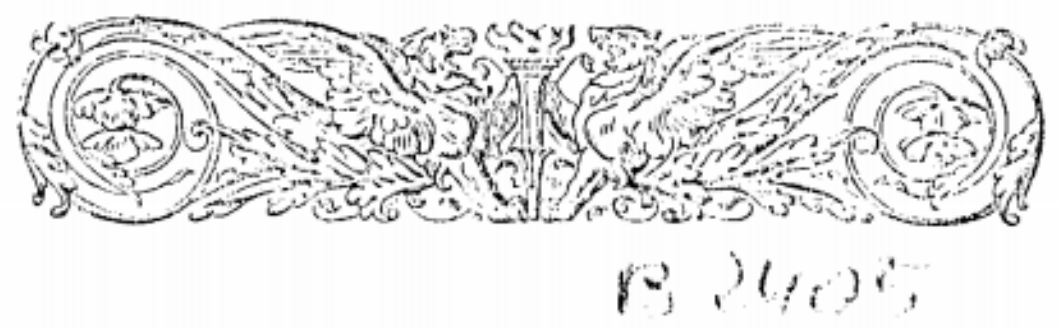

Itans von Bülow ülıergal, mir den nachstehenden kleinen Artikel in der letzten Zeit seiner Thätigkeit als 1)irigent der Philharmonischen Concerte zur Veroffentlichung an slieser Stelle der Programmbücher. Wenn ich während sciner Leidenszeit von der Veröffentlichungr Alstanıl nahm, so glaube ich jetzt den Besuchern der Concerte diese Aufklärungen über 13.'s oft missverstandenen Unmuth bei Störungen durch Zuspätkommen und zu frühes Gehen nicht vorenthalten zu dürfen.

H. W.

\section{Zum Schutze der Sinfonie-Componisten*) von Hans von Bülow.}

Bekanntlich hat das verchrliche Concert-Publikum Berlins bisher verschmäht, die löbliche Sitte der Zuhörer der Conservatoriums-Concerte in Paris oder der Gewandhaus-Concerte in Klein-Paris zu adoptiren, sich nämlich zu der für den Beginn der Musik festgesetzten Zeit so pünktlich einzufinden als es \%. B. bei der Benutzung von Eisenbahnzügen - für Geschăftsreisen ebensowohl als für Lustpartien - bekanntlich unerlässliche Bedingung ist. Unter diesem Umstande ist es kaum möglich, ein aus mehreren Abschnitten bestehendes grösseres Musikwerk, Suite, Serenade, Sinfonic zur Anfangsnummer eines Programms zu machen. Die massenhafte Nachströmung der "Spätlinge" nach einem ersten, sogar zweiten Sinfoniesatze schädigt oder stört einen ununterbrochenen Genuss seitens der auf-

\#) Mit Èrlaubniss der Èrbin.

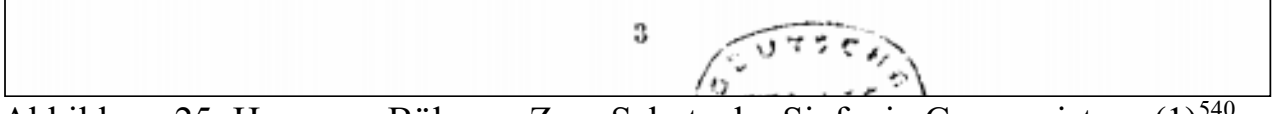

Abbildung 25: Hans von Bülow: »Zum Schutz der Sinfonie-Componisten« $(1)^{540}$

\footnotetext{
${ }^{540}$ Das Programmheft zum Berliner Philharmonischen Konzert vom 15. Oktober 1894, S. 3. Dieser Text wurde zwei Spielzeiten später im Programmheft zum Berliner Philharmonischen Konzert vom 26. Oktober 1896 wieder abgedruckt.
} 
merksamen pünktlichen Zuhörer recht empfindlich -zu geschweigen, dass die gesammelte und gehobene Stimmung der Ausführenden durch die mitunter ästhetisch unleidlich langen Pausen cbenfalls gefährdet wird. Wird die Sinfonie an den Schluss des Programms gestellt, was gewissermassen logisch das Richtigste ist, da sic in einem Orchesterconcerte als Krönung des Programmgebäudes betrachtet werden darf, so treffen die im vorhergehenden Falle bemerkten Misstände diesmal nicht die beiden ersten, sondern die beideu letzten Theile der Sinfonie. Statt der "Spätlinge" sind es jetzt die "Frühlinge", welche durch ihren — Garderobemarsch — den würdigen und ergötzlichen Verlauf des instrụmentalen Kunstwerks zum Scheitern bringen. Derjenige Dirigent, welcher sich vollbewusst zum Anwalt des von ihm vertretenen Componisten oder Werkes macht, sieht zur Abwehr oder Milderung solcher seinem "Clienten" drohenden Ungebühr kein anderes Mittel, als - wenn er es nicht für angemessen erachţet, eine patriotische Hymne als "Auszugsmarsch der Gäste" zuzugeben - der Sinfonie noch ein kurzes, klassisches, bekanntes Musikstück folgen zu lassen, welches den in gebührendem Respekt vor dem Namen des Autors erzogenen Theil der Zuhörer im Saale fesselt, dem anderen durch die \%wischenliegende asthetisch statthafte Pause Gelegenheit gewăhrt, seine Eillertigkeit mit der "dem Nächsten" gebührenden Rücksichtnahme in Einklang zu bringen.

Abbildung 26: Hans von Bülow: »Zum Schutz der Sinfonie-Componisten« (2) ${ }^{541}$

\section{Sinfonische Dichtungen von Richard Strauss in den Programmheften der}

\section{Abonnementkonzerte des Berliner Philharmonischen Orchesters}

Im Abschnitt 3.1.1. der vorliegenden Arbeit haben wurde ausgeführt, wie die sinfonischen

Dichtungen von Richard Strauss durch die umsichtige Planung von Hermann Wolf ins

Programm der Abonnementkonzerte des Berliner Philharmonischen Orchesters aufgenommen wurden. Im Folgenden soll es darum gehen, wie diese Werke in den Programmheften dieser Konzerte behandelt wurden. In seiner Arbeit Die Tondichtungen von Richard Strauss beschäftigte sich Walter Werbeck mit der Frage, in welchem Umfang und

\footnotetext{
${ }^{541}$ Das Programmheft zum Berliner Philharmonischen Konzert vom 15. Oktober 1894, S. 4.
} 
aus welchen Gründen Strauss zu den Aufführungen seiner Werke programmatische Informationen bereitstellte, und erklärte die Informationspolitik dieses Komponisten, die sich bei jedem Werk nach den jeweiligen Umständen anders darstellte. ${ }^{542}$ Durch die Untersuchung der Kommunikation zwischen Hermann Wolff und Richard Strauss über die Programmhefterstellung wird die folgende Darstellung der Arbeit von Werbeck einige Erkenntnisse hinzufügen.

In der Übersicht 7 sind die zweite Sinfonie und die sinfonischen Dichtungen von Strauss aufgelistet, die zu Hermann Wolffs Lebzeiten in den Abonnementkonzerten des Berliner Philharmonischen Orchesters mit einer Programmnotiz zur Aufführung gelangten.

\begin{tabular}{|l|l|l|l|}
\hline \multicolumn{1}{|c|}{ Werk } & \multicolumn{1}{|c|}{ Erstaufführung } & \multicolumn{1}{|c|}{ Dirigent } & \multicolumn{1}{c|}{ Programmheft } \\
\hline Sinfonie in f-Moll, op. 12 & 28.2 .1887 & $\begin{array}{l}\text { Karl } \\
\text { Klindworth }\end{array}$ & $\begin{array}{l}\text { Analyse vom } \\
\text { Komponisten }\end{array}$ \\
\hline Aus Italien, op. 16 & 23.1 .1888 & $\begin{array}{l}\text { Richard } \\
\text { Strauss }\end{array}$ & $\begin{array}{l}\text { Analyse vom } \\
\text { Komponisten }\end{array}$ \\
\hline Don Juan, op. 21 & 31.1 .1890 & $\begin{array}{l}\text { Hans von } \\
\text { Bülow }\end{array}$ & $\begin{array}{l}\text { Gedicht von Nikolaus } \\
\text { Lenau }\end{array}$ \\
\hline Tod und Verklärung & 23.2 .1891 & $\begin{array}{l}\text { Richard } \\
\text { Strauss }\end{array}$ & $\begin{array}{l}\text { Gedicht von Alexander } \\
\text { Ritter }\end{array}$ \\
\hline Macbeth, op. 23 & 29.2 .1892 & $\begin{array}{l}\text { Richard } \\
\text { Strauss }\end{array}$ & $\begin{array}{l}\text { Analyse von Heinrich } \\
\text { Reimann }\end{array}$ \\
\hline Also sprach Zarathustra, op. 30 & 30.11 .1896 & $\begin{array}{l}\text { Arthur } \\
\text { Nikisch }\end{array}$ & $\begin{array}{l}\text { Analyse von Heinrich } \\
\text { Reimann }\end{array}$ \\
\hline $\begin{array}{l}\text { Till Eulenspiegels lustige } \\
\text { Streiche, op. 28 }\end{array}$ & 19.11 .1900 & $\begin{array}{l}\text { Arthur } \\
\text { Nikisch }\end{array}$ & $\begin{array}{l}\text { Analyse von Heinrich } \\
\text { Reimann }\end{array}$ \\
\hline
\end{tabular}

Übersicht 7: Erstaufführungen der Werke von Richard Strauss in den Abonnementkonzerten des Berliner Philharmonischen Orchesters mit Programmheft

Das zum Konzert vom 28. Februar 1887 erstellte Programmheft enthält eine siebenseitige, vom Komponisten selbst verfasste Analyse der zweiten Sinfonie. ${ }^{543}$ Die zahlreichen Notenbeispiele, die die Hauptthemen vorstellen, machen den hauptsächlichen Bestandteil des Beitrags aus, die Funktionen der Themen und die Formen der Sätze sind mittels kurzer Texte ganz objektiv erläutert. Die Erläuterung zum ersten Satz schließt beispielsweise wie folgt:

\footnotetext{
${ }^{542}$ Walter Werbeck: Die Tondichtungen von Richard Strauss, Tutzing 1996, S. 234-280.

${ }^{543}$ Programmbuch des 5. Konzerts der Berliner Philharmonischen Gesellschaft (28.2.1887), Saison 1886/87, Serie B, redig. von Oscar Eichberg, hg u. verl. von Concert-Direction Hermann Wolff, S. 11-17. Die Darstellung von Werbeck, dass Strauss »nach dem Fehlschlag mit Aus Italien [nach der unerwünschten Reaktion auf seine eigene Analyse von Aus Italien, A. d. V] noch eine Analyse« dieser Sinfonie schrieb (Die Tondichtungen von Richard Strauss, S. 240), trifft nicht zu. Diese Analyse wurde nicht zum Hamburger Konzert vom 22. Januar 1890 unter Bülow, wie Werbeck glaubt, sondern zum Berliner Konzert vom 28. Februar 1887 unter Klindworth geschrieben, und später im Programmheft des Hamburger Konzertes abgedruckt. Diese Analyse ist neuerdings auch abgedruckt in Jürgen Schaarwächer: Richard Strauss und die Sinfonie, Köln-Rheinkassel 1994, S. 155-162.
} 
An die Wiederholung des ersten Teiles als dritten Teil, in welchem das Mittelthema in As dur auftritt, knüpft eine längere Coda an, welche nur in einer kleinen Episode die Tonart F dur berührt: [Notenbeispiel] und nach einem mächtigen Aufschwung den Satz in F moll und in derselben düstern Stimmung schliesst, in welcher er begonnen hat. $^{544}$

Auch zur Aus Italien-Aufführung im Philharmonischen Konzert vom 23. Januar 1888 fertigte Strauss auf Wolffs Wunsch ${ }^{545}$ eine Analyse. Dieser sechsseitige Beitrag ${ }^{546}$ enthält wieder zahlreiche Notenbeispiele, aber die eingefügten Texte unterscheiden sich deutlich von denjenigen der Analyse der zweiten Sinfonie, weil sie hauptsächlich das Programmatische, die Stimmungen und Gefühle beschreiben. Der Text zum dritten Satz heißt zum Beispiel:

3. Am Strande von Sorrent: Andantino (A dur 3/8)

In diesem Satze ist der Versuch gemacht, die zarte Musik der Natur, die das innere Ohr im Säuseln des Windes in den Blättern, in dem Gesang der Vögel und allen den feinen Naturstimmen, in dem fernen Rauschen des Meeres, von dem ein einsamer Gesang an's Ufer schallt: [Notenbeispiel] vernimmt, tonmalerisch darzustellen und in Gegensatz zu bringen zu der sie aufnehmenden menschlichen Empfindung, wie sie sich in dem melodischen Elemente des Satzes äussert. Das Wechselspiel im Auseinandertreten und der teilweisen Vereinigung dieser Gegensätze bilden den geistigen Inhalt dieses Stimmungsbildes. ${ }^{547}$

Offensichtlich forderte Wolff den Komponisten auf, auch zur Don Juan-Aufführung vom 31. Januar 1890 eine Analyse zu schreiben. Gegenüber Bülow, der die Berliner Erstaufführung dirigieren sollte, äußerte Strauss seine Absicht, nicht eine thematische Analyse, sondern, wie bei der Weimarer Uraufführung dieses Werkes, lediglich die schon in die Partitur aufgenommenen Lenauschen Verse im Programmheft abdrucken zu lassen:

\footnotetext{
${ }^{544}$ Programmbuch des 5. Konzerts der Berliner Philharmonischen Gesellschaft (28.2.1887), Saison 1886/87, Serie B, S. 13.

${ }^{545}$ Brief von Hermann Wolff an Richard Strauss vom 14.8.1887, RSI.

${ }^{546}$ Dieser Text wurde kurz vor Wiesbadener Tonkünstlerversammlung des ADMV Ende Juni 1889 in der Allgemeinen Musik-Zeitung wieder abgedruckt. Allgemeine Musik-Zeitung 16 (1889), S. 263, $265 \mathrm{f}$.

${ }^{547}$ Programmbuch des 5. Berliner Philharmonischen Konzerts (23.1.1888), Saison 1887/88, S. 6 f.
} 
Nun noch eine Bitte: wollen Sie die Güte haben, bei Wolff zu veranlassen, daß ja keine thematische Analyse des »Don Juan« ins Programmbuch kommt, sondern nur die der ersten Partiturseite vorgedruckten Lenauschen Verse mit allen Gedankenstrichen in dasselbe aufgenommen werden! ${ }^{548}$

Strauss scheint zu dieser Zeit der Meinung gewesen zu sein, dass kürzere dichterische Texte den programmatischen Gehalt seiner Werke besser vermitteln könnten als analytische Erläuterungen. Nach Werbecks Darstellung musste Strauss bei Aus Italien den Eindruck gewinnen, »eine Analyse von >poetischer Musik [...] sei letztendlich nutzlos, weil sie gerade das Gegenteil des Beabsichtigten erreichte oder doch nicht verhinderte: statt Erleichterung des Verständnisses Förderung von Mißverständnissen «. ${ }^{549}$ Wolff scheint dagegen immer noch oder immer mehr vom Sinn der erläuternden Analyse im Programmheft überzeugt gewesen zu sein. In der Vorbereitung der Berliner Aufführung von Tod und Verklärung schrieb er wieder an den Komponisten: »Wir müssen aber eine gute Analyse bringen. Wollen Sie sie nicht selbst machen? «550 Strauss jedoch verfolgte seine eigene Strategie, die er bei Don Juan erprobt hatte, und ließ das Gedicht von Alexander Ritter als Umschreibung des Programms dieses Werkes im Programmheft abdrucken. ${ }^{551}$

Im Programmheft zur Uraufführung der dritten Fassung von Macbeth im Philharmonischen Konzert vom 29. Februar 1892 erschien eine ausführliche Analyse dieses Werkes, nicht vom Komponisten, sondern von dem Redakteur Heinrich Reimann. ${ }^{552}$ Reimann war der Ansicht, dieses Werk folge dem Gange der dramatischen Handlung in ihren Hauptzügen, ${ }^{553}$ und versuchte, das vom dem Komponisten in der Partitur nicht ausführlich erklärte Programm in der Musik nachzuvollziehen. James Hepokoski vermutet, dass Strauss, der dieses Werk im Philharmonischen Konzert selbst leitete, mit dieser Analyse in keiner Weise zu tun hatte. ${ }^{554}$ Walter Werbeck führt die Tatsache, dass Strauss die Veröffentlichung

\footnotetext{
${ }^{548}$ Brief von Richard Strauss an Hans von Bülow vom 15.1.1890, Lieber Collega!, S. 90.

${ }^{549}$ Werbeck: Die Tondichtungen, S. 240.

${ }^{550}$ Brief von Hermann Wolff an Richard Strauss vom 9.1.[1891], RSI.

$551 »$ Ihre poetische Erklärung erhalten, wird so gedruckt. Verfasser?«, Brief von Hermann Wolff an Richard Strauss vom 19.1.[1891], RSI.

${ }_{552}$ Programmbuch des 8. Philharmonischen Konzerts (28.2.1892), Saison 1891/92, S. 10-15.

${ }^{553}$ Ebd., S. 10.

${ }^{554}$ James Hepokoski: Structure and Program in Macbeth: A Proposed Reading of Strauss's First Symphonic Poem, in Richard Strauss and His World, hg. von Bryan Gilliam, Princeton 1992, S. 67-89, S. 85, Fn. 5. Reimanns Deutung, dass der Königsmord im früheren Fortissimo-Höhepunkt zwischen den Takten 242-254 dargestellt worden sei, ist, im Unterschied zu den Interpretationen der späteren Verfasser dergleichen Leitfäden, für Hepokoski überzeugend. Vgl. ebd., S. 70.
} 
dieser Analyse gegen seine Absicht zuließ, auf das zu vermutende schwindende Interesse Strauss' an Macbeth zurück:

Wenn gleichwohl zur Aufführung der dritten Fassung von Macbeth am 29.2.1892 in Berlin eine ausführliche Analyse aus der Feder Heinrich Reimanns im Programmbuch abgedruckt wurde, so ist dies, wie schon das Fehlen eines dichterischen Textes in der Partitur, kein Indiz dafür, daß Strauss es sich nach Tod und Verklärung anders überlegt hatte.

Macbeth war für Strauss zu dieser Zeit bereits ein überholtes Stück. [...]

Offensichtlich schätzte Strauss Macbeth Anfang 1892 ähnlich ein wie seine 2.

Symphonie zwei Jahre zuvor: als Werk aus einem Stadium seiner Entwicklung, das er bereits hinter sich gelassen hatte, und bei dem eine ausführliche Analyse keinen Schaden mehr anrichten konnte. ${ }^{555}$

Strauss' verringerndes oder beschränktes Interesse am Werk mag eine Rolle gespielt haben, dass sich Wolff mit seinem konsequenten und zunehmenden Interesse an der Analyse durchsetzen konnte. Bei der zweiten Sinfonie und Aus Italien entsprach Strauss der Aufforderung Wolffs und schrieb die Analyse selbst. Nachdem der Komponist bei Don Juan und Tod und Verklärung die Aufforderung zu einer Analyse zweimal ablehnte und stattdessen lediglich dichterische Texte eines Dritten abdrucken ließ, entschließ sich Wolff, seine Absicht durchzusetzen und Reimann die ausführliche Analyse fertigen zu lassen.

Wie Werbeck darstellt, war Strauss' Vorgehensweise dagegen nicht konsequent. Bei der nächsten sinfonischen Dichtung Till Eulenspiegel änderte er seine Meinung aus verschiedenen, nicht gänzlich aufgeklärten Gründen ${ }^{556}$ und entschied sich dafür, eine von ihm autorisierte Einführungsschrift seiner Werke zu veröffentlichen. Wilhelm Maukes Analyse zu Till Eulenspiegels lustige Streiche stützt sich auf die Auskünfte, mit denen der Komponist den Verfasser versorgt hatte. Den Interessenten für den dichterischen und musikalischen Inhalt des Werkes konnte er nun die Lektüre dieser Schrift empfehlen. ${ }^{557}$ Auch Arthur Hahns Erläuterungsschrift zu Also sprach Zarathustra beruht auf direkten Informationen durch Strauss selbst. Dem Komponisten war daran gelegen, zu allen Zarathustra-Erstaufführungen diese Schrift verteilen zu lassen. ${ }^{558}$

\footnotetext{
${ }^{555}$ Werbeck: Die Tondichtungen, S. 244f.

${ }_{556}$ Dazu vgl. Werbeck: Die Tondichtungen, S. 250-252.

${ }^{557}$ Ebd., S. 251.

${ }^{558}$ Ebd., S. 259.
} 
Als diese beiden Werke in den Philharmonischen Konzerten zur Aufführung kamen (Also sprach Zarathustra am 30. November 1896 und Till Eulenspiegels lustige Streiche am 19. November 1900, beide unter Nikisch), wurde es wohl erwogen, dem Wunsch des Komponisten entsprechend diese von ihm autorisierten Analysen im Programmheft zu veröffentlichen. Das geschah aber nicht, und im Programmheft wurden stattdessen Reimanns ausführliche Analysen abgedruckt. ${ }^{559}$

Auch nachdem sich Strauss für die Bekanntmachung des Programmatischen seiner Werke durch Analysen entschied, scheint Wolffs Ideal mit demjenigen Strauss' nicht übereingestimmt zu haben. Dieser Meinungsunterschied wird anschaulich, wenn man die von Strauss autorisierte Analyse mit derjenigen von Reimann vergleicht. Tatsächlich sind sie so gegensätzlich, dass sie den Zuhörer zu andersartigem Musikhören führen würden.

Reimann zeigt größeres Interesse an motivisch-thematischer Arbeit und der organischen Struktur des Ganzen als am Programmatischen. Seine Analyse verfolgt die dynamische Entwicklung des Werkes in sachlicher Weise, wie die ersten zwei Seiten seiner Analyse zu Till Eulenspiegels lustige Streiche veranschaulichen (Abbildung 27 und 28):

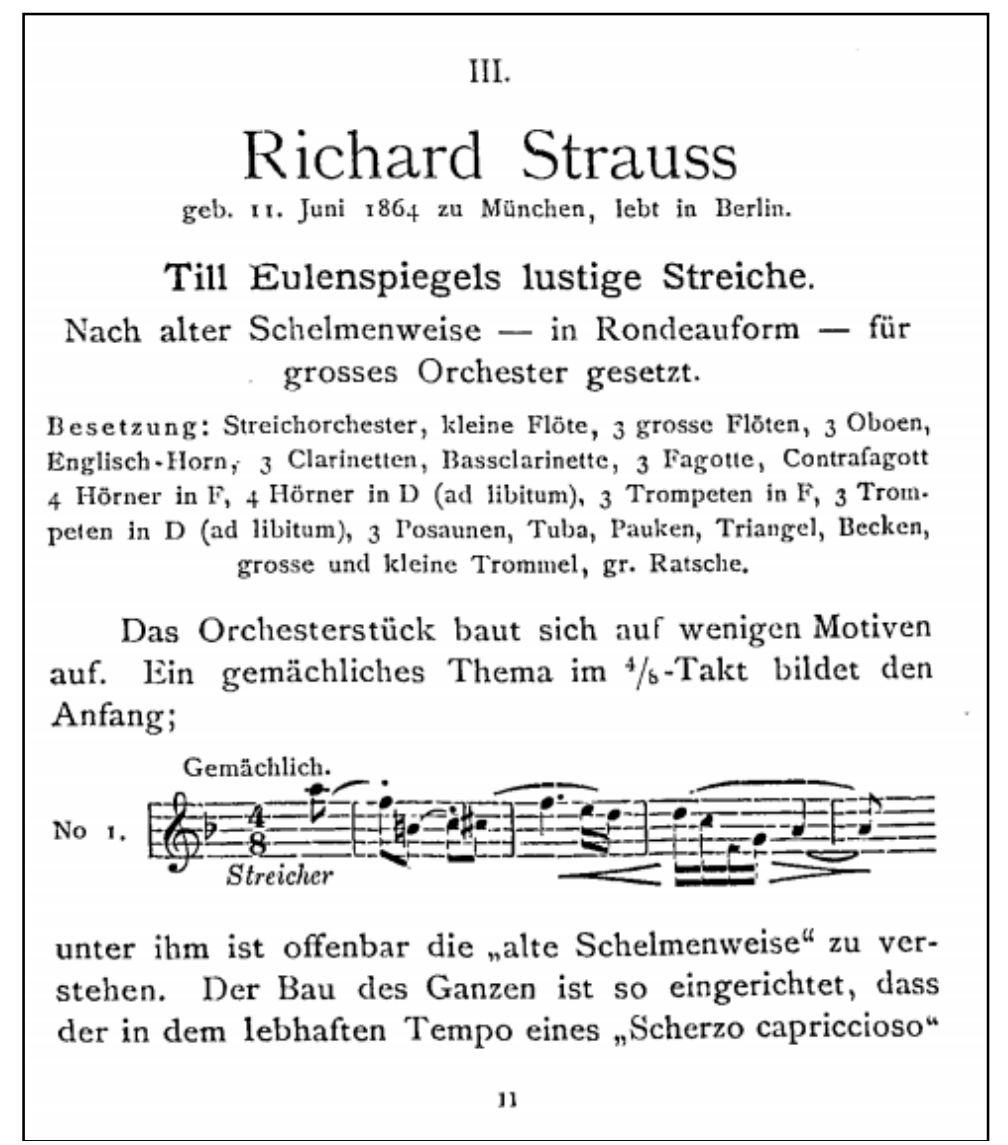

Abbildung 27.: Heinrich Reimanns Analyse zu Till Eulenspiegels lustige Streiche (1) ${ }^{560}$

${ }^{559}$ Reimanns Analyse zu Till Eulenspiegel erschien zuerst im Programmheft zum Hamburger Neuen Abonnementkonzert vom 12. November 1896 und wird hier abgedruckt.

${ }^{560}$ Programmheft zum 6. Philharmonischen Konzert der Saison 1900/01 (19.11.1900), S. 11. 
sich abspielende Satz dreimal durch eine volksthümliche Weise in $4 / 8$-Takt unterbrochen wird. Durch immer neue Wendungen wird, der Rondeauform entsprechend, jedesmal der Eintritt dieser Weise vorbereitet. Auf die wenigen Takte der Einleitung (No. I) folgt das Hauptmotiv des Ganzen:

No, 2 .

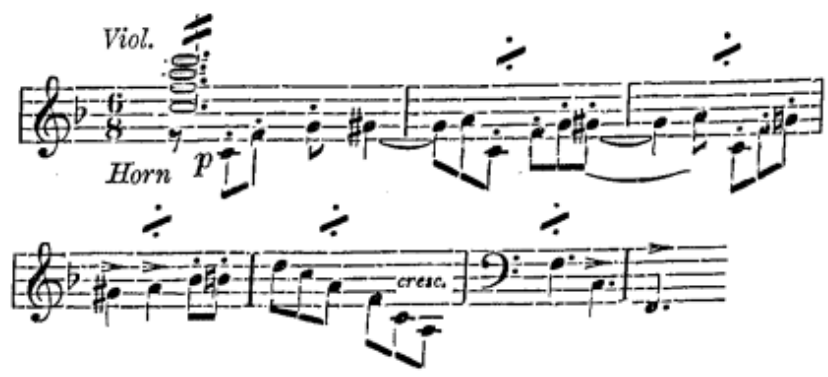

in langem Crescendo bis zum ff und dem Abschluss auf der Dominante. Sodann, aus No. I abgeleitet, ein echtes Schelmenmotiv:

No. 3

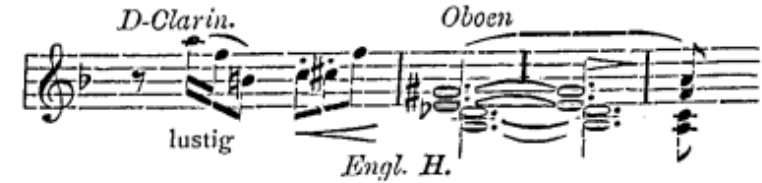

der Septimensprung wird vom ganzen Orchester nachgeahmt. Sodann folgt:

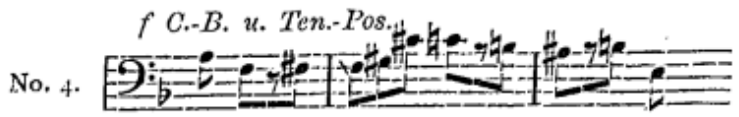

in längerer Entwickelung, zusammen mit Neubildungen aus No. 3 (bezw. No. I), das unter anderem auch folgende Form annimmt:

12

Abbildung 28: Heinrich Reimanns Analyse zu Till Eulenspiegels lustige Streiche $(2)^{561}$

Die von Strauss autorisierte Till Eulenspiegel-Analyse von Wilhelm Mauke weist einen ganz anderen Charakter auf (vgl. Abbildung 29 und 30). Sie stellt »[d]ie authentische Benennung der Motive ${ }^{562}$ vor und verfolgt in erster Linie die dramatische, programmatische Entwicklung des Werkes. Sie gehört zu jenen um 1900 häufig verfassten Musikerläuterungen, in denen »es um die Bildung der Gefühle ging und nicht nur um die Vermehrung des Wissens über ein bestimmtes Werk. « ${ }^{563} \mathrm{Ihr}$ Ziel ist, »dem `Empfinden des Zuhörers〈 die Musik näher zu bringen $\ll .564$

\footnotetext{
${ }^{561}$ Ebd., S. 12.

${ }^{562}$ Werbeck: Die Tondichtungen, S. 248.

${ }^{563}$ Hansjakob Ziemer: »Symphonischer Optimismus« im Konzertsaal. Zur Kulturgeschichtliche des Hörens um 1900, in Musik - Bürger - Stadt. Konzertleben und musikalisches Hören im historischen Wandel, hg. von Christian Thorau u. a., Regensburg 2011, S. 279-299, hier S. 283.

${ }^{564}$ Ebd.
} 


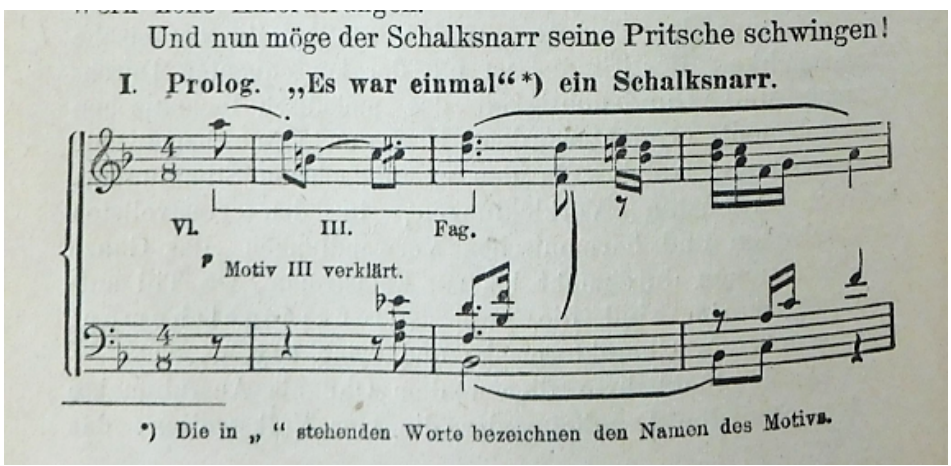

Abbildung 29: Wilhelm Maukes Analyse zu Till Eulenspiegel (1) ${ }^{565}$

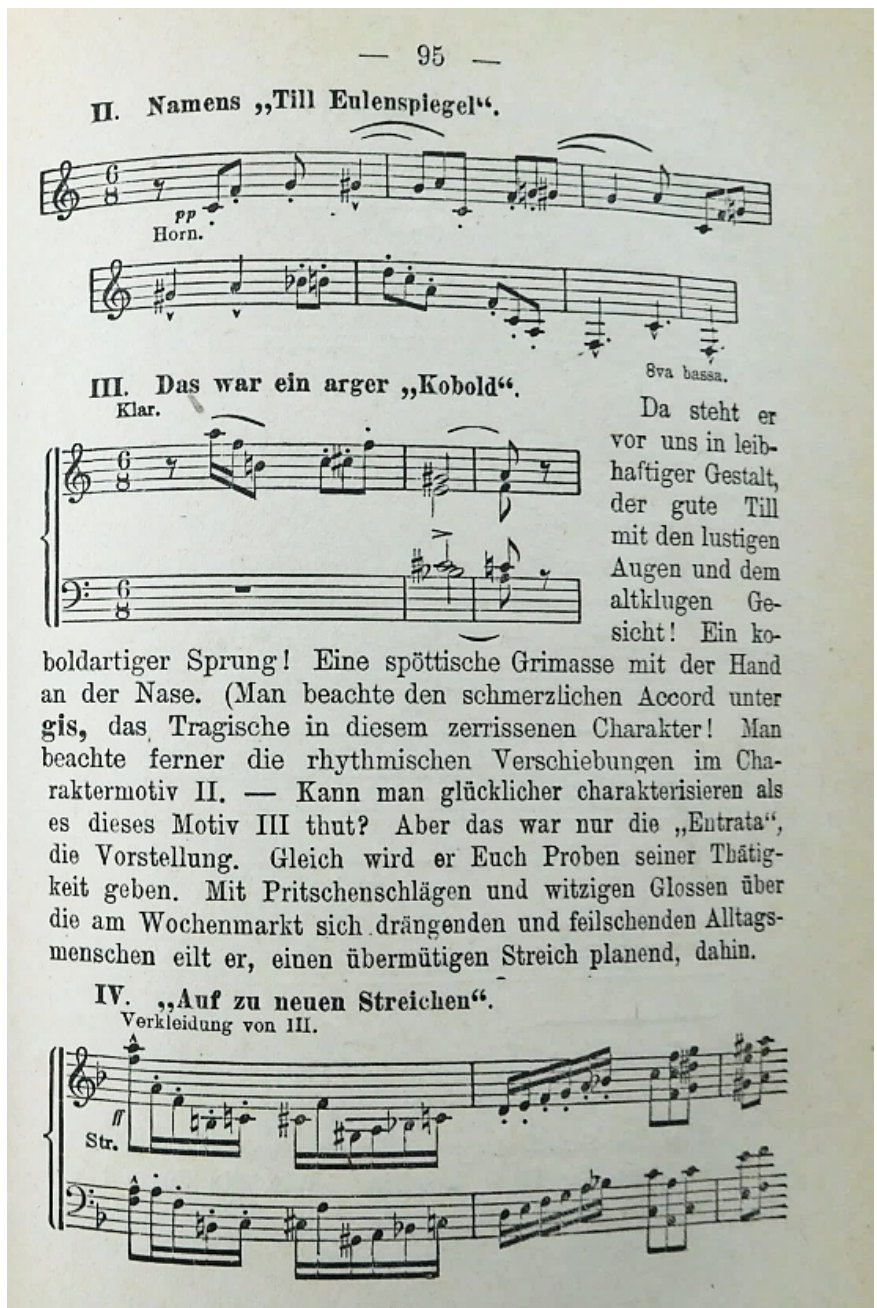

Abbildung 30: Wilhelm Maukes Analyse zu Till Eulenspiegel (2) ${ }^{566}$

Aus Lessmanns Besprechung der Berliner Aufführung von Also sprach Zarathustra, in der er die Analyse Reimanns als »sehr lesenswerth« lobte, ${ }^{567}$ geht deutlich hervor, dass das Programmheft nunmehr als ein fester Bestandteil einer Konzertveranstaltung galt. Zu Anfang

\footnotetext{
${ }^{565}$ Meisterführer Nr. 6. Richard Strauss. Symphonien und Tondichtungen, erl. von G. Brecher u. a., Berlin o. J., S. 94.

${ }^{566}$ Ebd., S. 95.

${ }^{567}$ Allgemeine Musik-Zeitung 23 (1896), S. 705.
} 
dieses Abschnittes wurde festhalten, dass Wolff sein Programmheft als Lesestoff mit überdauerndem Wert konzipiert hatte. Analysen vom Komponisten selbst, eine Idee, die vielerorts propagiert wurde und auf die Hermann Wolff Gewicht legte, waren ein idealer Inhalt, der dem Programmheft als Lesestoff Wert sichern konnte. Wie dargelegt wurde, führte Wolff selbst dafür die Verhandlungen mit dem Komponisten. Richard Strauss' Vorstellung von einem Programmheft dagegen, nämlich der Abdruck eines Gedichtes aus der Partitur oder der Abdruck einer bereits veröffentlichten Analyse eines Dritten, scheint dem Ideal Wolffs nicht entsprochen zu haben. Wohl deshalb entschloss er sich, mit Reimann seinen eigenen Weg zu gehen.

Der Programmheftverkauf erschloss dem Konzertveranstalter vermutlich eine neue Einnahmequelle. Auch die erzieherische Absicht, dem Publikum ein besseres Verständnis für die Werke zu ermöglichen und es dadurch zu bilden, mag für Wolff ein Grund zur Programmhefterstellung gewesen sein. Möglicherweise verstand Wolff das Programmheft seiner Abonnementkonzerte aber auch als Mittel, um sein eigenes Renommee zu verbreiten und zu bewahren. Hermann Wolff sah sich, wie oben bereits ausgeführt, als »Intellectuelle[n] Urheber ${ }^{568}$ dieser Konzerte. Wenn auch die Dirigenten das letzte Wort der Programmgestaltung behielten, so war es doch Wolff, der alles auf eigenes Risiko organisierte und alle Beteiligten, einschließlich der Dirigenten, engagierte. Die Konzerte waren sozusagen seine Werke. Möglicherweise wollte er durch die Programmhefterstellung dem Konzert, eigentlich einem einmaligen, lokalen Ereignis, eine dauernde, allgemeine Bedeutung verleihen, und deshalb konzipierte er die Programmhefte nicht nur auf jeweils ein konkretes Ereignis hin, sondern als Lektüre von dauerhaftem Wert.

${ }^{568}$ Brief von Hermann Wolff an Hugo Bock vom 22.3.1884, Berlin SBPK, Mus ep. H. Wolff 988. 


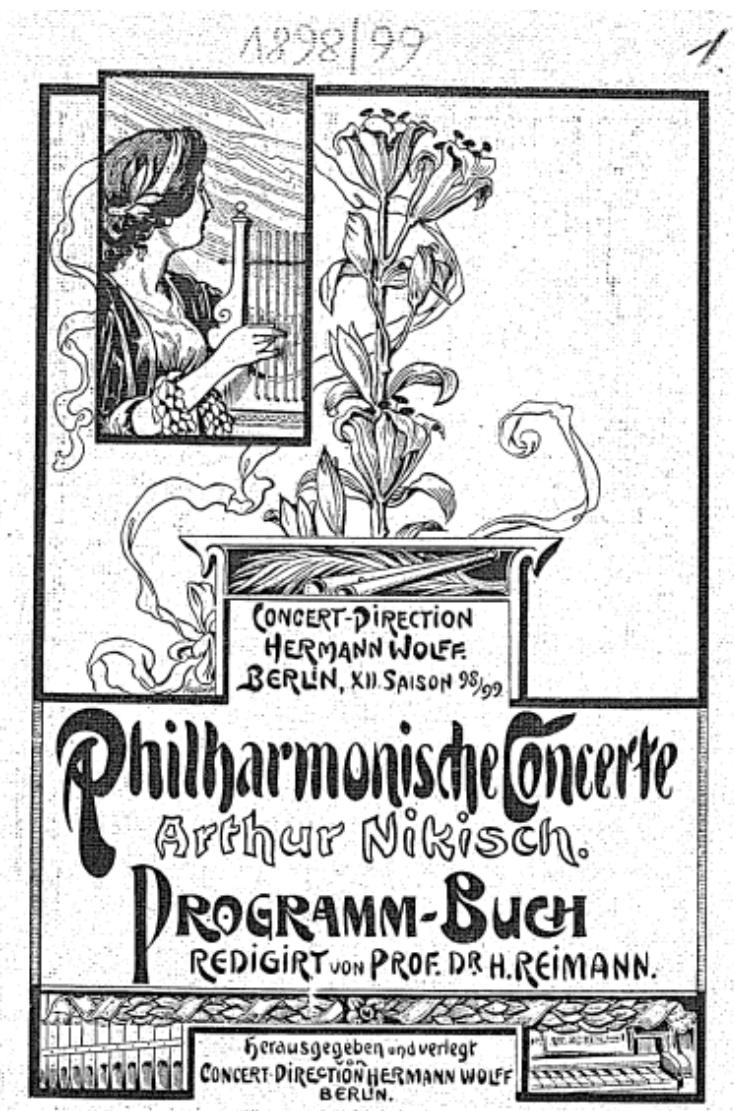

Abbildung 31: Umschlag des Programmheftes des Philharmonischen Konzertes vom 10. Oktober 1898

\subsubsection{Auswahl der Mitwirkenden für die Abonnementkonzerte des}

\section{Berliner Philharmonischen Orchesters}

Zwischen Hermann Wolff und den von ihm für die Abonnementkonzerte des Berliner

Philharmonischen Orchesters engagierten Dirigenten galt ein grundsätzliches Abkommen:

Der Dirigent behielte das letzte Wort bei der Programmgestaltung, während die Auswahl der

Solisten der Zuständigkeit Wolffs oblag. ${ }^{569}$

${ }^{569} \gg$ Das Engagement der Solisten habe ich immer als Ihre specielle Domaine betrachtet, und da Sie niemals etwas Unkünstlerisches, Antiakademisches proponieren werden, so acceptire ich ein für allemal die von Ihnen gewählten Personen, reserviere mir nur in programmistischer Hinsicht eine Entscheidung über die Sachen, mit welchen die betr. Personen paradieren wollen. « Brief von Hans von Bülow an Hermann Wolff vom 23.8.1887, Bülow-Briefe 7, S. 124f. Zwei Jahre später schrieb Bülow an seine Tochter wieder über diese Kompetenzverteilung: »Für die von mir hier und in Berlin dirigierten Konzerte bin ich selber vom Unternehmer (Hermann Wolff) engagiert: in das Was der Programme hat er mir nichts hineinzureden; dafür mische ich mich - meiner Abneigung gemäß - nicht in das Engagement der Solisten, die seine Domäne [sind]. « Brief von Hans von Bülow an seine Tochter Daniela vom 2.7.1889, in Hans von Bülow: Neue Briefe, hg. von Richard DuMoulin Eckart, München 1927, S. 670f. Auch Arthur Nikisch schreibt: »Bei den Philharmonischen Concerten in Berlin habe ich bezüglich der Solisten keinerlei Einfluss, werde aber Herrn Wolff auf alle Fälle auf Fräulein Meyer Aufmerksam machen.« Brief von Arthur Nikisch an Franz Wüllner vom 22.9.1901. Berlin SBPK, Mus. Nachl. Wüllner, F., 22, 431. Vgl. auch Hinrichsen: Musikalische Interpretation. Hans von Bülow, S. 84. 
Die Tabellen 8 und 9 zeigen die Pianisten und Streichersolisten, die zu Hermann Wolffs Lebzeiten auf der Bühne dieser Konzerte solistisch auftraten. Unter den Pianisten erscheint Eugen d'Albert mit weitem Abstand am häufigsten, da er von der ersten Spielzeit der Konzerte an fast jede Saison auftrat. Ihm folgen Teresa Carreño, Clotilde Kleeberg, Edouard Risler und andere. Unter den Streichern fallen Joseph Joachim und Pablo de Sarasate durch ihre häufigen Auftritte auf.

Die Wahl der Dirigenten, die eine ganze Saison dirigieren sollen, erfolgte sicherlich aufgrund strategischer Überlegungen. Zufällig oder absichtlich traf die Auswahl Hermann Wolffs immer auf Dirigenten, die ihren Sitz außerhalb von Berlin hatten und eigens für die Konzerte anreisten: Franz Wüllner aus Dresden (1882/83-1885/86), Hans von Bülow aus Hamburg (1887/88-1891/92), Richard Strauss aus Weimar (1894/95) und Arthur Nikisch aus Leipzig $(1895 / 96-1901 / 02) .{ }^{570}$

${ }^{570}$ Die vorliegende Arbeit beschränkt die Betrachtung auf Hermann Wolffs Lebzeiten. 
Tab. 8: Pianisten als Solisten der Abonnementkonzerte des Berliner Philharmonischen Orchesters (1882/831901/02).

\begin{tabular}{|l|r|}
\hline Eugen d'Albert & 18 \\
\hline Teresa Carreño & 7 \\
\hline Clotilde Kleeberg & 5 \\
\hline Edouard Risler & 5 \\
\hline Hans von Bülow & 4 \\
\hline Bernhard Stavenhagen & 3 \\
\hline Ferruccio Busoni & 3 \\
\hline Józef Hofmann & 3 \\
\hline Heinrich Barth & 3 \\
\hline Sofie Menter & 2 \\
\hline Franz Rummel & 2 \\
\hline Clara Schumann & 2 \\
\hline Nathalie Janotha & 2 \\
\hline Anna Nikolaevna Esipova & 2 \\
\hline Alfred Gründfeld & 2 \\
\hline Emil Sauer & 2 \\
\hline Alfred Reisenauer & 2 \\
\hline Anton Rubinštejn & 1 \\
\hline Johannes Brahms & 1 \\
\hline Ludwig Breitner & 1 \\
\hline Xaver Scharwenka & 1 \\
\hline Edmund Khym (Orgel) & 1 \\
\hline Anna Grosser & 1 \\
\hline Eugenie Menter & 1 \\
\hline Arthur Friedheim & 1 \\
\hline Camille Saint-Saëns & 1 \\
\hline Jules de Swert & 1 \\
\hline Wladimir von Pachmann & 1 \\
\hline Anna Hasters & 1 \\
\hline Max Pauer & 1 \\
\hline Ignaz Jan Paderewski & 1 \\
\hline Sophie von Poznanska & 1 \\
\hline Moritz Rosenthal & 1 \\
\hline Fannie Bloofield-Zeisler & 1 \\
\hline Wilhelm Stenhammer & 1 \\
\hline Frederic Lamond & 1 \\
\hline Louis Diémer & 1 \\
\hline Ossip Gabrilowitsch & 1 \\
\hline Moritz Moszkowski & 1 \\
\hline Ernst von Dohnányi & 1 \\
\hline Conrad Ansorge & 1 \\
\hline Bernhard Irrgang (Orgel) & 1 \\
\hline Leopold Godowsky & 1 \\
\hline Raoul Pugno & 1 \\
\hline
\end{tabular}

Tab. 9: Streicher als Solisten der Abonnementkonzerte des Berliner Philharmonischen Orchesters (1882/831901/02). ${ }^{571}$

\begin{tabular}{|l|l|}
\hline Joseph Joachim & 9 \\
\hline Pablo de Sarasate & 6 \\
\hline Stanislaw Barcewicz & 4 \\
\hline Emil Sauret & 4 \\
\hline Carl Halir & 4 \\
\hline Franz Ondriček & 3 \\
\hline $\begin{array}{l}\text { Robert Hausmann } \\
\text { (Cello) }\end{array}$ & 3 \\
\hline Marie Soldat & 3 \\
\hline Leopold Auer & 3 \\
\hline Hugo Becker (Cello) & 3 \\
\hline Gabriele Wietrowetz & 3 \\
\hline Alexander Petschnikoff & 3 \\
\hline Heinrich de Ahna & 2 \\
\hline Wilma Norman-Neruda & 2 \\
\hline Charles Gregorowitsch & 2 \\
\hline Ludwig Bleuer & 2 \\
\hline Jean Gérardy (Cello) & 2 \\
\hline Willy Burmester & 2 \\
\hline Eugène Ysaye & 2 \\
\hline Fritz Kreisler & 2 \\
\hline Martin Marsick & 1 \\
\hline August Wilhelmj & 1 \\
\hline Emil Sauret & 1 \\
\hline Henri Petri & 1 \\
\hline Johann Kruse & 1 \\
\hline David Popper (Cello) & 1 \\
\hline Enrique Fernández & \\
\hline Arbôs & 1 \\
\hline Adolf Brodsky & 1 \\
\hline Carl Davidoff (Cello) & 1 \\
\hline Bruno Steindel (Cello) & 1 \\
\hline César Thomson & 1 \\
\hline Florian Zajic & 1 \\
\hline Emanuel Wirth (Viola) & 1 \\
\hline Arno Hilf & 1 \\
\hline Hugo Herrmann & 1 \\
\hline Hermann Ritter (Viola) & 1 \\
\hline Betty Schwabe & 1 \\
\hline Anton Witek & 1 \\
\hline Irma Saenger-Sethe & 1 \\
\hline Henri Marteau & 1 \\
\hline Anton Hekking (Cello) & 1 \\
\hline Jacques Thibaud & 1 \\
\hline
\end{tabular}

${ }^{571}$ Keine Angabe bedeutet Violinisten. 


\section{Franz Wüllner}

Bei der Einrichtung der Abonnementkonzerte des Berliner Philharmonischen Orchesters im Oktober 1882 legte Wolff ihre Leitung nicht in die Hände von Ludwig von Brenner, den das neu gegründete Orchester Monate zuvor als seinen ständigen Dirigenten gewählt hatte. Seine Wahl fiel auf Franz Wüllner, der seit 1877 in Dresden - gleichgestellt mit Ernst von Schuch als Hofkapellmeister die Hofoper und die Sinfoniekonzerte der Hofkapelle geleitet und auch das Dresdner Konservatorium als Direktor geführt hatte.

Nachdem er sich als Pianist und als Klavierlehrer etabliert hatte, begann der 1832 in Münster geborene Wüllner seine Dirigententätigkeit 1858 als städtischer Musikdirektor in Aachen. ${ }^{572}$ Er hatte hier den städtischen Gesangverein, die städtischen Abonnementkonzerte und den Instrumentalverein zu leiten. Diese Stellung veranlasste den Musiker, der sich früher als Pianist fast ausschließlich der Instrumentalmusik zugewandt hatte, dem Gesang, vor allem dem Chorgesang, einen Teil seiner Tätigkeit zu widmen. Er brachte die Leistungen des städtischen Gesangvereins auf eine besondere Höhe, und die wichtigen Werke, einschließlich einer Anzahl der Oratorien von Händel, der Matthäuspassion sowie der h-Moll-Messe von Johann Sebastian Bach und der Missa solemnis von Beethoven, gelangten unter seiner Leitung zur dortigen Erstaufführung.

Am 1. März 1865 trat er das Amt des Hofkapellmeisters der Königlichen Vokalkapelle an. Wüllners Münchener Wirkungsbereich umfasste insgesamt vier Aufgabenkreise: Die Leitung der Königlichen Vokalkapelle, mit der er das bis dahin sehr beschränkt gebliebene, meist aus Werken der früheren bayerischen Kapellmeister zusammengesetzte Kirchenrepertoire vor allem um die italienische Kirchenmusik des 16. Jahrhunderts erweiterte, die Leitung der Chor- ${ }^{573}$ und Orchesterklassen an der Musikschule, die nach Richard Wagners Plan unter Hans von Bülow neu ins Leben gerufen worden war, die Leitung der Hofoper, in der er in den Wettstreit mit seinem 1872 berufenen Kollegen Hermann Levi trat, und die Leitung der Akademiekonzerte mit dem Hoftheaterorchester. 1869 und 1870 übernahm er das Dirigat der Uraufführung von Das Rheingold und Die Walküre von Wagner, die trotz der Missbilligung des Komponisten auf Wunsch des Königs in München erfolgte. ${ }^{574}$

\footnotetext{
572 Zur Biographie Wüllners vgl. »A. B.«: Biographisches. Franz Wüllner, in Musikalisches Wochenblatt 13 (1882), S. 394f, S. 408f, S. 419f; Dietrich Kämper: Franz Wüllner. Leben, Wirken und kompositorisches Schaffen, Köln 1963.

${ }^{573}$ Den Ertrag seines chorerzieherischen Wirkens legte Wüllner in seinen bekannten Chorübungen der Münchner Musikschule nieder, deren »erste Stufe« 1875 fertiggestellt wurde. Vgl. Chorübungen der Münchener Musikschule, zusammengest. von Franz Wüllner, 1 Stufe, München 1875.

${ }^{574}$ Zum ausführlichen Verlauf dieser Ereignisse vgl. Johannes Brahms im Briefwechsel mit Franz Wüllner, hg. von Ernst Wolff, Tutzing 1974 (Nachdruck der Ausgabe von 1922), S. 25-29; Dietrich Kämper: Franz Wüllner. Leben, Wirken und kompositorisches Schaffen, S. 28-31.
} 
Für die Leistung dieser Wagneraufführungen wurde er 1871 zum ersten Hofkapellmeister ernannt.

Auf dem Höhepunkt des Konflikts mit Levi wandte Wüllner sich Anfang August 1877 nach Dresden, wo er als Nachfolger von Julius Rietz den Ruf auf die Hofkapellmeisterstelle annahm. Diese Stellung beruhte auf der Vereinbarung, dass er mit dem jüngeren Hofkapellmeister Ernst von Schuch gleichgestellt sei. Demgemäß teilten sie sich in die Leitung der Hofoper und der Sinfoniekonzerte der Hofkapelle. Wüllner wurde außerdem am 1. November 1877 zum künstlerischen Direktor des Dresdner Konservatoriums ernannt.

Ein besonderes Verdienst Wüllners an der Dresdner Oper liegt in der Aufführung der Musikdramen Wagners. ${ }^{575}$ Unter Beseitigung aller »Striche« stellte er eine Originalfassung des Lohengrin wieder her. Auch den Tannhäuser führte er in einer neuen Fassung auf, die ein auf die Originalfassung zurückgeführtes Finale des zweiten Aktes enthielt. Als Konzertdirigent gab er der Dresdner Brahmspflege wichtige Impulse. Er gab den Anstoß zur intensiven Brahmspflege in Dresden, indem er dessen dort bislang unbekannte zweite Sinfonie am 6. März 1878 im Dresdner Aschermittwochskonzert aufführte.

Im Lauf der Zeit versuchte der intrigante Kollege Schuch, Wüllner mehr und mehr aus dem Theater zu verdrängen, sodass die vertraglich zugesicherte Gleichberechtigung der beiden Kapellmeister gefährdet wurde. Die Generalintendanz ergriff Schuchs Partei, indem sie schließlich ein Rundschreiben vom 28. März 1882 an das Theaterpersonal schickte, das Schuch als »in erster Linie für alle Opernaufführungen verantwortlich« erklärte und ihn damit de facto zum Operndirektor ernannte. ${ }^{576}$ Der Zuständigkeitsstreit zwischen Schuch und Wüllner, genannt $»$ Wüllner-Affäre«, erregte ein großes Interesse. Nicht nur die Freunde und Fachgenossen, an ihrer Spitze Bülow und Brahms, sondern auch weitere Kreise von Presse und Publikum ergriffen Wüllners Partei und zeigten ihm ihre Unterstützung. ${ }^{577}$

Dass seine Einstellung damals die Aufmerksam auf sich zog, ist zum Beispiel im folgenden Bericht im Musikalischen Wochenblatt vom 31. August 1882 zu sehen:

Her. Hofcapellmeister Prof. Dr. Wüllner in Dresden ist unter glänzenden Bedingungen das Directorat des Hoch'schen Conservatoriums in Frankfurt a. M. angetragen, doch verlautet noch nicht, ob der verdiente Künstler diesem Rufe Folge leisten wird oder nicht. Zu verdenken wäre es ihm wahrlich nicht, wenn er nach den

\footnotetext{
${ }^{575}$ Dietrich Kämper: Franz Wüllner. Leben, Wirken und kompositorisches Schaffen, S. 43.

576 Ebd., S. 47.

${ }^{577}$ Vgl. z. B. Brief von Hans von Bülow an Franz Wüllner vom 6.5.1882, Berlin SBPK Mus. ep. Hans von Bülow 1549.
} 
letzthin erfahrenen unglaublichen Kränkungen Dresden verlassen würde. Bei der Neubesetzung der Directorstelle an benannten Conservatorium ist übrigens einzig und allein nur Hr. Prof. Wüllner in Frage gewesen, mit welcher Bemerkung eine bez. Notiz, welche jüngst durch die meisten Blätter lief, richtig gestellt sein mag. ${ }^{578}$

Man verfolgte also neugierig die Entwicklung der Sache, als Wolff Wüllner die Stelle des Dirigenten der neu einzurichtenden Abonnementkonzerte des Berliner Philharmonischen Orchesters antrug. ${ }^{579}$ Der Dirigent verließ die Dresdner Hofoper und nahm den Berliner Antrag an - unter Beibehaltung aller übrigen Verpflichtungen ohne Einschränkungen sowie des Wohnsitzes in Dresden. In der Beilage zu ihrer Nummer vom 15. September 1882 berichtete die Neue Musikzeitung von diesem Entschluss:

Hofcapellmeister Dr. Franz Wüllner in Dresden, welcher die ihm angebotene Stellung als leitender Director des Frankfurter Conservatoriums und als Nachfolger Joachim Raff's definitiv ablehnte, hat den Antrag, in Berlin eine Reihe von großen Orchesterconcerten zu dirigieren, angenommen. Dieselben sollen als Abonnementsconcerte unter Mitwirkung der bedeutendsten Solisten in der »Philharmonie« stattfinden. ${ }^{580}$

Die Gründe, warum Wolffs Auswahl auf Wüllner fiel, kann man nur vermuten. Er war damals berühmt und erfahren genug, um durch die Leitung der Orchesterabonnementkonzerte das lokale Musikleben zu beleben. Er war ein Wagner- und Brahmsexperte zugleich, eine Eigenschaft, die die Programme seiner Berliner Konzerte prägen sollte. Auch der Ruf als hervorragender Beethovendirigent, den er in seinen Münchner Jahren erworben hatte, mag bei der Auswahl des Konzertdirigenten ein wichtiger Vorteil gewesen sein.

Von 1882/83 bis 1884/85 leitete Wüllner für drei Saisons die Abonnementkonzerte des Berliner Philharmonischen Orchesters. Wie im Abschnitt 3.1.1 der vorliegenden Arbeit ausgeführt, legten die Wüllner-Konzerte ihren Schwerpunkt auf die Aufführung von Neukompositionen und bildeten dadurch klaren Kontrast zu den Sinfonie-Soiréen der

\footnotetext{
${ }^{578}$ N. N.: Vermischte Mittheilungen und Notizen, in Musikalisches Wochenblatt 13 (1882), S. 426. Hervorhebung im Original.

${ }^{579}$ Wolff blickt auf seinen Dresdner Besuch bei Wüllner mit diesem Antrag in seinem Brief an Bock zurück. Vgl. Brief von Hermann Wolff an Hugo Bock vom 24.3.1883, Berlin SBPK, Mus ep. H. Wolff 986.

${ }^{580}$ N. N.: Vermischtes, in Neue Musikzeitung 3 (1882), 1. Beilage zu Nr. 18. Dieser Beilage ist mit keinen Seitenzahlen versehen. Hervorhebung im Original.
} 
Königlichen Kapelle und auch den Abonnementkonzerten der Königlichen Akademie der Künste, an denen das Philharmonische Orchester zwischen den Saisons 1883/84 und 1886/87 mitwirkte. Im Mai 1884 erhielt Wüllner als Nachfolge von Ferdinand Hiller den Ruf auf den Posten des Kölner städtischen Kapellmeisters, verbunden mit der Leitung des städtischen Konservatoriums. In der Saison 1884/85 hatte Wüllner eine Tripelfunktion in Dresden, Berlin und Köln erfüllt, bevor er sich ab 1885/86 der Kölner Tätigkeit widmete.

Das kooperierende Verhältnis zwischen Wolff und Wüllner wurde aufrechterhalten, auch nachdem der Dirigent seine Berliner und Dresdner Stellen zugunsten der Leitung der städtischen Gürzenichkonzerte sowie des Direktorats des städtischen Konservatoriums in Köln verlassen hatte. ${ }^{581}$ So arrangierte Wolff beispielsweise 1889 für Čajkovskij einige Auftritte in Deutschland mit seinen eigenen Werken, darunter ein Gastspiel im Konzert des Kölner Städtischen Orchesters vom 12. Februar 1889 im Gürzenich, was in Verbindung mit Wüllner zustande kam. ${ }^{582}$ Auch als das Gürzenich-Orchesterdirektorium 1901 einen Nachfolger für Willy Hess finden musste, der bisher am Kölner Konservatorium gelehrt und das Orchester als Konzertmeister sowie das Gürzenich-Quartett als erster Geiger angeführt hatte, wandte sich Wüllner vertraulich mit der Bitte an Wolff, einige geeignete Namen zu nennen. ${ }^{583}$ Den Posten bekam schließlich Bram Elderung, der unter Bülow im Berliner Philharmonischen Orchester als Konzertmeister fungiert hatte, obwohl nicht bekannt ist, ob Wolff ihn empfohlen hatte und ob seine Meinung bei der Auswahl ausschlaggebend gewesen war.

\section{Hans von Bülow}

Um 1880 begann Wolff seine Tätigkeit als mitreisender Sekretär bei dem Pianisten Hans von Bülow. ${ }^{584}$ Neben dieser Aufgabe übernahm er von 1881 bis 1885 auch die Organisation der Konzerttourneen der Meininger Hofkapelle, die das Orchester unter Bülow fast in den gesamten deutschsprachigen Raum und einige der angrenzenden Gebiete führten.

Die Tourneen dieser Hofkapelle hatten in den Worten Wolffs den Zweck, »die hohe künstlerisch informatorische Bedeutung der Meininger Hofkapelle ${ }^{585}$ zu verbreiten. Wolff

\footnotetext{
${ }^{581} \mathrm{Zu}$ Wüllners Kölner Tätigkeit und deren Bedeutung vgl. Karlheinz Weber, Vom Spielmann zum städtischen Kammermusiker. Zur Geschichte des Gürzenich-Orchesters, Bd. 1, Kassel 2009, S. 585-629. ${ }^{582}$ Brief von Hermann Wolff an Pëtr Il'ič Čajkovskij vom 19.1.1888 [1889], TSHM, Sig: a ${ }^{4}, \mathrm{Nr} .428$. ${ }^{583}$ Brief von Franz Wüllner an Hermann Wolff vom 15.4.1901, Bayerische Staatsbibliothek München, Marteau-Archiv, Ana 601.II. Wolff, Hermann.

${ }^{584}$ Die handschriftlichen Programmentwürfe der Klavierabende in verschiedenen Städten im WolffNachlass (ID 228, 229 und 294) wurden vermutlich für die Konzertreise Bülows konzipiert. Vgl. auch: Stargardt-Wolff: Wegbereiter großer Musiker, S. 68.

${ }^{585}$ Brief von Hermann Wolff an Georg II vom 3.6.1885. Berlin SBPK, Mus. ep. Hermann Wolff 330.
} 
betrachtete das reine Beethoven-Programm als »das eigentlich Typische ${ }^{586}$ der Meininger Hofkapelle, das durch die Tournee verbreitet werden solle. Die Konzerttournee nahm den wesentlichen Teil ihrer Tätigkeit ein: Während Bülows Amtszeit gab die Kapelle etwa 50 Konzerte in Meiningen und etwa 160 auf Tournee. ${ }^{587}$ Durch ihre Tourneen lieferte sie anspruchsvolle Musik bis in die Peripherie des deutschen Kulturraumes. Wie bahnbrechend ihre Tourneeprogramme waren, kann man beispielsweise aus einer Betrachtung von Eduard Hanslick aus dem Jahr 1884 ersehen. In Anspielung auf diese Kapelle bezeichnet er die anspruchsvollen Tourneeprogramme des reisenden Orchesters als eine merkwürdige Erscheinung seiner Zeit: »Ein ganzes Orchester, das auf Reisen geht, nicht mit Tanzmusik, sondern mit den größten symphonischen Werken, ist jedenfalls eine neue Erscheinung, ein unserer Eisenbahn-Epoche vorbehaltenes Unicum«. ${ }^{588}$

Die norddeutsche Tournee im Januar 1882 führte die Meininger Kapelle zum ersten Mal nach Berlin. Vom 4. bis 9. Januar 1882 gab sie in der Singakademie sechs Konzerte in zwei Zyklen, wobei der erste Zyklus von drei Konzerten ausschließlich mit Beethovens Musik bestritten wurde und der zweite aus einem Mendelssohn-Abend und zwei BrahmsAbenden bestand. ${ }^{589}$ Jedes Konzert war ein reines Orchesterkonzert ohne solistische Einlagen vom Typus Ouvertüre - Instrumentalkonzert - Symphonie. ${ }^{590}$ Hermann Wolffs kurzfristige Verhandlung mit Ludovico Sacerdoti von der Skating-Rink-Aktiengesellschaft ermöglichte der Kapelle, nach den Konzerten in Hamburg, Kiel und Bremen wieder weitere Konzerte in Berlin zu geben, ${ }^{591}$ und zwar im großen Saal der Rollschulbahn in der Bernburger Straße. ${ }^{592}$ Diese drei Konzerte wurden ebenfalls ausschließlich der Musik von Beethoven gewidmet, aber mit Abweichungen vom Programm des ersten Beethoven-Zyklus. 593

Neben der Musik von Beethoven legte das Meininger Projekt seinen Schwerpunkt auch auf die Werke von Johannes Brahms und trug zu ihrer Anerkennung und Verbreitung bei. Seit den 1870er-Jahren hatte Bülow sich intensiv mit der Musik von Brahms, den er

\footnotetext{
${ }^{586}$ Brief von Hermann Wolff an Hans von Bülow vom 30.10.1885, Berlin SBPK, Mus. ep. H. Wolff 360.

${ }^{587}$ Peter Clive: Brahms and His World. A Biographical Dictionary, Lanham 2006, S. 77.

${ }^{588}$ Eduard Hanslick: Concerte, Componisten und Virtuosen der letzten fünfzehn Jahre 1870-1885. Kritiken, Berlin ${ }^{4} 1896$, S. 413f.

${ }^{589}$ Die Programme der Berliner Konzerte im Januar 1882 sind aufgelistet in Hinrichsen: Musikalische Interpretation. Hans von Bülow, S. 61.

${ }^{590}$ Zum Plan dieser Tournee vgl. Hinrichsen: Die Reisen der Meininger Hofkapelle, S. 286.

${ }^{591}$ Eine Abschrift des Schreibens, das die Vereinbarungen zwischen Wolff und Sacerdoti enthält, befindet sich im Wolff-Nachlass. Wolff-Nachlass, ID 225. Vgl. 1.2.3 im Quellenteil der vorliegenden Arbeit.

${ }^{592}$ Bekanntlich wurde diese Einrichtung in den anschließenden Jahren mehrmals umgebaut und daraus entstand der Konzertsaal »(Alte) Philharmonie«.

${ }^{593}$ Die Programmwahl des letzten Konzertes wurde den Besuchern überlassen. Vgl. Hinrichsen: Musikalische Interpretation. Hans von Bülow, S. 61.
} 
bekanntlich für den legitimen Beethovenerben hielt, auseinandergesetzt. In seiner Meininger Zeit entstand eine enge Freundschaft mit diesem Komponisten, dem er auch die Hofkapelle zum Erproben seiner neuen Werke zur Verfügung stellte. Zu den in Meiningen erarbeiteten Werken gehören das zweite Klavierkonzert und die vierte Sinfonie dieses Komponisten. An den oben genannten von Hermann Wolff organisierten zwei Brahms-Abenden der Meininger Kapelle in der Berliner Singakademie im Januar 1882 wurden die beiden Klavierkonzerte aufgeführt, wobei Brahms am ersten Abend sein zweites Klavierkonzert unter der Leitung von Bülow spielte, und die beiden Musiker am zweiten Abend beim ersten Klavierkonzert ihre Rollen tauschten. Die vierte Sinfonie von Brahms wurde am 25. Oktober 1885 in Meiningen unter der Leitung des Komponisten uraufgeführt und stand auf fast jedem Programm in der wieder von Wolff organisierten Tournee der Kapelle nach Mitteldeutschland und den Niederlanden im November des gleichen Jahres. Auf dieser Tournee übernahm der Komponist das Dirigat dieses neuen Werkes in Frankfurt, Essen, Elberfeld, Utrecht, Amsterdam, Den Haag, Krefeld, Köln und Wiesbaden. ${ }^{594}$

Bülow war bekanntlich in seiner Jugend ein eifriger Propagandist für die Neudeutsche Schule. Der öffentliche Protest gegen die Neudeutschen von Joachim und Brahms im Frühjahr 1860 tat eine ästhetische Kluft zwischen diesen Musikern und Bülow auf, obwohl er sich zuvor der durch Joachim vermittelten Bekanntschaft mit Brahms erfreut hatte. ${ }^{595}$ Der persönliche Bruch mit Wagner im Jahr 1869, und wohl auch die schon im Jahr 1866 erfolgte Aussöhnung mit Joachim, führte in ihm um 1870 zu einer drastischen musikästhetischen Positionsänderung vom Wagner-Propagandisten zum Brahms-Apostel. Er distanzierte sich nun von seiner früheren Faszination für die Musik von Wagner und Liszt, und bekannte bei verschiedenen Gelegenheiten, dass er als Propagandist für die Musik von Brahms »ästhetisch

\footnotetext{
${ }^{594}$ Peter Clive: Brahms and His World. A Biographical Dictionary, S. 77. Wenn auch Bülows Verstimmung gegen Brahms um die Aufführung der vierten Sinfonie in Frankfurt, die eigentlich am Ende der Tournee am 24. November 1885 stattfinden sollte, die Freundschaft der beiden Musiker für eine Weile trübte, spielte sich seit dem Meininger Projekt eine kooperierende Trias Bülow-Wolff-Brahms ein, und diese Kooperation entwickelte sich später auch bei den Abonnementkonzerten in Hamburg und Berlin weiter. Zum Konflikt zwischen Bülow und Brahms vgl. Hinrichsen: Musikalische Interpretation, S. 52f. Für Wolff galt Brahms als einer der wenigen Musiker, auf die er bei den Hamburger und Berliner Abonnementkonzerten als Ersatz Bülows rechnen konnte. Als Bülows Gesundheitszustand kurz vor dem Beginn der Saison 1890/91 seine Mitwirkung in Frage stellte, konnte Wolff sich eventueller Hilfe von Brahms im Notfall versichern. Vgl. Briefe von Hermann Wolff an Johannes Brahms vom 10., 15., 18., und 24.9.1890, Archiv der Gesellschaft der Musikfreunde zu Wien (im Folgenden A-Wgm), Brahms-Nachlass, $381,2-5$.

${ }^{595}$ Vgl. z. B.: Heinrich Sievers: Die Musik in Hannover. Die musikalischen Strömungen in Niedersachsen vom Mittelalter bis zur Gegenwart unter besonderer Berücksichtigung der Musikgeschichte der Landeshauptstadt Hannover, Hannover 1961, S. 91.
} 
reaktionär« sei. ${ }^{596}$ Auch in seinem Brief an Hermann Wolff vom 18. Juli 1886 erklärte Bülow seine aktuelle ästhetische Gesinnung wie folgt: »Meine reactionäre Gesinnung ist in stetem Wachsen. Ich will die letzten Lebensjahre benutzen, sie zu bethätigen und die Sünden meiner ersten und auch zweiten Periode zu reparieren suchen. «597

In den Jahren um 1860 in Berlin war Bülow fanatisch im Kampf für den »Fortschritt«, nämlich die Neudeutsche Schule, gewesen. Durch Wolffs organisatorisches Geschick gefördert, stellten die Konzerte der Meininger Kapelle ihn einerseits dem Berliner Publikum in seiner neuen Einstellung vor. Als Apostel der Musik von Beethoven und Brahms war er jetzt »ästhetisch reactionär«, aber gleichzeitig fiel seine reformatorische Intention vor allem in der Programmgestaltung auf. ${ }^{598}$ Das Gastspiel der Meininger Kapelle erweckte andererseits in den Berlinern den Wunsch nach einem künstlerischen, der Großstadt würdigen Orchester mit einem weltberühmten Dirigenten in einem würdigen Raume. ${ }^{599}$ Und genau diesen Wunsch sollte Hermann Wolff in den anschließenden Jahren in Zusammenarbeit mit dem Berliner Philharmonischen Orchester erfüllen, wie noch zu zeigen ist.

Wie Hinrichsen beobachtet, bildete das Reiseprojekt der Meininger Kapelle eine »Testphase ${ }^{600}$ für die zukünftige Kooperation zwischen Wolff und Bülow, und zwar für die Zusammenarbeit bei den Neuen Abonnementkonzerten in Hamburg (ab 1886/87) und bei den Philharmonischen Konzerten in Berlin (ab 1887/88). Es ist aber etwas erstaunlich zu lesen, dass Wolff bereits im ersten Jahr des erfolgreichen Konzerttourneeprojektes versuchte, den Dirigenten zum Rücktritt von seinen Meininger Amtsgeschäften zu überreden.

Lassen Sie mich Ihnen nur heute nochmals wiederholen, daß ich von einem Alp befreit sein werde, wenn Sie von Meiningen befreit sind. Jede Stunde macht mir es unfaßbarer, daß sich Hans v. Bülow da herumpackt und so nothwendige Kräfte vergeudet. ${ }^{601}$

\footnotetext{
${ }^{596}$ Hinrichsen: Musikalische Interpretation. Hans von Bülow, S. 43.

${ }^{597}$ Brief von Hans von Bülow an Hermann Wolff vom 18.7.1886, Bülow-Briefe 7, S. 44.

${ }^{598} \mathrm{Zu}$ Bülows Politik der Programmgestaltung, vgl. Hinrichsen: Musikalische Interpretation. Hans von Bülow, vor allem S. 56-87.

${ }^{599}$ Zur Auswirkung der Tournee der Meininger Kapelle unter Bülow auf Berliner Musikleben vgl. Weissmann: Berlin als Musikstadt, S. 354f.

${ }^{600}$ Hinrichsen: Die Reisen der Meininger Hofkapelle und ihre Organisation durch die Agentur Hermann Wolff, S. 286.

${ }^{601}$ Brief von Hermann Wolff an Hans von Bülow vom 28.10.1881, Hans von Bülow, Briefe. VI. Band: Meiningen. 1880-1886, Leipzig 1907 (im Folgenden: Bülow-Briefe 6), S. 101, Fn. 1.
} 
In der Tat legte Bülow vier Jahre darauf sein Meininger Amt nieder, und seine Konzerttätigkeit trat ab 1886 in die letzte Phase seiner Laufbahn, die wesentlich auf der Grundlage der Geschäftsbeziehungen zu Wolff beruhte.

Nach dem fünfjährigen Machkampf um das Berliner Philharmonische Orchester ${ }^{602}$ war Hermann Wolff ab 1887/88 wieder in der Lage, die Abonnementkonzerte dieses Orchesters auf eigene Rechnung selbständig zu veranstalten. Zu ihrem Neubeginn versuchte er, Hans von Bülow als Dirigenten zu gewinnen. Die Verhandlung begann im Januar 1887, als die Auflösung der Philharmonischen Gesellschaft, die für die materielle Sicherung des Philharmonischen Orchesters im Frühjahr 1884 gegründet worden war, sicher wurde. In ihrem im Wolff-Nachlass überlieferte Tagebuch schrieb Louise Wolff am 13. Januar 1887, dass man ihrem Mann die Abonnementkonzerte überlassen wolle und dass er wünsche, Bülow als Dirigenten beizuziehen. ${ }^{603}$ Am Tag dieses Tagebucheintrags wandte sich Hermann Wolff brieflich an Hans von Bülow und erkundigte sich nach dessen Bereitschaft, die »Direktion der acht oder zehn Abonnementskonzerte« zu übernehmen. ${ }^{604}$

Das erste Philharmonische Konzert unter der Leitung von Bülow vom 21. Oktober 1887 brachte ohne Mitwirkung von Solisten drei Sinfonien von Haydn, Mozart und Beethoven zur Aufführung. ${ }^{605}$ Das Konzept des Programms ausschließlich mit Sinfonien der »klassischen Symphonistentrias « ${ }^{606}$ wurde auch seitens Wolffs gewünscht, und die dritte Sinfonie Beethovens wurde nicht vom Dirigenten, sondern von Wolff aufs Programm gesetzt. ${ }^{607}$ Dass dieses Antrittskonzert Bülows wie eine Wiedergabe oder eine Fortsetzung der erfolgreichen Tourneen der Meininger Kapelle konzipiert worden war, ist offensichtlich.

Es ist wohl eine zutreffende Vermutung, dass Wolff Bülow wegen seiner Leistung in Meiningen, vor wegen des auffälligen Fortschritts der Hofkapelle durch seine intensive Probenarbeit, als Dirigenten der Abonnementkonzerte des noch jungen Berliner Orchesters für die richtige Person hielt. Da Wolff eine Saison zuvor in Hamburg die Orchesterabonnementkonzerte unter der Leitung von Bülow ins Leben gerufen hatte, und dieser Musiker auch als Pianist zu seinen ältesten Klienten gehörte, war diese Berufung wohl

\footnotetext{
${ }^{602} \mathrm{Zu}$ diesem Machtkampf vgl. Abschnitt 3.1.1 der vorliegenden Arbeit.

$603{ }_{\gg} \mathrm{G}[$ estern] Abend war Sitzung der philh. Gesellschaft. Joachim u. Klindworth wollen zurücktreten. Man will Hermann das Orchester zu Abonnementsconcerten überlassen. Er möchte Bülow als Dirigenten herüberziehen - wie in Hamburg - das wäre herrlich. - - -« Eintrag vom 13.1.1887 im Tagebuch von Louise Wolff, S. 12. Vgl. 1.3 im Quellenteil der vorliegenden Arbeit.

${ }^{604}$ Dieser Brief ist im Erinnerungsbuch von Edith Stargardt-Wolff überliefert. Stargardt-Wolff:

Wegbereiter großer Musiker, S. 59-60.

${ }^{605}$ Die Sinfonie Nr. 12 von Haydn, Sinfonie Nr. 41 von Mozart und die Sinfonie Nr. 3 von Beethoven.

${ }^{606}$ Brief von Hans von Bülow an Hermann Wolff vom 23.8.1887, Bülow-Briefe 7, S. 126.

${ }^{607}$ Brief von Hans von Bülow an Hermann Wolff vom 14.9.1887, Bülow-Briefe 7, S. 135.
} 
auch den Zeitgenossen nicht verwunderlich. Wichtig ist aber, dass Wolff und Bülow in den Prinzipien der Programmgestaltung offenbar einer Meinung waren, was die Grundlage ihrer Zusammenarbeit gebildet zu haben scheint.

Edith Stargardt-Wolff schreibt, dass ihr Vater Bülow davon überzeugen konnte, dass er in der Leitung der Berliner Philharmonischen Konzerte »sseine wahre Aufgabe finden, von diesem großen Forum aus seine reformatorischen Ideale verwirklichen könne ${ }^{608}$ Wolffs Anerkennung für Bülow als »Reformator« zeigt sich auch in seinem Brief an den Dirigenten, der gerade im Begriff war, das Amt anzutreten:

Was das Berliner Publikum anbetrifft, so wird Ihnen dies mit »denkbarster« Sympathie entgegenkommen. Vertrauen hat man in Berlin eigentlich nur noch zu Ihnen. Längst hat sich die Überzeugung, auch bei den Gegnern, Bahn gebrochen, daß Sie das Beste wollen, das Reformatorische Ihrer Bestrebungen wird gewürdigt und als Nothwendigkeit empfunden, das zeigt mir die Qualität unseres AbonnementsPublikums. Ich gebe mich keiner Täuschung hin: diese Concerte werden eine »größte« Rolle in unserem Musikleben spielen, und mit der Eröffnung des umgebauten (kein Schwindel) Philh. Saales werden wir »des auditeurs imperméables« haben und machen absolut, was wir wollen. Darum komme ich immer wieder darauf zurück: Ihr Schwerpunkt wird doch fernerhin in Berlin liegen, und ich denke, hoffe, wünsche, daß die Concerte in Berlin und Hamburg dauernde Institutionen unter Ihrer Leitung werden müssen, und daß Sie Freude daran haben. ${ }^{609}$

Wie Hinrichsen in seiner Arbeit zur Bülows Programmpolitik sorgfältig und ausführlich darlegte, zeigen sich in Bülows Programmgestaltung die Momente, die Bülow selbst oder seinen Zeitgenossen als innovativ oder reformatorisch erschienen. ${ }^{610}$ Verkürzt und vereinfacht gesagt, handelt es sich hier um die Ideologien, die kurz ${ }^{611}$ und einheitlich gestaltete Konzertprogramme guthießen und die damals noch üblichen Mischprogramme als ästhetisch

${ }^{608}$ Stargardt-Wolff: Wegbereiter großer Musiker, S. 61.

${ }^{609}$ Brief von Hermann Wolff an Hans von Bülow, Datum unbekannt, Bülow-Briefe 7, S. 145f.

Hervorhebung im Original.

${ }^{610}$ Hinrichsen: Musikalische Interpretation. Hans von Bülow, vor allem S. 56-87.

${ }^{611} »$ Was meinen Sie zu consequenter Durchführung des Prinzips kurzer Programme? So, daß publicus sich wundert `schon aus? Sind Sie für diese Neuerung, dann autorisire ich Sie, zu kürzen, wo immer ich zu lange Vorschläge machen würde. Qualität der Ausführung würde natürlich gewinnen. Also kurze Programme und lange Proben. « Brief von Hans von Bülow an Hermann Wolff vom 4.9.1887, Bülow-Briefe 7, S. 134. 
unterlegen einschätzten. ${ }^{612}$ In den Formulierungen von Bülow selbst ${ }^{613}$ und auch von den mitgesinnten Publizisten gewann sein Programm selbst den Charakter des Kunstwerkes. ${ }^{614}$ Wenn er auch nicht ohne Vorbehalt durchgesetzt werden konnte, ${ }^{615}$ so bedeutete doch der »reformatorische Einfluss« von Bülows Programmgestaltung für die Berliner Philharmonischen Konzerte eine Weiterentwicklung. ${ }^{616}$ Ferner verliehen die erläuternden Programmhefte, die Wolff in der Saison 1886/87, und zwar zu Beginn der Hamburger Abonnementkonzerte unter Bülow, in seine Abonnementkonzerte eingeführt hatte, Bülows durchdachtem Plan dauerhaften Wert und bleibende Gestalt. ${ }^{617}$ Weder das eine noch das andere wäre vorgekommen, wenn Wolff mit Bülow in Prinzipien der Programmgestaltung nicht einer Meinung gewesen wäre.

Die Berufung Bülows zum Dirigenten der Philharmonischen Konzerte im Herbst 1887 kann wohl als ein Teil der damaligen, von Wolff durchgeführten größeren reformatorischen Bewegung verstanden werden: Die Konzerte wurden gerade in der neuen Organisationsform unter der alleinigen geschäftlichen Leitung von Wolff neu begonnen. Das Abonnement wurde nun wieder auf die billigen Preise der früheren Wüllner-Konzerte festgelegt. ${ }^{618}$ Wolff machte zudem die Generalprobe gegen Eintrittsgeld allgemein zugänglich, einerseits um dadurch die Einnahmen zu erhöhen, und andererseits, um auch minder Begüterten den Kunstgenuss zu ermöglichen. ${ }^{619}$ Er führte, wie gesagt, erläuternde Programmhefte in diese Konzerte ein. Darüber hinaus war damals ein großer Umbau der Philharmonie geplant. Die neue

\footnotetext{
${ }^{612}$ Hinrichsen: Musikalische Interpretation. Hans von Bülow, S. 57, Fn. 237.

${ }^{613}$ Z. B. »die raffinierte Anlage meines nächsten Berliner Konzertprogrammes«, Brief von Hans von Bülow an seine Tochter Daniela vom 20. Januar 1891, Bülow-Neue Briefe, S. 697.

${ }^{614}$ Hinrichsen: Musikalische Interpretation. Hans von Bülow, S. 58.

${ }^{615}$ Natürlich mussten bei der Programmgestaltung die lokalen Verhältnisse berücksichtigt werden, und die Ideen, die Bülow mit der Meininger Hofkapelle verwirklichen konnte, konnten nicht immer auf Hamburger oder Berliner Abonnementkonzerte übertragen werden. Dazu vgl. Hans-Joachim Hinrichsen: Der Dirigent Hans von Bülow und das Berliner Musikleben 1887 bis 1892, in Organisateurs et formes d'organisation du concert en Europe 1700-1920, hg. von Hans Erich Bödeker u. a., Berlin 2008, S. 157-170, vor allem S. $167 f$.

${ }^{616} 1884$ hatte sich Bülow zur Programmgestaltung der Wüllner-Konzerte kritisch geäußert: »Hermann mit dem besten Willen, Dir gegen ihn Recht zu geben (was bereits vorgekommen), vermag ich ihn nicht zu tadeln, daß er die Wü[llner] Konzerte schon deshalb so glänzend auszustatten sich bemüht, als möglich, weil der Dirigent planlos und die Programme unsystematisch-unkünstlerisch, nach der Devise `wer vieles bringt usw. hergerichtet werden müssen; daß er sich weder von seinen Glaubens(?)genossen noch von seinem Rassenfeind auffressen lassen will, mag das Gesetz des struggle for life verantworten! « Brief von Hans von Bülow an Karl Klindworth vom 18.7.1884, in Bülow-Neue Briefe, S. 96.

${ }^{617}$ Zur Programmhefte der Konzertdirektion Hermann Wolff vgl. Abschnitt 3.2.2 der vorliegenden Arbeit.

${ }^{618}$ Muck: Einhundert Jahre Berliner Philharmonisches Orchester, Bd. 1, S. 90.

${ }^{619}$ Altmann: Chronik des Berliner Philharmonischen Orchesters (1882-1901), S. 23.
} 
Philharmonie, die mit einer besseren Akustik ausgestattet sein sollte, ${ }^{620}$ wurde schließlich kurz vor der folgenden Saison 1888/89 fertiggestellt. In diesem Reformationsprozess mit kunst- und bildungsfördernder Absicht traf die Auswahl Wolffs auf den Reformator Bülow.

\section{Interimsdirigenten}

Bülow beendete seine regelmäßige Dirigententätigkeit in Berlin am 28. März 1892 mit dem zehnten, letzten Philharmonischen Konzert der Saison 1891/92. Da unsicher war, ob der leidende Dirigent imstande sein würde, die Leitung der Konzerte wieder zu übernehmen, bemühte Wolff sich zuerst darum, als Zwischenlösung das Dirigentenpult der verwaisten Konzerte mit Gastdirigenten zu besetzen. In diesen Konzerten erschien Bülow schließlich nur noch einmal am 13. März 1893, bevor er am 12. Februar des nächsten Jahres in Kairo starb. ${ }^{621}$ Die Konzerte in den Spielzeiten 1892/93 und 1893/94 fanden unter der Leitung der folgenden Dirigenten statt (vgl. Tab. 10).

\begin{tabular}{|l|c|l|c|}
\hline $\mathbf{1 8 9 2 / 9 3}$ & $\mathbf{1 8 9 3 / 9 4}$ & 5 \\
\hline Hans Richter & 3 & Ernst Schuch & 2 \\
\hline Raphael Maszkowski & 3 & Hermann Levi & 2 \\
\hline Felix Mottl & 2 & Richard Strauss & 1 \\
\hline Hermann Levi & 1 & Franz Mannstaedt und Anton Rubinštejn & 1 \\
\hline Hans von Bülow & 1 & & \\
\hline
\end{tabular}

Tabelle 10: Interimsdirigenten der Philharmonischen Konzerte und ihre Auftrittszahl (1892/93$1893 / 94)$

Während dieses Interregnums wurden der Ruhm und die Bedeutung der Philharmonischen Konzerte im Berliner Konzertleben beträchtlich beeinträchtigt. Karl Homann denkt, dass dieser Untergang vor allem an dem Vorzug bekannter Namen bei der Dirigentenauswahl liegt. Es gab, so Homann, mehr Operndirigenten, deren Namen dem weiten Publikum geläufig waren, als Sinfoniedirigenten. Aus der Notwendigkeit heraus, die Menge anzulocken, wurden Dirigenten eingeladen, die zwar bekannt waren, sich aber als mittelmäßige Sinfoniedirigenten herausstellen sollten. ${ }^{622}$

Aufgrund ihr vorliegender Aufzeichnungen ihrer Mutter schrieb Edith StargardtWolff, dass Felix Weingartner, der als Dirigent der Sinfoniekonzerte der Königlichen Kapelle in gewissem Sinne der Konkurrent der Philharmonischen Konzerte gewesen war, sich Anfang März 1894 an ihren Vater gewandt und selbst angeboten habe, mit der Bedingung einer

\footnotetext{
${ }^{620}$ Zur Akustik der umgebauten Philharmonie vgl. Muck: Einhundert Jahre Berliner Philharmonisches Orchester, Bd. 1, S. 119.

${ }^{621}$ Am 10. April 1893 trat Bülow übrigens noch im Extra-Konzert für die Pensionskasse des Berliner Philharmonischen Orchesters auf.

${ }^{622}$ Muck: Einhundert Jahre Berliner Philharmonisches Orchester, Bd. 1, S. 174.
} 
Garantie von 15.000 Mark die Leitung der Philharmonischen Konzerte zu übernehmen. ${ }^{623} \mathrm{Er}$ habe sich dazu bereit erklärt, auch die Hamburger Abonnementkonzerte zu leiten. Wenn seine alten und neuen Verpflichtungen unlösbar kollidieren sollten, werde er es sich auf sich nehmen, dem Königlichen Opernhaus gegenüber kontraktbrüchig zu werden. Da Weingartner so beliebt und populär in Berlin war, dass er sich nicht um des Publikums Gunst zu bemühen brauchte, wäre das Problem somit gelöst gewesen. Es sei dem Dirigenten aber nicht gelungen, durch friedliche Verhandlungen von seinen Opernhausverpflichtungen freizukommen, und er habe seinerseits im letzten Augenblick aus Rücksicht auf die Folgen eines Kontraktbruchs verzichtet. ${ }^{624}$

Die Richtigkeit dieser Darstellung kann angezweifelt werden. Im Februar 1894 stand Wolff schon in Verhandlung mit Richard Strauss, ${ }^{625}$ und aus den zeitgenössischen Musikzeitschriftenberichten lässt sich entnehmen, dass Weingartner erst im Frühling 1895 in Frage kam. ${ }^{626}$ Auf jeden Fall lag Stargard-Wolff mit ihrer Behauptung nicht richtig, Ernst Schuch, Hans Richter, Felix Mottl, Hermann Levi, Raphael Maszkowski und Richard Strauss hätten in der Saison 1894/95 die Philharmonischen Konzerte dirigiert. ${ }^{627}$ In der Tat übergab Hermann Wolff sämtliche Philharmonischen Konzerte dieser Spielzeit an Richard Strauss. Der junge Strauss, der damals als Kapellmeister in Weimar tätig war, hielt das Angebot von Wolff für eine günstige Zwischenstation, um bald die Kapellmeisterstelle von Weingartner an der Berliner Hofoper zu erwerben. ${ }^{628}$ Strauss war Schützling beider seiner

${ }^{623}$ Stargardt-Wolff: Wegbereiter großer Musiker, S. 90.

${ }^{624}$ Ebd. Zu den mehrmaligen Versuchen Weingartners, sich aus dem Vertrag mit der Berliner Hofoper zu lösen vgl: Leila Zickgraf: Verträge, Streit und Ehrgefühl. Die prekäre Beziehung zwischen Felix Weingartner und Berlin, in Im Mass der Moderne. Felix Weingartner - Dirigent, Komponist, Autor, Reisender, Basel 2009, S. 51-67, vor allem S. 52-58.

${ }^{625}$ Brief von Hermann Wolff an Richard Strauss vom 12.2.[1894], RSI. Am Folgetag dieses Schreibens teilte Wolff Strauss den Tod von Bülow mit und fragte an, ob er die Trauerfeier in Berlin dirigieren wolle, was nicht zustande kam, da Strauss erst zu spät antwortete. Vgl. Briefe von Hermann Wolff an Richard Strauss vom 13. und 14.2.[1894], RSI.

${ }^{626}$ Vgl. z. B. Musikalisches Wochenblatt 26 (1895), S. 176.

${ }^{627}$ Stargardt-Wolff: Wegbereiter großer Musiker, S. 90.

${ }^{628} »$ Wolff ist fest entschlossen, mich für Berlin zu gewinnen, ich reise morgen nach Berlin, um die Bedingungen festzustellen. Zwanzig Konzerte im Winter, sechs Monate ganz frei, verlangt habe ich 12000 M. . . . In Berlin sitze ich an erster Quelle als Bewerber um Weingartners Stellung, bin riesig berühmt, kann den Sommer zubringen wo ich will und komponieren usw. Wolff nimmt mich doch nur, wenn er darin seinen Vorteil sieht. Solange also unsere beiderseitigen Vorteile Hand in Hand gehen, ist alles von ihm zu haben, darüber hinaus darf man natürlich nichts verlangen! Künstlerische Garantien lasse ich mir schon geben, bezüglich der Programme etc. [...] Nun lieber Papa, nur keine Angst, kein Mißtrauen, ich suche mir jetzt aus allem das Vorteilhafteste und Bequemste heraus und das werden wahrscheinlich die Wolffschen Konzerte sein!«, Brief von Richard Strauss an seinen Vater vom 6.2.1894, Richard Strauss, Briefe an die Eltern. 1882-1906, S. 194f. Dem Verlangen Strauss' kam Wolff nicht entgegen: »[...] Auf Ihre Proposition kann ich nicht eingehen. Sie verkennen die Verhältnisse; ich kenne Sie besser u. muß Sie 
Vorgänger bei den Abonnementkonzerten des Berliner Philharmonischen Orchesters: Franz Wüllner und Hans von Bülow. Wüllners Plan, die Sinfonie in f-Moll von Strauss in einem dieser Konzerte im Winter 1884/85 zur Aufführung zu bringen, ${ }^{629}$ wurde zwar nicht verwirklicht, aber während der Bülow-Zeit wurden die neuen Werke von Strauss trotz der zunehmenden ästhetischen Differenzen zwischen Strauss und Bülow ${ }^{630}$ in fast jeder Saison der Philharmonischen Konzerte vorgestellt. ${ }^{631}$

Richard Strauss als Dirigent wurde von Bülow entdeckt, als dieser am 11. November 1884 in München dem jungen Komponisten die Leitung seiner eigenen Bläserserenade op. 7 in einer Matinee der Meininger Hofkapelle überließ. Aus der auch Hermann Wolff gegenüber geäußerten Überzeugung, Strauss sei »ein geborener Dirigent «, ${ }^{632}$ verschaffte Bülow dem 21-jährigen Strauss die Stelle des Hofkapellmeisters in Meiningen, wo dieser, zuerst unter Bülows Aufsicht und nach dessen Rücktritt auf sich allein gestellt, in der freilich nur kurzen Zeit von etwa einem halben Jahr wichtige Erfahrungen in der administrativen wie künstlerischen Leitung eines Hofmusikapparates sammelte. ${ }^{633}$

Schon bevor Hans von Bülow die Berliner Abonnementkonzerte verließ, hatte Wolff Strauss für Bülows Nachfolge vorgesehen ${ }^{634}$ und ihm sowohl die Berliner als auch die

besser kennen. Den Prozentantheil den ich Ihnen vorschlug wollte ich Ihnen im ersten Jahre geben, damit Sie die Chance hätten, über 8000 M. zu kommen. Auf die Dauer hätte ich nur ein bestes abgegrenztes Honorar contrahiert, denn anders ist es nie u. nirgends üblich. Aber nun fordern Sie gar 10.000 M. und Prozentantheil. Nein, lieber Freund, so glänzend sind die Verhältnisse nicht. Das kann nur ich genau wissen. Ich will mit dem Orchester sprechen u. suchen, Ihnen für die 10 Berliner Concerte glatt 5000 M. zu sichern. Sie können dann Weimar beibehalten, wenn wir uns wegen Hambg nicht noch verständigen. Ich bedauere lebhaft, aber sehr lebhaft, daß Sie Ihren pecuniären Vortheil, ohne die Lage zu berücksichtigen, so in den Vordergrund stellen. Sie verlangen ja mehr, als Bülow, da er die Concerte übernahm! Und damals waren die Verhältnisse günstiger für uns. Ueberlegen Sie ruhig, künstlerisch ohne das >Markgespenst` voranzustellen. Auf Ihre Forderung kann ich nicht eingehen. « Brief von Hermann Wolff an Richard Strauss vom 12.2.[1894], RSI. Hervorhebungen im Original.

${ }^{629}$ Briefe von Richard Strauss an seinen Vater vom 18.1.1884 und 25.1.1884, Richard Strauss: Briefe an die Eltern. 1882-1906, hg. von Willi Schuh, Zürich u. a. 1954, S. 37.

${ }^{630} \mathrm{Zu}$ diesen Differenzen vgl. z. B. Willi Schuh: Richard Strauss. Jugend und frühe Meisterjahre. Lebenschronik 1864-1898, Zürich 1976, S. 249-252; Hans-Joachim Hinrichsen, Des Meisters Lehrjahre. Der junge Richard Strauss und seine Meininger Ausbildungszeit bei Hans von Bülow, in Richard Strauss. Der Komponist und sein Werk, S. 17-36, vor allem S. 32-34.

${ }^{631}$ Dazu vgl. Abschnitt 3.1.1 der vorliegenden Arbeit.

${ }^{632}$ Brief von Hans von Bülow an Hermann Wolff vom 17.10.1885, Bülow-Briefe 6, S. 383. Hervorhebung im Original.

${ }^{633}$ Zur Lehrzeit Strauss' bei Bülow und seine Erfahrungen im Kreise seines Meisters vor allem mit Johannes Brahms und Alexander Ritter vgl. Richard Strauss: Erinnerungen an Hans von Bülow (original 1909), in Richard Strauss: Betrachtungen und Erinnerungen, hg. von Willi Schuh, Mainz 2014, S. 183193.

${ }^{634}$ Brief von Richard Strauss an Hans von Bülow vom 30.1.1892, in Lieber Collega!, S. 92. 
Hamburger Abonnementkonzerte angeboten. ${ }^{635}$ Die überlieferten Korrespondenzen beweisen, dass Wolff selbst die Werke von Strauss positiv einschätzte und sich für ihre Verbreitung einsetzte. ${ }^{636}$ Aber die Aufführung eigener Werke des Komponisten scheint kein entscheidender Faktor der Berufung Strauss' als Dirigent der Philharmonischen Konzerte gewesen zu sein, weil von seinen Werken nur die Auszüge aus der Oper Guntram im letzten, zehnten Konzert (18.3.1895) seiner Saison auf das Programm gesetzt wurden. ${ }^{637}$

Aus dem Brief von Hermann Wolff ergibt sich, dass er mit Strauss zunächst für mindestens drei Jahre rechnete. ${ }^{638}$ Tatsächlich abgeschlossen wurde dagegen offenbar ein Zweijahresvertrag. ${ }^{639}$ Die Strauss-Saison geriet aber zum finanziellen Fiasko. ${ }^{640}$ Das große Defizit zwang Wolff dazu, Strauss nach Ablauf der ersten Spielzeit vorzeitig zu kündigen.

Es gelang Richard Strauss nicht, als Dirigent die frühere Bedeutung und Anziehungskraft der Berliner Philharmonischen Konzerte zurückzuerobern. Aber trotz dieses Misserfolges konnte er 1898 die eigentlich erwünschte Stelle des Ersten Preußischen Kapellmeisters an der Berliner Hofoper antreten, während die Philharmonischen Konzerte bald danach einen neuen Stardirigenten bekamen, der das sinkende Schiff allmählich über Wasser bringen konnte.

${ }^{635}$ Strauss übernahm nur die Berliner Konzerte, da »der [Weimarer] Großherzog mich durchaus nicht fortlassen will«. Vgl. Brief von Richard Strauss an Cosima Wagner vom 21.2.1894, in Cosima WagnerRichard Strauss. Ein Briefwechsel, hg. von Franz Trenner unter Mitarbeit von Gabriele Strauss, Tutzing 1978, S. 175.

${ }^{636}$ Briefe von Hermann Wolff an Richard Strauss vom 29.8.[1887], 13.1.[1888] u. a., RSI. Vgl. Abschnitt 3.1.1 der vorliegenden Arbeit.

${ }^{637}$ Angesichts der Unbeliebtheit von Strauss' Programmgestaltung musste Hermann Wolff sogar vorschlagen, im letzten Konzert statt der angekündigten Szene aus seiner Oper Guntram die neunte Sinfonie von Beethoven aufzuführen, was der Dirigent jedoch ablehnte. Brief von Hermann Wolff an Richard Strauss vom 7.3.[1895], RSI; Muck: Einhundert Jahre Berliner Philharmonisches Orchester, Bd. 1, S. 197.

$638 »$ Ich werde jetzt den Contract zwischen uns anfertigen. Ich denke, daß wir ihn vorerst auf 3 Jahre machen. Sagen Sie mir umgehend ob Sie damit einverstanden sind. Ihr letzter Brief enthält wieder die Bemerkung, daß 5000 M. eigentlich nicht viel sei. Ich glaubte wirklich die Situation genügend auseinandergesetzt zu haben, ganz abgesehen davon, daß wir ja über die financielle Frage auch definitiv im Reinen sind. Ich will aber bei dreijährigem Contract für das 3te Jahr $6000 \mathrm{M}$ ansetzen, in der Hoffnung, daß sich Concerte wieder heben. Aber wir werden in den ersten Jahren Mühe haben, sie auf dem jetzigen Stand zu erhalten! Ich hoffe, Sie werden einen Ehrgeiz darin suchen, die Concerte zu heben. « Brief von Hermann Wolff an Richard Strauss vom 30.3.[1884], RSI.

${ }^{639}$ Muck: Einhundert Jahre Berliner Philharmonisches Orchester, Bd. 1, S. $210 f$.

${ }^{640} »$ Wenn es nicht gleich gut geht, verzage ich nie. Bedenklich macht mich's nur daß es vom Concert zu Concert schlechter wird u. nur die Zugkraft des Solisten noch eine Rolle spielt. Im letzten Concert haben die Einnahmen der öffentl. Generalprobe und des Concertes zusammen nicht die Saalmiethe gedeckt. Und wie jämmerlich das Abonnement ist, wissen Sie. Ich bin rechtlich besorgt. Nirvana hat übrigens bei der Presse nicht mehr Anklang gefunden, als beim Publikum u. das Bestehen auf Mahler Sinfonie wird auch die Sache nicht verbessern, fürchte ich.« Brief von Hermann Wolff an Richard Strauss vom 21.2.[1895], RSI. Hervorhebungen im Original. 


\section{Arthur Nikisch}

Schließlich fand Hermann Wolff den rechten Mann in Arthur Nikisch, einem in Berlin nahezu unbekannten Dirigenten, den ihm Liszt seinerzeit begeistert geschildert hatte und der bei ihm selbst im Jahr 1881 anlässlich der Tonkünstlerversammlung des ADMV in Magdeburg einen großen Eindruck hinterlassen hatte. ${ }^{641}$

Nach seinem Studium am Wiener Konservatorium mit dem Hauptfach Geige sammelte Nikisch seine ersten musikalischen Erfahrungen als Geiger im Wiener Hofopernorchester. 1879 berief Angelo Neumann, der sein Talent als Dirigent entdeckt hatte, Nikisch an das Leipziger Stadttheater, zuerst als Chordirektor und dann als Kapellmeister. In Leipzig blieb er über ein Jahrzehnt, wo er, bald mit Anton Seidl koordiniert, das gesamte Opernrepertoire dirigierte und vertretungsweise im Gewandhaus auftrat. $\mathrm{Zu}$ seinen damaligen Leistungen gehört die Leipziger Erstaufführung der siebten Sinfonie von Anton Bruckner im Jahr 1884. 1889 ging er nach Amerika, wo er vier Jahre lang als Chefdirigent des Boston Symphony Orchestra wirkte, ${ }^{642}$ und kam 1893 nach Europa zurück, um die Leitung der Budapester Oper zu übernehmen.

In ihren Erinnerungen bieten Louise Wolff und Edith Stargardt-Wolff eine fast übereinstimmende Darstellung zum Verlauf der gleichzeitigen Berufungen Nikischs als Dirigent der Gewandhauskonzerte in Leipzig und der Philharmonischen Konzerte in Berlin im Jahr 1895: Zuerst sei die Einladung von Hermann Wolff eingetroffen, zur Freude des Dirigenten, der unter den negativen Verhältnissen an der Königlichen Oper der ungarischen Hauptstadt nicht ganz glücklich war. Gerade in der Verlegenheit, wie sich die Posten in Budapest und Berlin miteinander vereinbaren lassen könnten, habe ihn ein Ruf aus der Gewandhausdirektion erreicht. Unter den Leipziger und Berliner Instituten sei dann ein Kompromiss vereinbart worden, der Nikisch ermöglichte, bei beiden ohne Störungen tätig zu werden. $^{643}$

\footnotetext{
${ }^{641}$ Louise Wolff: Arthur Nikisch und Berlin. Aus meinen Erinnerungen, S. 163.

${ }^{642}$ Zur Dirigententätigkeit und zum Repertoire von Nikisch in seiner Bostoner Zeit vgl. Raymond Holden: The Virtuoso Conductors. The Central European Tradition from Wagner to Karajan, New Haven u. a. 2005, S. 43-46. Nach den Firmenanzeigen 1890 und 1891 vertrat die Konzertdirektion Hermann Wolff die Konzerte des Boston Symphony Orchestra unter Nikisch. Vgl. Abbildung 14 und 15 der vorliegenden Arbeit.

${ }^{643}$ Louise Wolff: Arthur Nikisch und Berlin. Aus meinen Erinnerungen, S. 164; Stargardt-Wolff: Wegbereiter großer Musiker, S. 90-92. Die Darstellung von Ferdinand Pfohl weicht von denjenigen dieser Autorinnen ab. Vgl. Ferdinand Pfohl: Arthur Nikisch. Sein Leben, seine Kunst, sein Wirken, Ferdinand Pfohl, Arthur Nikisch. Sein Leben, seine Kunst, sein Wirken, Neue erweiterte und verbesserte Ausgabe mit zahlreichen Bildern und Facsimiles, Hamburg 1925, S. 45f und S. 54f.
} 
Vielleicht kann angezweifelt werden, ob die Leipziger und Berliner Institutionen tatsächlich zufällig ohne jede Abmachungen fast gleichzeitig dem gleichen Dirigenten günstige Angebote machten. Da das Gewandhaus zu den Instituten gehört, die sich der Konzertdirektion Hermann Wolff bald nach ihrer Eröffnung zu bedienen begonnen hatten, ${ }^{644}$ ist es denkbar, dass die beiden deutschen Direktionen im Voraus zur Beschaffung Nikischs und zu seinem Pendeldienst zwischen Leipzig und Berlin verhandelt hatten.

Nicht anders als in Berlin gab es auch in Leipzig ein starkes Verlangen nach einer neuen impulsgebenden Figur mit suggestiver Kraft. Schon längst bestanden sowohl im Direktorium wie in der Öffentlichkeit Vorbehalte gegenüber Carl Reinecke, der fast als Verkörperung der konservativen musikalischen Hochburg das Leipziger Gewandhausorchester seit 35 Jahren dirigiert hatte.

Nikisch trat seine Leipziger und Berliner Ämter, die er bis zu seinem Tod im Jahr 1922 mehr als ein Vierteljahrhundert lang bekleiden sollte, im Oktober 1895 im Abstand von vier Tagen an (vom 10. Oktober 1895 in Leipzig und vom 14. Oktober 1895 in Berlin). Diese zwei Konzertinstitute hatten gegensätzlichen Charakter: Das Leipziger Gewandhausorchester war ein ehrwürdiger Hüter der Tradition, während das Berliner Philharmonische Orchester als neuer Impulsgeber für das Musikleben der neuen Musikmetropole fungierte. Während 22 Gewandhauskonzerte in Leipzig in einer Spielzeit stattfanden, gab es nur zehn Philharmonische Konzerte in Berlin, ${ }^{645}$ und zwischen den beiden gab es unterschiedliche Ausgangssituation in der Programgestaltung. Während Hans von Bülow in Berlin eine modernisierte Konzertstruktur etabliert hatte, war unter Reinecke der Anteil der Orchestermusik in jedem Gewandhauskonzert, das fast immer länger als zwei Stunden dauerte, im Prinzip auf eine Ouvertüre, ein oder zwei Instrumentalkonzerte und eine abschließende Sinfonie beschränkt gewesen. Ein erheblicher Teil jedes Gewandhauskonzertes war dagegen von bunten, auflockernden Soloaufführungen bestritten worden. ${ }^{646}$

Die Kopierbücher des Gewandhauses belegen, dass Wolff in den 1890er-Jahren für die Gewandhauskonzerte zahlreiche Solisten engagierte. ${ }^{647}$ Interessanterweise traten nicht wenige Musiker, die durch Wolff den Gewandhauskonzerten vermittelt wurden, zeitnah auch in Berlin auf, manchmal mit der gleichen Musik. So erschien etwa Camilla Landi, die durch die

\footnotetext{
${ }^{644}$ Stargardt-Wolff: Wegbereiter großer Musiker, S. 51.

${ }^{645}$ Es darf dennoch nicht vergessen werden, dass Arthur Nikisch zu seiner Amtszeit nicht nur für die Philharmonischen Konzerte des Berliner Orchesters, sondern auch für ihre Extrakonzerte und Konzerttournee usw. oft zusätzlich engagiert wurde.

${ }^{646}$ Dazu vgl. Die Gewandhauskonzerte zu Leipzig. 1781-1981, hg. von Johannes Forner, Bd. 2, Leipzig 1981, S. 126.

${ }^{647}$ Stadtarchiv Leipzig, Copirbuch I, Sig.: Gewandhaus Nr. 25; Copirbuch II, Sig.: Gewandhaus Nr. 26.
} 
Vermittlung von Wolff im 12. Gewandhauskonzert der Saison 1898/1899 (12.1.1899) unter anderen mit La fiancée du timbalier op. 82 von Camilles Saint-Saëns auftrat, ${ }^{648}$ im 8. Philharmonischen Konzert der gleichen Saison (6.2.1899) mit dem gleichen Werk. Durch Wolffs Vorschlag und Engagement kamen die Pianistinnen Emma Koch, Wanda Landowska und Martha Siebold zu einem gemeinsamen Auftritt im »Konzert für drei Klaviere« in d-Moll BWV 1063 im 19. Gewandhauskonzert der Saison 1898/99 (2.3.1899) zusammen. ${ }^{649}$ Sie spielten dieses Werk wieder im Konzert zugunsten des Pensionsfonds des Berliner Philharmonischen Orchesters unter Nikisch (19.4.1899).

Die Vermutung liegt nahe, dass die traditionsreichen Gewandhauskonzerte für Hermann Wolff bei der Einrichtung der Berliner Abonnementkonzerte, ob im positiven oder negativen Sinne, als Vorbild dienten. Es ist aber auch wahrscheinlich, dass das neu gegründete, sich rasch entwickelnde Berliner Orchester und das renommierte, ehrwürdige Leipziger Orchester, nun mit einem gemeinsamen Dirigenten auf der Spitze ihrer Abonnementkonzerte, im gewissem Sinne zu Rivalen wurden. Es gab ein Tätigkeitsgebiet, das Wolff für das Berliner Orchester vor allem in der Nikisch-Zeit strategisch erschloss, und das dagegen der Direktion des Gewandhauses noch lang verschlossen bleiben sollte: die Konzertreise. Mit den Worten des Berichterstatters der Allgemeinen Musikzeitung schickte Wolff während der Nikisch-Zeit »wie ein Feldherr seine Armeekorps hierhin und dorthin auf alle Punkte des Erdballs [...], wo man seiner bedarf, um den Sieg der deutschen Musik zu sichern und zu entscheiden. $\ll^{650}$ Besonders kühn und bedeutsam war die Tournee des Berliner Philharmonischen Orchesters nach Paris im Mai 1897. Dieses Unternehmen wurde zunächst als Politikum befürchtet, weil auch 26 Jahre nach dem Deutsch-Französischen Krieg der Antagonismus zwischen den Nachbarstaaten und der Groll der Franzosen über den verlorenen Krieg fortbestanden. Die fünf Konzerte unter Nikisch in Paris verzeichneten jedoch sensationelle Erfolge, und das Unternehmen von Hermann Wolff wurde als Brückenschlag zwischen den beiden Völkern anerkannt. ${ }^{651}$ Im Frühjahr 1899 gastierte Nikisch mit dem Berliner Orchester vier Wochen lang in Russland, und 1901 für 45 Tage in Österreich, Italien, Spanien und Portugal.

Für die Direktion des Gewandhausorchesters war eine derartige Ausweitung des künstlerischen Wirkungsfeldes vorerst undenkbar. Mit deutlicher Anspielung auf die Reisetätigkeit des Berliner Philharmonischen Orchesters lehnte das Direktorium der

\footnotetext{
${ }^{648}$ Stadtarchiv Leipzig, Copirbuch II, Angefangen den 3. Januar 1899, Sig.: Gewandhaus Nr. 26, S. 2.

${ }^{649}$ Ebd., S. 26 und 28.

${ }^{650}$ N.N.: Berichte und kleine Mittheilungen, in Allgemeine Musikzeitung 23 (1896), S. 351.

${ }^{651} \mathrm{Zu}$ dieser Tournee nach Paris, vgl. u. a.: Stargardt-Wolff: Wegbereiter großer Musiker, S. 97f.
} 
Leipziger Anstalt ein Gastspiel in Halle 1896 ab, »weil zu fürchten ist, daß unser berühmtes Orchester, das bisher nur edeln Zwecken gedient hat, durch Concertreisen auf den Standpunkt eines philharmonischen Orchesters in Berlin und derartiger Gewerbsunternehmungen herabsinken könne«. ${ }^{652}$ Erst 1916 begab sich das Leipziger Orchester auf seine erste Reise, und zwar in die Schweiz.

Im Vergleich mit den Programmen der Gewandhauskonzerte, in denen Solo- und Choraufführungen normalerweise einen nicht geringen Teil des Programmes einnahmen, zeichnen sich die Berliner Philharmonischen Konzerte auch zur Nikisch-Zeit durch das Gewicht des Sinfonischen aus. Der statistische Vergleich der von Nikisch in den beiden Abonnementkonzerten aufgeführten sinfonischen Werke arbeitet die unterschiedlichen Ausrichtungen der Leipziger und Berliner Konzertdirektionen, wohl auch die unterschiedlichen Voraussetzungen beider Städte, heraus (vgl. Diagramm 12 und 13). Während die Werke von Wagner und Čajkovskij in Berlin einen auffällig hohen Anteil einnehmen (je $9 \%$ und $5 \%$ in Berlin, je $5 \%$ und $2 \%$ in Leipzig), besetzen Werke von Brahms, Robert Schumann, Mendelssohn und Mozart sichere Plätze in Leipzig (je 7 \%, 6 \%, $5 \%$ und $5 \%$ in Leipzig, je $3 \%, 4 \%, 3 \%$ und $3 \%$ in Berlin). Die Neudeutschen Liszt und Berlioz erlangen mehr Bedeutung in Berlin als in Leipzig (je $4 \%$ in Berlin, je $2 \%$ in Leipzig). Obwohl diese beiden Abonnementkonzertreihen einen gemeinsamen Dirigenten hatten und nicht selten dieselben Solisten und Werke auf die Bühne brachten, standen die Programme der beiden Institutionen insgesamt unabhängig da und zeigen jeweils eigene Prinzipien.

${ }^{652}$ Die Gewandhauskonzerte zu Leipzig. 1781-1981, Bd. 2, S. 132. 


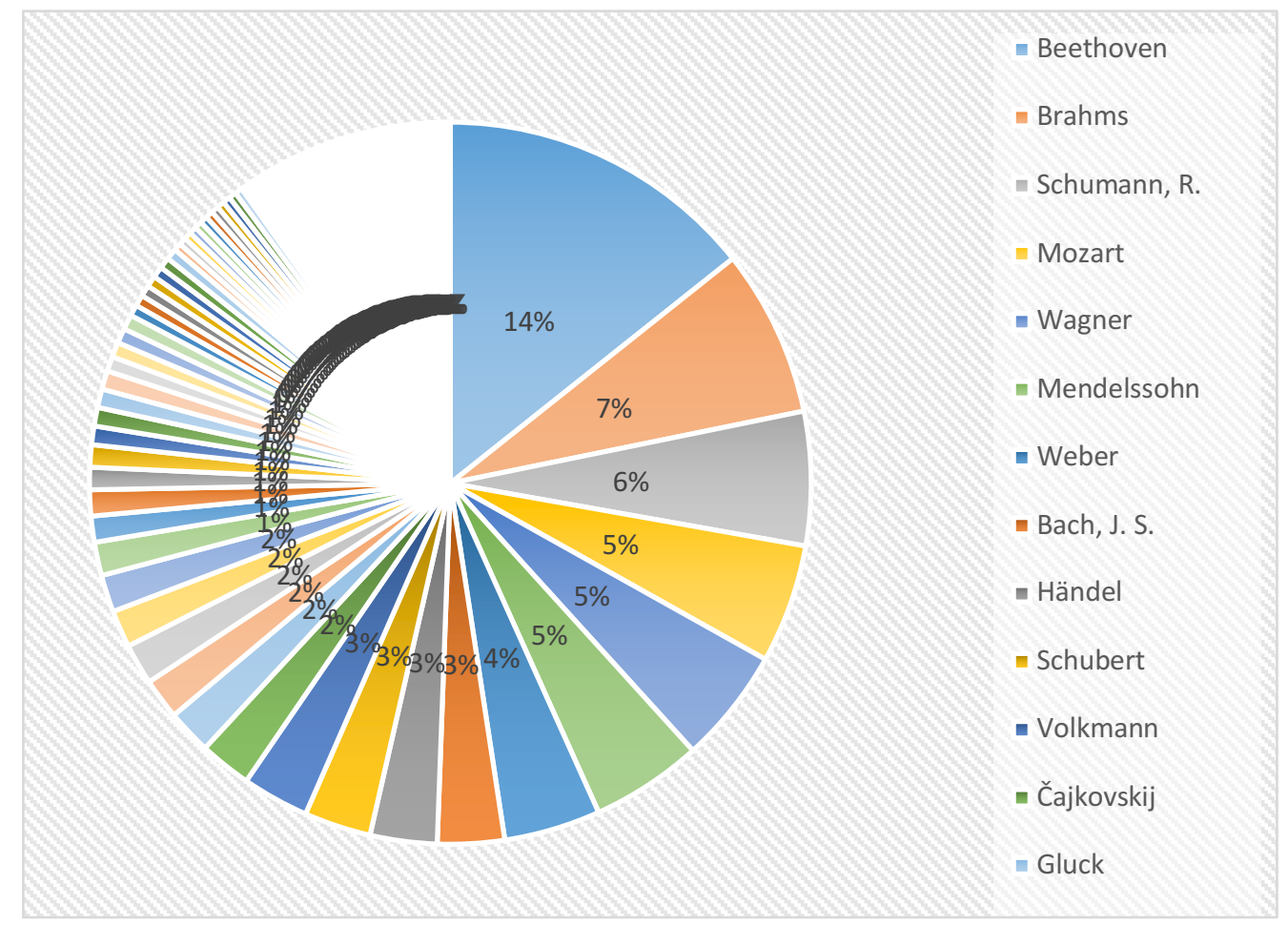

Diagramm 12: Die in den Leipziger Gewandhauskonzerten unter Nikisch aufgeführten sinfonischen Werke (1895/95-1901/02)

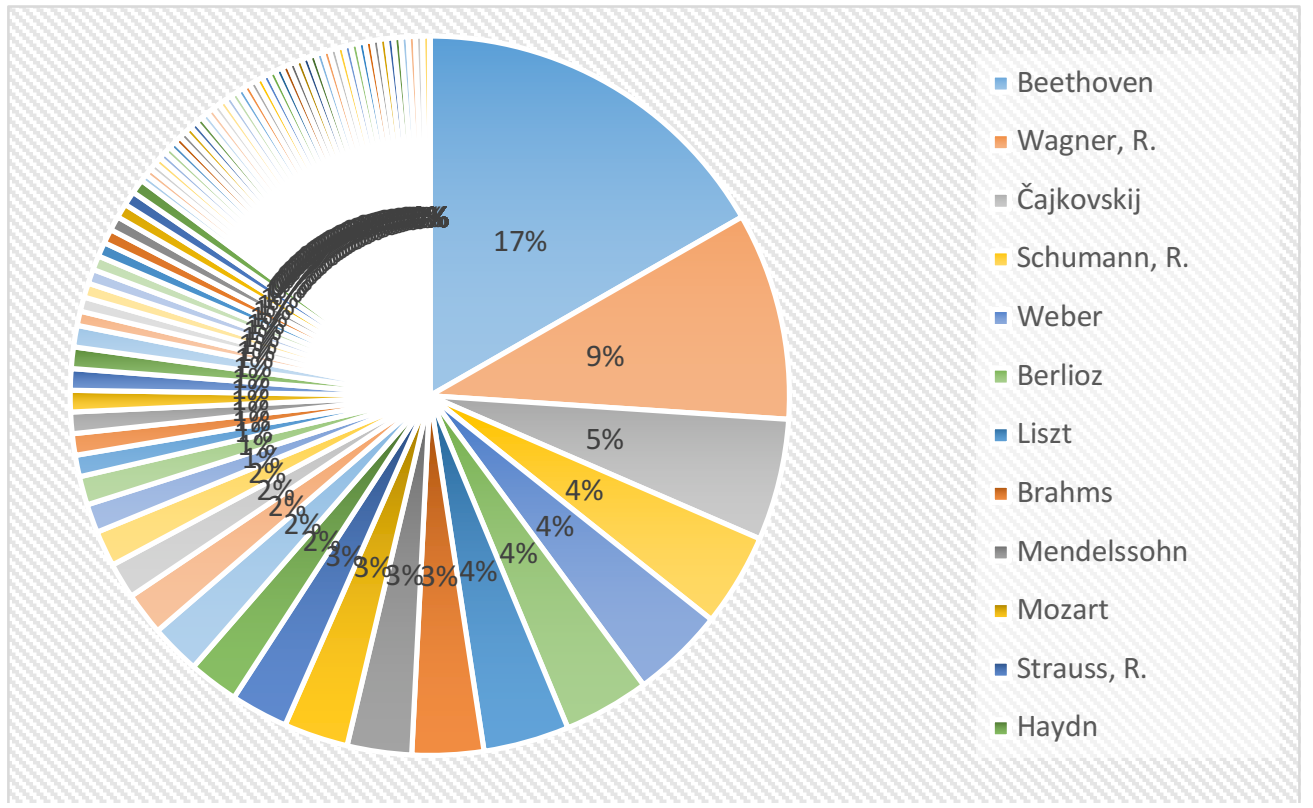

Diagramm 13: Die in den Berliner Philharmonischen Konzerten unter Nikisch aufgeführten sinfonischen Werke (1895/95-1901/02)

Als Dirigent gehörte Nikisch keiner Schule an. Auch in Berlin war er frei von Interessenskonflikten, etwa mit der Hofoper oder der Musikhochschule. Im Unterschied zu Bülow existierte einerseits das Problem der Neudeutschen für ihn nicht, andererseits fühlte er sich von Anfang an der Musik von Johannes Brahms und Robert Schumann tief verbunden. ${ }^{653}$ Zudem wurde er jetzt in seiner Leipziger Stellung der echte Erbe von Mendelssohn.

${ }^{653}$ Die Gewandhauskonzerte zu Leipzig. 1781-1981, Bd. 2, S. 138. 
Dass Nikisch in jeder Hinsicht im Gegensatz zu Hans von Bülow stand, wurde von verschiedenen Autoren bei vielen Gelegenheiten mit einer Fülle von Beispielen oder Anekdoten berichtet. ${ }^{654}$ Beabsichtigte Wolff demnach einen radikalen Richtungswechsel der Philharmonischen Konzerte durch die Berufung Nikischs? Welche musikalischen Folgen brachte diese Berufung dem Orchester?

In seiner Broschüre Arthur Nikisch und die Berliner Philharmonischen Konzerte 1895-1920 blickte Adolf Weissmann auf die 25jährige Berliner Tätigkeit Nikischs zurück und erklärte ihre Bedeutung für das Berliner Musikleben. Seiner Darlegung nach habe der »romantische Klanglyriker«, so stellt er den Dirigenten dar, nicht einfach neue Werke ins Programm eingeführt, sondern auch durch seine Interpretation die klassischen Werke neu beleuchtet.

Er [Nikisch] zerstört die Legende von dem allein seligmachenden Beethoven. Der seinige hat allmählich die Fremdheit überwunden; auch er hat bei aller Betonung des Melos Linie; auch er wächst kraftvoll an. Und wenn in dem Heldengesang der »Eroica« die Klage ertönt, hat sie in dem zartesten aller Ausklänge, in tropfenden Noten ihren versöhnenden, harmonischen Schluss, wie es dem harmoniesuchenden Musiker an der Spitze gemäss ist. ${ }^{655}$

Weissmann ist der Auffassung, dass Nikisch auch die Musik von Brahms zu besonderer Geltung gebracht habe. Er habe eine Dimension der Musik von Brahms erschlossen, mit der Hans von Bülow sich nicht ganz auseinandersetzt hatte.

Für Brahms wiederum wird er [Nikisch] ein Retter. Gewiss: der ist durch Bülow in seine Rechte eingesetzt. Aber um zur Höhe eines Überkultus zu gelangen, braucht Brahms einen Dirigenten, der ihn von aller Herbheit befreit, der seinem kammermusikalischen Orchester den Edelklang gibt und alle seine Härten abstumpft. $[\ldots]^{656}$

\footnotetext{
${ }^{654}$ Vgl. u. a.: Ferdinand Pfohl: Arthur Nikisch. Sein Leben, seine Kunst, sein Wirken, S. 133-134; Wolfgang Stresemann, Philharmonie und Philharmoniker, Berlin 1977, S. 56f.

${ }^{655}$ Adolf Weissmann: Arthur Nikisch und die Berliner Philharmonischen Konzerte 1895-1920. Ein Rückblick, Berlin 1920, S. 13. Zu den Charakteren der Nikischs Aufführung der Beethovens Werke vgl. auch Ferdinand Pfohl: Arthur Nikisch als Mensch und Künstler, S. 35-41.

${ }^{656}$ Weissmann: Arthur Nikisch und die Berliner Philharmonischen Konzerte, S. 13.
} 
Auf die Frage, warum Hermann Wolff schließlich Nikisch als Dirigenten der Philharmonischen Konzerte auswählte, sind verschiedene Antworten möglich. Angenommen, die Gewandhausdirektion hätte als erste ihre Absicht auf die Berufung Nikischs erklärt, dann könnte es ihm vorteilhaft erschienen sein, mit den ehrwürdigen Gewandhauskonzerten einen Dirigenten zu teilen und die Zusammenarbeit mit der traditionsreichen Konzertinstitution zu verstärken. Er mag auch von Nikisch erwartet haben, das von Bülow nicht akzeptierte Repertoire oder die von ihm nicht herangezogenen Publikumsschichten zu erschließen. Vielleicht erschien ihm der für Nikisch typische romantische Aufführungsstil wünschenswert, oder er mag gedacht haben, dass die Philharmonischen Konzerte, oder das Orchester selbst, jetzt einer anderen Art der Führungskraft als derjenigen von Bülow bedürfte.

Obwohl Nikisch kein Reformator im Sinne von Bülow war, entwickelten sich die Philharmonischen Konzerte unter Nikisch bezüglich des Repertoires, der Aufführungsstile und des Aktionsgebiets in einer Weise, wie sie in der Bülow-Zeit nie möglich gewesen wären. Wolffs Entscheidung für Nikisch hatte Einfluss nicht nur auf die Zukunft eines Berliner Orchesters, sondern auch auf die Beziehung zwischen der alten und neuen Musikmetropole in ihrem Konzertleben. 


\subsection{Der Bechstein-Saal in Berlin ${ }^{657}$}

\subsubsection{Neue Bretter im Stadtzentrum}

Anfang Oktober 1892 erschien in der Neuen Berliner Musikzeitung eine Illustration unter dem Titel »Zur Erinnerung an die Eröffnung des Saales Bechstein am 4. Oktober 1892« (vgl. Abbildung 32). In dieser Zeichnung kann man einige Berühmtheiten des damaligen Berliner Musiklebens identifizieren: Joseph Joachim legt die Violine an die Schulter, Hans von Bülow sitzt am Klavier, Anton Rubinštejn schaut in die Noten auf dem Klavier, Johannes Brahms hält ein gerolltes Notenblatt in seiner Hand. Während sich einige Musiker, wie Eugen d'Albert, Siegfried Ochs und Moritz Moszkowski, mit ihnen auf der Bühne im Glanz ihres Ruhms sonnen, stehen einige andere, wie Ignacy Jan Paderewski und Ferruccio Busoni, unscheinbar in ihrem Schatten.

Oben steht die bekannte Zeile aus der Göttlichen Komödie von Dante Alighieri: Lasciate ogni speranza, voi ch'entrate, »lasst alle Hoffnung fahren, die ihr hier eintretet!« Daneben sieht man den körperlosen Kopf des gefürchteten Kritikers Wilhelm Tappert. Auch andere wichtige Kritiker wie Otto Lessmann, Ernst Eduard Taubert und Alexander Moszkowski sind am Rand der Bühne zu finden.

Die wichtigste Figur in dieser Zeichnung ist jedoch der Zerberus, der über den ganzen Saal wacht. In der Göttlichen Komödie erscheint er als Wachhund zum Höllenkreis der Unersättlichkeit. Mit vielen bekannten Musikern zusammen gezeichnet, erinnert er uns aber auch an die Geschichte von Orpheus in der griechischen Mythologie, der auf dem Weg in die Unterwelt den wütenden Höllenhund mit seinem Lyraspiel und Gesang besänftigen konnte. Der »furchtbare« Höllenhund in dieser Zeichnung hat die Köpfe von Hermann Wolff und Carl Bechstein.

»Bechstein-Saal« ist ein missverständlicher Name, weil er den falschen Eindruck vermittelt, der Saal gehöre der bekannten Klavierfirma. Es war für damalige Klavierfabrikanten üblich, Konzertsäle mit eigenem Namen zu bauen. ${ }^{658}$ Die heutige Wigmore Hall wurde von der Firma Bechstein 1901 gegründet und damals »Bechstein Hall« genannt. Weitere Beispiele sind der Bösendorfer-Konzertsaal in Wien und die Salle Érard sowie die Salle Pleyel in Paris. Der Bechstein-Saal in Berlin war aber nicht Eigentum der Klavierfirma. Er wurde gebaut von dem Konzertagenten Hermann Wolff, dem er auch

\footnotetext{
${ }^{657}$ Dieser Teil ist eine erweiterte Fassung des folgenden englischen Aufsatzes: Sayuri Hatano: BechsteinSaal: A Lost Chamber Music Hall in Berlin, in Journal of Musicological Research 36 (2017), No. 3 , S. 234-251. ${ }^{658}$ Vgl. Borchard: Stimme und Geige, S. 466.
} 
gehörte. Die Zeichnung in der Neuen Berliner Musikzeitung berichtet von der Eröffnung eines neuen Konzertsaales, und gab gleichzeitig auch den großen Einfluss wieder, den dieser Konzertagent im damaligen Berliner Musikleben hatte.

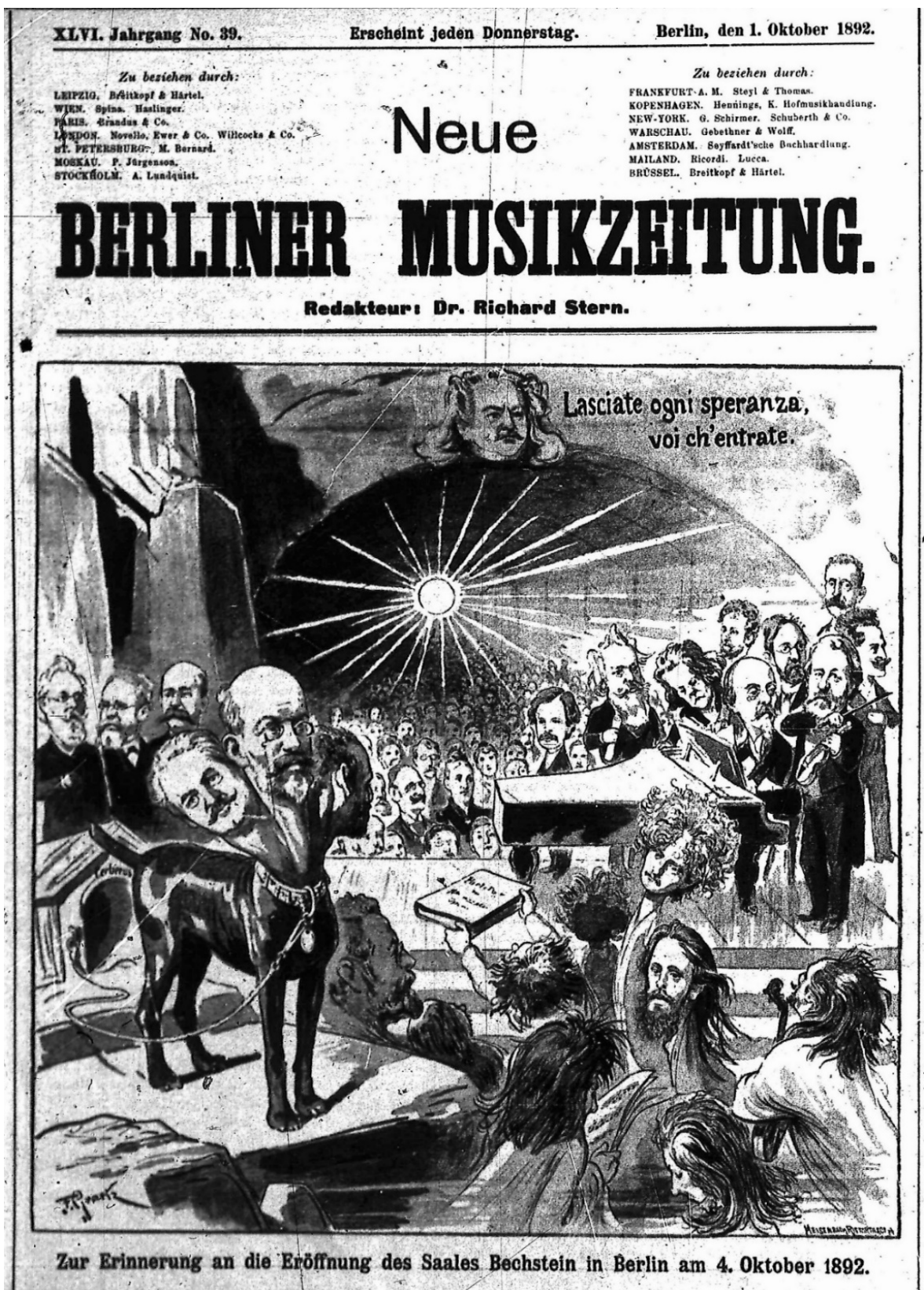

Abbildung 32: »Zur Erinnerung an die Eröffnung des Saales Bechstein in Berlin am 4. Oktober $1892 \ll^{659}$

Zum Motiv ihres Vaters für die Gründung des Saales schreibt Edith Stargardt-Wolff:

Berlin besaß zu Anfang der neunziger Jahre des vorigen Jahrhunderts [des 19.

Jahrhunderts, A. d. V.] nur zwei Konzertsäle von Bedeutung und guter Akustik: die

${ }^{659}$ Neue Berliner Musikzeitung 46 (1892), S. 499. 
große »Philharmonie« und die in der Nähe der Straße »Unter den Linden« gelegene, etwa neunhundert bis tausend Personen fassende traditionsreiche » Singakademie«. Der Beethovensaal existierte noch nicht, der Blüthnersaal und andere Konzertsäle entstanden erst viel später. Es fehlte der Hauptstadt vor allem an einem zentral gelegenen Konzertsaal mittlerer Größe, einem intimeren Raum, der besonders für Kammermusik- und Solistenabende geeignet war. Mit sicherem Instinkt erkannte mein Vater die Notwendigkeit eines solchen Saalbaus, ja, sie wurde zu seiner Lieblingsidee. Er ging also ans Werk. In der Linkstraße, einer stillen, altmodischen Seitenstraße der Potsdamer Straße, fand er, dich am Potsdamer Platz, dem Brennpunkt des Verkehrs gelegen, ein für seine Zwecke geeignetes Grundstück. Die Lage des neuen Saales, so nahe der Philharmonie, würde es den Kritikern leicht machen, am gleichen Abend Konzerte dort wie hier zu besuchen. ${ }^{660}$

Das Konzept war also ein Konzertsaal in einer verkehrsgünstigen Lage, der für Aufführungen in kleiner Besetzung geeignet war. Wie die Karte zeigt, hatte der Bechstein-Saal eine leicht erreichbare Lage, sowohl von der Philharmonie in der Bernburger Straße wie von der Konzertdirektion Hermann Wolff aus, die sich damals Am Karlsbad 19 befand.

${ }^{660}$ Stargardt-Wolff: Wegbereiter großer Musiker, S. 145. 


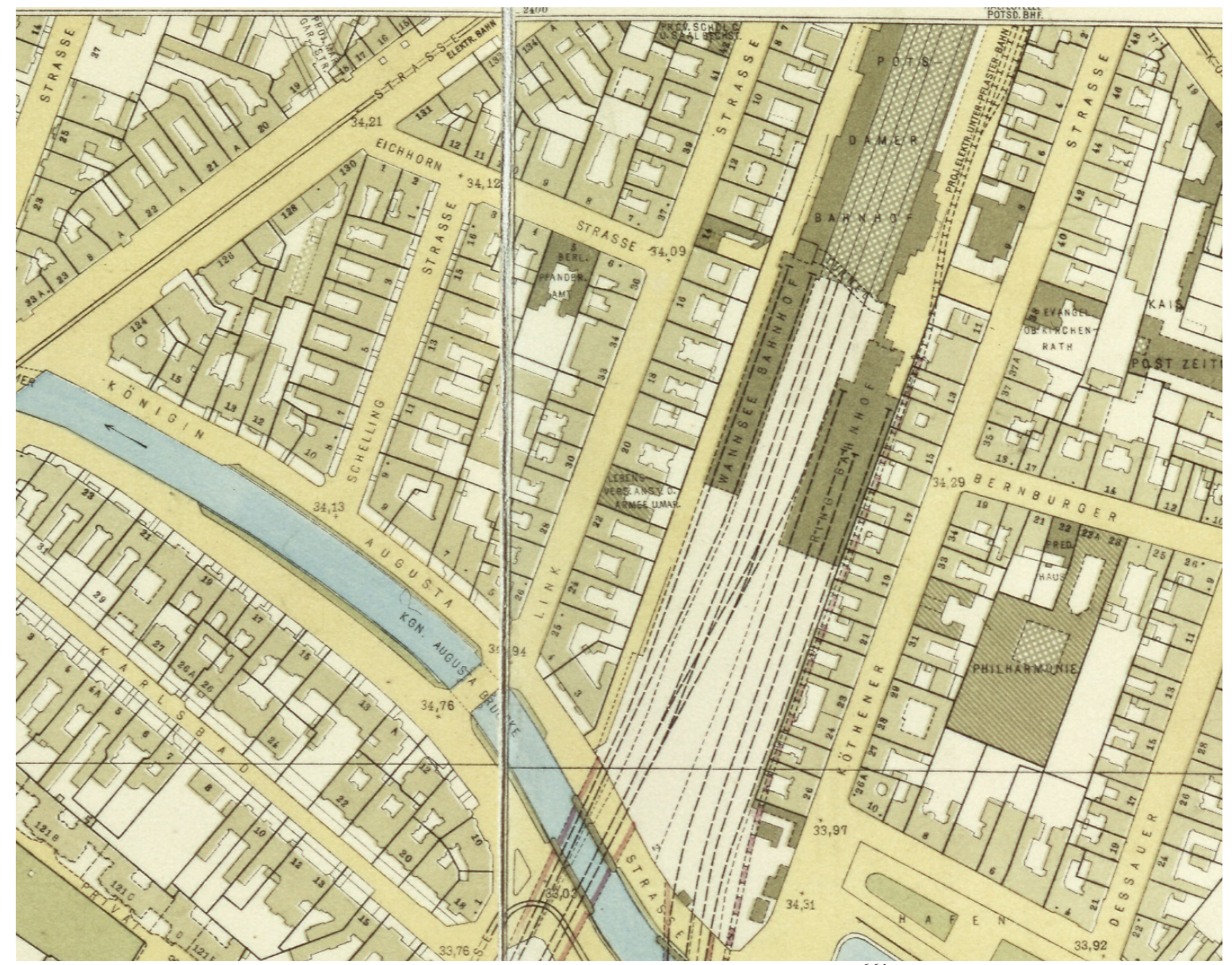

Abbildung 33: Gegend um die Linkstraße in Berlin-Tiergarten (1898) ${ }^{661}$

Die Tabelle 11 ist Auszug aus dem Handbuch der Architektur aus dem Jahr 1901. Sie zeigt die Größenverhältnisse der Konzertsäle, die Eduard Schmitt in der Rubrik »Berlin« angab.

Unter diesen Konzertsälen fällt der Bechstein-Saal tatsächlich durch sein kleines Format auf.

\begin{tabular}{|l|l|l|l|l|l|l|}
\hline Saal & Architekt & $\begin{array}{l}\text { Länge } \\
(\mathbf{m})\end{array}$ & $\begin{array}{l}\text { Breite } \\
(\mathbf{m})\end{array}$ & Höhe (m) & $\begin{array}{l}\text { Fußbodenflä } \\
\left.\mathbf{c h e}^{2} \mathbf{( m}^{\mathbf{2}}\right)\end{array}$ & $\begin{array}{l}\text { Sitzpl } \\
\text { ätze }\end{array}$ \\
\hline $\begin{array}{l}\text { »großer Saal } \\
\text { der } \\
\text { Philharmonie« }\end{array}$ & Schwechten & 35,00 & 24,00 & 15,40 & 990,00 & 1.334 \\
\hline $\begin{array}{l}\text { »Beethoven- } \\
\text { Saal der } \\
\text { Philharmonie« }\end{array}$ & Heim & 26,00 & 20,00 & 12,80 & 520,00 & 1.346 \\
\hline $\begin{array}{l}\text { »in der } \\
\text { Singakademie } \\
\text { « }\end{array}$ & $\begin{array}{l}\text { Ottmer, später } \\
\text { Reimer und } \\
\text { Körte }\end{array}$ & 34,00 & 12,65 & 10,00 & 407,00 & 973 \\
\hline »Bechstein« & Schwechten & 23,50 & 11,60 & 8,50 & 273,00 & 420 \\
\hline $\begin{array}{l}\text { »im Saalbau } \\
\text { des } \\
\text { zoologischen } \\
\text { Gartens }\end{array}$ & $\begin{array}{l}\text { Ende und } \\
\text { Boeckmann }\end{array}$ & 29,50 & 19,00 & 14,00 & 560,00 & - \\
\hline
\end{tabular}

${ }^{661}$ LAB, F Rep. 270, A 2012, 1898, Ausschnitt. 


\begin{tabular}{|l|l|l|l|l|l|l|}
\hline $\begin{array}{l}\text { »Hafenheide } \\
51-53 \text { (großer } \\
\text { Saal)« }\end{array}$ & Wanckel & 28,00 & 21,50 & 12,00 & 602,00 & - \\
\hline
\end{tabular}

Tabelle 11: Größenverhältnis einiger Konzertsäle in Berlin um $1900^{662}$

Ein für Solo- oder Kammermusikkonzerte geeigneter Konzertsaal in Berlin scheint eher ein Wunsch von Musikern als vom Publikum gewesen zu sein. Kurz nach der Eröffnung des Konzertsaales führte William Wolf in der Neuen Zeitschrift für Musik seine Bedeutung aus:

Ein neuer Concertsaal hat sich in der Hauptstadt des deutschen Reiches aufgethan! Es ist kein Riesensaal; er umfaßt nur 500 und einige Plätze, und soll - wie der Prospect besagt - hauptsächlich für Concerte intimen Characters, das ist Clavier-, Kammermusik-, Lieder-Concerte, dann auch für Vorträge dienen. Daß er damit einem Bedürfnis des Berliner Musiklebens entgegenkommt, ist nicht zu bezweifeln. Der Saal der »Singacademie« ist übermäßig in Anspruch genommen, so daß manche Künstler auf ein Concert daselbst, oder wenigstens auf die ihnen erwünschte Zeit desselben verzichten müssen. Der »Philharmonie«-Saal andererseits ist so groß, daß er nicht für alle Arten von Concerten paßt. Namentlich solchen Musikern, welche in Berlin zum ersten Male debütieren, wird der neue Saal willkommen sein. Er ist billiger als die Singacademie, und leichter zu füllen - was bekanntlich nicht gering in's Gewicht fällt, denn einen neuen, noch unerprobten Tonkünstler pflegt das Berliner Publikum keineswegs zahlreich zuzuströmen, ein spärlich besetzter Saal aber macht einen verstimmenden Eindruck, auf den Concertgeber, wie auf die Hörerschaft. ${ }^{663}$

1890 betraute Wolff Franz Schwechten, ${ }^{664}$ einen der angesehensten deutschen Architekten der damaligen Zeit, mit der Planung seines Konzertsaals. Der 1841 in Köln geborene Architekt war bereits Mitglied des Senates der Akademie der Künste und seit Oktober 1889 Außerordentliches Mitglied der Königlichen Akademie des Bauwesens. In Berlin hatte er unter anderem den Anhalter Bahnhof geschaffen, und auch der große Umbau der

\footnotetext{
${ }^{662}$ Quelle: Eduard Schmitt: Handbuch der Architektur.Teil 4, Entwerfen, Anlage und Einrichtung der Gebäude, Halbbd. 6, Gebäude für Erziehung, Wissenschaft und Kunst, H. 3, Stuttgart 1901, S. $200 f$.

${ }^{663}$ William Wolf: Correspondenzen. Berlin, in Neue Zeitschrift für Musik 59 (1892), S. 469. Hervorhebung im Original.

${ }^{664} \mathrm{Zu}$ Franz Schwechten, vgl. u.a. Vera Frowein-Ziroff: Die Kaiser Wilhelm-Gedächtniskirche. Entstehung und Bedeutung, Berlin 1982; Peer Zietz: Franz Heinrich Schwechten. Ein Architekt zwischen Historismus und Moderne, Stuttgart 1999.
} 
Philharmonie im Jahr 1888 war unter seiner künstlerischen Leitung ausgeführt worden. ${ }^{665}$ Der Grundstein seines Hauptwerkes, der Kaiser-Wilhelm-Gedächtniskirche in Berlin, wurde am 22. März 1892 gelegt.

In der Linkstraße 42 entstand ein Wohngebäude, dessen Hinterhaus in seiner ersten Etage einen Konzertsaal enthielt, wie die Entwürfe von Schwechten zeigen (vgl. 3 im Quellenteil). Im vorderen Teil des Grundstücks wurde ein Bürohaus errichtet, in das zunächst eine Behörde, das Provinzialschulkollegium, einzog, und später die Konzertdirektion Hermann Wolff. ${ }^{666}$ Der Saal war ein rechteckiger Raum von 23,5 m Länge, 11,6 m Breite und 8,5 m Höhe. Im Parkett befanden sich 420 Sitzplätze, während auf dem dem Podium gegenüberliegenden Balkon noch 100 Personen platziert werden konnten. ${ }^{667}$ In den Zeitschriftenberichten von der Eröffnung dieses Konzertsaales sind ausführlichere Darstellungen zu seiner Ausstattung zu finden. In der Neuen Berliner Musikzeitung beschrieb Arno Kleffel den Eindruck, den der neue Konzertsaal gab, und lobte die Leistung Hermann Wolffs wie folgt:

Der 23 1/2 Meter lange und etwa 11 1/2 Meter breite Saal macht durch seine stylvolle, wir möchten sagen elegante Einfachheit einen ausserordentlich behaglichen und sympathischen Eindruck. Der Grundton ist weiss mit Gold und nur an der Decke wird dieser Ton durch blau-weisse, sechseckige Felder in einer dem Auge durchaus wohlthuenden Weise unterbrochen. Da auch ferner die Beleuchtung, die Erwärmung und vor Allem die Akustik des Raumes nichts zu wünschen übrig lassen, so darf Herr Wolff mit vollem Recht den Ruhm für sich in Anspruch nehmen, für kleine Konzertaufführungen eine Art Mustersaal geschaffen zu haben. ${ }^{668}$

Im anschließenden Teil des oben zitierten Berichtes in der Neuen Zeitschrift für Musik wies William Wolf ebenfalls auf die gute Akustik dieses Saales hin und verglich ihn mit der Singakademie. Ferner berichtete er ausführlich von seinen Verzierungen, seiner Struktur und Ausstattung:

${ }^{665}$ Dazu vgl. LAB, B Rep. 206, Nr. 3076, B1. 46, 61, 62, 66 und 67. »Die Pläne zu dem Conzertsaal der Philharmonie in Berlin fertigte ich unter Benutzung der Mauern eines Skatingrinks im Winter 1887 auf 1888. Das Gebäude musste ich in der kurzen Zeit von 4 Monaten bei sehr knapp bemessenen Mitteln bis zum 1. October 1888 fertigstellen. « Handschriftlicher Lebenslauf des Architekten Franz Schwechten, in Frowein-Ziroff: Die Kaiser Wilhelm-Gedächtniskirche, S. 412.

${ }^{666}$ Stargardt-Wolff: Wegbereiter großer Musiker, S. 145

${ }^{667}$ Deutsche Bauzeitung 26 (1892), S. 510; Signale 50 (1892), S. 835.

${ }^{668}$ Arno Kleffel: Die feierliche Eröffnung des Saales Bechstein, in Neue Berliner Musikzeitung 46 (1892), S. 536. 
Der äußerst geschmackvolle und [...] akustisch vortrefflich gelungene Bau ist von dem königlich. Baurath Schwechten ausgeführt worden. Letzterem scheint unser Singacademie-Saal als Muster vorgeschwebt zu haben, man hat beim Betreten des Saales Bechstein zunächst den Eindruck, als sähe man die Singacademie in verjüngtem Maßstabe vor sich. Der Architect hat damit einen sehr glücklichen Griff gethan, denn die einfache Eleganz, sowie die akustischen Verhältnisse jenes alten Berliner Concertsaales sind wahrhaft mustergiltig. [...] Die Verzierungen des unteren und oberen Abschlusses der Wände sind von feinstem, zurückhaltendem Geschmack. Im Hintergrund, das ist hinter dem Podium, erblicken wir in einer schön gearbeiteten Nische die Gestalt einer Muse der Tonkunst, von Prof. Calandrelli nach griechischem Vorbilde gefertigt. Die Decke ist mit einer reichen, vom Bildhauer Ernst Westpfahl ausgeführten Stuckarbeit geschmückt. Auf der einen Schmalseite, dem Podium gegenüber, befindet sich ein Balkon mit 100 Sitzplätzen, welche so gut amphitheatralisch angeordnet sind, daß man von jedem derselben freien Ausblick auf das Podium hat. Die Beleuchtung ist vorzüglich, sie wird durch Glühlicht, welches eine Mittelkrone und zahlreiche Armleuchter spenden, bewirkt. Von besonderer Trefflichkeit ist die Ventilation: Die Luft wird von vornherein auf einen angenehmen Wärmegrad gebracht, der sich während der Concert-Stunden, trotz der Menschenansammlung, nicht erhöht. ${ }^{669}$

Wie die Tabelle 12 zeigt, hatte der Bechstein-Saal in seiner Form eine große Ähnlichkeit mit dem Kammermusiksaal des Leipziger Gewandhauses, das 1884 seinerseits nach dem Vorbild des Alten Gewandhauses gebaut wurde. Das Alte Gewandhaus war für seine gute Akustik bekannt gewesen und wurde im 19. Jahrhundert bei der Konstruktion von Rechtecksälen oft nachgeahmt. ${ }^{670}$ Diese Ähnlichkeit lässt die Vermutung aufkommen, dass das Leipziger Modell vielleicht auch bei der Planung des Bechstein-Saales in Betracht gezogen wurde. Das erscheint noch wahrscheinlicher, wenn man daran denkt, dass das Gewandhaus einer der ältesten Klienten des Konzertagenten Hermann Wolff war. ${ }^{671}$ Der Verfasserin sind aber keine Materialien bekannt, die diese Beziehung belegen.

\footnotetext{
${ }^{669}$ Wolf: Correspondenzen. Berlin, in Neue Zeitschrift für Musik 59 (1892), S. 469. Hervorhebungen im Original.

${ }^{670}$ Zum Saal des Gewandhauses, vgl. Hope Bagenal: The Leipzig Tradition in Concert Hall Design, in Journal of the Royal Insitute of British Architects 36 (1929), S. 756-63.

${ }^{671}$ Stargardt-Wolff: Wegbereiter großer Musiker, S. 51.
} 


\begin{tabular}{|l|l|l|l|l|}
\hline Saal & Länge (m) & Breite (m) & Höhe (m) & Sitzplätze \\
\hline $\begin{array}{l}\text { Altes Gewandhaus } \\
(1781)^{672}\end{array}$ & 22,85 & 11,35 & 7,35 & 500 \\
\hline $\begin{array}{l}\text { Kammermusiksaal im Neuen } \\
\text { Gewandhaus (1884) }\end{array}$ & 23,50 & 11,50 & 8,00 & 517 \\
\hline Bechstein-Saal (1892) & 23,50 & 11,60 & 8,5 & 520 \\
\hline
\end{tabular}

Tabelle 12: Größenverhältnisse der Säle des Gewandhauses und des Bechstein-Saales

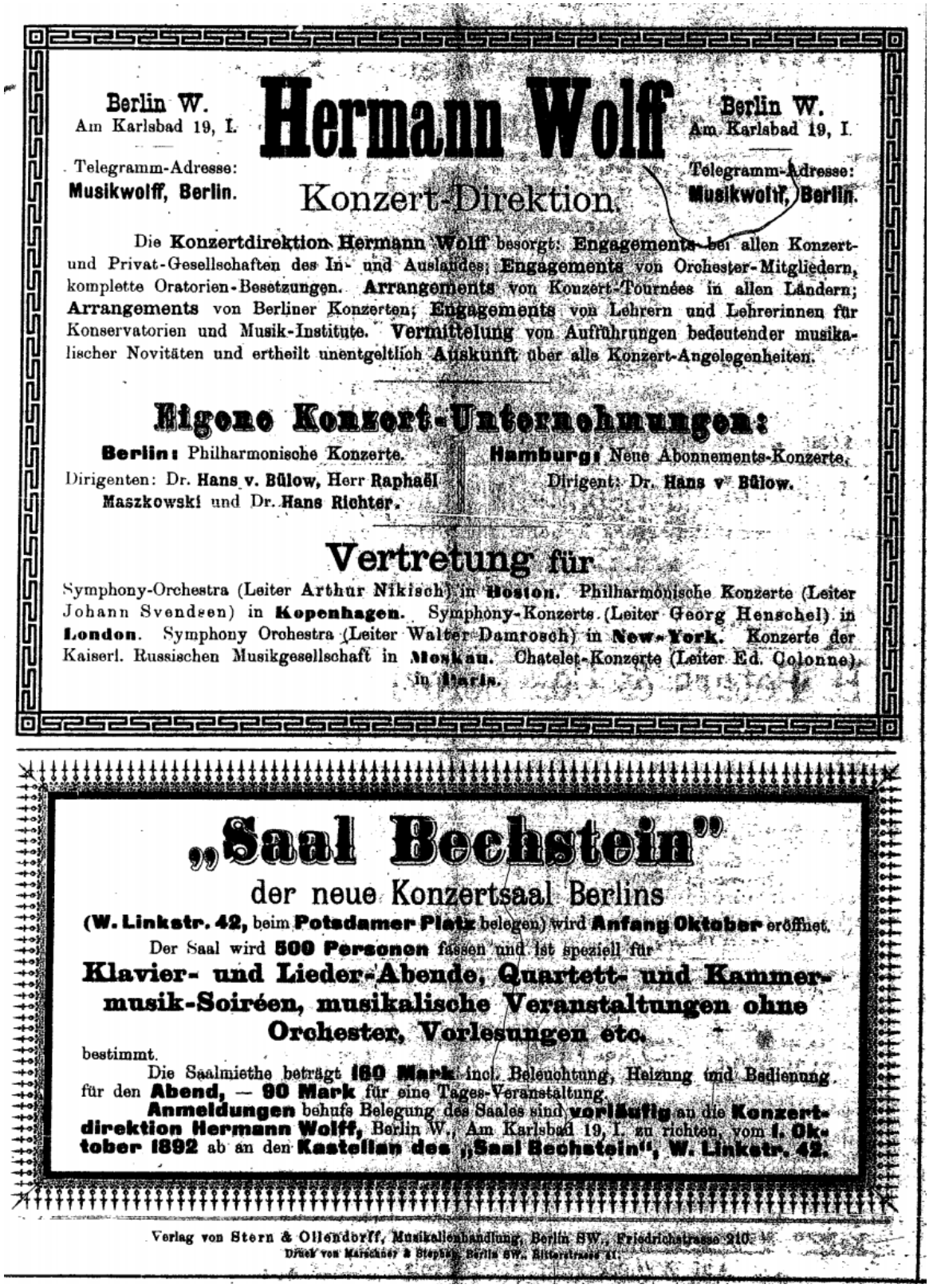

Abbildung 34: Anzeige der Konzertdirektion Hermann Wolff und des Bechstein-Saales (1892) ${ }^{674}$

${ }^{672}$ Quelle: Rudolf Skoda: Die Leipziger Gewandhausbauten. Konzertgebäude im internationalen

Vergleich, Berlin 2001, S. 44.

${ }^{673}$ Ebd.

${ }^{674}$ Neue Berliner Musikzeitung 46 (1892), S. 820. 


\subsubsection{Idee des Konzertsaals »für nicht 〉sensationelle〈 Concerte«}

In seinem Brief vom 20. Juli 1892 teilte Wolff Brahms den Plan von der Einweihung des im Entstehen begriffenen Konzertsaals mit und bat ihn, in einem der Eröffnungskonzerte aufzutreten.

Ein brieflicher Ueberfall in Ihrer Sommerfrische. Aber ich wage ihn, dem eignen Triebe, nicht der Noth gehorchend:

Sie wissen - oder Sie wissen vielleicht noch nicht - daß ich einen neuen Concertsaal gebaut habe, für Kammermusik, Klavier u. Liederabende, à la Boesendorfer Saal. Der Saal wird am 4 Octob eingeweiht durch einen Klav. Abend von Bülow, am 5 Oct soll ein Kammermusikabend des Joachimquartett[s] sein. Als II Einweihungsabend. Und diesen möchte ich, um ihm einen historischen Werth zu geben, zu einem Brahmsabend gestalten, wenn Sie meiner hiermit an Sie gerichteten Einladung Folge leisten wollten u. könnten. Es wäre eine Freude, die Sie mir u. allen bereiten ein Dienst den Sie mir leisten, für den ich Ihnen zeitlebens danken würde. Geht es, kommen Sie? Ich habe soeben mit Joachim, der mich besuchte, das Programm $\mathrm{f}$ diesen Fall besprochen.

\section{Sonate Klav u. Violine}

Trio

Clarinettenquintett

Natürlich würde ich Mühlfeld einladen. Der Ertrag würde - falls das Concert nicht vor geladenem Publ. stattfinden soll - einem wohlthätigen Zweck zuließen.

[...] Die Eröffnung des Saales ist ein Ereigniß für unser Musikleben u. wenn etwas im Stande ist, diesen Tagen Glanz zu verleihen, ist es Ihr Erscheinen. Darum wage ich die kühne Bitte: Kommen Sie. ${ }^{675}$

Die Eröffnungskonzerte fanden ab dem 4. Oktober 1892 an drei aufeinanderfolgenden Abenden vor geladenen Gästen statt. Das erste Konzert war, wie Wolff in seinem Brief ausgeführt hatte, ein Klavierabend von Hans von Bülow. Sein Programm umfasste die cMoll-Fantasie KV 475 von Mozart, die Klaviersonate Les Adieux op. 81a von Beethoven, die f-Moll-Variationen op. 17 von Friedrich Kiel, den Faschingsschwank aus Wien op. 26 von Robert Schumann und vier Kompositionen von Chopin. Bülow war damals schon sehr krank

\footnotetext{
${ }^{675}$ Brief von Hermann Wolff an Johannes Brahms vom 20.7.1892, A-Wgm, Brahms-Nachlass, 381, 7.
} 
und seine Mitwirkung war noch tags zuvor Gegenstand dunkler Gerüchte. Dennoch konnte er auftreten; ${ }^{676}$ es sollte sein letzter öffentlicher Auftritt am Klavier werden. ${ }^{677}$

Der zweite Abend war der Musik von Brahms gewidmet. Es kamen sein Streichsextett op. 18, seine Violinsonate op. 108 und sein Klarinettenquartett op. 115 zur Aufführung. Der Komponist folgte der Einladung Wolffs. Er spielte die Violinsonate mit Josef Joachim, und dieser führte mit seinen Kammermusikkollegen die anderen zwei Werke auf.

Die Hauptfigur des dritten Abends war Anton Rubinštejn, der allein und zusammen mit einer Sängerin und einem Bratschisten auftrat. Das Programm bestand mit Ausnahme zweier italienischer Arien aus seinen Kompositionen. Zur Aufführung gebracht wurden seine Variationen op. 88, die Ballade Leonore und die beiden ersten seiner sechs Etüden op. 81, seine Lieder und seine Bratschensonate op. $49 .{ }^{678}$

Jeder Musiker, den Wolff zu den Eröffnungskonzerten einlud, verkörperte gleichsam den bisherigen Erfolg der Konzertdirektion Hermann Wolff. Es war Wolff, der Bülow für die Philharmonischen Konzerte des Philharmonischen Orchesters gewonnen und mit ihm seit der Saison 1887/88 den fast unbestrittenen Mittelpunkt des Berliner Konzertlebens gestaltet hatte (vgl. Abschnitt 3.2.3 der vorliegenden Arbeit). Die Mitwirkung von Joseph Joachim und seiner Kollegen symbolisierte die Verbindung zwischen Wolff und dem akademischen Kreis in Berlin. Seit den 1880er-Jahren hatte er diesen Berliner Hochschuldirektor und auch sein Quartett für ihre Konzerttätigkeiten vertreten (vgl. 2.3.1). Die Musik von Brahms hatte immer eine wichtige Stelle in der Zusammenarbeit mit Bülow (vgl. 3.2.3), Joachim und den anderen Brahms-Vertretern in Berlin eingenommen. Und auch Brahms selbst war von Wolff gelegentlich vertreten worden. ${ }^{679}$ Rubinštejn war Wolffs ältester Klient. Die Zusammenarbeit mit dieser Prominenz von internationalem Ruhm brachte Wolff die Verbindungen ein, denen der internationale Erfolg seiner Konzertdirektion viel verdankte (vgl. 3.2.1). In den Eröffnungskonzerten des Bechstein-Saales wurde sozusagen eine Erfolgsbilanz der Konzertdirektion Hermann Wolff in ihren ersten zwölf Jahren vorgestellt.

\footnotetext{
${ }^{676}$ Marie von Bülow erinnert sich an ihren Mann an diesen Tagen wie folgt: »Die zunehmenden Schmerzen veranlaßten Bülow, in Berlin den ihm seit den Bismarktagen persönlich bekannten Professor Schweninger zu consultiren. Nachdem sich aber herausgestellt, daß die Behandlung (heiße Kopfbäder) mit den unabweisbaren Vorbereitungen für den Klavierabend nicht vereinbar war, da sie die Schmerzen noch mehr aufpeitschte, wurde der Versuch am Tage vor dem Concerte aufgegeben; quälende Sorge, ob bei der Pein das Gedächtnis auch Stand halten würde, verließ Bülow keinen Augenblick. Um sie zu betäuben, spielte er stundenlang. Es war ein Tag wie in Agonie. Beim Verlassen des Zimmers vor dem Concert rief er: >wer mir jetzt eine Kugel durch den Kopf schösse, wäre mein Freund.« Bülow-Briefe 7, S. 403.

${ }^{677}$ Stargardt-Wolff: Wegbereiter großer Musiker, S. 146.

${ }^{678}$ Kleffel: Die feierliche Eröffnung des Saales Bechstein, S. 536.

${ }^{679}$ Vgl. z. B.: Brief von Hermann Wolff an Johannes Brahms vom 23.1.1882, A-Wgm, Brahms-Nachlass, 381,1 .
} 
In seiner ersten Saison, vom 4. Oktober 1892 bis 20. April 1893, fanden nicht weniger als 135 Konzerte und Vorlesungen im Bechstein-Saal statt. ${ }^{680}$ In der nächsten Spielzeit, 1893/94, organisierte die Konzertdirektion Hermann Wolff 147 Veranstaltungen in diesem Saal. ${ }^{681}$ In der Saison 1894/95 fanden hier 140 Konzerte und Vorlesungen statt. ${ }^{62}$ Das im Abschnitt 2.3.2 der vorliegenden Arbeit betrachtete Concert-Verzeichnis enthält für die vier Saisons zwischen 1901/02 und 1904/05 582 Konzerte und Vorlesungen in diesem Saal, durchschnittlich wurden also 145,5 Veranstaltungen pro Spielzeit im Bechstein-Saal abgehalten. Grob geschätzt fanden in diesem Saal während der Saison wöchentlich mindestens fünf öffentliche Veranstaltungen statt. Wenn man dazu Proben und geschlossene sowie im Verzeichnis nicht aufgenommene Veranstaltungen rechnet, ${ }^{683}$ kann auch aus diesen lückenhaften Daten geschlossen werden, dass der Bechstein-Saal zu Hermann Wolffs Lebzeiten ziemlich gut ausgelastet war.

Die inhaltliche Gliederung der im Conzert-Verzeichnis verzeichneten 582 Veranstaltungen zwischen 1901/02 und 1904/05 geht aus Diagramm 14 hervor. Die »Solistenkonzerte (vokal)« und »Solistenkonzerte (instrumental)« nehmen mit $38 \%$ und $36 \%$ die größten Anteile ein, es folgen die »Kammermusikkonzerte«.

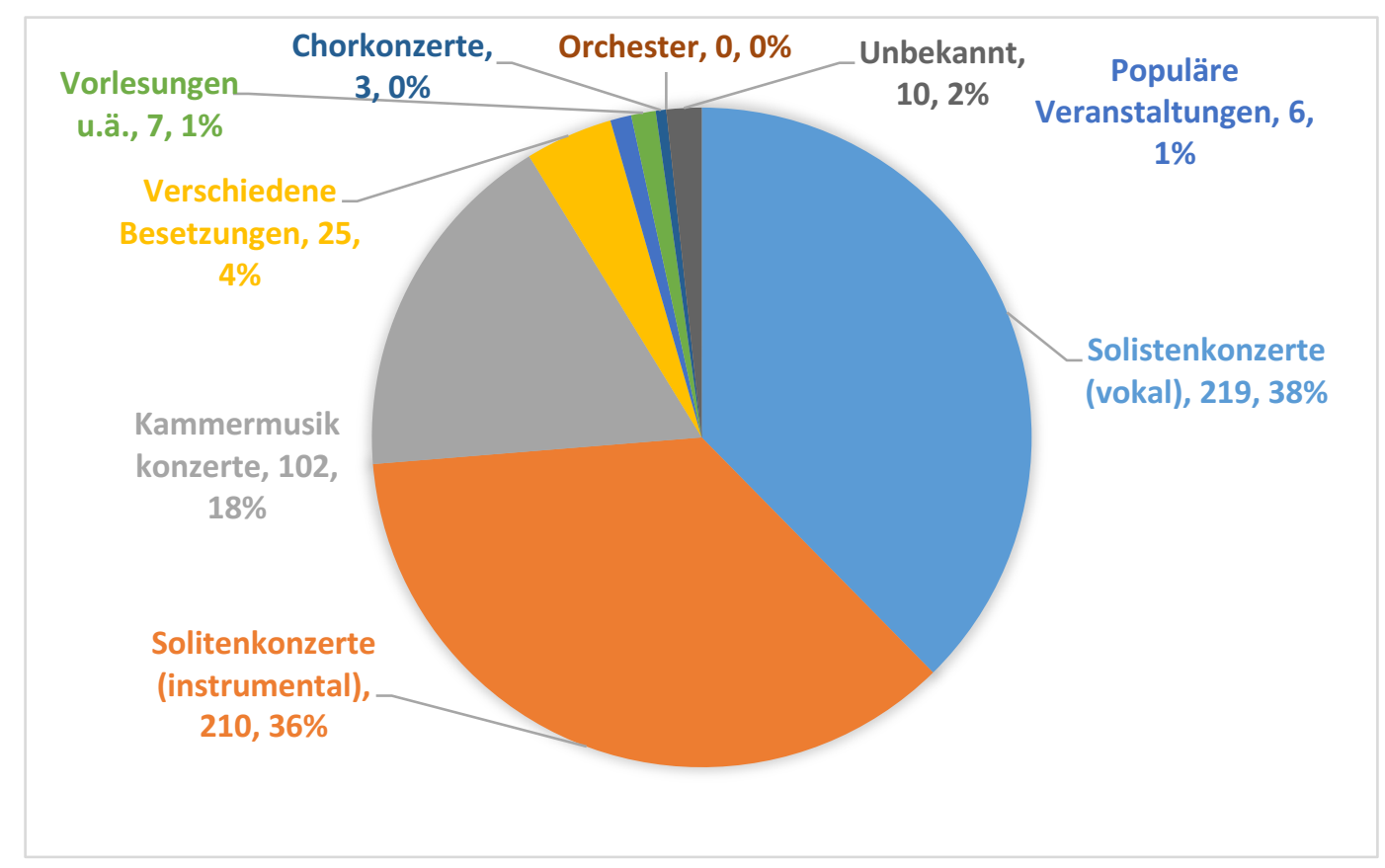

Diagramm 14: Konzerte im Bechstein-Saal zwischen 1901/02 und 1904/05 (582 Konzerte)

\footnotetext{
${ }^{680}$ Neue Berliner Musikzeitung 47 (1893), S. 246.

${ }^{681}$ Allgemeine Musik-Zeitung 21 (1894), S. 200.

${ }^{682}$ Allgemeine Musik-Zeitung 22 (1895), S. 281f.

${ }^{683}$ Edith Stargardt-Wolff erinnert sich, dass der Philharmonische Chor unter Leitung von Siegfried Ochs seine Proben viele Jahre hindurch regelmäßig in diesem Saal abhielt. Stargardt-Wolff: Wegbereiter großer Musiker, S. 148.
} 
Wie oben ausgeführt, wurde der Bechstein-Saal von den berühmtesten Künstlern der Zeit feierlich eingeweiht. Dass Wolff aber damit gerechnet hatte, dass dieser Konzertsaal auch für Konzerte genutzt werden würde, die kein großes Publikum anzogen, lässt sich an einer anderen Stelle seines oben zitierten Briefs an Brahms nachweisen.

Es handelt sich mit diesem Saal um keine banale geschäftliche Sache. Ein Geschäft ist ausgeschlossen, wie hier die Verhältnisse liegen. Ich will dazu beitragen, das Musikleben Berlins zu verbessern $u$. dem ewigen Freibilletthum engere Grenzen zu ziehen, indem für nicht »sensationelle« Concerte ein würdiger kleinerer Saal vorhanden ist, der allen künstlerischen Ansprüchen genügt. ${ }^{684}$

Wie Wolff bzw. seine Konzertdirektion von diesem Konzertsaal profitierte, kann aufgrund der jetzigen Quellenlage nicht geklärt werden. Aber ich habe im Abschnitt 2.3.2 die Vermutung geäußert, dass das Arrangement der klein besetzten, auf Rechnung der Künstler stattfindenden Konzerte den größten Teil der gewöhnlichen Aufgabe dieser Konzertdirektion ausmachte. Und aus den überlieferten Quellen einschließlich des Concert-Verzeichnisses ergibt sich, dass solche Konzerte hauptsächlich im Bechstein-Saal abgehalten wurden.

Die hohe Auslastungsrate bestätigt, dass dieser Saal dem Bedürfnis der Musiker entsprach. Wie William Wolf im oben zitierten Artikel vorausgesehen hatte, wurde der Bechstein-Saal vor allem von Debütanten oder unerprobten Musikern gern genutzt, weil er leichter zu füllen und günstiger zu mieten war als die anderen großen Veranstaltungsorte in Berlin. Die Errichtung eines solchen Saals war eine vorausschauende Idee von Wolff, die sowohl den Interessen seines Geschäfts als auch dem Bedürfnis der Musiker zugute kam.

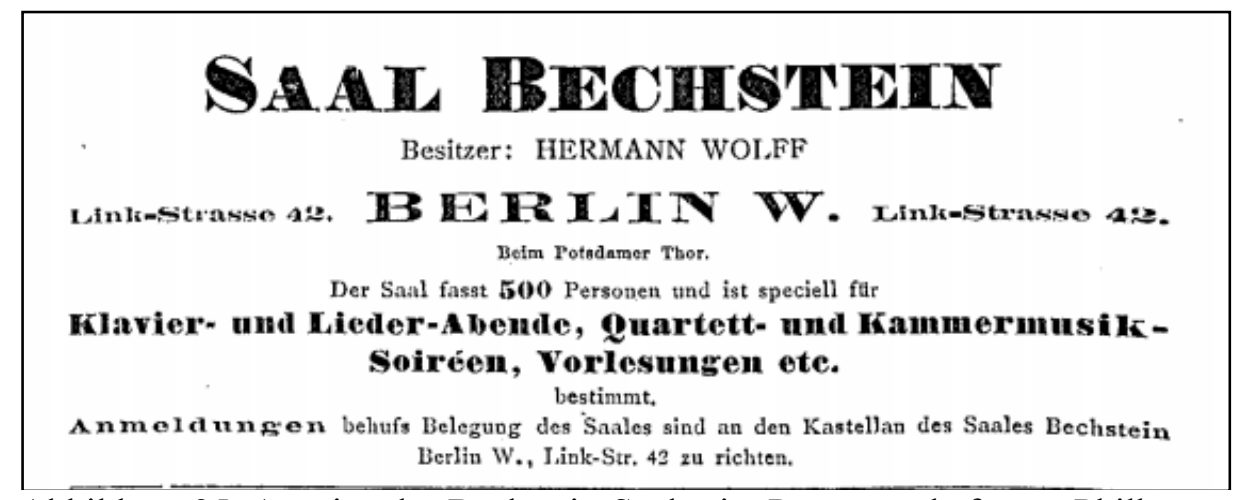

Abbildung 35: Anzeige des Bechstein-Saales im Programmheft zum Philharmonischen Konzert vom 10. Oktober 1898

${ }^{684}$ Brief von Hermann Wolff an Johannes Brahms vom 20.7.1892, A-Wgm, Brahms-Nachlass, 381, 7. 


\subsubsection{Hermann Wolff und Carl Bechstein}

Edith Stargardt-Wolff führt die Benennung dieses Saales auf die alte Verbundenheit Hermann Wolffs mit Carl Bechstein zurück. ${ }^{685}$ In der Tat verband die beiden eine langjährige Freundschaft im beruflichen sowie im privaten Leben. ${ }^{686}$ Der Darstellung von StargardtWolff zufolge beauftragte Bechstein 1892, im Jahr der Eröffnung des Bechstein-Saales, den Konzertagenten, die Eingangsworte für einen neu herauszugebenden illustrierten Katalog der Firma zu verfassen. ${ }^{677}$ Wie Hagen W. Lippe-Weißenfeld nachweist, wirkte Wolff durch seine Freundschaft mit Carl Bechstein einerseits und seinen beruflichen Kontakt zu allen bekannten Musikern der damaligen Zeit andererseits als »Multiplikator« für die Instrumente der Firma Bechstein. ${ }^{688}$ In einigen Arbeiten über Bechstein wurde auch vermutet, dass Wolff die Pianofabrik Bechsteins finanziell unterstützt hat. ${ }^{689}$

Im Bechstein-Saal wurden nur Bechsteinflügel benutzt. ${ }^{690}$ Der Saal muss sicherlich als Werbung der gleichnamigen Klavierfirma eine große Rolle gespielt haben. Welchen Vorteil hatte nun Wolff, dass er seinen Konzertsaal mit dem Namen eines anderen versah? Die Benennung nach der renommierten Klavierfirma war vermutlich günstiger als die nach seinem eigenen Namen, weil sich sein Konzertsaal dadurch in die Tradition der bekannten Konzertsäle der Klavierfirmen wie den Bösendorfer-Konzertsaal in Wien und die Salles Érard und Pleyel in Paris einreihte. Aus dem folgenden Brief von Eugen d'Albert an Hermann Wolff vom 30. Juli 1895 geht aber auch hervor, dass Wolff seine werbekräftige Wirkung von Bechstein vergütet wurde.

Nun spiele ich seit zwölf Jahren Bechstein u. kann wol ohne Unbescheidenheit sagen, daß ich jetzt der bedeutendste Pianist bin, der für ihn Reclame macht. Daß dies bisher

\footnotetext{
${ }^{685}$ Stargardt-Wolff, Wegbereiter großer Musiker, S. 145.

${ }^{686}$ Ebd., S. 103. Zum siebzigsten Geburtsjahr Carl Bechsteins im Jahr 1896 wurde ihm u. a. ein Album mit Liedern von Franz Schubert als Überraschung überreicht, das genau nach dem Muster der Edition Peters mit hellgrünem Umschlag versehen war. Über die humorvollen Texte, die Wolff zu diesem Anlass für Bechstein zu den bekannten Melodien schrieb, vgl. Bernd Rühle: Carl Bechstein (1826-1900). Über Leben und Lebenswerk eines großen Klavierbauers und seine Spuren in Erkner, Erkner 2001, S. 12f.

${ }^{687}$ Stargardt-Wolff: Wegbereiter großer Musiker, S. 103.

${ }^{688}$ Hagen W. Lippe-Weißenfeld: Das Klavier als Mittel politischer Distinktion im Zusammenhang mit der Entwicklung des Klavierbaus in London und Berlin an den Beispielen Broadwood und Bechstein, Ph. D. Freie Universität Berlin 2006, S. 124f.

${ }^{689}$ Richard Krogmann: Der Klavierbauer Carl Bechstein und sein privates Umfeld, Hamburg 2001, S. 9; Hagen W. Lippe-Weißenfeld: Das Klavier als Mittel politischer Distinktion im Zusammenhang mit der Entwicklung des Klavierbaus in London und Berlin an den Beispielen Broadwood und Bechstein, S. 179 und 194; Gunna Wendt, Die Bechsteins. Eine Familiengeschichte, Berlin 2016, S. 96.

${ }^{690}$ Allgemeine Musik-Zeitung 21 (1894), S. 200.
} 
stets meinerseits in uneigennütziger Weise geschah, ist mir nur lieb, trotzdem die Herren Blüthner, Steinway u. s. w. wie auch das Publikum fest glauben, ich sei dafür ordentlich bezahlt $u$. trotzdem mir seit Jahren u. von den verschiedensten Seiten, darunter von Personen, welche es genau wissen müssen, versichert wird, Sie erhalten von B[echstein] 12,000 Mk jährlich dafür: daß Sie seine Instrumente loben u. Ihren Kunden zu Benutzung derselben anrathen. ${ }^{691}$

Es ist interessant, dass der Konzertagent so großzügig bezahlt wurde, während der Pianist, der seit seinem sensationellen Erfolg im Jahr $1883^{692}$ Instrumente dieser Firma benutzt und, wie er selbst schrieb, ihren Namen verbreitet hatte, nie eine Vergütung erhielt. Dies bedeutet, dass die Empfehlung dieses Konzertagenten im damaligen Berliner Musikleben große Wirkung hatte.

Der enorme Einfluss des Konzertagenten, als dessen Verkörperung jetzt ein Konzertsaal entstanden war, wurde in den 1890er-Jahren nicht selten Gegenstand der Kritik oder Satire. Ironischerweise erschienen die schärfsten Kritiken gegen den Bechstein-Saal in der Neuen Berliner Musikzeitung, als deren Redakteur Hermann Wolff bis 1880 gearbeitet hatte ${ }^{693}$ und, die, wie oben gezeigt wurde, die Eröffnung des Saales willkommen geheißen hatte. Seitdem August Ludwig am 1. Januar 1894 Redakteur dieser Zeitschrift geworden war, nahm sie eine auffällig feindselige Haltung gegen Wolff und seine Konzertdirektion ein.

Merkwürdiger Weise aber hat, zum Unterschied von den genannten Sälen, den »Bechstein-Saal« die Firma Bechstein selbst gar nicht erbaut, sondern der Konzertagent. Da dieser sich aber genirte, den Saal nach seinem (wie er wohl weiss) verhassten Namen (etwa »Wolffsaal« oder »Wolffsschlucht«) zu benennen, borgte er sich dafür den der Firma Bechstein, welche im Uebrigen jeden weiteren Zusammenhang mit diesem Saalunternehmen leugnet. Es ist recht bezeichnend für den niedrigen Stand des Berliner Konzertlebens, dass ein Agent, der sich nicht einmal

\footnotetext{
${ }^{691}$ Brief von Eugen d'Albert an Hermann Wolff vom 30.7.1895, Sächsische Landesbibliothek - Staats- und Universitätsbibliothek Dresden (SLUB), Mscr.Dresd.App.2824, 236. Hervorhebungen im Original.

${ }^{692}$ Für den Januar 1883 organisierte Hermann Wolff für d'Albert zwei Solokonzerte in Berlin, zudem lud ihn zum Abonnementkonzert des Berliner Philharmonischen Orchesters vom 22.1.1883 als Ersatz für die erkrankte Solistin Anna Nikolaevna Esipova ein, was diesen unbekannten jungen Musiker plötzlich bekannt machte. Die guten Kritiken zum sensationellen Konzert vom 10. Januar 1883 in der Singakademie veröffentlichte Wolff in einer Broschüre von 26 Seiten, in der wiederholt wurde, dass der Pianist ein Bechstein-Klavier benutzte. Vgl.: Hermann Wolff, Eugen d'Albert, Berlin o. J. [1883]

${ }^{693}$ Zur Tätigkeit von Hermann Wolff für die Neue Berliner Musikzeitung, vgl. 2.1.1 der vorliegenden Arbeit.
} 
getraut, seine Unternehmungen nach seinem Namen zu nennen, sondern dafür Namensanleihen bei Anderen macht, derjenige ist, von dem die Künstler vollständig abhängig zu sein vorgeben! - Der Bechsteinsaal ist vollsten Sinne des Wortes »monopolisirt $\ll .694$

Carl Bechstein starb 1900 und Hermann Wolff 1902. ${ }^{695}$ Obwohl der Name des Saales unverändert blieb, wurde die kooperative, freundschaftliche Beziehung der beiden Häuser nicht aufrechterhalten. In einem undatierten, nur als Teil aufbewahrten Briefentwurf erwähnt Louise Wolff den Saal und die Nachfolge Carl Bechsteins wie folgt:

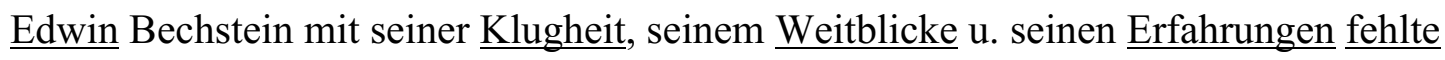
eben - nur Unfähigkeit u. falsche Eitelkeit regierte - die ältesten u. treuesten Freunde Ihres Hauses wurden boycottiert, ignoriert u. zwar ging der Hass der Direktion des Hauses gegen uns so weit, daß in der Reclameschrift nicht einmal der Saal Bechstein figurierte, der doch als Zeichen unserer Freundschaft, u. als große Reclame für Bechstein gedacht u. gebaut war[.] Wir haben uns nicht gerächt, sondern den Namen dieses Saales treu erhalten, der [als] ein Denkmal der Freundschaft zwischen Bechstein u. Wolff in der Geschichte Berlins u. der Kunst überhaupt bestehen bleiben soll. ${ }^{696}$

Wie bekannt, waren Edwin Bechstein und seine Frau Helene schon vor dem Hitlerputsch mit dem zukünftigen Reichskanzler freundschaftlich verbunden und unterstützten ihn auch finanziell. ${ }^{697}$ Wie sich die Beziehung der beiden Häuser in den 1920er-Jahren entwickelte, kann aufgrund der jetzigen Quellenlage nicht erklärt werden. ${ }^{698}$ Im Konzert-Kalender der Konzertdirektion Hermann Wolff und Jules Sachs ist die Werbung der Klavierfabrik Bechstein bis zur Saison 1928/29 zu sehen.

${ }^{694}$ Aug[ust] Ludwig, Der Konzertagent, in Neue Berliner Musikzeitung 48 (1894), S. 14. Vgl. auch: N. N. [ders.?], Bechsteinsaalisches, in Neue Berliner Musikzeitung 50 (1896), S. 25f.

${ }^{695}$ Im Oktober 1902 wurde eine Büste Hermann Wolffs von dem belgischen Bildhauer Charles Samuel, dem Mann der Pianistin Clotilde Kleeberg, im Foyer des Saales aufgestellt. Le guide musical 48 (1902), S. 752.

${ }^{696}$ Briefentwurf von Louise Wolff, o. D., Wolff-Nachlass: ID 238.

${ }^{697}$ Vgl. z. B., Wendt: Die Bechsteins, S. 229f.

${ }^{698}$ Edith Stargardt-Wolff berichtet nur von einem »skandalöses Benehmen« von Edwin Bechstein in ihrem Erinnerungsbuch: Stagardt-Wolff: Wegbereiter großer Musiker, S. $202 \mathrm{f}$. 
Was brachte dieser Saal dem damaligen Berliner Musikleben, als er im Jahr 1892 erbaut wurde? Es ist zu vermuten, dass er es jungen und / oder unerprobten Musikern erleichterte, auf eigene Rechnung Konzerte abzuhalten, und dadurch die Schicht derer erweiterte, die als Musiker ein öffentliches Auftreten in der Reichshauptstadt wagten.

Auf die Errichtung des Bechstein-Saales folgte in Berlin eine Reihe von für die Musikaufführung bestimmten Stätten, darunter auch einige kleinere Säle, die ein Publikum von weniger als 500 Leuten fassten. Im Konzert-Kalender für die Saison 1930/31 der Konzertdirektion Hermann Wolff und Jules Sachs sind als »Berliner-Konzertsäle« die folgenden Musikstätten aufgelistet:

\begin{tabular}{|l|l|}
\hline Saal & Plätze \\
\hline Philharmonie & 2110 Saalplätze \\
\hline Marmor-Saal & 1600 Saalplätze \\
\hline Oberlichtsaal der Philharmonie & 720 Saalplätze \\
\hline Beethoven-Saal & 1036 Saalplätze und Podiumplätze \\
\hline Bach-Saal & 1153 Saalplätze und Podiumplätze \\
\hline Sing-Akademie & 988 Saalplätze, 310 Podiumplätze \\
\hline Konzertsaal, Hochschule & 1023 Saalplätze und Podiumplätze \\
\hline Bechstein-Saal & 504 Saalplätze \\
\hline Meister-Saal & 358 Saalplätze \\
\hline Künstlerhaus & 440 Saalplätze \\
\hline Feurich-Saal & 326 Saal plätze \\
\hline Breitkopf-Saal & 191 Saalplätze \\
\hline Schwechten-Saal & 495 Saalplätze \\
\hline
\end{tabular}

Tabelle 13: »Berliner-Konzertsäle« aufgelistet im Konzert-Kalender 35 (1930/31) ${ }^{699}$

Ab 1908 gehörten auch zwei große Konzertsäle zum Klindworth-ScharwenkaKonservatorium in der Genthiner Straße 11 in Berlin-Tiergarten: der KlindworthScharwenka-Saal und der nach einer bekannten Klavierfirma genannte Blüthner-Saal.

Dass der Bechstein-Saal auch nach dem Tod Hermann Wolffs für Konzerte in kleiner Besetzung weiter rege genutzt wurde, geht aus verschiedenen Konzertanzeigen hervor. Aber Berlin hatte im 20. Jahrhundert verschiedene Alternativen, wie die Tabelle 13 zeigt.

${ }^{699}$ Konzert-Kalender 35(1930/1931), hg. von Konzertdirektion Hermann Wolff und Jules Sachs, Berlin [1930], S. 80. 
Im Frühjahr 1941 richtete die Deutsche Reichspost im Bechstein-Saal das erste Fernsehtheater ein, das ausschließlich für die Öffentlichkeit bestimmt war. ${ }^{700}$ Das Gebäude wurde durch den Luftangriff in der Nacht von 22. November 1944 völlig zerstört. ${ }^{701}$

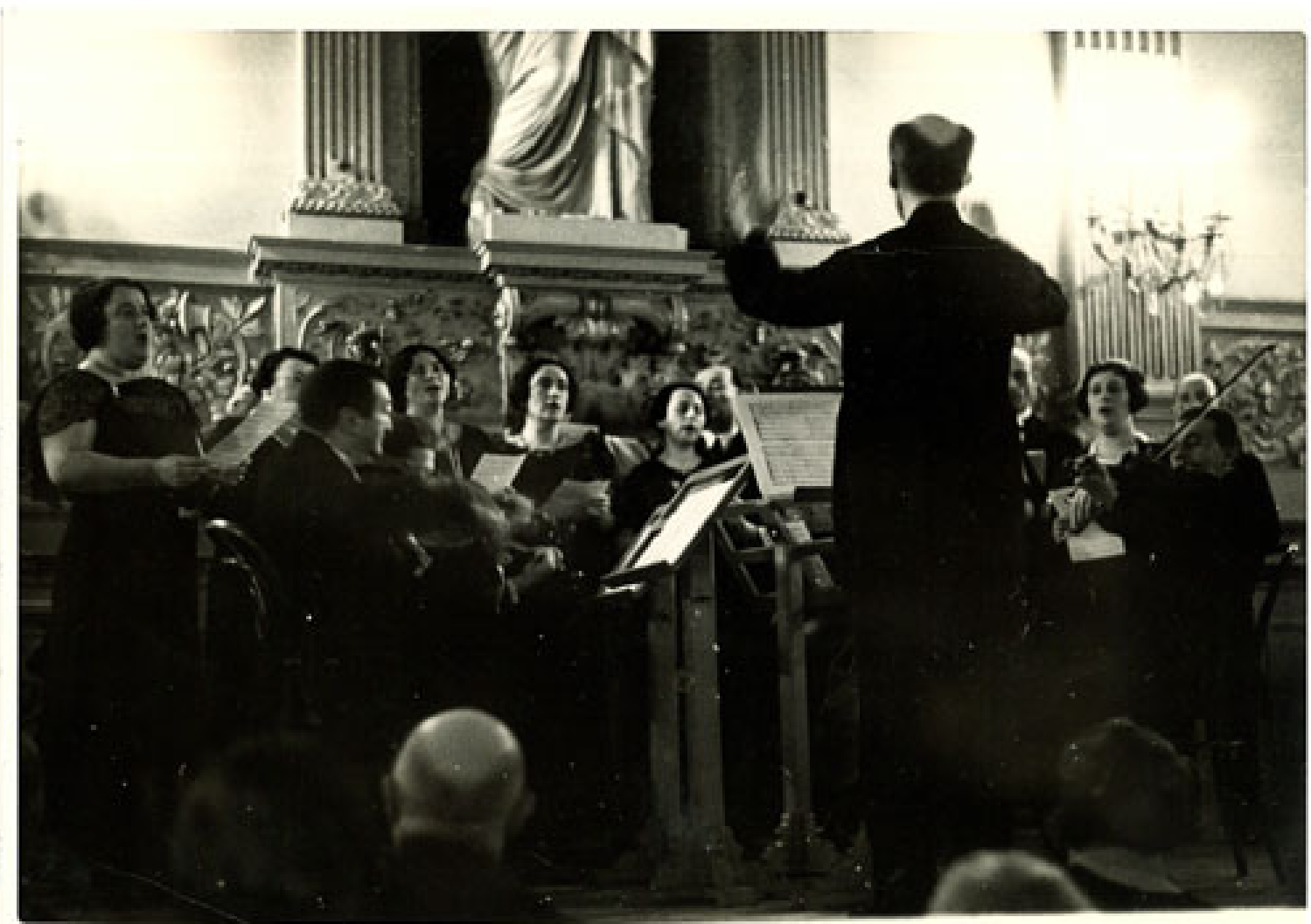

Abbildung 36: Ludwig Misch leitet die Jüdische Madrigalvereinigung im Bechstein-Saal, Dezember $1934^{702}$

\footnotetext{
${ }^{700}$ Hoch- und Tiefbau: H und T; schweizer. Baumeister- u. Zimmermeister-Zeitung 40 (1941), S. 329.

${ }^{701}$ Entschädigungsakte (Edith Stargardt), EBB, Reg. Nr. 22238, B1. D28r; D29v.

${ }^{702}$ LBI-Archives, keine Signatur.
} 


\section{Schlussbetrachtung}

In der vorliegenden Arbeit wurde die Tätigkeit und der Wirkungskreis der Konzertdirektion Hermann Wolff (und Jules Sachs) (Kapitel 2) umrissen und der Frage konkreter nachgegangen, welche Impulse ihr Gründer Hermann Wolff dem Berliner Musikleben im Zeitraum zwischen der Gründung seiner Konzertdirektion 1880 und seinem Tod 1902 gegeben hat (Kapitel 3). Aufgrund dieser Betrachtungen möchte ich hier zur Signifikanz Hermann Wolffs zwei Schlüsse vorlegen. 1: Der Einfluss seiner Tätigkeit auf das Berliner Musikleben zeigt sich nicht nur in der Quantität der stattgefundenen Konzerte, sondern auch in ihrer künstlerischen Qualität sowie in ihrem Inhalt. 2: Er verdient es vor allem deshalb, als eine wichtige Triebkraft der Entwicklung Berlins als Musikstadt zu seiner Zeit betrachtet zu werden, weil er durch die Auswahl der Dirigenten und durch die Veranlassung der Aufnahme von Neukompositionen ins Programm die Ausrichtung der Abonnementkonzerte des Berliner Philharmonischen Orchesters in maßgeblicher Weise prägte. Hervorzuheben ist auch, dass er durch die Gründung des Bechstein-Saales und die dadurch bedingte Erleichterung der Organisation eigener Konzerten vielen Musikern ein öffentliches Auftreten in Berlin ermöglichte, und dass er verschiedene Akteure des Musiklebens inner- und außerhalb Berlins in Verbindung brachte und zusammen wirken ließ.

Um die Frage zu beantworten, ob er die ästhetische Norm der Konzertkultur, die Erwartung, den Geschmack oder die Verhaltungsnorm des Publikums beeinflusste, braucht man nähere Betrachtungen zum Kommunikationsprozess zwischen Produzenten und Rezipienten im damaligen Konzertleben, die ich mir zu einer zukünftigen Aufgabe machen möchte. Man kann jedoch mit Sicherheit sagen, dass er durch seine Tätigkeit große Autorität erwarb, wie sie seine Vorgänger nie gehabt hatten, und dass er dadurch die Einflussmöglichkeit von Konzertagenten erweiterte. Zu dieser Wirkungskraft Hermann Wolffs schrieb August Ludwig im Jahr 1894:

Konzertagent ist eigentlich ein nur ein fest ansässiger Sekretär, welcher nicht mehr mit dem Künstler reist, sondern von seinem Büreau aus die Reise- und KonzertAngelegenheiten eines oder mehrerer Künstler regelt. [...] Wenn daher seine [Hermann Wolffs, A. d. V.] Agentur sich darauf beschränken würde, wäre dieses Institut ein höchst segensreiches zu nennen. Aber schon durch den Namen » Konzertdirektion « tritt die Agentur ganz und gar aus dem ihr gebührenden Rahmen 
heraus. Der Name »Konzertdirektion« sagt nämlich (halb unbeabsichtigt!) ganz richtig » Ich dirigire die Konzerte ${ }^{703}$

Während sich seine Autorität festigte, wurden die Missstände, die als Folge der Erweiterung des Einflusses von Konzertagenten entstanden seien, in den 1890er-Jahren immer lauter und öfter beklagt. Am häufigsten bemängelt wurde die Überflutung Berlins mit Konzerten. Carl Flesch, der in der Saison 1896/1897 unter Hermann Wolffs Ägide in Berlin im Bechstein-Saal debütierte, sah den Grund für dieses Phänomen eher im Übereifer von Konzertagenten, die unerfahrene Künstler sozusagen ausbeuten wollen, als in gesteigertem Bestreben von Musikern, sich in der Reichshauptstadt hören zu lassen:

At that time, when there were never more than two nightly concerts on the average, Wolff had no suspicions that fifteen years later there would be occasions when as many as fourteen musical functions would be given at the same hour. This morbid efflorescence of a principle logical in itself was only partly due to the artists' natural exertions to get a hearing and favourable reviews in the German capital in order to find paying engagements in the provinces - and thus first of all to cover the deficit inevitably incurred in Berlin. The unhealthy over-cultivation of the capital's concert life was, above all, the result of unfounded and unrealistic promises on the part of the agents, who prompted the inexperienced beginner to waste his or other people's money on independent concerts. ${ }^{704}$

Nach Heinrich Ehrlich, der die Konzertagenten als »ein Produkt der Zeit « ${ }^{705}$ betrachtet, erwiesen sie sich im Laufe der Zeit einerseits als Einrichtungen, die dem bedeutenden Künstler, besonders dem nicht ansässigen reisenden Virtuosen, viele Annehmlichkeiten und sogar Nutzen bringen konnten. Andererseits führten sie Verhältnisse herbei, die dem Kunstleben tiefen Schaden zufügten. ${ }^{706}$ Ehrlich zufolge wurden in Berlin dreißig Jahre zuvor während eines ganzen Jahres genauso viele (75-80) Konzerte gegeben wie in sechs Wochen

\footnotetext{
${ }^{703}$ Aug[ust] Ludwig: Der Konzertagent, in Neue Berliner Musikzeitung 48 (1894), S. 27. Hervorhebung im Original. Es sei jedoch zu bemerken, dass Hermann Wolff nicht der einzige Konzertagent war, der die eigene Firma »Konzertdirektion« nannte. Als Beispiel zu nennen ist die 1881 entstandene Konzertdirektion Jules Sachs, mit der sich die Konzertdirektion Hermann Wolff 1916 fusionieren sollte.

${ }^{704}$ Flesch: The Memoirs of Carl Flesch, S. 133f.

${ }^{705}$ Ehrlich: Modernes Konzertleben, S. 8.

${ }^{706}$ Ebd., S. 17.
} 
des Jahres 1895, dem Jahr, in dem sein Buch erschien. ${ }^{707}$ Er äußert genau die gleiche Ansicht wie Flesch, nämlich, dass dieses Konzertübermaß den Konzertagenten zuzuschreiben sei: Der fremde Musiker, die in der Hauptstadt ein Konzert geben wolle, brauche sich dort nicht mehr für Vorbereitungen wochenlang aufzuhalten. Er könne einfach den Konzertagenten mit der Organisation beauftragen und einen Tag vor dem Konzert eintreffen. Dieser Umstand habe zur Folge, dass eine ganze Menge Leute, die früher nie gewagt hätten, auf die heißen Bretter des Konzertsaales zu steigen, nun »verleitet« würden, das Wagnis zu unternehmen. ${ }^{708}$ Es handele sich dabei nicht darum, irgendwelche Einnahmen zu erzielen. Die Musiker hätten nur das Ziel, in den Zeitungen genannt zu werden, gedrucktes Lob bekommen, sodass sie dann in der Provinz in bezahlten Konzerten auftreten und hoffentlich die in der Hauptstadt investierte Summe nach und nach hereinholen könnten.

Die Eitelkeit ist ein so starker Impuls, daß selbst Mißerfolge manche Konzertgeber nicht abhalten, sich wieder an die Öffentlichkeit zu wagen, besonders wenn sie genug Geld besitzen, um die Unkosten ohne besondere Schmerzen ertragen zu können. »Die Konzertinfluenza« [...] dauert fort, und wird durch die Konzertagenturen verstärkt. Denn diese erleiden ja niemals Schaden, sichern sich ihre Prozente oder feste Summe, auch wenn das Konzert nur ein Defizit bringt. ${ }^{709}$

Im Abschnitt 3.3.3 habe ich vermutet, dass der von Hermann Wolff 1892 gegründete Bechstein-Saal es jungen und / oder unerprobten Musikern erleichterte, auf eigene Rechnung Konzerte abzuhalten, und sich dadurch die Schicht derer erweiterte, die als Musiker ein öffentliches Auftreten in der Reichshauptstadt wagten. Das trifft sicherlich auch auf das Konzertarrangement von Konzertagenten zu. Jeder, der die Geldmittel aufbringen konnte, konnte durch den Beistand des bestellten Konzertagenten öffentlich auftreten.

Angesichts der Überflutung Berlins mit Konzerten, und zwar mit solchen, in denen sich lediglich mittelmäßige Musiker aus der Provinz oder unerfahrene hören ließen, wurden wiederholte Klagen gegen die Konzertagenten laut, ${ }^{710}$ die sich in der Forderung zuspitzten, die Konzertagenten möchten nicht jedem behilflich sein, der die Absicht habe, eines oder mehrere Konzerte zu geben, sondern die allgemeinen künstlerischen Interessen

\footnotetext{
707 Ebd., S. 92.

${ }^{708}$ Ebd., S. 18.

${ }^{709}$ Ebd. Zum Phänomen »Konzertinfluenza«, vgl. auch S. 98.

${ }^{710}$ Vgl. z. B. Zabel: Konzerte und Konzertunternehmer, S. $285 \mathrm{f}$.
} 
berücksichtigen. Gegen einen dieser Vorwürfe verteidigte sich Hermann Wolff 1900 in der Vossischen Zeitung:

Gestatten Sie mir zu erwidern, daß nach meiner Ansicht die Rechte und Pflichten des Konzertagenten verkannt werden. Was thut der Agent, um einem Debütanten das Auftreten zu erleichtern? Für eine vereinbarte Vergütung besorgt der Agent demjenigen, der ein Konzert zu geben wünscht und einen Ausweis darüber bringt, daß er den Zeitungen die Annoncen, dem Saalbesitzer die Saalmiethe, der Buchdruckerei den Programm- und Billetdruck u. s. w. bezahlen kann und wird, Annoncen, Saal und Drucksachen. Er theilt außerdem den Zeitungen mit, was der Auftretende verspricht. Damit ist vorläufig die Tätigkeit des Agenten beendet. Die Nothwendigkeit, die Zeit, hat die Konzertbüreaus hervorgerufen, an die sich der Konzertgeber zur Besorgung rein technischer Dinge wendet, um sich nicht wie früher selbst um alle Lappalien kümmern zu müssen. Giebt man zu, daß für die Künstler ein solches Büreau eine Wohlthat ist - und mich haben meine verstorbenen Freunde Rubinstein und Bülow zur Begründung eines solchen Institutes veranlaßt - so wird man auch zugeben müssen, daß ich nicht nur für die bekannten Künstler da sein darf, sondern gerade den Unerfahrenen zur Hand zu sein die Verpflichtung habe. Darüber zu urtheilen und zu entscheiden, ob der Konzertgeber den Ansprüchen der Kritik und des Publikums genügen wird[,] dazu habe ich kein Recht. Es wäre eine Anmaßung, welche die unheilvollsten Folgen für die junge Kunstwelt haben könnte, wollte ich bestimmen, wer ein Konzert geben soll oder nicht. Ich habe geradezu die Pflicht, mich eines subjektiven Urtheiles zu enthalten; nur durch diese Enthaltung kann eine gerechte und natürliche Entwicklung des Konzertlebens gefördert werden. Ja wenn ich in den philharmonischen Konzerten einen minderwerthigen Künstler auftreten lassen würde, wenn ich auf diese Weise all und jedem das Auftreten erleichtere, dann würde ich allerdings die künstlerische Rücksicht mit der geschäftlichen nicht eng genug verbunden haben. Aber demjenigen[,] der zeigen will, was er gelernt hat oder nicht, der an sich selbst glaubt oder von seinem Lehrer zu diesem Glauben veranlaßt wird und daraufhin auf seine Kosten und Gefahr den Versuch machen will, ob er vor der Oeffentlichkeit bestehen kann, warum soll der Konzertagent dem verweigern, Saal, Annoncen und Drucksachen zu besorgen? Man glaube doch nicht, daß eine junge Kraft, die ein Privatlehrer oder ein Konservatorium ausgebrütet hat und die zu mir kommt, um öffentliche Auftreten abhalten ließe. Der Grund des Uebels ist an ganz 
anderer Stelle zu suchen; er liegt lediglich in der auch auf diesem Gebiete durch den Kampf ums Dasein entstandenen Ueberproduktion. ${ }^{711}$

Diese Äußerung ist mehr als eine reine Selbstverteidigung eines Konzertagenten, da sie die damaligen Verhältnisse um die Laufbahn und die Tätigkeit von Musikern widerspiegelt. Hier erklärt Wolff, dass er für die künstlerische Qualität der Philharmonischen Konzerte, also der Konzerte, die auf seine eigene Rechnung stattfinden, verantwortlich sei, während er sich nicht davor scheue, Konzerte, die Konzertgeber jegliches Niveaus auf eigene Rechnung veranstalten, zu organisieren. Ihm zufolge liege der Grund des Konzertübermaßes nicht an der Tätigkeit seiner Berufsgenossen, sondern an der Überproduktion an Musikern in der Gesellschaft.

Wie ich im Abschnitt 2.3.2 ausgeführt habe, machte das Arrangement von klein besetzten, auf Rechnung der Künstler stattfindenden Konzerte den größten Teil der gewöhnlichen Veranstaltungen seiner Konzertdirektion aus. Die Ansicht scheint plausibel zu sein, dass Wolff die Bedürfnisse seiner Klienten, und zwar der Musiker, gut kannte, und er genau das bieten konnte, was sie wollten. Und zwar waren das: ein Konzertsaal, der leicht zu füllen und für Konzerte in kleiner Besetzung geeignet war (vgl. 3.3.3), ein System, mit dem man eigene Konzerte in der Reichshauptstadt leicht veranstalten konnte (vgl. 2.3.2), und ein tüchtiges Orchester, das Solisten in ihren Konzerten unterstützen konnte (vgl. 3.1.1). Ein Großteil des Erfolgs von Wolff beruht meiner Ansicht nach auf diesen für ihre Bedürfnisse maßgeschneiderten Angeboten an die Musiker seiner Zeit.

Die vorliegende Arbeit konnte die Tätigkeit der Konzertdirektion Hermann Wolff (und Jules Sachs) in der Zeit nach dem Tod des Gründers nicht mehr berücksichtigen. Auch dies möchte ich als zukünftiges Forschungsvorhaben im Auge behalten. Es ist zu vermuten, dass sie sich in der großen Veränderung der sozialen, wirtschaftlichen und politischen Verhältnisse und im viel größeren Musikmarkt in einem anderen Spannungsfeld des Musiklebens befand als zu Hermann Wolffs Lebzeiten, und dass sie in anderer Weise mit ihren Geschäftspartnern verbunden war.

Wie man sich nach der alten Zeit zurücksehnen konnte, bringt Siegfried Ochs in seinem 1922 erschienenen Erinnerungsbuch im Rückblick auf den seit 20 Jahren verstorbenen Konzertagenten zum Ausdruck:

\footnotetext{
${ }^{711}$ Zuschrift von Hermann Wolff an die Vossische Zeitung, zit. in Allgemeine Musik-Zeitung 27 (1900), S. 338 .
} 
Wann kommt ein Hermann Wolff wieder, ein Mann, der nicht in kleinlicher Knickerei nach dem Kassenbericht von heute handelt, sondern kunstverständig, weitblickend und großzügig, der es versteht und nicht zu geizig ist, der »melkenden Kuh, die ihn Butter versorgt«, frische Kräfte zuzuführen! Muse, nenne den Mann mir! und er soll sich über Geringschätzung nicht zu beklagen haben. ${ }^{712}$

Hermann Wolff war ein Produkt der Zeit, in der die Infrastruktur des modernen Musiklebens der deutschen Reichshauptstadt gebildet wurde. Die historische Untersuchung dieses Konzertagenten als Institution, die die Interessen der verschiedenen Akteure des Musiklebens vertrat und ausglich, die Voraussetzungen für die musikalischen Aufführungen schuf, und sowohl reproduzierenden als auch komponierenden Künstlern ein Podium zur Verfügung stellte, ist deshalb ein höchst aufschlussreicher Beitrag zur Forschung über den Aufschwung Berlins als Musikstadt von Weltrang.

712 Ochs: Geschehenes, Gesehenes, S. 391. 


\section{Literaturverzeichnis}

d'Albert, Wilhelm: Die Verwertung des musikalischen Aufführungsrechts in Deutschland, Jena 1907

Altmann, Wilhelm: Chronik des Berliner Philharmonischen Orchesters (1882-1901).

Zugleich ein Beitrag zur Beurteilung Hans von Bülows, Berlin u. a. 1902

Aster, Mischa: »Das Reichsorchester«. Die Berliner Philharmoniker und der

Nationalsozialismus, München 2007

Astruc, Gabriel: Meine Skandale. Strauss, Debussy, Stravinsky, Berlin 2015

Bagenal, Hope: The Leipzig Tradition in Concert Hall Design, in Journal of the Royal Insitute of British Architects 36 (1929), S. 756-63

Barnum, P[hineas] T[aylor]: The Life of P. T. Barnum, Written by Himself, New York 1855

Bashford, Christina: Not Just »G.«: Towards a History of the Programme Note, in George Grove. Music and Victorian Culture, hg. von Michael Musgrave, London 2003, S. $115-142$

Bashford, Christina: The Pursuit of High Culture. John Ella and Chamber Music in Victorian London, Woodbridge 2007

Bekker, Paul: Das deutsche Musikleben, Stuttgart u. a. 1922

Borchard, Beatrix: Stimme und Geige. Amalie und Joseph Joachim: Biographie und Interpretationsgeschichte, Wien u. a. 2005 (Wiener Veröffentlichungen zur Musikgeschichte, Bd. 3)

Briefe von und an Joseph Joachim, 3 Bde., hg. von Johannes Joachim und Andreas Moser, Berlin 1911-1913

Briefwechsel zwischen Franz Liszt und Hans von Bülow, hg. von La Mara, Leipzig 1898

Bülow, Hans von: Briefe und Schriften, 8 Bde., hg. von Marie Bülow, Leipzig 1895-1908

Bülow, Hans von: Neue Briefe, hg. von Richard DuMoulin Eckart, München 1927

Cahn-Speyer, Rudolf: Der Konzertagent und Gesetzgebung, in Melos 2 (1921), S. 161-164

Calvocoressi, Michel-Dimitri: A propos de Concerts Historiques. D'Antoine Rubinstein à Ricardo Vines, in Revue Musicale de Lyon 2 (1905), S. 325-327

Clive, Peter: Brahms and His World. A Biographical Dictionary, Lanham 2006

Corbière, Laetitia: Le Concert et la Tournée. Perspectives sur la Direction de Concerts Albert Gutmann, in Artl@s Bulletin 4 (2015), S. 26-38 
Cosima Wagner - Richard Strauss. Ein Briefwechsel, hg. von Franz Trenner unter Mitarbeit von Gabriele Strauss, Tutzing 1978 (Veröffentlichungen der Richard-StraussGesellschaft München, Bd. 2)

Cui, César: Les Concerts historiques d'Antoine Rubinsten ( $2^{\mathrm{e}}$ partie), in Le Ménestrel. Musique et Théatres 52 (1886), Nr. 19 (11.4.1886), S 148f.

Dale, Catherine: The »Analyrical« Content of the Concert Programme Note Re-examined: Its Growth und Influence in Nineteenth-Century Britain, in Nineteenth-Century British Music Studies 2, hg. von Jeremy Dibble u. a., Aldershot 2002, S. 199-222

Die Gewandhauskonzerte zu Leipzig. 1781-1981, Bd. 2, hg. von Johannes Former, Leipzig 1981

Die »Konzert-Direktion Gutmann«, hg. von Andreas Holzer, Wien 1999 (Dokumente des Musiklebens: aus dem Archiv des Instituts für Musikgeschichte, Bd. 7)

Domingo, Plácido / Matheopoulos, Helena: My Operatic Roles, London 2000

Dümling, Albrecht: Musik hat ihren Wert. 100 Jahre musikalische Verwertungsgesellschaft in Deutschland, Regensburg 2003

Edler, Arnfried: Von Joachim zu Bronsart. Ästhetische Positionen zwischen 1850 und 1890 im Spiegel des hannoverschen Musiklebens, in Schubert und Brahms. Kunst und Gesellschaft im frühen und späten 19. Jahrhundert, hg. von Arnfried Edler, Augsburg 2001, S. 97-114 (Publikation der Hochschule für Musik und Theater Hannover, Bd. 11).

H. E. [Heinrich Ehrlich]: Richard Wagners Jugendsymphonie, in Berliner Tageblatt vom 1.11.1887, Morgen-Ausgabe, S. $2 \mathrm{f}$.

Ehrlich, Heinrich: Dreißig Jahre Künstlerleben, Berlin 1893

Ehrlich, Heinrich: Modernes Musikleben, Berlin 1895

Ermen, Reinhard: Musik als Einfall. Hans Pfitzners Position im ästhetischen Diskurs nach Wagner, Aachen 1986

Eshbach, Robert W.: The Joachim Quartet Concerts at the Berlin Singakademie: Mendelssohnian Geselligkeit in Whilhelmine Germany, in Brahms in the Home and the Concert Hall. Between Private and Public Performance, hg. von Katy Hamilton u. a., Cambridge 2004, S. 22-42.

Fauser, Annegret: Creating Madame Landowska, in Women and Music. A Journal of Gender and Culture 10 (2006), S. 1-23

Fifield, Christopher: Ibbs and Tillett: The Rise and Fall of a Musical Empire, Aldershot 2005

Flesch, Carl: The Memoirs of Carl Flesch, aus dem deutschen Manuskript übers. von Hans Keller und hg von demselben unter Mitarbeit von C. F. Flesch, London 1957 
Fornoff, Christine: Die Konzertagentur Wolff und ihre Bedeutung für Virtuosinnen im Berliner Musikleben des 19. Jahrhunderts, in Musikerinnen im Netzwerke im 19. Jahrhunderts, hg. von Annkatrin Babbe u. a., Oldenburg 2016 (Schriftenreihe des Sophie Drinker Institutes, Bd. 12), S. 41-67

Frowein-Ziroff, Vera: Die Kaiser Wilhelm-Gedächtniskirche: Entstehung und Bedeutung, Berlin 1982 (Bauwerke und Kunstdenkmäler in Berlin, Bd. 9)

Glatzer, Ruth: Das Wilhelminische Berlin. Panorama einer Metropole 1890-1918, Berlin 1997

Grotjahn, Rebecca: Die Sinfonie im deutschen Kulturgebiet 1850 bis 1875. Ein Beitrag zur Gattungs- und Institutionengeschichte, Sinzig 1998 (Musik und Musikanschauung im 19. Jahrhundert. Studien und Quellen, Bd. 7)

Grotjahn, Rebecca: Die Entdeckung der Terra incognita. Benjamin Bilse und sein reisendes Orchester, in Le musicien et ses voyages. Pratiques, réseaux et représentations, hg. von Christian Meyer, Berlin 2003, S. 253-281

Gutmann, Albert: Aus dem Wiener Musikleben. Künstlererinnerungen 1873-1908, Wien 1914

Hanslick, Eduard: Concerte, Componisten und Virtuosen der letzten fünfzehn Jahre 18701885. Kritiken, Berlin ${ }^{4} 1896$

Hatano, Sayuri: »Wohlgemuth ziehe zur Schweiz, lass’ tönen die herrliche Fidel«: Arrangement der Konzerttournee von der Konzertdirektion Hermann Wolff, in Jahresblätter für japanische und deutsche Forschung in Japan 6 (2013), S. 31-41

Hatano, Sayuri: Ein Paperchase. Auf der Suche nach dem Nachlass der Berliner Konzertagenten Hermann und Louise Wolff und ihrer Familie, in Archive zur Musikkultur nach 1945. Verzeichnis und Texte, hg. von Antje Kalcher und Dietmar Schenk, München 2016, S. 38-44

Hatano, Sayuri: Bechstein-Saal: A Lost Chamber Music Hall in Berlin, Journal of Musicological Research 36 (2017), S. 234-251

Heister, Hanns-Werner: Das Konzert. Theorie einer Kulturform, 2 Bde., Wilhelmshaven u. a. 1983

Hepokoski, James: Structure and Program in Macbeth: A Proposed Reading of Strauss's First Symphonic Poem, in Richard Strauss and His World, hg. von Bryan Gilliam, Princeton 1992, S. 67-89

Hinrichsen, Hans-Joachim: Musikalische Interpretation. Hans von Bülow, Stuttgart 1999 (Beihefte zum Archiv für Musikwissenschaft, Bd. 46) 
Hinrichsen, Hans-Joachim: Die Reisen der Meininger Hofkapelle und ihre Organisation durch die Agentur Hermann Wolff, in Le musicien et ses voyages. Pratiques, réseaux et représentations, hg. von Christian Meyer, Berlin 2003, S. 283-290

Hinrichsen, Hans-Joachim: Der Dirigent Hans von Bülow und das Berliner Musikleben 1887 bis 1892, in Organisateurs et formes d'organisation du concert en Europe 1700-1920, hg. von Hans Erich Bödeker u. a., Berlin 2008, S. 157-170

Hinrichsen, Hans-Joachim: Des Meisters Lehrjahre. Der junge Richard Strauss und seine Meininger Ausbildungszeit bei Hans von Bülow, in Richard Strauss. Der Komponist und sein Werk. Überlieferung, Interpretation, Rezeption. Bericht über das internationale Symposium zum 150. Geburtstag. München, 26.-28. Juni 2014, hg von Sebastian Bolz u. a., München 2017, S. 17-36

Holden, Raymond: The Virtuoso Conductors. The Central European Tradition from Wagner to Karajan, New Haven u. a. 2005

Homann, Karl: Von der 28. Tonkünstler-Versammlung, in Neue Berliner Musikzeitung 45 (1891), Nr. 24 (11.6.1891), S. 223-225; Nr. 26 (26.6.1891), S. 240-242; Nr. 27 (2.7.1891), S. 249-251

»Ich schreibe keine Symphonien mehr«. Richard Wagners Lehrjahre nach erhaltenen Dokumenten, hg. von Otto Dauber, Köln [1960]

Jahrbuch der deutschen Musikorganisation 1931, hg. von Leo Kestenberg, Berlin 1931 Johannes Brahms. Das Symphonische Werk: Entstehung, Deutung, Wirkung, hg. von Renate Ulm, Kassel 1996

Johannes Brahms im Briefwechsel mit Franz Wüllner, hg. von Ernst Wolff, Tutzing 1974 (Nachdruck der Ausgabe von 1922)

Kalbeck, Max: Johannes Brahms, 4 Bde., 3. durchges. Aufl., Berlin 1908-14 Kaminiarz, Irina: Richard Strauss. Briefe aus dem Archiv des Allgemeinen Deutschen Musikvereins (1888-1909), Weimar u. a. 1995 (Schriftenreihe der Hochschule für Musik »Franz Liszt«, Bd. 1)

Kämper, Dietrich: Franz Wüllner. Leben, Wirken und kompositorisches Schaffen, Köln 1963 (Beiträge zur rheinischen Musikgeschichte, Bd. 55)

Kastan, Isidor: Berlin wie es war, Berlin 1919

Kleffel, Arno: Die feierliche Eröffnung des Saales Bechstein, in Neue Berliner Musikzeitung 46 (1892), Nr. 41 (13.10.1892), S. 535f.

Krause, M[artin]: Die 28. Tonkünstlerversammlung des Allgemeinen deutschen Musikvereins zu Berlin, in Musikalisches Wochenblatt 22 (1891), Nr. 25 (18.6.1891), S. 327-329; Nr. 26 (25.6.1891), S. 340f.; Nr. 27 (2.6.1891), S. 351f. 
Kretzschmar, Hermann: Das Meer, in Neue Berliner Musikzeitung 45 (1891), S. 188f.

Krogmann, Richard: Der Klavierbauer Carl Bechstein und sein privates Umfeld, Hamburg 2001

Lackner, Robert: Hugo Botstiber und das Wiener Konzerthaus. Leben und Wirken eines Kulturmanagers vom Fin de Siècle bis zum Anschluss, Wien u. a 2016

Langner, Thomas-M.: Bülow, Strauss und die Berliner Erstaufführung von »Tod und Verklärung«, in Philharmonische Blätter 6 (1973/74), S. 2-5

Lerner, Laurence Marton: The Rise of the Impresario: Bernard Ullman and the Transformation of Musical Culture in Nineteenth Century of America, Ph. D. The University of Wisconsin, 1970

Lessmann, Otto: Aus dem Conzertsaal [Idee des erläuternden Programmheftes], in Allgemeine Deutsche Musik-Zeitung 10 (1883), Nr. 5 (2.2.1883), S. 44

Lessmann, Otto: Die »Verstaatlichung« des philharmonischen Orchesters, in Allgemeine Deutsche Musik-Zeitung 10 (1883), Nr. 6 (9.2.1883), S. 56f; Nr. 7 (16.2.1883), S. 6567

Lessmann, Otto: Kleine Mittheilungen und Berichte [Historische Konzerte von Anton Rubinštejn], in Allgemeine Musik-Zeitung 12 (1885), Nr. 40 (2.10.1885), S. 361f. Lessmann, Otto: Aus dem Conzertsaal [Historische Konzerte von Anton Rubinštejn], in Allgemeine Musik-Zeitung 12 (1885), Nr. 43 (23.10.1885), S. 398f.; Nr. 44 (30.10.1885), S. 408f.; Nr. 45, (6.11.1885), S. 420f.; Nr. 46, (13.11.1885), S. 430

Lessmann, Otto: Aus dem Concertsaal [Konzert des Berliner Wagner-Vereins], in Allgemeine Musik-Zeitung 14 (1887), Nr. 45 (4.11.1887), S. 430

Lessmann, Otto: Zur 28. Tonkünstler-Versammlung des Allgemeinen Deutschen Musikvereins, in Allgemeine Musikzeitung 18 (1891), Nr. 22/23 (29.5. / 5.6.1891), S. $267 f$.

Lessmann, Otto: Berichte und kleine Mittheilungen [Zuschrift von Hermann Wolff an die Vossischen Zeitung], zit. in Allgemeine Musik-Zeitung 27 (1900), Nr. 21/22 (25.5. / 1.6.1900), S. 339f.

Lessmann, Otto: Hermann Wolff †, in Allgemeine Musik-Zeitung 29 (1902), Nr. 6 (7.2.1902), S. $113 \mathrm{f}$.

Lichtenfeld, Monika: Zur Geschichte, Idee und Ästhetik des historischen Konzerts, in Die Ausbreitung des Historismus über die Musik, hg. von Walter Wiora, Regensburg 1969, S. $41-53$ 
Lippe-Weißenfeld, Hagen W.: Das Klavier als Mittel politischer Distinktion im Zusammenhang mit der Entwicklung des Klavierbaus in London und Berlin an den Beispielen Broadwood und Bechstein, Ph. D. Freie Universität Berlin 2006

Löschhorn, Albert: Anton Rubinstein's Concerte, in Neue Berliner Musikzeitung 39 (1885), Nr. 44 (29.10.1885), S. 346f;; Nr. 45 (5.11.1885), S. 356f.; Nr. 46 (12.11.1885), S. 364; Nr. 47 (19.11.1885), S. 375

Lott, R. Allen: From Paris to Peoria. How European Piano Virtuosos brought Classical Music to the American Heartland, New York 2003

Lucke-Kaminiarz, Irina: Der Allgemeine Deutsche Musikverein und seine Tonkünstlerfeste 1859-1886, in Liszt und die Neudeutsche Schule, hg. von Detlef Altenburg, Laaber 2006 (Weimarer Liszt-Studien, Bd. 3), S. 221-235

Ludwig, Aug[ust]: Der Konzertagent, in Neue Berliner Musikzeitung 48 (1894), Nr. 2 (11.1.1894), S. 13f; Nr. 3 (18.1.1894), S. 27-29; Nr. 4 (25.1.1894), S. 39-41; Nr. 5 (1.2.1894), S. 51-53

Mahler, Gustav: »Verehrter Herr College!«, Briefe an Komponisten, Dirigenten, Intendanten, hg. von Franz Willnauer, Wien 2010

Mahling, Christoph-Hellmut: »... ich glaube, die Herren würden vor Wut platzen!«. Drei Briefe von Max Reger an Louise Wolff, in Festschrift Wolfgang Rehm zum 60. Geburtstag, hg. von Dietrich Berke u. a., Kassel u. a. 1989, S. 238-245

Moelle, Janina: Die Leipziger Erstaufführung des Ring des Nibelungen und ihre zeitgenössische Rezeption, in Musik und Bürgerkultur. Leipzigs Aufstieg zur Musikstadthg. von Stefan Horlitz u. a, Leipzig 2007 (Leipzig Musik und Stadt. Studien und Dokumente, Bd. 2), S. 334-357

Muck, Peter: Einhundert Jahre Berliner Philharmonisches Orchester. Darstellung in Dokumenten, 3 Bde., Tutzing 1982

Musik! Die Entstehung eines Weltorchesters. Die Berliner Philharmoniker im 19. Jahrhundert (Katalog anlässlich der Ausstellung vom 21.03.2015 bis 30.08.2015 im Museum für Kunst und Technik des 19. Jahrhunderts Baden-Baden), hg. von Barbara Wagner und Matthias Winzen, Oberhausen 2015

Neumann, Angelo: Erinnerungen an Richard Wagner, Leipzig ${ }^{5} 1907$

N. N.: Tagesgeschichte. Musikbrief. Berlin [Wüllner-Konzerte], in Musikalisches Wochenblatt 14 (1883), Nr. 47 (15.11.1883), S. $580 f$.

N. N. [Ludwig, August?], Bechsteinsaalisches, in Neue Berliner Musikzeitung 50 (1896), Nr. 3 (16.1.1896), S. 25f.

Ochs, Siegfried: Geschehenes, Gesehenes, Leipzig u. a. 1922 
Pfohl, Ferdinand: Arthur Nikisch. Sein Leben, seine Kunst, sein Wirken, Neue erweiterte und verbesserte Ausgabe mit zahlreichen Bildern und Facsimiles, Hamburg 1925

Prieberg, Fred K.: Kraftprobe. Wilhelm Furtwängler im dritten Reich, Wiesbaden 1986

Reimann, Heinrich: Abriss der Entwicklung der Oper. mit literarischen Hinweisen von Emil Krause, in Allgemeine Musik-Zeitung 18 (1891), Nr. 15, S. $195 f$.

Richard Strauss und Franz Wüllner im Briefwechsel, hg. von Dietrich Kämper, Köln 1963 (Beiträge zur rheinischen Musikgeschichte, Bd. 51)

Riemenschneider, Georg: Jean Louis Nicodé. Das Meer, Symphonie-Ode für Männerchor, Solostimmen, grosses Orchester und Orgel. Op. 31, Leipzig o. J. (Musikführer, Bd. 185)

Ring, Peter: Bevölkerung. I. Von den Anfängen bis 1945, in Berlin Handbuch. Das Lexikon der Bundeshauptstadt, hg. vom Presse- und Informationsamt des Landes Berlin, Berlin 1992, S. 236-239

Rubinštejn, Anton: Erinnerungen aus fünfzig Jahren. 1839-1889, aus dem Russischen übers. von Eduard Kretschmann, Leipzig ${ }^{2} 1895$

Rubinštejn, Anton: Anton Rubinstein's Gedankenkorb. Mit einem Vorwort von Hermann Wolff, Leipzig 1897

Rühle, Bernd: Carl Bechstein (1826-1900). Über Leben und Lebenswerk eines großen Klavierbauers und seine Spuren in Erkner, Erkner 2001 (Erkneraner Hefte, Bd. 3: Beiträge zur Stadtgeschichte).

Ryding, Erik / Pechefsky, Rebecca: Bruno Walter. A World Elsewhere, New Haven u. a. 2001 Salmen, Walter: Das Konzert. Eine Kulturgeschichte, München 1988

Schaarwächer, Jürgen: Richard Strauss und die Sinfonie, Köln-Rheinkassel 1994

Schabbing, Bernd: Gustav Mahler als Konzert- und Operndirigent in Hamburg, Berlin 2002

Scheffler, Karl: Berlin. Ein Stadtschicksal, Berlin³1910

Schenk, Dietmar: Die Hochschule für Musik zu Berlin. Preußens Konservatorium zwischen romantischem Klassizismus und Neuer Musik, 1869-1932/33, Stuttgart 2004 (Beiträge zur Universitäts- und Wissenschaftsgeschichte, Bd. 8)

Schenk, Dietmar: Berlins »Richard-Strauss-Epoche«. Richard Strauss und das Musikleben im kaiserlichen Berlin, in Richard Strauss. Der Komponist und sein Werk. Überlieferung, Interpretation, Rezeption. Bericht über das internationale Symposium zum 150. Geburtstag München 26.-28. Juni 2014, hg. von Sebastian Bolz u. a., München 2017 (Münchener Veröffentlichungen zur Musikgeschichte, Bd. 77), S. 37-49

Schlicht, Ernst: Berliner Liedertafel 1884-1909, o. O. o. J. [Berlin 1909] 
Schmidt, Manuela Maria: Die Anfänge der musikalischen Tantiemenbewegung in Deutschland, Berlin 2005

Schmidt, Mark-Daniel: The Early Reception of Richard Strauss's Tone Poems, in The Richard Strauss Companion, hg. von Mark-Daniel Schmidt, London 2003, S. 145-190

Schmitt, Eduard: Handbuch der Architektur. Teil 4, Entwerfen, Anlage und Einrichtung der Gebäude, Halbbd. 6, Gebäude für Erziehung, Wissenschaft und Kunst, H. 3, Stuttgart 1901

Schnabel, Artur: Aus dir wird nie ein Pianist, Hofheim 1991

Schnapper, Laure: Bernard Ullmann - Henri Herz: An Example of Financial and Artistic Partnership, 1846-1849, in The Musicians as Entrepreneur, 1700-1914: Managers, Charlatans, and Idealists, hg von William Weber, Bloomington 2004, S. 130-144

Schrenk, Oswald: Berlin und die Musik. Zweihundert Jahre Musikleben einer Stadt 1740 1940, Berlin 1940.

Schuh, Willy: Richard Strauss. Jugend und frühe Meisterjahre. Lebenschronik 1864-1898, Zürich 1976

Schwab, Heinrich W.: Konzert. Öffentliche Musikdarbietung vom 17. bis 19. Jahrhundert, Leipzig 1971 (Musikgeschichte in Bildern, Bd. IV-2)

Seidl, Arthur: Zur Frage des musikalischen Urheberrechtes. Kritischer Bericht über die Verhandlungen des Dresdener Kongresses, in Allgemeine Musik-Zeitung 22 (1895), Nr. 43 (25.10.1895), S. 547f.; Nr. 44 (1.11.1895), S. 561ff.; Nr. 45 (8.11.1895), S. 577f; Nr. 46 (15.11.1895), S. 595f.

Shirakawa, Sam H.: The Devil's Music Master. The Controversial Life and Career of Wilhelm Furtwängler, New York u. a. 1992

Sittard, Josef: Geschichte des Musik- und Konzertwesens in Hamburg vom 14. Jahrhundert bis auf die Gegenwart, Altona u. a. 1890

Skoda, Rudolf: Die Leipziger Gewandhausbauten. Konzertgebäude im internationalen Vergleich, Berlin 2001

Souchon, Victor: Offener Brief an Oskar von Hase vom 12.12.1895, abgedr. in Mittheilungen des Vereins der Deutschen Musikalienhändler 33 (1896), S. 330-336

Splitt, Gerhard: Richard Strauss 1933-1935. Ästhetik und Musikpolitik zu Beginn der nationalsozialistischen Herrschaft, Pfaffenweiler 1987

Stargardt-Wolff, Edith: Wegbereiter großer Musiker. Unter Verwendung von Tageblättern, Briefen und vielen persönlichen Erinnerungen von Hermann und Louise Wolff, den Gründern der ersten Konzertdirektion 1880-1935, Berlin u. a. 1954

Strauss, Richard: Briefe an die Eltern 1882-1906, hg. von Willy Schuh, Zürich u. a. 1954 
Strauss, Richard: Lieber Collega! Richard Strauss im Briefwechsel mit zeitgenössischen Komponisten und Dirigenten 1, hg. von Gabriele Strauss, Berlin 1996 (Veröffentlichungen der Richard-Strauss-Gesellschaft 14)

Stuckenschmidt, Hans Heinz: Zum Hören geboren. Ein Leben mit der Musik unserer Zeit, München 1979.

Szatmari, Eugen: Das Buch von Berlin, München [1927] (Was nicht im »Baedeker« steht, Bd. 1)

Taylor, Philip S.: Anton Rubinstein. A Life in Music, Bloomington 2007

Tewinkel, Christiane: »In Ansehung der erheblichen für unser Musikleben zu erhoffenden Vorteile«: Einige Beobachtungen zu den Programmheften der Berliner Philharmoniker, in Gibt es sie noch: »die« Musik? Vorüberlegungen zu einer Allgemeinen Musiklehre, hg von Marie-Agnes Dittrich u. a., Wien 2011 (Anklaenge. Wiener Jahrbuch für Musikwissenschaft, Bd. 2010), S. 198-221

Tewinkel, Christiane: Muss ich das Programmheft lesen? Zur populärwissenschaftlichen Darstellung von Musik seit 1945, Kassel u. a. 2016

Thorau, Christian: Semantisierte Sinnlichkeit. Studien zu Rezeption und Zeichenstruktur der Leitmotivtechnik Richard Wagners, Stuttgart 2003 (Archiv für Musikwissenschaft, Beiheft 50)

Thorau, Christian: Die Hörer und ihr Cicerone. Werkerläuterung in der bürgerlichen Musikrezeption, in Musik - Bildung - Textualität, hg. von Andreas Jacob u. a., Erlangen 2007, (Erlanger Forschungen, Reihe A, Bd. 114), S. 207-220

Trenner, Franz: Richard Strauss. Chronik zu Leben und Werk, hg. von Florian Trenner, Wien 2003

Variationen mit Orchester. 125 Jahre Berliner Philharmoniker, Bd. 1: Orchestergeschichte, hg. von der Stiftung Berliner Philharmoniker, [Leipzig] 2007

Vogel, Bernhard: Anton Rubinstein. Biographischer Abriß nebst Charakteristik seiner Werke, Leipzig 1888

Wagner, Richard: »Ich schreibe keine Symphonien mehr«. Richard Wagners Lehrjahre nach erhaltenen Dokumenten, zusammengestellt und hg. von Otto Daube, Köln [1960]

Warfield, Scott: Strauss and the Business of Music, in The Cambridge Companion to Richard Strauss, hg. von Charles Youmans, Cambridge 2010, S. 242-256

Weber, Karlheinz: Vom Spielmann zum städtischen Kammermusiker. Zur Geschichte des Gürzenich-Orchesters 1, Kassel 2009 (Beiträge zur rheinischen Musikgeschichte, Bd. 169) 
Weber, William: The Origins of the Concert Agent in the Social Structure of Concert Life, in Le concert et son public: Mutations de la vie musicale en Europe de 1780 à 1914, hg. von Hans Erich Bödeker u. a., Paris 2002, S. 121-147

Weber, William: From the Self-Managing Musician to the Independent Concert Agent, in The Musician as Entrepreneur, 1700-1914. Managers, Charlatans, and Idealists, hg. von William Weber, Bloomington 2004, S. 105-129

Weber, William: The Great Transformation of Musical Taste, Cambridge 2008

Weibel, Samuel: Die deutschen Musikfeste des 19. Jahrhunderts im Spiegel der zeitgenössischen musikalischen Fachpresse, Kassel 2006 (Beiträge zur rheinischen Musikgeschichte, Bd. 168).

Weissmann, Adolf: Berlin als Musikstadt. Geschichte der Oper und des Konzerts von 1740 bis 1911, Berlin u. a. 1911

Weissmann, Adolf: Arthur Nikisch und die Berliner Philharmonischen Konzerte 1895-1920. Ein Rückblick, Berlin 1920

Weissweiler, Eva: Ausgemerzt! Das Lexikon der Juden in der Musik und seine mörderischen Folgen, unter Mitarbeit von Lilli Weissweiler, Köln 1999

Wendt, Gunna: Die Bechsteins. Eine Familiengeschichte, Berlin 2016

Werbeck, Walter: »Macbeth« von Richard Strauss. Fassungen und Entstehungsgeschichte, in Archiv für Musikwissenschaft 50 (1993), S. 232-253

Werbeck, Walter: Die Tondichtungen von Richard Strauss, Tutzing 1996 (Dokumente und Studien zu Richard Strauss, Bd. 2)

Williams, Jeannie: Jon Vickers. A Hero's Life, Boston 1999

Wolf, William: Die 28. Tonkünstlerversammlung des Allgem. Deutschen Musikvereins zu Berlin, in Neue Zeitschrift für Musik 58 (1891), Nr. 23 (10.6.1891), S. 277-279; Nr. 25 (24.6.1891), S. 297f.

Wolf, William: Correspondenzen. Berlin, in Neue Zeitschrift für Musik 59 (1892), Nr. 42 (19.10.1892), S. 469f.

-f. [Wolff, Hermann], Correspondenzen. Leipzig, 29. September 1878, in Neue Berliner Musikzeitung 32 (1878), Nr. 41 (10.10.1878), S. 325f.

-f. [Wolff, Hermann], Correspondenzen. Leipzig, 30. September 1878, in Neue Berliner Musikzeitung 32 (1878), Nr. 42 (17.10.1878), S. 333f.

H. W. [Wolff, Hermann], Pariser Musikzustände. I. Lohengrin in Paris, in Neue Berliner Musikzeitung 33 (1879), Nr. 19 (8.5.1879), S. 145-147; Nr. 20 (15.5.1879), S. $153 f$.

-f. [Wolff, Hermann], Die Berliner Concertsaison 1878/79, in Neue Berliner Musikzeitung 33 (1879), Nr. 28 (10.7.1879), S. 220f. 
-f. [Wolff, Hermann], Berlin. Revue, in Neue Berliner Musikzeitung 33 (1879), Nr. 41 (9.10.1879), S. 325f.

-f. [Wolff, Hermann], Ein neues Violin-Concert von Johannes Brahms, in Neue Berliner Musikzeitung 33 (1879), Nr. 42 (16.10.1879), S. 332f.

-f. [Wolff, Hermann], Bilse-Woche, in Neue Berliner Musikzeitung 33 (1879), Nr. 39 (25.9.1879), S. 310; Nr. 40 (2.10.1879), S. 318; Nr. 43 (23.10.1879), S. 340f.; Nr. 52 (25.12.1879), S. 413

Wolff, Hermann: Eugen d'Albert, Berlin o. J. [1883]

Wolff, Louise: Arthur Nikisch und Berlin aus meinen Erinnerungen, in Arthur Nikisch. Leben und Wirken, hg. von Heinrich Chevalley, Berlin 1922, S. 163-171

Zabel, Eugen: Konzerte und Konzertunternehmer, in Neue Berliner Musikzeitung 46 (1892), Nr. 23 (4.6.1892), S. 282-286; Nr. 28 (9.7.1892), S. 373-376

Zickgraf, Leila: Verträge, Streit und Ehrgefühl. Die prekäre Beziehung zwischen Felix Weingartner und Berlin, in Im Mass der Moderne. Felix Weingartner - Dirigent, Komponist, Autor, Reisender, Basel 2009, S. 51-67

Ziemer, Hansjakob: »Symphonischer Optimismus« im Konzertsaal. Zur Kulturgeschichte des Hörens um 1900, in Musik-Bürger - Stadt. Konzertleben und musikalisches Hören im historischen Wandel, hg. von Christian Thorau u. a., Regensburg 2011, S. 279-299

Zietz, Peer: Franz Heinrich Schwechten: Ein Architekt zwischen Historismus und Moderne, Stuttgart 1999

\section{Notenausgaben, Werbungsmittel und Programmhefte}

Anton Rubinstein's Cyclus von sieben Klavier-Vorträgen mit historischen und erläuternden Anmerkungen versehen von Wilhelm Tappert, hg. von der Concertdirection Hermann Wolff, Berlin. o. J. [1885]

A. Rubinstein. Concerts historiques, 7 Bde., Moskau o. J. (Noten)

Eugen d'Albert, hg. von Concert-Agentur: Hermann Wolff, Berlin o. J.

Ferruccio Busoni's Cyclus von vier Clavier-Orchester-Abenden. Die Haupterscheinungen auf dem Gebiete des Clavier-Concertes von J. S. Bach bis Fr. Liszt. Mit historischkritischen Erläuterungen von José Vianna da Motta und einer thematischen Uebersicht der zum Vortrag gelangenden Clavier-Concerte, Berlin 1898

Kalaschnikoff, der Kaufman von Moskau: Oper in drei Acten nach einer Dichtung von Lermontoff (mit Beibehaltung der Originalverse) bearbeitet von N. Kulikoff, Deutsch 
von Hermann Wolff, Musik von Anton Rubinstein, vollständiger Clavierauszug mit

Text vom Componisten, Leipzig 1880

Konzert-Kalender, hg. von der Konzertdirektion Hermann Wolff

Künstler-Almanach 6 (1932/33), hg. von der Arbeitsgemeinschaft, Konzertdirektion Hermann

Wolff und Jules Sachs, Berlin und Westdeutsche Konzertdirektion (Dubois und Dr.

Schriff), Köln

Piano Recitals by Anton Rubinstein. Analytical and Historical Remarks on Anton Rubinstein's

Cycle of Seven Pianoforte Recitals by Oscar Eichberg, übersetzt von George E.

Prince, [London 1886]

Richard Wagner's Sinfonie in C-Dur analysiert von Oscar Eichberg, Berlin 1887

\section{Siglenverzeichnis}

AMO: Archiv der Metropolitan Opera, New York

A-Wgm: Gesellschaft der Musikfreunde in Wien, Archiv

BArch: Bundesarchiv, Standort Berlin-Lichterfelde

Berlin SBPK: Staatsbibliothek zu Berlin - Preußischer Kulturbesitz Musikabteilung mit

Mendelssohn-Archiv, Berlin

EBB: Entschädigungsbehörde Berlin, Berlin

GSA: Goethe- und Schiller-Archiv, Weimar

GSPK: Geheimes Staatsarchiv Preußischer Kulturbesitz, Berlin

LAB: Landesarchiv zu Berlin, Berlin

LBI: Leo Baeck Institut, New York

SLUB: Sächsische Landesbibliothek - Staats- und Universitätsbibliothek Dresden, Dresden

SIM: Staatliches Institut für Musikforschung - Preußischer Kulturbesitz, Berlin

RSI: Richard-Strauss-Institut, Garmisch-Partenkirchen

TSHM: Tchaikovsky State Haus-Museum 


\section{Bildverzeichnis}

Abb. 1: »Karikatur auf den Geschäftssinn der Berliner Konzertunternehmer«, Ulk vom 21.4.1899, abgedr. in Ruth Glatzer, Das Wilhelminische Berlin. Panorama einer Metropole 1890-1918, Berlin 1997, S. 210

Abb. 2: Portrait von Hermann Wolff mit handschriftlicher Notiz von Louise Wolff, Wolff-

Nachlass: ID 272

Abb. 3: Geburtsurkunde von Hermann Wolff, Zivilstandsregister, Landgerichtsbezirk Köln, Standesamt Köln, Geburten, 1845, Nr. 2496

Abb. 4: Portrait von Louise Wolff, o. D. Wolff-Nachlass: ID 257

Abb. 5: Gästebuch von Louise Wolff, »Zum Jubiläum Arthur Nikisch« am 29. Februar 1920, Archiv der Berliner Philharmoniker

Abb. 6: Arthur-Abendblatt vom 29. Februar 1920, Wolff-Nachlass: ID 284

Abb. 7: Louise Wolff (Mitte) mit ihrem Sohn Werner (rechts) in ihrer Wohnung, o. D., WolffNachlass: ID 269

Abb. 8: Portrait von Edith (Stargardt-)Wolff, o. D., Wolff-Nachlass: ID 244

Abb. 9: Anzeige der »Concertagentur« Hermann Wolffs (1880), Signale 38 (1880), S. 780

Abb. 10: Gegend um Am Karlsbad, Flottwell- und Linkstraße in Berlin-Tiergarten (1888),

LAB, F Rep. 270, A 8162, 1888 (Ausschnitt)

Abb. 11: Anzeige der Konzertdirektion Hermann Wolff(1886), Neue Zeitschrift für Musik 53 (1886), S. 264

Abb. 12: Anzeige der Konzertdirektion Hermann Wolff (1887), Neue Zeitschrift für Musik 54 (1887), S. 300

Abb. 13: Anzeige der Konzertdirektion Hermann Wolff (1888), Neue Zeitschrift für Musik 55 (1888), S. 230

Abb. 14: Anzeige der Konzertdirektion Hermann Wolff(1890), Neue Zeitschrift für Musik 57 (1890), S. 312

Abb. 15: Anzeige der Konzertdirektion Hermann Wolff(1891), Neue Zeitschrift für Musik 58 (1888), S. 268

Abb. 16: Künstlerliste im Konzertkalender 27 (1921/22), hg. von der Konzert-Direktion Hermann Wolff und Jules Sachs, S. 69

Abb. 17: Concert-Verzeichnis (10.-18. Januar 1904)

Abb. 18: Beilage zum Vertrag für Joseph Rosenstock vom 24.9.1928, Metropolitan Opera Archives, New York 
Abb. 19: Werbung für die Druckausgabe von Till Eulenspiegels lustige Streiche von Richard Strauss, Allgemeine Musikzeitung 22 (1895), S. 479

Abb. 20: Eugen John, Bild zum Berliner Tonkünstlerfest des Allgemeinen Deutschen Musikvereins 1891, Neue Berliner Musikzeitung 45 (1891), S. 184

Abb. 21: Titelblatt des Programmheftes Anton Rubinstein's Cyclus von sieben KlavierVorträgen mit historischen und erläuternden Anmerkungen versehen von Wilhelm Tappert

Abb. 22: Auszug aus dem deutschen Programmheft Anton Rubinstein's Cyclus von sieben Klavier-Vorträgen mit historischen und erläuternden Anmerkungen versehen von Wilhelm Tappert

Abb. 23: Auszug aus dem englischen Programmheft Piano Recitals by Anton Rubinstein. Analytical and Historical Remarks on Anton Rubinstein's Cycle of Seven Pianoforte Recitals by Oscar Eichberg

Abb. 24: Ankündigung des ersten historischen Konzerts von Berthe Marx-Goldschmidt im April 1910, Le Figaro vom 10.4.1910, S. 5

Abb. 25-26: Hans von Bülow, »Zum Schutz der Sinfonie-Componisten«, Programmheft zum Berliner Philharmonischen Konzert vom 15. Oktober 1894, S. 3f.

Abb. 27-28.: Heinrich Reimanns Analyse zu Till Eulenspiegels lustige Streiche,

Programmheft zum Philharmonischen Konzert vom 19.11.1900, S. 11f

Abb. 29-30: Wilhelm Maukes Analyse zu Till Eulenspiegel, Meisterführer Nr. 6. Richard

Strauss. Symphonien und Tondichtungen, erl. vonG. Brecher u. a., Berlin o. J., S. 94f. Abb. 31: Umschlag des Programmheftes des Philharmonischen Konzertes vom 10. Oktober 1898

Abb. 32: »Zur Erinnerung an die Eröffnung des Saales Bechstein in Berlin am 4. Oktober 1892«, Neue Berliner Musikzeitung 46 (1892), S. 499

Abb. 33: Gegend um die Linkstraße in Berlin-Tiergarten (1898), LAB, F Rep. 270, A 2012 , 1898 (Ausschnitt)

Abb. 34: Anzeige der Konzertdirektion Hermann Wolff und des Bechstein-Saales (1892), Neue Berliner Musikzeitung 46 (1892), S. 820

Abb. 35: Anzeige des Bechstein-Saales im Programmheft zum Philharmonischen Konzert vom 10. Oktober 1898

Abb. 36: Ludwig Misch leitet die Jüdische Madrigalvereinigung im Bechstein-Saal, Dezember 1934, LBI Archives, keine Signatur 


\section{Quellenteil}

\section{Nachlass der Familie Wolff 1.1 Überblick}

Der Nachlass Familie Wolff, der in der vorliegenden Arbeit zum ersten Mal einer systematischen Untersuchung unterzogen wurde, ${ }^{713}$ ist eine vielfältige Quellensammlung, die drei Generationen in einer Zeitspanne von mehr als einem Jahrhundert umfasst. Die Datierung der Überlieferung erstreckt sich von der Zeit vor der Gründung der Konzertagentur bis zur Nachkriegszeit. Als Ergebnis der Untersuchung dieser Quellen entstand eine Datenbank mit 333 Einträgen, die der vorliegenden Arbeit als Anhang beigefügt ist. ${ }^{714}$

Die Materialien sind hier nach ihrer Eigenschaft in acht Kategorien eingeordnet: »Korrespondenzen«, »Dokumente: Wegbereiter großer Musiker«, »Bildmaterialien«, »Konzertmaterialien«, »Zeitungsausschnitte«, »Geschäftsakten«, »Tagebücher« und »Varia« (vgl. Tabelle 1).

\begin{tabular}{|l|l|}
\hline Kategorie & Zahl \\
\hline Korrespondenzen & 148 \\
\hline Dokumente: Wegbreiter großer Musiker & 87 \\
\hline Bildmaterialien & 28 \\
\hline Konzertmaterialien & 26 \\
\hline Zeitungsausschnitte & 13 \\
\hline Geschäftsakten & 10 \\
\hline Tagebücher & 3 \\
\hline Varia & 18 \\
\hline Tabelle 1.1: Nachlass der Familie Wolff (333 Materialien)
\end{tabular}

Die Kategorie »Korrespondenzen« enthält 58 Künstlerbriefe, 42 Briefe von Hermann Wolff an Louise Wolff, 11 Familienbriefe, 8 Geschäftsbriefe, 7 Brief (-entwürfe) von Louise Wolff usw. Die meisten handschriftlichen Briefe sind in der Datenbank im Anhang der vorliegenden

\footnotetext{
${ }^{713}$ Zur Herkunft dieser Quellen. vgl. Sayuri Hatano: Ein Paperchase. Auf der Suche nach dem Nachlass der Berliner Konzertagenten Hermann und Louise Wolff und ihrer Familie, in: Archive zur Musikkultur nach 1945. Verzeichnis und Texte, hg von Antje Kalcher und Dietmar Schenk, München 2016, S. 38-44. Vgl. auch Teilkapitel 1.3 des Textteils der vorliegenden Arbeit.

${ }^{714}$ Die Datenbank wird in Kürze in den Kalliope-Verbundkatalog eingeschlossen und öffentlich zugänglich: https://kalliope-verbund.info, 02.06.2020.
} 
Arbeit mit Transkriptionen versehen. Die Transkriptionen einiger ausgewählter Briefe sind auch in 1.3 dieses Quellenteils vorgelegt.

Die Datierung der Künstlerbriefe erstreckt sich von den 1880er Jahren bis zur Nachkriegszeit. Zu den Adressanten gehören nicht nur Musiker, sondern auch Schriftsteller, Maler und andere Personen, die mit der Familie Umgang hatten. Zu ihnen gehören Siegfried Ochs, Fritz Steinbach, Felix Weingartner, Bruno Walter, Maria Ivogün, Amalie Joachim, Lilli Lehmann, Marcella Sembrich, Teresa Carreño, Joseph Joachim, Heinrich Reimann, CharlesMarie Widor, Julius Rodenberg und Ludwig Pietsch. Die eigentlichen Adressaten scheinen nicht immer die Familienmitglieder der Wolffs gewesen zu sein, denn einige Briefe sind offensichtlich an Musiker gerichtet, an die die Briefe weitergeleitet oder deren Inhalte mitgeteilt worden sollten. Allerdings sind die Briefumschläge meistens nicht mehr erhalten und die Adressaten mit Anreden wie »Hochgeehrter Herr Doktor« oder »Cher Docteur« nicht immer eindeutig auszumachen. Inhaltlich sind diese Briefe sehr vielfältig. Es gibt einfache Begrüßungen, Kondolenzen, Danksagungen und Empfehlungsschreiben, aber auch Mitteilungen verschiedener Pläne, Antworten auf Anfragen, Angebote, Verhandlungen von Geschäftsbedingungen, Rechtfertigungen in Streitigkeiten und anderes mehr.

Den Briefen von Hermann Wolff an seine Frau fehlt es oft an Daten- und Ortsangaben, aber der Vergleich mit den Fakten, die in anderen Quellen nachweisbar sind, lässt vermuten, dass diese Briefe im Zeitraum von 1879 bis 1892 entstanden sind. Vor allem in den erhaltenen Briefen gut dokumentiert ist die Reise mit Anton Rubinštejn anlässlich der historischen Konzerte dieses Musikers in der Saison 1885/1886, die im Abschnitt 3.2.1 des Textteils der vorliegenden Arbeit behandelt ist.

Die Kategorie »Dokumente: Wegbereiter großer Musiker« besteht hauptsächlich aus Korrespondenzen und Akten, die im Zusammenhang mit dem 1954 erschienenen gleichnamigen Erinnerungsbuch von Edith Stargardt(-Wolff) ${ }^{715}$ entstanden sind. Aus diesen Quellen geht hervor, dass die Autorin nach der Veröffentlichung ihres Buches auf erbitterte Widerstände stieß, von denen sich zwei Angelegenheiten zu heftigen Streitigkeiten entwickelten.

Wilhelm Furtwängler protestierte gegen die Äußerung, die Edith Stargardt-Wolff in ihrem Buch als eine Aussage Furtwänglers zu ihrem Bruder Werner Wolff, ebenfalls Dirigent, wiedergab, nämlich, dass dieser seine Ausdrucksbewegung vor dem Spiegel einstudiere. ${ }^{716}$ Furtwängler widersprach entschieden, dies gesagt zu haben, und fasste die Darstellung als

\footnotetext{
${ }^{715}$ Edith Stargardt-Wolff: Wegbereiter großer Musiker, Berlin u. a. 1954.

716 Ebd., S. 237f.
} 
Beleidigung auf. Edith und Werner hielten an der Richtigkeit ihrer Darstellung fest. Nach Furtwänglers Tod, baten die Hinterbliebenen darum, vor der Veröffentlichung einer neuen Auflage rechtzeitig benachrichtigt zu werden und die strittige Stelle zu ändern. Der betreffende Band erfuhr jedoch bis heute keine neue Auflage. Im Nachlass sind 30 Materialien, die auf diese Angelegenheit Bezug nehmen.

Der andere Vorwurf kam von Julius Kopsch, dem damaligen Präsidenten der Internationalen Richard Strauss-Gesellschaft. Es geht dabei um das wohlbekannte Konzert vom 20. März 1933, in dem Richard Strauss anstelle des zwangsweise abgesetzten Bruno Walter das Berliner Philharmonische Orchester dirigierte. Kopsch warf der Autorin vor, ihre Schilderung zu diesem Ereignis sei ungenau, insbesondere ihre Behauptung, Richard Strauss habe vor den neuen Machthabern kapituliert. ${ }^{717}$ Der vormalige Besitzer des Nachlasses, Wolfgang Zuelzer, stellte diese Briefe in den 1980er-Jahren Gerhard Splitt für dessen Arbeit über das künstlerische und kulturpolitische Verhalten von Richard Strauss während des NSRegimes zur Verfügung, und die Ergebnisse seiner Untersuchung wurden 1987 veröffentlicht. ${ }^{718}$

Die Kategorie »Geschäftsakten« enthält unter anderem einige Verträge für Vertragspartner wie das Berliner Philharmonische Orchester (ID 223), die Skating-RinkAktiengesellschaft (ID 225), der die alte Philharmonie gehörte, Angelo Neumann (ID 226), Joseph Joachim und Bernhard Pollini (ID 224). Betrachten wir als Beispiel den Vertrag zwischen dem Berliner Philharmonischen Orchester und Hermann Wolff vom 29. Januar 1891. Er klärt die von der bisherigen Literatur nicht eindeutig beantwortete Frage, auf welche Art und Weise das Orchester in seiner Anfangsphase mit Hermann Wolff zusammenarbeitete, und wie der Konzertagent davon profitierte. Der vorliegende Vertrag, der für die Zeitdauer bis zum 30. April 1893 geschlossen worden war, bestimmt Hermann Wolff zum alleinigen Vertreter des Orchesters. Von allen Engagements und eigenen Konzerten des Orchesters erhielt der Konzertagent fünf Prozent der Bruttoeinnahmen, provisionsfrei waren die Engagements mit dem Stern'schen-Gesangverein, dem Cäcilien-Gesangverein, dem WagnerVerein und der Singakademie, ferner Engagements für Künstlerkonzerte und die Konzerte in Scheveningen. Wolff war verpflichtet, zehn Abonnementskonzerte, sogenannte »Philharmonische Konzerte«, pro Saison zu veranstalten, wobei das Orchester die Hälfte des Reingewinns erhielt. Wenn keiner der Vertragspartner zwei Monate vor Ablauf des Vertrags eine Kündigung aussprach, konnte der Vertrag immer auf drei Jahre verlängert werden.

\footnotetext{
${ }^{717}$ Ebd., S. 278.

${ }^{718}$ Gerhard Splitt: Richard Strauss 1933-1935. Ästhetik und Musikpolitik zu Beginn der nationalsozialistischen Herrschaft, Pfaffenweiler 1987, vgl. vor allem S. 42-59.
} 
Die Kategorie »Tagebücher« enthält je ein Tagebuch von Hermann Wolff (ID 128) und Louise Wolff (ID 130). Während des Deutsch-Französischen Kriegs war Hermann Wolff als Dolmetscher an einen Etappenort eingezogen worden. In seinem Tagebuch mit 210 beschriebenen Seiten beschreibt der zukünftige Konzertagent auf anschauliche Weise seine Kriegserlebnisse. Die Tatsache, dass diesem Tagebuch eine fast vollständige maschinengeschriebene Transkription beigefügt ist (ID 129), lässt vermuten, dass seine Tochter Edith Stargardt-Wolff, die in ihrem Buch dieses Tagebuch ausführlich darstellt, es mit großem Interesse las und vielleicht veröffentlichen wollte. Louise Wolffs Tagebuch mit 65 beschriebenen Seiten entstand in der Zeit, als die Verfasserin ihrem Mann in der Konzertagentur zur Seite stand. Der erste Eintrag datiert vom 8. Januar 1887, der letzte vom 14. März 1892, und dazwischen ist das Tagebuch ganz sporadisch geführt. Obwohl Louise Wolff keine regelmäßige Tagebuchschreiberin war und der Zeitraum der Einträge sehr eng bemessen ist, beinhaltet dieses Tagebuch viele interessante Darstellungen von damals wichtigen Ereignissen und Persönlichkeiten. Unter 1.3 des Quellenteils ist dieses Tagebuch vollständig transkribiert.

Die meisten Materialien der Kategorie »Varia« stammen von den beiden Folgegenerationen von Hermann und Louise Wolff. Hier sind einige teilweise unveröffentlichte Texte und Tonaufnahmen enthalten, in denen Edith Stargardt-Wolff und ihr Sohn Wolfgang Zuelzer aus ihrem jeweiligen Blickwinkel an die Zeit der Konzertdirektion erinnern. Das wohl für eine Rundfunksendung erstellte Manuskript von Edith Stargardt (Wolff) mit keiner Datenangabe (ID 131) ist vollständig unter 1.4 dieses Quellenteils übertragen. Die ca. dreißigminütige englische Gesprächsaufnahme »Queen Louise« von Wolfgang Zuelzer, vermutlich aus den 1980er Jahren (ID 132), ist unter 1.5 des Quellenteils transkribiert. Zu dieser Kategorie gehören darüber hinaus Gedichte, die Otto Stargardt, der zweite Mann von Edith Stargardt-Wolff, im Konzentrationslager in Theresienstadt verfasste.

Die Transkription erfolgte so genau wie möglich, auch in Rechtschreibung und Zeichensetzung, etwa bei Abkürzungen. Sie gibt aber nur Absätze und nicht den exakten Zeilenfall wieder. Einschübe und Erläuterungen erfolgten, wo nötig; sie sind recte gesetzt, wogegen Kommentare und Erklärungen kursiv gesetzt sind. 


\title{
1.2 Ausgewählte Briefe und Dokumente (Transkription)
}

\subsubsection{Briefe von Hermann an Louise Wolff}

\author{
ID 14: Brief vom 13.1.1879 aus Breslau
}

[Briefpapier: Ed. Bote \& G. Bock, Hof-Musikhandlung]

Bresl, den 13 Jan 1879

An Frau Louise Wolff.

Hofdame der

Frau Geheimrath Ebert.

Mein geliebtes Weib.

Jetzt Schätzchen sind wir allein.

Nun können gemüthlich wir plaudern.

Ach du arme Strohwitwe, wie ich dich bedauere, allein, ohne deine männliche, wenn auch ganz sichere Stütze. Aber komm, daß ich dich zu erst recht ordentlich „hinabküsse“, dich frage, wie es dir in der Wolffshöhle geht und dann deine furchtbare Neugierde befriedige. „Wir" sind also in Breslau und geben heute Abend unser erstes Concert, das einen großen materiellen Erfolg schon jetzt geliefert hat. Die Fahrt begann in pompöser Weise in offener Droschke vom Hotel Petersburg aus. Ich wagte fast nicht, die Passanten anzusehen, aus Furcht, sie möchten denken, ich bilde mir etwas darauf ein, neben R[ubinstein] zu sitzen. Als es auf Richards Uhr 3 schlug, brauste der Zug fort; zuerst nach Frankf[ur]t a/O. Diese Stadt lag noch vor 4 Jahren sehr entfernt von Berlin; man fuhr zwar auch nur $2 \frac{1}{2}$ Stunden, aber es dauerte eine Ewigkeit, ehe man ankam. Jetzt liegt Frankfurt ganz nahe, lesend u plaudernd waren wir da, ehe wir's gedacht. Ich machte in Gedanken gewisse Wege und war noch nicht jene berühmten 3 Treppen hinauf, als wir weiterfuhren. Diesmal wurden die bis dahin sehr interessanten, das Wesen der Kunst durch aus nicht oberflächlich geführten Gespräche durch stellenweisen Klatsch ersetzt. Wenn R[ubinstein] schläft macht er die Augen zu und öffnet erst wieder wenn er erwacht; und doch will er ein berühmter Mann sein[.] Um 1015 waren wir in Breslau, wurden von unserm Vertreter empfangen u in Galisch's Hotel geführt, wo wir fürstlich, auf dem 1 Stock wohnen. Geschlafen habe ich die Nacht nicht - erstens weil ich - es ist mir dies ein peinliches Geständniß - zuviel an Frau Louise Wolff denken mußte und dann war mir auch - natürlich nicht aus diesem Grunde - ein wenig sensibel. Heute früh ließ ich mich von einer Männlichen Marie um halb 8 wecken u stand auf, 
als meine Studentenuhr $1 / 29$ zeigte. In kaffetrunkenen Zustand begrüßte ich Rubinstein und ging trotz des scheußlichen Wetters zu unserm Agenten u dann mit diesem zu dem Concertsaal. Inzwischen wurde mir wieder ganz wohl und nun warte ich mit Sehnsucht, daß es bald ein's sei; dann diniren wir.

Ist das genau rapportirt? Mein geliebtes Mädel, der Reiz der Berühmtheit wird auf die Dauer für die andern entschieden etwas langweilig; glücklicher Weise habe ich mich gleich so zu $\mathrm{R}$ [ubinstein] gestellt, daß ich mich jener andauernden geistigen u körperlichen Reverenzen, die ihm beständig gemacht werden, ganz entheben kann. In diesem Augenblick spielt er Dvorak's Compositionen. Ich aber Louise, bin froh, daß ich ein paar Minuten mit dir habe plaudern, resp. dir vorplaudern können. Die Entfernung sei sie zeitlich und räumlich noch so gering, macht einem die liebsten Personen noch lieber $\mathrm{u}$ du zweifelst, trotz des brockenweisen Wochengeldes nicht meiner ganzen und aufrichtigen Liebe. Und so magst du mir glauben, das Angenehmste, was ich in Breslau erleben kann, wird wohl dein morgen eintreffender Brief sein. Inzwischen, mein geliebtes Mädel, leb wohl, grüße die Eltern u Geschwister alle u komm in [d]ie Arme deines treuen liebenden Hermann

\section{ID 29: Brief vom 14.1.1879 aus Krakau}

[Briefpapier: Ed. Bote \& G. Bock, Hof-Musikhandlung]

Meine innigst geliebte Louise

Nun ists tiefe Nacht und wir sind erst von einer langen Eisenbahnfahrt in der alten Königstadt der Polen angekommen. Aber kann ich mich zur Ruhe begeben, ohne an dich gedacht zu haben, und kann ich an dich denken ohne an dich zu schreiben, wenn mir grade Feder u Dinte zur Verfügung steht. Hat doch dein lieber Brief, der mir der Hotelportier noch in die Droschke mit welcher wir in Breslau nah dem Bahnhof fahren wollte[n], nachbrachte einen so warmen herzbewegenden Eindruck gemacht, daß ich ihn fast so oft las als es Stationen zwischen Dresden u Krakau gibt. Und dabei muß ich wahrscheinlich recht selig gelächelt haben, denn der Maestro [Rubinstein] fragte, was die viermonatliche Gattin so erfreuliches schriebe. Und dann las ich ihm einiges aus deiner lieben Epistel vor und höflich zog er die Reisemütze als ich deine Empfehlungen bestellte, die er zu erwidern mir auftrug. Die Fahrt, mein Mädel bis zur poln. Grenze verbrachte R mit Lesen, ich mit Niesen u Schnauben, denn ich habe einen Schnupfen Kind, daß ich nicht höre, sehe, schmecke und rieche. In Oswiecin war Zollrevision. mit einem Schlage waren wir da in die polnische Wirthschaft versetzt. Im Wartesalon stieß man sogleich auf 8 „Peies“ mit 4 daran klebenden polnischen Juden, reinsten 
oder vielmehr schmutzigsten Wassers. Am andren Tisch saßen 2 Judenfrauen mit Perücken und neben diesen in holdem Gegensatz ein Nönnchen fein. Außerdem war das Local gefüllt mit Polinnen in rothen Jacken, rothen Cravatten u Pelzmüzzen u. allerlei Lauten, die dem Ganzen schon etwas Pittoreskes verliehen. Rubinstein hatte 30 Cigarren im Koffer für die er 3 Fl Steuer zahlen musste; der Steuererheber konnte einen fünf Guldenschein nicht wechseln und als er es konnte gab er mir zu viel heraus; der Kellner schielte und die Dame an der Kasse kokettirte, der Floh lag theilweise in Ruhe bei den Peiesbesitzern, theils als Witzblatt auf dem Tische, kurz man war in Oestreich-Polen. Von Oswiecin nach Krakau waren's nur noch 1 1/2 Stunden. In unsrem Coupé plauderte der Offizier mit einem alten Kaufmann, doch dauerte die Unterhaltung nur immer 10 Minuten, dann verschwand immer einer in jenes inodore Local, in welchem selbst Minister nicht für ihre Fürsten wirken können. Der Officier war uebrigens ein General, wenn er auch aussah wie ein Feldwebel. Um halb 9 waren wir in Krakau ein Abgesandter des Bösendorfers u ein junger Professor, Beliczky, empfing uns und hielt eine feierliche Ansprache an den ,großen Künstler“, während welcher R sein Löwenhaupt entblößt hielt. Der Prof. ein sehr gebildeter junger Pole, gesprächig wie eine Elster u wie alle Polen stolz auf sein Vaterland unterhielt uns vortrefflich $\mathrm{u}$ als ich die Rechnung bezahlte stellte sich heraus, daß wir Chateau Margaux à $10 \mathrm{M}$. die Flasche getrunken hatten.

Nachdem ich Rubinstein die nöthig[en] Vorwürfe gemacht u er sich damit entschuldigt hatte daß er keine Ahnung davon gehabt, trennten wir uns zum Schlafen zu gehen, ich aber wie du siehst, ziehe es vor mit dir mein geliebtes Mädel zu plaudern. Wir bleiben hier bis Donnerstag Abend 9 Uhr, dann fahren wir nach Lemberg, wo wir um 5.22. früh ankommen. Also am $17 \mathrm{u}$ 20 sind wir in Lemb[erg], am 18 in Czernowitz am 21 u 22. in Breslau; am 23 in Posen - am 24 - bei Muttern! Briefe in Lemberg per Adresse Gebrynviritz u Schmidt In Czernowitz Postrestante

Breslau Hotel Galisch.

Posen Bote u. Bock.

Du weißt ja wie lange Briefe dauern. Kannst dich also einrichten.

Und nun mein geliebtes theueres Kind, „laß mich schlafen“. Ich habe mir schon im Waggon überlegt, daß ich oft mich doch nicht von dir auf längere Zeit trennen könnte, so angenehm meine Lage auch ist, denn du bist ja die einzig anhaltende Note in meiner Lebensmusik: Mit dir steht $u$ fällt das ganze Concert. Leb wohl geliebte Louise - ich will mich für den morgigen Orpheus durch einen guten Morpheus vorbereiten. Ich umarme dich mit polnischem Feuer.

Dein treuster Hermann

Krakau

14/1/79 11[?] Uhr Abends 


\section{ID 30: Brief vom 16.1.1879 aus Krakau}

[Briefpapier Ed. Bote \& G. Bock, Hof-Musikhandlung]

Krakau 16. Januar 1879

Kurz vor unserer Abfahrt nach Lemberg und grade nach einem guten Diner bei Prof Belicky schreibe ich dir, mein geliebtes Weib, diese wenigen Zeilen. Dein 2ter Brief traf mich gestern Abend, grade als ich ins Concert ging; Ich kann dir nicht sagen, wie es mich ergreift, wenn ich deine Handschrift auf dem Couvert sehe. Es ist noch ganz derselbe Impuls noch immer sehe ich in Krakau, wie früher in Berlin alle Briefträger fragend an, als wenn sie weiter nichts zu thun hätten als unseren postillon d'amour zu spielen. Diesmal hatte dein Brief den Erfolg daß das Concert fünf Minuten später anfing als es sollte; Erst muss ich lesen, sagte ich zu $\mathrm{R}$ [ubinstein] - und dann ging er erst in den Saal. Der war nicht groß, aber die Menschen saßen u. standen darin wie die Häringe und - o Wunder - in Krakau - und nur Anfänger deines „hinabgelegten“ Glaubens. Der Beifall war polnisch lebhaft; das Publicum interessant, aber weniger schöne Frauen als ich „gehofft“. Um halb 10 war die Musik beendet und wir soupirten in Gesellschaft - alle wie gewöhnlich auf R's Kosten - davon habe [ich] ihn noch nicht abbringen können. Heute habe ich nun mit Rechnungen telegrafiren $u$ Wechseln zu thun gehabt, viel mit R geplaudert - das ist das Angenehmste von der langen Reise und heute Abend befinde ich mich nun zum ersten Male seit meiner Abreise wohl. Bis dahin hatte mich der Schnupfen förmlich krank gemacht.

Je mehr ich mit R zusammen bin, desto lieber wird er mir, er ist abgesehen von einigen vielen großen Leuten anhaftenden Einseitigkeit ein lieber gemüthlicher einfacher, aber denkender u. oft geistvoller, fast immer interessanter Mann, von dem ich Dir viel erzählen werde, wenn ich, geliebtes Mädel, erst wieder bei Dir bin. Ach mein theueres, einziges Kind, es ist sehr schön, der Freund u Helfer eines großen Mannes zu sein, aber noch schöner, der Mann eines kleinen Frauchens zu sein. - Ich muß kurz abbrechen, packen, bezahlen u. s. w. Leb wohl Louise, grüße Mama Papa u Alle Mädels Buben etc u glaube mir es liebt Dich mehr wie je Dein Hermann

Wenn Du bei Erhalt dieser Zeilen an mich schreibst, so trifft mich Dein Brief in Lemberg, Hotel Georges! 


\section{ID 31: Brief vom 13.11.1882 aus St. Petersburg}

Liebste. Dir noch ei[n]mal zu schreiben war mir gestern nicht möglich, ich hatte fast den ganzen Vormittag im Conservatorium zu thun, war Mittags im Ks. Theater, Nachm. u. Abends bei Rubinstein u. dann natürlich wieder im Theater. Aber enttäuscht war ich soeben, als mir der Kellner nur einen Brief v. Fernow u. keinen von Dir brachte. Du willst mich doch nicht „strafen“ liebste Frau, dafür, daß die Gedanken, welche augenblicklich doch alle „gesammelt“ bei meinem Beruf sein müssen, an der Außenseite der formalen Zärtlichkeit zu ermangeln scheinen. Nein Kind, wenn ich in diesen paar Jahren nicht mein bis[s]chen Gedankenkraft concentrire, dann bringen wir es nicht zu was Rechtem u. du möchtest doch auch einmal auf ältere Tage

1 Köchin

1 Gouvernante

1 Hausmädchen

1 Diener der mit weißen Handschuhen servirt haben. Dafür, Geliebte, sei[']s gethan.

Nun will ich dir, weils dich doch gewiß am meisten interessiert, mittheilen, daß Rubinst[ein] sehr einfache, aber ganz gemüthliche Wohnung hat u daß wir bei ihm sehr einfach gegessen haben. Suppe (schwach) Suppenfleisch (härtlich) Rebhuhn (mager) mit [nicht lesbar], Eis, nicht kälter wie in Deutschland. Er componirt den ganzen Tag, geht fast nie aus, wird wie ein Abgott geliebt, aber allgemein meinen, auch seine besten Freunde, er müsste aus financiellen Gründen wieder spielen. Er aber will davon weniger wissen als je!

Und nun unsre Hauptangelegenheit: Wir haben noch gar nichts erreicht, nur uns orientirt: erfahren, daß es wahrsch im December unmöglich, im Maerz aber wahrscheinlich wird. Erst heute um 12 haben wir Conferenz mit dem Director d. Kais Theaters, dann gehe ich zur Frau des ehemal Ministers Abasas, die Wagnerianerin u. einflußreich u. s. w. [ist] Die colossalen Einnahmen aber, von denen wir so lange geträumt, sind überhaupt deshalb nicht zu machen, weil der Rubelcours so schlecht ist. Früher wenn man 5600 Rbl. einnahm, so war das ca. 17000 Mk., jetzt sind es nur $11.000 \mathrm{u}$ das ist wohl das Maximum. Indessen werde ich vielleicht durch einflußreiche Connexionen gewisse Concessionen erreichen, die die Sache lucrativer gestalten. Ich bleibe aber keinesfalls mehr lange hier, denn fällt der December so habe ich hier die einleitenden Schritte gethan, ja Zeit genug später. Unterbrochen, weil gebadet - (halb 11 Vorm.) Vor 11-12. kein Mensch zu sehn. Von Petersburg selbst habe ich außer dem Riesen Winterpallast, der eine ganze Stadt ist, der Sühnekapelle (Attentat Alexand. II) dem enorm belebten durch das unglaublichste 
Schlittentreiben sehr interessanten $u$ amüsanten Newski Prospect (unsere Linden[)] - u. dem bekannten Wiener Restaurant Leumer, wo Brassin verkehrt noch nichts gesehen. Nur finde ich, daß es nicht übertrieben theuer hier ist. -

Und Du Kind. (,aha“ jetzt kommst du u fragst du) wie geht es dir. War der Doctor da u hat dich ordentlich untersucht.

Ich weiß zwar, es ist gar nichts, als das verdammte Corsetttragen, aber die Hauptsache ist, den Vorschriften d. Doct. jetzt genau zu folgen, dann - nehme ich dich im Maerz mit nach

Petersborg, wie unser geliebtester Dittel sagen würde.

Hoffentlich erhalte ich heute noch einen Brief v. dir. Ich habe zwar eine Depesche, die u. A. auch ,,alles wohl“ enthält, aber das genügt doch nicht. Bei solchen Entfernungen.

Ich habe v. Wirballen $u$. hier bis jetzt täglich geschrieben.

Geh doch oft ins Contoir. Lasse dir, wie ich 's angesagt, etwaige Gelder, geben u. verwahre sie.

Küsse den Dittl, Geliebte u komm in die Arme deines treuen Hermann

13 Nov 1882

Hier vollständigster Winter 2-3 Grad Kälte

\section{ID 32: Brief vom 19.11.1882 aus St. Petersburg}

\section{Geliebte}

Eben ist Foerster weg und nun bin ich, ein zartes Reis, allein, u. einsam in dem hohen Norden und sehne mich nach meiner schlanken „Fichte“ im relativen Süden! Wahrhaftig, Louise, glücklich fühle ich mich in diesem Augenblick nicht und ich beneide den thatenlosesten aller Helden, den Characterspieler Foerster, um seine Rückfahrt. Aber was nützt es, vor Dienstag komme ich nun einmal aus dieser Schneemühle nicht fort, wie dir der einliegende „Entschuldigungszettel“ besagt. Hätte ich gewußt, wie dies u jenes sich von einem Tage zum andren verschleppte, ich wäre auf 48 Stunden nach Moskau gefahren, was mir nun auf später verspart bleibt.

Gestern war hier das erste Concert, mit der Artot, Barcevicz u[nd] Rummel. Bei weitem am wenigsten gefiel der letztere, welcher nur 1 mal schwach herausgerufen wurde. B. gefiel, die Artót auch. Und denk dir, im Zwischenact erscheint plötzlich im Künstlerzimmer, tief in Schmerz, mit vorne kurz u kokett geschnitten[em] Haar - Frau Sadowski! Die Freude des Wiedersehens glich von ihrer Seite der Extase. Du kennst ja die Ach u. Ohs ihrer Exclamationen. Sie erkundigte sich eifrigst nach dir, fragte mich - im [B]eisein Antons d. 
Großen über diesen aus u erzähl[t]e athemlos - sie sei Wittwe geworden die Situation war insofern neu, als ich sie mit ihrem Wittwenschmerz neckte, meine Freude über ihr Wohlsein u wie vortheilhaft ihr Schwarz stände äußerte sie fragte ob sie sich nicht frei u. von ihrer Wittwenschaft durchdrungen fühlt, kurz, es war eine animirte, äußerst komische Begegnung, umso mehr als sie Alles ernst nimmt.

Nach dem Concert Souper (ohne Sadowski) mit Rub[instein] den Künstlern Directoren u. s. w. Im Ganzen etwas ledern!

Heute habe ich meinen täglichen mehrstündigen Besuch bei der allmächt[igen] Frau Abassa gemacht. (Unsre Sache kommt definitiv im Maerz zu Stande!) Abends bin ich bei Rubinstein. Morgen werde ich noch viel zu thun haben und dann Dienstag - es wird wohl nichts dazwischen kommen - verlasse ich den Newastrand u. eilge in die wärmeren Regionen meiner geliebten Gattin.

Vom Gesch[ä]ftlichen in Berlin will ich hier nichts wissen. Ich habe hier durch das ewige Sprechen so viel Aufregung, daß ich nicht mehr der Nervenreizung brauchen kann. Besser munden mir alle guten Nachricht[en] v dir u. dem lieben Kinde. Heute habe ich übrigens an dich telegraph[iert] damit du mich nicht vergeblich erwartest.

Leb wohl, Geliebte, Einzige, lieb mich wie ich dich, Louise liebe,

Dein Herm[ann]

19 Novb 1882

\section{ID 33: Brief vom 15.2.1884 aus Pest}

Pest 15. Feb. 1884

Geliebte. Wärst Du gestern Abend doch in Pest gewesen, wie würdest Du von manchem Vorurtheil curirt worden sein. Laß Dir in kurzen Worten die Gesellschaft bei Dunkel schildern. Vor allem Plan der Wohnung:

[Zeichnung]

Zwei Salons, ohne jede Eleganz, in der Größe unseres Salons in Carlsbad, höchstens, dann ein schmales Zimmer in dem 2 Betten stehen u. dann ein ebenso schmales einfenstriges Zimmer, wo dann gegessen wurde $\mathrm{u}$. das so klein ist, daß die beiden Kellner jedes mal wenn sie servirten, weiße Rücken hatten, denn die Wände waren gestrichen. Du kannst dir keine Idee von der Beschränktheit, Uneleganz, Mittelmäßigkeit dieser Räume machen u. nach seinen jüdischen Begriffen dürfte man kein Schwein einladen so aber saßen Cardinal Haynald, 
Minister Treford[,] Liszt, Rubinstein, Poliz[ei]präsident Talis, Graf Apponyi etc. darin, lange darin u. war ganz gemüthlich u. ungeniert. Und das Geschirr: Das bekannte weiße

Halbporcellan. Jeden Augenblick mußte einer aufstehen, um den Kellner durchzulassen; man saß dabei so eng nebeneinander, daß man in jeder Bewegung gehemmt war, wenn der Nachbar sich nahm. Ich ließ mal meine Serviette fallen um sie wieder aufheben zu können, mußte meine Nachbarin links (Frl Dunkel 16 Jahre) u. mein Nachbar rechts aufstehen. Kurz, Kind, das Modell der Einfachheit, Nichtäußerlichkeit, ohne daß es Jemanden aufzufallen schien. Du hättest das sehn müssen. Das wäre Wasser auf meine Mühle gewesen. Am meisten unterhielt [ich] mich mit Cardinal Haynald, ein reizender, verfluchter Kerl. Nachdem wir vorgestellt waren $\mathrm{u}$ ein paar Worte gewechselt, fetzten er $\mathrm{u}$ ich in einer Ecke $\mathrm{u}$. plauderten, als wenn's für Geld ginge. Er erzählte mir, wie er zuerst die Musik lieber gelernt, wie er 1848 als politischer Oppositionär ins Gefängnis gekommen etc u. schließlich gings aufs Theater über. Ich mußte ihm von Frl. Ramazette erzählen, die zum Theil auf seine Kosten ausgebildet und der er correspondirt u für die er sich sehr interessiert. Ich werde Dir das Alles mündlich ausführlich erzählen. Es war famos: er bat mich Frl. Ram[azette]. zu besuchen um seine Grüße zu bringen, Wir wollen das nächstens zusammen thun, denn ich habe ihm versprochen, darüber hinzuschreiben. Ich hab ihm auch erzählt, daß du selbst Tragödin gewesen etc. Na, uns verfluchte Kerl. Mit deinem Freund, dem Münster plauderte ich auch ziemlich viel über Künstlerfahrten nach Amerika. Im Allgemeinen hatte man den Eindruck gestern Abend, sich unter alten Bekannten zu finden, von irgend einem Stand, Steifheit, Vorurtheil war nichts zu merken.

Nach Tisch wurde Whist gespielt, während welcher Zeit ich mit der Wirthin, nette dicke Frau, früher Sängerin u den Mädel, 2 junge üppige ausgelassene Füllen plauderte u von Dir u den Kindern erzählte.

Dann fuhren wir um halb 2 Uhr - zum Maskenball (calicotball). Der Polizeipraesident, u Graf Apponyi waren unsere Mentoren. Indeß blieben wir nur eine Stunde, denn nicht eine elegante Toilette, nicht ein feines Kostüm, nicht eine signante Persönlichkeit war zu sehen. Graf Apponyi meinte was fein sei, wäre vor der Demaskirung fortgegangen. $\mathrm{Na}$, wer sich demaskirt hat, das war auch danach. Wir verließen darum schnellstens das Local u gingen noch ein Glas Bier trinken u dann zu Bett. Kind, das liebe Vaterland kann nichts sein, wenn so die Maskenbälle ausschauen. Morgen früh gehts nach Wien. Ich bin sehr froh, denn so schön Pest liegt, ich vermag ihm sonst nichts abzugewinnen. Bei Liszt habe ich übrigens ein Wort gesagt, das vielen Beifall fand. Er wollte R. einladen zur Baronin Etvoes zu gehen; als Rub [binstein]. refüsirte. [...] 


\section{ID 40: Brief vom 11.3.1886 aus Leipzig}

\section{Liebste}

Nur schnell einen innigen Gruß \& Kuß. Habe Rub[instein] erst heute früh gesehen, nachdem ich eine durch innerliche Unruhe schlaflose Nacht gehabt. Er war erst verstimmt, wegen Wien, ist aber jetzt wieder absolut der Alte. Hier wird's kü[h]l. O, ach! o weh?

Aber das sehe ich wie von allen Seiten gegen mich agitirt wird u wo ich auf dem Posten sein muß in diesem Kampfe. Aber ich mache mir hier jetzt an [Bartholf] Senff einen Freund, der übrigens meine Notiz über Franz aufgenommen hat u dessen Mitarbeiter zu werden ich versprochen habe.

$\mathrm{Na}$, meine heutige Aufgabe, Rub[instein] wieder in Stimmung zu bringen, habe ich erfüllt $\mathrm{u}$ das ist wenigstens was. Außer bei Eulenburg war ich noch nirgends, habe bis jetzt (5 Uhr) mit Rub Piquet gespielt u er hat $3 \mathrm{Mk}$ gewonnen, das ist auch gut.

Liebste, ich hatte eine scheußliche Nacht - ganz ohne Schlaf. Jetzt will ich einige Correspondenz für Rub. besorgen u dann mit ihm ins Concert gehen. Inzwischen liebes Kind, hoffe ich auf Nachrichten von dir: Wahrhaftig, es ist doch nöthig, daß man sich noch aneinander anschließt $\mathrm{u}$ im großen Kampfe nicht wegen Kleinigkeiten sich verbittert. Nicht wahr, Kind?

Lebwohl, geh` ins Geschäft. Ich k[ü]sse dich u d[ie] Kinder

Dein getreuer Hermann

Leipzig 11 Maerz 1886

\section{ID 15: Brief vom 12.3.1886 aus Leipzig}

\section{Liebste.}

was höre ich hier Alles, hier am Grunde der Verschwörungen. Man erzählt mir, wie die Senkrah überall verbreitet, wie sie ausgebeutet würde, wie sie überall raisonnirte u versuchte, mit Klein anzuknüpfen. Rub[instein] hat mir gesagt, ganz Rußland sei aufgebracht gegen mich, wegen der [Arma] Senkrah. Na, ich habe ihn aufgeklärt. Aber es ist scheußlich, aus den Aufregungen kommt man gar nicht mehr heraus.

Ich fahre heute Abend nach Wien (Grand Hotel) und bin Montag früh in Dresden, wo ich dich [im] Bellevue erwarte. 
Sei nicht boese, wenn ich nicht mehr schreibe, aber ich kam bisher nicht dazu. Uebrigens hast du mich mit einem Kärtchen abgespeist.

Hast du mich bei Frau Meyerheim entschuldigt[,] hast du schon zu Bock geschickt?

Rub. ist wieder sehr nett, aber unbehaglich ist mir's doch, daß ich so lange wegbleiben muß.

Sehr unbehaglich.

Liebste, ich muß schließen dich u die Kinder in meine Arme u dann den Brief

Mit innigst[en] Küssen

dein Herm[ann]

Leipzig 12 März 1886

ID 20: Brief vom 30.3. o. J. [1886] aus Prag

Prag 30 Maerz.

Liebste.

Ich bin ganz gut angekommen, habe auch zieml. (II Klasse) geschlafen, was ich im Blauen Stern bis 10 Uhr fortgesetzt habe. Rubinstein fand ich sehr wohl \& vergnügt, nur vor dem Concert war ihm mies, aber sehr. Seine Sachen sind ihm schon zuwider, meint ${ }^{\star}$ er, die Sinfonie sei ihm gradezu eine Qual. Wir haben, nachdem wir alles mögliche besprochen, gefrühstückt (Wiener Rostbraten, Möhlspeis u Caffé) dann unser Piquet gemacht, von dem mich Boesendorfer, der schon seit 3 Tagen hier ist, eben abgelöst hat. Dadurch daß ich erst heute ankam, bin ich einer Einladung entgangen. Heute um 6 ist n[ä]mlich Diner bei der Waldstein, wo Rub[instein] \& Neumann auch sind \& zu dem ich, wie N. sagt, auch eingeladen worden wäre. Dafür bin ich morgen um 3 bei Neumann zu Tisch. Merkwürdig, Liebste, wie unangenehm, aber direct unangenehm mir ,zu Tisch[“] Einladungen sind. Und nun gar ein großes Diner, wie es bei der „Tirök“ sein soll. Ich war natürlich auch bei Neumann \& hörte ein Stück Kinder der Haide. Wie das am 3 April herauskommen soll, ist mir ein Räthsel. Ganz elend geht es. Na, und das Concert ist noch nicht mal ausverkauft! Hier war es gestern 20 Grad Wärme \& heute ist es scharf kalt; aber mein Husten ist wie die Temperatur, unter Null.

So, Schatz, jetzt habe ich mich des „Historischen“ entledigt, nun komme ich zu dem „Menschlichen“ zu dem Lebenden, Wahren, zu dir, geliebtes Weib, die ich schon wieder einmal zur Strohwittwe gemacht. Ich kann dir sagen, Geliebte, daß mir diese Reise eigentl. 
überflüssiger als alle vorkommt \& doch - ich sehe, aus R[ubinstein]s Correspondenz mit Gutmann - daß man einen bedeutenden Klienten möglichst wenig allein lassen soll. Aber ich denke, die Reiserei wird doch nun nächstens auf ein Minimum beschränkt, denn von Post ist absolut keine Rede \& diesen Trennungsschmerz erspare ich dir also. Geliebte, ich fühle in dem ich diese Zeilen schreibe, wie warm mein Herz bei dir ist; dein letzter Bahnhofsblick ruht noch auf mir. Glaube, trotz aller Zerfahrenheit, Sorgen \& Nervosität, mein ganzes Herz gehört dir \& nichts an meiner Liebe haben die Jahre gemindert. - Die Form, na ja, die hatte bei mir nie etwas Bestechendes. Ich bin eben ein Sohn - wie du zu sagen pflegst. - O weh, da kommt Frl Rössler, du kennst sie doch, sie ist verheirath[et.] Denke, so eine Schachtel. Leb' wohl, bis morgen früh. Abends, dank` dir mein Glück, ist Eugen Onegin v. Tschaikovsky, der interessirt mich. Küsse die Kinder \& sei zärtlich umarmt v. deinem Hermann

ID 8: Brief o. D. [April 1886?] o. O. [Paris?]

\section{Liebe Louise[,]}

Du kennst mich immer noch nicht, denkst nicht daran, daß ich gradezu körperlich leide, wenn ich in Unruhe deinetwegen bin $-u$. doch weißt du, daß ich diese eine Rücksicht wohl verdiene: Jeden Tag zur Zeit meinen Brief zu haben. Schon seit Längerem bemerke ich an der Ankunftszeit deiner Briefe, daß deren Absendung stets in letzter Minute geschieht, es also mehr Pflichtgefühl denn Bedürfnis ist - und heute ist auch mit der zweiten Post nichts gekommen, also hast du nicht geschrieben, denn abhanden kommt kein Brief. Nun bin ich so wie so unruhig, es drückt mich ein beängstigendes Gefühl, als wärst du nicht mein - ein Gedanke, der mich in der Entfernung oft krankhaft verfolgt - u. nur nicht einmal die Taube, welches das Oelblatt bringe. Das ist herzlos. Da habe ich deine letzten 5 Briefe vor mir, in keinem ist gesagt, was du abends beginnst - in keinem[.] Und siehst du da mache ich mir allerlei schreckliche Vorstellungen $\mathrm{u}$. fühle mich unglücklich - fern von euch - in aufreibender, aufregender Thätigkeit - für wen? Für Euch.

Nein siehst du, ich brächte es nicht fertig dich ohne eine Zeile zu lassen. Ich denke eben immer an dich - weil ich dich liebe. Nenne es Egoismus, daß ich täglich schreibe - u. sei egoistisch.

Gestern war [ich] mit Rubinstein u. Tretjakoff auf dem Grand Bal der Oper (nach dem Concert), leer, langweilig, ohne Toiletten

alte Hetären kurz abscheulich. 
Saurets habe ich gesprochen. Sie sind hier, wozu scheint ein Geheimnis.

Gerard, das schrieb ich wohl schon, hat sich vor 8 Tagen erhängt. Er hinterlässt nur Schulden, darunter 50.000 fr. an Rubinstein.

Heute esse ich bei Helene.

\section{ID 10: Brief vom 18.4.1886 aus Paris}

Paris 18 April [1886]

\section{Liebste.}

Endlich habe ich heute einen ordentlichen Brief von dir. Er enthält zwar Vorwürfe, aber das ist egal - abgesehen davon, daß sie unverdient sind - ist es doch wenigstens ein Brief, der meinen Sonntag rettet. Wenn auch mein „Ich liebe dich“, dir nicht genügt, wie du schreibst, von dir kann eine Zeile mich zum frohesten Menschen machen. Und so unangenehm es dir auch sein mag: „Ich liebe dich“.

In einem Punkte hast du allerdings Recht: Ich beschreibe zu wenig. Das liegt an meinem Temperament, im Mangel an Geduld. Aber vielleicht bessere ich mich noch, jedenfalls schreibe ich immer besser, wenn du mir nett geschrieben.

Vorgestern Abend habe ich bei Helene gegessen, wo deren jüngster Bruder mit seiner reizenden Frau war. Die Frau ihres andern Bruders, eines Cornels, (ich glaube, du kennst sie) ist dagegen durch Krankheit sehr herunter gekommen. Sie war auch da. Nach 10 Uhr ging ich ins Edentheater, wo ich wegen unsres großen Concertes jeden Tag bin.

Gestern habe ich bei Siegmund gegessen, nachdem v 2-5. die 4te Wiederholung stattgefunden. Um 9 warf ich mich in mein vielgeplagtes Habit u ging in die musikalische Soireé zu Dreyfus, wo Helene, Charles, Maxime usw waren, auch Massenet u. A. Es wurde eine fürchterliche Musik verzapft, nur Frau Lalo sang großartig.

Heute, wie beinahe jeden Tag frühstücke ich mit Rubinstein[.] Der arme Kerl hat große Familiensorgen. Sein Ältester scheint ein Faulpelz. und Taugenichts zu werden u seine Tochter Anna vom Liebesteufel geplagt zu sein. Er war gestern so gedrückt, wie ich ihn nur sah. Auf die Gefahr hin, dich wieder durch meinen docirenden Ton zu fatiguiren: Die gute Erziehung der Kinder muß - namentlich dir - wir Männer sind zu gehetzt - eine sehr ernste Aufgabe sein. [...]

Onkel Salomon ist wieder zurück. Ich lasse ihm morgen den heute erhaltenen Wechsel zur Prolongation praesentiren. Onkel Albert sagt mir, daß Tinas Marcuse viel für Salomons 
gethan hat - ohne seine Garantie[.] Von Alberts Wohnung machst du dir keine Idee. So zu wohnen, ist wirklich ein Vergnügen. Aber Alb. hat auch wieder Bilder verkaufen müssen, um sich Geld zu machen. Nein, Kind, lasse uns nur erst im sicheren Hafen sein. Wie wirst du mir noch einmal danken, daß ich so „doctrinär“" war.

Nach Wien habe ich vor ungefähr 8 Tagen geschrieben \& schreibe heute an Mutter; der Mizi hatte ich ein paar Zeilen - wegen des Sommeraufenthaltes der Deinigen. Natürlich werde ich wie im vorigen Jahre mich bei diesem Geschäft betheiligen.

Gern möchte ich dir ein Bild entwerfen, wie ich hier, durch diese Wiederholung namentlich in Anspruch genommen bin, denn die Correspondenzwuth kennt hier kaum Grenzen. Ich habe der Curiosität halber alle Briefe u Karten aufgehoben u bringe sie dir mit. Es ist allerdings sehr schwer für mich hier abzukommen wegen der neuen [C]oncerte. Aber ich bin doch am 23 in Berlin Abends u hoffe dich bei guter Gesundheit zu treffen. Zwar fürchte ich um diese Zeit bei dir ein gewisses Ereignis - ich weiß nicht ganz genau - Geliebte wie steht es mit dieser Datierung.

Ach, dein heutiger Brief war so richtig das Weib als Antwort auf meinen „Gram“ über deinen Laconismus! Nebbich ich bin unglücklich, aufgeregt, verzweifelt - u dann habe ich schließlich noch Unrecht? Na, komm süßes Weib, ,ich liebe dich“ (was dir ja nicht genügt aber mir, wenn du mich wiederliebst.) Wir sind ja nun einmal bestimmt, zusammen durchs Leben zu wandeln, seien wir uns unseres Glückes und unserer Liebe bewußt - diese Philosophie ist zum Glücke nicht ganz unnöthig.

Und nun lebe wohl. Ich küsse dich und bin sehr glücklich daß du liebe Edith, mir einen so lieben Brief geschrieben. Auch der dicke Pumpel sei bedankt. Auf Lili mit Zahn freue ich mich schon sehr.

1000 Küsse dein

Herm[ann]

ID 9: Brief o. D. [19.4.1886 aus Paris]

\section{Liebste}

Ein Theil meines gestrigen Briefes erledigt sich durch deinen heutigen, der auch Edith's Manuscript enthielt. Ich habe das Vertrauen zu deiner Liebe u. Intelligenz daß du mich nicht mißverstanden hast. Hier gibt's nichts Neues, als recht schlechtes Wetter u. den ewigen alten Trubel. Heute II Concert. So was von Correspondenz wie hier in Paris habe ich doch noch nie erlebt. Gestern habe ich $\underline{63}$ Briefe erhalten. Heute nachdem alle Billets f. d. Wiederholungen 
vergeben waren, habe ich noch 10 Plätze gemacht $u$. diese unter 100 Aspiranten verlost. Das war urkomisch. Jeder einzeln mußte eine halbgeöffnete Thür passiren u. ohne hinzugucken, ein Loos aus meinem Cylinder hut nehmen.

Onkel Charle gibt nach wie vor 2000 fr. jährlich. Er behauptet ich hätte seinen letzten Brief falsch verstanden, aber ich meine, es [er] hat Reue bekommen als ich mit ihm sprach. Nun sind die 2000 fr für immer gesichert. Der lieben Edith danke ich für ihren lieben Brief und küsse sie 1000 mal!

Ich danke dir, Kind, daß du aufmerksam zu Mama bist, glaube mir, sie erkennt das sehr an. Wir sollten nie vergessen, daß auch wir einmal älter werden!! Rubinst[ein] ist sehr fidel daß Franz v. [Wenndel?] $250 \mathrm{M}$ nahm - ich kann es kaum glauben. Lieber $50 \mathrm{Mk}$ von der größten Musikgesellschaft, von einem vielfachen [Fortsetzung fehlt]

\section{ID 23: Brief vom 20.4.[1886] aus Paris}

Gestern Abend war das V Concert (Clementi bis Liszt). Beim letzten Stück (Fantasie Rob. d Teufel) sank Rubinstein ohnmächtig zusammen! Denke dir, ich stehe hinter der Thüre des Podiums, höre auf einmal, wie Rub. plötzlich aufhört - stürze hinauf - u. finde ihn so bewußtlos am Klavier. Natürlich war's zu Ende; wir bringen ihn in’s Künstlerzimmer; nach 20 Minuten hat er sich erholt - ein Schwächeanfall, in Folge der Hitze - nach 15 raucht er eine Cigarre. Wir fahren dann ins Hotel, wo wie immer soignirt wird. Als Rub. seinen Salat ohne Oel gegessen, zweite aber viel stärkere Ohnmacht!!! Wir brachten ihn zu Bett, der Doctor kam, constatirte nur Schwäche u beruhigte uns. Ich blieb natürlich in Rub's Zimmer, gab ihm Camillenthee u. während ich ihm zu trinken gab, bekam er unter meinen Händen einen dritten Anfall. Du kannst dir auch meinen Zustand - ich war allein mit ihm - denken. Um 5 Uhr morgens fiel er endlich in Schlummer, den ich wie ein treuer Kurvenal bewachte und jetzt - 9 Uhr ist er wieder gesund und munter, wie immer.

Hermännchen ist allerdings ganz krank von Aufregung.

Rub. überschätzt seine Kräfte. Ich überlasse es dir, die Scenen detaillierter auszumalen, dich in meine Verfassung zu versetzen. - Hoffentlich hat es keine Folgen.

Vielleicht schreibe ich dir heute noch einmal, augenblicklich bin ich zu kaput[t] von Erregung und Nachtwache. Aber ich wollte dir doch gleich berichten $u$. auch danken $\mathrm{f}$. deinen heutigen sehr lieb[en]. Brief. 
Leb’ wohl, Geliebte mit 1000 Küssen

Dein Hermann

Sauret's habe [ich] gesprochen, auch Scharwenka

\section{ID 34: Brief vom 21.4.1886 aus Paris}

[Briefpapier: Erard \& Co.]

\section{Liebste.}

Rubinstein ist wieder ganz wohl, ich finde ihn aber seit gestern im Gesicht etwas verändert. Liebste, es wird mir schwer, dir es zu sagen: ich wage nicht morgen zu fahren ich muß bei dem Concerte sein, muß ihn nach Hause bringen, denn wenn ihn die Schwäche wieder übermannte u. ich wäre nicht da \& müsste ihn in einem solchen fatalen Moment Fremden überlassen!?

Du weißt, daß ich schon am 19. nach Berlin reisen wollte; ein Glück, daß ich blieb und ihm zur Seite war. Welche Vorwürfe hätte ich mir gemacht - u. bei der Nachricht wäre ich doch Hals - Kopf zurückgefahren. Nun ich weiß, du billigst meinen Entschluß. Was du aber nicht ganz ermessen kannst, ist das unglaubliche Opfer, welches ich mir bringe, indem ich nicht reise, halte ich es doch oft vor Sehnen u. Verlagen nach dir kaum aus! Aber das ist's nicht allein. Das Concert am 10 Mai arrangire ich absichtlich ganz, ganz allein. Uebermorgen muss ich Correctur der Placate u. Billets lesen, am 27. beginnt der Verkaufauch das zwingt mich hier zu bleiben. Liebste und nun wollen wir es so machen: du kommst am 3. Mai nach Brüssel, machst das letzte Concert mit, am 5. geht Rubinst[ein] nach Utrecht u. wir nach Paris wo wir bis zum $\underline{9}$ ganz frei sind, am 10. ist das große Concert, am 11. reisest du zurück, damit ich in Ruhe meine Rechnungen machen kann. Du warst dann 9 Tage bei mir. An diesem Plane wollen wir nicht rütteln; richte dich also danach ein u. vor allem sorge, daß jemand vom Lützowplatz bei uns wohnt, um bei den Kindern zu sein.

Das Geschäft ist - für mich - hier glänzend, u. auf das große Eden Concert nehme ich bei meinem Arrangement (!) sehr stark. Du begreifst nun auch leichter, daß ich hier sehr auf dem Posten sein will. Wie gesagt, bei diesem Concert mache ich alles ganz allein! Und nun, Geliebte, erleichtere mir meinen Aufenthalt durch deine lieben Briefe; du kannst wirklich nicht ermessen, was sie mir sind. Hier werde ich ein feines Hotel suchen, wo wir wohnen. Nicht im Helder. Ich will R[ubinstein] glauben machen, daß du mit mir zu deinen Verwandten ziehst. Schreibe doch an R[ubinstein], freue dich daß der kleine Unfall ohne 
Folgen geblieben [ist] u. sage ihm, daß du wahrscheinlich, von deinen Tanten eingeladen, nach der Serie nach Paris kämst. Thu' das gleich. Und jetzt adieu, Geliebteste - ich kann es selbst kaum fassen, daß ich zu Ostern nicht bei Dir sein soll, aber ich weiß, du begreifst. Küsse die Kinder u. sei innigst umarmt von deinem treuesten Hermann $[\ldots]$

\section{ID 16: Brief [vom 22.4.1886 aus Paris]}

Liebste.

Welch` eine bewegte Zeit. Von allen Seiten erhalte ich Depeschen, alles fleht mich an, Rubinst. nicht mehr spielen zu lassen \& zum Ueberfluß erhalte ich auch noch viele Telegrame seiner Frau. Ein ähnliches hatte ich von seiner Mutter. Natürlich habe ich ihm das alles nicht verheimlicht. Aber er lacht darüber u. fühlt sich wohler wie je. Aber - das verrathe um Gotteswillen Keinem, ich bin doch ängstlich \& erregt \& sehe herzklopfend dem heutigen Abend entgegen. Du wirst nun meine vorgestrige Depesche voll verstehen \& begreifen, daß ich hier bleiben muss, ganz abgesehen von meiner Unentbehrlichkeit für das neue Concert. Uebrigens war mehr sein Eigensinn in der Lebensweise schuld, als die Anstrengung. Es herrschte an jenem verhängnisvollen Abend eine große Schwüle, er hatte zum Frühstück lauter unmögliches Zeug, Crevetten, Hummer, Salat [u.] s. w. gegessen. Dann die Hitze zum Schluß auf seinen Magen. Die Nacht, die ich bei ihm gewacht, werde ich nie vergessen, ebenso wenig wie den heutigen Tag.

Und, merkwürdig, in all dem [nicht lesbar] war mir das Bewußtsein meiner Liebe zu dir stärker als je so weit meine Aufmerksamkeit nicht durch den „,verwundeten Löwen“ in Anspruch genommen war, weilten meine Gedanken in tiefster Innigkeit bei dir, Geliebte. Immer empfand ich es wie einen Stich, daß ich nun nicht zu dir eilen könnte - u. es wird mir schwer mich in dieses harte Schicksal zu fügen. Auch wegen Bülow ist es mir unangenehm, aber da bitte ich dich, mein Dollmetscher zu sein u ihm auch ja die einliegende Depesche zu zeigen. Es thut mir unendlich leid, ihn jetzt nicht sprechen zu können, wir werden uns vorläufig schriftlich verständigen u ich denke dir am 3 Mai bis Frankf. entgegen zu reisen u dort zu besuchen.

Ich bitte dich, ihm das sofort zu sagen. Ich werde ihm, auch das sage ihm, morgen oder übermorgen schreiben. 
Es bleibt bei unserer Verabredung. Du kommst nach Brüssel u wir gehen zusammen nach Paris. Sorge nur, Geliebte, daß unsere lieben Kleinen, von denen du mir etwas wenig schreibst, gut versorgt werden u. Louise, liebe mich. Ich bedarf deiner Liebe, sie ist mein Hafen in diesem Lebensorkan.

Morgen mehr. 10000 Küsse auch den Kindern. Edith soll schreiben. Dein Herm[ann]

\section{ID 24: Brief vom 23.4.[1886] aus Paris}

[Briefpapier: Hotel du Helder, Paris]

Paris, 23 April

Es scheint Geliebte, daß du mein Telegramm vom Mittwoch nicht rechtzeitig erhieltest, sonst hätte ich heute einen Brief von dir.

Ich athme wieder - der gestrige Abend ist gut verlaufen, er (R)[ubinstein] war zwar nachher erschöpfter als sonst u. erschien mir beim Souper sogar etwas nachdenklich über sich selber er hat aber großartig gespielt $u$. wird die Campagne zu Ende führen. Aber an diese Zeit werde ich denken u. ruhig bin ich noch nicht. Natürlich habe ich Rub. wiederholt gefragt, ob er wirklich weiter machen wollte, er lachte einfach über meine Zweifel - aber wenn etwas passierte, es hieße doch: der Wolff hat ihn gezwungen, der arme Rubinstein - namentlich nachdem ihn die Petersburger + resp. mir - geradezu untersagen, die Concerte weiter zu geben. Du wirst ihn etwas verändert finden, glaube ich. Ich habe dir heute telegrafiert - und bin etwas erstaunt, jetzt um 4 Uhr noch ohne Antwort zu sein. Ich halte es ja für selbstverständlich, daß du kein Wort $u$. keine Empfindung des Vorwurfs wegen meines Nichtkommens haben kannst, sondern daß du mich wie ich es verdiene beklagst, denn die Enttäuschung ist für mich größer, empfindlicher als für dich. Aber brauche ich dir noch einmal zu sagen, daß ich hier sein muß?

Geliebte, ich will am 3 Mai in Frankfurt sein, um Bülow zu sprechen. Fahre also am 2 Mai Abends 8 Uhr vom Anhalter Bahnhof ab. Du kommst um 6 Uhr 50. früh in Frankfurt an. Ich komme von Brüssel um 6.58 an. Du erwartest mich auf deinem Ankunftsbahnhof. Wir fahren dann ins Hotel. Abends um 10 Uhr, fahren wir nach Brüssel.

Ich nahm sicher an, daß du einverstanden bist. Es muß so sein, Geliebte und du sollte sehen, wie nett ich sein werde. -

Ich habe verschiedene neue Sachen. 1) übernehme ich die Vertretung der Société des droits d'auteur für die Opern Frankreichs. 
2) mache Tournée mit Lassalle Scandinavien.

3) habe ich wahrscheinlich eine sehr große russ. Unternehm[un]g unter dem Protectorat des russ. Kaisers. Rub. hat mir das verschafft.

4) habe ich Aussicht Talazac zu bekommen für eine deutsche Tournée u. s. w.

Was mich am meisten hier beschäftigt, außer Rub; ist die Aussicht, eine Actiengesellschaft für den Lohengrin u. Tannhäuser im Edentheater zu gründen! Kurz, ich bin voll von Aussichten.

Ach, Kind, die diesmaligen Pariser Flittertage wollen wir auskosten. Ich bin selig beim Gedanken [daran]. Versorge nur die Kinder gut, bring alle Liebe - allen Frohsinn mit, du wirst mit Sehnsucht erwartet von deinem

dich liebenden

Hermann

Abend[s] gehe [ich] ins Wagner Concert Lamoureux

Paris 23 Ap

ID 1: Brief vom 18.5.1886 aus London

[Briefpapier Hotel Dieudonné in London]

18 Mai 1886

Liebste.

Schnell während Rubinstein spielt, diese Zeilen, dich zu grüßen, herzgeliebte Seele. Heute aber das begreife ich - bin ich noch ohne message d'amour, diese jedoch muß meiner Vernehmung nach heute Abend noch kommen.

Wir werden hier in London wenig Einladungen annehmen, sondern fast nur Theater $\mathrm{u}$ Concerte besuchen. Gestern waren wir im Richter concert, heut sind wir im eigenen, morgen im Philharm. und übermorgen im „Mikado“. Am Sonnabend wieder Richter mit D’Albert's Sinfonie.

Daß Bülow mir mitgetheilt daß Lessmann mit Klein Concertagent wird, hat dir vielleicht Fernow gesagt - wenn du ins Contörchen gegangen bist. Entrenous B. - doch ein famoser Kerl - hat mir Lessmanns wedelnden Brief [nicht lesbar] eingesendet u. unterzeichnet: „Treulichst“.

$\mathrm{Na}$, wir werden ja sehen. Jedenfalls heißt es, auf dem Posten sein. 
Schreib mir recht viel von den Kindern, es fängt an, mir unbegreiflich zu sein, daß ich sie solange nicht sehen soll. Lasse Edith auch an mich täglich schreiben $u$. Du - vergiß deine kalten Abreibungen nicht. Wahrscheinlich werde ich auf 2 Tage nach Paris müssen. Rub. hat einen Brief von Advocaten bekommen, in Gerard's Sache, der mich ruft.

Lebe wohl, geliebtes Weib u sei innigst umarmt von Deinem getreuesten Hermann

\section{ID 2: Brief vom 19.5.1886 [aus London]}

\section{Liebste.}

Ich bin heute von diesem verfl. London Wetter, diesem Nebel dieser Luft etwas angegriffen \& spüre meinen Magen, in folge dessen ich zu dem bekannten Burgunder gegriffen habe - aber noch ohne Erfolg.

Vor allem Liebste hoffe ich, daß du wieder ganz dem Posten bist, es wird wohl nur so ein bisschen Erkältung gewesen sein. Jedenfalls möchte ich aus der Seitenzahl deines ersten Briefes schließen, daß du schon wieder auf dem Posten bist. Die Schilderung deiner Wiedervereinigung mit den „Dreien“ hat mich wahrhaft erquickt. Ach, was muß man doch alles entbehren!

Lessmann's Associat. hat mich doch weniger erregt, als du glaubst. Das muß sonderbar zugehen, wenn die beiden zusammenhalten.

Kind, sei nicht boese, ich kann nicht, kann nicht schreiben.

Ich habe nicht grade viel zu thun aber Dinte und Feder sind mir eine Qual heute.

Lebe wohl u glaube an meine Liebe. Küsse die Kinder u sei innigst umarmt von deinem Hermann

19 Mai 1886

ID 3: Brief vom 20.5.1886 [aus London]

20. Mai 1886

Liebste, 
Dank für deinen heutigen lieben Brief und gleichzeitig schweren Undank, indem ich nur flüchtig antworte. Aber Geliebte, ich schreibe an die Gott u die Welt von hier aus, um mein Feuer zu schüren und wenn du dabei scheinbar zu kurz kommst, in Wirklichkeit ist es ja doch nicht der Fall.

Der Fall mit General Berger hat mich gradezu erschreckt. Sei nur mit Deinem Hühnerauge vorsichtig, vernachlässige die Sache nicht einen Augenblick u frage den Doctor, nicht die alten Weiber.

Rege dich nicht über Lessm. Klaus zu sehr auf. Ich unterschätze die Concurrenz nicht, aber ich überschätze sie auch nicht. Sie werden namentlich vorrübergehend mir schaden, auf die Dauer sich. Wenn sie nur viele fest engagiren wollten.

Aber Du siehst, liebes Kind, daß ich Recht habe, mir zu vertrauen und in die Zukunft zu sein und sparen zu wollen. Bedenke auch du das, du Liebste, weißt gar nicht, wie sehr du den Begriff der „Summen“ verloren hast.

Uebrigens beruhige dich es ist noch immer derselbe (50 W.) Weizen die ich bei Salomon habe. Da komme ich auch wieder heraus.

Bock hat gar kein Recht ärgerlich zu sein, ich habe ihm das auch geschrieben, die Schuld liegt natürlich an Rubinstein, dessen Verlagsverhältnisse ich ja nur oberflächlich kenne.

Nun, ich weiß, du bist in Berlin für mich auf dem Posten - gehe zu Klindworth (der ist durch Bülow gezwungen zu mir zu halten, steht auch jetzt zu Krause zu gut, um mit Lessm zu sein na, diese complicationen.

Eben Saint Saëns gesprochen dessen neue Sinf. gestern hier gespielt. Morgen kommt Moschkowski.

Leb' wohl, geliebtes Weib, du hast keine Ahnung von meiner augenblicklichen Arbeitskraft. Sei nicht boese. Wenn mich mein Beruf erfüllt, so bin ich ein wenig unbrauchbar, das weiß ich, aber du kennst mich und glaubst an meine Liebe.

Leb wohl, küsse die Kinder u sei innigst umarmt von deinem Hermann

\section{ID 4: Brief vom 21.5.1886 [aus London]}

\section{Mai 1886}

\section{Liebe Louis[e]}

Während des ebenstattfinden[den] Concertes erhalte [ich] Dein einl. Telegramm, dessen vorletztes ich nicht entziffern kann. 
„Sei ruhig, bleibe ruhig, mein Kind““

Wüllner wird sich nicht von Lessmann noch von einem andern als mir engagiren lassen. Ich nehme an, daß Klind[worth] u Lessm[ann] gebrochen haben. Meine Concurrenz will mit einem Mal alles das machen, was ich allmähl[ich] geschaffen. Das geht nicht und ich glaube, daß ich Recht habe, diesem stürmischen Anlauf mit einiger Ruhe zuzusehen. Die Wogen werden sich wieder verlaufen. An Wüllner schreibe ich trotzdem, aber sehr ruhig und bewußt. Rege dich nur nicht auf, geliebte Seele, forsche u. benachrichtige mich, aber in Ruhe. Was nicht zu ändern ist, muss ertragen werden, was zu verbessern ist, verbessert werden. Das alles hätte meine Anwesenheit in Berlin auch nicht geändert. Und wenn ich zurückkomme, bleibt mir Zeit genug. Übrigens wisse, daß ich von hier aus hart arbeite, viel schreibe, den ganzen Tag! Nat[ü]rlich müssen wir in der Nähe v. Berlin bleiben. Und du siehst immer wieder, Louise, daß ich Recht habe, nicht bedingungslos auf die Zukunft zu bauen. Aber, Kind, es wird auch weiter gehen, ich fühle Arbeitskraft. Unterstütze mich nur, du kannst es, aber m[it] Ruhe, ohne Aufregung.

Und nochmal, vergiß dein Hühnerauge nicht.

Ich muss ins Concert zurück, leb wohl Geliebte. Nachts nach Liverpool, übermorg[en] Nacht zurück.

Küsse d[ie] Kinder \& behüte sie. Da sind wir ja vor Concurrenz geschützt. Es lebe die Liebe u wir mit ihr!

Dein Hermann

\section{ID 35: Brief vom 22.5.1886 aus Liverpool}

[Briefpapier: Adelphi Hotel, Liverpool]

Liverpool, 22 Mai 1886

Gute Nacht, Geliebte. Jetzt rutschen wir zurück nach London. Rub[instein] sagte das II Conc[ert] hier ab, weil es heute zu leer war. Er war einen Moment verstimmt, natürlich gegen mich, obgleich ihm seine Einnahme garantirt war. - nun ist's vorüber. Aber so ist gesorgt, daß ich nie ohne Aufregung bleibe. Es wäre oft zum Verzweifeln.

Zum Weinen, hielte mich nicht der Gedanke an euch, meine Geliebten. Und so will ich auch jetzt nicht zur Bahn gehen, ohne dir diesen Nachtgruß zu senden. Es ist keine Portoverschwendung, wenn in diesen Briefen nichts weiter drin steht, Liebste - soweit vom Heim, im fremden Land $u$. mit so vieler Verantwortlichkeit, da erlöst ein Wort der Liebe, des 
Grußes. Küsse Edith Werner \& Lilli. Sind es denn noch meine Kinder?

Ach, leb“ wohl Geliebte

Dein

Hermann

\section{ID 36: Brief vom 23.5.1886 [aus London]}

Wie geht's dir, Liebste?

Ich bin heute von den 2 auf der Bahn verbrachten Nächten etwas caput, muß aber Abends doch zu Emil Friedlaender, der mich zum Essen eingeladen. Rubinst[ein] ißt heute beim Grafen Bylandt.

Deinen gestrigen Brief erhielt ich natürlich erst heute bei meiner Rückkehr. An Bülow, siehst du, habe ich auch nicht einen Augenblick gezweifelt. Ueberhaupt, Liebste, ist auch diese Concurrenz noch nicht die richtige. Das, du wirst es sehn - wird nicht halten - ich aber halte und werde schließlich noch dadurch gewinnen. Habe ich dir erzählt, daß ich neulich mit Rubinst. im „Micado“ war, der ja auch nach Berlin kommt. Ich kann mir nicht denken, daß, ohne das Textbuch zu verstehen, bei uns ein längeres Gastspiel reüssiren kann: Noch sträube ich mich nach Paris zu gehen - die Seefahrt ist mir schrecklich, aber es ist möglich, daß ich muß! Der olle Massart hat direct an Rub[instein], ich müsse kommen. Nun, ich werde sehen. Ich bin heute fabelhaft ermattet u möchte am liebsten schlafen. Weder Geist, Herz noch Feder sind eines Aufschwungs fähig - ich fühle nur durch alles hindurch, daß ich dich liebe $u$ daß du begreifst, wie nach allen diesen Aufregungen eine absolute Abspannung eintreten kann.

Kusse [Küsse] die Kinder, Liebste, u sei umarmt von deinem treuen Hermann

23 Mai 1886

ID 12: Brief vom 25.5.1886 aus Manchester

Manchester 25 Mai 1886. 


\section{Geliebte.}

Heute früh um 6 Uhr aufgestanden \& nach Manchester gefahren, wo heute Abend Concert [ist]. Es muß wohl die innerliche Aufregung der letzten Tage sein, daß ich mich so matt \& abgespannt fühle $\mathrm{u}$ am liebsten immerfort schlafen möchte. Nun, ich kann dir nicht beschreiben, wie müde ich bin u welche Ungeduld \& Nervosität mich dabei verzehrt. Hoffentlich vergeht das bald wieder, denn ich bin sonst gesund.

Gestern Abend war ich im Richterconcert und hörte D’Alberts Sinfonie, die recht guten Erfolg hatte. Wirklich! Ich war manchmal geradezu gerührt. Er ist ein Genie.

Frau Slaviansky ist hier - nachdem sie in Paris hereingefallen - hier finden sie (ich meine in London) auch nichts Rechtes. Jedenfalls verlieren sie fortwährend viel Zeit und verdienen blutwenig. Diese Leute sind ordentlich bestraft.

Einl. liebes Kind, die neueste Heirathsanzeige im Original.

Könnte ich weg, ich würde nach London; so aber wo Petersen dabei [ist], muß ich umso mehr bleiben - aber auch in Lond. könnte ich nicht viel ausrichten. Die Gesellschaften engagiren doch nur die Künstler, welche sie wollen. Was mir weggeschnappt werden kann, kann \& muß ich entbehren[.]

Ich bin nicht zu ruhig, liebes Kind, aber ich denke nicht darüber nach, was Jene thun, sondern wie ich weiterkomme. Ich glaube, das ist das Richtige \& denke, ich werde im nächsten Winter genug zu thun haben.

Rege du dich nur nicht auf, lasse dich abreiben, (du hast mir immer noch nicht geschrieben, ob du das thust $u$ ob du an deinen Fuß gedacht) $u$. nenne es nicht Vorwürfe, wenn ich in Momenten, wo man an die Zukunft ernstlicher als sonst denken muß, zur Sparsamkeit anhalte. Warum braucht dich das zu ärgern, Kind, sei doch duldsam.

Auch darin, daß meine Zeilen so wenig Glut ausströmen, aber ich „bin matt zum Niedersinken“. Zeit ists daß ich heimkomme. Ich leide. Zu Friedländer sei nur nett; er bemüht sich wegen Carl!

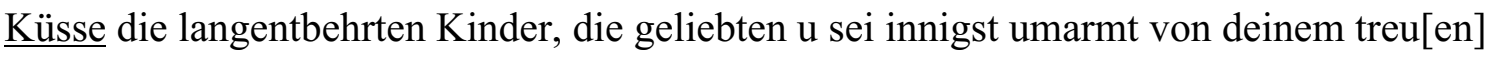
Herm[ann]

\section{ID 37: Brief vom 29.5.1886 aus London}

Lond. 29 Mai 1886

Liebste. 
Wie, du bist einen Tag ohne einen Brief von mir geblieben? Es ist eben kein Tag vergangen, daß ich dir nicht mindestens einmal geschrieben. Das wird sich inzwischen wohl aufgeklärt haben. Und da sagen wir, Religion sei Unsinn. Ich habe mir selber eine construirt, ohne die ich nicht glücklich sein kann: Ich muß - und seien es auch nur wenige Minuten - täglich dir etwas schreiben, etwas sagen. Es ist mein Gebet, das ich zu meiner Göttin sende und das in allem Wortreichthum stets den einen Sinn enthält:

I love you.

Schließe aus dieser zweiten Zeile nicht etwa, daß ich große Fortschritte im Englischen gemacht. Im Hotel spricht man nur französisch, bei Rub[instein] deutsch und unsere englischen Gesellschaften sind vom Deutschen förmlich zersetzt. Unser Hotel! Die „Schwaben“ [sic] kriechen auf den Treppen herum und jeden Augenblick wird eine von einem Gaste zerknackt. Pfui Teufel. Und diese Unruhe, dies Treiben. Nie hättest du hier absteigen können. Dabei horriblement cher. O du mein Paris. Victor Hugo, verzeih' mir, daß ich einmal gelacht, weil du Paris für le coeur de monde proclamirtest.

Gestern Abend war ich zum Diner bei Semons. Meine Tischnachbarin Frau Wwe Haas, Schwester von Gundel Schweitzer der noch Unentbundenen?

Heute gehe ich wieder in die Colonial Exhibition, nachdem ich mit Rub[instein] 2 Concerte Sarasate (3 Uhr) u Neruda (4 Uhr) absolvirt haben werde.

Klind[worth] schrieb mir; nach seinem Brief zu urtheilen wird er wohl kaum ins L[essmann]'sche Lager übergehen. Und thäte er es, er würde es bald zu bereuen haben. Er wird (L.) mit Klein nicht fertig werden.

Moszkowsk[i] seit gestern Abend hier, auch im Diendonné. Das Wetter noch immer kalt u regnerisch. Winterüberzieher hat mir schon oft gefehlt.

Geliebte, wie oft frug ich schon: hast du noch keine kalte Abreiberin? Und Edith schreibt nicht mehr? Als Fräulein allein bei den Kindern war, schrieb sie beinah jeden Tag. Ich habe seit 14 Tagen keinen Brief. Es ist für mich schmerzlich genug, so lange fort zu sein. Da solltest du sie doch etwas zur Liebe zu mir erziehen.

Am 2 Juni bin ich wieder in Manchester.

Leb' wohl, geliebte Frau, ich liebe dich unendlich \& bitte dich, mir recht lieb zu schreiben. Habe ein wenig Mitleid mit Ahasver. Komm, daß ich dich küsse. Dein Hermann

[Am Rand: D’Albert muß noch nichts vom Tode s. Vaters wissen, sonst wäre er schon in London.] 


\section{ID 7: Brief vom 30.5.1886 [aus London]}

30. Mai 1886

Liebste Louise

Auf dem verdächtigen Briefpapier entsende ich dir meinen Sonntagsgruß. Mir gegenüber sitzt M. Moszkowski u. schreibt seiner Frau nach Paris. Es ist der heilige Tag, an dem London ausgestorben ist. Aber auch ich bin es, denn fühle mich sehr matt u. schläfrig. Dabei kann man hier in diesen „Sauhotel“ nicht mal ein Bad bekommen u. es ist mir zu kalt u. naß um auswärts zu baden. Das Schlimmste aber ist, daß der liebe Gott den Briefträgern auf das Strengste untersagt hat, am Sonntag Briefe auszutragen, so daß ich heute ein Nachez ohne Geige - ein Mensch ohne Berechtigung bin; denn noch immer ist es der ungeschwächte Reiz, das unver[ä]nderte Bedürfnis täglich von dir Nachricht zu haben. -

Wir sind hier täglich eingeladen, aber ich erfahre jetzt das Meiste, es hat doch keinen Sinn. Gestern Abend an Queens Birthday, war ich mit einem Herrn Guellemet mit dem ich wegen Charles in Bearbeitung bin, wieder in der Ausstellung, die doch das Großartigste ist, was man träumen kann. -

Soeben kommt Frau Mescheke u bringt mir eine Kravate zum Anknüpfen, weil sie durch ihren Mann erfahren hat, daß ich bisher in London eine solche nicht habe finden können. Nachmittags gehen wir Petersen u ich in den Zoologischen Garten. Ach, du siehst an diesen unvermittelten Sätzen, wie mühsam ich schreibe. Ich bin durch die Londoner Luft abgespannt, u glaube, das war vor 5 Jahren ähnlich.

Conried ist hier, er ist ganz der alte Schwindler $u$ hat bereits diesen Ruf in Amerika.

Kind, heute Abend schreibe ich weiter u wohl besser. Jetzt sei nicht boese - Non possumus; Küsse die Kinder und glaube trotz der Mattigkeit meiner Ausdrücke an die Frische meiner Liebe.

Dein getreuester Herm[ann]

\section{ID 39: Brief vom 4.6.1886 aus London}

\section{Liebe Louise.}

Dein heutiger Brief enthält ein Curiosum - nämlich kein Wort von den Kindern! Ich mache hierzu kein[en] Commentar, denn ich würde vielleicht ungerecht sein. 
Gestern Abend aß ich mit Rub[instein] bei Pauer, D’Alberts Lehrer. Es ist, incl. Größe des Vaters, Sohnes u[nd] 2 Töchtern die ganze Familie Wüllner. Der junge Pauer ist ein famoser Pianist. Heute VI Conc. (Chopin) ausverkauft. Abends wie dann immer Diner. - Morgen esse [ich] mit van Dyk dem Tenor aus Brüssel, der mit der Frl Servais verlobt ist, Sonntag Landparthie nach Hampton Court \& Richmond unter Rub[instein]'s Leitung!

Ich kann mich immer noch nicht entschließen, nach Paris zu fahren \& doch, f[ü]rchte ich, werde ich müssen. Donnerwetter, davor graut mir.

Mozkowski, der hier eine neue Suite dirigirt hat, großer Erfolg.

Das, Liebste, sind die uninteressanten trockenen Facta, die ich dir mitzutheilen habe. Ich weiß, ich schreibe sie womöglich noch uninteressanter als sie sind, aber Kind c'est plus fort que moi. Ich befinde mich in einem krankhaften Zustand der Aufregung; denn diese Correspondenz mit hier mit Zeitungen \& Künstlern macht mich nervös wie ich nie war[.] Da gehe ich herum, mit den zärtlichsten Gedanken, mit Briefen an dich im Kopf, voll Nettheit u dann setze ich mich hin $u$ irgend ein fauler Künstler kommt, irgend ein Brief $u$ dahin ist Zeit $u$ Ruhe zum ordentlichen Schreiben. Nun, es ist gut, daß es zu Ende; ich hielte es doch nicht mehr aus -

Hast du im Boers. Couri[er] meinen kl[einen] Artikel über „Nettie“ gelesen. Heute etwas an Voss gesendet, die hoffentl[ich] aufnimmt.

Was hier aus Carl werden soll? Er ist energielos, schlapp verrannt, ich habe ihn mit den Leuten in Verbindung gebracht, von denen [ich] einen Nutzen für ihn erhoffte, aber hier wird es nichts; er muß fort von hier.

$\mathrm{Na}$, ich sage nur immer: Louise, sein wir froh mit unsrem Geschick u seien wir vernünftig u bescheiden.

Küsse die geliebten Kinder u sei auf das Innigste umarmt von deinem treuen

Herm[ann]

Lond. 4 Juni 1886

ID 39: Brief vom 10.6.1886 aus London

Liebe Louise. 
Deinen Brief auf d. Rückseite von Franzen's Brief erhielt [ich] noch gestern abend, den in Aussicht gestellten zweiten natürlich nicht. Ich erwarte nun in Ergebung den Moment, wo du mir mit weniger Flüchtigkeit zu schreiben geruhen solltest.

Deine Frage verstehe ich nicht, was wir nach dem 23! machen? wir haben dann noch 4 Concerte! Das letzte am 4 Juli!

Dein Onkel ist noch nicht hier; daß du in Berlin nicht mit ihm über deine Eltern sprechen konntest, ist sehr bedauerlich ich hätte es doch für dringender gehalten, als Manches Andre. Ich kenne ihn übrigens ja nicht, u. weiß noch nicht, ob ich so entzückt von ihm bin, wie du. Leider bin ich am Sonntag, wo er wohl ankommt, in Oxford, es ist der einzige Tag u. ich kann die Sache mit Tadene deshalb nicht einmal mitmachen.

Jetzt (8 Uhr früh) fahren wir nach Sydenham (Crystalpallast) wo die Proben zum Thurm zu Babel sind. Wir bleiben den Tag über dort. -

\section{Abends 7 Uhr}

Soeben zurück! Ich muß vor Allem zu meinem Schneider, der mir einen unglaublichen Anzug geschickt hat. Die Engländer finden ihn schön, ich auch, knapp, kurz. Marianne Brandt ist hier, Lilli Lehm[an] auch, sie alle essen Montag mit uns, wie es denn in unserm Hotel sehr flott hergeht.

Ich bin recht verstimmt; ich verstehe dich nicht recht; Ich glaube nie große Wünsche zu haben u auf die kleinen nimmst du wenig Rücksicht. -

Vorgestern aß ich bei Friedländer. Sie ist in der „besten“ Hoffnung; geht aber mit mir ein Kleid für dich kaufen, das du dir in einem der wenigen längeren Briefe wünschtest.

Adieu, liebe Louise. Ich sehe, ich habe es dir doch noch nicht eindringlich genug geschildert, was es für einen Mann, der die Seinen u. s. Haus liebt, heißt, lange fern zu bleiben.

Küsse unser Dittel u sei geküsst von deinem treuen Herm[ann]

10 Juni 1886

[London]

\section{ID 25: Brief vom 3.8 o. J. [1888?] aus Scheveningen}

Schevening[en] 3 Aug Ab[ends] Geliebte. Sehr unruhig fahre ich weg, denn auf mein heutiges Telegr. mit bez. Rückantwort bin ich ohne Antwort geblieben. Du bist doch wohl, den Kindern ist doch auch nichts? Ich lasse ein Telegramm zurück, das morgen früh expedirt werden soll, um deine Nachtruhe nicht zu stören. Ich fahre mit Bülow via Delfft nach Rott. 
wo ich ein paar Stunden bleibe um - B[ülow] ist doch ein famoser Kerl - einen Dirigenten f. eine neue Gesellsch. in Amst[erdam], meiner Wahl (Moszkowski aus Coblenz) durchzusetzen - Um 11[12?] Uhr Nachts bin ich in Berlin. Ach, Kind, du ahnst nicht, welche Sehnsucht ich nach dir habe \& wie unruhig ich innerlich bin. Der Gedanke so weit von dir zu sein, ist mir beinah unerträglich. Nie weilten meine Gedanken, mein Herz so lebhaft bei dir, wie seit unserer letzten Trennung. Nun, ich hoffe gute Nachrichten in Berlin zu finden. Der heutige Tag war fabelhaft interessant. Da mir Bülow über seine Beziehungen zu Wagner u die Beziehung v Frau Wesendonk zu W. erzählte, stundenlang.

Adieu, küsse die Kinder, grüße Mama.

Dein Herm[ann]

ID 22: Brief vom 12.9. o. J. [1888?], o. O.

\section{Liebes Kind.}

In größter Eile: Es ist möglich, daß ich Nachmittag nach Hamburg muß, weil die Bildung des Orchesters daselbst, durch neue Intriguen v. Bernuth gefährdet ist. Die Sache regt mich momentan natürlich auf, hoffentl. ordne ich sie. Jedenfalls telegrafire ich dir noch. Du hast keine Ahnung Kind, was alles zu thun [ist]. Es ist ein Geschäft, wie so viel vom Moment abhängt. Schließlich gehört mehr Kaltblut dazu, als selbst ich habe!

Auch mit Kleinmichel bin ich wegen der Programmbücher - im Guten allerdings auseinander. Langhans macht sie nunmehr. Aber das alles will stets sofort erwogen sein u. das Richtige soll man auch treffen.

Nun schnell leb wohl, mein liebes Kind; wenn ich dich erst wieder bei mir habe, bin ich vielleicht, so ,unangenehm“ wie immer, aber wohler ist mir doch.

1000 Küsse Dir u. den Kindern

Dein Hermann

ID 26: Brief vom 5.11. o. J., o. O.

[Briefpapier: ,, Concert Rubinstein Hermann Wolff"]

Geliebte, 
Wie gewöhnlich dehnte sich die Schlemmerei gestern Abend wieder so aus, daß ich meinem Vorhaben dir noch einmal zu schreiben untreu werden mußte. Dabei mußte ich noch meine ganze Energie entfallen, um mich von dem Loewy, der durchaus noch weiter wollte, loszumachen und so ging ich dann mit Rubinstein und Bechstein „zu Bette“. Heute Abend leider gibt Rubinstein wieder ein großes Banquett im Hotel Strett, um sich für Concert v Nero zu bedanken; da ich am ersten Neroabend beim Souper eine sehr beifällig aufgenommene Rede gequatscht hatte, so lässt mir R[ubinstein] keine Ruh[e] und will durchaus ich solle heute für ihn reden; es ist mir das umso fataler, als in der Gesellschaft sehr viel gute Redner sein werden. $\mathrm{Na}$, wir wollen sehen.

Die Concerttournée wird nun glücklicher Weise wohl bestehen bleiben. Die ganze Route steht immer noch nicht fest, in Berlin am 13. Nov. - welch ein Gedanke, wirst du sie aber erfahren. Gestern Abend waren wir übrigens vor dem Abendbrot in der Oper: Der Vampyr. Im Lauf des gestrigen Nachmittags regte sich in mir auf einmal der Makler und ich war angenehm überrascht, in der Zeitung zu finden, daß es doch wieder flau geworden. Hoffentlich wird es noch viel viel viel flauer, dann werde ich recht leichten Herzens zurückkommen.

Es sind heute 8 Tage bereits, daß ich fort bin. Soll ich dir sagen, daß es mich sehr lange dünkt und daß der Gedanke noch fünf Wochen Reisen zu müssen nur durch den pecuniären Vortheil erträglich wird? Glaube mir Louise, es ist einträglich aber schwer Impresario eines Mannes wie R[ubinstein] zu sein. Und Du Kind, die Du mir im jeden Briefe einen anderen Schmerz klagst, bist du jetzt wenigstens wieder von allen Leiden frei? Wie viele Fragen hätte ich an dich zu stellen, die ich dem Papier nicht anvertrauen mag, daß du mir aber nicht einmal von selbst meldest, daß du frühstückst, das, Kind, finde ich einfach herzlos. Lass mich es dir noch einmal sagen, daß du dich recht in Acht nehmen, schonen sollst, denn der Gedanke an Dein Wohl, die Hoffnung auf ein glückliches Verlaufen der nächsten Monate beschäftigt mich unaufhörlich und ich bin glücklich, wenn du dich wohl befindest. Also schaue Geliebte, mir so viel es in deiner Macht steht, dies Glück zu verschaffen.

Was machen Linda u. Emil du schreibst mir gar nichts von ihnen. Frage Emil ob er auch schon einmal nach Amsterdam geschrieben - Und sage Papa daß ich heute Abend mit einer Tochter des Prof. Weiden aus Cöln zusammen sein werde. Grüße alle, besonderes aber Mama, der es hoffentlich doch gut geht. Du aber mein liebes Kind glaube mir, daß mir keine Trennung so schwer gefallen ist wie diese - und was das Schlimmste - immer schwer fallen wird

Leb wohl, Louise, komm laß Dich ans Herz drücken. Deines treuen liebenden 5 Nov. $1 / 28$ Uhr früh Hermann 


\section{ID 27: Brief vom 3.12. o. J. aus Moskau}

\section{Moskau Hotel Billo}

3 December.

\section{Geliebte.}

In aller Eile einen riesigen $\mathrm{Ku} ß$ aus Moskau wo wir um $10 \mathrm{Uhr}$ früh angekommen. Es ist nicht möglich, Geliebte, bei diesen colossalen Reisen, der Kürze des Aufenthaltes, der Fülle der Eindrücke \& der Masse von bekannten resp. neuen Freunden viel u. geregelt zu schreiben. Vor Allem nicht interessant. Die Postzeiten sind hier unmöglich; ich muß Alles gesehene \& erlebte erzählen; verlaß’ dich auf meine Ausführlichkeit u daß ich dir Interessantes berichten werden, dafür bürgt das Interessante, das ich erlebt \& gehört.

Rubinstein hat sich, ebenso seine Frau noch oft für das Kissen bedankt; das war eine gute Idee. Petersen war vor meiner Abreise noch bei mir. Rubinst. hätte uns gern noch zum Frühstück gehabt; Bock wird das wohl allein genießen. Es ist ganz gut so; nach Petersens Aufregung halte ich es nicht für ausgeschlossen, daß ich doch noch einige Tourneen für R. machen werde, denn er greift sein Capital bereits an. Rub. ist ganz Conservatoriumsdirector. Seine Frau interessirt sich für nichts, was nicht in den Concerten, nicht beim officiellen (faulen) Festdiner (mit Damen), kurz es ist eine ,äußerliche“ Geschichte. Die Gegenparthei Rub. ist leider 10 mal größer, als die Zahl seiner Freunde. In den Concerten wurde ostentativ nur der Pianist gefeiert, der Componist kühl behandelt. Die russ Z[ei]t[un]gen wüthen gegen ihn; eine Geldsammlung ist so erbärmlich ausgefallen, daß man die Ziffer nicht zu sagen wagt, die Hofparthei ‥ der Kaiser ist gegenwärtig gegen ihn. Niemand vom Hofe war dabei, die kais. Oper \& d. kais. Orch. haben nicht gratulirt, kurz, wenn Rub. nicht blind [ist], muß er über kurz oder lang einen Ekel vor der ganzen Wirthschaft bekommen. Und welch' eine Wirthschaft! Wenn ich dir meine Ausweisungsgeschäfte ausführlich erzählen werde, wirst du begreifen, was hier „los“ ist \& „gehen“ wird.

Moskau ist als Stadt mit halb asiatischem Characte[r] auf jedem Schritt interessanter als ganz Petersb[urg]. Ich bin glücklich, meinen Star ausgeführt zu haben. Eben wa[en] wir Gäste des Musicalienhändlers Gutheil in der „Eremitage“. Von dieser märchenhaften Zauberpracht machst du dir keine Vorstellung. Was raffinirter Luxus ist, lernt man da kennen! Es lässt sich nicht beschreiben, namentlich nicht brieflich, wenn man, wie wir, gleich in die russ. NationalOper will um Rubinst[ein]s Daemon zu hören. 
Stangel-Sembrich scheint in Warschau allerlei Dummheiten zu machen, telegrafirt, [ich] solle sofort hinkommen. Natürlich thue ich das nicht. Für $5 \%$ auch noch commandiren. Es sind unglückliche Leute.

Liebste, Geliebte, deine Briefe athmen Zauberduft echtester Liebe; deine Worte fallen auf den empfänglichsten Herzensboden, ich bin selig, glücklich \& meine immer, du müsstest aus jedem meiner täglichen Depeschenworte die Intensivität meiner Gefühle herauslesen. Zürne nicht, wenn ich im Gegensatz zu diesen Empfindungen flüchtig schreibe. Es ist nicht anders möglich, wenn man eine halbe Welt durchrast \& so viele Menschen sehen soll \& dabei so viele Vorurtheile bekämpfen soll, wie ich hier gegen mich finde.

Am Son[n]tag früh 6 Uhr bin ich in Berlin; Freitag früh in Warschau, von wo ich Sonnab[end]. Nachm[ittag] abfahre. Lebe wohl, Geliebtes ..., innigst Geliebte, ich küsse dich mit Enthusiasmus \& Bräutigamsfeuer Dein Hermann Eben erhalte [ich] Deinen Brief v. 30 Nv., so wie Gesch[ä]ftsbriefe, mit Einlagen aus Amerika.

ID 28: Brief vom 16.12. o. J. aus Wien

[Briefpapier A. Kührer's Hôtel Bristol Wien]

Geliebte.

Als ich vorher herunter ging, gab mir der Portier dein Telegramm! Gestern Abend um $1 / 212$ als ich in's Hotel kam, war noch nichts da; ich nahm also an daß du es Abends sehr spät aufgegeben hast. Wohl nach dem Diner?

Gutmann hatte mir 2 Plätze zu Tristan geschickt, wovon ich einen Mizi schickte und so sahen wir, mit Gutm[ann], der mit seiner Gattin nicht auf den besten Füßen zu stehen steht, eine mäßige Vorstellung unter Richter, mit dem ich auch sprach.

Meine Besprechung mit Mottl findet gleich - 11 Uhr statt. Ich war gestern gleich bei der Standhartner - Mottl muß schon seit vorgestern hier sein, behauptet auch Richter. Ebenso Schönaich, der ein „Vetter“ der St., sich mit Mottl wegen dieser Heirath entzweit hat. Gegessen habe ich gestern bei Euch - sehr gut. Vater zu dem ich jetzt schnell hingefahren, soll glänzend geschlafen haben \& fühlt sich wohl. Ich habe dir das auch telegrafirt; du kannst ganz beruhigt sein. Mutter ist auch wohl.

Ich denke sicherst heute Abend zurück zu fahren; bin selbst gespannt auf meine Unterredung. Wenn doch das Alles überflüssig würde! Ist auch nicht das Rechte! 
Ich will diese[n] Brief noch mit der Frühpost abgehn lassen, damit du ihn vor meine[r]

Rückkehr hast. Darum Schluß.

Rub[instein] muß natürlich nach Stutt[gart]. Weiß er auch. Hat wohl nur verschwitzt. Tendre weiß Bescheid.

Dr. Hirschfeld \& Stefanolt sind getrennt.

Panteo soll nicht lohnen.

Leb wohl, Geliebte, ich bin $\underline{s e h r}$ in meinen Gedanken bei dir \& freue mich auf die Heimkehr. Ich küsse dich \& die Kinder innigst

Dein

Hermann

16 Dec.

$10 \mathrm{Uhr}$

ID 19: Brief vom 28.2. o. J. aus Wien

Wien 28 Feb 9 Uhr früh

Liebste.

Was gestern im letzten Concert an Enthusiasmus geleistet worden, lässt sich nicht beschreiben. So viel steht fest, Wien liebt Rubinstein am meisten. Die Zeitungen feiern ihn, das Publicum vergöttert ihn, ist wahnsinnig vor Entzücken u thut alles, um dem Manne seine Liebe zu beweisen. Am Dienstag, dem Verkaufstag für das letzte Concert war bei Gutm[ann] der Andrang so stark, daß Verwundungen, Erkrankung[en], Verhaftungen vorkamen \& alle Scheiben im Geschäft zertrümmert wurden. Wien ist im Rubinst[ein]-fasching. Nach dem Conc[ert] großes Festsouper im Hotel Sonnenthal, Hartmanns, Gabillons, Wolter, Krastel, Thimig, Lewinsky, Jauner, Rosa Papier, Marie Lehmann, Reichmann, Boesendorfer, Therese, E. Robert, Bamin[nicht lesbar], Hallenstein, Walther etc. Wilbrandt (ohne Gattin). Sehr heiter, viele Reden - aber wie immer im großen Kreise - ich war absolut unbrauchbar, sentimental u langweilig. Rub[instein] hatte leider wieder allen gesagt „wartet, wenn der Wolff kommt, wird's lustig["] u so hatte ich dann mal wieder Enttäuschung hervorgerufen. Die Deinen waren (10 Mann hoch) im Concert, die Mutter kam auch zu Rub[instein] Abends fand ich deine Bleistiftkarte, die mir lieber war als alles Uebrige u glaub' mir Geliebte, schwerer als du annimmst, ist mir der Abschied von dir geworden. Ich bin in solchen Momenten, noch dazu vom Geschäft bedrängt, ganz hirnlos; ich empfinde, was ich empfand, 
erst später. So gehörte der gestrige Tag trotz allen Trubels nur dir, denn du Louise, bist mir doch das Höchste, Einzige.

[...] Addieu. Louise, ich liebe dich d[ein] Herm[ann]

ID 21: Brief vom 20.6. o. J. aus Nauenahr

\section{Liebste.}

Ein Gewitter eröffnete heute den Tag, als wollte der sich für seinen Verlauf reinigen und nun sitze ich bei geöffneten Fenstern und schreibe. Balsamisch dringt es in mein Zimmer, das gegen die Gewohnheit - zum ersten Mal seitdem ich hier, noch nicht in Ordnung gebracht ist. Hier geht nämlich alles sehr regelmäßig \& pünktlich zu. Der Gemeindevorsteher betrachtet seine Gäste als seine Privatgemeinde und legt ihr auch genügend Steuer auf.

Gestern entschloß ich mich noch, Nachm nach Bonn zu fahren[.]

Ich habe es nicht bereut, denn ich traf Dr Prieger, der als Besitzer Beethovenscher Handschriften bekannt ist, ein reicher Mann, bewohnt eine prachtvolle Villa in herrlichem Park. Er zeigte mir vor allem den Schlußsatz der neunten Sinfonie, die ich mit wirklicher Ergriffenheit u. Ehrfurcht betrachtete. Dann sah ich - u. spielte auch ein wenig - eine Reihe unveröffentlichter Compositionen Beethovens u. Haydns so wie ein authentisches Bild Beethovens, lauter Dinge, die Prieger veröffentlichen will, sobald das neue Urhebergesetz heraus ist, das den Nachlaß nachdrückl. freier Autoren noch 10 Jahre schützen soll. All' diese Schätze lässt er Tag und Nacht von 3 Hunden bewachen. Wie er behauptet, repraesentiren seine musicalischen Manuscripte allein ein großes Vermögen. Ich blieb ungefähr $1 \frac{1}{2}$ Stunden - er wollte noch aufs Grab seiner grade vor einem Jahr verstorbenen Mutter, mir zu Lieb' war er als ich ihm vor seinem Hause begegnete, umgekehrt, um mir seine Schätze zu zeigen - was er gern und mit Stolz thut - dann wandelte ich durch das an schönen Villen reiche Bonn, verbrachte einige Zeit in einer großen Buchhandlung und fuhr dann nach Neuenahr zurück. Ich dachte vielleicht noch etwas von dir zu finden, aber du hast dich, wie ich merkte, am Montag auf eine Postkarte beschränkt. Ich fand nur einen Brief vom Bureau u. Emil Sauer, der mich wegen seines kl. concertes unangenehm „dremmelt“. Und so unumwunden hatte ich es abgelehnt.

Heute vormittag hatte ich auch ein paar Zeilen von Edwin, der in Carlsbad, seines Magens halber, sitzt und mir gern ein Lebenszeichen geben wollte.

Und unser Sommer! 
Dein Kopf ist leer, schreibst du - und der meine ist voll. Und beides kommt auf dasselbe hinaus. Wenn wir einige Wochen alle zusammen und wir zwei dann allein sein wollen, so ist die Lösung der Frage nicht so einfach. Ich möchte nicht gern ganz auf die Berge verzichten und andrerseits nicht zu viele colossale Reisen machen. Tirol und dann Ostende Scheveningen, ist etwas hastig! Aber du siehst ja so Viele in Berlin, frag doch auch, wo lassen wir die Kinder wenn wir fort? Na, ich bin ja Anfang nächster Woche zu Hause, dann wollen wir alles gründlich erledigen. Aber Liebste, ich wäre dir für durchdachte Vorschläge dankbar. Nach den Zeitungen und den Thatsachen sind wir ja eigentlich schon im schönsten Krieg mit dem lieben China, wir haben sogar schon unsere Todten und Verwundeten. Mehr kann man beim besten Willen nicht verlangen. Mobil gemacht wird auch. Die Flottenvorlage hat wirklich Glück. Aber - man könnte Pessimist werden und düster sehen, was entsteht aus all dem!

Jetzt, in dem ich das Wort „düster“ schreibe, ist das Gewitter wieder gekommen, der Himmel ist schwarz, es gießt fürchterlich, die so nahen Berge sind verschwunden in Nebelwolken, es stürmt und rauscht - wie lebhaft, sehnsuchtsvoll fliegen da die Gedanken zu dir, Geliebte, mehr noch als bisher fühle ich, geistig dir näher, die thatsächliche Trennung. Aber lebhafter auch malt sich mir die Freude des Wiedersehens.

Ich schreibe dir noch ganz genau, wann \& wo ich ankomme ich muß nämlich, meines Rundreisebilletes wegen über Fulda fahren kaum ein Umweg.

Leb wohl, Louise, heute brauche ich noch dringend einen Brief von dir, es ist sonst zu „düster".

Küsse die Kinder und sei umarmt von

Deinem dich innigst

liebenden

Hermann

20. Juni.

ID 18: Brief vom 26.6. o. J. aus Köln

[Briefpapier Hotel Disch Cöln]

Liebste. Als ich gestern Abend um 10 Uhr hier ankam, war ich in jener halbverzweifelten Stimmung, der ich immer verfalle, wenn wir beide gleichzeitig u. doch getrennt von [zu] Hause weg sind. Dann habe ich so das Gefühl, als seist du mir entrissen, es ist mir wie ein 
Stück Wirklichkeit aus jenen Träumen, die ich dir sooft erzählt. Und dabei war ich ohne Brief von dir abgereist. Kurz ich legte mich ohne Ruhe u ohne Hemd in's Bett. Ohne Hemd, weil man vergessen hatte, mir ein Nachthemd einzupacken \& ich in der Hitze kein gesteiftes anhaben mochte.

Heute war bereits von $10 \mathrm{Uhr}-2 \mathrm{Uhr}$ Concert, du kennst das ja von Weimar her, Nachm. die heilige verfluchte Elisabeth. D'Albert ist hier (mit Frau). Bülow kommt Abends, Brahms auch, Ochs, Lessmann (Frau Nathan auch) Brodsky, Litt, alle Musicdirecto[re]n sind da, Marie Schneider hat bereits sehr schön gesungen, ich bin beständig umlagert, nebbich, ich bin ja der „einzige“, aber trotz des Trubels wünsche ich, ich wäre zu Hause \& ich will auch nicht alle 4 Tage bleiben, obgleich der 4te der schönste, sondern am Dienstag zurückfahren. Ich nehme an, Geliebte, daß meine Cölner Reise keine Fiber in dir mehr erregt. Ich werde morgen ,sie“ im Concert, indem sie in einem Wüllnerschen Psalm mitwirkt, zwar sehen \& hoffentlich auch sprechen, aber ich denke, daß dies geschäftliche Factum keine Wunden schlägt. Laß mich über dies un[n]ütze Thema nicht weiter sprechen. ich berührte es nur, um es berührt zu haben. Denn Geliebte, du kannst an meiner Liebe nicht zweifeln. Du bist mir zu theuer, dich zu haben, ist so der einzige befriedigende Gedanke, der mich erfüllt, - du u die Kinder. -

Eben kommt dein Telegramm. Natürlich, am 3. komme ich; wir wollen dann auch nach Marienbad. Weißt du, daß ich immer eine gewisse Unruhe habe, dich in Fr. zu wissen; ich möchte bei dir sein.

Kind, ich kann nicht schreiben, der Gedanke an dich erregt mich schon seit einigen Tagen krankhaft. Ich bedarf einer Versich[e]rung deiner Liebe.

Lebe wohl, küsse Werner Lili \& sei umarmt von Deinem bewegten sehnsuchtsvollen, unzufriedenen

Hermann

C[ö] $\ln .26$ Jun.

Gille lässt grüßen.

ID 13: Brief vom 8.11. o. J., aus Hamburg

Mein liebes Kind

Ich bin nicht böse, trotzdem ich es nach deinem heutigen wuthschnaubenden Zeilen sein dürfte; denn schon mein gestriger Brief muß dich wieder auf's Neue belehrt haben, daß es nicht allein versehentlich sondern sogar unausbleiblich ist, wenn man in Hamb[ur]g, in 
R[ubinstein]'s Gesellschaft als eine verspenderei nicht immer das gewünschte leistet. Das[s] andere Männer - manchmal führst du ja andere Männer an, unter solchen Verh[ä]ltnissen, vielleicht nicht einmal jeden Tag schreiben würden, ist sehr wahrscheinlich - aber ich könnte es eben nicht übers Herz bringen, dich einen Tag ohne Nachricht zu lassen und deshalb, Louise, wäre es vielleicht netter gewesen, wenn du deinem Zorn keinen wenn auch noch so verhüllten Ausdruck gegeben. Auch hat dich mein Brief von gestern inzwischen über Manches aufgeklärt wonach du heute fragst. Trotzdem muß ich dir wieder von einem neuen Gelage schreiben, das gestern Abend Barnay uns gab, nachdem er im Stadttheater vorher den Lear theils nicht gut, theils schlecht - immer aber zu jung gespielt hatte. Es war ein sehr gemüthlicher Abend, die kleine hübsche Arndt, die früher am Schauspielhaus war, war meine Tischnachbarin. Rub[instein] ist ganz in das Mädchen verliebt, das übrigens seinerseits nur für Barnay „erbrannt[“]. Glücklicherweise kamen wir schon um halb 2 nach Hause. Pollini, der gestern Abend von Berlin zurück ist, hat mich zu heute Mittag wieder eingeladen. Du hast keine Ahnung, wie der Mann aufmerksam gegen mich ist, ich kann ihn aber auch wirklich gut leiden. Heute Abend ist endlich einmal Rub[instein] in einer Familie, die mich nicht kennen. wenn ich daher nicht mit Pollini, Sauer zusam[m]en sein muß, so werde ich mal ins Thalia Theater gehen, wo, wie Levi sagt, Conzert. Stücke wie im Burgtheater gespielt werden. Am Sonntag gibt Rub eine Matineé im Theater, Abends dirigirt er Nero und Montag früh verlassen wir diese[n] Sündenpfuhl, in welchem ich vielleicht der einzige bin, der stolz an seine Brust schlagen darf - und dem doch sein -hätten wir unterdrückt „Papiergardinenpredigt“ hält. Aber wie gesagt, ich bin nicht böse, weil ich dich viel zu gern habe. Trotz dieser Liebe muß ich aber jetzt schließen, da ich noch viel zu thun habe $u$ Vormittags schon bei Pollini sein muß. Sei gut, Kind - und laß dich umarmen von Deinem Hermann

Hamb[urg] 8 Novb 9 Uhr

ID 17: Brief o. D. [1892?] aus Wien

[Briefpapier Grand Hotel Vienne]

Liebste.

Obgleich noch ohne deine charactervolle Handschrift, will ich doch, da ich nicht rachsüchtig angelegt bin, dir einen kurzen Bericht meiner bisherigen Erlebnisse geben. Die Versicherung, daß ich wohlbehalten im seuchenfreien Wien angekommen [bin], hast du gestern schon telegrafisch erhalten. Es war mir in Dresden ein ungemein wohlthuendes Gefühl gewesen, 
Eure lieben Stimmen noch durch das Telefon zu vernehmen. Das gab mir eine gewisse Ruhe zur Reise, denn ich war durch den bei Rubinst[ein] verlebten Tag etwas exaltirt. R. war famoser denn je! Wir machten das Programm, sprachen über seinen Winter; er äußerte eine vollständige (ich glaube aber vorübergehende) Apathie gegen alles Musikbetreffende, so daß ich zuerst zagte, ihm vom Einweihungsconcert zu sprechen. Glücklicherweise fing er selbst davon an. Dann gingen wir zu Tisch \& saßen bis 3 Uhr zusammen, in unsere beliebten philosophischen Unterhaltungen vertieft, daß wir nicht merkten, wie der Speisesaal sich längst entleert hatte. Du kennst ja diese Stimmung bei mir, in der ich dann Cognac trinke ohne es zu merken, Cigaretten rauche, um es zu bereuen - aber es sind dann doch wenigstens Stunden gewesen, die man nicht vergißt. Nach Tisch kam der Kl. Hofmann, um Stunde zu nehmen. Es gibt keinen Lehrer, wie Rubinst[ein]. Bülow ist der sarcastische kritische scharfe dialectische Professor, Rubinstein ist der poesievolle, geistreiche inspirirende, weihegebende Priester, welcher predigt \& lehrt u. - ausübt. Staunen Bewunderung \& Rührung erfüllten mich - will man Rub. ganz kennenlernen, so muß man einer solchen Stunde beiwohnen. Das kann man, das liebt er sogar u. auch vorgestern war die Zuhörerschaft zahlreich. [...] Und nun leb wohl, Liebste, ich bin Samstag Mittag zurück.

Der Vater ist wohl Mutter auch \& was dir hoffentl. nicht unwichtig [ist,] ich auch. Küsse die Kinder \& sei innigst umarmt von deinem treuen Hermann

\subsubsection{Künstlerbriefe}

\section{Fritz Busch}

ID 124: Brief von Fritz Busch an Edith Stargardt vom 3.8.1949

\section{August 1949}

Mrs. Otto Stargardt

19 Oakdale

Pleasant Ridge, Michigan

Liebe Frau Stargardt:

Leider habe ich Ihren freundlichen Brief im Augenblick nicht zur Hand, und meine Frau legt die Hand an das ver...... Buch, so dass sie mir auch nicht beistehen kann. Nur kurz, dass die Ihnen gewordenen Informationen ueber mein Verhaeltnis zu Krenek nicht stimmen. „Jonny 
spielt auf" wurde selbstverstaendlich, wie fast alle Opern, die damals von Interesse oder Bedeutung waren, in Dresden von mir zur Auffuehrung angenommen und kam erstmalig unter der Leitung von Kutzschbach am 29. Oktober 1927 aus, und erlebte eine Anzahl von Auffuehrungen, obwohl der Erfolg kein eindeutiger war.

Soweit vom Geschaefte. Meine Frau und ich wurden nach Konzerten in Ravinia Park von einer Virus Infektion befallen, die zwar mit dem neuen Wundermittel Aueromycin in relativ kurzer Zeit geheilt wurde, uns aber doch sehr schwaechte. Wir mussten die geplante Gastspielreise nach Suedamerika aufgeben und gingen statt dessen nach Riverdale zurueck. Mitte August wollen wir per Schiff nach Holland und von dort nach der Schweiz fahren und ab Mitte September geht das Dirigieren wieder los. Erst Weihnachten sind wir hier zurueck. Ihnen und Ihrem verehrten Gatten alles Gute, auch von meiner Frau, die sehr um Entschuldigung bittet, dass sie Ihnen nicht selbst schreiben kann, und Ihrem - trotz der Ferien immer stark beschaeftigten

Fritz Busch

\section{Teresa Carreño}

ID 118: Brief von Teresa Carreño an Louise Wolff vom 18.6.1895 $5^{719}$

Kurfürsten Damm 28

le 18 Juin 1895

\section{Chère Madame}

J'avais tant espéré pouvoir venir vous dire un petit bonjour avant mon départ, et avoir le plaisir de serrer la main à vous et à votre cher et si bon mari; mais, à l'heure que vous m'avez indiquée il m'a été tout à fait impossible de venir vous voir, à cause des tristes affaires qui m'on tenue ici si occupée, et maintenant que ma présence à Berlin n'est plus nécéssaire, je sens un tel besoin de me retrouver avec mes enfants, que je pars demain soir pour aller auprès d'eux. Vous qui êtes une mère si aimante me comprendrez, et surtout, dans ma triste position, pourrez vous imaginer combien j'ai besoin de mes enfants! Je viens donc vous dire au revoir jusqu'à la fin de Septembre lors de mon retour en ville et je compte sur votre si bonne

\footnotetext{
${ }^{719}$ Ich bedanke mich Frau Gisela Fleischmann für ihre Hilfe bei der Transkription der französischen Briefe im Rahmen der vorliegenden Arbeit. Die Verantwortung für die Korrektheit liegt jedoch bei der Verfasserin.
} 
promesse, de me donner le plaisir, aussi souvent que possible, de nous voir, ainsi que votre cher mari, à qui je vous prie de dire mille amitiés de ma part.

En vous souhaitant à vous et à toute votre chère famille un Été plein de bonheur et surtout de santé, agréez, je vous prie, chère Madame, l'assurance de mes sentiments d'amitié et de sincère simpathie $[$ sic $]$

Teresa Carreño

\section{Carl Halir}

ID 103: Brief von Carl Halir an Hermann Wolff, o. D. [1894?]

Sonntag Vormtg.

\section{Lieber Herr Wolff!}

Leider kann ich nicht, nächsten Montag das Rubinst[ein] conc[ert] in Hamburg spielen, da ich es nicht in den Fingern habe u. meine freie Zeit augenblicklich zum Studium des Joachim'schen Concert verwenden muß, welches ich Sonnabend auf der Hochschule (zum 25. Jubiläum derselben) spiele.

Mit Bedauern Ihr

Carl Halir

ID 83: Brief von Carl Halir [an Hermann Wolff?] vom 17.9.1895

B. 17.9. 95

\section{Lieber Freund!}

Vor allem meinen Dank für Ihre Freundlichkeit. Wenn ich heute nochmals eine längere Epistel an Sie richte, so geschieht es um Ihnen vis à vis mich zu rechtfertigen, damit Sie mich nicht etwa für ein leichtsinniges Huhn oder gar für ein Pumpgenie halten. In den letzten Jahren meines Weimarschen Aufenthaltes lebte ich in sehr geordneten Verhältnissen, fing sogar an mir ein par tausend Mark zurückzulegen - da kam der Krach des dortigen Sparvereins, ich verlor nicht nur die par Groschen sondern muß noch heute monatlich 100 Mark nachzahlen da sich alle Mitglieder verpflichten mußten 4000 M. zu berappen. 
Durch meinen Weggang von Weimar mußte ich aber noch eine 2. Verpflichtung übernehmen: Die Frau Großherzogin hatte mir s. Z. eine Geige für 10.000 M. gekauft, d. h. sie hatte mir das Geld gegeben unter der Bedingung[,] wenn ich Weimar verließe, diese Summe zurückzahlen zu müssen. Dieß thue ich nun u. habe ich meine ganzen Concerteinnahmen des letzten Winters dazu hergegeben. Noch muß ich $100 \mathrm{Mk}$ monatlich für eine Lebensversicherung bezahlen, denn Sie begreifen, daß man seine Familie f. alle Fälle sichern muß!

So sind meine Verhältnisse.

Sie sehen darin hoffentlich auch eine Entschuldigung, daß ich im letzten Jahre u. heuer meinen geschäftlichen Verpflichtungen bei Ihnen noch nicht nachgekommen bin. Ich vergaß vorhin auch noch den Umzug zu bemerken, der mit dem 1. Aufenthalt in Berlin wo ich keine Nebenverdienste hatte, ein großes Loch in meine Tasche riß: Nun Gott lob kann ich ja nicht klagen - wenn ich auch wie es scheint wenig Aussichten auf Concerte habe, so ist doch meine Lehrthätigkeit jetzt schon so in Anspruch genommen, daß ich hoffe in nicht allzulanger Zeit wieder den Kopf hoch zu halten. Ich bitte Sie also, lieber Freund, mir nicht falsch zu deuten daß ich Sie belästigt habe u. daß ich geschäftlich noch ihr Schuldner bin.

Sie haben sicher mit vielen Menschen \& Künstlern traurige Erfahrungen gemacht, Sie sollen es an mir niemals! Gerade weil ich eine persönliche Zuneigung und Freundschaft zu Ihnen fühle, die ganz unabhängig von Geschäftsinteressen ist, habe ich mich Ihnen anvertraut $u$. Sie um einen Dienst gebeten, und bleibe Ihnen stets in Treue ergeben.

Mit herzl. Gruße

C. Halir

\section{Amalie Joachim}

ID 89: Brief von Amalie Joachim [an Heinrich Reimann?] vom 19.10.1894

BERLIN W., 19. Oct. 1894

\section{Mein verehrter Herr Doctor}

[...] Sie verstehen mich ja gewiß - u. sind lieb u. gut! - Brahms hat ja nun auch Volkslieder gesetzt. Ich kann nicht sie umgehen - aus vielen Gründen u. habe nun den Gedanken, daß $\underline{\text { Sie }}$ gerade mir diesmal helfend zur Seite stehen müßten. Ich singe am 26ten d. M. hier davon; würden Sie mir sie begleiten. Ich sage Ihnen offen, daß ich es geradezu großartig von Ihnen 
fände - weiß aber ja leider nicht, was Ihr Bein dazu sagen wird!! Mich bedrückt es doch sehr, daß ich an der Stelle, wo Sie mit den Volksliedern Triumpfe feierten, welche von einem andern singen soll $-u$. ich kann es nur mit freiem Herzen, wenn Sie neben mir sind.

Bitte, grüßen sie Ihre liebe Frau u. die süßen Kinder

tausendmal von mir.

Treu u. dankbar

Ihre

Amalie Joachim

\section{Lilli Lehmann}

ID 73: Brief von Lilli Lehmann vom 16.10.1896

Col. Grunewald

16-10-96.

Hochgeehrter Herr Dr.!

Mein getreuer Professor: Rheinhold Herman ist leider durch seine Oper welche in Cöln \& Breslau aufgeführt wird verhindert diesmal meine beiden Liederabende zu begleiten welche am 5 \& 20 Nov. stattfinden.

Ich komme nun mit der Frage ob Sie geehrter Herr Dr. geneigt sein würden mir dieselben zu begleiten \& unter welchen Bedingungen? Wir möchten natürlich 2-3 mal die Sachen ordentlich zusammen durchprobieren, denn die Schönheit liegt auch im guten Zusammengehn \& empfingen. Für den Fall daß Sie Lust dazu haben \& mich aufsuchen wollten so wäre ich Sonntag fast den ganzen Tag zu Hause von Früh 9 Uhr an, dann aber reise ich Abends fort \& bin dann erst am 25 de retour. Wollen Sie so gut sein mich davon in Kenntniß zu setzen, ob ja ob nein \& wann Sie kommen wollen.

Mit herzlichem Gruße

Lilli Lehmann Kalisch.

Herbertstr. 20.

Man fährt mit der Dampfstrassenbahn bis St. Hubertus \& geht dann scheinbar zurück in die Herbertstr, - 2 Minuten zu meinem Hause. 


\section{Siegfried Ochs}

ID 76: Brief von Siegfried Ochs [an Heinrich Reimann?] vom 5.2.1896

den 5. Februar 1896.

\section{Lieber Herr Dr!}

haben Sie nochmals vielen Dank für Ihre Mitwirkung am Montag. Daß ich Ihnen, mit dem zusammen zu wirken mir seit Jahren zur größten Freude zählt, noch besonders sage, wie famos Sie uns wieder beigestanden haben, dessen bedarf es unter uns nicht. Ich sage nur: Auf Wiederzusammen-Musiciren!

Nehmen Sie's nicht übel, daß ich die gleichzeitig abgehenden Mk. 150 durch Postanweisung übersende; es ist die einfachste Beförderung und ich muß heute Abend mit Herrn Maas die ganzen Concertangelegenheiten erledigt haben.

Nun von etwas Anderem! Ich war am Dienstag, trotz sehr starker Migräne, in der Kirche und habe mich über Sie sehr gefreut, Freudenberg hat mich geschmerzt, aber die Ziedler fand ich geradezu empörend. Wie kann man das schöne Händel'sche Stück so verweichlichen und mit Mätzchen ausstatten! Ich hörte dort, daß der edle Schmerzenthal die arme Katharina Lange stante pede entlassen hat, weil sie bei uns am Montag mitsang. So groß ist also die Wuth dieses Impotentaten auf mich. Na warte Du! Jetzt thut es mir doch sehr leid, daß der Kaiser unseren Chor am 7. Januar nicht - überhaupt noch nie! - gehört hat; das möchte ich denn doch einmal erreichen. Ich bin ganz außer mir über diesen Gewalt-Akt. Kann man denn da via Mirbach gar nichts thun? Man müßte doch dem Alten so etwas nicht hingehen lassen. Sie würden ein gutes Werk thun, wenn Sie die Sache einmal zur Sprache brächten; die arme Lange, die eine sehr treffliche, zuverlässige Chorstütze ist, verdient es. Denken Sie doch daran! Sie stehen ja Mirbach nahe; ich kann nicht an ihn heran, sonst würde ich es sofort unternehmen, das Treiben des Herrn Schmerzenthal aufzudecken.

Viele Grüße von Ihrem treuergebenen

Siegfried Ochs.

ID 72: Brief von Siegfried Ochs [an Heinrich Reimann] vom 28.7.1899

Igls, den 28. Juli 1899.

Schreibstelle oben im Wald 
beim Hotel.

Mein lieber, verehrter Freund!

Als ich Ihre Handschrift erkannte, war mein erster, im lauten Freudenschrei kundgegebener Gedanke: Reimann's kommen wieder nach Igls.

Umso größer war die Enttäuschung, als ich aus Ihrem Brief nicht allein erfuhr, daß, sondern auch warum wir Sie weder hier erwarten, noch in Schlesien suchen dürfen. Ich kann Ihnen gar nicht sagen, wie es uns leid thut, das liebe Frl. Sanni [?] nicht wohl zu wissen. Meine Frau glaubt, sie schon vor einiger Zeit erregt und nervös gefunden zu haben, mir ist nie etwas derart aufgefallen. Wir sind merkwürdigerweise auch wegen ähnlicher Zustände besorgt um unser Berthelchen, die infolge von Anämie an Ohnmachten u. dergl. leidet und in der letzten Zeit geradezu abgemagert ist. Nun thut ihr seit Kurzem ein Medikament glänzende Dienste, wenigstens hat sich seitdem sie es gebraucht, kein Anfall mehr gezeigt. Es ist dies Dr. Hommel's Hämatogen, dreimal täglich einen Eßlöffel in Milch zu nehmen. Freilich kann ich nicht beurtheilen, ob es sich mit dem Pyrmonter Brunnen verträgt. Auf alle Fälle aber will ich nicht versäumen, es Ihnen zu nennen.

$\mathrm{Ob}$ nun auf eine oder die andere Art, jedenfalls hoffen und wünschen wir auf das Herzlichste, $\mathrm{da}$ es bald wieder gut gehen und diese Sorge von Ihnen Allen genommen sein möge. Auch ich bin augenblicklich kein Froher. Gestern schrieb mir mein Bruder, daß unser Vater ernstlich erkrankt sei und ich erwarte sehnlichst weitere Nachrichten, die morgen eintreffen sollen. Möglicherweise fahre ich morgen Abend nach Frankfurt. Sie können sich denken, daß meine Stimmung unter dem Drucke der mich unablässig quälenden Gedanken keine des wundervollen Aufenthaltes hier würdige ist. Es wird Einem eben in solcher Zeit das Schönste gleichgültig.

An Herrn Maas werde ich sofort schreiben und ihm mittheilen, daß seine Sache steigen kann. Und am 22. März — ! na, das basteln wir zwei zusammen, wie schon so manches Andere. A propos, am 30. Oktober haben „wir“ die H moll-Messe. Ob (!!!) das Töchterlein mitsingen darf? Ob? Nun, die Antwort brauche ich Ihnen nicht zu geben.

Schluß nun und nochmals außer tausend Grüßen die besten Wünsche für gänzliche Wiederherstellung von uns Beiden. Ihr treuergebenster Siegfried Ochs. 


\section{ID 75: Brief von Siegfried Ochs an Hermann Wolff vom 24.10.1899}

Den 24. October 1899.

\section{Lieber Wolff!}

Ich höre soeben vom Orchester, daß es im Mai nach Paris geht. Nun könnten wir doch Colonne's Einladung annehmen, da die Orchesterfrage leicht zu lösen ist. Also, was uns betrifft, wir gehen nach Paris!

Ich komme heute Abend zu Ihnen. Herzlichst Ihr Ochs.

\section{Heinrich Reimann}

ID 84: Brief von Heinrich Reimann an Hermann Wolff vom 3.10.1894

\section{Geehrter Herr Wolff}

Gleichzeitig mit Ihren Zeilen erhielt ich von Herrn Prof. Breslauer eine Zuschrift mit einem einliegenden an den genannten Herrn gerichteten Brief der Frau v. Bülow. Der letzte Brief enthält eine Anzahl von Verdächtigungen gegen mich, die Frau v. Bülow ohne den geringsten Anlass zu haben gegen mich in nahezu beleidigender, jedenfalls nichts weniger als freundlichen Form ausspricht. Das veranlasst mich, Ihnen zu erklären, dass ich jede Auskunft verweigere. Hätte Frau v. Bülow die Güte gehabt, sich an mich direkt zu wenden, ich würde ihr jede Auskunft gern gegeben haben. Übrigens kann es Frau v. Bülow doch wohl nicht unbekannt sein, dass mir als Bibliothekar Quellen zugänglich sind, die für sie - als „Erben“ nicht uninteressant gewesen wären. Was ich da gefunden habe, bleibt zunächst mein Eigenthum und die Spur, die zu dem Schatze führt, ist nicht leicht zu finden. Wann u. ob ich überhaupt publicire, das steht dahin, darüber spreche ich mich jedenfalls jetzt nicht aus, wo Frau v. Bülow - der ich stets mit ausgezeichneter Hochachtung begegnet bin - so eigenthümliche Stellung zu mir nimmt, vor allem mich selbst keines schriftlichen Wortes würdigt.

Ich meine auch, daß mich Herr v. Bülow i. J. 1891 selbst gebeten hat, nach einigen seiner Aufsätze aus den 40er und 50er Jahren zu fahnden.

Mit bestem Gruß

Ihr ergebenster 
H. Reimann

Charlottenburg II

Kantstrasse 177

d. 3/X 94.

\section{Julius Rodenberg}

ID 112: Brief von Julius Rodenberg an Anton Rubinstein vom 31.3.1885

Bologna, 31. März, 85.

Lieber Rubinstein!

Unserer Abrede gemäß sende ich Ihnen anbei durch Vermittlung des Herrn Bock die „Boadicea“, ${ }^{720}$ welche ich nach dem Ihnen in Leipzig vorgelegten Plan u. mit Berücksichtigung Ihrer zu demselben geäußerten Wünsche ausgeführt habe. Hoffentlich ist es dem Gedichte nicht schlecht bekommen, daß ich es mit nach Italien genommen u. noch ein bischen italienische Sonne habe darauf scheinen laßen. Vor der Thür unsrer hiesigen Zimmer stehen die Büsten der römischen Kaiser; unter ihnen auch Nero, dem ich immer, beim Vorübergehen, in Anbetracht der Wiener Aufführung, meine tiefe Reverenz mache.

Von hier begeben wir uns heute nach Rom u. Anfangs Mai gedenken wir in Berlin zurück zu sein. Meine Damen bitten Ihnen empfohlen zu sein u. ich mit herzlichem Gruß aufrichtig ergeben

$\mathrm{Ihr}$

Julius Rodenberg.

\section{Marcella Sembrich}

ID 71: Brief von Marcella Sembrich an Louise Wolff vom 24.2.1899

New York 24ten Febr. 1899

${ }^{720}$ Dieser Plan wurde schließlich vom Komponisten aufgegeben. Neue Berliner Musikzeitung 39 (1885), S. 151. 
Meine liebe Wölffin.

Herzlichsten Dank für Ihren amüsanten Brief u. die Depesche zum 15ten Febr:

Diesen Tag hasse ich immer mehr da er mich erinnert - wie unendlich alt ich schon bin. Trotzdem halte ich mich fesch u singe weiter mit größtem Erfolge. Diese Woche - leider mußte ich 2 Vorstellungen absagen - da ich nicht ganz wohl war; - morgen, aber, singe ich wieder u. hoffentlich immer weiter .......! Bis jetzt habe ich 35 Abende hinter mir! - Maurice Grau macht enorme Geschäfte. - Das Theater ist beinahe immer ausverkauft. Nächste Woche findet die dritte Wiederholung des Wagner-Cyclus statt. - Dabei sind sehr viel Lohengrin, Tanhäuser [sic], Figaros Hochz. Don Juan, Romeo, Faust. Hugenotten mit Star-cast jeder Oper - wie ... Jean u. Eduard de Reszke, Van Dyck, Plancan, Maurel, Nordica, Eames, Lehman $[s i c]$, Sembrich ... gegeben worden. - Meine alten Traviata, Lucia, Barbier machen auch sehr gute Häuser - auf was ich stolz bin - besonders, bei der Wagner-Epidemie mit welcher die Americaner momentan befallen sind. - Ende März geht die ganze „Bagage“ nach Boston auf 2 Wochen, dann noch [ein] paar Abende in Chicago - Washington, Baltimore um zum Schluß gegen 22ten April hier zu endigen. Den 25ten April schiffen wir uns bereits auf dem [sic] „Friedrich der Grosse“ ein u. werden, so Gott will, Anfang Mai zu Hause sein. Wir dachten noch, den Monat Mai hier zu bleiben u einige Festivals mitzunehmen, aber gerade dieses Jahr finden keine statt. Vielleicht wird sich was mit der italienischen oper à la Wien, in Berlin machen lassen. Wilhelm hat darüber an Wolff depeschirt.

Wir hatten hier vor 2 Wochen furchtbare Kälte u. Schneeverwehungen. Vor einigen Tagen war es so warm, daß man bei offenem Fenster sitzen konnte. Heute tüchtiger Frost. Ich führe wie gewöhnlich ein freudloses Leben - nichts, wie Nerven!! Gehe nirgends [hin], trotz vielen Einladungen. Rosenthal in Amerika kein großes Geschäft. Sauer mit unglaublicher Reclame durch Knabe, künstlerisch gut, aber kein Geld, in New York, glaube aber in anderen Städten.

Vom Hause habe ich auch nicht gute Nachrichten. Willy hat schon „Malerei“ im Stich gelassen $u$ ist wieder nach Dresden um am 1ten April sein Militärjahr anzutreten. Vielleicht wird er da zum Verstand kommen. Vorläufig arbeitet er bei Emil in der Fabrik.

Ich freue mich sehr zu hören, daß bei Ihnen alles gut geht. - Wölffchen macht gewiß wieder riesige Geschäfte. - Wilhelm ist unberufen, gesund u gar nicht verpimpelt - geht in jedes schlechte Wetter aus - u beinahe jede Nacht um 1 Uhr nach Hause. Was sagen Sie dazu? Nun lebt wohl u auf frohes Wiedersehen im Mai!

Es grüßt u küßt Sie herzlich

Ihre in Freundschaft

ergebene 


\section{Fritz Steinbach}

\section{ID 104: Brief von Fritz Steinbach an Heinrich Reimann}

Meiningen, den 23. 3.99

Lieber hochverehrter Freund!

Nehmen Sie meinen herzlichen Dank für Ihren lieben Brief vom Februar, den ich gern früher beantworten hätte, wenn nicht ein Uebermaß von Arbeit auf mir geruht hätte. Ich habe jetzt bereits 32 Konzerte in dieser Saison dirigiert, was bei der Art und Weise, wie mir unsere Konzerte vorbereiten, sehr viel sagen will. Aber noch mehr künstlerischer, machen die geschäftlichen Vorbereitungen der auswärtigen Konzerte Arbeit. -

Vorigen Sonntag führte ich das herrliche Requiem unseres Meisters Johannes in Hildburghausen mit der verschiedenen Chorvereinnen des Landes auf, als Vorbereitung zu unserem im Oktober stattfindenden Musikfest.

Acht Tage vorher habe ich in Erfurt und Leipzig unter ungeheurem Erfolge mit der Hofkapelle konzertiert. Mit ganz wenig Ausnahmen hatte ich jeden Sonntag ein auswärtiges Konzert. - Von meinem hiesigen d'Albert-Konzert werden Sie vielleicht gelesen haben. Eine große Freude haben Sie mir mit der Nachricht gemacht, daß Sie zu unserem Musikfest im Oktober kommen werden. Auch bei Hofe freut man sich sehr, den Brahms-Biographen zu sehen und kennen zu lernen. -

Ihre warmen Worte über den Verlust der einzigen Joachim war mir aus der Seele gesprochen und ist mir zu Herzen gegangen. Nur bezüglich Ihrer Verurtheilung der Operation der Frau J. habe ich sowohl von ihrer Tochter, wie von Simrock Gegentheiliges gehört. Simrock schrieb mir, daß die Aerzte versichert hätten, ihr Tod wäre ohne Operation in längstens 3 Monaten grausam \& qualvoller gewesen; aber die Operation dauerte zu lange und die Betäubungsmittel hätten das Ende herbeigeführt. Aber Sie sind ja jedenfalls auch genau unterrichtet.

Für heute möchte ich Ihnen nur noch schreiben, wie sehr ich mich freue, daß mir das Komitee die Leitung des Jubiläum-Konzerts Joachims am 22. April übertragen hat. Das wird ja ein Orchester werden, wie die Welt noch keines gesehen und gehört hat! 96 Violinen, fast lauter Konzertmeister und bekannte Größen, 34 Bratschen, 24 Celli u. 20 Bässe!

Ich fürchte nur, daß die Presse die Wahl eines Nichtberliners als Dirigenten bekritteln wird. Aber ich habe mich nicht angeboten, und war selbst aufs Höchste überrascht, als die 
ehrenvolle Einladung an mich herantrat. So fahre ich mit herzlicher Freude und guten Muths am 19. April nach Berlin und freue mich auch ganz besonders, mit Ihnen bei dieser Gelegenheit zusammen zu kommen.

Nach dem Fest werde ich noch einige Tage bleiben, und hoffe, mit meiner Frau zu einem gemüthlichen Plauderstündchen, zu einer Ihnen angenehmen Zeit zu Ihnen zu kommen. Dann wollen wir auch den Feldzugsplan für die Winterkonzerte in Berlin besprechen. Ich glaube, daß wir wieder in die Singakademie einziehen werden.

Nun noch eine vertrauliche Anfrage. Würden Sie in Anbetracht des besonderen Umstandes der Einweihung des Denkmals bei der Aufführung des Requiems die Orgelparthie übernehmen? Unsere Orgel ist ja neu, von Schlimbach in Würzburg gebaut, aber sie ist meiner Ansicht nach kein besonders gutes Instrument.

Können wir nicht etwas für Orgel und Orchester machen? Nun darüber werden wir ja in Berlin verhandeln können.

In herzlicher Verehrung mit besten Grüßen von Haus zu Haus

Ihr treu und dankbar ergebener

Fritz Steinbach

ID 66: Brief von Fritz Steinbach [an Hermann Wolff?] vom 1.8.1899

[Briefpapier: II. S. Meiningen'sches Landesmusikfest]

Berchtesgaden Villa Wahl

Meiningen, den 1. Aug. 1899

Mein lieber Freund!

Das waren 4 Wochen, an die ich zeitlebens denken werde.

Heute vor 4 Wochen fing meine Krankheit an. Ich kam in einen tollen Regen, wurde bis auf die Haut durchnäßt, bekam Zahnweh mit Fieber, + mußte mich legen. Der hiesige Arzt behandelte mich auf Mandelentzündung weil der Hals sofort sehr geschwollen + entzündet war. Und doch war es etwas ganz anderes: eine Zahnwurzel + Kiefernentzündung. Am 2ten Tag konnte ich schon den Mund kaum mehr öffnen. Am 8ten Tag wurde Prof. v. Heinleth [?] aus Reichenhall gerufen, der eine halbe Stunde lang an mir herum schnitt. Der Mund wurde gewaltsam geöffnet, der Zahn entfernt + zum durchlassen der großen Menge Eiter der Hals geöffnet. Dann wurde der angegriffene Kiefer angebohrt + ausgeschabt. Es war gräßlich, 
entsetzlich. Damit der Eiter nicht in den Hals fließen + Erstickungsgefahr herbeiführte wurde ich armer Teufel nicht betäubt. Zum Glück war die Natur barmherziger + den letzten Theil der Operation lag ich in Ohnmacht. Dann kamen die quälenden Manipulationen mit dem Entfernen + Wiedereinführen des Tombon in die Wunde. Nachdem ich 18 Tage gelegen, war ich so schwach, daß ich nicht gehen konnte. Jetzt geht es besser, die Hauptwunde heilt von Innen im Schlund + die äußere Wunde fängt an sich zu schließen. Sie wird wegen fortgesetzter Eiterung immer noch künstlich durch Einlagen offen gehalten. Seit 8 Tagen darf ich ausfahren + mache auch kleine Spaziergänge im Wald. Es war mir aber ganz unmöglich zu schreiben, ich war ganz theilnahmslos + stumpfsinnig. Gestern war ich wieder in Reichenhall zu einer kleinen Nachoperation. Das wilde Fleisch mußte entfernt + die äußeren Wundränder frisch angeschnitten werden, damit die Heilung besser vor sich geht. 12 Tage habe ich durch ein Glasröhrchen etwas Fleischsaft genommen, das war meine ganze Nahrung. Wie nervös herunter ich bin, kannst Du Dir denken.

In 10 Tagen hofft der Arzt auf Heilung. Dann reise ich nach solchen vergnügten Ferien in die Arbeit nach Hause! Das war meine Erholung!! Anbei sende ich Dir die Daten der Anwesenheit v. Brahms in Meiningen + der Konzerte, die er sowohl in Meiningen als auf Reisen mit der Hofkapelle dirigirt hat. Ferner sende ich Dir 1. den letzten Brief v. Br. 16 Febr. 97. + 2. den Brief nach dem Musikfest 95. ferner 2 Postkarten, die eine nach Neapel (Ital. Reise nach dem Musikfest.) Wenn Du etwas davon benutzen willst, steht es Dir frei. Nur bitte ich um recht baldige Zurücksendung.

Ich lege noch eine Abschrift eines Briefes v. Br. an den Herzog bei, zu Neujahr 1897. Zur Veröffentlichung wäre die Genehmigung des Herzogs nöthig, die er aber nach Äußerungen zu schließen, nicht geben will. Aber Dich wird der liebe Brief interessiren, auch kannst Du eine Abschrift nehmen. Schreibe mir recht bald eine Karte, daß Du nicht zürnst Deinem Dich + Deiner verehrten Frau herzl. [Einschub: auch von meiner Frau] grüßenden treuen Freund Fritz Steinbach

Vom 15. Aug. an in Meiningen.

Brauch den Werthbrief zurück!

Bitte auch die Daten zurückzusenden.

\section{Felix Weingartner}

Brief von Felix Weingartner an Edith Stargardt vom 10.6.1923 
Zürich, 10/6 23

\section{Liebste Edith!}

Tausend Dank für Eure und Ollys liebe Glückwünsche, auch für das Musikwolff-Telegramm. Indem war herrlich und es war eine besondere Freude, Olly in bezaubernder Frische wiederzusehen.

Am 4/5 Nov. kann ich leider nicht, weil da Philh. in Wien.

Ich muss überhaupt nicht Berlin warten, bis Schweden all rhight (ich glaube übrigens man schreibt es all right, nicht wahr?), denn bei den treulosen Verhältnissen kann ich Berlin ja nur mehr auf der Durchreise machen.

Ich werde von Italien aus in Schweden engagieren und auch dann sofortissimo (gutes Wort!) benachrichtigen.

Warmer Gruesse, bitte aber nur für Euch, da möglichst ungestört sein muss.

Montechiaro

Pontecchio di Bologna (Italia)

Herzlichste Grüsse

Dein “alter" (??) Felix W.

Bettychen ist in Wien

Ich küsse Olly für ihren goldigen Brief.

ID 110: Brief von Felix Weingartner an Edith Stargardt vom 29.8.1924

Wien, 29/8 1924

Liebste Edith!

Ich mußte Dir - leider nur telegraphisch - einen Kuss senden, denn daß du mir so rasch einen Kopisten verschafft hast, nachdem mich der Wiener Ganeff im Stich gelassen hat, ist wirklich rührend lieb.

Nun kann ich wieder ruhig schlafen. 
Der Herr Steffens (sympathischer Name) in Friedenau (auch sympathisch!) möge nun ruhig anfangen und kann mir nach Hotel Hessler partienweise liefern, aber immer mit einer Vorlagstimme, damit ich danach revidieren kann, z. B. die von mir revidierte, in Wien geschriebene I. Violine und seine 7 Kopieen [sic]. u. s. w.

Gelt, Edith, Du sagst ihm so? - Bitte!

Ich bin am 12. Sept. Abends in Berlin, freu' mich furchtbar, Euch alle zu sehen.

Also nochmals tausend Dank, liebste Edith, und alles Liebe, Dir, Deinem Mann, Olly, Lili von uns beiden

Dein Felix

Bitte nur um eine bestätigende Postkarte, sobald die Sendung (5 Stimmen) eingetroffen ist

ID 105: Brief von Felix Weingartner an Edith Stargardt vom 6.9.1924

$6 / 91924$

Liebe Edith!

Deine Z[ettel] für „Rheingold“ liegen auf Deinen Namen an der Textbuch-Kasse.

Bitte schreib dem Kopisten, daß er sehr viel Fehler gemacht hat. Die Korrektur der I. Violinen war eine Heidenarbeit. Eine gut geschriebene Orchesterstimme abzuschreiben, ist doch wahrhaft nicht schwer.

Auf Wiedersehen! Herzlichste Euch Beiden

Il tuo vecchio

FW

\section{Charles-Marie Widor}

ID 91: Brief von Charles-Marie Widor [an Heinrich Reimann?] vom 30.11.1892

30 nov. 92

3, Rue de l'Abbaye

Cher Docteur! 
Je ne sais comment Vous remercier de l'envoi de votre beau travail Johannes Brahms! Comme l'œuvre de Brahms m'a toujours et de plus en plus inspiré la plus vive admiration, comme d'autre part je ne connais que peu de détails de la vie de ce grand musicien, je suis on ne peut plus curieux de lire votre étude qui me paraît si intéressante rien qu'en la feuilletant au moment où elle m'arrive. L'édition est superbe, et votre prose me semble très claire même pour le peu de compréhension que j'ai de la langue Allemande.

= Mais comme, ich habe einen Lehrer mit welchem ich, zwei Male jedem Woche, lese oder schreibe, ich hoffe leichter Verstehen -

Encore une fois Merci!

Liebster Doctor, Glauben Sie Mihr [sic] sehr dankbar,

Sehr herzlich

Widor

Ich habe mehrere Male Ihren Vortrefflichen Stuck Vur [sic] die Orgel gespielt.

ID 90: Brief von Charles-Marie Widor [an Heinrich Reimann?] vom 29.8.1896

29 août 96 3, Rue de l'Abbaye

\section{Cher Docteur!}

Merci mille fois de votre amabilité pour la Symphonie Gothique, et pour l'aimable envoi du programme.

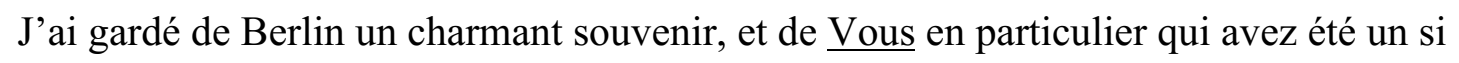
excellent guide à travers les richesses de Votre admirable bibliothèque et une aide si secourable à l'orgue de Gedächtniskirche et à celui de Apostel-Paulus!

Je parle souvent des annales Berlinois avec l'ambassadrice d'Autriche à Paris, la $C^{\text {tesse }}$ de Wolkenstein autrefois $C^{\text {tesse }}$ de Schleinitz, l'amie de Wagner. Elle vient me voir assez souvent soit à St-Sulpice soit chez moi dans la vieille Abbaye.

Quand viendrez-vous à Paris? Je voudrais bien pouvoir vous montrer nos curiosités artistiques aussi, et surtout continuer les rapports si sympathiques de l'été dernier!

Veuillez me rappeler à tous nos Camerades du Congrès Rubinstein et me croire Votre dévoué Confrère, reconnaissant de tout Cœur

Widor

$\underline{\text { Sehr herzlich! }}$ 
ID 92: Brief von Charles-Marie Widor [an Heinrich Reimann?] vom 7.12.1896

7 Dec. 96 3, Rue de l'Abbaye

Mon Cher et Charmant Confrère !

Merci mille fois de la pensée et de l'envoi! Bien certainement oui, je vais travailler votre Fantaisie et la jouer à St-Sulpice.

Pourquoi craignez[-]vous que je la juge trop sérieuse? Est-il possible d'écrire „trop sérieux“ pour l'instrument de notre Père Bach, le seul de nos moyens d'exprimer la pensée qu'évoque l'idée de l'Infini, de l'Eternité, le seul donc les sons puissent durer et se perpetuer sans commencement ni fin! ...

In Secunda Secundorum!

$=$ Votre Morceau est d'une écriture de Contrepoint tout à fait intéressante.

= Voulez[-]Vous me permettre une légère critique de technique manuelle? Pourquoi écrivez vous des dixièmes que les grandes mains elles-mêmes ne pourront jamais exactement lier, "Singen, Klingen" (page 19) = on est alors forcé d'arpèger ce qui est contraire à tous nos principes. $=$ Vous voyez que je me permets cette remarque de petit détail, parce que, ne pensant que le plus grand bien de l'œuvre en elle-même, je sens que ça ne vous blesserait nullement, ce dont je suis sûr, d'ailleurs.

Je vais faire connaître Votre Fantaisie à toute la jeune génération d'organistes d'ici, laquelle sait par Cœur tout son Bach.

De tout Cœur

Sehr herzlich!

Ch M Widor

\section{Hans von Wolzogen}

ID 67: Brief von Hans von Wolzogen [an Heinrich Reimann] vom 10.5.1896 ${ }^{721}$

Bayreuth 10/5. 91

Sehr geehrter Herr,

${ }^{721}$ Vgl.: Heinrich Reimann: Abriss der Entwicklung der Oper. mit literarischen Hinweisen von Emil Krause, in: Allgemeine Musik-Zeitung 18 (1891), Nr. 15, S. $195 f$. 
zufällig kam mir gestern erst die Nr. 15 der Allg. Musikzt. zu Gesicht, welche Ihre vortreffliche Abhandlung des E. Krause'schen „Abrisses“ enthält. Ich habe mich ungemein daran erfreut. Ohne Ihre mir gütigst zugesagte anderweitige Mitarbeitschaft an unsern „Blättern“ dadurch beeinträchtigen zu wollen, drängt es mich doch, Ihnen alsbald mitzuteilen, daß ich eine gelegentliche kritische Äußerung dieser Art, natürlich nur über einigermaßen für „typisch“ anzusehende bittersüße Erklärungen, bei uns gar nicht ungern sehen würde.

Zwar besorgt der „Umschlag“ schon für gewöhnlich die Sichtung der Spreu vom Weizen; aber mitunter thut es doch gut, auch dem „bösen Feinde“, der das Unkraut dazwischen sät, mag er es von der Dummheit oder der Bosheit auch Frechheit, oder günstiger den „Rest“ zu lesen. Haben sie also einmal so etwas „Spanisch-Schönes“ so vergessen Sie unsere „Blätter“ nicht! Überhaupt möchte ich sie Ihnen gern wieder in die Erinnerung rufen, wenn ich auch beruhigend hinzufügen darf: für das nächste Jahr!

Mit hochachtungsvollen Grüßen

Ihr ergebenster

S. O. H. v. Wolzogen

\subsubsection{Verträge}

\section{ID 225: Vereinbarungen zwischen Skating-Rink Actien-Gesellschaft und}

\section{Hermann Wolff vom 10.12.1881}

Skating-Rink Actien-Gesellschaft

Berlin S.W. den 10. Dezbr. 1881

Herrn Hermann Wolff

Hier

Carlsbad 20

Ihr Geehrtes vom 9. ds. haben wir empfangen.

Wir bestätigen hiermit die gestern zwischen uns stattgehabte Vereinbarungen, nämlich: 
1.) Unser Etablissement steht an den Abenden des 16. u. 17. Januar 82 u. einem anderen noch feststellenden Abend derselben Woche zum Zweck der Abhaltung von Concerten unter Leitung des Herrn Hans von Bülow zu Ihrer Verfügung.

2.) Wir tragen die Kosten der Beleuchtung u. stellen unser Personal Ihnen unentgeldlich [sic] zur Verfügung.

3.) Sie zahlen uns für jeden Concert Abend $500 \mathrm{Mk}$. Miethe für das Etablissement.

4.) Die Directions Loge (Parterre Loge No. v bleibt unentdeldlich [sic] für uns reserviert.

5.) Zahlung der vereinbarten Miethe hat praenumerando oder sogleich nach Beendigung eines Concertes stattzufinden.

Trotzdem wir glauben, dass es in Ihrem Interesse liegen würde, wenn das Publikum bei Zeiten erführe, dass die Bülow-Concerte in unserem Etablissement stattfinden, überlassen wir doch Ihnen dies ganz, da es Sie u. Herrn v. Bülow ja mehr interessiert denn uns.

Mit Hochachtung

Stating-Rink Actiengesellschaft (Stempel)

gez. L. Sacerdoti

ID 225: Vereinbarungen zwischen Angelo Neumann aus dem Richard-WagnerTheater und Hermann Wolff vom 4.12.1882

Auf Grund der zwischen uns stattgefundenen mündlichen Besprechungen fixiere ich die Bedingungen unserer gegenseitigen Uebereinkunft wie folgt:

Von 4 Dezember d. J incl ab bis Ende Mai 1883 übernehmen Sie, Hermann Wolff, das Arrangement sämtlicher Tourneen für das unter meiner Direktion stehende „Richard Wagner Theater“ sowol hinsichtlich der zu veranstaltenden Theatervorstellungen wie Concerte. Für diese Ihre Thätigkeit erhalten Sie $2 \%$ von der Brutto-einnahme mit der ferneren Maassgabe [sic], dass ich Ihnen für die ersten drei Monate, also Dezember 1882, Januar Februar 1883 für eine Provision von mindestens 5000 M (fünftausend Mark) garantiere, gleichgültig, ob die Ihnen zukommenden $2 \%$ der Bruttoeinnahme diesen Betrag erreichen oder nicht.

Ueber den vorerwähnten Beitrag von 5000 Mark sind Sie schon von heute (Datum dieses Schreiben $[s i c]$ ) ab berechtigt dergestalt zu verfügen, dass Sie von mir bis zur Höhe von 5000 Mark Vorschüsse jederzeit nach Ihrer Wahl fordern können. 
Sämmtliche Auslagen für Porti, Telegramme, Reisen und sonst gemein Interesse des obengedachten Unternehmens von Ihnen zu machenden Aufwendungen werden Ihnen von mir besonders vergütet.

Zugleich bemerke ich ausdrücklich, dass die vorstehende Vereinbarung den zwischen uns bereits angeschlossenen Vertrag vom [Lücke]ten betreffend Ihre Thätigkeit für das Richard Wagner-theater in Russland durchaus unberührt lässt und selbständig unabhängig von diesen von uns getroffen ist.

Sollten über die Bedeutung der obigen Bestimmungen Meinungsverschiedenheiten, welcher Art auch immer, zwischen uns entstehen, so unterwerfen wir uns unbedingt dem Schiedsspruch des Herrn Hugo Bock zu Berlin (Wohnung) und begeben uns jeder sonstigen Einwendung gegen dessen Ausspruch.

\section{ID 224: [Entwurf zum] Vertrag zwischen Joseph Joachim und Bernhard Pollini vermittelt von Hermann Wolff, Oktober 1883}

Zwischen den Unterzeichneten, nämlich Herrn Professor Joseph Joachim zu Berlin einerseits und Herrn B. Pollini, Director des Stadt-Theaters in Hamburg andererseits, ist durch Vermittlung des Herrn Hermann Wolff in Berlin am Carlsbad 19 wohnhaft, nachstehender Vertrag geschlossen worden.

\section{$\S 1$.}

Herr Director Pollini engagirt Herrn Professor Joachim für eine Reise von Hundert Concerten in Städten der vereinigten Staaten u. Canada in der Zeit von [Lücke] bis [Lücke] und zahlt dafür an Herrn Professor Joachim ein baares [sic] Honorar von Zweihundertzwanzig Tausend Mark.

\section{$\S 2$.}

Herr Director Pollini zahlt außer diesen Mk 220.000 die Kosten für die Reise des Herrn Professor Joachim und eines Dieners desselben von Berlin aus nach Amerika, für die Reisen in Amerika während der ganzen Tournée, sowie für die Rückreise nach Berlin. Unter Reisekosten sind zu verstehen: die Eisenbahn-, Dampfschiff- und alle durch die Concerte bedingten Fahrten, die Wohnung und vollständige Verpflichtung während der Reisen und in den Hotels. 


\section{$\S 3$.}

Herr Professor Joachim ist verpflichtet, bis zwei und zwanzig Mal monatlich, aber nicht mehr wie im Ganzen hundertmal im Laufe der fünf Monate von [Lücke] bis [Lücke] zu spielen.

\section{$\S 4$.}

Die Wahl der Städte bleibt Herrn Director Pollini überlassen, doch ist Mexico und SüdAmerika von dieser Tournée ganz ausgeschlossen.

\section{$\S 5$.}

Die Concerte finden nach von Belieben des Herrn Director Pollini mit oder ohne Orchester statt. Doch ist Herr Director Pollini verpflichtet, Herrn Professor Joachim in New York, Boston, Philadelphia und Cincinnati je einmal mit Orchester auftreten zu lassen.

\section{$\S 6$.}

Herr Director Pollini hat stets für würdige künstlerische Mitwirkung Sorge zu tragen, doch ist Herr Professor Joachim verpflichtet, den Haupttheil des Concertes auszufüllen und zwar viermal in einem Concert aufzutreten. Das Programm, soweit es die Mitwirkung des Herrn Professor Joachim betrifft, bestimmt dieser.

\section{$\S 7$.}

Alle während der Dauer der Tournée, auf diese selbst bezügliche, etwa an Herrn Professor Joachim herantretende Concert-Anträge hat derselbe an Herrn Dirctor Pollini zu übermitteln, und ist dieser berechtigt, von denselben Gebrauch zu machen.

$\S 8$.

Herr Professor Joachim ist verpflichtet, spätestens am [Lücke] in New York einzutreffen.

\section{$\S 9$.}

Sollte Herr Director Pollini, bis zum [Lücke] einschließlich, erklären, daß er die Tournée auf einen sechsten Monat mit zwanzig Concerten ausdehnen will, so ist Herr Professor Joachim verpflichtet, gegen ein weiteres Honorar von Vierundfünfzig Tausend Mark und Zahlung aller in $\S 2$ erwähnten Kosten bis zum [Lücke] in diesen ferneren zwanzig Concerten in der in den $\S \S 5$ und 6 angegebenen Weise mitzuwirken. 
$\S 10$.

Die Zahlung des im $\S 1$. bestimmten Honorars erfolgt in der Art, daß Herr Director Pollini an Herrn Professor Joachim am Montage einer jeden Woche, vom [Lücke] ab, zwanzig Wochen hindurch, die Summe von Elftausend Mark zahlt.

Wird die Tournée in Gemäßheit der Bestimmung des $\S 9$ um einen Monat verlängert, so zahlt Herr Director Pollini das hierfür bestimmte Honorar in einer gleichen wöchentlichen Raten von Dreizehntausendfünfhundert Mark, die erste fällig am ersten Montage der verlängerten Tournée.

Bleibt Herr Director Pollini mit einer dieser Ratenzahlungen länger als drei Tage im Rückstand, so ist Herr Professor Joachim berechtigt, die Fortsetzung der Tournée zu verweigern, den Vertrag für aufgehoben zu erklären; er behält die ihm bis dahin gezahlten Raten und die volle im $\S 11$ gedachte Caution verfällt ihm als Conventionalstrafe zu Eigenthum.

\section{$\S 11$.}

Herr Director Pollini hinterlegt bei Vollziehung gegenwärtigen Vertrags die Summe von Zwanzig Tausend Mark bei dem Bankhause Mendelssohn \& Co. in Berlin und am [Lücke] weitere Neunzig Tausend Mark bei demselben Bankhause. Diese Beträge bleiben zur Sicherheit des Herrn Professor Joachim so lange bei dem genannten Bankhause hinterlegt, bis Herr Professor Joachim den vollen Betrag des im $\S 1$ stipulirten Honorars von Zweihundertzwanzig Tausend Mark beziehungsweise des im $\S 9$ stipulirten Honorars von Vierundfünfzig Tausend Mark erhalten hat.

Unterläßt Herr Director Pollini die Hinterlegung der Neunzig Hausend Mark bis zum [Lücke] einschließlich, so sind die zuerst hinterlegten Zwanzig Tausend Mark als Conventionalstrafe dem Herrn Professor Joachim zu Eigenthum verfallen, und der gegenwärtige Vertrag gilt als aufgehoben.

Die ganze hinterlegte Summe verfällt dem Herrn Professor Joachim als Conventionalstrafe zu Eigenthum in den in den $\S 10$ und 16 angegebenen Fällen.

Andererseits erfolgt die Rückzahlung der ganzen hinterlegten Summe an Herrn Director Pollini, sobald Herr Professor Joachim dem Bankhause Mendelssohn \& Co. anzeigt, daß die Rückzahlung erfolgen kann, oder auch ohne solche Anzeige, gegen Vorlegung der Quittungen des Herrn Professor Joachim über das ihm zustehende Honorar.

Dem Bankhause Mendelssohn \& Co. ist daher eine beglaubige Abschrift dieses Vertrages zu übergeben, um dasselbe in den Stand zu setzten, übersehen zu können, an wen die hinterlegte Sicherheit zu zahlen ist. 


\section{$\S 12$.}

Sollte durch Verschulden des Herrn Professor Joachim, d. h. ohne daß Herr Professor Joachim durch Krankheit, äußere Verletzung oder sonstige von seinem Willen unabhängige Ereigniße an der Ausübung seiner Kunst verhindert wäre, ein Concert ausfallen, so ist Herr Professor Joachim verpflichtet, dieses Concert an einem von Herrn Director Pollini zu bestimmenden Tage innerhalb der Zeitdauer der Tournée nachzugeben, oder einen Abzug vom Zweitausendzweihundert Mark zuzüglich der durch den Ausfall verursachten Kosten, welche zu diesem Zwecke auf [Lücke] arbitrirt und festgesetzt worden, zusammen also einen Abzug von [Lücke] von dem stipulirten Honorare zu erdulden. Giebt Herr Professor Joachim das Concert nach, so sind ihm nur die entstehenden Mehrkosten, welche zu diesem Zweck auf [Lücke] arbitrirt und festgesetzt wurden von seinem Honorare in Abzug zu bringen.

\section{$\S 13$.}

Der Ausfall von Concerten, welcher nicht von Herrn Professor Joachim verschuldet wird, läßt die volle Zahlungsverpflichtung des Herrn Director Pollini bestehen.

Sollte jedoch Herr Professor Joachim durch Krankheit oder sonst länger als acht Tage verhindert sein[,] in Concerten aufzutreten, so ist Herr Director Pollini berechtigt, den auf diese Zeit verhältnismäßig entfallenden Theil des Honorars zu kürzen.

Sollte die Behinderung des Herrn Professor Joachim länger als drei Woche dauern, so ist Herr Director Pollini berechtigt, die Fortsetzung der Tournée aufzugeben und den Vertrag für aufgehoben zu erklären; er hat in diesem Falle nur die Zahlung des Honorars bis zum Eintritt der Verhinderung des Herrn Professor Joachim zu leisten und die Kosten der Rückreise des Herrn Professor Joachim und seines Dieners zu tragen.

In gleicher Weise hat Herr Professor Joachim das Recht, wenn er länger als drei Wochen durch Krankheit oder äußere Verletzung verhindert ist, in Concerten aufzutreten, die Fortsetzung der Tournée zu verweigern, und es wird dann in vorstehend angegebener Weise abgerechnet.

\section{$\S 14$.}

Krieg oder Epidemien in den Ländern, in welchen die Concerte stattfinden sollen, oder solche Naturereigniße in denselben, welche eine Theilnahme der Bevölkerung an Kunstgenüßen nicht erwarten laßen, heben den Vertrag auf; derselbe gilt mit dem Tage des Eintritts solcher Ereigniße für aufgehoben und ist nur bis zu diesem Tage zu erfüllen, jedoch bleibt die 
Verpflichtung des Herrn Director Pollini, die Kosten für die Rückreise des Herrn Professor Joachim und seines Dieners zu tragen, bestehen.

\section{$\S 15$.}

Sollte Herr Director Pollini Concerte ausfallen laßen, die Tournée abkürzen oder dieselbe nach dem [Lücke] ganz aufgeben, so bleibt er demnach zur Zahlung der in $\S \S 1$ und 2 angegebenen Beträge verpflichtet.

\section{$\S 16$.}

Sollte Herr Director Pollini bis zum [Lücke] einschließlich erklären, daß er von der ganzen Tournee Abstand nehmen will, so ist die ganze gemäß $§ 11$ hinterlegte Summe der Herrn Professor Joachim als Conventionalstrafe zu Eigenthum verfallen.

\section{$\S 17$.}

Herr Professor Joachim hinterlegt bis zum [Lücke] bei dem Bankhause Mendelssohn \& Co. in Berlin die Summe von [Lücke]. Diese Summe verfällt dem Herrn Director Pollini als Conventionalstrafe zu Eigenthum, wenn Herr Professor Joachim bis zum [Lücke] einschließlich erklärt, daß er von der Tournée Abstand nehmen und diesen Vertrag nicht zur Ausführung bringen will.

Herr Professor Joachim hinterlegt ferner bei dem genannten Bankhause bis zum [Lücke] die Summe von [Lücke]. Diese gesammte Summe verfällt dem Herrn Director Pollini als Conventionalstrafe zu Eigenthum, wenn Herr Professor Joachim durch sein Verschulden, also ohne durch Krankheit, Verletzung oder sonstige von seinem Willen unabhängige Ereigniße, - zu denen unter Anderem auch die Verweigerung des von seiner vorgesetzten Behörde zu ertheilenden Urlaubs zu rechnen wäre, - gehindert zu sein, sich nicht zum Beginn der Concertreise zur festgesetzten Zeit in New York einfindet.

Die freie Verfügung über die hinterlegte Summe steht Herrn Professor Joachim zu, sobald er die Concerte in Amerika begonnen hat.

$\S 18$.

Sollten zwischen den Contrahenten Streitigkeiten über die Auslegung irgend einer Bestimmung dieses Vertrages entstehen, so sollen solche Streitigkeiten durch ein Schiedsgericht entschieden werden, welches aus den Herren [Lücke] besteht.

Derjenige, welcher das Schiedsgericht anruft, hat demselben seine Klage in 2 Exemplaren zu Händen des Herrn [Lücke] einzusenden. Das eine Exemplar sendet Herr 
[Lücke] an den Gegencontrahenten mit der Aufforderung zur Gegenerklärung binnen einer Nothfrist von 3 Wochen. Demnächst ruft Herr [Lücke] das Schiedsgericht zusammen, dasselbe hat das Recht, die Contrahenten zur mündlichen Verhandlung vor sich zu laden und entscheidet nach Lage des ihm vorgelegten Materials durch Mehrheitsbeschluß nach seiner gewissenhaften, freien Ueberzeugung. Das Schiedsgericht ist verpflichtet, seiner Entscheidung, welche schriftlich zu erfolgen hat, die Entscheidungsgründe beizufügen.

Dem Ausspruche dieses Schiedsgerichts unterwerfen sich die Contrahenten hindurch unbedingt und unter Verzicht auf jedes ordentliche oder außerordentliche Rechtsmittel. Gegenwärtiger Vertrag ist in zwei gleichlautenden Exemplaren von den Contrahenten zum Zeichen ihrer Anerkennung eigenhändig unterschrieben worden, und soll die Anerkennung der Unterschriften vor einem Notar erfolgen.

Berlin, den [Lücke] October 1883

ID 223: Vertrag zwischen dem Berliner Philharmonischen Orchester und Hermann Wolff vom 29.1.1891

Vertrag

Zwischen dem „Berliner Philharmonischen Orchester“ vertreten durch seinen Vorstand, den Herren Carl Mahns, Robert Hiller und Adolf Burg und Herrn Hermann Wolff[,] Inhaber der Concertdirection Hermann Wolff Berlin W am Carlsbad 19 ist heute folgender Vertrag geschlossen worden.

$\S 1$.

Herr Hermann Wolff wird alleiniger Vertreter des Berliner Philharmonischen Orchesters.

$\S 2$.

Von allen Engagements und eigenen Concerten des Berliner Philharmonischen Orchesters erhält Herr Hermann Wolff 5 \% (fünf Procent) der Brutto-Einnahme.

$\S 3$. 
Provisionsfrei sind die Engagements mit dem Stern'schen Gesang-Verein, Cäcilien-Verein, Wagner-Verein und der Sing-Academie, sowie die populären Concerte bis zum 30 April, die Engagements für Künstlerconcerte bis zur Höhe des vereinbarten Tarifs und das Engagement in Scheveningen.

$\S 4$.

Sämmtliche Spesen, die Herrn Hermann Wolff im Interesse des Orchesters erwachsen, erhält er zurückerstattet.

$\S 5$.

Herr Hermann Wolff verpflichtet sich gemeinsam mit dem Berliner Philharmonischen Orchester, während der Concert-Saison October bis Mai 10 (zehn) Concerte zu geben welche den Namen „Philharmonische Concerte[“] tragen. Das Orchester erhält die Hälfte des Reingewinns dieser Concerte. Die Abrechnung dieser Concerte hat spätestens 14 Tage nach dem letzten Concerte zu erfolgen. Das Orchester hat das Recht während der Dauer der Concerte à conto Zahlungen zu erheben.

$\S 6$.

Uebersteigen die Einnahmen des Orchesters den Jahres-Etat von 136.140 Mark, so erhält Herr Hermann Wolff vom etwaigen Ueberschusse 10 \% (zehn Procent).

\section{$\S 7$.}

Die Einnahmen des Orchesters bilden alle aus Concert-Veranstaltungen vereinnahmten Erträge. Zuwendungen privater Natur an das Orchester sind in die Einnahmen nicht hineinzurechnen.

\section{$\S 8$.}

Dieser Vertrag ist für die Zeitdauer bis zum 30 April 1893 festgesetzt und gilt immer auf 3 Jahre verlängert, wenn keiner der Contrahenten zwei Monate vor Ablauf desselben eine Kündigung beansprucht.

Berlin d. 29. Januar 1891

gez: Carl Mahns 


\subsection{Tagebuch von Louise Wolff 1887/92 (Transkription) $)^{722}$}

Tagebuch meiner Mutter

Louise Wolff

1887 / und 1892

\section{[Eingelegter Zettel]}

Meine Herrschaften, es sind zwei Jahre über ein Viertel Jahrhundert, daß ich die Ehre hatte, in einem der Concerte unseres verehrten Professors Stern die Tannhäuser Ouverture zu dirigiren. Damals wurde sie ausgezischt.

Ich danke der neuen Generation für die Nichtbefolgung der Prinzipien des alten, u Befolgung der Lehre

„Und ehret unsere deutschen Meister[“]

„So bannt Ihr gute Geister["]

Dies der ungefähre Wortlaut der Bülow-schen Rede

Berlin Januar 87

bis 15 März 1892

Winterfeldtstr. 5/6

1. Heft

Louise Wolff

Lützowstraße 75 III

Auf dringenden Wunsch meines Mannes beginne ich diese Blätter und ich glaube selbst, daß mir später ein Zurückblicken auf diese Zeit, die so abwechslungsreich ist, viel Freude machen wird. ... vielleicht auch haben sie einst Interesse für meine geliebten Kinder.

$[1]^{723}$ Freitag, 8. Januar 1887,

Freitag! ein Unglückstag?! Ich glaube es nicht! War es doch ein Freitag[,] der mir mein geliebtes Kind brachte, dessen 7 ten Geburtstag wir heute feiern - u. so nenne ich den Freitag

\footnotetext{
${ }^{722}$ Wolff-Nachlass: ID 130.

${ }^{723}$ Dieses Tagebuch ist mit handschriftlichen Seitenzahlen versehen, die hier übernommen sind.
} 
einen Glückstag u. beginne mit dem freudigen Mute diese Blätter, daß ich nur eitel Glück und Freude werde zu verzeichnen haben. - - -

Heute vor sieben Jahren! - Ich erinnere mich jeder Minute dieses denkwürdigen Tages, der mich zu dem machte, was mein höchstes reinstes Glück werden sollte: zur Mutter!

Mein gutes Mutterl, war aus Wien gekommen, um mir beizustehen

[2] u. wie nötig hat man in einer so schweren Stunde ein liebendes Mutterherz! - Und als endlich um 3/4 11 Uhr Abends ein zartes, süßes Wesen mir zum Kusse hingereicht wurde: Mein Kind! O was habe ich da empfunden! Es giebt Momente, die nie im Leben wiederkehren, Momente so erhaben, so unermesslich groß, - so rein ... daß man sich der Gottheit nahe fü[h]lt ... und ein solcher war es, als ich mein Kind zum ersten Male unter Tränen reinster Freude küsste, und mir selbst gelobte, es so gut, so brav so edel zu machen, als es in meinen Kräften stehe.

[3] Nun bisher darf ich zufrieden sein. Edith hat die besten Anlagen[.] Sie ist geweckt, klug u. talentvoll - aber ihr Bestes ist das Herz!

Wie gut, zartfü[h]lend u. zärtlich ist dieses kleine Herz. Was für ein Schatz ist dieses Kind! Sie weiß nicht, was eine Lüge heißt, selbst eine Notlüge ist ihr unmöglich. Und wie gewissenhaft ist das geliebte Mädel! Vorgestern Nacht brachte sie einige Stunden schlaflos zu, weil ein rosa Bändchen am Fließpapier in einem Heft fe[h]lte[.] Am vorigen Geburtstag als sie 6 Jahre alt war, haben wir ihr eine Clavierlehrerin - Cornelia Kirchhoff - aufgebaut, welche behauptet, Edith sei sehr talentvoll! $\mathrm{Na}$ ich

[4] sehe nichts Besonderes in ihren musikalischen Anlagen, aber ich bin froh, daß sie wenigstens gewissenhaft übt, u. die für ihr Alter möglichen Fortschritte macht. Ich glaube, unser geliebter Dicker wird musikalischer. Er hat schon mit 9 Monaten „Alles neu macht der Mai“ gesungen, u. jetzt - mit 3 Jahren, singt er jede Melodie nach - ja noch mehr - ohne lesen zu können findet er beinahe u. unfe[h]lbar, jedes Lied, daß er ein paar Mal gesungen in dem Liederheft.

Der geliebte Werner schwärmt von nichts anderem, als Capellmeister zu werden, besonders seit er

[5] sich im vorigen Jahre an den Leistungen der Tomaschek'schen Badekapelle in Franzensbad begeistert, giebt es für ihn, nur Einen Beruf: „,Tomaschek werden!“‘ 
Übrigens ist er auch darin etwas schwankend geworden, indem er gestern hinzufügte: „oder Droschkenkutscher, oder Kaiser"! - Auch dem Soldatenstande ist er nicht abhold, u. wenn er in der von der Wiener Großmama geschenkten k. k. österreichischen Ulanen-Uniform mit Lili spricht, Infanterie um den Tisch im Paradeschritt marschirt, so ist das ein Anblick für Götter! Das Lilimäuschen - obzwar erst 1 1/2 Jahre hält tapfer Schritt, u. singt alle Soldatenlieder

[6] u. patriotischen Gesänge vollständig richtig mit lauter Stimme mit. In diesem kleinen zierlichen Püppchen scheint mir ein starker, selbstständiger Geist zu leben. - Heute ist große Liedergesellschaft - da heißt es viel besorgen!

Das war ein Trubel u. Jubel, mir schwirrt noch heute der Kopf. Aber die Freude des geliebten Geburtstagskindes, läßt die kleinen Umstände die so eine Kinderheerde macht gern ertragen. Hermann hat sogar von Wien aus, wo er mit der Sembrich ist, an Edith geschrieben und depeschirt .... freilich habe ich ein paar Mal brieflich daran erinnert, damit es nicht geht, wie im vorigen Jahr!!

Dienstag 11.1

Gestern Concert v. Wladimir v. Pachmann!

Das 4te Mal daß er sich in Berlin öffentlich hören läßt, mit dem kolossalsten Erfolg ... aber vor leeren Bänken. - - Wie dumm ist die Welt - sie läuft nur wenn sie einen berühmten Namen hört, - der Modesache wegen - aber um einen wirklichen künstlerischen Genuß zu haben - dazu fe[h]lt beinahe immer Zeit u. Geld. Pachmann ist eine der phänomenalsten Erscheinungen am Clavier - eine unfe[h]lbare Technik - die aber bei ihm nur Mittel zum Zweck ist, die wasserhellste Klarheit zeichnen sein Spiel aus. Sein Ton ist der süßeste, zauberhafteste, den man sich denken kann - sein Spiel ist im Meer von Schönheit ... manche behaupten

[8] einige scharf hervorstehende Felszacken, würden dies Meer interessanter machen - aber wer kann sagen, ob an diesen Zacken, nicht die ganze Poesie dieses Tones scheiterte? - Ich glaube, $\mathrm{P}$ [achmann] ist der Spieler, der unter den Lebenden am meisten kann, diese Unfe[h]lbarkeit, diese spielende Leichtigkeit mit der die größten Ungeheuerlichkeiten der modernen Technik überwunden werden, ist die Frucht eines mühseligen Fleißes während 
langer harter Jahre. P[achmann] erzä[h]lt, daß er - als fertiger Künstler, nachdem er schon große Erfolge hinter sich hatte, sich acht Jahre vollständig

[9] von der Welt zurückgezogen, um zu studiren... mit Fingerübungen anzufangen! Dazu gehört Energie! -

Aber wie sieht dieser energische Mann im Leben aus? - Ein Mann!? Nein - ein Männchen, Zwerg Mime in höchsteigener Person - ein von Größenwahn besessener Mensch in seinem Wahn u. seiner Eitelkeit unendlich komisch - am Clavier sogar durch sein manierirtes Wesen die Lachlust reizend. Wenn er von sich spricht, verklärt sich sein Gesicht, bläht sich der ganze Mensch u. er spricht wie ein Liebender von der Geliebten - wie ein Priester von seiner Gottheit!

[10] Aussprüche wie: „Ich spielte wie ein Gott“ oder „Keiner spielt wie ich!“ od: „Mein wunderbares Spiel“" etc sind ihm so an den Leib gewachsen, daß man allmälig daran gewöhnt wird. Er ist aber zum Schreien komisch, wenn er im Concert nach einer wo[h]lgelungenen Passage sich selbst ein „bravo“ zuruft - oder wie seine Frau erzä[h]lt, sich nach dem Concert vor den Spiegel stellt und streichelt ... in dem Falle, als er unzufrieden ist, sich jedoch selbst ohrfeigt. - Der ganze Mensch ist eine Carricatur - etwas Unmögliches - kein Individuum sondern ein göttliches Spiel-Automat!

[11] Und doch hat dieser Automat sich das reizendste, entzückendste Frauchen erobert, eine kleine Engländerin belle race. Maggie ist selbst Klavierspielerin, und Componistin u. hat sich in ihn verterzt wie Wittkowsky neulich sehr witzig sagte.

Hermann ist heute aus Wien zurückgekehrt - auf 3 Tage nur, um wieder zu Marcella Sembrich zurückzukehren und mit ihr nach Pesth zu gehen. Er erzä[h]lt, daß M[arcella] S[embrich] in Wien bei dem Publikum den denkbar größten Erfolg gehabt, aber von den Zeitungen mit Ausnahme Hanslick schrecklich verrißen worden sei. - Und hier konnten die Kritiker gar keine Worte finden um

[12] ihre Begeisterung auszudrücken.

O diese einmütige, verständnisvolle Kritik! -

G[estern] Abend war Sitzung der philh. Gesellschaft. 
Joachim u. Klindworth wollen zurücktreten. Man will Hermann das Orchester zu Abonnementsconcerten überlassen. Er möchte Bülow als Dirigenten herüberziehen - wie in Hamburg - das wäre herrlich. - - -

Im Reichstag jetzt sehr besorgte Sitzungen, wegen Annahme eines auf 7 Jahre berechneten Militaer-Gesetzes - Bismark lässt uns fürchten, daß Frankreich uns überfallen könnte, wenn es sich stärker glaubt. Der Hintergedanke - obzwar er dementirt wird, ohne daß Jemand ihn ausgesprochen, ist doch, daß

[13] das liebe heilige Rußland dem französischen Freunde gegebenen falls helfen könnteWerner kommt herein - „, A bas la politique - vive l'amour maternel![“]

Er frägt natürlich, ob er „bobom“ haben darf! - natürlich! u. tausend Küsse dazu, geliebter Bengel!

Eine Woche voll Neuigkeiten: Der Reichstag aufgelöst, weil das Septennat nicht angenommen wurde. - Sarasate am 14 sein Concert an der Philharmonie gegeben BeethovenConcert zum 1. Mal gespielt mit geteiltem Erfolg wie sich denken lässt, denn die JoachimPartei lässt keinen Ausländer als Beethoven-Interpreten aufkommen. - u. doch brachte Sarasate so viel neue Schönheiten

[14] zu Gehör, daß man über dem Sinnenreiz gar nicht schwer die unendliche Tiefe der Joachim'schen Art vergessen könnte.

Das Mendelssohn Concert war sans pareil! - Der Pachmann auf der Geige, möchte ich sagen, dieselbe Süßigkeit, überirdische Schönheit des nicht allzu großen Tones, die vollständige Verachtung aller technischen Schwierigkeiten. -

Sonntag den 16. Diner bei Bechstein - gemütlich, nett wie immer. Es thut so wo[h]l, in einem Kreise von Menschen zu sein, von dem man fü[h]lt, daß man ihnen sympatisch ist. H[einrich] Ehrlich u. Pachmann war da. Die „süße Tante Maddie“

[15] wie Werner sagt, spielt im nächsten Klindworth-Concert.

Gestern speisten Pachmann u. der kleine Jos. Hofmann, das Wunderkind par excellence mit Vater u. Schwester bei mir.

Nach Tisch spielte Josef dem großen Wladimir etwas vor, ich glaube die Variationen von Rameau. Pachm[ann] war sehr überrascht von den ,guten Fingern“ des Knaben, ließ sich hierauf erbitten, dem Kleinen etwas vorzuspielen: zuerst Chopin, hierauf Mendelssohns 
Rondo Capriccioso im rasendsten Tempo, mit allen Finessen u. Zauber, deren er fähig ist. Hierauf setzt sich unser kleine Kerl, der Josef,

[16] mit einer Keckheit ans Clavier u. sagt: ,Moi, je joue ça comme ça' und spielt dasselbe Stück in demselben Tempo, vielleicht mit weniger Feinheit, aber mit größerer Genialität. Wir alle waren paff - P[achmann] am meisten. Er war vielleicht im ersten Moment sogar neidisch, u. machte dem Kleinen einige Vorträge über Auffassung, die das Bengelchen sehr respectvoll anhörte, jedoch nachher ruhig zu uns sagte. Je le trouve mieux comme moi je le joue, c'est plus expressiv. - Danach gab ihm Frau P[achmann] ein Thema ihrer eigenen Composition, welches Josef entzückend fortführte, u. variirte, um schließlich auf Anregung seines Vaters ein

[17] „Gewitter“ auf dem Clavier zu entfesseln. - Es war ein kindliches Gewitter, wie alles was der Kleine erfindet, den Stempel der Einfachheit u. Kindlichkeit trägt, dieses Genie reißt alles mit sich fort. - Es ist so aufregend zu sehen, wie groß diese Fähigkeit des Erratens von Noten $\mathrm{u}$. falschen Accorden ist, zu bewundern, wie spielend er die schwierigsten Disharmonien, ohne daß er gesehen hat, welche Noten man greift, auflöst, wie diesen kleinen Händen nichts zu schwer ist, u. wie dieses süße-piquante Kinderköpfchen ohne sichtliche Anstrengung arbeitet.

[18] Jedesmal, wenn er Proben seines Genies ablegt, ist man erstaunt u. gerührt - „der kleine Mozart" geht es von Mund zu Mund, wenn er am Clavier sitzt, selbst der gestrenge Herr Gumprecht in der Nationalz[ei]t[un]g hat es gesagt, u. seitdem macht es die Runde. Pachmann ward schließlich so überschwänglich, daß er zu Papa Hofmann sagte: In 10 Jahren werden wir alle zu seinen Füßen sitzen u. zu ihm aufblicken, denn er ist Chopin u. Liszt in einer Person. Ich machte meinen Gefü[h]len dadurch Luft, daß ich dem Kleinen eine Bonbonniere schenkte - und ich glaube meine

[19] Art des Enthusiasmus ist ihm lieber - denn er ist tro[t]z seines Genies ein echtes Kind heute (20.1. 87) ist er 10 Jahre, gilt aber natürlich noch für $9 \mathrm{u}$. ist kindlich $\mathrm{u}$. verspielt für $7[]-$.

Mit dem Spielzeug der Kinder mit Säbel Helm u. Pferd beschäftig[t] er sich, sowie er ins Zimmer tritt, aber auf einen Blick seines Vaters, der ihn vortrefflich erzieht, stellt er das Spielzeug bei Seite u. geht ans Clavier. - - - 
Hermann schreibt aus Wien, daß die Sembrich, tro[t]zdem sie von der Kritik schlecht behandelt wurde, vom Publikum vergöttert wird, u. in ihrem 2ten Concert circa 6000 Fl. einge-

[20] nommen hat. Der Kaiser will, sie soll im Opernhaus singen, doch die Lucca intrigiert dagegen. - Now I am beginning to take english lessons.

\section{$\underline{\text { 4. März } 87}$}

„Man soll nur schreiben, wenn man den Drang in sich fü[h]lt“ - aber ich komme selten dazu, weil ich fast immer abgespannt bin, wenn ich überhaupt zu Hause bin. Es ist mir nur nicht möglich über ein Ereignis hinwegzugehen, das zu interessant ist, um der Vergessenheit anheim zu fallen. Es war am 28. v[origen] Monats - vorigen Montag - Rüfers Merlin wurde z. 1. Mal im

[21] Opernhaus aufgeführt, u. Hermann hatte für uns u. Bülow’s Parquets zur premiére besorgt. Vergnügt betraten wir das Theater, legten unsere Garderobe ab, und waren im Begriff in den Saal zu treten, als plötzlich der baumstarke Portier des Hauses vor Bülow stand, und ihn aufs kategorischste aufforderte dasselbe sofort zu verlassen. B[ülow] blaß und erregt forderte Aufschluß über diese unerhörte Behandlung[,] jedoch der famose Ex-Unteroffizier hatte nur die drohend wiederholte Aufforderung

[22] u. den Hinweis auf den Schutzmann zur Antwort, welche er mit einer nicht mißzuverstehenden Handbewegung nach dem Kragen B[ülow]'s unterstützte. Wir alle, u. ... es hatten sich verschiedene Freunde bei dieser reizenden Scene eingefunden - waren sprachlos - da half auch kein Protestiren und Parlamentiren, man mußte eben der rohen Gewalt weichen. Natürlich gingen wir mit Bülow, der sich sehr gentlemanlike benahm.

[23] Vor der Thür brachen wir Alle in ein allerdings etwas nervöses Lachen aus. - B[ülow] gewann zuerst seine Fassung wieder u. meinte scherzend, nun könnten wir ja zur Philharmonie zum Concert v. Klindworth. Na, und wie freute sich „Freund K[arl] $\mathrm{K}[$ lindworth“, ] als er Bülow erblickte, der ,lieber“" in sein Concert als zur première on Merlin gegangen war. Bül[ow] hatte uns das Wort abgenommen über den Vorfall zu schweigen - $u$. so fiel der gute K1[indworth] fast auf den Rücken 
[24] als er am nächsten Morgen den wahren Grund des Conzertbesuches aus den Zeitungen erfuhr, die beinahe ausnahmslos das Gebaren des Grafen Hochberg tadeln. - Bülow, der wegen seines Kokettieren[s] mit den Czechen fast vervehmt [verfemt] war, wurde plötzlich der „Dulder“, der Märtyrer, u. die Aureole[,] die Grobheit ihm gewebt, ward ihm ein schützendes Palladium gegen alle ,nationalen“ Zisch und Au-laute,

[25] die sich unfe[h]lbar bei seinem Concert vom 2ten d. M. gegen ihn geltend gemacht hätten. Als Bülow an diesem Abend erregt und nervös vor das Publikum trat, empfing ihn eine Demonstration, wie wir sie in den kühnsten Erwartungen nicht geträumt hatten. Minutenlanger Jubel: „Hoch, Bülow“, Klatschen - es war das Gerechtigkeitsgefühl der Berliner, das sich Luft machte.

[26] Ich saß neben Bülows Frau, die sich stolz u. glücklich erhob - als ob sie sich mitverneigen wollte, um zu danken, für die Ovation die man ihrem Mann machte. Diese spontanen Ausbrüche wiederholten sich oft während und am Schlusse des Abends. Bülow war gerührt u. glücklich, u. in solchen Momenten ist er beinahe kindlich liebenswürdig. Diese „Affaire Hochberg“ war besser für B[ülow] als die raffinirteste Reclame, u.

[27] wird sowo[h]l dem Beethoven-Cyclus, als den von ihm im nächsten Jahre zu dirigirenden Concerten zu Gute kommen. Vorläufig ist sie Tagesgespräch. -

Ob der Herr Graf Bülow für den verjährten „Circus Hülsen“ od für persönliche Beleidigungen bestrafen wollte, ist unentschieden. - - -

Noch nachtragen will ich, daß Bülow das „russische Tanzlied“ v. Beethoven im Concert mit dem gewiß in diesem Falle sehr sinnigen: „Will der Herr Graf ein Tänzchen wagen“ präludierte. -

[28] Gestern waren wir bis $1 / 23$ bei Meyerheims - einige exotische Celebritäten: Ossip Schubin, die Malerin Parlaghy Vilma, haute finance Künstler - schlechtes souper schlechtere Musik - oder umgekehrt. - Ich habe mich famos amüsirt[.] Der vielbeliebte, umworbene L. P. [?] unterhielt sich sehr viel mit mir. Er ist interessant u. belehrend. - Hermann gestern u. heute famos eifersüchtig! Das macht mich glücklich! 
Unser 10 jähriger Hochzeitstag!

Möge das zweite - u. so Gott will die folgenden Decennien nicht schlechter sein!

Viel Glück, Freude, Ehre - u. nur wenig ernste - keine traurigen Momente haben uns diese Jahre gebracht. Wie gering sind die Enttäuschungen im Verhältnis zu den unerwarteten Freuden gewesen, die die Ehe uns gebracht hat: das junge Elternglück, dieses höchste u. schönste aller menschlichen Empfindungen - wäre es nur

[30] dieses Glück allein - es lohnte sich, gelebt zu haben!

Unser Verhältnis ist in diesen Jahren ein innigeres festeres geworden, als es selbst im Rausche der Leidenschaft zu werden versprach. Hermann hat zur Liebe für mich, auch noch das eisernste Vertrauen hinzugewonnen $-u$. ich habe kennengelernt, daß das meinige nie getäuscht wurde. - Hermann hat uns durch sein Thatkraft, Energie u. Intelligenz eine Stellung geschaffen, auf die ich in den ersten Jahren unserer Ehe nie zu hoffen gewagt

[31] hätte. - Ich kann mir ruhig das Zeugnis ausstellen, daß ich die Frau geworden bin, die er braucht, - nach innen u. außen. -Man kann es sich nicht länger verhehlen: Ich komme allmä[h]lig in das Alter, wo man sich vertieft, wo Äußerlichkeiten aufhören einen größeren Wert zu haben, als den, den sie in Wirklichkeit verdienen. - Ich arbeite an mir um besser u. vielseitiger zu werden, um gewappnet zu sein gegen die Schrecknisse des Älterwerdens;

[32] Viel denke ich über die Erziehung der geliebten Kinder nach - u. hoffe sie dereinst zu guten braven wahrhaftigen $u$. mutigen Menschen zu machen.

Edith hat viel Gemüt u. Intelligenz - hat die besten Anlagen - mit einer Masse von ungezogenen Gewohnheiten. Sie ist liebebedürftig, wahrhaftig bis zum Extrem u. zeigt keine Spur von Tro[t]z, wenn sie auch recht schnell Verdrossenheit zeigt. - In der Schule ist sie gut Mittelsorte - begabt - aber zerstreut.

[33] Werner ist unbewußt das Ebenbild Hermanns, in seinen Gefü[h]lsäußerungen, u. Scherzen[.] Ein bildhübscher Bengel mit famosen braunen Augen u. blondem Haar. Etwas schwerfällig mit der Zunge - trifft er doch den Nagel auf den Kopf! „Wimmelt“ wie Vater. Zeigt sehr viel Lust u. Anlage zur Musik. Fiedelt auf jedem Stück Holz! - Ein guter zärtlicher Kerl - manchmal berückend - ein echter Herzensjunge! - 
[34] Lili - niedlich, schelmisch, neckisch, - launenhaft - zum Zerküssen - oder zum Zerhauen - sehr klug. - Minna - meine Schwester war 2 Winter hier - ist mit Karl versprochen - Verlobung sobald Carl gesicherte Stellung.

Vor einigen Tagen erschien das Tagebuch Kaiser Friedrich III in der deutschen Rundschau. Mit neuen Schmerzen erfüllt uns der Verlust, dieses heldenhaften edlen Dulders - wenn wir lesen, was er erstrebt u. gewollt -

[35] Eine Schiller'sche Figur - wie sie in Jahrhunderten nur einmal kommt, war dieser einzige Mann, dem alle Herzen jubelnd zuflogen, wenn er sich zeigte - $u$. den Millionen in treuer Liebe u. innigster Herzenstreue nachweinten, als sein herrliches sonnenreines Leben, so elend so entsetzlich schloß.-

Sein Tagebuch zeigt klar, welch fester edler Geist er war - was die deutsche Nation an ihm verloren. -

Gestern mit Emil u. Hedwig im Kaiserhof Hochzeitstag gefeiert! -

Lili wird reizend - hat heute zum ersten Mal die Thüre aufgemacht, worauf sie sehr stolz ist. Friedrichs Tagebuch wird von den Offizieren - Bismark an der Spitze - angezweifelt.

$9 / 121891$

Soeben gingen Brahms u. Joachim von uns, wo sie gemütlich ein echt österreichisches $\mathrm{Ma}[\mathrm{h}] 1$ - Suppenfleisch u. Paprikahuhn - mit größtem Enthusiasmus verzehrt hatten. - Brahms - der Held des Tages - in 3 Tagen zum zweiten Male bei mir, vorgestern mit Bülow - heute mit Joachim! Ich bin stolz u. glücklich über die Art[,] in der er bei uns verkehrt. Ich glaube, er fü[h]lt sich wo[h]l - so fern von allem

[38] Parteigetriebe und lästigen Lobhudeleien - er weiß, daß wir ihn verehren und lieben - $u$. daß ich keine schlechte Küche führe - quelle attraction! - Wenn große Geister ihre Göttlichkeit abstreifen $u$. liebenswürdige Menschen werden, gewährt es einen eigentümlichen mit nichts zu vergleichenden Reiz. Brahms ist als Mensch ebenso bedeutend wie als Künstler, er ist 
[39] gelehrt - ohne jeden Anflug von Pedanterie, ironisch, ohne - oder doch nur mit einer wo[h]ltuenden Art von Bosheit - eine glückliche - ehrliche Natur, der im Stande ist, die höchsten Forderungen, die er an sich stellt - auch zu befriedigen. - Und wer kann das von sich sagen? Heute drehte sich das Gespräch meistens um Musik und Musiker. Joachim der auf ziemlich einseitigem

[40] Standpunkt steht, ist voll von Schwäche u. Vorurteilen - Brahms bekämpft alles Kleinliche - Zimperliche - Akademische mit Feuereifer[.] Als auf Meyerbeer die Rede kam u. Joachim ihn der sträflichen Eitelkeit zieh, sagte Brahms: Wer von uns ist es nicht. Ein Komponist dessen Domäne das Theater ist, muß den Teufel im Leibe haben - er muß Propaganda für seine Musik machen. Bei Meyerbeer wird nur alles - ich weiß

[41] nicht warum - viel strenger u. härter beurteilt, die dasselbe od. doch viel mehr ihre Sache

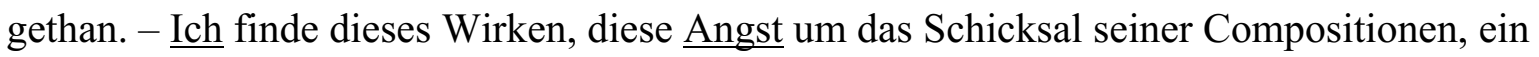
Zeichen rührender Bescheidenheit. Wer einen „Robert“ u. die „Hugenotten“ geschrieben, der dürfte stolz und übermütig sein. Wir hören doch aber nur Bescheidenes, Liebenswürdiges von Meyerbeer,

[42] u. tro[t]zdem hat er das Schicksal, daß man ihm nur zögernd etwas Gutes zugesteht. Ich halte seine Werke mit für das Beste, was geschrieben wurde - besonders groß, wenn man die elende, armselige Zeit bedenkt, in der sie geschrieben wurden. - Seine Bescheidenheit, sein Zweifeln an sich selbst, war echt deutsch - und echt deutsch ist es auch, an ihm nicht

[43] viel Gutes zu lassen, weil er ein Deutscher war.“-

Von Richard Wagner spricht Brahms mit großer Bewunderung u. Ehrerbietung - er sagte Sonntag zu Bülow: „Das Vorspiel zu Tristan und Isolde ist so groß, so herrlich instrumentirt, daß es kein Werk vor noch hinter sich verträgt - meine arme Symphonie!“ (№ 4 hatte tro[t]zdem kolossalen Erfolg, den Bülow trefflich inscenirte.)

[44] Wenn von Wilhelm III die Rede ist[,] murmelt er nur: „Cäsarenwahnsinn“! Er ist sehr demokratisch - übrigens sonst ohne jede politische Tendenz.

Wenn er spricht, u. sein Gegenstand reißt ihn fort, - da leuchten seine wundervollen blauen Augen wundersam, u. er wird so warm, so eindringlich - wie man dem sonst so Phlegmatischen nicht zutrauen könnte. Die Person ist ihm meistens 
[45] nichts - Alles die Sache! Ich möchte sein Bild so gern fixiren - wie ich ihn heute gesehen - das wäre mir die liebste Erinnerung an ihn! -

Von Person ist er kleine Mittelgröße mit einem prachtvollen Oberkörper u. mächtigem Haupte das von schlichten, graumelirten Haaren umwallt ist - sein herrlicher blond und weiß melirter Bart umrahmt ein blühendes - viel[leicht]

[46] etwas zu stark gerötetes Angesicht, die Stirne ist exc[e]ptionel hoch u. gewölbt, die Augenbrauen fein doch stark[,] die herrlichen blauen - nicht großen aber ausdrucksvollen Augen überschattend. Die Nase ist ein Prachtstück von Ebenmaß - der Mund jedoch zu stark, die Unterlippe geradezu unproportionirt hervortretend u. üppig, der Hals kurz[,] Brust und Rücken mächtig.

[47] Damit sind die Vorzüge d. körperlichen Reize des lieben Meisters aber erschöpft - sein Ränzlein u. die viel zu kurzen Beine[,] die noch dazu in viel zu kurzen Höschen stecken, geben dem „Göttlichen“ etwas recht spießbürgerlich-prosaisches, u. wenn er mit seinem Beethoven-Gang - die Hände auf dem Rücken, den Hut etwas aus der Stirn - durch die Straßen

[48] wandelt, erkennt niemand den Genius - man merkt nur den gemütlichen Menschen, dem ein guter Tropfen $u$. kein schlechter Bissen schmeckt.

Gestern dirigirte Brahms seine 4te Sinfonie, die Tragische und Akademische Ouverture u. die herrlichen Variationen in seiner ruhigen ebenmäßigen Weise ganz vortrefflich. Das Publikum des populären Concertes

[49] machte ihm viel Spaß. Bülow ordnet sich ihm ganz unter - ist rührend demütig u. über alle Maaßen enthusiastisch gegen od. für ihn.

[50] 10. März 92

Gestern wurde ich durch Stettenheim sehr angeregt ein regelmäßiges Tagebuch zu führen. Er thut es schon seit 30 Jahren.

Wir hatten Stettenheims, Frau Consul Lürßen eine sehr geistvolle lustige Frau, den italienischen Componisten Martuzzi, (Capellmeister in Bologna - u. als solcher bahnbrechend für Wagner in Italien thätig. hat vor einigen Jahren 12 Mal in Mailand den „Tristan“ dirigirt) u. Alice Barbi bei uns zum Frühstück.

Diese Sängerin ist neben Amalie Joachim die einzige 
[51] ,große“ die wir im Concertsaale haben. Sie ist eben so geistvoll als schön, u. von einer bestrickenden Eigenart als Sängerin. Sie gestaltet jedes Lied drückt ihm beim ersten Ton die Signatur seines Charakters auf.

Sie hat kein Genre, denn sie beherrscht sie beinahe alle - mit Ausnahme des deutsch$\underline{\text { schlichten. }}$ - Das alt-Italienische u. Brahms sind ihre Force. - Sie macht augenblicklich viel Furore - besonders in

[52] Österreich, wo sie das enfant chérie der Aristocratie ist.

Sie hat viel Grazie - angeborene u. erlernte - ist eine kalte Statur - egoistisch u. berechnend.

Stettenheim coquettirt viel mit seinen 60 Jahren - u. wünscht zu hören daß er noch gefährlich werden könnte. Er liebt es für einen Classiker! gehalten zu werden. Seine Eitelkeit - hält mit seinem Humor zum mindesten gleichen Schritt.

Gestern kam Hermann aus Wien, brachte die besten

[53] Nachrichten von allen Lieben - Vaterl ist wieder wo[h]l, nur Willy ist angegriffen[,] geht nach Meran, wohin auch Charles muß, der einen bösen Husten mit Blutauswurf hatte. - Der Doktor kann nichts besonderes entdecken - doch genügt das Faktum - u. mahnt zur Vorsicht.

- Bülow will im nächsten Jahr nicht mehr dirigiren - der Erfolg Weingartners verschnupft ihn.

Er sinnt 1000 Intriguen aus, wechselt im Hand-

[54] umdrehen Laune und Gesinnung.

Gestern nach der Probe aßen Bülow, Ehrlich u. ein paar Damen v. Emma Koch, Frl. Ritter u. Frl. v. Graba - die augenblickliche Favorite Bülows bei uns. Bülow nach der Probe der Haraldsinfonie die brillant ging - famoser Laune geistsprühend, Bosheit - träufelnd - mit einem kleinen Stich in's Lächerliche als verliebter Saladon - alt-ritterlich - enthusiastisch u. doch sich selbst

[55] ironisirend. - Alle Jahre ein bis 2 Mal erwacht solch ein Johannistrieb in ihm, u. fällt blind auf Würdige u. Unwürdige[.] Wir haben schon eine ganze Reihe von „Sr. Majestät 
Gnaden“ erstehen - u. in den Staub sinken sehen. - Die tollste Leidenschaft flößte ihm vor 3 Jahren Frau Merzenbecher[,] eine Abenteurerin schlimmster Sorte ein, die um so gefährlicher für ihn war, als sie schön gebildet geistreich, u.

[56] raffinirt war. Letzteres liebt B[ülow] bei Frauen am meisten - nichts imponirt ihm so, als das Raffinement $\mathrm{u}$. das kommt daher, weil er nur ein Bündel Nerven ist - mit einer eminenten Dosis Geist - aber jedes gesunden Gefü[h]les bar. - Er findet nur Genuß in der Überreizung u. nach jeder solchen Excursion in so ein Stück verbotenen Genuss, sinkt er doppelt erschlafft u. angeekelt von sich u. vom Leben

[57] in einen erbärmlich katzenjammerlichen Zustand in dem er alle Welt schikanirt, intriguirt u. peinigt - am meisten den armen Hermann, den er eine gute Dosis „Nerven“ als Andenken an die Bülow-Zeit zum ewigen Andenken hinterlassen hat ...

Eine seiner verrücktesten Launen ist, daß er im nächsten Jahr nicht mehr dirigiren will. „Alle sollen wissen, was sie

[58] an mir hatten" sagte er als ich ihn neulich nach dem Grunde seiner Demission fragte, die er seit 4 Jahren angekündigt, aber dies Jahr bestimmt zur Ausführung bringen will. - Was heißt aber bei Bülow „,bestimmt“"?? Während er das Wort ausspricht[,] hat er seine Meinung bereits gewechselt. - Er handelt nie nach Prinzip - nur nach Stimmung und

[59] Laune. Darin liegt sein Verdammungsurteil[,] aber auch seine „mildernden Umstände[“].

Nur als Künstler ist er ernst zu nehmen - da ist er groß - ohne Humbug u. Lüge - ganz in Begeisterung aufgehend, unermüdlich strebend u. schaffend. Auch als Künstler ist er prinzipienlos- stets den Geschmack wechselnd - aber das ist eher ein Vorzug - so hilft er Jedem zu seinem Recht.

[60] Er ist einer der geistvollsten Menschen[,] die je existirt haben, u. manchmal regt sich etwas bei ihm das man für Herz halten könnte. Meistens ist - dies aber eine generöse Laune. Über sein Verhältnis zu seiner Frau - ist Niemand klar - am wenigsten ich der er sein Herz ganz ausgeschüttet.

Es war am 28 November 1889 - ich weiß den Tag so genau, weil Hermann gerade zu dem 50 jährigen 
[61] Rubinstein-Jubiläum nach Petersburg fuhr - als Bülow zu mir kam und mich um Rat frug, ob er sich scheiden solle. Er weinte u. fluchte u. knirschte - u. sagte er könne mit seiner Frau nicht mehr leben. - Sie sei eine „Polin“ d. h. falsch u. hinterlistig - „elle joue la baronne" u. das sei ihm in der Seele zuwider, denn sie sei doch von unsren Herkommen, das sie nicht berechtige sich derartige Scherze zu erlauben. - Er erzä[h]lte mir daß sie ihm Briefe der Frau M. aus dem Schreibtisch gesto[h]len, und sie auswendig gelernt, um

[62] sie nun bei jeder Gelegenheit zu citiren. - Er hätte die größte Dummheit seines Lebens begangen indem er diese Person geheirat[et] - daß er überhaupt geheiratet, sei ein Verbrechen - er erzä[h]lte mit welchem Haß uns seine Frau beehre, wie jeder Brief meines Mannes Anlaß zu Streit gebe! - ich widerrieth ihm tro[t]zdem, sich scheiden zu lassen u. das war gut denn 8 Tage darauf - als er wieder kam, erschien auch Madame - u. er war - der gehorsamste Diener - knirschte zwar - aber fügte sich mit Grazie ins Joch.

Diät f. Werner Staßfurter Salz - 2 Kilo od. Malz Calnis[?]

Wiegen alle 14 Tage

Morgens 1 Tasse Milch im Bett

um 8 1/2 Milch m. Cacao u. Buttersemmel

um 11 Semmel m Schinken, Fleisch, Malzbier od. Wein

Craftbouillon -

$1 \mathrm{lb}[=1$ Pfund $=500 \mathrm{~g}=1 / 2 \mathrm{~kg}]$ Fleisch 1 Löffel Wasser

$3 \mathrm{St}$ [unden]. Kochen

um 1 Uhr 1 Tasse Milch m. Brödchen

Zu Tisch: Erbsen - Bohnen - Linsen Pürre, Reis, Spinat, Mondaminbrei, Hartenstein'sche Leguminose, viel Fleisch - 23 Löffel Laifflend'scher Malzextrakt.

5 Uhr Milch m. Brödchen, Abds. 


\subsection{Manuskript des Rundfunkgesprächs von Edith Stargardt(-Wolff) $[1957]^{724}$}

Musiker von nah' gesehen.

Von Edith Stargardt Wolff

Liebe Hörerinnen und Hörer!

Ich lade Sie ein zu einem Flug über sechs Jahrzehnte hinweg in eine musikalische Vergangenheit, deren Nachklänge in mir noch so frisch und lebendig sind, daß ich Sie gern daran teilnehmen lassen möchte. Es gibt viele musikgeschichtliche Werke, viele Biographien, in denen Sie vom Leben und Wirken bedeutender Komponisten, Dirigenten und Solisten lesen können. Ich aber möchte Ihnen eine Anzahl großer Meister und aufstrebender Talente zeigen, die ich von früher Kindheit an bis in den zweiten Weltkrieg hinein gehört und persönlich gekannt habe - kurz „Musiker, von nah’ gesehen“. Ja, ich habe das große Glück gehabt, schon in ganz jungen Jahren die herrliche Musik zu hören und ihre Interpreten nicht nur vom Podium her zu kennen, sondern ihnen in meinem Elternhaus in Berlin zu begegnen. Ihr Ringen, ihre Erfolge, ihr Bemühen um Verständnis für das Neue, ihre persönlichen Erlebnisse und Nöte, alles fand Widerhall im Hause meiner Eltern, des „Konzertdirektors“ Hermann Wolff, der im alten Berlin unter dem Namen „Musikwolff“ eine bekannte Figur war und seiner Gattin Frau Louise. „Musikwolff“ lautete übrigens auch die Telegrammadresse der Konzertdirektion.

Hermann Wolff hatte selber Musik studiert, war ein Sprachenkundiger, humorvoller, auch schriftstellerisch begabter Mann, der als Redakteur bei der noch heute blühenden Verlagsanstalt und Musikhandlung von Bote und Bock in Berlin angestellt war. Von hier aus führte ihn ein glückliches Geschick dem Berufe an, den es bis dahin in dieser Form noch nicht gab, und für den er der geeignete Mann war. Das kam so: Anton Rubinstein, der weltberühmte, glänzende Klaviervirtuose, ein Fürst im Reiche der Musik und ein grand'seigneur im Leben, kam damals gerade nach Berlin. Im geschäftlichen Leben unerfahren, bedurfte er eines Ratgebers und Reisebegleiters, der seine Tourneen arrangierte und leitete, ihm alles Geschäftliche abnahm und ein angenehmer Gefährte auf den langen Reisen war. Diese Aufgabe übernahm auf Empfehlung des Hauses Bock mein Vater Hermann

${ }^{724}$ Wolff-Nachlass: ID 131. Die Streichungen im Original. 
Wolff. Von diesem Augenblick an wurde er zum „Wegbereiter großer Musiker“, und „Wegbereiter großer Musiker“ habe ich auch mein Erinnerungsbuch genannt, das vor 3 Jahren im Verlag von Bote und Bock mit einer schönen, freundlichen Vorrede von Bruno Walter erschienen ist. Die erste gemeinsame Reise führte Rubinstein und Wolff nach Spanien, und ich besitze noch zahlreiche Briefe meines Vaters von dieser Tournee, die ein farbiges Bild von den Triumphen Rubinsteins, von Empfang am Königshof, von Stiergefechten und Volksleben geben. Rubinsteins Erscheinung steht mir noch deutlich vor Augen, nicht nur, weil sein lebengroßes [sic] Portrait, solange ich denken kann, in unserem Musikzimmer hing, sondern auch, weil ich, ein Kind noch, den illustren Gast oft in meinem Elternhaus gesehen habe, wenn wir nach Tisch zu den Erwachsenen hereingerufen wurden und artig unseren Knicks machen mußten. Eine dunkle Mähne, etwas schräg gestellte Augen, die dem Gesicht etwas Slawisches gaben, so lebt er in meiner Erinnerung fort. Unvergessen ist auch neben seiner fast unheimlichen Kraft und Virtuosität seine menschliche Güte, die ihn große Teile seiner Einnahmen zu wohltätigen Zwecken spenden ließ, gleichviel welchen politischen oder religiösen Bekenntnisses. Meinem Vater lag die Verteilung dieser Summen ob und die Listen haben sich noch erhalten. Mich beglückte der große Zauberer mit einer stattlichen, als russische Bäuerin verkleideten Puppe, deren zahlreiche Spitzenunterröcke mich besonders entzückten.

Von den großen unsterblichen Komponisten meiner frühen Jugend habe ich noch Brahms und Bruckner als Gäste bei meinen Eltern gesehen. An meine erste Begegnung mit Brahms erinnere ich mich freilich selbst nicht mehr, aber meine Mutter erzählte, daß ich ihm als vierjähriges Kind sein „Wiegenlied“ vorgesungen und „Guten Abend, gut' Nacht“ mit reinem Kinderstimmchen intoniert habe. Brahms war besonders zur Bülowzeit oft bei meinen Eltern. Die Jahre mit Hans von Bülow gehörten zu den an- und aufregendsten ihres Lebens. Dieser geistvolle, vielseitig gebildete, aber auch übernervöse, reizbare Mann war überaus schwer zu behandeln. Er war von Ironie und Schärfe, konnte aber auch gelegentlich von bestrickender Liebenswürdigkeit sein. Meiner Mutter schickte er seine Photographie mit der Unterschrift ,à l'animable, quoique spirituelle Madame Wolff, un flatteur“, also: der liebenswürdigen, obwohl geistreichen Frau Wolff, ein Bewunderer", ein Zeichen, daß er der Unterhaltung mit ihr Gefallen gehabt haben muß. Uns Kinder beglückte er regelmäßig zu Weihnachten durch Übersendung eines riesigen Baumkuchens. Mit dem Auftreten Bülows als Dirigent war eine neue Zeit im Musikleben Berlins angebrochen. Philharmonische Konzerte hatte es bisher hier noch nicht gegeben und auch noch kein Philharmonisches Orchester. Erst als die Bilse'sche Kapelle sich auflöste, die bis dahin im „Konzerthaus“ in der Leipziger Straße konzertiert 
hatte, gab Hermann Wolff der sich neu konstituierenden Gemeinschaft den Namen „Philharmonisches Orchester“, unter dem es berühmt wurde und bis zum heutigen Tage in der ganzen Welt geblieben ist. Und Philharmonie wurde der Raum getauft, der, an der Stelle der alten Rollschubahn in der Bernburger Straße erbaut, bis zur Zerstörung gegen Ende des zweiten Weltkrieges die Stätte für die Philharmonischen und viele andere große Orchesterund Solistenabende wurde. Es gab aber auch nicht nur Philharmonische Konzerte, sondern auch Philharmonische Diners, nämlich kleine intime Essen im Hause Wolff nach den öffentlichen Generalproben an Sonntagsvormittagen, bei denen der Dirigent präsidierte. Die mitwirkenden Solisten und andere bedeutende Persönlichkeiten bildeten eine angeregte Tafelrunde, bei der der witzige Cellist Heinrich Grünfeld jederzeit ein besonders beliebter Tischgast war.

Will ich nun zunächst die große Linie der Philharmonischen Konzerte weiter verfolgen, so muß ich nach dem viel zu früh erfolgten Tode Bülows dessen Nachfolgers gedenken: Arthur Nikisch. Er war von mittlerer Gestalt, mit grazilen aber eindringlichen Bewegungen, einem Spitzbärtchen und einer dunklen Locke, die ihm in die Stirn fiel. Der stets reimfreudige Berliner prägte daher die Bezeichnung „Arthur mit der Haartour“. Nikisch war im vielen der Widerpart seines gestrengen Vorgängers, vom großem Charme, konziliant, nie Jemanden verletzend. Und doch gehorchte das Orchester seinem Zauberstab ebenso willig und hingerissen. Natürlich änderte sich nun auch der Charakter der Programme, in denen Nikisch Tschaikowski’schen Symphonien breiten Raum gewährte. Wie glücklich hätte es Altmeister Bruckner gemacht, hätte er erlebt, wie sich Nikisch für ihn einsetzte! Hatte Bruckner sich doch - unvergessen in unserer Familie - einst bei einem Besuch meiner vierjährigen Schwester zu Füßen geworfen und um ihre Fürsprache bei dem ablehnenden Bülow gefleht! Einen Höhepunkt der Nikischperiode bildete die von meinem Vater unternommene erste Auslandstournée des Philharmonischen Orchesters, die 1897 nach Paris führte. Obwohl 26 Jahre nach Beendigung des Deutsch-französischen Krieges verflossen waren, erschien diese Masseninvasion deutscher Musiker der Pariser Polizei doch bedenklich, so daß sie von meinem Vater die Weglassung der Bezeichnung „Orchestre de Berlin“ auf den Plakaten verlangte, was dieser aber strickt ablehnte. Die begeisterte Aufnahme, die dem Berliner Orchester, seinem Dirigenten und dadurch der deutschen Kunst bereitet wurde, gab ihm recht. Unter den enthusiasmierten Hörern befanden sich der große französische Komponist SaintSaëns und der Staatsmann Clemenceau, sowie Oberst Piquart, der neben Zola der tapfere Streiter für Gerechtigkeit in dem unseligen Dreyfußprozeß gewesen war. Mit solchen Männern nach den Konzerten zu plaudern war für meine Eltern ein Erlebnis, wie denn 
überhaupt die Berührung mit bedeutenden geistigen Persönlichkeiten verschiedener Länder ihnen immer wieder neue Anregungen gaben. Nikisch überlebte meinen schon 1902 gestorbenen Vater um 20 Jahre und bewahrte allezeit seine treue Freundschaft Louise Wolff, die nun mit starker Hand die Leitung des Hauses übernahm. Eine schwere Aufgabe harrte ihrer, als Nikisch starb und es den Posten des Dirigenten der Philharmonischen Konzerte neu zu besetzen galt. Denn damals war es noch nicht Sache einer Behörde, eines Senates, diese für unser Musikleben so eminent wichtige Frage zu lösen, sondern es war Aufgabe der Begründer der Philharmonischen Konzerte, also des Hauses Wolff, sie im Einverständnis mit dem Philharmonischen Orchester zu regeln. Da stellte sich - wie ein deus ex machina - eine der attraktivsten Dirigentenerscheinungen der Zeit selbst zur Verfügung: Wilhelm Furtwängler. Er hatte bis dahin die Konzerte der Staatskapelle geleitet, konnte sich aber von seinen alten Verpflichtungen reibungslos freimachen, und so war der neue Mann für die Philharmonischen Konzerte und mit ihm die glänzendeste Lösung gefunden. Furtwänglers grandiose Beethoveninterpretation ist bekannt, ebenso wie sein Eintreten für Hindemith. Die Tradition der Philharmonischen Diners wurde auch unter ihm fortgesetzt und viele interessante Aussprachen mit anderen großen Musikern und Kritikern fanden statt. Er hat das Orchester im In- und Ausland von Triumph zu Triumph geführt, bis der Tod das Band zerriss. - Als gewaltige Erscheinung unter den Dirigenten nenne ich auch Otto Klemperer, der von schwerer Erkrankung genesen, kürzlich zu unserer Freude wieder in Berlin dirigiert hat und mit dem es für mich ein herzliches Wiedersehen gab.

Lassen Sie mich nun meinen Blick wieder rückwärts wenden zu Dirigenten, die vor Jahren und Jahrzehnten regelmäßig gefeierte Gäste in Berlin waren. Wer von Ihnen hat noch Felix Weingartner am Pult gesehen? Die Berliner haben ihn geradezu vergöttert, und die Bereicherung des Konzertlebens durch Weingartner-Konzerte mit dem Philharmonischen Orchester noch während des ersten Weltkrieges jubelnd begrüßt. Vorher hatte er eine Zeitlang gleichzeitig mit Karl Muck, Richard Strauß und Leo Blech am Königlichen Opernhaus gewirkt. Leo Blech, ein Aachener Kind, feierte im April [Einschub: vor wenigen Tagen] in höchster geistiger Frische seinen 86. Geburtstag. Ab und zu führen er und ich noch ein lebhaftes, telephonisches Gespräch. Vom Rheinland her kam gleich Blech auch Hermann Abendroth als gern gesehener Gast. Aus Dresden kam Fritz Busch, dem Richard Strauss so gern die Uraufführungen seiner Opern anvertraute. Busch, der als großer Nazigegner frühzeitig Deutschland verließ, habe ich in USA wieder am Dirigentenpult gesehen und mit dem Ehepaar Busch köstliche Stunden nach den Konzerten verlebt. Bald danach hat ihn leider der Tod dahingerafft. 
Glanzpunkte für das Berliner Konzertleben waren die Bruno Walter-Konzerte, die meine Mutter ähnlich den Philharmonischen als Cyklen eingerichtet hatte. Da gab es, wie in seinen Opernaufführungen viel bezaubernde Mozartmusik, oft auch unter Mitwirkung der von ihm und uns besonders geliebten Maria Ivogün. Auch Gustav Mahler, den Bruno Walter besonders schätzte, kam in diesen Konzerten oft zu Gehör. Etwas von der Wärme, der Harmonie, die Walters Musizieren beseelte, kam auch in den Unterhaltungen zutage, die nach den Generalproben dieser Konzerte bei den kleinen, nun schon traditionellen Essen im Hause Louise Wolffs mit gleichgesinnten Freunden stattfanden. Walter war es auch, der ein junges, bis dahin unbekanntes Genie, ein Wunderkind mit dem Können eines Meisters[,] den 11jährigen Geiger Jehudi [sic] Menuhin, in Berlin einführte. Der Knabe entzückte uns auch durch sein liebenswürdig-bescheidenes Wesen und war von seinem einsichtigen Vater vortrefflich erzogen, ebenso wie seine pianistisch hervorragend begabte kleine Schwester Hepsiba [sic]. Und nun gehe ich zu anderen Geigern über. Von den großen Violinisten meiner frühen Kindheit habe ich noch Sarasate und Joachim gehört, 2 stark akzentuierte Gegensätze: der graziöse, brillante spanische Virtuose Sarasate, der mein Kinderherz nicht nur durch sein zauberhaftes Spiel entzückte, sondern auch durch ein originelles Geschenk für das kleine norddeutsche Mädchen; einen Trockenplatz für die Puppenwäsche mit allem Zubehör. Und der Ehrfurcht gebietende, professorale Joseph Joachim, dessen Kammermusikabenden in der Singakademie ich tief ergriffen lauschen durfte. Erlesene Kammermusik brachten auch der Belgier Eugène Ysaye und der französische Pianist Raoul Pugno, mit denen es oft ein lustiges Zusammensein im Haus Wolff gab. Wie schwirrten da alle Sprachen durcheinander und alle Dialekte. Denn auch das Wiener Roséquartett fand sich ein zu Backhändln und anderen Leibgerichten aus seiner und meiner Mutter Wiener Heimat. Ja, an Gästen fehlte es da nie, und ich empfinde es als großes Glück, daß trotz aller Zerstörungen des zweiten Weltkrieges das Gästebuch meiner Mutter vom Jahre 1902 bis zu ihren Tode 1935 sich erhalten hat, voll der klangvollsten Namen. Von großen Empfängen liest man da, zu Ehren von Mengelberg, von Cortot, von Orchestre de Paris und seinem Dirigenten Pierre Monteux. „Wer zählt die Völker, nennt die Namen, die gastlich hier zusammenkamen.“ Da hat sich auch Fritz Kreisler eingezeichnet, der große Geiger und verehrungswürdige Wohltäter der Notleitenden[,] und Bronislaw Hubermann, der als einer der ersten für die Idee Paneuropa eintrat. Im Gästebuch sieht man auch die charakteristische Handschrift von Ferruccio Busoni, dem großen Komponisten und Klavierspieler, von dem ich stolz noch ein paar handgezeichnete Karikaturen besitze, die er[,] auch in dieser Kunst ein Meister, für meinen Vater gezeichnet hatte. Als Gäste sind auch andere große zeitgenössische Komponisten, wie Humperdinck, der 
Schöpfer der lieblichen Märchenoper Hänsel und Gretel, ein stiller, freundlicher Gast, und Max Reger, der in einem besonderen Vertrauensverhältnis zu meiner Mutter stand.

Lassen Sie mich nun noch von einigen bedeutenden Pianisten sprechen: Da hat sich der Name Eugen d'Albert noch strahlend lebendig erhalten, sein Genie wirkt noch heute beispielhaft. Als Ehemann kann ich ihn freilich nicht als Modell empfehlen, denn er hat sich sechs mal scheiden lassen und jedes Mal schütteten die unglücklichen Frauen meiner Mutter ihr Herz aus, während d'Albert im Nebenzimmer meinem Vater seinen Standpunkt erklärte. Eine der Verlassenen war die feurige. bildschöne, d'Albert als Künstlerin ebenbürtige Venezolanerin Teresa Carreño, für die wir Wolff'schen Kinder schwärmten. Ich vermag bei der Kürze der mir vergönnten Zeit neben Edwin Fischer nur noch einen großen Klavierspieler zu erwähnen, für den mein Vater noch Wegbereiter gewesen ist und der uns noch bis vor einigen Jahren begeistert hat: Artur Schnabel, ein herrlicher Schubertinterpret, ein geistiger Mensch von hohen Graden. Übrigens war er auch ein Meister in der Kunst der Schüttelreime, von denen mir gerade ein Beispiel einfällt, „Von jedem Schund a bissel, das nennt man bunte Schüssel““. Wie delikat war er als Liedbegleiter seiner Gattin Therese Behr, deren ernste Vertiefung in Brahms'sche Gesänge noch in Erinnerung ist. Ungefähr zur gleichen Zeit konzertierte die holländische Mezzosopranistin Julia Culp, begleitet von ihrem lustigen Landsmann Conrad V. Bos, auch sie eine wunderbare Brahms- und Hugo Wolf-Interpretin. Beide Sängerinnen excellierten nicht durch gewaltige Stimmittel, sondern durch Gestaltung und reizvollen Vortrag. Ganz auf Geist und Ausdruck gestellt waren die Abende von Ludwig Wüllner. Die Ältesten meiner Zuhörer werden sich vielleicht noch seines Vaters, des Kölner Dirigenten und Musikdirektors Franz Wüllner erinnern. Ludwigs Organ war eigentlich spröde, aber wie vermochte er in Lied und Rezitation zu ergreifen und zu erschüttern. Lassen Sie mich schliessen mit dem Gedenken an eine Sängerin, die vielseitig und ausdrucksfähig auch eines der schönsten Organs besass, das von den hohen strahlenden Tönen bis zum pastosen Alt reichte: Sigrid Onegin. Wer sie gehört, vergisst sie nicht. Diese und viele andere Bilder ziehen an mir vorüber, und ich bin froh, dass ich Ihnen, liebe Hörer, einige Ausschnitte übermitteln durfte und hoffe, dass sie auch in Ihnen Erinnerungen an glückliche Eindrücke erweckt haben. 


\subsection{Gesprächsaufnahme von Wolfang Zuelzer “Queen Louise", o. D. (Transkription) ${ }^{725}$}

\section{Wolfgang Zuelzer}

[...] I have been thinking about this for a long time, because when you have led as many diverse lives as I have, then you realize that all this tradition that I brought over with my arrival in this country is going to come to a rather abrupt end, and even my own family doesn't really know many things that I think that they would or should know.

This audience, I think, is loaded and I have in my favor - I mean, I have rolled the dice in my favor, because most or all of you are interested in music, and this particular chapter deals largely with musical life as I knew it, and before me, my family. The Berlin Philharmonic Orchestra which is the orchestra that I grew up with, so to speak, had its centennial in '83, I think it was. ${ }^{726}$ And, for that occasion I wrote a sketch describing essentially the role that my grandparents played in the history of the orchestra, and that was broadcast over Radio Free Berlin a couple of years ago. And I had help from Bob Craft here who let me make the tape that I sent over there, and then they interspersed it with recordings from some of the musicians of way back when it was sort of interesting.

Well, anyway, the chapter in my forthcoming but not yet even clearly projected book is essentially an English version of that script that I sent in, and I will read and see how far I get, and if I notice that you are getting restless I can always stop. It's entitled Queen Louise - A Portrait.

My grandmother Louise Wolff was a remarkable woman by any standard: grand dame and shrewd business woman, diplomat and mother hen, matriarch of a family of strong personalities of both sexes, a trusted friend of great and little people, a power in the world of music and beyond, and an idealist with both feet firmly planted on the ground. Her biography has not been written. She was often asked, especially by her friend the American journalist Geraldine de Courcy of the Musical Courier, to write or dictate her memoires, but she was always and almost to the last too busy, too involved with the present and the future to take time out for her reminiscences. At her funeral, Wilhelm Altmann, a renowned musicologist and custodian of the famous manuscript collection of the Prussian State Library, spoke with feeling of the unique role she had played in the musical and social life of Berlin. And Fritz Kreisler,

\footnotetext{
${ }^{725}$ Wolff-Nachlass: ID 132.

${ }^{726}$ Die Berliner Philharmoniker haben ihr einhundertjähriges Jubiläum im Jahr 1982 gefeiert.
} 
for many years her close friend, added these words "Today we close a chapter in the history of music." Her daughter Edith, my mother: in her book "In the Service of Great Musicians" which has not been translated into English, was published in 1954, she filled many gaps in that chapter, but left much of her mother's personal life unexplored. It now falls to me, her favorite grandson (for she was too human not to have favorites), to attempt a portrait, even though I am neither as unbiased nor as well informed as a biographer ought to be.

She was born in 1855 in Brünn, then the city of the Austrian province of Moravia (today the city of Brno in Czechoslovakia), the eldest of 12 children of Johann Evangelist and Elisabeth Schwarz, and given the names Aloysia Wilhelmina which she later streamlined into "Louise". Her parents, good Catholics and loyal subjects of the Emperor Franz Joseph, had come to Brünn from Reichenberg, the chief town of the Sudetenland in what was then Bohemia. The father was a government clerk, at home a benign tyrant, otherwise an easygoing man, even a bit of a dandy with sideburns and carefully trimmed whiskers, whose passion was the theater. In her old age, Louise could still quote whole passages from the comedies of Nestroy and Raimund, representatives of uniquely Viennese humor and her father's favorites.

Johann's style as a domestic tyrant is illustrated by the method he used to make his children's guests leave if, in his opinion, they were staying too late in the evening. "I am in the habit of opening the windows 5 minutes before our guests leave", he would announce and proceed to do just that.

His wife Elisabeth was a good Victorian housewife, but she too seems to have had a right sense of humor as shown by an anecdote she told on herself when she was an old lady living on her widow's pension in the city of Breslau. When, after a long illness, she ventured forth for the first time in many weeks, the owner of the corner grocery greeted her with the word, "Lord Almighty! The Frau Councilor and here I thought I had missed the funeral."

Evidently, she had the gift of spotting the small absurdities of life so often overlooked by less observant people, a gift she passed on to her granddaughter, Edith, my mother. Aloisa, called Loisel, not yet Louise, was given a good Catholic education. The nuns at the convent school she attended as a day student taught her the skills she would presumably need as the wife of another Austrian bureaucrat, that is, sewing, embroidery, arithmetic, a little French. Cooking she learnt at home.

The parish priest instructed her in the Catechism and heard her confession preparatory to the first Communion. That little girl, so she told me when she was an old woman, knew that the greatest sin of all was that of withholding anything from the confessor, but she didn't know what sin really was. To be on the safe side she put a check mark on every sin on the list, including adultery, what might that word mean, and murder. Had she not squashed an innocent 
flea now and then? But coming home afterwards in her white muslin dress, she experienced a sense of purity and joy she would always remember, though she hesitated to drink the hot chocolate and eat the delicious cake that awaited her, for didn't she have the body of our Lord in her?

Louise remained a Catholic, albeit a lukewarm one who in later life seldom went to church, married outside the faith, and allowed her children to be raised as Protestants, a compromise and quasi-diagonal between the religion of her ancestors and the agnosticism of her husband. But when the end came, a priest was called, probably at the urging of her sister Mitzi, my grand aunt, a spinster whose full name, Maria Theresia Antoinette, justified both of the Catholicism and the Austrian loyalties of the Schwarz family.

Louise received absolution. The sins she confessed on this occasion cannot have been as serious as those she had taken upon herself at her first Communion and died at peace with the church. Throughout her life, she retained a child-like respect for the truth. Truthfulness, purity, and cleanliness, the father at Brno had taught her, were the carnal virtues of a Christian girl, although it was hard to be consistently truthful in the face with the many white lies required by her position as a woman of the world and head of a world-renowned firm, the Konzertdirektion Wolff.

In that capacity, she would consider it her duty even in her late 70 s to attend the concerts and recitals of every musician who performed in Berlin under the auspices of the Konzertdirektion. This was difficult, for, on any given night, there might be three or more such events. Fortunately, the concert halls were located in the center of town within walking distance of each other or at most a short taxi ride away. Louise's strategy was to arrive at one concert at its beginning, sit conspicuously in her balcony box, rush backstage in the intermission to embrace and compliment the artist, then move on to the next hall, slip into her seat and greet that performer at the first opportunity, and finally with luck repeat the maneuver once again before the third concert ended.

On one of these occasions, she arrived at the last event of the evening just as the performer was making his final bows on stage. Dashing back stage, she had caught her breath by the time he returned and was able to greet him with a radiant smile and the words "noch nicht dagewesen", a double entendre, difficult to translate but meaning roughly 'simply unheard of'. It was the literal, but only the litera, 1 truth. She had not heard the concert, but it sounded like a compliment. When she told me the story the next day, she was pleased as Punch, mainly because her presence of mind had saved her from an embarrassment, but also, no doubt, because by telling the truth she had played a joke on the devil. 
Sometime in the 1860 s, Johann Schwarz was promoted to the rank of councilor in the Ministry of Finances and transferred to Vienna where he could indulge his passion for the theater, a passion soon shared by his eldest daughter. But for her, being a spectator was not enough. At the age of 16 she announced her decision to go on the stage herself. This was nothing short of scandalous at a time when actresses were looked upon as women of easy virtue. The father raged, the mother pleaded, brothers and sisters were perplexed, but the young woman stood firm. Finally, it was agreed that she would undergo a test by one Herr Strakosch, director of the well-known theatrical school in Vienna. He pronounced her talented and accepted her as a pupil.

A year later Louise left Vienna as a member of a traveling company that brought culture or at least entertainment to the provinces. Idealist that she was, she may have seen herself as Gothe's chaste Iphigenia or one of Schiller's or Hebel's great heroines. If so, her hopes were disappointed. The plays staged for the benefit of provincial audiences in Bohemia, Silesia, and Pomerania were for the most part melodramas or farces geared to simple tastes. Only twice was she allowed to play a serious part, once as the heroine of Schiller's Maria Stewart, another time as Thekla in Wallenstein, but she was in earnest about her career and would make short trips to Berlin whenever she could get away to observe the famous actors and actresses of the German capital.

The life of an unattached actress was not an easy one in those days. Louise Schwarz was not a classical beauty, but attractive enough to the opposite sex, though strikingly different from the demure, blond, young women she saw in Germany. With her expressive brown eyes, high Slavic cheekbones, the slightly retroussé nose that somehow looked mischievous, delicately curved lips, and firm chin, the whole surmounted by a mass of black tresses, she was not easily overlooked in any group of women. As for men, she was very particular and rejected the attention of the clerks and commercial travelers who were the only unattached males a young actress was likely to encounter in the backwater of provincial towns. Her virtue, or was it pride, threatened to become an obstacle to her career, for as she confided to her diary, "word got around" and ticket sales fell when the company's best customers realized that the leading lady was unapproachable. Even the manager complained!

Her dilemma resolved itself in an unexpected manner. On one of her visits to Berlin to widen her theatrical horizon, she found herself seated next to a young gentleman who was so knowledgeable and intelligent and at the same time so respectful and well-mannered that she could not help but respond, and after the play allowed him to see her home, that is, to the modest pension where she was staying. The next day he sent flowers and a card, later increasingly ardent letters. Her answers could not have been discouraging. For next he came to see her in 
whatever provincial town the company happened to be and finally he asked her to marry him. She accepted, probably to the renewed despair of her Catholic parents in Vienna. He was Hermann Wolff, an agnostic young businessman and music lover of Jewish descent whose parents had moved to Berlin from the Rhineland sometime after the Napoleonic Wars. He was my grandfather, 10 years older than his bride.

The marriage was a success, the attraction of opposites. He was a rationalist to the core, cool, witty, ironic, whereas she was guided by instinct and temperament, his [an] analytical mind, hers relying largely on intuition. She was more than a good wife and mother to their three children, an equal to be consulted in all matters of importance, a hostess with poise and charm, capable of receiving the most distinguished guests. For soon they would have very distinguished guests indeed. But, the strongest bond between husband and wife was love of music, resting in his case on solid technical knowledge, in hers on inborn musicality.

Hermann had abandoned a career in music in deference to his father's wish, but earlier he had studied piano and composition at the renowned Stern Conservatory in Berlin. He could read an orchestral score, was thoroughly familiar with both the classical and the contemporary repertoire. He was an ardent admirer of Richard Wagner and, quasi as a side line, served as an occasional music critic for several Berlin newspapers. A facile and amusing writer, he also wrote occasional poetry for weddings, anniversaries and the like, sometimes for the money, sometimes for his own pleasure. Later, he composed piano pieces in the manner of Anton Rubinstein, not great or original music, but good enough to earn a mention in German music dictionaries down to my time.

His ambition to become a performing musician remained unfulfilled. For the time, he settled for position in the offices of Bote \& Bock, Berlin's leading music publisher, the respected firm which is still in existence in West Berlin today more than a hundred years later. But Hermann Wolff was destined to play a far larger role in the world of music than that of performer, critic, publisher. He became an impresario, or rather, starting as an impresario, he created something entirely new, an organization that would stimulate and soon dominate the musical life of the German capital and ultimately the entire country, and extend its influence throughout Europe and as far away as America. This was the Konzertdirektion Wolff, known the world over by its telegraphic address Musikwolff. It was largely through Musikwolff's efforts that Berlin became one of the great centers of music.

For most of the 19th century, traveling virtuosos had to make their own arrangements for such matters as printing and selling tickets, renting a hall, hiring an accompanist or an orchestra, to say nothing of accommodations in unfamiliar cities. In Berlin, they would turn to 
Bote \& Bock for help, but there was no one really competent enough to meet all the needs of discriminating artists.

One day, Anton Rubinstein, second only to Liszt as a piano virtuoso, asked the old Mr. Bock if he could recommend someone to accompany him on his concert tours. The specifications were; a musical background, a good head for business and other practical matters, command of French and English, and familiarity with the game of whist to help pass the time on long train rides. Herr Bock knew just the man. Without hesitation, he recommended his young assistant Hermann Wolff, and off they went, the leonine grandseigneur Rubinstein [who] was married to a princess and carried himself like an aristocrat, and the adroit young Berliner, to London, Paris and Madrid, Warsaw and St. Petersburg, playing whist on the train, staying in carefully selected hotels, taking in the bullfights and other local attractions, and enjoying each other's company. Hermann proved to be a competent impresario and a good conversationalist. And, by the time the odd pair returned to Berlin, they had become friends. Hermann's young wife shared in this friendship, saw to it that that the great man ate properly, bought him badly needed shirts, for Rubinstein was utterly helpless in practical matters, and in other ways mothered Anton Petrovich, something his princess had neglected to do.

Soon he poured out his marital troubles into her sympathetic ears, for she was a good listener, and Rubinstein would not be the last to confide in her. Brahms, for example, who as a boy had played the piano in the disreputable establishments of the Hamburg waterfront and who as a matured man could satisfy his erotic needs only with prostitutes, would talk to Louise about his "little girls" and the problems they were causing him. Louise was completely free of the moral prejudices of her contemporaries. In later years, Anton Rubinstein's life-size portrait, a majestic figure with a Beethovenesque head, standing upright in a resplendent fur coat before the viewer, occupied a place of honor in her living room, a compelling presence for as long as I can remember. What became of it after she died I do not know.

Hermann Wolff's success as Rubinstein's impresario caused other artists to demand his services. Since it was manifestly impossible for him to satisfy these demands - after all, he could not travel with more than one musician at a time - he conceived the idea of creating a central organization, the Konzertdirektion, which could provide essentially the same services Rubinstein had enjoyed. The enterprise was so successful that soon they were few artists performing anywhere in Germany who were not represented by Musikwolff. But Hermann was no ordinary impresario. For one thing, he was a trained musician who spoke the language of musicians and could offer expert advice on such matters as programming, selecting soloists for orchestral concerts, [and] finding the right conductor for an orchestra. It was he who brought Hans von Bülow, and, after Hans von Bülow's death, the incomparable Arthur Nikisch, to 
Berlin as music directors of the Berlin Philharmonic, and who knew when and where the public was ready for the première of a new work.

For another, he was far more concerned with raising musical standards and discovering new talent than with making money, although he was by no means averse to it. His widow would be a wealthy woman. He not only risked his capital and his reputation by sponsoring unknown young artists, but often he guided their steps until they had made a name for themselves. He took a personal as well as professional interest in these men and women, bringing them home and introducing them to his wife. He would suggest the most suitable teachers for perfecting their technique and recommend them to the Musikverein and other carefully chosen cities where critic and public would not be too demanding for budding talent.

Like a general planning a military campaign, he would map the strategy of a concert tour that might take a performer from relatively uncritical provincial towns, to say, Cologne or Hamburg, then to Leipzig with his great musical tradition, and finally, if he or she lived up to his expectations, on to Berlin. No detail was too small to be overlooked by him. Thus, as Arthur Rubinstein, no relation to Anton, would record in his memoires 'My Young Years,' somebody was talking about this this evening "Hermann Wolff maintained an updated list of musicians and students on whom he could call, if he anticipated less than a sellout."

Arthur Rubinstein, who after an early childhood in Poland grew up in Berlin and was himself a protégé of the man he called "the Omnipotent Hermann Wolff", has related the story of how Wolff introduced him to the famous pianist Eugen d'Albert after one of the latter's recital. "This is the young Rubinstein", he said. D'Albert asked, with a touch of irony (I am quoting now from Rubinstein's book), “by name or by talent?”, and Wolff answered seriously, "by both", whereupon the great man challenged the young boy to prove it, and Rubinstein then and there played two Brahms Rhapsodies opus 79, and afterward was embraced by d'Albert who said "yes, you are a true Rubinstein."

The anecdotal trait of Hermann Wolff that became proverbial in his own time was his presence of mind. On another occasion, when a flatterer or perhaps competitor compared him with a menagerie owner, he replied instantly, "with the difference that I don't have to feed my lions: they feed me." He was a master of repartee and many of his bon mots became part of the family lore, but this esprit is no more than the frosting on the cake of competence and reliability.

Bruno Walter, another of Wolff's protégés before the turn of the century, in his memoires 'Theme and Variations' speaks of his efficiency and enterprising spirit and calls him "a good friend and advisor of his artists." Walter refers to Wolff's correspondence with Hans von Bülow whom he describes as an upright, but very difficult and unpredictable, genius. "In Bülow's often witty and friendly, but at other times impatient or ill-humored letters," Walter 
wrote, "we always recognized the foundation of respect and confidence in his relationship to his impresario, while on Wolff's side one sees musical understanding, personal openness, and firmness the qualities that earned him the good will of Bülow and other artists."

In dealing with the temperamental Bülow and all the other musicians, whether they were celebrities or unknown quantities, Hermann had the help of Louise. She was as well-known for her warm and gracious personality as for her superb Viennese cuisine. In a fragment of her diary that has survived she recorded a visit of Johannes Brahms and Joseph Joachim, the friend of Clara Schumann, himself a great violinist and founder of the Joachim-String-Quartet at the time, director of the Hochschule für Musik in Berlin.

The entry of December 9, 1891 begins, "just now Brahms and Joachim left our home. Were completely at ease they had with the greatest enthusiasm partaken of a true Austrian repast, boiled beef and chicken paprika. Brahms, the hero of the day, his fourth symphony had just been performed by the Berlin Philharmonic under Bülow, in my home twice in two days. Day before yesterday with Bülow, today with Joachim. I am happy with the way he acts towards us. I think he feels at home, so far from all party strife and annoying flattery, for he knows that we revere and love him and that my cooking is pretty good. Quelle attraction! It is a special pleasure, to compare with no other, to see a great man shed his Olympian image and become a human being. Brahms the man is every bit as impressive as Brahms the musician. He is erudite without the slightest touch of pedantry, ironic without being malicious or at most with a good-natured kind of malice, an honest harmonious personality capable of satisfying the highest demands he makes on himself and who can say that of himself?"

In the same entry, Louise relates how Brahms defended the composer Mayerbeer - his operas were then still in vogue - against the charge of vanity. "Who amongst us is free of it," he said, "a composer whose domain is the theater must have the devil in his guts. He must make propaganda for his music." At that time, the public was divided into two enemy camps, the Wagnerians and the Brahmsians. Brahms himself refused to be drawn into these squabbles. On the contrary, as Louise wrote, "Of Richard Wagner, he speaks with great admiration and reverence. On Sunday, he said to Bülow, the prelude to Tristan and Isolde is so great so magnificently scored that it tolerates no other work before or after it. My poor fourth symphony nevertheless achieved a colossal success splendidly staged by Bülow." It was probably after this visit that Brahms gave Louise his photograph inscribed with the opening bars of one of his loveliest songs “Du bist meine Königin”, roughly translated “verily, thou art my Queen." Her description of Brahms, without pedantry, good-naturedly malicious, honest, harmonious and self-critical, has stood the test of time. 
Hans von Bülow, of course, was a frequent if at times rather prickly guest. It was many years since his wife Cosima, Franz Liszt's daughter, had deserted him to live with, have a child by, and finally marry Richard Wagner. Bülow had manfully suffered, but never quite overcome the trauma caused him by this treachery. Eventually he had remarried. His second wife, whom I still remember, was a formal, colorless woman who always signed her name in Louise's guest book "Marie Baroness von Bülow", but he remained irritable and caustic. He had begun his career as a pianist and only secondarily turned to conducting. But, as a conductor, he was a martinet who insisted on a degree of perfection, hitherto unknown to Berlin audiences. With him in place, Hermann Wolff founded the series of subscription concerts known to this day as the Philharmonic Concerts.

Bülow inscribed his photograph for Louise with the words “à l'aimable quoique spirituelle Mme. Wolff', a perceptive summing up of her personality. Such was Bülow's reputation as a severe task master that Anton Bruckner, in Berlin for the performance of one of his symphonies, fell on his knees before my then 4-year-old mother and begged her, as the daughter of Hermann and Louise Wolff, to put in a good word for him with the maestro. It is also part of the family lore that, on this occasion, Bruckner, failing to recognize the purpose of the various kinds of silvers surrounding his plate, broke and ate the fish with his fingers.

Such gaucheries notwithstanding, my mother's younger brother, Werner, later became a devoted Bruckner conductor. He also wrote a book appropriately entitled 'Anton BrucknerRustic Genius', which combined the empathy of a musician for the composer with the objectivity of the biographer towards the awkward personality of Bruckner.

Other guests at Hermann and Louise's table around the turn of the century were the young Richard Strauss, the great Belgian violinist Ýsaye, Ferruccio Busoni, who had lived in his Berlin home and who, as a sideline, did hilarious caricatures of his critics and fellow musicians. Two of them decorated Louise's office. They already-mentioned Eugen d'Albert, known especially for his Beethoven interpretations, the tempestuous Venezuelan pianist Teresa Carreño, famous for her stupendous octave runs, who was briefly the wife of the much married and much divorced d'Albert, the legendary soprano Lilli Lehmann, Arthur Nikisch of course, Nikisch's colleague Karl Muck, then in Berlin as capellmeister of the Royal Opera and for many years conductor of the Bayreuth Festival, and the composer Max Reger.

Hermann Wolff built the Bechstein Saal, an architectural jewel designed for chamber music and the intimate art of the German Lied. Its importance for the musical life of Berlin is underlined by the caliber of the men who inaugurated it: Brahms, Bülow, and Joachim. In the foyer at the foot of the marble stairway that led to the balcony stood the portrait bust of the builder, in later years, a source of pride for me, his grandson. The Bechstein Saal, where I heard 
so many beautiful recitals, was destroyed in an allied air raid during the Second World War, a victim of Hitler's madness like all the other concert halls of Berlin.

I have already spoken of Hermann Wolff's most lasting achievement, the Philharmonic Concerts. Earlier, he had played an important part in the history of the orchestra itself. As late as 1880, Berlin lacked a first-rate orchestra. There was Bilse's Kapelle, a popular group whose performances, somewhat like the Boston Pops, were occasions for Berliners to enjoy music both classical and light, while drinking beer or coffee and exhibiting their marriageable daughters. When Bilse's Kapelle was disbanded, the musicians decided to stay together and entered into negotiations with Hermann Wolff. With his advice, they organized themselves as the Berlin Philharmonic Orchestra and gave themselves a constitution which to this day enables them to elect their own music director.

A clause, and I think the members of NSO would like that, a clause in the original contract gave Hermann and after him Louise as head of the Konzertdirektion a voice in this appointment. He proposed Bülow, and, after Bülow's death, Nikisch, the conductors who would make the Berlin Philharmonic the great orchestra it still is today. Similarly, Louise had a voice in the appointment of Furtwängler as Nikisch's successor. By the time Furtwängler died in the mid-1950s, the Konzertdirektion had long ceased to exist, another victim of Hitlerism. Herbert von Karajan was chosen by the orchestra alone. Perhaps this history explains the remarkable fact that in the more than 100 years since its founding, the Berlin Philharmonic has had only four principal conductors.

Hermann Wolff was a lover of all things French. He corresponded with Gounod and Saint-Saëns and became friendly with Colonel Picquart, the hero of the Dreyfus Affair. He arranged for Nikisch and the orchestra to perform in Paris, a risky undertaking at a time when the wounds of the Franco-Prussian war were still festering. But, the Parisians applauded enthusiastically and Hermann could congratulate himself for having built a bridge of understanding between Frenchmen and Germans. He had tried to build such a bridge on a much smaller scale in 1870 when, as a Corporal in the Prussian army, he had played Schubert's songs on the parson's parlor-organ for the inhabitants of an Alsatian village. What the villagers thought of this ludicrous but touching gesture is not recorded, but the message was clear: music is the universal language, war or no war.

Francophilia must have run in the family. Hermann's uncle Charles emigrated with Jacques Offenbach from the Rhineland to Paris, where in my own time his granddaughters, two elderly, completely frenchified spinsters, ran an art gallery on [Boulevard spy?]. And no doubt Hermann would have approved of the aims of the foundation that sent me, his grandson, to Paris in 1928-29 as part of a program intended to foster Franco-German rapprochement. 
Louise was not in Paris for Nikisch's and the orchestra's trial, but she did accompany Hermann on many of his journeys. On one such occasion, he introduced her to the aged Franz Liszt who had long since retired from the world and was living as an Abbé in the town of Weimar. The great man and erstwhile lothario graciously invited the young woman to kiss him and expectantly offered his cheek, but as she recalled later it took her a long time to find a suitable place between his warts. Liszt gave Hermann an engraved portrait which now in the custody of my daughter Jacqueline inscribed to the victorious field marshal of many successful campaigns.

Inevitably, the marriage of two such strong and contrasting personalities as Hermann and Louise had its stresses and strains. Both loved the mountains, and each summer, the Wolff family would go to the Tyrol, then in its entirety an Austrian province - but he insisted on a Spartan regime, staying at simple country inns and living out of the backpack, whereas she liked greater comforts and would have preferred the luxury hotels of Bad Gastein or Ischl. At times, his cool and sarcastic wit clashed with her spontaneous warmth. Even in her old age, Louise could tremble with rage when her adult children teased her with one of Papa's sarcasms.

It seems that, at least once, the very existence of the marriage was in danger. For us, the grandchildren, our grand-aunt Mitzi was a self-effacing old maid who lived with her sister Louise as a sort of genteel companion, supervising the help, drawing up guest lists for the receptions, and most important for us children, capable of baking the most delicious Viennese vanilla kipferl. If I had thought about it, I would have said that Mitzi had no life of her own, but of course I didn't think about it at the time. The explanation may have lain in the rumors that did not reach my ears until I had become an adult, a rumor that may well have been a false one, but did sound plausible, that long ago, in the 1890s, Louise had found her husband in the arms of her attractive younger sister. If this were true, she would never have forgiven either of them, for she was a woman of strong passions. She might well have forced Mitzi to atone for her transgression in the kind of lifelong servitude. She was, after all, human.

Hermann died comparatively young in 1902 of cancer of the stomach. It was my father, then a young internist and already engaged to Hermann's daughter Edith, who diagnosed the condition of his future father-in-law. The famous surgeon Ernst von Bergmann was called, but could do nothing. The wedding date was advanced so that the young couple would not have to wait while observing a prolonged period of mourning. Hermann must have known this. A photograph of the wedding party, now lost, showed him, the erstwhile victorious field marshal, sitting in a wheelchair apart from the rest of the company, emaciated and admitted as if he resented the cruel joke life had played on him. 
After her husband's death, Louise unhesitatingly and firmly grasped the reins of the Konzertdirektion. For a time, she had the help of Hermann Fernow, a member of the staff whom Wolff had broken in, but there was never any question as to who was in charge. Under Louise's guidance, Musikwolff grew still further in scope and importance. Her style was at once regal and intimate, feminine and bold. It was then that people began to call her, half admiringly, half ironically, 'Queen Louise'. Her sphere of influence extended far beyond the realm of music into the social life of the city, into the world of politics and diplomacy, all connected through the power of her personality. It was the combination of joie de vivre, common sense, judgment in personal as well as artistic matters, her disdain for hypocrisy, and her reverence for beauty and art as well as nature that drew men and women into her orbit, young and old, ordinary folk and the elite. Now you can see that I am hardly an unprejudiced reporter.

A symbol of Louise's emancipation was the elegant and spacious apartment on Rankestraße in the New West of Berlin into which she moved sometime after her husband's death and which became a cultural oasis in the days of the Weimar Republic when there was no longer a court or a society in the traditional sense in Berlin. I remember it well because it was my second home and a place filled with magic. She had decorated it with period furniture, fine paintings, antiques, and exquisite oriental carpets. I remember particularly [a] Renaissance wood-carving of the Apostles over the fire place and the great chandelier of Venetian glass in the living room, the huge Rubinstein portrait, the Brahms autograph, Lieberman park landscape, a bronze bust of Nikisch by the sculptor Hugo Lederer, and Louise's set of chairs in the salon, and, best of all to my childish eyes, an authentic 18th-century gilded litter whose sides had been replaced by glass windows offering to the viewer a miniature orchestra of Meissen figurines with different animals playing the different instruments and presided over by a monkey in white shirt with tails.

The grand piano was, of course, a Bechstein put at Louise's disposal by the famous company whose founder Carl Bechstein had been a friend of her husband's and herself. For some 30 years, until the advent of Hitler, this house was the scene of many memorable gatherings. Rachmaninov was here and Prokofiev, Busoni, Richard Strauss and Fredrick Delius, the French Swiss conductor Ernest Ansermet and his French colleague Pierre Monteux, Willem Mengelberg of the Amsterdam Concertgebouw, Arthur Nikisch, Bruno Walter, Fritz Kreisler, Ossip Gabrilowitsch, Alexander Glazunov, Myra Hess, Alfred Cortot, Artur Schnabel, Gregor Piatigorsky. The list is endless.

Now I think, time being what it is, I will skip a few paragraphs here. A very special occasion was the reception Louise gave in honor of the 25th anniversary of Nikisch's tenure as music director of the Berlin Philharmonic. A vast throng came to celebrate the beloved 
maestro's jubilee. Victor Hahn, publisher of the daily 8-Uhr-Abendblatt, a paper catering to sensationalism but employing first-rate music critics - he himself was a notorious homosexual but nevertheless as an intelligent and amusing poseur, a friend of the unprejudiced hostess -, had printed a fake edition of his paper with "Arthur-Abendblatt," a pun with Nikisch's first name as a masthead.

The featured story purported to be an eyewitness account of a day in Louise's office at the Konzertdirektion. Scenes of utter chaos presided over with souvereign calm by the Frau director, unannounced visitors, interrupted phone calls, unexpected cancellations and, for good measure, a call from home for instructions for tonight's dinner. There were telegrams from beyond: Mozart, Beethoven, Schubert, and Bruckner sending greetings to their favorite conductor.

Richard Strauss was set to be setting the stock-market report to music a là symphonia domestica. Among the ads was one offering to trade a 5-room apartment for a seat on the podium for the Nikisch concerts. Only the editorial was semi-serious. No one "is as well qualified" to bring about an international understanding as Arthur Nikisch. "The entente can take everything away from us", this was a reference to the Treaty of Versailles, but not German music. "We should send him at government expense to England, France, Italy and America. He can do much to restore Germany's prestige", he had the orchestra. The Arthur-Abendblatt was a hit. I, then 10-year-old, dressed as a news-boy, ran from room to room shouting "extra, extra" at the top of my voice until all the copies were gone. I was very proud of myself. None of the many conductors I have heard in my time was as universally beloved by musicians, critics, and the public at large as was Arthur Nikisch.

Nikisch died a year after this jubilee mourned by everyone, though by none more deeply than his intimate friend Louise. The choice of his successor was agonizing for her, because the two leading candidates, Furtwängler and Bruno Walter, were equally qualified and both were available. The orchestra opted for Furtwängler, and Louise went along, although her personal relationship with him was far less cordial than that with Bruno Walter. Furtwängler was a man possessed, a great conductor but a cold personality, an intellectual, austere on the podium and distant as he [Unterbrechung der Aufnahme] fellow conductor that he practiced his movements in front of the mirror. This was surely not vanity, but self-discipline.

Once Nikisch's succession was settled, it felt to Louise to tell Bruno Walter that he had been passed over. Nothing shows more clearly what kind of a woman she was than the way she handled this crisis. Walter happened to be in America and she did not want him to learn this yet confidential decision from the press. First, she tried to sweeten the bitter pill in a hand-written letter saying that his standing as one of the foremost conductors was in no way diminished, but, 
after all, only one man could hold the position, that it had been a close thing and so forth. But she tore up one draft after another. Some of them are still in my possession until the inspiration came. She would create the Bruno-Walter-concerts, an independent cycle, in every respect the equal of the Philharmonic concerts, to be performed under his direction by the Philharmonic orchestra in the Philharmonie with soloists of his choosing. But, even this was not enough, for it lacked the personal touch.

The nearly 70-year-old Queen Louise took the train to Hamburg to greet Walter on his return from America and tell him the good news in person. He accepted and the Bruno-WalterConcerts became as popular and as important as the Philharmonic Concerts under Furtwängler. If Nikisch and, to an even greater degree, Furtwängler were Bruckner interpreters, Bruno Walter opened our eyes, or rather our ears, to the world of Gustav Mahler with whom who he had been closely associated in Vienna, and to the Lied von der Erde he had received from the composers own hands later to conduct his world premiere in Munich.

At the opposite pole of Walter's musical universe was Mozart, to whom he came late in his career, but for whom he had a unique affinity, perceiving the tragic element as well as the serenity in his music. The Bruno-Walter-Concerts ended abruptly in 1933, shortly after the Nazis came to power. Walter had been scheduled for a performance at the famous Gewandhaus in Leipzig, but had found the hall closed, the statue of Felix Mendelssohn torn down, and a placard announcing the abrupt cancellation of the concert. In Berlin, the next day, it was the same, only less overt. The Konzertdirektion received a warning from Goebbels's propaganda ministry, and on checking with the high official, was told that no form of Verbot would be forthcoming. The concert would have to take place, but that everything, and this is verbatim, in the Philharmonic would be smashed into 1,000 pieces if the Jew Walter were to conduct.

In his memoirs, Walter described the scene in Louise's office. "Now she saw all the things threatened that were dear to her heart: her social position, her professional achievement, and, on top of it all, my concerts, but when I arrived for the conference in the afternoon, I found the old lady in her customary regal posture and utterly serene. Only her partners betrayed excitement and helplessness." But the warning had ended with a trumped-up charge that Walter was "politically suspect." Actually, he was the most apolitical person imaginable. And, he took the train for Vienna the same night, not to return until after the Second World War, when the city was in ruins. The conductor that substituted for him in 1933 was Richard Strauss.

Now, I think I have just about used up time and my listeners' patience, so I will just very briefly mention something that, sort of, is dear to my own heart. Speaking of the musicians and artists that I myself remember hearing and listening to, I mentioned particularly Schnabel is for me the greatest pianist. Schnabel, Austrian by birth living and teaching in Berlin, was for 
me the ultimate Mozart, Schubert, and Beethoven interpreter, especially Beethoven, whose sonatas he had edited. My conception of these works was unalterably shaped by Schnabel. When he played them, it seemed to me that he was no mere interpreter, but Beethoven reincarnated. After all these years, I can still hear them exactly as Schnabel rendered them, objectively, but devoutly, as if he were listening to himself or perhaps to the composer. Recently, I happened to find a notebook from the year 1933, in which I had tried to describe a Schnabel recital.

Schnabel comes on stage, I wrote, a short stocky figure with short grizzled hair and an immobile face. Seemingly unaware of the audience, he strides towards the piano as if towards a distant goal. He acknowledges the initial applause briefly, as if reluctantly, and sits down but has to rise again and again, for the audience continues to clap demonstratively with the special warmth of the initiated. It is not clear whether he is pleased or annoyed. His eyes seemed charged with gentle irony. At last the hall is silent. Now he is god before the creation. God begins to play. A few soft chords, he strokes the keys as one might pat the neck of an impatient horse. Suddenly he is in the saddle. The pace is slow, until he gives the spurs and chases the melody like a seasoned jockey riding a beautiful animal, and he tightens the rein and gracefully returns to his starting point, and so on. One can carry this sort of thing too far.

I cite this passage only to show how deeply I revered this particular artist. As a person, Schnabel was highly articulate and an original thinker with certain rather comical quirks. $\mathrm{He}$ was far to the left politically and pretended to despise money, but he charged a hefty fee for his lessons which his students had to place discreetly under a vase, out of sight, but not out of mind. Once, at my grandmother's house, I heard him talk about records. He would never prostitute his art by making records that would enable anonymous, uncivilized persons to put their feet on the table and eat sausages while listening to Mozart or Beethoven. Eventually, when he saw the lucrative possibilities of recordings, he forgot about feet on the table and sausages.

Many years later, I heard him again in Boston. He was still unequalled as a Mozart and Beethoven interpreter. Strangely enough, he was asked the absurd question, which of Mozart's compositions he considered the greatest? He is supposed to have answered seriously, the G minor string quartet, which is a perfectly sound choice, but not one we might expect from an artist greatly admired for his matchless performances of the Mozart piano work. Well, if you will excuse me I think I shall stop here while the going is good. Thank you for your attention. 


\section{Veranstaltungen im Concert-Verzeichnis 1902/03 (466 Konzerte) $)^{727}$}

\begin{tabular}{|c|c|c|c|}
\hline Datum & Veranstaltungen & Saal & Anmerkungen \\
\hline 16.09 .1902 & $\begin{array}{l}\text { I. Concert des Römischen Vokal-Quintetts für } \\
\text { geistliche Musik. Dir.: Pie di Pietro }\end{array}$ & Bechstein-Saal & \\
\hline 18.09.1902 & $\begin{array}{l}\text { II. Concert des Römischen Vokal-Quintetts } \\
\text { für geistliche Musik. Dir.: Pie di Pietro }\end{array}$ & Bechstein-Saal & \\
\hline 27.09 .1902 & Klavier-Abend von Gregor Beklemischeff & Bechstein-Saal & \\
\hline 29.09 .1902 & $\begin{array}{l}\text { Concert des Opern- und Liedersängers Alfred } \\
\text { Arnold }\end{array}$ & Bechstein-Saal & \\
\hline 29.09 .1902 & $\begin{array}{l}\text { I. Populärer Musik-Abend. Anton Hekking } \\
\text { (Violoncello), Artur Schnabel (Klavier), } \\
\text { Alfred Wittenberg (Violine) Mitw.: Therese } \\
\text { Behr (Gesang) }\end{array}$ & Sonstiger & $\begin{array}{l}\text { Ort: Oberlichtsaal } \\
\text { der Philharmonie }\end{array}$ \\
\hline 30.09 .1902 & $\begin{array}{l}\text { Lieder-Abend mit eigenen Compositionen von } \\
\text { Bernhard Sekles. Mitw.: Clara Bornmüller, } \\
\text { Alexander Heinemann (Gesang) } \\
\end{array}$ & Bechstein-Saal & Komponistenkonzert \\
\hline 02.10 .1902 & $\begin{array}{l}\text { Concert von Elsie Playfair (Violine) und Emil } \\
\text { Liepe (Gesang) }\end{array}$ & Singakademie & \\
\hline 03.10 .1902 & $\begin{array}{l}\text { Concert von Hanna Schütz (Gesang). Mitw.: } \\
\text { Otto Hegner (Klavier) }\end{array}$ & Singakademie & \\
\hline 04.10 .1902 & $\begin{array}{l}\text { Concert von Fred. W. Schalscha (Violine). } \\
\text { Mitw.: Charles Bünte (Klavier) }\end{array}$ & Bechstein-Saal & \\
\hline 04.10 .1902 & $\begin{array}{l}\text { Concert von Edwin Grasse (Violine) mit dem } \\
\text { Philharm. Orchester. Dir.: J. Rébicek }\end{array}$ & Beethoven-Saal & \\
\hline 06.10 .1902 & Concert von Richard Hartzer (Violine) & Bechstein-Saal & \\
\hline 06.10 .1902 & $\begin{array}{l}\text { Concert von Fritz von Bose (Klavier) mit dem } \\
\text { Philharm. Orchester. Dir.: J. Rébicek } \\
\end{array}$ & Beethoven-Saal & \\
\hline 06.10 .1902 & Lieder-Abend von Antonia Beel & Singakademie & \\
\hline 07.10 .1902 & Klavier-Abend von Martha Küntzel & Bechstein-Saal & \\
\hline 07.10 .1902 & Lieder-Abend von Heinrich Bruns & Beethoven-Saal & \\
\hline 07.10 .1902 & $\begin{array}{l}\text { Concert von Franz Fitzau (Gesang). Mitw.: } \\
\text { Georg Schumann, Hugo Dechert } \\
\end{array}$ & Singakademie & \\
\hline 08.10 .1902 & Klavier-Abend von Helene Rombro & Bechstein-Saal & \\
\hline 08.10 .1902 & Lieder-Abend von Margarethe Petersen & Beethoven-Saal & \\
\hline 08.10 .1902 & $\begin{array}{l}\text { Concert von Max Lewinger (Violine). Mitw.: } \\
\text { Catarina Hiller (Sopran) }\end{array}$ & Singakademie & \\
\hline 09.10 .1902 & $\begin{array}{l}\text { Concert von Alexander Petschnikoff mit dem } \\
\text { Philharm. Orchester. Mitw.: Lili Petschnikoff. } \\
\text { Dir.: J. Rébicek }\end{array}$ & Beethoven-Saal & \\
\hline 10.10 .1902 & $\begin{array}{l}\text { Concert von Helene Berard (Gesang) und } \\
\text { Michael Zacharewitsch (Violine) mit dem } \\
\text { Philharm. Orchester. Dir.: J. Rébicek } \\
\end{array}$ & Singakademie & \\
\hline 11.10 .1902 & $\begin{array}{l}\text { Concert von Paul Elgers (Violine) mit dem } \\
\text { Philharm. Orchester. Dir.: J. Rébicek }\end{array}$ & Singakademie & \\
\hline 12.10 .1902 & $\begin{array}{l}\text { I. Vorlesung von Emanuel Reicher „Ein } \\
\text { Jahrtausend deutscher Dichtung“ }\end{array}$ & Beethoven-Saal & \\
\hline
\end{tabular}

\footnotetext{
${ }^{727} \mathrm{Zu}$ dieser Quelle vgl. 2.3.2 im Textteil der vorliegenden Arbeit.
} 


\begin{tabular}{|c|c|c|c|}
\hline 12.10 .1902 & $\begin{array}{l}\text { Öffentliche Hauptprobe zum I. Philharm. } \\
\text { Concert. Dir.: Arthur Nikisch, Sol.: Ferruccio } \\
\text { Busoni }\end{array}$ & Philharmonie & \\
\hline 13.10 .1902 & $\begin{array}{l}\text { I. Philharm. Concert. Dir.: Arthur Nikisch, } \\
\text { Sol.: Ferruccio Busoni } \\
\end{array}$ & Philharmonie & \\
\hline 14.10 .1902 & Lieder- Abend von Werner Alberti & Beethoven-Saal & \\
\hline 14.10.1902 & $\begin{array}{l}\text { I. Populärer-Abend des Waldemar-Quartetts. } \\
\text { Mitw.: Eugen d'Albert }\end{array}$ & Singakademie & \\
\hline 14.10 .1902 & $\begin{array}{l}\text { Öffentliche Hauptprobe des Philharm. Chores } \\
\text { (Dir.: Siegfried Ochs) }\end{array}$ & Sonstiger & $\begin{array}{l}\text { Ort: Kaiser Wilhelm } \\
\text { Gedächtniskirche }\end{array}$ \\
\hline 15.10 .1902 & $\begin{array}{l}\text { Concert des Leipziger Vocal-Damen- } \\
\text { Quartetts. J. Gertrud Schmidt, Johanna } \\
\text { Deutrich, Anna und Sophie Lücke. Mitw.: } \\
\text { Michael von Zadora (Klavier) }\end{array}$ & Bechstein-Saal & \\
\hline 15.10 .1902 & Lieder-Abend von Elly Bern & Beethoven-Saal & \\
\hline 15.10 .1902 & $\begin{array}{l}\text { Concert des Philharm. Chores (Dir.: Siegfried } \\
\text { Ochs). Cantaten von J. S. Bach. Sol.: J. } \\
\text { Grumbacher, Muriel-Foster, Raoul Walter, } \\
\text { Joh. Messchaert }\end{array}$ & Sonstiger & $\begin{array}{l}\text { Ort: Kaiser Wilhelm } \\
\text { Gedächtniskirche }\end{array}$ \\
\hline 16.10 .1902 & $\begin{array}{l}\text { Concert von Ida Kopetschni (Gesang) und } \\
\text { Maximilian Pilzer (Violine) }\end{array}$ & Bechstein-Saal & \\
\hline 16.10 .1902 & $\begin{array}{l}\text { Concert von Fannie Bloomfield Zeisler } \\
\text { (Klavier) mit dem Philharm. Orchester. Dir.: } \\
\text { J. Rébicek }\end{array}$ & Beethoven-Saal & \\
\hline 16.10 .1902 & $\begin{array}{l}\text { I. Quartett-Abend von Joachim, Halir, Wirth, } \\
\text { Hausmann }\end{array}$ & Singakademie & \\
\hline 17.10 .1902 & $\begin{array}{l}\text { Arien- und Lieder-Abend von Sophie } \\
\text { Heymann-Engel }\end{array}$ & Bechstein-Saal & \\
\hline 17.10 .1902 & Lieder-Abend von Hansi Delisle & Beethoven-Saal & \\
\hline 17.10 .1902 & $\begin{array}{l}\text { Lieder- und Balladen-Abend von Felix } \\
\text { Lederer-Prina }\end{array}$ & Singakademie & \\
\hline 18.10 .1902 & Lieder-Abend von Martha Braun & Bechstein-Saal & \\
\hline 18.10 .1902 & II. Lieder-Abend von Heinrich Bruns & Beethoven-Saal & \\
\hline 18.10 .1902 & $\begin{array}{l}\text { II. Populärer Musik-Abend. Anton Hekking } \\
\text { (Violoncello), Artur Schnabel (Klavier), } \\
\text { Alfred Wittenberg (Violine). Mitw.: Richard } \\
\text { Koennecke (Gesang) }\end{array}$ & Sonstiger & $\begin{array}{l}\text { Ort: Oberlichtsaal } \\
\text { der Philharmonie }\end{array}$ \\
\hline 19.10.1902 & $\begin{array}{l}\text { II. Vorlesung von Emanuel Reicher „Ein } \\
\text { Jahrtausend deutscher Dichtung“" }\end{array}$ & Beethoven-Saal & \\
\hline 20.10 .1902 & $\begin{array}{l}\text { Concert von Erna Schulz (Violine). Mitw.: C. } \\
\text { V. Bos (Klavier) }\end{array}$ & Bechstein-Saal & \\
\hline 20.10 .1902 & II. Lieder-Abend von Werner Alberti & Beethoven-Saal & \\
\hline 21.10 .1902 & Klavier-Abend von Gustav Loeser & Bechstein-Saal & \\
\hline 21.10 .1902 & Lieder-Abend von Helene Berard & Beethoven-Saal & \\
\hline 22.10 .1902 & $\begin{array}{l}\text { Concert von Renata Hermes (Gesang). Mitw.: } \\
\text { Leopold Przemysler (Violine) }\end{array}$ & Bechstein-Saal & \\
\hline 22.10 .1902 & $\begin{array}{l}\text { Concert von Max Garrison (Gesang) aus } \\
\text { Wien. Mitw.: Margarethe Eussert (Klavier), } \\
\text { Hans Hermann }\end{array}$ & Beethoven-Saal & \\
\hline 22.10 .1902 & Klavier-Abend von Ernesto Drangosch & Singakademie & \\
\hline 23.10 .1902 & $\begin{array}{l}\text { Lieder-Abend von Hedwig Kaufmann. Mitw.: } \\
\text { Gustav Lazarus }\end{array}$ & Bechstein-Saal & \\
\hline
\end{tabular}




\begin{tabular}{|c|c|c|c|}
\hline 23.10 .1902 & $\begin{array}{l}\text { II. Concert (Klavier-Abend) von Fannie } \\
\text { Bloomfield Zeisler }\end{array}$ & Beethoven-Saal & \\
\hline 23.10 .1902 & $\begin{array}{l}\text { Concert von Marie von Stubenrauch (Violine) } \\
\text { mit dem Philharm. Orchester. Dir.: J. Rébicek }\end{array}$ & Singakademie & \\
\hline 24.10 .1902 & Concert von Robert Erben & Bechstein-Saal & \\
\hline 24.10 .1902 & Klavier-Abend von Otto Hegner & Beethoven-Saal & \\
\hline 25.10 .1902 & Lieder-Abend von Helene von Hauwf & Bechstein-Saal & \\
\hline 26.10 .1902 & $\begin{array}{l}\text { III. Vorlesung von Emanuel Reicher „Ein } \\
\text { Jahrtausend deutscher Dichtung“ }\end{array}$ & Beethoven-Saal & \\
\hline 26.10 .1902 & $\begin{array}{l}\text { Öffentliche Hauptprobe zum II. Philharm. } \\
\text { Concert. Dir.: Arthur Nikisch, Sol.: Felia } \\
\text { Litvinne vom Théâtre de la Monnaie in } \\
\text { Brüssel }\end{array}$ & Philharmonie & \\
\hline 27.10 .1902 & $\begin{array}{l}\text { Concert von Clara Krause (Gesang) und Paul } \\
\text { Heilbrun (Klavier) }\end{array}$ & Beethoven-Saal & \\
\hline 27.10 .1902 & $\begin{array}{l}\text { II. Philharm. Concert. Dir.: Arthur Nikisch, } \\
\text { Sol.: Felia Litvinne vom Théâtre de la } \\
\text { Monnaie in Brüssel }\end{array}$ & Philharmonie & \\
\hline 28.10 .1902 & Concert von Ossip Schnirlin (Violine) & Bechstein-Saal & \\
\hline 28.10 .1902 & $\begin{array}{l}\text { I. Abonnement-Soirée des Böhmischen } \\
\text { Streichquartetts. Mitw.: Fannie Bloomfield } \\
\text { Zeisler (Klavier) }\end{array}$ & Beethoven-Saal & \\
\hline 29.10 .1902 & Klavier-Abend von Anna von Gabain & Bechstein-Saal & \\
\hline 29.10 .1902 & I. Lieder-Abend von Lula Mysz-Gmeiner & Beethoven-Saal & \\
\hline 29.10 .1902 & $\begin{array}{l}\text { I. Kammermusik-Abend von Georg } \\
\text { Schumann, Carl Halir, Hugo Dechert }\end{array}$ & Singakademie & \\
\hline 30.10 .1902 & Hugo Wolf-Abend von Anton Dressler & Bechstein-Saal & \\
\hline 30.10 .1902 & $\begin{array}{l}\text { Concert von Marcel Herwegh (Violine) mit } \\
\text { dem Philharm. Orchester. Dir.: J. Rébicek }\end{array}$ & Beethoven-Saal & \\
\hline 30.10 .1902 & $\begin{array}{l}\text { Lieder- und Balladen-Abend von Ludwig } \\
\text { Strakosch }\end{array}$ & Singakademie & \\
\hline 31.10 .1902 & Klavier-Abend von Richard Buhlig & Bechstein-Saal & \\
\hline 31.10 .1902 & $\begin{array}{l}\text { Concert von Wassili Besekirsky (Violine) mit } \\
\text { dem Philharm. Orchester. Dir.: J. Rébicek }\end{array}$ & Beethoven-Saal & \\
\hline 31.10 .1902 & $\begin{array}{l}\text { Concert von Agnes Fahlbusch (Flöte). Mitw.: } \\
\text { Otto Hegner (Klavier) }\end{array}$ & Singakademie & \\
\hline 31.10 .1902 & $\begin{array}{l}\text { III. Populärer Musik-Abend. Anton Hekking } \\
\text { (Violoncello), Artur Schnabel (Klavier), } \\
\text { Alfred Wittenberg (Violine) Mitw.: Ferruccio } \\
\text { Busoni }\end{array}$ & Sonstiger & $\begin{array}{l}\text { Ort: Oberlichtsaal } \\
\text { der Philharmonie }\end{array}$ \\
\hline 01.11 .1902 & $\begin{array}{l}\text { Concert von Sophie Bonny (Klavier) und } \\
\text { Julius von Rácz-Brockmann (Gesang) } \\
\end{array}$ & Bechstein-Saal & \\
\hline 01.11 .1902 & $\begin{array}{l}\text { Concert von Irma Saenger-Sethe (Violine) mit } \\
\text { dem Philharm. Orchester. Dir.: J. Rébicek }\end{array}$ & Beethoven-Saal & \\
\hline 01.11 .1902 & Lieder-Abend von Ettore Gandolfi & Singakademie & \\
\hline 02.11 .1902 & Lieder-Abend von Martha Braun & Bechstein-Saal & \\
\hline 02.11 .1902 & $\begin{array}{l}\text { Einziger Klavier-Abend von Clotilde } \\
\text { Kleeberg }\end{array}$ & Beethoven-Saal & \\
\hline 03.11 .1902 & $\begin{array}{l}\text { Concert von Elsa Heile (Gesang) und } \\
\text { Wilhelm Eylau (Violine) }\end{array}$ & Bechstein-Saal & \\
\hline 03.11 .1902 & $\begin{array}{l}\text { I. Abonnement-Concert des Streichorchesters } \\
\text { Berliner Tonkünstlerinnen. Dir.: Willy Benda }\end{array}$ & Beethoven-Saal & \\
\hline
\end{tabular}




\begin{tabular}{|c|c|c|}
\hline 03.11 .1902 & $\begin{array}{l}\text { Lieder- und Duett-Abend von Madeleine } \\
\text { Walther (Sopran) und Leontine de Ahna } \\
\text { (Mezzosopran) }\end{array}$ & Singakademie \\
\hline 03.11 .1902 & $\begin{array}{l}\text { Stern'scher Gesangverein (Dir.: Friedrich } \\
\text { Gernsheim). „Die Jahreszeiten“ von J. Haydn. } \\
\text { Sol.: Emilie Herzog, A. Jungblut, A. } \\
\text { Heinemann. Mitw.: Das Philharm. Orchester }\end{array}$ & Philharmonie \\
\hline 04.11 .1902 & Klavier-Abend von Etelka Freund & Bechstein-Saal \\
\hline 04.11 .1902 & Lieder-Abend von Hertha Dehmlow & Beethoven-Saal \\
\hline 05.11 .1902 & $\begin{array}{l}\text { Klavier-Abend von James Kwast und Frieda } \\
\text { Kwast-Hodapp }\end{array}$ & Bechstein-Saal \\
\hline 05.11 .1902 & $\begin{array}{l}\text { I. Lieder-Abend von Raimund von Zur } \\
\text { Mühlen }\end{array}$ & Beethoven-Saal \\
\hline 05.11 .1902 & $\begin{array}{l}\begin{array}{l}\text { Lieder- und Duett-Abend von Gertrud Fischer } \\
\text { (Alt) und Sergei Klibansky (Bariton) }\end{array} \\
\end{array}$ & Singakademie \\
\hline 06.11 .1902 & $\begin{array}{l}\text { I. Populärer Quartett-Abend von Gustav } \\
\text { Hollaender, Willy Nicking, Waller } \\
\text { Rampelmann, Eugen Sandow. Mitw.: Ernst } \\
\text { Jedliczka }\end{array}$ & Bechstein-Saal \\
\hline 06.11 .1902 & $\begin{array}{l}\text { I. Concert von Henri Marteau mit dem } \\
\text { Philharm. Orchester. Dir.: J. Rébicek }\end{array}$ & Beethoven-Saal \\
\hline 06.11 .1902 & $\begin{array}{l}\text { II. Quartett-Abend von Joachim, Halir, Wirth, } \\
\text { Hausmann }\end{array}$ & Singakademie \\
\hline 06.11 .1902 & $\begin{array}{l}\text { Concert des Berliner Lehrer Gesangsvereins. } \\
\text { Dir.: Felix Schmidt. Mitw.: Thessa Gradl }\end{array}$ & Philharmonie \\
\hline 07.11 .1902 & Klavier-Abend von Georg Gundlach & Bechstein-Saal \\
\hline 07.11 .1902 & $\begin{array}{l}\text { Concert von Elvira Schmuckler (Violine) mit } \\
\text { dem Philharm. Orchester. Dir.: J. Rébicek }\end{array}$ & Beethoven-Saal \\
\hline 08.11 .1902 & Lieder-Abend von Marie Henke & Bechstein-Saal \\
\hline 08.11 .1902 & $\begin{array}{l}\text { I. Orchester-Abend mit dem Philharm. } \\
\text { Orchester veranstaltet von Ferruccio Busoni. } \\
\text { Sol.: César Thomson (Violine) }\end{array}$ & Beethoven-Saal \\
\hline 09.11 .1902 & Matinée der Gesangschule Valesca von Facius & Bechstein-Saal \\
\hline 09.11 .1902 & $\begin{array}{l}\text { III. Vorlesung von Emanuel Reicher „Ein } \\
\text { Jahrtausend deutscher Dichtung“ }\end{array}$ & Beethoven-Saal \\
\hline 09.11 .1902 & $\begin{array}{l}\text { Öffentliche Hauptprobe zum III. Philharm. } \\
\text { Concert. Dir.: Arthur Nikisch, Sol.: Anton } \\
\text { Witek }\end{array}$ & Philharmonie \\
\hline 10.11 .1902 & Lieder-Abend von Anna Rother & Bechstein-Saal \\
\hline 10.11 .1902 & \begin{tabular}{|l|} 
I. Concert von Bruno Hinze-Reinhold \\
(Klavier). Mitw.: Susanne Dessoir (Gesang)
\end{tabular} & Beethoven-Saal \\
\hline 10.11 .1902 & \begin{tabular}{|l|} 
I. Sonaten-Abend von Otto von Gruenewaldt \\
(Klavier) und Leo Schrattenholz (Violoncello)
\end{tabular} & Singakademie \\
\hline 10.11 .1902 & $\begin{array}{l}\text { III. Philharm. Concert. Dir.: Arthur Nikisch, } \\
\text { Sol.: Anton Witek }\end{array}$ & Philharmonie \\
\hline 11.11 .1902 & $\begin{array}{l}\text { Concert von Etelka Freund (Klavier) und } \\
\text { Iduna Walter-Choinanus (Gesang) }\end{array}$ & Bechstein-Saal \\
\hline 11.11 .1902 & I. Lieder-Abend von Therese Behr & Beethoven-Saal \\
\hline 11.11 .1902 & $\begin{array}{l}\text { II. Populäres Concert des Waldemar Meyer- } \\
\text { Quartetts. Mitw.: Willibald Wagner (Viola) }\end{array}$ & Singakademie \\
\hline 12.11 .1902 & Klavier-Abend von Waldemar Lütschg & Bechstein-Saal \\
\hline
\end{tabular}




\begin{tabular}{|c|c|c|c|}
\hline 12.11 .1902 & $\begin{array}{l}\text { Lieder-Abend von Wilhelm Kienzl mit Emmy } \\
\text { Destinn. Lieder und Gesänge von Wilhelm } \\
\text { Kienzl }\end{array}$ & Beethoven-Saal & Komponistenkonzert \\
\hline 13.11 .1902 & Lieder-Abend von Tilly Erlenmeyer & Bechstein-Saal & \\
\hline 13.11 .1902 & $\begin{array}{l}\text { II. Concert von Henri Marteau mit dem } \\
\text { Philharm. Orchester. Dir.: J. Rébicek } \\
\end{array}$ & Beethoven-Saal & \\
\hline 13.11 .1902 & $\begin{array}{l}\text { Populärer Lieder-Abend von Margarethe } \\
\text { Petersen }\end{array}$ & Sonstiger & $\begin{array}{l}\text { Ort: Oberlichtsaal } \\
\text { der Philharmonie }\end{array}$ \\
\hline 14.11 .1902 & Klavier-Abend von Therese Slottko & Bechstein-Saal & \\
\hline 14.11.1902 & $\begin{array}{l}\text { Concert von Frieda Lautmann (Gesang) und } \\
\text { Henriette Schmidt (Violine) }\end{array}$ & Beethoven-Saal & \\
\hline 14.11.1902 & $\begin{array}{l}\text { I. Abonnement-Concert. Florian Zajic - } \\
\text { Heinrich Günfeld. Mitw.: Grace Fobes } \\
\text { (Gesang), Ernst Jedliczka }\end{array}$ & Singakademie & \\
\hline 14.11.1902 & $\begin{array}{l}\text { IV. Populärer Musik-Abend von Anton } \\
\text { Hekking (Violoncello), Artur Schnabel } \\
\text { (Klavier), Alfred Wittenberg (Violine). Mitw.: } \\
\text { Elisabet Saatz (Gesang) }\end{array}$ & Sonstiger & $\begin{array}{l}\text { Ort: Oberlichtsaal } \\
\text { der Philharmonie }\end{array}$ \\
\hline 15.11 .1902 & Lieder-Abend von Paul Haubrich & Bechstein-Saal & \\
\hline 15.11 .1902 & $\begin{array}{l}\text { II. Orchester-Abend mit dem Philharm. } \\
\text { Orchester veranstaltet von Ferruccio Busoni. } \\
\text { Mitw.: Théophile Ysaye (Klavier) }\end{array}$ & Beethoven-Saal & \\
\hline 15.11 .1902 & Lieder-Abend von Emmy von Linsingen & Singakademie & \\
\hline 17.11 .1902 & $\begin{array}{l}\text { Concert von Margit von Téssenyi (Klavier) } \\
\text { und Ettore Gandolfi (Gesang) }\end{array}$ & Bechstein-Saal & \\
\hline 17.11 .1902 & $\begin{array}{l}\text { I. Concert des Männer-Gesangvereins Cäcilia } \\
\text { Melodia (Leiter: Max Eschke). Mitw.: Luise } \\
\text { Pinoff (Gesang), Fritz Fuhrmeister (Klavier) }\end{array}$ & Beethoven-Saal & \\
\hline 18.11 .1902 & Lieder-Abend von Catharina Hennig-Zimdars & Bechstein-Saal & \\
\hline 18.11 .1902 & II. Lieder-Abend von Lula Mysz-Gmeiner & Beethoven-Saal & \\
\hline 18.11 .1902 & $\begin{array}{l}\text { I. Quartett-Abend von Bernh. Dessau, Bernh. } \\
\text { Gehwald, Rob. Könecke, Fritz Espenhahn. } \\
\text { Mitw.: Richard Strauss }\end{array}$ & Singakademie & \\
\hline 20.11 .1902 & Lieder-Abend von Heinrich Meyn & Bechstein-Saal & \\
\hline 20.11 .1902 & $\begin{array}{l}\text { Concert von Jacques Thibaud (Violine) mit } \\
\text { dem Philharm. Orchester. Dir.: J. Rébicek } \\
\end{array}$ & Beethoven-Saal & \\
\hline 20.11 .1902 & $\begin{array}{l}\text { III. Quartett-Abend von Joachim, Halir, } \\
\text { Wirth, Hausmann }\end{array}$ & Singakademie & \\
\hline 20.11 .1902 & $\begin{array}{l}\text { Concert der Berliner Liedertafel (Chormeister: } \\
\text { A. Zander, M. Werner). Mitw.: Marie Blanck- } \\
\text { Peters, Hugo Dechert }\end{array}$ & Philharmonie & \\
\hline 21.11 .1902 & $\begin{array}{l}\text { I. Trio-Abend von Joseph Thibaud (Klavier), } \\
\text { Jacques Thibaud (Violine), André Hekking } \\
\text { (Violoncello) }\end{array}$ & Bechstein-Saal & \\
\hline 21.11 .1902 & $\begin{array}{l}\text { Concert von Ernesto Consolo (Klavier) mit } \\
\text { dem Philharm. Orchester. Dir.: J. Rébicek }\end{array}$ & Beethoven-Saal & \\
\hline 22.11 .1902 & Lieder-Abend von Berta Jahr & Bechstein-Saal & \\
\hline 22.11 .1902 & Lieder-Abend von Eva Lessmann & Beethoven-Saal & \\
\hline 22.11 .1902 & $\begin{array}{l}\text { Concert von Alfred Wittenberg (Violine) mit } \\
\text { dem Philharm. Orchester. Dir.: J. Rébicek }\end{array}$ & Singakademie & \\
\hline 24.11 .1902 & Lieder-Abend von Alfred Smolian & Bechstein-Saal & \\
\hline
\end{tabular}




\begin{tabular}{|c|c|c|c|}
\hline 24.11 .1902 & $\begin{array}{l}\text { Concert von Joseph Thibaud (Klavier) und } \\
\text { André Hekking (Violoncello) mit dem } \\
\text { Philharm. Orchester. Dir.: J. Rébicek } \\
\end{array}$ & Beethoven-Saal & \\
\hline 24.11 .1902 & $\begin{array}{l}\text { Concert zum Besten des Orgelfonds der } \\
\text { Amerikanischen Kirche. Mitw.: Geraldine } \\
\text { Farrar (Gesang), Marie Bender (Klavier), } \\
\text { Joseph Joachim (Violine), Robert von } \\
\text { Mendelssohn (Violoncello) }\end{array}$ & Sonstiger & $\begin{array}{l}\text { Ort: Saal der } \\
\text { Königlichen } \\
\text { Hochschule }\end{array}$ \\
\hline 25.11 .1902 & Klavier-Abend von Hedwig Wiszwianski & Bechstein-Saal & \\
\hline 25.11 .1902 & Lieder-Abend von Susanne Dessoir & Beethoven-Saal & \\
\hline 25.11 .1902 & Lieder-Abend von Lydia Illyna & Singakademie & \\
\hline 26.11 .1902 & $\begin{array}{l}\text { I. Musik-Abend von Alfred Schmidt- } \\
\text { Badekow (Klavier) und Heinz Beyer } \\
\text { (Violoncello) }\end{array}$ & Bechstein-Saal & \\
\hline 26.11 .1902 & I. Lieder-Abend von Ludwig Wüllner & Beethoven-Saal & \\
\hline 26.11 .1902 & $\begin{array}{l}\text { II. Kammermusik-Abend von Georg } \\
\text { Schumann, Carl Halir, Hugo Dechert }\end{array}$ & Singakademie & \\
\hline 27.11 .1902 & $\begin{array}{l}\text { Sonaten-Abend von Willy und Margarete } \\
\text { Benda }\end{array}$ & Bechstein-Saal & \\
\hline 27.11 .1902 & $\begin{array}{l}\text { II. Concert von Ernesto Consolo (Klavier). } \\
\text { Mitw.: Arthur Argiewicz (Violine) }\end{array}$ & Beethoven-Saal & \\
\hline 27.11 .1902 & $\begin{array}{l}\text { Concert des Weinbaum'schen Männerchores. } \\
\text { Dir.: Alexander Weinbaum. Mitw.: Isabella } \\
\text { Berger (Sopran), Jenny Alexander (Alt), } \\
\text { Heinr. Scheden (Tenor), Herm. Gura } \\
\text { (Bariton), Das Philharm. Orchester }\end{array}$ & Singakademie & \\
\hline 27.11 .1902 & $\begin{array}{l}\text { Concert zum wohltätigen Zweck. Mitw.: } \\
\text { Emilie Herzog, Joseph Mödlinger (Gesang), } \\
\text { Florian Zajic (Violine), Bloch'scher } \\
\text { Gesangverein (Dir.: Georg Bloch) }\end{array}$ & Sonstiger & $\begin{array}{l}\text { Ort: Festsaal des } \\
\text { Logenhauses }\end{array}$ \\
\hline 28.11 .1902 & $\begin{array}{l}\text { Kammermusik-Abend von Bianca Panteo } \\
\text { (Violine) und Otto Hegner (Klavier). Mitw.: } \\
\text { Jul. Röntgen (Viola), Jul. Vogel (Violoncello) }\end{array}$ & Bechstein-Saal & \\
\hline 28.11 .1902 & $\begin{array}{l}\text { II. Concert von Jacques Thibaud (Violine) mit } \\
\text { dem Philharm. Orchester. Dir.: J. Rébicek }\end{array}$ & Beethoven-Saal & \\
\hline 29.11 .1902 & $\begin{array}{l}\text { II. Trio-Abend von Joseph Thibaud (Klavier), } \\
\text { Jacques Thibaud (Violine), André Hekking } \\
\text { (Violoncello) }\end{array}$ & Bechstein-Saal & \\
\hline 29.11.1902 & $\begin{array}{l}\text { Concert von Frederick Dawson (Klavier) mit } \\
\text { dem Philharm. Orchester. Dir.: Karl } \\
\text { Klindworth }\end{array}$ & Beethoven-Saal & \\
\hline 29.11 .1902 & $\begin{array}{l}\text { Lieder- und Balladen-Abend von Alexander } \\
\text { Heinemann. Mitw.: Fr. Gernsheim }\end{array}$ & Singakademie & \\
\hline 29.11 .1902 & Klavier-Abend von Wladimir von Pachmann & Philharmonie & \\
\hline 30.11 .1902 & $\begin{array}{l}\text { IV. Wohltätigkeits-Concert zum Besten des } \\
\text { Schweizerinnen Heims. Mitw.: Mary Garnier } \\
\text { (Gesang), Lucy Lindner-Orban } \\
\text { (Deklamation), Ettore Gandlfi (Gesang), } \\
\text { Arthur Argiewicz (Violine), Otto Hegner } \\
\text { (Klavier) }\end{array}$ & Beethoven-Saal & \\
\hline 30.11 .1902 & $\begin{array}{l}\text { Öffentliche Hauptprobe zum IV. Philharm. } \\
\text { Concert. Dir.: Arthur Nikisch, Sol.: Karl } \\
\text { Scheidemantel }\end{array}$ & Philharmonie & \\
\hline
\end{tabular}




\begin{tabular}{|c|c|c|c|}
\hline 01.12 .1902 & $\begin{array}{l}\text { Concert von Louis Savart (Horn) und Alfred } \\
\text { Finger (Violine) }\end{array}$ & Bechstein-Saal & \\
\hline 01.12 .1902 & $\begin{array}{l}\text { IV. Philharm. Concert. Dir.: Arthur Nikisch, } \\
\text { Sol.: Karl Scheidemantel }\end{array}$ & Philharmonie & \\
\hline 02.12 .1902 & Klavier-Abend von Irene Schaefsberg & Bechstein-Saal & \\
\hline 02.12 .1902 & $\begin{array}{l}\text { II. Concert (Klavier-Abend) von Frederick } \\
\text { Dawson }\end{array}$ & Beethoven-Saal & \\
\hline 02.12 .1902 & Lieder-Abend von Julius Muhr & Singakademie & \\
\hline 03.12 .1902 & $\begin{array}{l}\text { I. Soirée für neue Kammermusik von Adalbert } \\
\text { Gülzow (Violine), José Vianna da Motta } \\
\text { (Klavier). Mitw.: Marie Blanck-Peters } \\
\text { (Gesang), Paul Müller, Hans Diestel, Franz } \\
\text { Borisch }\end{array}$ & Bechstein-Saal & \\
\hline 03.12 .1902 & $\begin{array}{l}\text { II. Lieder-Abend von Raimund von Zur- } \\
\text { Mühlen }\end{array}$ & Beethoven-Saal & \\
\hline 03.12 .1902 & $\begin{array}{l}\text { II. Lieder- und Balladen-Abend von Felix } \\
\text { Lederer-Prina }\end{array}$ & Singakademie & \\
\hline 04.12 .1902 & $\begin{array}{l}\text { Concert von Miecio Horszowski (Klavier). } \\
\text { Mitw.: Leopold Przemysler (Violine), Otto } \\
\text { Hutschenreuter (Violoncello) }\end{array}$ & Bechstein-Saal & \\
\hline 04.12 .1902 & Klavier-Abend von Vera Jachles & Beethoven-Saal & \\
\hline 05.12 .1902 & $\begin{array}{l}\text { Lieder-Abend von Jetta Rintel. Mitw.: } \\
\text { Walther Habenicht (Violine) }\end{array}$ & Bechstein-Saal & \\
\hline 05.12 .1902 & Lieder-Abend von Ludwig Hess & Beethoven-Saal & \\
\hline 04.12 .1902 & $\begin{array}{l}\text { Philharm. Chor (Dir.: Siegfried Ochs). II. } \\
\text { Concert. Sol.: Emilie Herzog, Marie Blanck- } \\
\text { Peters, Antonie Stern, R. von Milde. Mitw.: } \\
\text { Das Philharm. Orchester }\end{array}$ & Philharmonie & \\
\hline 05.12 .1902 & $\begin{array}{l}\text { II. Klavier-Abend (Chopin-Abend) von } \\
\text { Wladimir von Pachmann }\end{array}$ & Philharmonie & Komponistenkonzert \\
\hline 05.12 .1902 & $\begin{array}{l}\text { V. Populärer Musik-Abend von Anton } \\
\text { Hekking, Artur Schnabel, Alfred Wittenberg. } \\
\text { Mitw.: Fr. Gernsheim }\end{array}$ & Sonstiger & $\begin{array}{l}\text { Ort: Oberlichtsaal } \\
\text { der Philharmonie }\end{array}$ \\
\hline 06.12 .1902 & Concert von Annie de Jong (Violine) & Bechstein-Saal & \\
\hline 06.12 .1902 & $\begin{array}{l}\text { Einziger Lieder-Abend von Tilly Koenen. } \\
\text { Mitw.: Joh. Snoer (Harfe), Wilh. Berger } \\
\text { (Klavier) }\end{array}$ & Beethoven-Saal & \\
\hline 06.12 .1902 & $\begin{array}{l}\text { Winterfest zum Besten der Berliner } \\
\text { Rettungsgesellschaft }\end{array}$ & Philharmonie & \\
\hline 07.12 .1902 & $\begin{array}{l}\text { Concert von Elsa Laura von Wolzogen } \\
\text { (Gesang). Mitw.: Gregor von Akimoff } \\
\text { (Violine), Emil Del Ley (Bariton), Erich Band } \\
\text { (Klavier) }\end{array}$ & Beethoven-Saal & \\
\hline 08.12 .1902 & $\begin{array}{l}\text { I. Kammermusik-Abend von Marie Bruno } \\
\text { (Klavier), Gabriele Wietrowetz (Violine), Leo } \\
\text { Schrattenholz (Violoncello) }\end{array}$ & Bechstein-Saal & \\
\hline 08.12 .1902 & Klavier-Abend von Harold Bauer & Singakademie & \\
\hline 08.12 .1902 & $\begin{array}{l}\text { Philharm. Chor (Dir.: Siegfried Ochs). III. } \\
\text { Concert „Die Schöpfung“" von J. Haydn. Sol.: } \\
\text { Erika Wedekind, Raimund von Zur-Mühlen, } \\
\text { R. von Milde. Mitw.: Das Philharm. Orchester }\end{array}$ & Philharmonie & \\
\hline 09.12 .1902 & II. Klavier-Abend von Irene Schefsberg & Bechstein-Saal & \\
\hline 09.12 .1902 & Klavier-Abend von Gisella Grosz & Beethoven-Saal & \\
\hline
\end{tabular}




\begin{tabular}{|c|c|c|c|}
\hline 09.12 .1902 & $\begin{array}{l}\text { III. Populäres Concert des Waldemar Meyer- } \\
\text { Quartetts }\end{array}$ & Singakademie & \\
\hline 10.12 .1902 & II. Klavier-Abend von Waldemar Lütschg & Bechstein-Saal & \\
\hline 10.12.1902 & $\begin{array}{l}\text { Klavier-Abend (Chopin-Abend) von Gastone } \\
\text { Bernheimer }\end{array}$ & Beethoven-Saal & \\
\hline 10.12.1902 & $\begin{array}{l}\text { II. Lieder- und Balladen-Abend von Ludwig } \\
\text { Strakosch. Mitw.: Heinrich Burkhardt } \\
\text { (Violine) }\end{array}$ & Singakademie & \\
\hline 11.12 .1902 & II. Klavier-Abend von Richard Buhlig & Bechstein-Saal & \\
\hline 11.12.1902 & $\begin{array}{l}\text { Concert von Franz Schörg (Violine) und } \\
\text { Jacques Gaillard (Violoncello) mit dem } \\
\text { Philharm. Orchester. Dir.: J. Rébicek }\end{array}$ & Beethoven-Saal & \\
\hline 11.12 .1902 & Lieder-Abend von Maly von Trützschler & Singakademie & \\
\hline 11.12.1902 & $\begin{array}{l}\text { Kinder-Lieder-Abend von E. Jaques- } \\
\text { Dalcroze. Mitw.: Nina Fellero-Dalcroze, ein } \\
\text { Frauen- und Kinderchor }\end{array}$ & Sonstiger & $\begin{array}{l}\text { Ort: } \\
\text { Architektenhaus }\end{array}$ \\
\hline 12.12.1902 & $\begin{array}{l}\text { Soirée des Brüsseler Streichquartetts. Franz } \\
\text { Schörg, Hans Daucher, Paul Miry, Jacques } \\
\text { Gaillard }\end{array}$ & Bechstein-Saal & \\
\hline 12.12 .1902 & II. Lieder-Abend von Ludwig Wüllner & Beethoven-Saal & \\
\hline 13.12 .1902 & $\begin{array}{l}\text { Lieder-Abend moderner französischer } \\
\text { Compositionen veranstaltet von Albert } \\
\text { Bertelin. Mitw.: Henriette Menjaud, Lucien } \\
\text { Berton }\end{array}$ & Bechstein-Saal & Komponistenkonzert \\
\hline 13.12.1902 & $\begin{array}{l}\text { Concert von Lucien Capet (Violine) mit dem } \\
\text { Philharm. Orchester. Dir.: J. Rébicek }\end{array}$ & Beethoven-Saal & \\
\hline 13.12.1902 & $\begin{array}{l}\text { Lieder- und Balladen-Abend von Hermann } \\
\text { Gura. Mitw.: Richard Strauss }\end{array}$ & Singakademie & \\
\hline 13.12.1902 & $\begin{array}{l}\text { I. Abonnement-Concert der Hugo } \\
\text { Goldschmidt'schen Madrigalvereinigung. } \\
\text { Dir.: Hugo Leichtentritt }\end{array}$ & Sonstiger & $\begin{array}{l}\text { Ort: Oberlichtsaal } \\
\text { der Philharmonie }\end{array}$ \\
\hline 14.12.1902 & $\begin{array}{l}\text { Kinder-Lieder-Matinée von E. Jaques- } \\
\text { Dalcroze }\end{array}$ & Singakademie & \\
\hline 14.12 .1902 & II. Klavier-Abend von Harold Bauer & Singakademie & \\
\hline 14.12.1902 & $\begin{array}{l}\text { Öffentliche Hauptprobe zum V. Philharm. } \\
\text { Concert. Dir.: Arthur Nikisch, Sol.: Eugen } \\
\text { d'Albert. Mitw.: Bella Alten (Sopran), } \\
\text { Charlotte Huhn (Alt), Ludwig Wüllner } \\
\text { (Tenor), Hermann Gura (Bass). Mitw.: Das } \\
\text { Philharm. Chor }\end{array}$ & Philharmonie & \\
\hline 15.12 .1902 & $\begin{array}{l}\text { V. Philharm. Concert. Dir.: Arthur Nikisch, } \\
\text { Sol.: Eugen d'Albert. Mitw.: Bella Alten } \\
\text { (Sopran), Charlotte Huhn (Alt), Ludwig } \\
\text { Wüllner (Tenor), Hermann Gura (Bass). } \\
\text { Mitw.: Das Philharm. Chor }\end{array}$ & Philharmonie & \\
\hline 14.12 .1902 & II. Lieder-Abend von Julius Muhr & Bechstein-Saal & \\
\hline 16.12.1902 & $\begin{array}{l}\text { II. Concert des 8jährigen Klaviervirtuosen } \\
\text { Miecio Horszowski }\end{array}$ & Bechstein-Saal & \\
\hline 16.12 .1902 & Klavier-Abend von Severin Eisenberger & Beethoven-Saal & \\
\hline 17.12.1902 & $\begin{array}{l}\text { Soirée des Streichquartetts. Alb. Zimmer, Frz. } \\
\text { Doehaerd, Mestor Lejeune, Emile Doehaerd } \\
\text { aus Brüssel }\end{array}$ & Bechstein-Saal & \\
\hline 17.12 .1902 & II. Klavier-Abend von Gastone Bernheimer & Beethoven-Saal & \\
\hline 17.12 .1902 & Lieder-Abend von Nanny Meren & Singakademie & \\
\hline
\end{tabular}




\begin{tabular}{|c|c|c|c|}
\hline 17.12.1902 & \begin{tabular}{|l} 
Concert von Jean Gérardy mit dem Philharm. \\
Orchester. Dir.: J. Rébicek
\end{tabular} & Philharmonie & \\
\hline 18.12.1902 & $\begin{array}{l}\text { Concert von Luise Pinoff (Gesang). Mitw.: } \\
\text { Ida Wanoschek (Violine) }\end{array}$ & Bechstein-Saal & \\
\hline 18.12 .1902 & $\begin{array}{l}\text { Concert von Rosa Luise Samuels (Violine) } \\
\text { mit dem Philharm. Orchester. Dir.: J. Rébicek }\end{array}$ & Beethoven-Saal & \\
\hline 18.12 .1902 & Lieder-Abend von Richard Koennecke & Singakademie & \\
\hline 19.12.1902 & $\begin{array}{l}\text { VI. Populärer Musik-Abend von Anton } \\
\text { Hekking, Artur Schnabel, Alfred Wittenberg. } \\
\text { Mitw.: Magda und Franz Henri von Dulong } \\
\end{array}$ & Sonstiger & $\begin{array}{l}\text { Ort: Oberlichtsaal } \\
\text { der Philharmonie }\end{array}$ \\
\hline 19.12.1902 & $\begin{array}{l}\text { Concert von Frieda Crampe (Violine). Mitw.: } \\
\text { Fanny Opfer (Gesang) }\end{array}$ & Bechstein-Saal & \\
\hline 19.12.1902 & $\begin{array}{l}\text { Concert von Paula Szalit (Klavier) mit dem } \\
\text { Philharm. Orchester. Dir.: J. Rébicek }\end{array}$ & Beethoven-Saal & \\
\hline 20.12.1902 & $\begin{array}{l}\text { II. Abonnement-Soirée des Böhmischen } \\
\text { Streichquartetts. Mitw.: Eugen d'Albert }\end{array}$ & Beethoven-Saal & \\
\hline 27.12.1902 & $\begin{array}{l}\text { Concert von Karl Klinger (Violine) mit dem } \\
\text { Philharm. Orchester. Dir.: J. Rébicek. Mitw.: } \\
\text { Rob. Hausmann }\end{array}$ & Beethoven-Saal & \\
\hline 29.12 .1902 & Lieder-Abend von Richard Fischer & Bechstein-Saal & \\
\hline 29.12.1902 & $\begin{array}{l}\text { IV. Quartett-Abend von Joachim, Halir, } \\
\text { Wirth, Hausmann }\end{array}$ & Singakademie & \\
\hline 30.12 .1902 & Klavier-Abend von Florence Bassermann & Bechstein-Saal & \\
\hline 30.12 .1902 & $\begin{array}{l}\text { Concert von Vittorio Arimondi. Mitw.: } \\
\text { Michael Zacharewitsch (Violine) } \\
\end{array}$ & Beethoven-Saal & $\begin{array}{l}\text { handschriftlich } \\
\text { gestrichen }\end{array}$ \\
\hline 30.12 .1902 & Einziger Klavier-Abend von Ernest Schelling & Singakademie & \\
\hline 02.01 .1903 & Lieder-Abend von Clara Neiper & Bechstein-Saal & \\
\hline 02.01 .1903 & $\begin{array}{l}\text { Concert von Johann Wijsman (Klavier) mit } \\
\text { dem Philharm. Orchester. Dir.: J. Rébicek. } \\
\text { Mitw.: Ferruccio Busoni }\end{array}$ & Beethoven-Saal & \\
\hline 02.01 .1903 & Lieder-Abend von Maria Walter & Singakademie & \\
\hline 03.01 .1903 & Klavier-Abend von Elsie Hamilton & Bechstein-Saal & \\
\hline 03.01 .1903 & $\begin{array}{l}\text { Concert von Jean ten Have (Violine) mit dem } \\
\text { Philharm. Orchester. Dir.: J. Rébicek }\end{array}$ & Beethoven-Saal & \\
\hline 05.01 .1903 & $\begin{array}{l}\text { Concert von Vera Goldberg (Gesang). Mitw.: } \\
\text { Leopold Przemysler (Violine) }\end{array}$ & Bechstein-Saal & \\
\hline 05.01 .1903 & Lieder-Abend von Marie Hertzer-Deppe & Beethoven-Saal & \\
\hline 05.01 .1903 & $\begin{array}{l}\text { VII. Populärer Musik-Abend von Anton } \\
\text { Hekking, Artur Schnabel, Alfred Wittenberg. } \\
\text { Mitw.: Alexander Heinemann }\end{array}$ & Sonstiger & $\begin{array}{l}\text { Ort: Oberlichtsaal } \\
\text { der Philharmonie }\end{array}$ \\
\hline 05.01 .1903 & Einziger Klavier-Abend von Eugen d'Albert & Philharmonie & \\
\hline 06.01 .1903 & Lieder-Abend von Minnie Tracey & Bechstein-Saal & \\
\hline 06.01 .1903 & III. Lieder-Abend von Lula Mysz-Gmeiner & Beethoven-Saal & \\
\hline 06.01 .1903 & $\begin{array}{l}\text { Concert von Gabriele Wietrowetz. Mitw.: J. } \\
\text { Joachim (Violine), Ida Sothmann (Klavier), } \\
\text { Antonie Liebeskind (Gesang) }\end{array}$ & Singakademie & \\
\hline 07.01 .1903 & Klavier-Abend von Ernst Lochbrunner & Bechstein-Saal & \\
\hline 07.01 .1903 & I. Klavier-Abend von Edouard Risler & Beethoven-Saal & \\
\hline 07.01 .1903 & $\begin{array}{l}\text { III. Kammermusik-Abend von Georg } \\
\text { Schumann, Carl Halir. Hugo Dechert }\end{array}$ & Singakademie & \\
\hline 08.01 .1903 & Klavier-Abend von Joseph Lhévinne & Bechstein-Saal & \\
\hline
\end{tabular}




\begin{tabular}{|c|c|c|c|}
\hline 08.01 .1903 & $\begin{array}{l}\text { Concert von Georg Liebling mit dem } \\
\text { Philharm. Orchester. Dir.: J. Rébicek }\end{array}$ & Beethoven-Saal & \\
\hline 08.01 .1903 & $\begin{array}{l}\text { II. Abonnement-Concert. Florian Zajic - } \\
\text { Heinrich Grünfeld. Mitw.: Bernhard } \\
\text { Stavenhagen, Raimund von Zur Mühlen, Hans } \\
\text { Hasse, Hans Diestel, Carl Höhne, Jos. Clam } \\
\end{array}$ & Singakademie & \\
\hline 09.01 .1903 & $\begin{array}{l}\text { II. Populärer Quartett-Abend von Gustav } \\
\text { Hollaender, Willy Nicking, Walter } \\
\text { Rampelmann, Eugen Sandow. Mitw.: Joseph } \\
\text { Lhévinne (Klavier), Rob. Koennecke, Jul. } \\
\text { Sandow } \\
\end{array}$ & Bechstein-Saal & \\
\hline 09.01 .1903 & $\begin{array}{l}\text { II. Concert von Jean Gérardy. Mitw.: Susanne } \\
\text { Dessoir (Gesang) }\end{array}$ & Beethoven-Saal & \\
\hline 09.01 .1903 & $\begin{array}{l}\text { Concert von Mateo Crickbooom (Violine) mit } \\
\text { dem Philharm. Orchester. Dir.: J. Rébicek }\end{array}$ & Singakademie & \\
\hline 10.01 .1903 & Klavier-Abend von Gertrude King & Bechstein-Saal & \\
\hline 10.01 .1903 & $\begin{array}{l}\text { Concert von Artur Schnabel mit dem } \\
\text { Philharm. Orchester. Dir.: J. Rébicek. Mitw.: } \\
\text { Therese Behr }\end{array}$ & Beethoven-Saal & \\
\hline 10.01 .1903 & $\begin{array}{l}\text { I. Darstellung von Vorgängen aus } \\
\text { „Christus“von Anton Rubinstein }\end{array}$ & Sonstiger & $\begin{array}{l}\text { Ort: Theatersaal der } \\
\text { Königlichen } \\
\text { Hochschule }\end{array}$ \\
\hline 11.01 .1903 & $\begin{array}{l}\text { Recitations-Abend von Irene Triesch und } \\
\text { Marcell Salzer }\end{array}$ & Bechstein-Saal & \\
\hline 11.01 .1903 & $\begin{array}{l}\text { Öffentliche Hauptprobe zum VI. Philharm. } \\
\text { Concert. Dir.: Arthur Nikisch, Sol.: Emile } \\
\text { Sauret }\end{array}$ & Philharmonie & \\
\hline 12.01 .1903 & $\begin{array}{l}\text { Concert der Dortmunder } \\
\text { Kammermusikvereinigung. Ernst Potthoff } \\
\text { (Klavier), H. Schmidt-Reinecke, Otto } \\
\text { Assmuss (Violine), Carl Hermann (Viola), } \\
\text { Ernst Cahnbley (Violoncello). Mitw.: Tilly } \\
\text { Hinken (Gesang) } \\
\end{array}$ & Bechstein-Saal & \\
\hline 12.01 .1903 & $\begin{array}{l}\text { II. Darstellung von Vorgängen aus } \\
\text { „Christus“ von Anton Rubinstein }\end{array}$ & Sonstiger & $\begin{array}{l}\text { Ort: Theatersaal der } \\
\text { Königlichen } \\
\text { Hochschule }\end{array}$ \\
\hline 12.01 .1903 & $\begin{array}{l}\text { VI. Philharm. Concert. Dir.: Arthur Nikisch, } \\
\text { Sol.: Emile Sauret }\end{array}$ & Philharmonie & \\
\hline 13.01 .1903 & $\begin{array}{l}\text { Concert von Fanni Merten (Klavier) und } \\
\text { Helene Linsener (Gesang) }\end{array}$ & Bechstein-Saal & \\
\hline 13.01 .1903 & $\begin{array}{l}\text { IV. Populäres Concert des Waldemar Meyer- } \\
\text { Quartetts. Mitw.: O. Schubert }\end{array}$ & Singakademie & \\
\hline 13.01 .1903 & $\begin{array}{l}\text { III. Darstellung von Vorgängen aus } \\
\text { „Christus“v von Anton Rubinstein }\end{array}$ & Sonstiger & $\begin{array}{l}\text { Ort: Theatersaal der } \\
\text { Königlichen } \\
\text { Hochschule }\end{array}$ \\
\hline 14.01.1903 & $\begin{array}{l}\text { Lieder-Abend (zum Besten der } \\
\text { Lungenheilstätten) von Hermann Brause. } \\
\text { Mitw.: Fr. Struss }\end{array}$ & Bechstein-Saal & \\
\hline 14.01 .1903 & II. Klavier-Abend von Edouard Risler & Beethoven-Saal & \\
\hline 14.01 .1903 & Klavier-Abend von Getrude Peppercorn & Singakademie & \\
\hline 15.01 .1903 & Klavier-Abend von Douglas Boxall & Bechstein-Saal & \\
\hline 15.01 .1903 & $\begin{array}{l}\text { Concert von Aldo Antonietti (Violine) mit } \\
\text { dem Philharm. Orchester. Dir.: J. Rébicek }\end{array}$ & Beethoven-Saal & \\
\hline
\end{tabular}




\begin{tabular}{|c|c|c|c|}
\hline 15.01.1903 & $\begin{array}{l}\text { V. Quartett-Abend von Joachim, Halir, Wirth, } \\
\text { Hausmann }\end{array}$ & Singakademie & \\
\hline 16.01 .1903 & $\begin{array}{l}\text { II. Soirée des Brüsseler Streichquartetts. Franz } \\
\text { Schörg, Hans Daucher, Paul Miry, Jacques } \\
\text { Gaillard }\end{array}$ & Bechstein-Saal & \\
\hline 16.01 .1903 & Klavier-Abend von Carl Friedberg & Beethoven-Saal & \\
\hline 16.01 .1903 & $\begin{array}{l}\text { Concert von René Schidenhelm (Violoncello) } \\
\text { mit dem Philharm. Orchester. Dir.: J. Rébicek }\end{array}$ & Singakademie & \\
\hline 17.01 .1903 & II. Concert von Mateo Crickboom (Violine) & Bechstein-Saal & \\
\hline 17.01 .1903 & Einziger Lieder-Abend von Rosa Olitzka & Beethoven-Saal & \\
\hline 18.01 .1903 & $\begin{array}{l}\text { Stern'scher Gesangverein (Dir.: Friedr. } \\
\text { Gernsheim). Öffentliche Hauptprobe zum II. } \\
\text { Concert }\end{array}$ & Philharmonie & \\
\hline 19.01.1903 & $\begin{array}{l}\text { Kammermusik-Abend von Bella Edwards } \\
\text { (Klavier) und Eva Mudocci (Violine) }\end{array}$ & Bechstein-Saal & \\
\hline 19.01.1903 & $\begin{array}{l}\text { Concert von Corinne Coryn (Violine). Mitw.: } \\
\text { Gertrud Fischer (Gesang) }\end{array}$ & Beethoven-Saal & \\
\hline 19.01.1903 & $\begin{array}{l}\text { Stern'scher Gesangverein (Dir.: Friedr. } \\
\text { Gernsheim). II. Concert. Mitw.: Emillie } \\
\text { Herzog, Iduna Walter-Choinanus, Alexander } \\
\text { Heinemann, Albert Jungblut, Heinr. Reimann } \\
\text { (Orgel), Das Philharm. Orchester }\end{array}$ & Philharmonie & \\
\hline 20.01.1903 & $\begin{array}{l}\text { I. Vortrags-Abend des Henri Marteau- } \\
\text { Quartetts. Henri Marteau, Eugène Reymond, } \\
\text { Waldemar Pahnke, Adolphe Rehberg } \\
\end{array}$ & Bechstein-Saal & \\
\hline 20.01 .1903 & II. Lieder-Abend von Therese Behr & Beethoven-Saal & \\
\hline 20.01 .1903 & $\begin{array}{l}\text { II. Quartett-Abend von Bernh. Dessau, Bernh. } \\
\text { Gehwald, Rob. Könecke [Koennecke], Fritz } \\
\text { Espenhahn. Mitw.: Otto Hegner (Klavier) } \\
\end{array}$ & Singakademie & \\
\hline 21.01 .1903 & Lieder-Abend von Ella Kunwald & Bechstein-Saal & \\
\hline 21.01 .1903 & III. Klavier-Abend von Edouard Risler & Beethoven-Saal & \\
\hline 21.01 .1903 & $\begin{array}{l}\text { Concert von Anna Feiten (Gesang). Mitw.: } \\
\text { Eugen Sandow (Violoncello) }\end{array}$ & Singakademie & \\
\hline 22.01 .1903 & Klavier-Abend von José Vianna da Motta & Bechstein-Saal & \\
\hline 22.01 .1903 & $\begin{array}{l}\text { II. Abonnement-Concert des Streichorchesters } \\
\text { Berliner Tonkünstlerinnen. Dir.: Willy Benda. } \\
\text { Mitw.: Arthur van Eweyk (Gesang) }\end{array}$ & Beethoven-Saal & \\
\hline 22.01 .1903 & $\begin{array}{l}\text { Concert von Bruno Hinze-Reinhold (Klavier) } \\
\text { mit dem Philharm. Orchester. Dir.: J. Rébicek }\end{array}$ & Singakademie & \\
\hline 22.01 .1903 & Lieder-Abend von Marie Leval & Sonstiger & $\begin{array}{l}\text { Ort: Oberlichtsaal } \\
\text { der Philharmonie }\end{array}$ \\
\hline 23.01 .1903 & $\begin{array}{l}\text { II. Concert von René Schidenhelm } \\
\text { (Violoncello). Mitw.: Alfred Schmidt- } \\
\text { Badekow (Klavier) }\end{array}$ & Bechstein-Saal & \\
\hline 23.01 .1903 & I. Klavier-Abend von Ferruccio Busoni & Beethoven-Saal & \\
\hline 23.01 .1903 & $\begin{array}{l}\text { Concert von Joseph Hollmann (Violoncello) } \\
\text { mit dem Philharm. Orchester. Dir.: J. Rébicek }\end{array}$ & Singakademie & \\
\hline 23.01 .1903 & $\begin{array}{l}\text { VIII. Populärer Musik-Abend von Anton } \\
\text { Hekking, Artur Schnabel, Alfred Wittenberg. } \\
\text { Mitw.: Anton Sistermans (Gesang) } \\
\end{array}$ & Sonstiger & $\begin{array}{l}\text { Ort: Oberlichtsaal } \\
\text { der Philharmonie }\end{array}$ \\
\hline 24.01 .1903 & $\begin{array}{l}\text { Lieder- und Duett-Abend von Paula } \\
\text { Weinbaum (Alt) und Betty Loewen (Sopran) }\end{array}$ & Bechstein-Saal & \\
\hline
\end{tabular}




\begin{tabular}{|c|c|c|c|}
\hline 25.01 .1903 & \begin{tabular}{|l} 
II. Kammermusik-Abend von Marie Bruno \\
(Klavier), Gabriele Wietrowetz (Violine), Leo \\
Schrattenholz (Violoncello)
\end{tabular} & Bechstein-Saal & \\
\hline 25.01 .1903 & $\begin{array}{l}\text { III. Concert von Jean Gérardy. Mitw.: Arthur } \\
\text { Argiewicz (Violine) }\end{array}$ & Beethoven-Saal & \\
\hline 25.01 .1903 & $\begin{array}{l}\text { Öffentliche Hauptprobe zum VII. Philharm. } \\
\text { Concert. Dir.: Arthur Nikisch, Sol.: Erika } \\
\text { Wedekind (Gesang) }\end{array}$ & Philharmonie & \\
\hline 26.01 .1903 & $\begin{array}{l}\text { Concert von Margarete Zennig (Gesang). } \\
\text { Mitw.: Felix Meyer }\end{array}$ & Bechstein-Saal & \\
\hline 26.01 .1903 & $\begin{array}{l}\text { Concert zum Besten der Wirtschaftlichen } \\
\text { Frauenschulen auf dem Lande. Mitw.: } \\
\text { Susanne Dessoir (Gesang), Fr. Sörensen-Klein } \\
\text { (Gesang), Hedwig Niemann-Raabe } \\
\text { (Deklamation), Rud. Christians, Georg } \\
\text { Molenar, Bianca Panteo (Violine), Bruno } \\
\text { Hinze-Reinhold (Klavier) }\end{array}$ & Singakademie & \\
\hline 26.01 .1903 & $\begin{array}{l}\text { VII. Philharm. Concert. Dir.: Arthur Nikisch, } \\
\text { Sol.: Erika Wedekind (Gesang) }\end{array}$ & Philharmonie & \\
\hline 27.01 .1903 & $\begin{array}{l}\text { Concert von Elisabet Saatz (Gesang). Mitw.: } \\
\text { Anton Hekking (Violoncello) }\end{array}$ & Bechstein-Saal & \\
\hline 28.01 .1903 & $\begin{array}{l}\text { II. Vortrags-Abend von Henri Marteau- } \\
\text { Quartetts. Henri Marteau, Eugène Reymond, } \\
\text { Waldemar Pahnke, Adolphe Rehberg }\end{array}$ & Bechstein-Saal & \\
\hline 28.01 .1903 & III. Lieder-Abend von Ludwig Wüllner & Beethoven-Saal & \\
\hline 28.01 .1903 & $\begin{array}{l}\text { Concert von Martha Gentz-Malte (Gesang) } \\
\text { und Aug. Gentz (Violine und Viola). Mitw.: } \\
\text { Ernesto Drangosch (Klavier), Willibald } \\
\text { Wagner (Violine) } \\
\end{array}$ & Singakademie & \\
\hline 29.01 .1903 & $\begin{array}{l}\text { Lieder-Abend von Emily Müller. Mitw.: } \\
\text { Gustav Friedrich (Gesang) }\end{array}$ & Bechstein-Saal & \\
\hline 29.01 .1903 & $\begin{array}{l}\text { Concert von Teresa Carreno mit dem } \\
\text { Philharm. Orchester. Dir.: J. Rébicek }\end{array}$ & Beethoven-Saal & \\
\hline 29.01 .1903 & $\begin{array}{l}\text { Concert von Paula Meyer (Gesang) und } \\
\text { Lucien de Flagny (Komposition). Mitw.: } \\
\text { Michael Zachrewitsch (Violine) }\end{array}$ & Singakademie & Komponistenkonzert \\
\hline 30.01 .1903 & $\begin{array}{l}\text { I. Kammermusik-Abend von Wilma Norman- } \\
\text { Neruda (Lady Hallé) und Friedrich Gernsheim }\end{array}$ & Bechstein-Saal & \\
\hline 30.01 .1903 & IV. Lieder-Abend von Lula Mysz-Gmeiner & Beethoven-Saal & \\
\hline 31.01 .1903 & Lieder-Abend von Maria Seret & Bechstein-Saal & \\
\hline 31.01 .1903 & II. Klavier-Abend von Ferruccio Busoni & Beethoven-Saal & \\
\hline 31.01 .1903 & $\begin{array}{l}\text { II. Sonaten-Abend von Otto von Gruenewaldt } \\
\text { (Klavier) und Leo Schrattenholz (Violoncello) }\end{array}$ & Singakademie & \\
\hline 02.02 .1903 & III. Klavier-Abend von Richard Buhlig & Bechstein-Saal & \\
\hline 02.02 .1903 & II. Lieder-Abend von Helene Berard & Beethoven-Saal & \\
\hline 02.02 .1903 & $\begin{array}{l}\text { Concert von Gertrud Proskaur (Klavier) mit } \\
\text { dem Philharm. Orchester. Dir.: J. Rébicek }\end{array}$ & Singakademie & \\
\hline 03.02 .1903 & Lieder-Abend von Polly Victoria Blumenbach & Bechstein-Saal & \\
\hline 03.02 .1903 & $\begin{array}{l}\text { Sonaten-Abend von Edouard Risler und } \\
\text { Jacques Thibaud }\end{array}$ & Beethoven-Saal & \\
\hline 03.02 .1903 & $\begin{array}{l}\text { Concert von Corally Böttcher (Gesang) und F. } \\
\text { della Sudda (Klavier) }\end{array}$ & Singakademie & \\
\hline
\end{tabular}




\begin{tabular}{|c|c|c|c|}
\hline 04.02 .1903 & \begin{tabular}{|l} 
II. (letzte) Soirée für neue Kammermusik von \\
Adalbert Gülzow und José Vianna da Motta. \\
Mitw.: Paul Knüpfer, Paul Müller, Hans \\
Diestel, Franz Borisch
\end{tabular} & Bechstein-Saal & \\
\hline 04.02 .1903 & $\begin{array}{l}\text { I. Klavier-Abend (Beethoven-Abend) von } \\
\text { Frederic Lamond }\end{array}$ & Beethoven-Saal & \\
\hline 05.02 .1903 & I. Klavier-Abend von Alfred Reisenauer & Bechstein-Saal & \\
\hline 05.02 .1903 & Lieder-Abend von Helene Staegemann & Beethoven-Saal & \\
\hline 05.02 .1903 & $\begin{array}{l}\text { VI. Quartett-Abend von Joachim, Halir, } \\
\text { Wirth, Hausmann }\end{array}$ & Singakademie & \\
\hline 06.02 .1903 & II. Concert von Aldo Antonietti (Violine) & Bechstein-Saal & \\
\hline 06.02 .1903 & $\begin{array}{l}\text { Concert von Sophie von Dieterichs (Gesang) } \\
\text { und Boris Sibor (Violine) mit dem Philharm. } \\
\text { Orchester. Dir.: J. Rébicek }\end{array}$ & Beethoven-Saal & \\
\hline 06.02 .1903 & $\begin{array}{l}\text { Concert von Else Vetter (Gesang), Bianca } \\
\text { Becker-Samolewska (Violine und Viola) und } \\
\text { Otto Becker (Klavier) }\end{array}$ & Singakademie & \\
\hline 07.02 .1903 & Lieder-Abend von Ferdinand Jäger & Bechstein-Saal & \\
\hline 07.02 .1903 & III. Klavier-Abend von Ferruccio Busoni & Beethoven-Saal & \\
\hline 07.02 .1903 & $\begin{array}{l}\text { Concert von Anton Foerster (Klavier) mit dem } \\
\text { Philharm. Orchester. Dir.: J. Rébicek }\end{array}$ & Singakademie & \\
\hline 07.02 .1903 & \begin{tabular}{|l|} 
IX. Populärer Musik-Abend von Anton \\
Hekking (Violoncello), Artur Schnabel \\
(Klavier), Alfred Wittenberg (Violine). Mitw.: \\
Susanne Dessoir (Gesang), Rob. Kahn \\
(Klavier)
\end{tabular} & Sonstiger & $\begin{array}{l}\text { Ort: Oberlichtsaal } \\
\text { der Philharmonie }\end{array}$ \\
\hline 08.02 .1903 & $\begin{array}{l}\text { Öffentliche Hauptprobe zum VIII. Philharm. } \\
\text { Concert. Dir.: Arthur Nikisch, Sol.: Eugène } \\
\text { Ysaye }\end{array}$ & Philharmonie & \\
\hline 09.02 .1903 & $\begin{array}{l}\text { VIII. Philharm. Concert. Dir.: Arthur Nikisch, } \\
\text { Sol.: Eugène Ysaye }\end{array}$ & Philharmonie & \\
\hline 10.02.1903 & $\begin{array}{l}\text { Concert von Otto Hutschenreuter } \\
\text { (Violoncello). Mitw.: Elisabeth Feininger } \\
\text { (Gesang), Martha Hornig-Flemming } \\
\text { (Klavier), Alfred Holy (Harfe) }\end{array}$ & Bechstein-Saal & \\
\hline 11.02 .1903 & Lieder- und Balladen-Abend von Josef Loritz & Bechstein-Saal & \\
\hline 11.02.1903 & $\begin{array}{l}\text { III. Lieder-Abend von Raimund von Zur } \\
\text { Mühlen }\end{array}$ & Beethoven-Saal & \\
\hline 11.02.1903 & $\begin{array}{l}\text { Concert von Xaver Scharwenka. Mitw.: } \\
\text { Jaques van Lier (Violoncello) }\end{array}$ & Singakademie & \\
\hline 12.02 .1903 & $\begin{array}{l}\text { III. (letzter) Klavier-Abend von Waldemar } \\
\text { Lütschg }\end{array}$ & Bechstein-Saal & \\
\hline 12.02 .1903 & Klavier-Abend von Arthur Rubinstein & Beethoven-Saal & \\
\hline 12.02 .1903 & $\begin{array}{l}\text { Klavier-Abend von Theodor Lemba aus } \\
\text { Petersburg }\end{array}$ & Singakademie & \\
\hline 12.02 .1903 & $\begin{array}{l}\text { Concert zum Besten der Berliner Stadtmission } \\
\text { gegeben von der Akademischen Liedertafel. } \\
\text { Dir.: Adolf Schulze. Mitw.: Ida Hiedler } \\
\text { (Gesang), Joseph Malkine (Violoncello) } \\
\end{array}$ & Sonstiger & $\begin{array}{l}\text { Ort: Concertsaal der } \\
\text { Königlichen } \\
\text { Hochschule }\end{array}$ \\
\hline 13.02 .1903 & $\begin{array}{l}\text { III. (letzter) Quartett-Abend von Gustav } \\
\text { Hollaender, Willy Nicking, Walter } \\
\text { Rampelmann, Eugen Sandow }\end{array}$ & Bechstein-Saal & \\
\hline 13.02 .1903 & I. Klavier-Abend von Conrad Ansorge & Beethoven-Saal & \\
\hline
\end{tabular}




\begin{tabular}{|c|c|c|c|}
\hline 13.02.1903 & $\begin{array}{l}\text { Letzter Klavier-Abend von Wladimir von } \\
\text { Pachmann }\end{array}$ & Philharmonie & \\
\hline 14.02.1903 & II. Lieder-Abend von Ferdinand Jäger & Bechstein-Saal & \\
\hline 14.02 .1903 & $\begin{array}{l}\text { II. Klavier-Abend (Brahms-Abend) von } \\
\text { Frederic Lamond }\end{array}$ & Beethoven-Saal & Komponistenkonzert \\
\hline 14.02 .1903 & $\begin{array}{l}\text { Concert von Alexandrine Zanolli (Violine) } \\
\text { mit dem Philharm. Orchester. Dir.: J. Rébicek }\end{array}$ & Singakademie & \\
\hline 15.02 .1903 & $\begin{array}{l}\text { Populärer (letzter) Klavier-Abend von } \\
\text { Clotilde Kleeberg }\end{array}$ & Beethoven-Saal & \\
\hline 16.02 .1903 & $\begin{array}{l}\text { Concert von Louise Hövelmann (Gesang). } \\
\text { Mitw.: Marg. Eussert (Klavier), Martha } \\
\text { Drews (Violine), Eugenie Stoltz (Violoncello) }\end{array}$ & Bechstein-Saal & \\
\hline 16.02.1903 & $\begin{array}{l}\text { II. Concert von Sophie von Dieterichs } \\
\text { (Gesang) und Boris Sibor (Violine). Mitw.: } \\
\text { Sandra Droucker (Klavier) }\end{array}$ & Singakademie & \\
\hline 17.02 .1903 & II. Klavier-Abend von Alfred Reisenauer & Bechstein-Saal & \\
\hline 17.02 .1903 & $\begin{array}{l}\text { Concert von Juana Hess (Gesang) und } \\
\text { Therese Slottko (Klavier) }\end{array}$ & Beethoven-Saal & \\
\hline 17.02 .1903 & $\begin{array}{l}\text { Letztes Concert von Paula Szalit (Klavier). } \\
\text { Mitw.: Alfred Wittenberg (Violine) }\end{array}$ & Singakademie & \\
\hline 18.02 .1903 & II. Lieder-Abend von Ferdinand Jäger & Bechstein-Saal & \\
\hline 18.02 .1903 & II. Klavier-Abend von Carl Friedberg & Beethoven-Saal & \\
\hline 19.02.1903 & Klavier-Abend von Auguste Goetz-Lehmann & Bechstein-Saal & \\
\hline 19.02.1903 & $\begin{array}{l}\text { Concert von Hermann Rubin (Violine) mit } \\
\text { dem Philharm. Orchester. Dir.: J. Rébicek }\end{array}$ & Beethoven-Saal & \\
\hline 19.02.1903 & \begin{tabular}{|l|} 
X. Populärer Musik-Abend von Anton \\
Hekking (Violoncello), Artur Schnabel \\
(Klavier), Alfred Wittenberg (Violine). Mitw.: \\
Marie Blanck-Peters (Gesang), Wilhelm \\
Berger (Klavier)
\end{tabular} & Sonstiger & $\begin{array}{l}\text { Ort: Oberlichtsaal } \\
\text { der Philharmonie }\end{array}$ \\
\hline 20.02.1903 & Klavier-Abend von Egon Petri & Bechstein-Saal & \\
\hline 20.02.1903 & $\begin{array}{l}\text { Concert von Lucien Wurmser (Klavier) mit } \\
\text { dem Philharm. Orchester. Dir.: J. Rébicek }\end{array}$ & Beethoven-Saal & \\
\hline 20.02 .1903 & II. Lieder-Abend von Helene Staegemann & Singakademie & \\
\hline 20.02 .1903 & Marta Sandal (Lieder aus neuerer Zeit) & Sonstiger & $\begin{array}{l}\text { Ort: Oberlichtsaal } \\
\text { der Philharmonie }\end{array}$ \\
\hline 21.02.1903 & $\begin{array}{l}\text { I. Kammermusik-Abend von Wilma Norman- } \\
\text { Neruda (Lady Hallé) und Friedrich Gernsheim }\end{array}$ & Bechstein-Saal & \\
\hline 21.02 .1903 & $\begin{array}{l}\text { Concert von Felix Grossi (Violine) mit dem } \\
\text { Philharm. Orchester. Dir.: J. Rébicek }\end{array}$ & Beethoven-Saal & \\
\hline 22.02 .1903 & $\begin{array}{l}\text { Einziger populärer Kammermusik-Abend von } \\
\text { Edwin Grasse (Violine) und Otto Heguer } \\
\text { (Klavier) }\end{array}$ & Bechstein-Saal & \\
\hline 22.02 .1903 & Klavier-Abend von Flora Schrres-Friedenthal & Singakademie & \\
\hline 22.02 .1903 & $\begin{array}{l}\text { Öffentliche Hauptprobe zum IX. Philharm. } \\
\text { Concert. Dir.: Arthur Nikisch, Sol.:Raoul } \\
\text { Pugno }\end{array}$ & Philharmonie & \\
\hline 23.02 .1903 & $\begin{array}{l}\text { Lieder- und Duett-Aben von Elly von } \\
\text { Glasenapp (Sopran) und Hildegard Dietrich } \\
\text { (Alt) }\end{array}$ & Bechstein-Saal & \\
\hline 23.02 .1903 & $\begin{array}{l}\text { IX. Philharm. Concert. Dir.: Arthur Nikisch, } \\
\text { Sol.: Raoul Pugno }\end{array}$ & Philharmonie & \\
\hline
\end{tabular}




\begin{tabular}{|c|c|c|c|}
\hline 24.02 .1903 & \begin{tabular}{|l} 
Concert von Paula Olshausen (Gesang) und \\
Theophil Ziller (Klavier)
\end{tabular} & Bechstein-Saal & \\
\hline 24.02 .1903 & $\begin{array}{l}\text { II. Concert von Conrad Ansorge. Mitw.: } \\
\text { Richard Koennecke (Gesang), das } \\
\text { Höllandische Streichquartett }\end{array}$ & Beethoven-Saal & \\
\hline 24.02 .1903 & $\begin{array}{l}\text { Mustel Harmonium-Concert von Alphonse } \\
\text { Mustel und Carl Stabernack. Mitw.: Antonie } \\
\text { Stern (Gesang), Leopold Przemysler (Violine) }\end{array}$ & Singakademie & \\
\hline 25.02 .1903 & Klavier-Abend von Frida Kindler & Bechstein-Saal & \\
\hline 25.02 .1903 & $\begin{array}{l}\text { I. Quartett-Abend von Jeannette Grumbacher } \\
\text { de Jong, Therese Behr, Ludwig Hess, Arthur } \\
\text { van Eweyk. Mitw.: Arthur Schnabel }\end{array}$ & Beethoven-Saal & \\
\hline 26.02 .1903 & II. Klavier-Abend von Egon Petri & Bechstein-Saal & \\
\hline 26.02 .1903 & Einziger Klavier-Abend von Josef Weiss & Beethoven-Saal & \\
\hline 26.02 .1903 & $\begin{array}{l}\text { Concert von Pablo Sarasate und Berthe Marx- } \\
\text { Goldschmidt mit dem Philharm. Orchester. } \\
\text { Dir.: J. Rébicek }\end{array}$ & Philharmonie & \\
\hline 27.02 .1903 & $\begin{array}{l}\text { Concert von Anna Stahlknecht-Borgwardt } \\
\text { (Gesang) und Willy Deckert (Violoncello) }\end{array}$ & Bechstein-Saal & \\
\hline 27.02 .1903 & IV. Lieder-Abend von Ludwig Wüllner & Beethoven-Saal & \\
\hline 27.02 .1903 & $\begin{array}{l}\text { Concert der Pianistinnen Bessie und Mamie } \\
\text { Silberfeld }\end{array}$ & Singakademie & \\
\hline 27.02 .1903 & $\begin{array}{l}\text { II. Concert des „Berliner Lehrer- } \\
\text { Gesangvereins““. Dir.: Felix Schmidt. Mitw.: } \\
\text { Erna Schulz (Violine) } \\
\end{array}$ & Philharmonie & \\
\hline 28.02 .1903 & $\begin{array}{l}\text { Concert von Gertrud Marcks (Klavier). Mitw.: } \\
\text { Heinrich Grünfeld (Violoncello) }\end{array}$ & Bechstein-Saal & \\
\hline 28.02 .1903 & $\begin{array}{l}\text { III. Klavier-Abend (Beethoven-Abend) von } \\
\text { Frederic Lamond }\end{array}$ & Beethoven-Saal & \\
\hline 28.02 .1903 & $\begin{array}{l}\text { Concert von Hedwig Kirsch (Klavier) mit } \\
\text { dem Philharm. Orchester. Dir.: J. Rébicek }\end{array}$ & Singakademie & \\
\hline 02.03 .1903 & Geigen-Abend von Martin Collin & Bechstein-Saal & \\
\hline 02.03 .1903 & $\begin{array}{l}\text { Compositions-Concert von Max Reger. } \\
\text { Aufführende: Ludwig Hess und der } \\
\text { Componist }\end{array}$ & Beethoven-Saal & Komponistenkonzert \\
\hline 02.03 .1903 & $\begin{array}{l}\text { Philharm. Chor (Dir.: Siegfried Ochs). „Israel } \\
\text { in Egypten“ von G. F. Händel. Sol.: Maly von } \\
\text { Trützschler, Luise Geller-Wolter, Rob. } \\
\text { Kaufmann, Alexander Heinemann, Paul } \\
\text { Knüpfer. Mitw.: Das Philharm. Orchester } \\
\end{array}$ & Philharmonie & \\
\hline 03.03 .1903 & $\begin{array}{l}\text { Concert von Irene von Brennerberg (Violine). } \\
\text { Mitw.: Selma Thomas (Gesang) }\end{array}$ & Beethoven-Saal & \\
\hline 04.03 .1903 & Klavier-Abend von Frank O’Brien & Bechstein-Saal & \\
\hline 04.03 .1903 & II. Lieder-Abend von Hertha Dehmlow & Beethoven-Saal & \\
\hline 04.03 .1903 & $\begin{array}{l}\text { III. (letztes) Abonnement-Concert von Florian } \\
\text { Zajic - Heinrich Grünfeld. Mitw.: Jeannette } \\
\text { Grumbacher de Jong, Alfred Grünfeld, Hans } \\
\text { Hasse }\end{array}$ & Singakademie & \\
\hline 05.03 .1903 & Klavier-Abend von Hedwig Klimek & Bechstein-Saal & \\
\hline 05.03 .1903 & $\begin{array}{l}\text { II. Concert von Lucien Wurmser (Klavier) mit } \\
\text { dem Philharm. Orchester. Dir.: J. Rébicek }\end{array}$ & Beethoven-Saal & \\
\hline 05.03 .1903 & $\begin{array}{l}\text { VII. Quartett-Abend von Joachim, Halir, } \\
\text { Wirth, Hausmann }\end{array}$ & Singakademie & \\
\hline
\end{tabular}




\begin{tabular}{|c|c|c|c|}
\hline 06.03 .1903 & $\begin{array}{l}\text { III. Kammermusik-Abend von Marie Bruno } \\
\text { (Klavier), Gabriele Wietrowetz (Violine), Leo } \\
\text { Schrattenholz (Violoncello) }\end{array}$ & Bechstein-Saal & \\
\hline 06.03 .1903 & IV. Klavier-Abend von Frederic Lamond & Beethoven-Saal & \\
\hline 06.03 .1903 & $\begin{array}{l}\text { Concert von Wassili Sapellnikoff mit dem } \\
\text { Philharm. Orchester. Dir.: J. Rébicek }\end{array}$ & Singakademie & \\
\hline 06.03 .1903 & Letzter Klavier-Abend von Teresa Carreno & Philharmonie & \\
\hline 06.03 .1903 & $\begin{array}{l}\text { XI. Populärer Musik-Abend von Anton } \\
\text { Hekking, Artur Schnabel, Alfred Wittenberg }\end{array}$ & Sonstiger & $\begin{array}{l}\text { Ort: Oberlichtsaal } \\
\text { der Philharmonie }\end{array}$ \\
\hline 07.03 .1903 & Concert von Max Donner (Violine) & Bechstein-Saal & \\
\hline 07.03 .1903 & $\begin{array}{l}\text { III. Abonnement-Soirée des Böhmischen } \\
\text { Streichquartetts. Carl Hoffmann, Josef Suk, } \\
\text { Oskar Nedbal, Hans Wihan. Mitw.: Vera } \\
\text { Maurina (Klavier) }\end{array}$ & Beethoven-Saal & \\
\hline 07.03 .1903 & $\begin{array}{l}\text { Concert von Zdzislaw Alex Birnbaum } \\
\text { (Violine) mit dem Philharm. Orchester. Dir.: } \\
\text { J. Rébicek }\end{array}$ & Singakademie & \\
\hline 08.03 .1903 & $\begin{array}{l}\text { Vortrag über Gesangskunst von Cornelie van } \\
\text { Zanten (Obergesanglehrerin am } \\
\text { Conservatorium zu Amsterdam) }\end{array}$ & Bechstein-Saal & \\
\hline 08.03 .1903 & $\begin{array}{l}\text { Concert von Walter Meyròwitz mit dem } \\
\text { Philharm. Orchester. Mitw.: Emmy Destinn, } \\
\text { Carl Jörn (Gesang) }\end{array}$ & Beethoven-Saal & \\
\hline 09.03 .1903 & I. Klavier-Abend von Anton Foerster & Bechstein-Saal & \\
\hline 09.03 .1903 & $\begin{array}{l}\text { Populärer Concert-Abend von Bruno Hinze- } \\
\text { Reinhold (Klavier). Mitw.: Susanne Dessoir } \\
\text { (Gesang), Georg Schumann }\end{array}$ & Sonstiger & $\begin{array}{l}\text { Ort: Oberlichtsaal } \\
\text { der Philharmonie }\end{array}$ \\
\hline 10.03 .1903 & Klavier-Abend von Michael Zadora & Bechstein-Saal & \\
\hline 10.03 .1903 & $\begin{array}{l}\text { II. Concert von Minnie Tracey (Gesang). } \\
\text { Mitw.: Annie de Jong (Violine) }\end{array}$ & Beethoven-Saal & \\
\hline 10.03 .1903 & $\begin{array}{l}\text { III. Quartett-Abend von Bernh. Dessau, } \\
\text { Bernh. Gehwald, Rob. Könecke, Fritz } \\
\text { Espenhahn. Mitw.: Robert Kahn, Max Poike } \\
\end{array}$ & Singakademie & \\
\hline 10.03 .1903 & $\begin{array}{l}\text { Kammermusik-Abend von Otto Hegner } \\
\text { (Klavier), Boris Sibor (Violine), Heinz Beyer } \\
\text { (Violoncello). Mitw.: Vera Goldberg } \\
\text { (Gesang) }\end{array}$ & Sonstiger & $\begin{array}{l}\text { Ort: Oberlichtsaal } \\
\text { der Philharmonie }\end{array}$ \\
\hline 11.03 .1903 & $\begin{array}{l}\text { IV. Lieder-Abend von Raimund von Zur } \\
\text { Mühlen }\end{array}$ & Beethoven-Saal & \\
\hline 11.03 .1903 & Lieder-Abend von Martha Schley & Singakademie & \\
\hline 12.03 .1903 & $\begin{array}{l}\text { Concert von Irma Saenger-Sethe, Waldemar } \\
\text { Lütschg, Ludwig Hess }\end{array}$ & Bechstein-Saal & \\
\hline 12.03 .1903 & $\begin{array}{l}\text { Concert von Sergei von Bortkewicz (Klavier) } \\
\text { mit dem Philharm. Orchester. Dir.: J. Rébicek }\end{array}$ & Beethoven-Saal & \\
\hline 12.03 .1903 & $\begin{array}{l}\text { Vocal-Concert veranstaltet von Cornelie van } \\
\text { Zanten mit einigen von ihr ausgebildeten } \\
\text { Künstlern und Kunstschülern }\end{array}$ & Singakademie & \\
\hline 13.03 .1903 & Lieder-Abend von Thekla Raschka & Bechstein-Saal & \\
\hline 13.03.1903 & $\begin{array}{l}\text { Lieder-Abend mit eigenen Compositionen } \\
\text { veranstaltet von Alphonse Maurice. Mitw.: } \\
\text { Maria Knüpfer-Egli, Vilma von Mayburg, } \\
\text { Carl Jörn }\end{array}$ & Beethoven-Saal & Komponistenkonzert \\
\hline 13.03 .1903 & $\begin{array}{l}\text { Concert von Pablo Sarasate und Berthe Marx- } \\
\text { Goldschmidt }\end{array}$ & Philharmonie & \\
\hline
\end{tabular}




\begin{tabular}{|c|c|c|c|}
\hline $\mid 14.03 .1903$ & II. Lieder-Abend von Heinrich Meyn & Bechstein-Saal & \\
\hline 14.03 .1903 & $\begin{array}{l}\text { IV. Abonnement-Soirée des Böhmischen } \\
\text { Streichquartetts. Carl Hoffmann, Josef Suk, } \\
\text { Oskar Nedbal, Hans Wihan }\end{array}$ & Beethoven-Saal & \\
\hline 14.03 .1903 & $\begin{array}{l}\text { Concert von Hans Lange (Violine) mit dem } \\
\text { Philharm. Orchester. Dir.: J. Rébicek. Mitw.: } \\
\text { Lonie Basche (Klavier) }\end{array}$ & Singakademie & \\
\hline 15.03 .1903 & Matinée von Etelka Gerster's Gesangschule & Bechstein-Saal & \\
\hline 15.03 .1903 & $\begin{array}{l}\text { Öffentliche Hauptprobe zum X. (letzten) } \\
\text { Philharm. Concert. Dir.: Arthur Nikisch }\end{array}$ & Philharmonie & \\
\hline 16.03 .1903 & $\begin{array}{l}\text { X. (letztes) Philharm. Concert. Dir.: Arthur } \\
\text { Nikisch }\end{array}$ & Philharmonie & \\
\hline 17.03 .1903 & Concert von Nicolas Lambinon (Violine) & Bechstein-Saal & \\
\hline 17.03 .1903 & $\begin{array}{l}\text { II. Quartett-Abend von Jeannette } \\
\text { Grumbacher-de Jong, Therese Behr, Ludwig } \\
\text { Hess, Arthur van Eweyk. Mitw.: Artur } \\
\text { Schnabel }\end{array}$ & Beethoven-Saal & \\
\hline 17.03 .1903 & $\begin{array}{l}\text { VI. (letztes) Concert des Waldemar Meyer- } \\
\text { Quartetts. Mitw.: O. Schubert, H. Lange, } \\
\text { Hugo Rüdel, Gustav Krüger }\end{array}$ & Singakademie & \\
\hline 18.03 .1903 & $\begin{array}{l}\text { Concert von Gisela Springer (Klavier) und G. } \\
\text { Guarnieri-Pavan (Violine) }\end{array}$ & Bechstein-Saal & \\
\hline 18.03 .1903 & Einziger Klavier-Abend von Raoul Pugno & Beethoven-Saal & \\
\hline 18.03 .1903 & $\begin{array}{l}\text { Lieder-Abend von Brigitta Thielemann. } \\
\text { Mitw.: Eduard Behm }\end{array}$ & Singakademie & \\
\hline 19.03 .1903 & II. Klavier-Abend von Anton Foerster & Bechstein-Saal & \\
\hline 19.03 .1903 & $\begin{array}{l}\text { II. Concert von Wassili Sapellnikoff mit dem } \\
\text { Philharm. Orchester. Dir.: J. Rébicek }\end{array}$ & Beethoven-Saal & \\
\hline 19.03 .1903 & $\begin{array}{l}\text { VIII. (letzter) Quartett-Abend von Joachim, } \\
\text { Halir, Wirth, Hausmann }\end{array}$ & Singakademie & \\
\hline 19.03 .1903 & $\begin{array}{l}\text { Concert der Berliner Liedertafel (Chormeister: } \\
\text { A. Zander, M. Werner). Mitw.: Jeannette } \\
\text { Grumbacher-de Jong }\end{array}$ & Philharmonie & \\
\hline 20.03 .1903 & $\begin{array}{l}\text { Concert von Franz Larack (Gesang). Mitw.: } \\
\text { Annie de Jong (Violine) }\end{array}$ & Bechstein-Saal & \\
\hline 20.03 .1903 & $\begin{array}{l}\text { Concert von Elsa Kohlmann (Violine) mit } \\
\text { dem Philharm. Orchester. Dir.: J. Rébicek. } \\
\text { Mitw.: Alexander Heinemann }\end{array}$ & Beethoven-Saal & \\
\hline 20.03 .1903 & $\begin{array}{l}\text { Concert von Marguerite Melville (Klavier). } \\
\text { Mitw.: Bernh. Dessau, Bernh. Gehwald, Rob. } \\
\text { Könecke, Fritz Espenhahn }\end{array}$ & Singakademie & \\
\hline 21.03 .1903 & $\begin{array}{l}\text { III. (letzter) Klavier-Abend von Alfred } \\
\text { Reisenauer }\end{array}$ & Bechstein-Saal & \\
\hline 21.03 .1903 & $\begin{array}{l}\text { Concert eigener Compositionen von } \\
\text { Mieczyslaw Karlowicz mit dem Philharm. } \\
\text { Orchester. Dir.: J. Rébicek. Mitw.: Stanislaus } \\
\text { Barcewicz (Violine) }\end{array}$ & Beethoven-Saal & Komponistenkonzert \\
\hline 21.03 .1903 & $\begin{array}{l}\text { Concert zu einem wohltätigen Zweck von } \\
\text { Adolf Schulze. Mitw.: Adolf Schulze-Chor. }\end{array}$ & Sonstiger & $\begin{array}{l}\text { Ort: } \\
\text { Architektenhaus }\end{array}$ \\
\hline 23.03 .1903 & $\begin{array}{l}\text { Concert von Käthe Albrecht (Sopran) und } \\
\text { Geert Ravensberg (Tenor) }\end{array}$ & Bechstein-Saal & \\
\hline 23.03 .1903 & $\begin{array}{l}\text { Concert von Ernesto Drangosch (Klavier) mit } \\
\text { dem Philharm. Orchester. Dir.: J. Rébicek }\end{array}$ & Beethoven-Saal & \\
\hline
\end{tabular}




\begin{tabular}{|c|c|c|c|}
\hline 24.03.1903 & \begin{tabular}{|l} 
Concert von Luise Sckerl (Gesang). Mitw.: \\
Adrian Rappoldi (Violine)
\end{tabular} & Bechstein-Saal & \\
\hline 24.03 .1903 & Lieder-Abend von Ottilie Metzger & Beethoven-Saal & \\
\hline 24.03 .1903 & Klavier-Abend von Victor Benham & Singakademie & \\
\hline 25.03 .1903 & $\begin{array}{l}\text { Concert von Lina Goldenberg (Gesang) und } \\
\text { Max Anton (Klavier) }\end{array}$ & Bechstein-Saal & \\
\hline 25.03 .1903 & $\begin{array}{l}\text { IV. (letzter) Kammermusik-Abend von Gerog } \\
\text { Schumann, Carl Halir, Hugo Dechert. Mitw.: } \\
\text { Bruno Hinze-Reinhold (Klavier) }\end{array}$ & Singakademie & \\
\hline 26.03 .1903 & Lieder-Abend von Irma da Motta & Bechstein-Saal & \\
\hline 26.03.1903 & $\begin{array}{l}\text { Populäres Concert des Streichorchesters } \\
\text { Berliner Tonkünstlerinnen. Dir.: Willy Benda. } \\
\text { Mitw.: Waldemar Lütschg (Klavier), Adelina } \\
\text { Metzdorff-Löwenberg (Violoncello) }\end{array}$ & Beethoven-Saal & \\
\hline 26.03 .1903 & $\begin{array}{l}\text { Concert von Anna von Gabain (Klavier) mit } \\
\text { dem Philharm. Orchester. Dir.: J. Rébicek }\end{array}$ & Singakademie & \\
\hline 26.03.1903 & $\begin{array}{l}\text { XII. Populärer Musik-Abend von Anton } \\
\text { Hekking, Artur Schnabel, Alfred Wittenberg. } \\
\text { Mitw.: Eva Lessmann (Gesang) }\end{array}$ & Sonstiger & $\begin{array}{l}\text { Ort: Oberlichtsaal } \\
\text { der Philharmonie }\end{array}$ \\
\hline 27.03 .1903 & Klavier-Abend von Sophie Rybaltowska & Bechstein-Saal & \\
\hline 27.03 .1903 & $\begin{array}{l}\text { III. Concert (Klavier-Abend) von Conrad } \\
\text { Ansorge }\end{array}$ & Beethoven-Saal & \\
\hline 27.03 .1903 & $\begin{array}{l}\text { Concert von Sergei Kussewitzky (Kontrabass, } \\
\text { Prof. der Moskauer Philharm. } \\
\text { Conservatoriums) und Sergei Mamontoff } \\
\text { (Klavier) }\end{array}$ & Singakademie & \\
\hline 27.03 .1903 & Populärer Lieder-Abend von Ludwig Wüllner & Philharmonie & \\
\hline 28.03.1903 & $\begin{array}{l}\text { II. Kammermusik-Abend von Wilma } \\
\text { Norman-Neruda (Lady Hallé) und Friedrich } \\
\text { Gernsheim }\end{array}$ & Bechstein-Saal & \\
\hline 28.03.1903 & $\begin{array}{l}\text { Concert von Hakon Schmedes (Violine) mit } \\
\text { dem Philharm. Orchester. Dir.: J. Rébicek }\end{array}$ & Beethoven-Saal & \\
\hline 28.03.1903 & $\begin{array}{l}\text { Lieder- und Duett-Abend von Emmy von } \\
\text { Linsingen (Sopran) und Sina Felser (Alt) } \\
\end{array}$ & Singakademie & \\
\hline 29.03 .1903 & $\begin{array}{l}\text { Wohltätiges-Matinée veranstaltet von } \\
\text { Mitgliedern der Königlichen Theater }\end{array}$ & Beethoven-Saal & \\
\hline 29.03 .1903 & $\begin{array}{l}\text { Populärer Lieder-Abend von Alexander } \\
\text { Heinemann }\end{array}$ & Beethoven-Saal & \\
\hline 29.03 .1903 & $\begin{array}{l}\text { Öffentliche Hauptprobe zum Pensionsfonds- } \\
\text { Concert des Philharm. Orchesters. Dir.: } \\
\text { Arthur Nikisch, Sol.: Anton Witek } \\
\end{array}$ & Philharmonie & \\
\hline 30.03 .1903 & $\begin{array}{l}\text { Concert von Agnes Szarka-Ahlers mit ihren } \\
\text { Schülerinnen }\end{array}$ & Bechstein-Saal & \\
\hline 30.03 .1903 & $\begin{array}{l}\text { Pensionsfonds-Concert des Philharm. } \\
\text { Orchesters. Dir.: Arthur Nikisch, Sol.: Anton } \\
\text { Witek }\end{array}$ & Philharmonie & \\
\hline 31.03 .1903 & Klavier-Abend von Eduard Zeldenrust & Bechstein-Saal & \\
\hline 31.03 .1903 & $\begin{array}{l}\text { Concert (zum wohltätigen Zweck) von Etelka } \\
\text { Gester's Gesangschule }\end{array}$ & Beethoven-Saal & \\
\hline 31.03 .1903 & $\begin{array}{l}\text { Lieder-Abend von Gustav Friedrich. Mitw.: } \\
\text { Heinr. Grünfeld. Artur Schnabel }\end{array}$ & Singakademie & \\
\hline 01.04 .1903 & $\begin{array}{l}\text { V. (letzter) Lieder-Abend von Lula Mysz- } \\
\text { Gmeiner }\end{array}$ & Beethoven-Saal & \\
\hline
\end{tabular}




\begin{tabular}{|c|c|c|c|}
\hline 02.04 .1903 & Klavier-Abend von Silvio Risegari & Bechstein-Saal & \\
\hline 02.04 .1903 & Lieder-Abend von Julie Müllerhartung & Beethoven-Saal & \\
\hline 02.04 .1903 & Concert von Aurelie Révy (Gesang) & Sonstiger & $\begin{array}{l}\text { Ort: Oberlichtsaal } \\
\text { der Philharmonie }\end{array}$ \\
\hline 03.04 .1903 & $\begin{array}{l}\text { Concert von Marie von Horvath (Gesang). } \\
\text { Mitw.: Bruno Hinze-Reinhold (Klavier) }\end{array}$ & Bechstein-Saal & \\
\hline 03.04 .1903 & Concert von Therese Behr und Artur Schnabel & Beethoven-Saal & \\
\hline 04.04 .1903 & $\begin{array}{l}\text { Concert von Anna Berg (Gesang). Mitw.: } \\
\text { Elisabeth Bleicher (Klavier) }\end{array}$ & Bechstein-Saal & \\
\hline 05.04 .1903 & $\begin{array}{l}\text { Liedercompositions-Abend von Max Gus. } \\
\text { Ausführende: Lilli Lehmann, Hansi Delisle, } \\
\text { Else Schünemann, Franz Egenieff }\end{array}$ & Beethoven-Saal & Komponistenkonzert \\
\hline 05.04 .1903 & $\begin{array}{l}\text { Stern'scher Gesangverein (Dir.: Friedr. } \\
\text { Gernsheim). Öffentliche Hauptprobe zur } \\
\text { „Missa solemnis“ von L. van Beethoven }\end{array}$ & Philharmonie & \\
\hline 06.04 .1903 & $\begin{array}{l}\text { Stern'scher Gesangverein (Dir.: Fr. } \\
\text { Gernsheim). Missa solemnis“ von L. van } \\
\text { Beethoven. Sol.: Maly von Trützschler, Marie } \\
\text { Henke, Ludw. Wüllner, Anton Sistermans. } \\
\text { Mitw.: H. Reimann (Orgel), Das Philharm. } \\
\text { Orchester }\end{array}$ & Philharmonie & \\
\hline 07.04 .1903 & $\begin{array}{l}\text { Concert des } 12 \text { jährigen Walter Joseph } \\
\text { (Klavier) mit dem Philharm. Orchester. Dir.: } \\
\text { J. Rébicek }\end{array}$ & Beethoven-Saal & \\
\hline 08.04 .1903 & II. Lieder-Abend von Tilly Erlenmeyer & Beethoven-Saal & \\
\hline 09.04 .1903 & $\begin{array}{l}\text { XIII. Populärer Musik-Abend von Anton } \\
\text { Hekking, Artur Schnabel, Alfred Wittenberg. } \\
\text { Mitw.: Rosa Sucher }\end{array}$ & Sonstiger & $\begin{array}{l}\text { Ort: Oberlichtsaal } \\
\text { der Philharmonie }\end{array}$ \\
\hline 15.04 .1903 & Lieder-Abend von Gerda Rombell & Bechstein-Saal & \\
\hline 15.04 .1903 & Concert von Raoul Pugno und Jean Gérardy & Beethoven-Saal & \\
\hline 16.04 .1903 & Klavier-Abend von Guido Peters & Bechstein-Saal & \\
\hline 17.04.1903 & $\begin{array}{l}\text { Compositions-Concert von Robert Wiemann } \\
\text { mit dem Philharm. Orchester. Dir.: J. Rébicek. } \\
\text { Mitw.: Herm. Brune (Bariton) }\end{array}$ & Singakademie & Komponistenkozert \\
\hline 18.04 .1903 & $\begin{array}{l}\text { Lieder-Abend von Anton Sistermans. Mitw.: } \\
\text { Fr. Gernsheim, Rob. Kahn }\end{array}$ & Bechstein-Saal & \\
\hline 19.04 .1903 & $\begin{array}{l}\text { Musikalische Schülerinnen Aufführung von } \\
\text { Emilie von Cramer }\end{array}$ & Bechstein-Saal & \\
\hline 23.04 .1903 & $\begin{array}{l}\text { Wohltätigkeits-Concert veranstaltet von } \\
\text { Emily Hamann-Martinsen mit einigen ihrer } \\
\text { Schülerinnen. Mitw.: Carl Stabernack } \\
\text { (Mustel-Harmonium) }\end{array}$ & Bechstein-Saal & \\
\hline 23.04 .1903 & $\begin{array}{l}\text { XIV. Populärer Musik-Abend von Anton } \\
\text { Hekking, Artur Schnabel, Alfred Wittenberg. } \\
\text { Mitw.: Therese Behr }\end{array}$ & Sonstiger & $\begin{array}{l}\text { Ort: Oberlichtsaal } \\
\text { der Philharmonie }\end{array}$ \\
\hline 26.04 .1903 & $\begin{array}{l}\text { Matinée der Gesang-Schule von Mathilde } \\
\text { Mallinger }\end{array}$ & Bechstein-Saal & \\
\hline
\end{tabular}




\section{Entwürfe des Bechstein-Saales in Berlin}

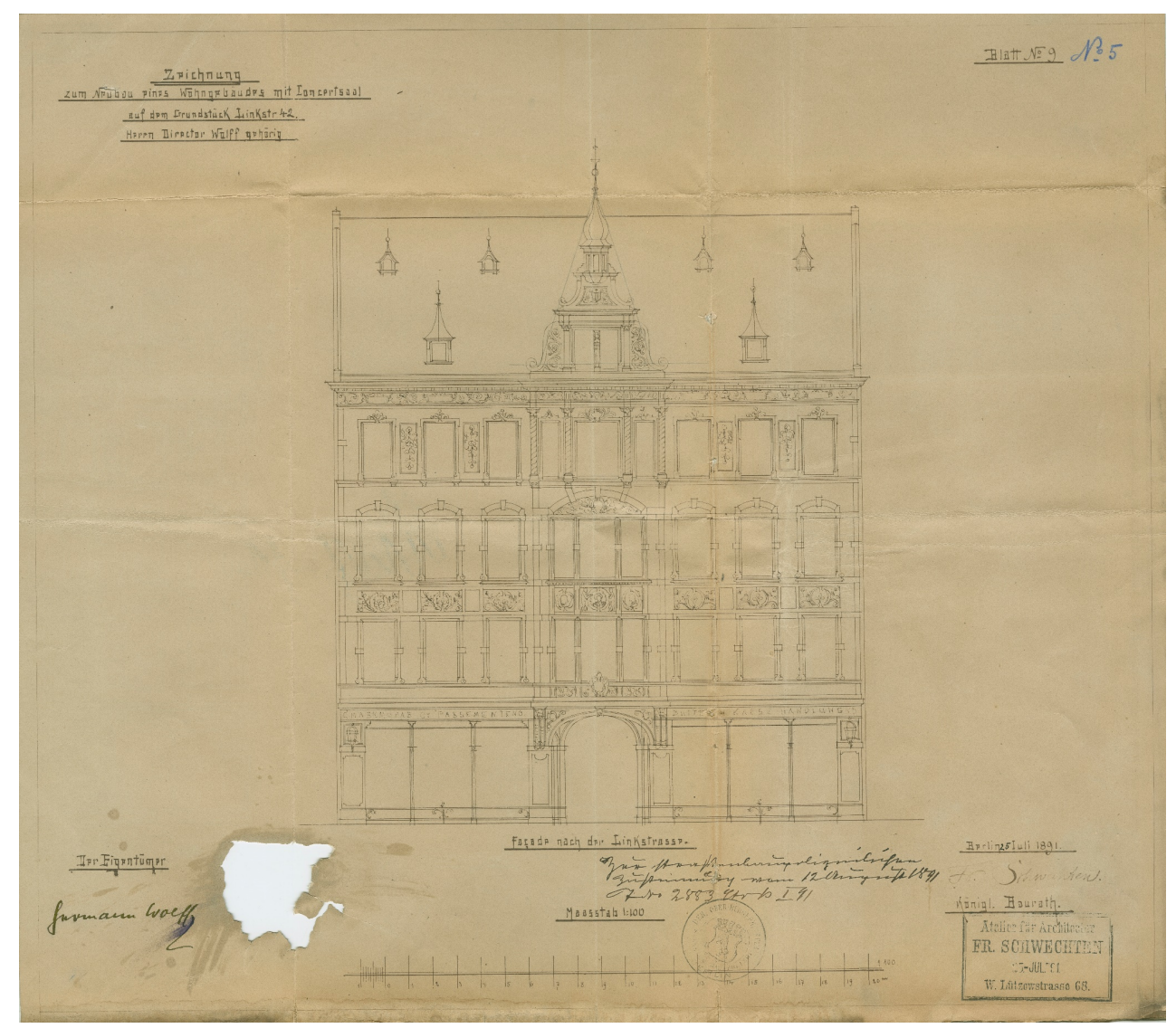

Abb. 1: »Zeichnung zum Neubau eines Wohngebäudes mit Concertsaal auf dem Grundstück Linkstr. 42, Herrn Director Wolff gehörig, Façade nach der Linkstrasse« (LAB, B Rep 202, Nr. 4300, B1. 124)

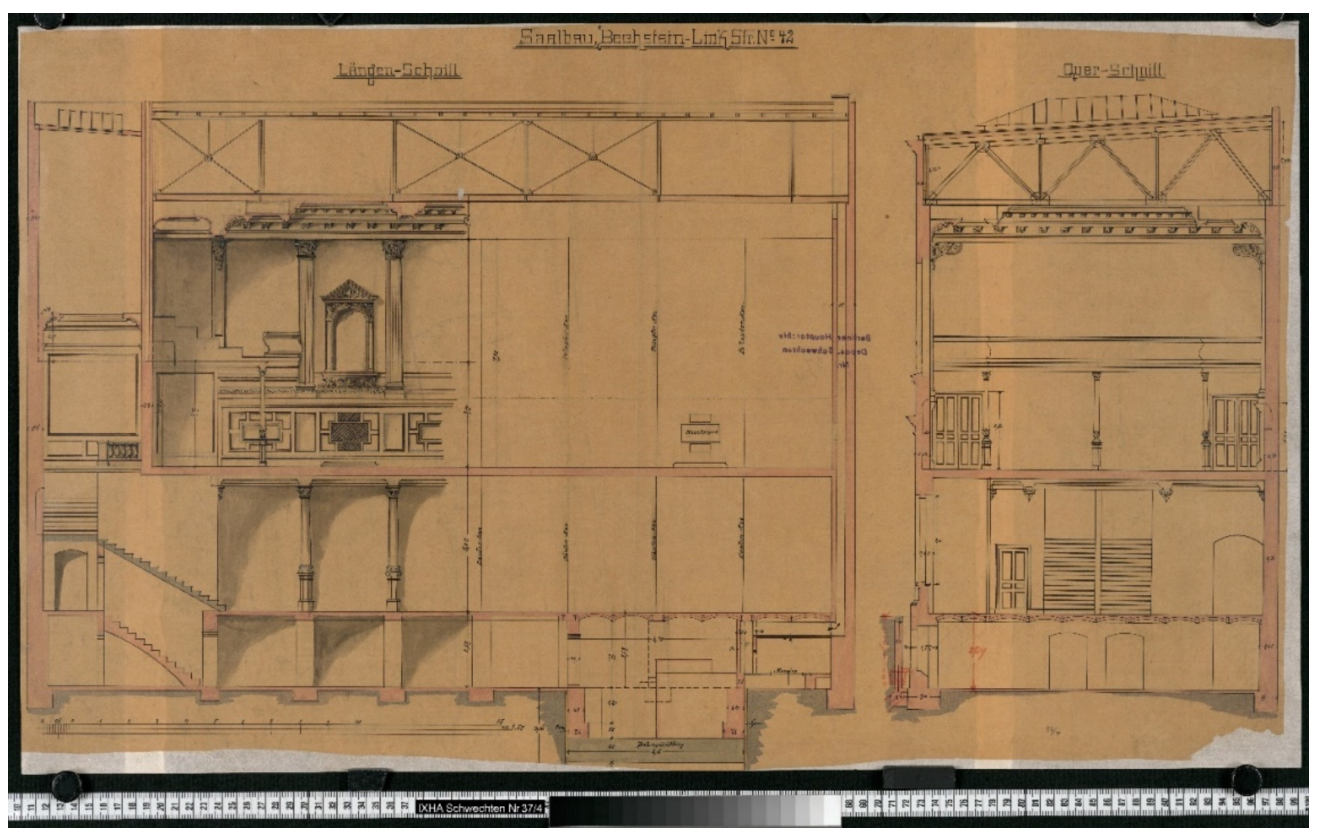

Abb. 2: »Längen- und Querschnitt« (GSPK, Bestand IX. HA Architekturatelier Schwechten, Nr. 37, B1. 4) 


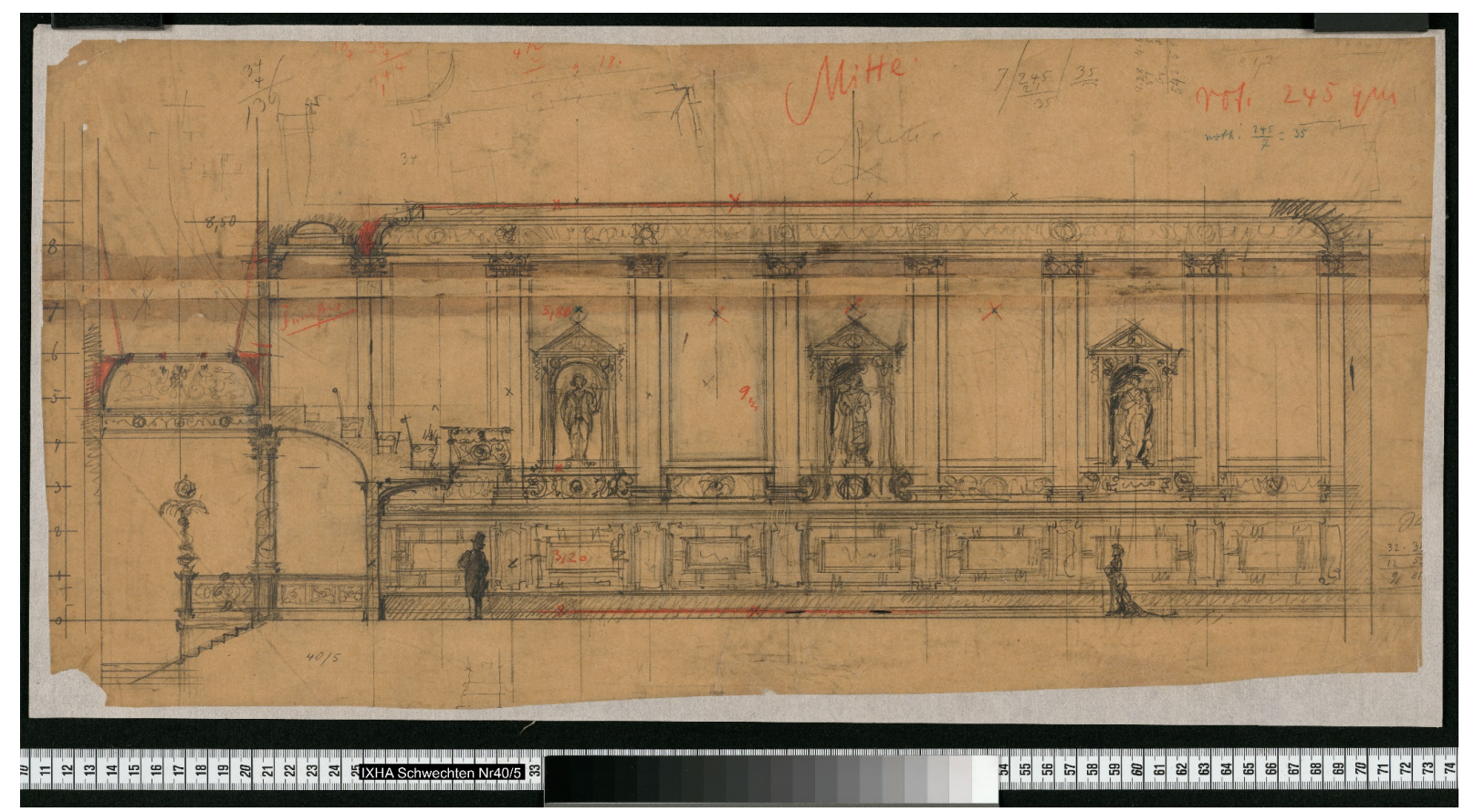

Abb. 3: »Wandgestaltung« (GSPK, Bestand IX. HA Architekturatelier Schwechten, Nr. 40, B1. 5)

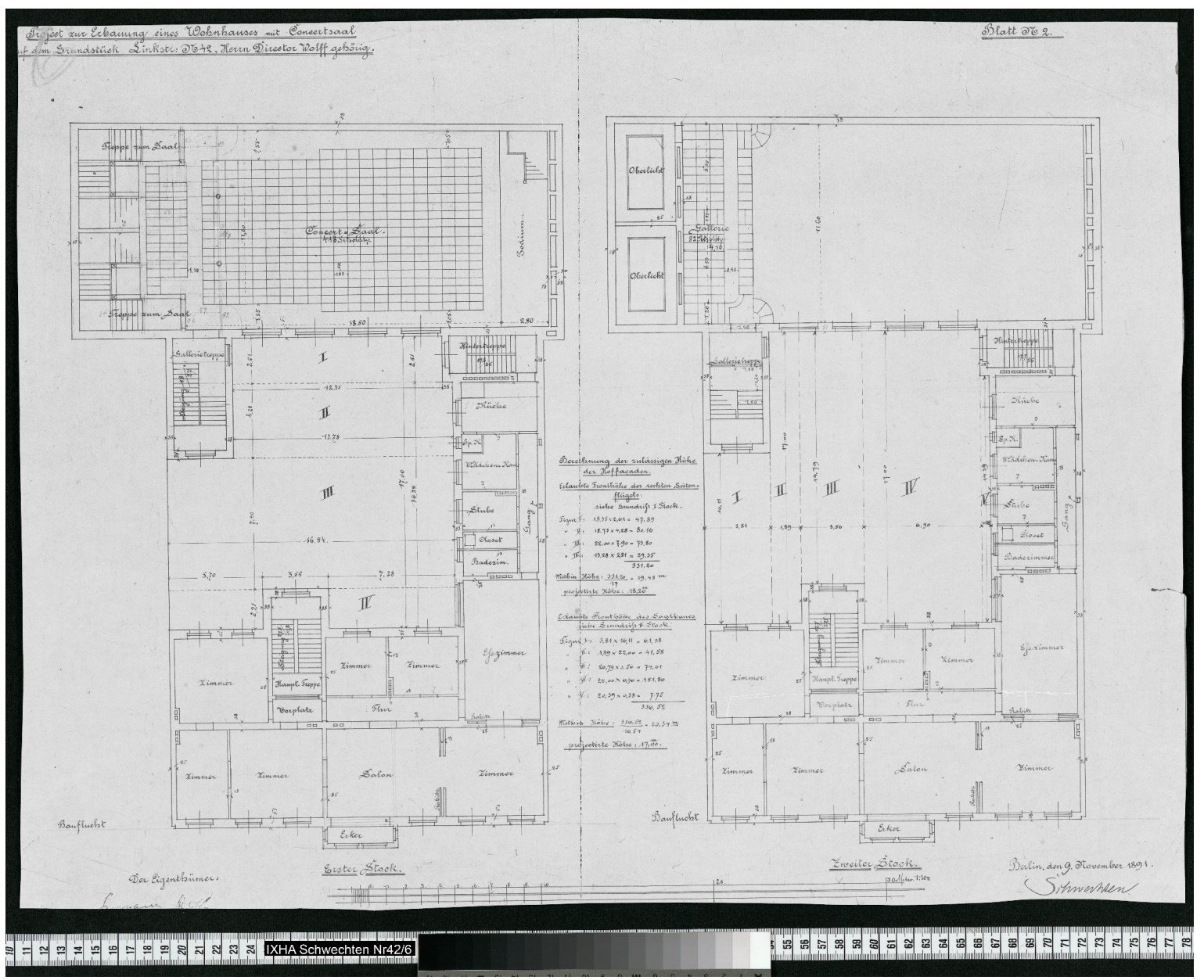

Abb. 4: »I. und II. Stockwerk, Blaupause« (GSPK, Bestand IX. HA Architekturatelier Schwechten, Nr. 42, B1. 6) 


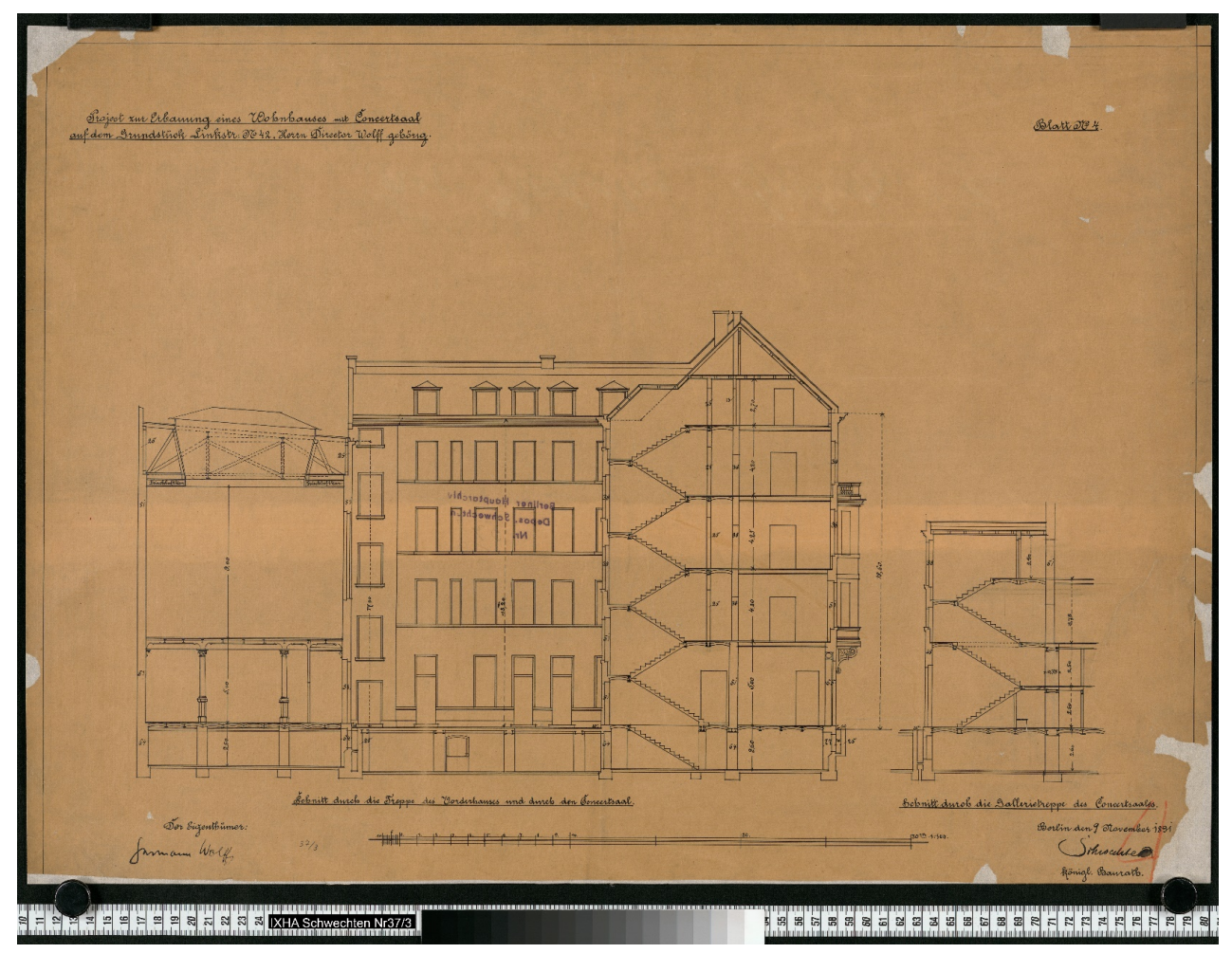

Abb. 5: »Schnitt durch die Treppe des Vorderhauses und Konzertsaal« (GSPK, Bestand IX. HA Architekturatelier Schwechten, Nr. 37, B1. 3)

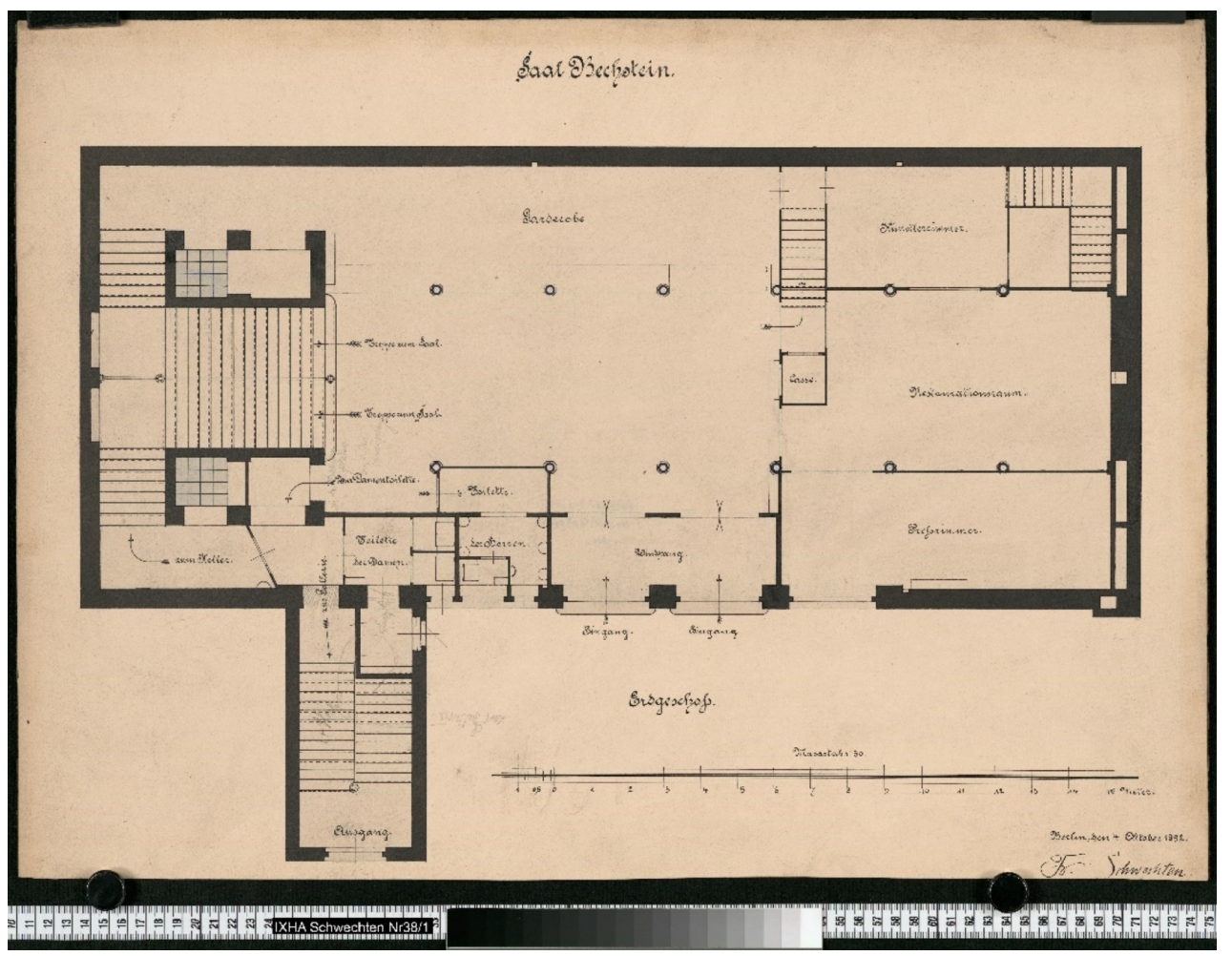

Abb. 6: »Grundriß Erdgeschoß« (GSPK, Bestand IX. HA Architekturatelier Schwechten, Nr. 38, B1. 1) 


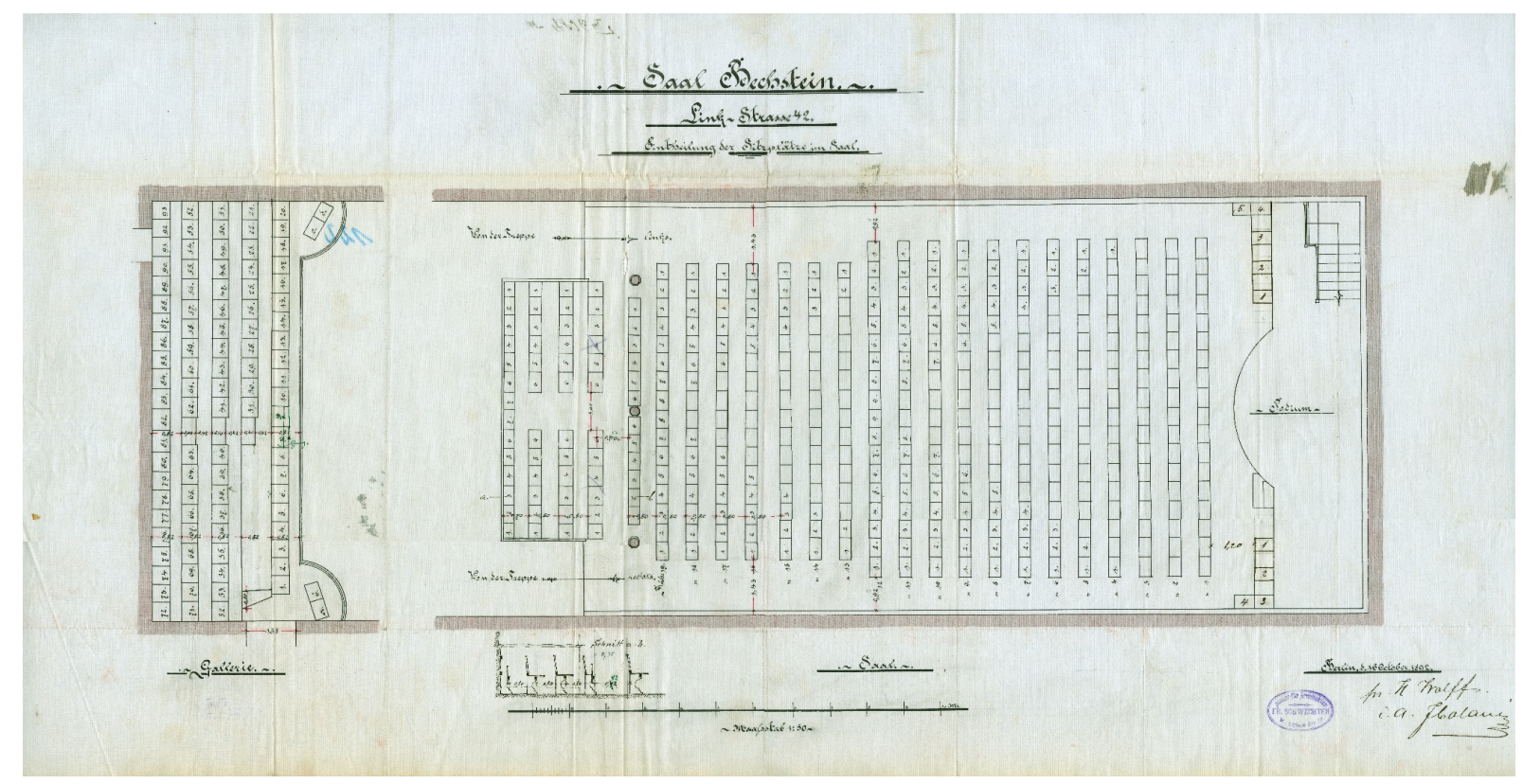

Abb. 7: »Eintheilung des Sitzplätze im Saal« (LAB, B Rep 202, Nr. 4302, B1. 122)

\section{Vorschriften über den Betrieb der Konzertagenten vom 9. März 1914 (HMB1. S. 134)}

Auf Grund des $\S 8$ des Stellenvermittlergesetzes vom 2. Juni 1910 (RGB1. S. 860) wird über den Umfang der Befugnisse und Verpflichtungen sowie über den Geschäftsbetrieb der Konzertagenten folgendes bestimmt:

1. Konzertagent im Sinne dieser Bestimmungen ist, wer das Gewerbe eines Stellenvermittlers ( 11 Nr. 1 und 2 StVG.) vorbehaltlich der Bestimmung in Ziff. 10 Abs. 2 nur für solche gewerbsmäßig oder nicht gewerbsmäßig betriebene Unternehmungen ausübt, durch welche Instrumentalkonzerte, Vokalkonzerte, Gesangs- oder andere Vorträge dargeboten werden, bei denen ein höheres Interesse der Kunst oder Wissenschaft obwaltet.

2. Der Konzertagent ist verpflichtet, ein Geschäftsbuch für die abgeschlossene Vermittelung (Abschlussbuch) nach dem anliegenden Muster zu führen. Das Buch muss dauerhaft gebunden und mit fortlaufenden Seitenzahlen versehen sein; es muss vor der Ingebrauchnahme von der Ortspolizeibehörde unter Beglaubigung der Seitenzahl abgestempelt werden. In dem Buche dürfen weder Rasuren vorgenommen noch Eintragungen unleserlich gemacht werden; auch darf das Buch weder ganz noch zum Teil vernichtet werden.

3. Die Abschlüsse von Vermittelungen und die Zahlungen sind in das Abschlussbuch im Laufe des Tages, an welchem die Abschlüsse erfolgen, Zahlungen eingehen oder - bei 
laufender Rechnung - das Konto des Auftraggebers belastet wird, in der Reihenfolge des Abschlusses des Einganges oder der Belastung unter fortlaufenden Nummern vollständig und übersichtlich einzutragen.

4. Abschlussbücher, welche nicht mehr benutzt werden sollen, sind unter Angabe des Datums abzuschließen, der Ortspolizeibehörde zur Bestätigung des Abschlusses vorzulegen und sodann 10 Jahre aufzubewahren. Nach dem Abschlusse dürfen weitere Eintragungen nicht mehr gemacht werden.

Dasselbe gilt, wenn der Geschäftsbetrieb eingestellt wird.

5. Die Konzertagenten sind verpflichtet, für ihren gesamten Geschäftsbetrieb Handelsbücher oder Geschäftsbücher nach kaufmännischer Art zu führen. Sie sind verpflichtet, eine Abschrift (Kopie oder Abdruck) der abgesendeten Geschäftsbriefe zurückzubehalten und diese Abschrift sowie die empfangenen Geschäftsbriefe geordnet 10 Jahre lang aufzubewahren.

6. Die Ortspolizeibehörde kann von der Führung des Abschlussbuchs ganz oder teilweise befreien, wenn die sonstige Buchführung geeignet ist, ihr einen klaren Überblick über die für das Abschlussbuch vorgeschriebenen Eintragungen zu gewähren.

7. Binnen einer Woche nach Eröffnung des Betriebs, bei bestehenden Unternehmungen binnen einer Woche nach Inkrafttreten dieser Vorschriften hat der Konzertagent der Ortspolizeibehörde anzuzeigen, für welche der in Ziff. 1 genannten Veranstaltungen er seine Vermittlungstätigkeit ausüben will. Gleichzeitig hat er die unter Ziff. 13 Abs. 2 und 14 fallenden Tätigkeiten und diejenigen Gewerbe, welche er außer der Stellenvermittelung ausüben will, zu bezeichnen. Die Art der Geschäftstätigkeit ist hiernach von der Ortspolizeibehörde festzusetzen.

Der Konzertagent ist verpflichtet, seinen Familiennamen und mindestens einen ausgeschriebenen Vornamen mit der Bezeichnung „Konzertagent“" oder „Konzertagentur“ in deutlich lesbarer Schrift an der Straßenseite des Hauses, auf, neben oder über dem Hauseingange und am Eingange zu den Geschäftsräumen anzubringen.

8. Die Konzertagenten haben alle Anzeigen in Zeitungen, Anschlägen, Reklamen und dergleichen sowie die von ihnen bei der Vermittlung benutzten Vertragsformulare mit der genauen Angabe des Geschäftslokals und ihren Vor- und Zunamen zu versehen.

Wahrheitswidrige Angaben, insbesondere solche über die Zahl der offenen Stellen oder der Stellung suchenden Personen, sowie alle marktschreierischen Angaben (die Hervorhebung besonderer Vorzüge, die Zusage von Vorteilen oder Geschenken) sind dabei verboten.

9. Die Ortspolizeibehörde bestimmt, inwiefern eine Stellvertretung zulässig ist. Bei Beschäftigung von Hilfspersonal einschließlich der Familienangehörigen sind der 
Ortspolizeibehörde nach näherer Anweisung regelmäßig Verzeichnisse der beschäftigten Personen einzureichen.

Von der Beschäftigung sind Personen ausgeschlossen, welche für den Geschäftsbetrieb und hinsichtlich ihrer persönlichen Verhältnisse nicht die erforderliche Zuverlässigkeit besitzt oder eine der nach $\S 3$ des Stellenvermittlergesetztes oder nach Ziff. 13, 15 und 16 Buchst. a und e dieser Vorschriften den Konzertagenten verbotenen Tätigkeiten ausüben.

10. Konzertagenten dürfen eine Vermittelungstätigkeit im Sinne des $\S 1$ des Stellenvermittlergesetztes nur für Veranstaltungen der in Ziff. 1 genannten Art und innerhalb der durch die ortspolizeiliche Festsetzung (Ziff. 7) gegebenen Grenzen ausüben.

Soweit die gemäß $§ 2$ des StVG. erteilte Erlaubnis es zulässt, kann die Ortspolizeibehörde ausnahmsweise die Vermittelungstätigkeit auch für andere unter Ziff. 1 der Vorschriften über den Geschäftsbetrieb der gewerbsmäßigen Stellenvermittler für Bühnenangehörige vom 19. August 1910 (HMB1. S. 465) fallende Unternehmungen gestatten.

Personen, welche die zum Vertragsabschluss erforderliche Zustimmung des gesetzlichen Vertreters nicht nachweisen können, darf eine Dienstleistung nicht gewährt werden.

11. Der Konzertagent darf dem Stellensuchenden etwa ihm bekannt gewordene Tatsachen nicht verschweigen, welche die Zuverlässigkeit der Unternehmung, für welche die Vermittelung erfolgen soll, zweifelhaft erscheinen lassen.

12. Die Konzertagenten dürfen auch bei Aufträgen, welche die Besorgung von Personen bezwecken, die bei nichtgewerbsmäßigen Privatveranstaltungen mitwirken, für die eigene Müheverwaltung nur Gebühren und bare Auslagen in Rechnung stellen, die nach $\S 5$ des Stellenvermittlergesetztes statthaft sind.

13. Den Konzertagenten ist untersagt, die in Ziff. 1 der Vorschriften über den Geschäftsbetrieb der gewerbsmäßigen Stellenvermittler für Bühnenangehörige bezeichneten Unternehmungen zu betreiben, sich an solchen Unternehmungen geschäftlich zu beteiligen, den Unternehmern Darlehen zu gewähren oder mit ihnen in irgend einer anderen Art in vertragliche Verbindung zu treten, welche die unparteiische und ordnungsmäßige Ausübung ihrer Berufspflichten als Konzertagenten in Frage stellt.

Die Konzertagenten sind jedoch befugt, Instrumental- und Vokalkonzerte sowie deklamatorische oder andere Vorträge, bei denen ein höheres Interesse der Kunst und Wissenschaft obwaltet, als Unternehmer zu veranstalten. Konzertagenten, welche sich in dieser Weise bestätigen, dürfen weder Stellungsuchende zur Mitwirkung bei ihren Veranstaltungen noch bei ihren Veranstaltungen Mitwirkende zur Inanspruchnahme ihrer 
Vermittlertätigkeit verpflichten oder anhalten. Sie dürfen keine Vergütungen oder andere Vorteile dafür annehmen, fordern oder sich versprechen lassen, dass Künstler oder Vortragende für die Mitwirkung bei den Veranstaltungen angenommen oder zur Mitwirkung zugelassen werden.

14. Die Konzertagenten dürfen eine nicht unter $\S 1 \mathrm{Nr}$. 1 und $2 \mathrm{StVG}$. fallende Geschäftsbesorgung für die Veranstaltung von Instrumental- und Vokalkonzerten, deklamatorischen und anderen Vorträgen, bei denen ein höheres Interesse der Kunst oder Wissenschaft obwaltet, nur unter folgenden Bedingungen übernehmen:

a) Sie dürfen weder ihre Auftraggeber zur Inanspruchnahme ihrer Vermittlertätigkeit noch Stellungssuchende zur Übertragung einer Geschäftsbesorgung verpflichten oder anhalten.

b) Der Konzertagent hat die gesamte Tätigkeit, die das ordnungsmäßige

Zustandekommen der Veranstaltung erfordert, zu leisten. Er darf dafür als Gebühr bis zu $10 \%$ des Reingewinns der Veranstaltung, mindestens aber einen Betrag nach Maßgabe eines Tarifs beanspruchen, welchen die Ortspolizeibehörde für die verschriebenen Arten von Veranstaltungen und die dabei in Betracht kommenden Leistungen der Konzertagenten festsetzt. Dieser Tarif bestimmt auch, in welchen Fällen und bis zu welchem Höchstbetrage die Konzertagenten von Teilnehmern an den Veranstaltungen (Solisten, Begleitern usw.) für die Vermittelung ihrer Mitwirkung Gebühren erheben dürfen.

c) Neben den Gebühren dürfen Vergütungen anderer Art weder von den Auftraggebern noch von den sonstigen Teilnehmern an den Veranstaltungen erhoben werden. Die Erstattung barer Auslagen darf nur insoweit gefordert werden, als sie auf Verlangen und nach Vereinbarung mit den Auftraggebern verwendet sind.

Die Konzertagenten sind verpflichtet, ihren Auftraggebern Rabatte oder sonstige Vorteile, die ihnen aus Anlass der Geschäftsbesorgung zufallen, in voller Höhe gutzubringen. Ausgenommen sind Rabatte für Anzeigen, Ankündigungen und Drucksachen, wenn sie auf Grund schriftlicher, die Rabattsätze enthaltender Verträge gewährt werden und die geschäftsüblichen Grenzen nicht überschreiten.

d) Die Konzertagenten dürfen sich von ihren Auftraggebern Vorschüsse nur bis zu $3 / 4$ der veranschlagten baren Auslagen (Buchst. f) gewähren lassen.

e) Die Ausgabe von Eintrittskarten für die Veranstaltungen zu einem gegenüber dem Kassenpreis ermäßigten Preise ist nur auf Grund eines ausdrücklichen Auftrags des Auftraggebers zulässig. Ist auch der Verkauf der Eintrittskarten dem Konzertagenten übertragen, so müssen die von ihm ausgegebenen Freikarten als solche (z. B. durch 
den Ausdruck ,unverkäuflich“) deutlich gekennzeichnet werden. Die nicht verausgabten Karten sowie die von den Besuchern abgegebenen Kontrollabschnitte sind dem Auftraggeber bei der Rechnungslegung (Buchst. f) auszuhändigen.

f) Der Konzertagent ist verpflichtet, dem Auftraggeber vor Übernahme der Geschäftsbesorgung die gemäß Buchst. b zur Anwendung kommenden Gebührensätze und einen Anschlag über die erforderlichen baren Auslagen mitzuteilen. Binnen einer Woche nach Abschluss seiner Tätigkeit hat er dem Auftraggeber unter Vorlage der zur Nachprüfung erforderlichen Belege Rechnung zu legen.

15. Auch abgesehen von den Fällen des $\S 4$ des Stellenvermittlergesetzes ist es den Konzertagenten untersagt, mit konzertierenden Künstlern, Vortragenden oder solchen Personen, für welche sie eine Vermittlungstätigkeit ausnahmsweise ausüben dürfen (Ziff.10 Abs. 2), als Impresarien oder Alleinvertreter Verträge einzugehen, durch welche die Verwertung der Tätigkeit der genannten Personen oder eine Geschäftsbesorgung für diese nicht nur für einzelne bestimmte Veranstaltungen übernommen wird.

Die Ortspolizeibehörde kann den Abschluss von Verträgen, welche hiernach verboten sind, ausnahmsweise mit einzelnen Personen auf einen Zeitraum bis längstens 3 Jahre gestatten.

Jede andere als die hier nach und gemäß Ziff. 14 zulässige Geschäftsbesorgung für die in Ziff. 1 dieser Vorschriften und in Ziff. 1 der Vorschriften über den Geschäftsbetrieb der gewerbsmäßigen Stellenvermittler für Bühnenangehörige bezeichneten Unternehmungen ist den Konzertagenten verboten.

16. Den Konzertagenten ist untersagt:

a) Fachschulen, welche die Vorbereitung für die in Ziff. 1 dieser Vorschriften und in Ziff. 1 der Vorschriften über den Geschäftsbetrieb der gewerbsmäßigen

Stellenvermittler für Bühnenangehörige bezeichneten Berufe bezwecken, zu betreiben oder sich an dem Betriebe solcher zu beteiligen;

b) mit auswärtigen Stellenvermittelungen, die von den Regierungspräsidenten (im Landespolizeibezirke Berlin von dem Polizei-Präsidenten) als unzuverlässig bezeichnet sind, in Verbindung zu treten;

c) Verträge zu vermitteln, in denen der Unternehmer die den Künstlern versprochene Vergütung von vornherein durch bestimmte Abzüge (Rabatt, Prozentabzüge usw.) kürzt;

d) mit Unternehmern in geschäftliche Beziehungen zu treten, von denen sie wissen oder den Umständen nach annehmen müssen, dass sie Kürzungen der versprochenen Vergütungen in der Absicht vornehmen, aus diesen Abzügen die ihnen zur Last 
fallenden Vermittlungsgebühren zu bestreiten, oder dass sie sich für die Annahme oder Zulassung von Künstlern oder Vortragenden bei ihren Veranstaltungen in der in Ziff. 13 Abs. 2 Satz 3 gekennzeichneten Weise entschädigen lassen;

e) Druckschriften herauszugeben oder zu verlegen oder sich an der Herausgabe oder dem Verlage von Druckschriften zu beteiligen, wenn darin entgeltliche Ankündigungen oder Besprechungen Aufnahme finden, die ein von den Konzertagenten betriebenes Unternehmen, die Tätigkeit des Konzertagenten oder eines konzertierenden Künstlers oder einer Person, welche deklamatorische oder andere Verträge darbietet, zum Gegenstande haben;

f) Räumlichkeiten, welche ausschließlich oder vorwiegend zur Veranstaltung von Konzerten oder Vorträgen verwendet werden, eigentümlich zu erwerben und sich an der Verwertung von Räumlichkeiten, welche ihnen nicht eigentümlich gehören, zu solchen Zwecken geschäftlich zu beteiligen.

17. Die Konzertagenten haben in den von ihnen vermittelten Verträgen den Betrag der an den Künstler tatsächlich auszuzahlenden Vergütung anzugeben.

18. Die Ausübung der nach Ziff. 13 Abs. 2 Satz 1 und Ziff. 14 Satz 1 zugelassenen Tätigkeiten und der Tätigkeit als Impresario oder Alleinvertreter (Ziff. 15 Abs. 1) kann von der Ortspolizeibehörde untersagt werden, wenn sich aus Handlungen oder Unterlassungen des Konzertagenten seine Unzuverlässigkeit in Beziehung auf diese Tätigkeiten ergibt oder wenn durch sie die unparteiische und ordnungsmäßige Ausübung der Berufspflichten als Konzertagent in Frage gestellt wird.

Die gemäß Ziff. 10 Abs. 2 und 15 Abs. 2 zugelassenen Ausnahmen können unter denselben Voraussetzungen sowie dann widerrufen werden, wenn die bei der Zulassung gestellten Bedingungen nicht eingehalten werden.

19. Die Polizeibehörden und ihre Organe sind befugt, in den Geschäftsbetrieb des Konzertagenten jederzeit Einsicht zu nehmen. Die Konzertagenten sind verpflichtet, dem Beamten jederzeit den Zutritt zu allen für den Geschäftsbetrieb bestimmten Räumlichkeiten zu gestatten, ihnen die Geschäftsbücher und Geschäftspapiere auf Verlangen im Dienstraume der Polizeibehörde vorzulegen und jede über den Geschäftsbetrieb verlangte Auskunft wahrheitsgetreu zu erteilen.

20. Die Vorschriften treten am 1. April 1914 für Konzertagenten an Stelle der Vorschriften über den Geschäftsbetrieb der gewerbsmäßigen Stellenvermittler für Bühnenangehörige vom 17. August/28 September 1910 (HMBl. S. 465, 509) in Kraft. 
21. Ein Abdruck dieser Vorschriften ist jedem im Gebrauche befindlichen Geschäftsbuche vorzuheften. Außerdem ist ein Abdruck in großer Schrift in den Geschäftsräumen am Eingange an gut zugänglicher Stelle aufzuhängen.

Gebührentarif für Konzertagenten.

Auf Grund des $\S 5$ Absatz 1 des Stellenvermittlergesetztes vom 2. Juni 1910 (RGB1. S. 860) bestimme ich nach Anhörung von Vertreten der Stellenvermittler und der gemäß Ziff. 1 der Vorschriften über den Geschäftsbetrieb der Konzertagenten vom 9. März 1914 beteiligten Unternehmer und Künstler (Vortragenden), dass Konzertagenten im Sinne der gedachten Vorschriften für die Vermittlung einer Stelle nicht mehr als folgende Bruchteile der dem Künstler (Vortragenden) für die vermittelte Tätigkeit zustehenden Gesamtvergütung erheben dürfen:

a) bei Vermittelungen für eine einzelne Veranstaltung (Konzert, Vortrag, Musikfest usw.):

$7 \frac{1}{2} \%$ von den Veranstaltern,

$7 \frac{1}{2} \%$ von den Künstlern.

b) bei allen anderen Vermittelungen:

$2 \frac{1}{2} \%$ von den Veranstaltern,

$2 \frac{1}{2} \%$ von den Künstlern.

Die Gebühren, welche die Konzertagenten in den Fällen einer Geschäftsbesorgung gemäß Ziff. 14 der Vorschriften von ihren Auftraggebern und vom Teilnehmern an den Veranstaltungen (Solisten, Begleitern usw.) für die Vermittelung ihrer Mitwirkung erheben dürfen, bestimmen sich ausschließlich nach dem von der Ortspolizeibehörde gemäß Ziff. 14 Buchst. $\mathrm{b}$ aufzustellenden Tarif.

Berlin, den 9. März 1914.

De Minister für Handel und Gewerbe. 